US Army Corps

of Engineers:

Portland District

Prepared for the U.S. Army Corps of Engineers, Portland District.

under a Government Order with the U.S. Department of Energy

Contract DE-AC05-76RL01830

\title{
Total Dissolved Gas Effects on Incubating Chum Salmon Below Bonneville Dam
}

\author{
FINAL REPORT
}

$\begin{array}{ll}\text { EV Arntzen } & \text { EM Dawley } \\ \text { KD Hand } & \text { VI Cullinan } \\ \text { KM Carter } & \text { RA Elston } \\ \text { DR Geist } & \text { J Vavrinec III } \\ \text { KJ Murray } & \end{array}$

January 2009 


\title{
DISCLAIMER
}

This report was prepared as an account of work sponsored by an agency of the United States Government. Neither the United States Government nor any agency thereof, nor Battelle Memorial Institute, nor any of their employees, makes any warranty, express or implied, or assumes any legal liability or responsibility for the accuracy, completeness, or usefulness of any information, apparatus, product, or process disclosed, or represents that its use would not infringe privately owned rights. Reference herein to any specific commercial product, process, or service by trade name, trademark, manufacturer, or otherwise does not necessarily constitute or imply its endorsement, recommendation, or favoring by the United States Government or any agency thereof, or Battelle Memorial Institute. The views and opinions of authors expressed herein do not necessarily state or reflect those of the United States Government or any agency thereof.

\author{
PACIFIC NORTHWEST NATIONAL LABORATORY \\ operated by \\ BATTELLE \\ for the \\ UNITED STATES DEPARTMENT OF ENERGY \\ under Contract DE-AC05-76RL01830 \\ Printed in the United States of America \\ Available to DOE and DOE contractors from the \\ Office of Scientific and Technical Information, \\ P.O. Box 62, Oak Ridge, TN 37831-0062; \\ ph: (865) 576-8401 \\ fax: (865) 576-5728 \\ email: reports@adonis.osti.gov
}

\author{
Available to the public from the National Technical Information Service, \\ U.S. Department of Commerce, 5285 Port Royal Rd., Springfield, VA 22161 \\ ph: (800) 553-6847 \\ fax: (703) 605-6900 \\ email: orders@ntis.fedworld.gov \\ online ordering: http://www.ntis.gov/ordering.htm
}




\title{
Total Dissolved Gas Effects on Incubating Chum Salmon Below Bonneville Dam
}

\section{Final Report}

\author{
EV Arntzen EM Dawley \\ KD Hand VI Cullinan \\ KM Carter RA Elston \\ DR Geist J Vavrinec III \\ KJ Murray
}

January 2009

Prepared for the

U.S. Army Corps of Engineers, Portland District, under a Government Order with the

U.S. Department of Energy

Contract DE-AC05-76RL01830

Pacific Northwest National Laboratory

Richland, Washington 99352 



\section{Summary}

At the request of the U.S. Army Corps of Engineers (USACE), Portland District, the Pacific Northwest National Laboratory (PNNL) conducted research to measure the concentration of total dissolved gas (TDG) in chum salmon (Oncorhynchus keta) spawning areas downstream of Bonneville Dam and to assess the impact of elevated dissolved gas on chum salmon survival. Spring spill at the dam occurs when chum salmon sac fry are still in the gravel. Prior to this study, no data existed on the concentration of TDG within the incubation habitat of riverbed gravels. Further, little research has been conducted recently on the effects of gas supersaturation on incubating and larval stages of salmonids. A literature review early in this study suggested that impacts to chum salmon sac fry could occur at gas levels as low as 103\% TDG, but this had not been studied previously on this species. The overall goal of the study was to evaluate potential impacts on chum salmon survival and development from elevated TDG that occurs during spring spill operations at Bonneville Dam. Specifically, we were interested in learning whether chum salmon were impacted by TDG under a range of hydraulic conditions created downstream from Bonneville Dam and also in determining physiological response to a range of TDG levels.

The study was conducted over a three-year period from 2006 through 2008 and included both a field and laboratory component. The field component consisted of measuring total dissolved gas levels in the riverbed at egg pocket depth as well as in the river at chum salmon spawning sites below Bonneville Dam in the Ives Island and Multnomah Falls areas. In addition, chum salmon sac fry were sampled from natural redds in 2007 and from artificial egg tubes in 2008 to determine if there was a physiological response to TDG that resulted from operations at Bonneville Dam. The laboratory component consisted of a two-year study (2007 and 2008) using toxicity tests on hatchery chum salmon fry at several static gas levels ranging up to 113\% TDG; an additional incremental exposure to TDG levels up to 129\% was conducted in 2008.

Results from the field and laboratory components of this study conducted in 2006 and 2007 were submitted previously in annual reports to the USACE and, with the exception of occasional references to those results, will not be repeated here. This report covers the field and laboratory components of this study that were conducted in 2008. The 2008 research activities resulted in six key findings:

- Chum salmon sac fry in the Ives Island area were exposed to depth-compensated TDG greater than $103 \%$ for up to 200 hours and greater than $105 \%$ for up to 100 hours. These exposure times represent up to $8 \%$ and $4 \%$, respectively, of the total estimated 2008 incubation time.

- Most exposure occurred prior to spring spill during 2008 when the Bonneville Dam corner collector was operating. This finding contrasts with previous years' monitoring when exposure to elevated TDG was distributed before and after the onset of spring spill.

- Chum salmon sac fry in the Multnomah Falls area were not exposed to depth-compensated TDG greater than $103 \%$.

- In the laboratory, static levels of dissolved gas ranging up to 113\% TDG did not influence survival, growth, or development of chum salmon sac fry. There was no relationship between TDG concentration and histological lesions; control samples exhibited lesions. This was not observed in 2007 and is an unexplainable finding from this year's work. 
- In the laboratory, incremental exposures to gas levels ranging up to 129\% TDG found symptoms of gas bubble disease beginning at 121\% TDG; mortality began at 124.6\% TDG.

- Quantitative assessments of sac fry sampled from an artificial redd in the Ives Island area found that survival in March and April ranged from 0\% to 89\%. External signs of gas were found following periods when depth-compensated TDG was elevated above 103\% TDG. It was not clear whether these signs were related to elevated dissolved gas levels.

The U.S. Environmental Protection Agency has adopted a nationwide water-quality criterion maximum of $110 \%$ TDG for the protection of aquatic life. Previous research in the Columbia River basin showed that this level of protection was overly conservative, and as such, state management agencies have issued waivers to the federal standards that allow gas levels to increase up to 115\% TDG in the forebay of hydroelectric dams and up to 120\% TDG in dam tailwaters. Guidance that managers have used to provide protection for pre-emergent chum salmon fry has been to limit TDG in the Bonneville Dam tailwater to 105\% TDG after allowing for depth compensation. The results from this study would support this guidance; that is, 105\% TDG appears to provide a conservative level of protection to chum salmon sac fry incubating in the gravel downstream of Bonneville Dam. We based this conclusion on the fact that our laboratory results from 2007 and 2008 did not reveal significant differences in survival, growth, or development at concentrations up to $113 \%$ TDG. The only exception to this conclusion is from the histological results in 2007, although this finding may have been confounded by temperature and not due exclusively to dissolved gas levels as previously reported. Having said that, we have no explanation why control fish in the 2008 laboratory study exhibited tissue lesions, and this may warrant further study. Although we noted unusual bubbles in the pupils of fish that were sampled in artificial redds during a period when dissolved gas levels were between $105 \%$ and $110 \%$, the significance of these bubbles is unclear because the sample sizes were quite small. Further investigation into this may be warranted.

Our monitoring of dissolved gas in the field showed that depth-compensated TDG levels in the Ives Island chum salmon spawning area exceeded the 105\% TDG management guideline when water levels were low (up to $4 \%$ of the incubation period in 2008). The relative risk to the chum salmon population in the Ives Island area can be determined through knowledge of the redd elevations, the hyporheic TDG concentrations, and the river surface elevation. We have shown that the elevation of redds within the Ives Island area can be variable, and that shallow redds are not always protected from elevated TDG because water depths cannot compensate for the elevated gas level. Further, due to groundwater interactions within the hyporheic zone, the surface water concentrations of TDG are not representative of the concentration of TDG experienced by the sac fry incubating in the gravel. These findings suggest that redd location, surface water depth within the spawning areas, and dissolved gas at the depth of an egg pocket should be monitored during the period before chum salmon emergence in order to more fully understand the impacts of dissolved gas to chum salmon sac fry incubating in the gravel downstream of Bonneville Dam. 


\section{Contents}

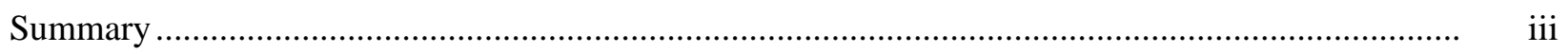

Abbreviations and Acronyms ................................................................................................ ix

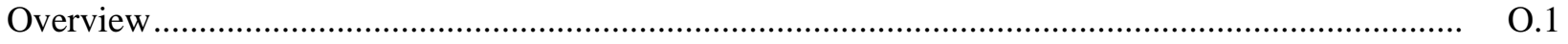

Chapter 1 - Assessment of Total Dissolved Gas Within Chum Salmon Spawning Areas in the Columbia River Downstream of Bonneville Dam ............................................................ 1.1

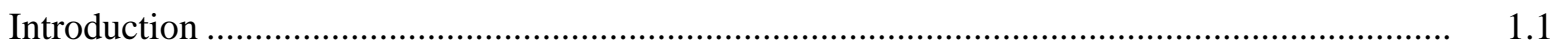

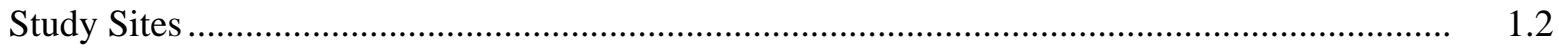

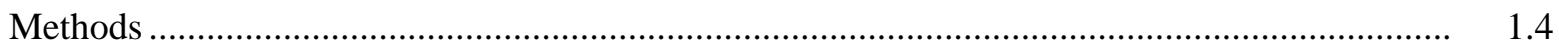

Water Quality Monitoring at Ives Island and Multnomah Falls Spawning Locations......... 1.4

Estimated Exposure of Chum Salmon Redds to Total Dissolved Gas ................................ 1.7

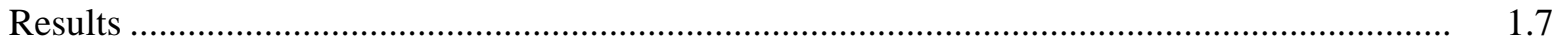

Comparison of PNNL Surface Water Total Dissolved Gas Monitoring to Other Columbia River Monitoring Locations ................................................................ 1.7

Water Quality Monitoring at Ives Island and Multnomah Falls Spawning Locations......... 1.9

Estimated Exposure of Chum Salmon Redds to Total Dissolved Gas ................................ 1.19

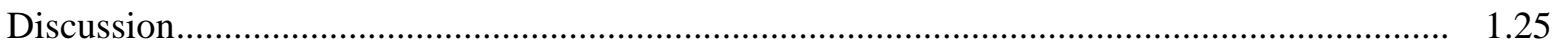

Chapter 2 - Bioassays on the Formation of Gas Bubble Disease in Chum Salmon Fry at Total

Dissolved Gas Levels Ranging up to 129\% Saturation.................................................... 2.1

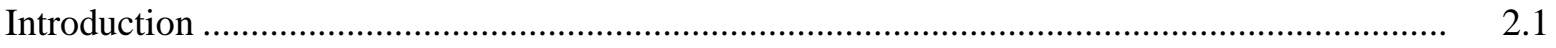

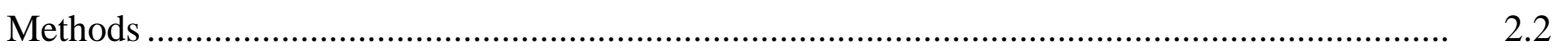

Static Exposure to Supersaturated Total Dissolved Gas Levels up to 113\% ...................... 2.2

Incremental Exposure to Supersaturated Total Dissolved Gas Levels up to 129\% ............. $\quad 2.7$

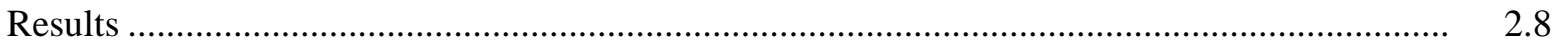

Static Exposure to Supersaturated Total Dissolved Gas Levels up to 113\% ...................... 2.8

Incremental Exposure to Supersaturated Total Dissolved Gas Levels up to $129 \%$............ 2.22

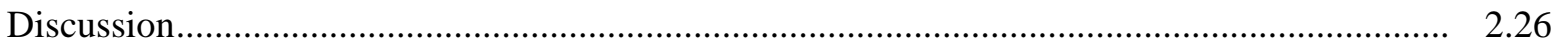

Chapter 3 - Field Analysis of Incubating Chum Salmon Sac Fry Exposed to In-River Total

Dissolved Gas Levels Downstream of Bonneville Dam ..................................................... 3.1

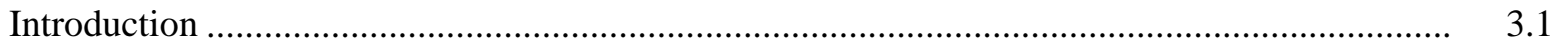

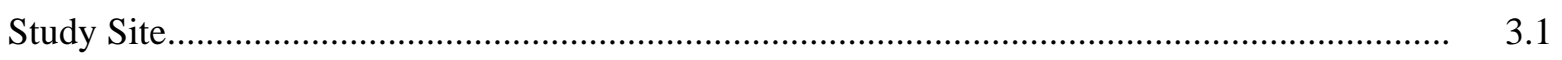

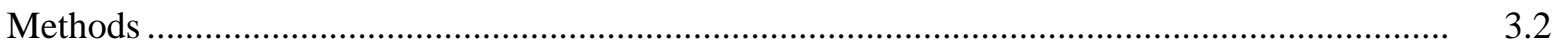

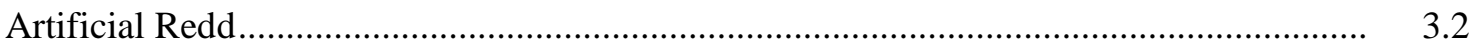

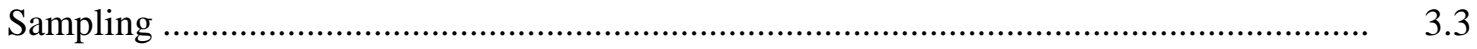

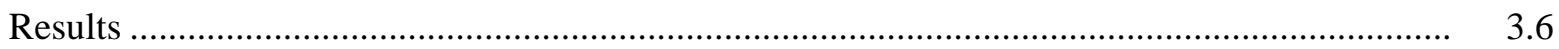

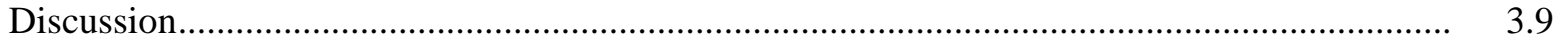



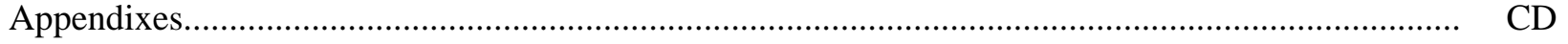




\section{Figures}

1.1 Ives Island and Multnomah Falls study sites

1.2 Piezometer stations (black and white circles) near Ives Island. Red circles represent chum salmon redds marked from spawning years 2000 through $2007 .$.

1.3 Piezometer stations (black and white circles) near Multnomah Falls. Red circles represent chum salmon redds marked from spawning years 2003 through 2007.

1.4 Total dissolved gas monitoring stations downstream of Bonneville Dam

1.5 Comparison of 2008 total dissolved gas values obtained at PNNL monitoring stations and USGS surface water monitoring stations ....

1.6 Deployment periods for water quality sensors in Ives Island and Multnomah Falls area monitoring locations.

1.7 Ives Island uncompensated TDG values ......

1.8 Ives Island area depth-compensated TDG values measured in surface water and the hyporheic zone

1.9 Ives Island area dissolved oxygen values.

1.10 Ives Island site temperature values.....

1.11 Ives Island site hyporheic temperatures, March 22-April 14, 2008.

1.12 Ives Island site specific conductance values.

1.13 Multnomah Falls total dissolved gas values.

1.14 Multnomah Falls depth-compensated total dissolved gas

1.15 Multnomah Falls dissolved oxygen.

1.16 Multnomah Falls temperature values

1.17 Multnomah Falls specific conductance values

1.18 Water surface elevations during chum emergence for the Ives Island area, 2003-2008 .....

1.19 Estimated TDG exposure to chum salmon sac fry

1.20 Estimated hours of TDG exposure and dewatering to chum salmon sac fry based on hyporheic results from incubation year 2008 .

1.21 Estimated hours of TDG exposure and dewatering to chum salmon sac fry based on surface water results from incubation year 2008.

1.22 Temporal distribution of chum salmon sac fry exposure to elevated TDG during 2007 and 2008.

2.1 Total dissolved gas experimental system....

2.2 Alevin retained large yolk sacs when placed in the exposure cups......................................... 2.7

2.3 Daily mean total dissolved gas levels for the exposure period ............................................... 2.9

2.4 Daily mean temperatures for the study period ................................................................. 2.10

2.5 Number of days to 50\% and 100\% emergence for each treatment group ................................. 2.11

2.6 Number of days post-fertilization at 50\% emergence for each exposure period

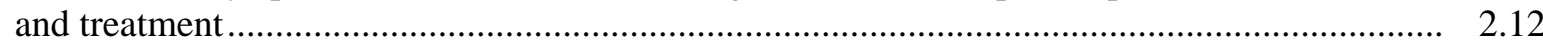

2.7 Average daily weight gain from $50 \%$ hatch to $50 \%$ emergence ........................................... 2.15 
2.8 Average daily length gain from 50\% hatch to 50\% emergence .............................................. 2.15

2.9 Epithelial hypertrophy appears as a thickening of the outer layer, or epithelium of the secondary lamellae ......................................................................................................... 2.17

2.10 Percentage occurrence of moderate severity or greater gill lesions in the overall preemergence and emergence samples from the long and short exposures .....

2.11 Proportions of fish sampled by exposure and treatment that exhibited crenated erythrocytes of moderate severity or greater in the secondary gill lamellae.

2.12 Proportions of fish sampled by exposure and treatment that exhibited dilated lamellar tips of moderate severity or greater.

2.13 Proportions of fish sampled by exposure and treatment that exhibited epithelial hypertrophy of moderate severity or greater.....

2.14 Proportions of fish sampled by exposure and treatment that exhibited epithelial cell separation of moderate severity or greater

2.15 Proportions of fish sampled by exposure and treatment that exhibited hepatic glycogen depletion of moderate severity or greater.

2.16 Proportions by treatment of fish sampled at pre-emergence that exhibited protozoan parasite infection of mild or moderate severity in the skin .....

2.17 General increase in total dissolved gas levels over the study period

2.18 Small clusters of bubbles observed in the pupil of fish exposed to 121\% TDG and above.

2.19 Temperature range during incremental exposure study

2.20 Coagulated yolk in fish exposed to $124.6 \%$ total dissolved gas and above

2.21 Mortality found when total dissolved gas levels reached $125.9 \%$ was observed with numerous large bubbles on the head, eyes, and jaw.

2.22 A very large bubble in the vitelline membrane of a fish exposed to $127.5 \%$ total dissolved gas

2.23. Percentage of fish experiencing mortalities with increasing total dissolved gas levels in both cup A (grey line - squares) and cup B(black line - circles).

3.1. Egg tube to house wild chum salmon eggs and alevin while in the artificial redd .....

3.2 Artificial redd and egg tube configuration.

3.3 Mobile laboratory and equipment used to examine chum salmon sac fry

3.4 Alevin were removed from the egg tube and placed into a shallow pan with the tube substrate.

3.5 Total dissolved gas levels over the sampling period...

3.6 Comparison of fish from egg tube 6 to fish from egg tube 8 


\section{Tables}

1.1 MiniSonde 5 water quality sensor specifications

1.2 Exposure estimates of Multnomah Falls area chum salmon redds to depth-compensated TDG based on 2008 river monitoring results.

1.3 Percentage of chum salmon redds constructed at riverbed elevations higher than Ives Island area monitoring locations for total dissolved gas, 2005-2007 spawning years

2.1 Total dissolved gas levels used in the exposure experiments and expressed as daily means between February 6 and March 25, 2008

2.2 Mean daily temperature during the 48-day exposure period.

2.3 Mean survival, days post-fertilization, date, and accumulated thermal units at $50 \%$ emergence

2.4 Size of chum salmon sampled at 50\% hatch and at time of transfer to emergence tubes

2.5 Size of chum salmon sampled at 50\% emergence

2.6 Tissue, yolk, and total dry weights of emergent fry 2.16

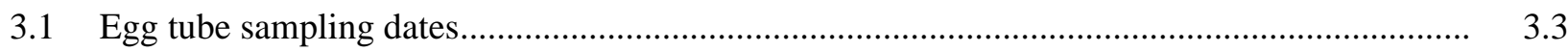

3.2 Mortality and survival in incubation tubes held in the artificial redd .................................... 3.8

3.3 Results of gross examinations of sac fry housed in the eight tubes inside the artificial redd ..... 3.8 


\section{Abbreviations and Acronyms}

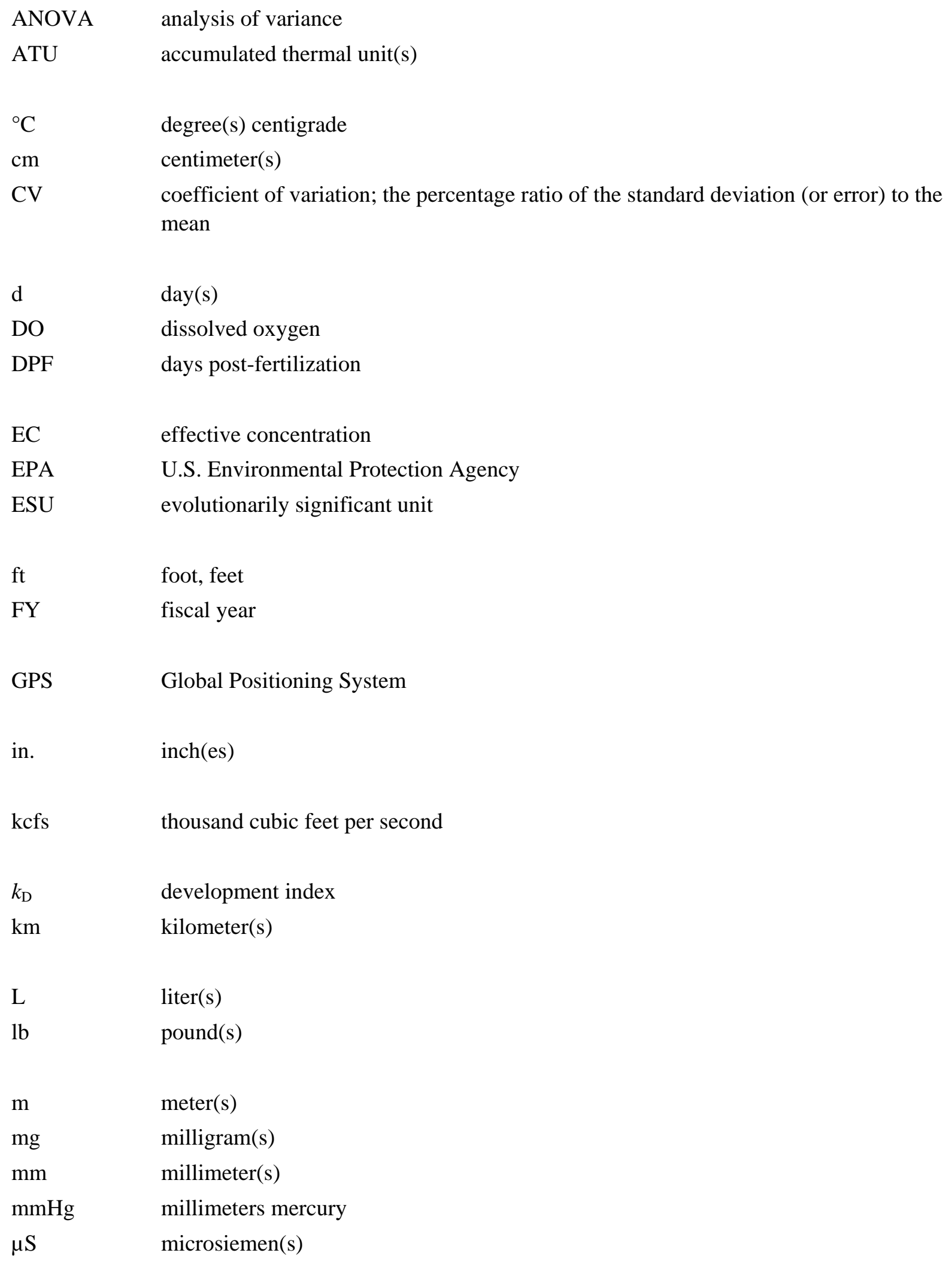




$\begin{array}{ll}\text { MS-222 } & \text { tricaine methanesulfonate } \\ \text { MSL } & \text { mean sea level } \\ N & \text { population size } \\ n & \text { subsample size } \\ \mathrm{N}_{2} & \text { dinitrogen } \\ \text { NaCl } & \text { sodium chloride } \\ \text { NAS } & \text { National Academy of Sciences } \\ \text { NAE } & \text { National Academy of Engineering } \\ \text { NBF } & \text { neutral buffered formalin } \\ \text { NGVD } & \text { national geodetic vertical datum } \\ \text { NMFS } & \text { National Marine Fisheries Service } \\ \text { NOAA } & \text { National Oceanic and Atmospheric Administration } \\ & \\ \mathrm{O}_{2} & \text { oxygen } \\ \text { ODFW } & \text { Oregon Department of Fish and Wildlife } \\ \text { V } & \text { U.S. Geological Survey } \\ \text { PSACE } & \text { probability } \\ \text { psi } & \text { Pacific Northwest National Laboratory } \\ \text { PVC } & \text { pounds per square inch } \\ \text { rkm } & \text { polyvinyl chloride } \\ & \\ & \\ & \end{array}$




\section{Overview}

Gas supersaturation caused by spill from dams on the Columbia River was first acknowledged as an environmental concern in the mid 1960s (Ebel and Raymond 1976). Several studies monitored dissolved gas levels and investigated occurrence of gas bubble disease in the Columbia River from 1966 through 1969. These studies reported dissolved gas saturation levels ranging from $120 \%$ to $143 \%$ and found significant signs of gas bubble disease and associated mortalities for both juvenile and adult salmonids (Ebel 1969; Beiningen and Ebel 1970, 1971; Meekin and Allen 1974). In response, research on the causes and effects of gas supersaturation and resulting modifications to dam structures and operations reduced supersaturated gas levels. A nationwide water quality standard for total dissolved gas (TDG) saturation was set at 110\% by the U.S. Environmental Protection Agency (EPA) in 1972 and remains in effect (NAS/NAE 1973; EPA 1987).

Waivers to the water quality standard were approved beginning in the 1990s to aid juvenile salmonid downstream migration. Studies reviewed as part of the 1995 and 2000 Biological Opinions (NOAA 1995,2000 ) indicated that TDG saturation levels between $110 \%$ and $120 \%$ had minimal effects on aquatic organisms. Therefore, levels up to 115\% TDG saturation in dam forebays and up to 120\% TDG saturation in dam tailraces have been allowed on a limited basis (NOAA 1995).

The issue of gas supersaturation has once again become a concern regarding, in particular, the chronic effects on incubating embryos and larvae of salmonids downstream from Bonneville Dam (USACE et al. 2004). At the request of the U.S. Army Corps of Engineers (USACE; Portland District), Pacific Northwest National Laboratory (PNNL) undertook a two-part project in 2006 to look further into issues of TDG supersaturation in the lower Columbia River. First, PNNL conducted an extensive review and synthesis of literature related to the impacts of TDG supersaturation on fish species in the lower Columbia River. The product of that effort was a technical report, Total Dissolved Gas Effects on Fishes of the Lower Columbia River (McGrath et al. 2006). Second, a field study was initiated to monitor water quality in selected spawning habitats of chum salmon (Oncorhynchus keta) downstream from Bonneville Dam. The results of the field study are detailed in a 2007 technical report, Total Dissolved Gas Monitoring in Chum Salmon Spawning Gravels Below Bonneville Dam (Arntzen et al. 2007a).

Our literature review determined that recent research supports previous findings in regard to migratory juvenile or adult salmonids, that short-term exposure up to 120\% TDG saturation does not produce significant effects when compensating depths are available. During periods of voluntary spill when TDG saturation averaged $120 \%$ or less, monitoring and assessment programs in the Snake and Columbia rivers from 1995 to the early 2000s consistently documented low incidence of significant gas bubble disease in migrating juvenile or adult salmonids as well as resident fishes or other taxa (Toner and Dawley 1995; Ryan and Dawley 1998; NMFS 1999; NOAA 2000; Ryan et al. 2000; Backman and Evans 2002; Backman et al. 2002; Weitkamp et al. 2003).

However, our review found that little research had been conducted recently on the effects of gas supersaturation on incubating and larval stages of salmonids. Most recent works focus on post-emergent juveniles and adults, which present a different case because of their mobility within the environment. Methods have advanced since older studies documented incidence of gas bubble disease in salmonid sac fry exposed to TDG supersaturation within levels currently authorized (McGrath et al. 2006). In addition, most studies conducted on larval fish did not include temperature, exposure duration, or TDG levels 
relevant to conditions occurring downstream from Bonneville Dam. Therefore, the effects of supersaturated TDG exposure in hyporheic environments that support incubating life stages of salmonids warrant additional study.

Recommendations from the literature review and preliminary analysis of data from the 2006 field study led to the development of a more comprehensive research proposal. For fiscal year (FY) 2007, three objectives were proposed. The first was to repeat the 2006 field effort to collect empirical data on TDG from the Ives Island and Multnomah Falls study sites. These data would provide a more thorough understanding of TDG levels during different river stage scenarios (i.e., high-water year versus low-water year). The second objective was to conduct laboratory toxicity tests on hatchery chum salmon fry at gas levels likely to occur downstream from Bonneville Dam. Findings of effects to fish at different TDG concentrations, in conjunction with field data, could be used by managers when deciding on spill levels. The third objective was to sample chum salmon sac fry during Bonneville Dam spill operations to determine if there is a physiological response to TDG levels. The measured response provided a snapshot of fish health at a given place and time to use in comparison with the results from the other two tasks. The PNNL research conducted in support of those three objectives is documented in Effects of Total Dissolved Gas on Chum Salmon Fry Incubating in the Lower Columbia River (Arntzen et al. 2008a).

Field monitoring and laboratory toxicity testing were conducted again during 2008, to both verify the 2007 results and answer some additional questions about how sac fry respond to elevated TDG in the field and the laboratory. For FY 2008, three objectives were proposed. The first was to repeat the 20062007 field effort to collect empirical data on TDG from the Ives Island and Multnomah Falls study sites. These data would represent a third river stage scenario, increasing the range of river conditions over which we are able to assess risk to chum salmon redds. The second objective was two-fold. First, it involved repeating the static laboratory toxicity tests on hatchery chum salmon fry to verify 2007 results. Second, it involved exposing wild chum salmon fry to incremental increases in TDG, above those of the static test, until external symptoms of gas bubble disease were clearly present. The third objective was to assess physiological responses to TDG levels in wild chum salmon sac fry incubating below Bonneville Dam during spill operations. We created egg tubes to hold wild chum eggs in an artificial redd, which allowed us to quantitatively assess physiological responses to TDG levels. The measured response at several different time periods during 2008 provided a quantitative snapshot of fish health during various river conditions while spring spill occurred.

This report summarizes the tasks conducted and results obtained in pursuit of the three objectives. Chapter 1 discusses the field monitoring, Chapter 2 reports the findings of the laboratory toxicity tests, and Chapter 3 describes the field-sampling task. Each chapter contains an objective-specific introduction, description of the study site and methods, results of research, and discussion of findings. Literature cited throughout this report is listed in Chapter 4. Additional details on the monitoring methodology and results are provided in Appendices A and B included on the compact disc bound inside the back cover of the printed version of this report. 
Final Report

\title{
Chapter 1
}

\section{Assessment of Total Dissolved Gas Within Chum Salmon Spawning Areas in the Columbia River Downstream of Bonneville Dam}

\author{
E. V. Arntzen, K. J. Murray, D. R. Geist, E. M. Dawley, J. Vavrinec III
}

\section{Introduction}

Chum salmon that spawn and incubate downstream from Bonneville Dam near Ives Island and an associated site near Multnomah Falls collectively represent one of two remaining populations of the Lower Columbia River evolutionarily significant unit (ESU) listed under the Endangered Species Act. Spring spill from Bonneville Dam is initiated each year to assist downstream migrating juvenile salmonids. Spring spill produces supersaturated gas conditions, which may be causing negative impacts to chum salmon incubating within these reaches. The guidance that managers have used to provide protection for pre-emergent chum salmon fry has been to limit total dissolved gas (TDG) to 105\% after allowing for depth compensation. However, signs of gas bubble disease have been found in sac fry at levels of 103\% TDG (Wood 1979). Prior to 2006, no data were available on the TDG levels in incubation habitats downstream of Bonneville Dam.

During 2006, Pacific Northwest National Laboratory (PNNL) initiated research to determine whether TDG concentrations are elevated in chum salmon redds during spring spill operations at Bonneville Dam. Water quality was monitored at egg pocket depth and in the river at two chum salmon spawning locations downstream from Bonneville Dam during 2006 and 2007. Water quality sensors measured TDG, dissolved oxygen, temperature, specific conductance, and water depth at each location.

Results from 2006 and 2007 (Arntzen et al. 2007a, 2008b) showed that groundwater-surface water interaction differed between the Ives Island and Multnomah Falls locations. Egg pocket concentrations of TDG, dissolved oxygen, and temperature remained relatively stable at Multnomah Falls monitoring locations despite significant fluctuations in river depth. In contrast, water quality in the egg pocket fluctuated widely at some Ives Island monitoring locations, suggesting that spawning gravels in this area are in much closer contact with river water. Chum salmon redds were constructed at relatively low elevations during the 2005 spawning season, and water levels during spring spill 2006 were relatively high. Consequently, TDG was generally depth-compensated sufficiently to mitigate negative impacts to sac fry during 2006. During the 2006 spill season, we estimated that $80 \%$ of the chum salmon redds were exposed to 103\% depth-compensated TDG for less than 13 hours. In contrast, chum salmon redds were constructed at relatively high riverbed elevations during the 2006 spawning season, and water levels during spring spill 2007 were lower than during the 2006 spill season. Exposure estimates showed that $80 \%$ of the chum salmon redds were exposed to 103\% depth-compensated TDG for less than 240 hours.

The first objective in the FY 2008 study was to repeat the field effort to collect empirical data on TDG from the Ives Island and Multnomah Falls study sites during a third water year. This chapter 
describes our assessment and presents monitoring results for TDG, dissolved oxygen, temperature, and specific conductance from FY 2008 in these locations. These data are compared to previous monitoring results from similar locations during FY 2006 and FY 2007, and the data from all three study years are used to estimate the exposure of Ives area chum salmon redds to TDG.

\section{Study Sites}

Two major chum salmon spawning areas were selected for monitoring. One site was a side channel downstream from Bonneville Dam on the right bank, north of Ives Island at river kilometer (rkm) 230, which is $4.3 \mathrm{~km}$ downstream from Bonneville Dam. The other site was on the left bank near Multnomah Falls at rkm 220, 14.8 km downstream from Bonneville Dam (Figure 1.1).

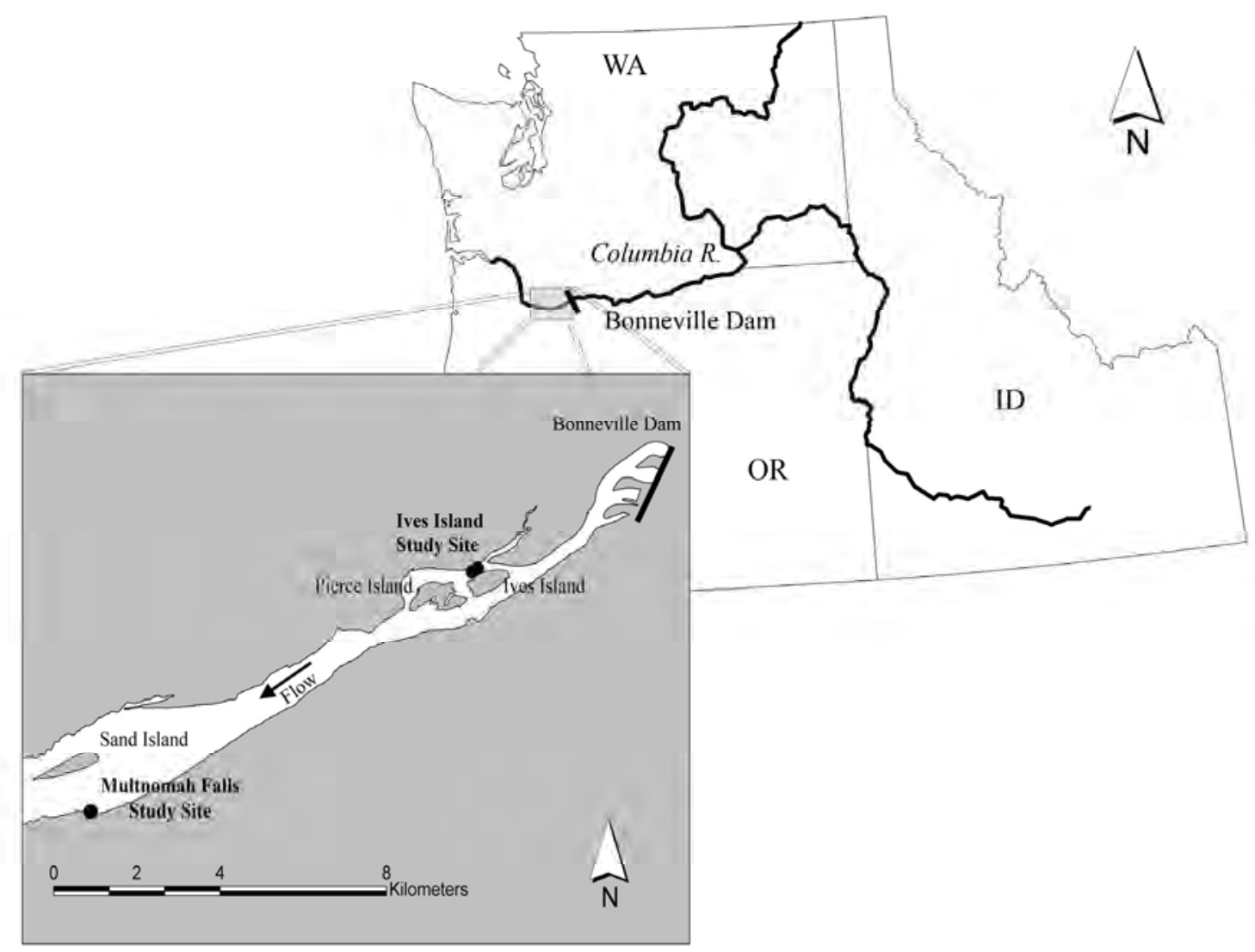

Figure 1.1. Ives Island and Multnomah Falls study sites

At the Ives Island site, we utilized five pairs of piezometers that were installed during either February 2006 or February 2007 (Figure 1.2; Arntzen et al. 2008b). Each pair of piezometers consisted of one river and one hyporheic piezometer. During 2008, Ives pair 4 was not used. At Multnomah Falls, pairs installed during February 2006 and February 2007 were used (Figure 1.3; Arntzen et al. 2008b). Pairs 1 and 3 were used during the sampling period; pair 2 at Multnomah Falls was considered an alternative location during 2008 and was not used. 


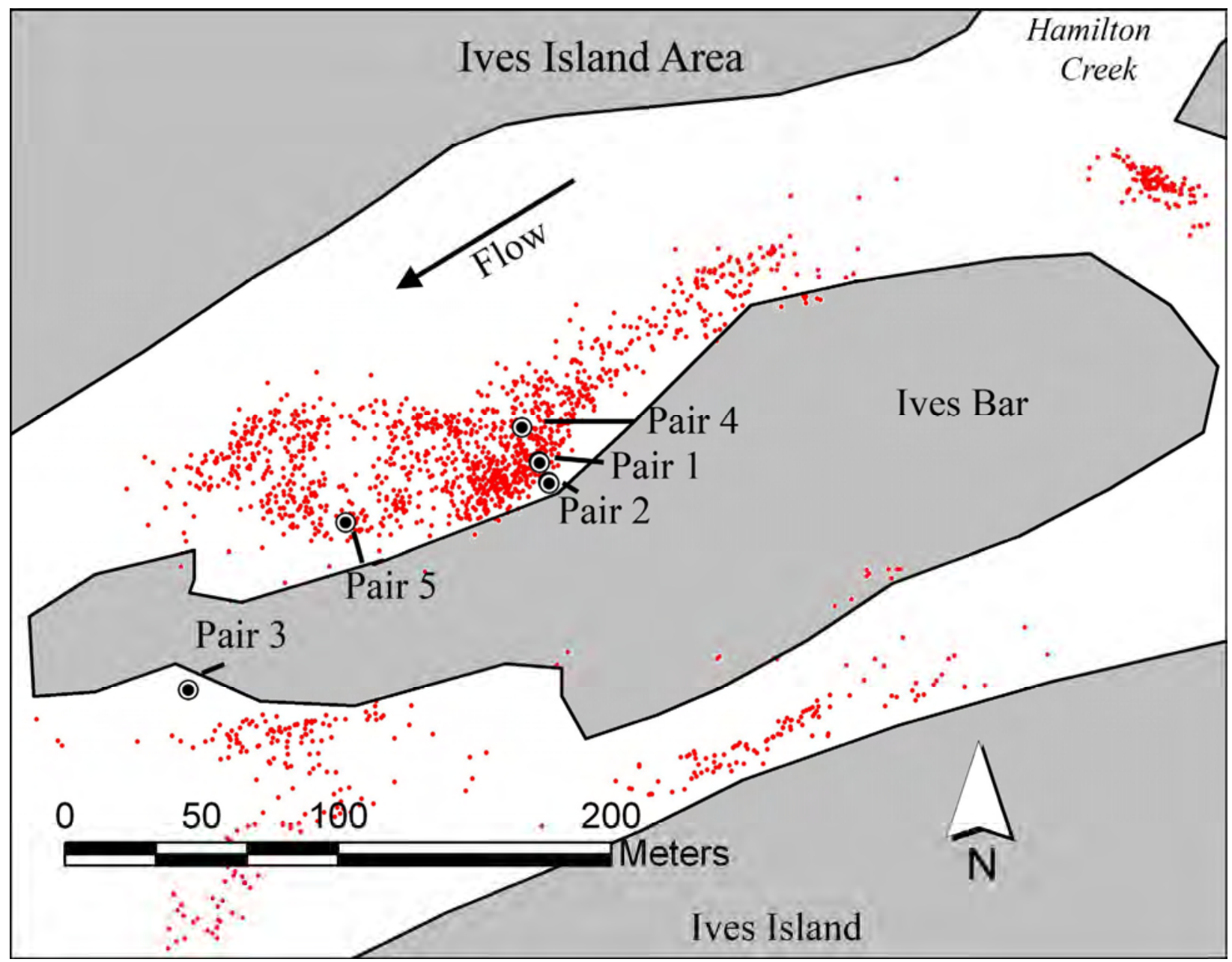

Figure 1.2. Piezometer stations (black and white circles) near Ives Island. Red circles represent chum salmon redds marked from spawning years 2000 through 2007. 


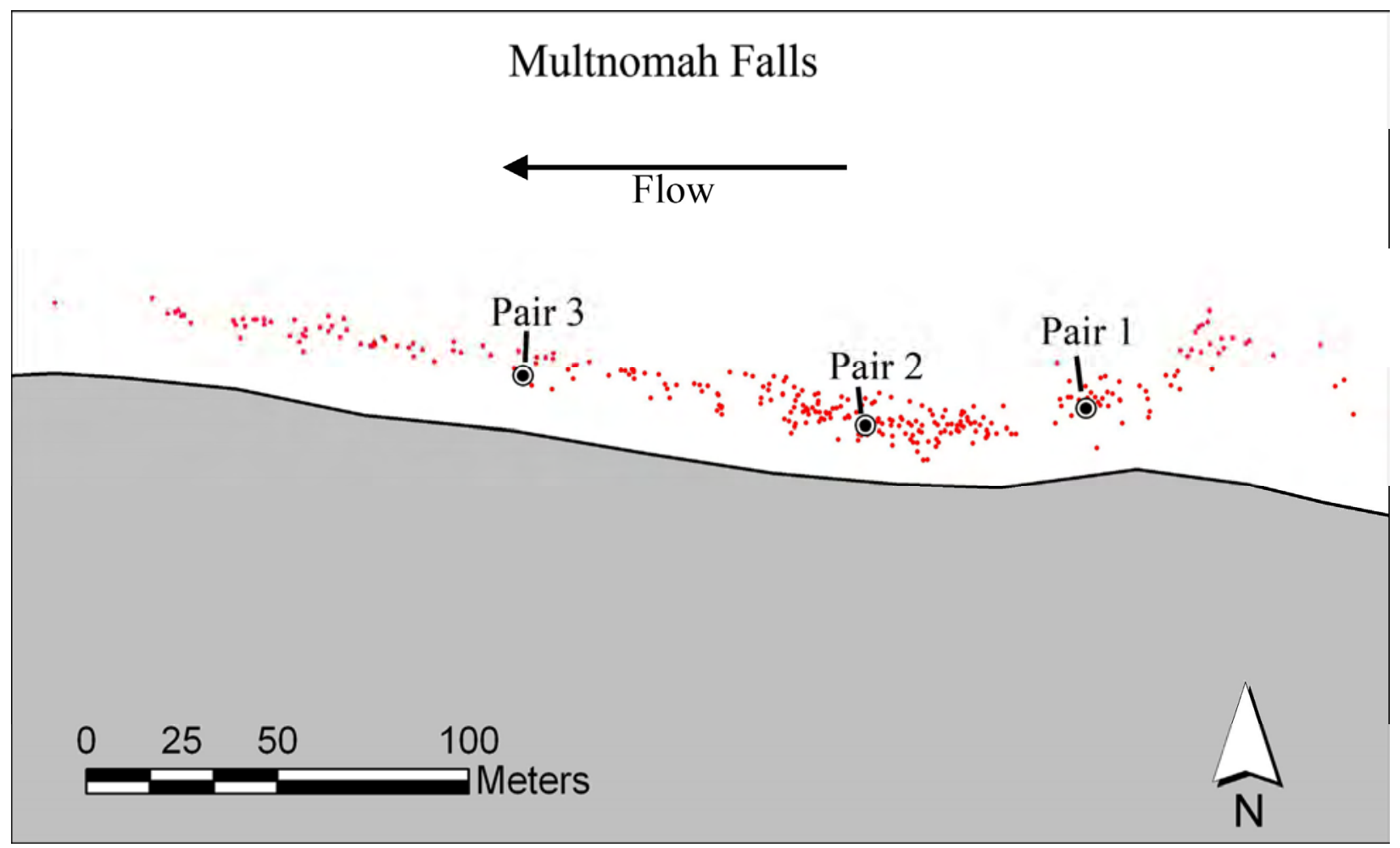

Figure 1.3. Piezometer stations (black and white circles) near Multnomah Falls. Red circles represent chum salmon redds marked from spawning years 2003 through 2007.

\section{Methods}

\section{Water Quality Monitoring at Ives Island and Multnomah Falls Spawning Locations}

During 2008, we used previously installed piezometers at Ives Island and Multnomah Falls locations (Arntzen et al. 2008b). To aid in recovering the sensors, a fixed diver line, similar to that installed in 2007 (Arntzen et al. 2008b), was installed at both the Ives Island and Multnomah Falls sites during early March 2008. Hydrolab Model 5 MiniSonde sensors (MS5; Hach Environmental, Loveland, Colorado) were used to monitor water quality. Each MS5 included sensors to monitor dissolved oxygen, specific conductance, salinity, depth, TDG, and temperature. Detailed specifications, including accuracies and resolutions of the sensors, are listed in Table 1.1. All MiniSondes were equipped with stirrers, which were shown during 2006 laboratory testing to be necessary to remove air bubbles from the TDG sensor (Arntzen et al. 2007a). The stirrers consisted of a 1.27-cm-wide revolving plastic blade attached to the MS5 next to the TDG sensor. 
Table 1.1. MiniSonde 5 water quality sensor specifications (Hach Environmental 2006)

\begin{tabular}{lccc}
\hline \multicolumn{1}{c}{ Sensor } & Range & Stated Accuracy & Resolution \\
\hline Total dissolved gas & 400 to $1400 \mathrm{mmHg}$ & $\pm 1.5 \mathrm{mmHg}$ & $1.0 \mathrm{mmHg}$ \\
Luminescent dissolved oxygen & 0 to $60 \mathrm{mg} / \mathrm{L}$ & $\begin{array}{c}0.1 \mathrm{mg} / \mathrm{L} \mathrm{at}<8 \mathrm{mg} / \mathrm{L} \text { and } \\
\pm 0.2 \mathrm{mg} / \mathrm{L} \text { at }>8 \mathrm{mg} / \mathrm{L}\end{array}$ & $0.01 \mathrm{mg} / \mathrm{L}$ \\
& & $\pm 2 \mu \mathrm{S} / \mathrm{cm}$ & 0.001 \\
Specific conductance & 0 to $100 \mathrm{mS} / \mathrm{cm}$ & $\pm 0.05 \mathrm{~m}$ & $0.01 \mathrm{~m}$ \\
Depth & 0 to $25 \mathrm{~m}$ & $\pm 0.10^{\circ} \mathrm{C}$ & $0.01^{\circ} \mathrm{C}$ \\
Temperature & -5 to $50^{\circ} \mathrm{C}$ & & \\
\hline
\end{tabular}

Prior to deployment, fully charged AA batteries were installed in all MS5 sensors. One measurement was recorded for each parameter every hour until the batteries were spent. The MiniSondes were given a 3-minute sensor warm-up and a 1-minute stirrer warm-up. MiniSondes were deployed with the sensor tips located in the center of the piezometer screen, pointed upward. Every two to three weeks from March 4 through May 14, 2008, MS5 sensors were recovered, downloaded, maintained, and redeployed. After the final deployment in May, the MiniSondes were left logging data in the piezometers until they were recovered during lower river discharge during July. During a typical deployment, power lasted approximately 20 days.

The accuracy of TDG readings was ensured by collecting post deployment data adjacent to a freshly calibrated unit (hereafter termed a side-by-side test). To collect the side-by-side test data, we placed the laboratory-calibrated MiniSonde and the recovered MiniSondes in the river at an approximate depth of $1 \mathrm{~m}$. For side-by-side deployments, we logged depth, temperature, TDG, dissolved oxygen, specific conductance, and salinity every 3 minutes for a minimum of 60 minutes. The Minisondes were programmed to have a 1-minute sensor and 1-minute stirrer warm-up prior to sampling. Following sideby-side tests, each TDG membrane was removed and later transported back to PNNL facilities in Richland, Washington, for quality assurance checks. Following membrane removal, we attached the TDG pressure sensor on the Minisonde to a Druck pressure calibrator (Druck Inc., Houston, Texas) that was certified to 0.0015-psi accuracy. We checked the TDG sensor for accuracy at 0, 100, 200, and $300 \mathrm{mmHg}$. If the pressure reading was off by more than $1 \mathrm{mmHg}$, the unit was recalibrated. A barometric pressure reading was obtained from a laboratory-calibrated Garmin Global Positioning System (GPS) unit (Garmin Vista, Olathe, Kansas) and used to reset the pressure sensor. Before each field trip, the barometric pressure from the Hanford Meteorological Station was used to calibrate the Garmin GPS unit. After recalibration, the sensor was checked once more for accuracy at 100, 200, and $300 \mathrm{mmHg}$. We calibrated the dissolved oxygen sensor by attaching a calibration cap filled with air-saturated water to the MiniSonde. The MiniSonde was held upright for the duration of the calibration by a clamping laboratory stand. The specific conductance sensor was also calibrated. First, it was rinsed three times and then immersed in a calibration cap full of $100-\mu \mathrm{S} / \mathrm{cm} \mathrm{NaCl}$ standard. If the sensor read between $90 \mu \mathrm{S} / \mathrm{cm}$ and $110 \mu \mathrm{S} / \mathrm{cm}$, we did not recalibrate. The depth sensor was calibrated by holding the sensor out of the water, pointing upward, and setting the depth value to zero. We also checked stirrers to ensure that the stirrers were functioning correctly and cleaned them if they were not. The laboratory calibrated unit was calibrated using the same procedure outlined for field calibration.

After all calibrations were completed, a laboratory-tested TDG membrane was attached to the pressure sensor. Each MiniSonde was then given a fully charged set of eight AA batteries and reprogrammed for a long-term deployment. All data were backed up using a SanDisk thumb drive 
(SanDisk Corporation, Milpitas, California). The membranes brought back to Richland were tested for functionality before they were reused in the field, as outlined in Tanner and Johnston (2001) and described in Arntzen et al. (2008b). All membrane test results are listed in Appendix A. For quality assurance, we looked at both the membrane test results and the side-by-side data. If either appeared questionable, we omitted the data. The Ives 1 river TDG data from the second deployment (March 20-April 3) were discarded because the membrane failed the tests and performed poorly during the side-by-side test. Ives 2 river TDG data from the fifth deployment (March 30-May 14) were discarded also due to membrane failure. During periods when TDG data were omitted due to membrane failure, other water quality parameters were retained. Data were omitted also due to problems with sensor dewatering, battery life, or stirrer failure. Whenever the specific conductance values were zero and depth was less than $0.15 \mathrm{~m}$, we assumed that dewatering was imminent and omitted data from all parameters. Although many of these instances occurred at the end of a deployment when we took the MiniSondes out of the water, there were times when the MiniSondes became dewatered during a deployment. When the battery life of a MiniSonde dropped below approximately $4.3 \mathrm{~V}$, zero values were recorded by some sensors. Zero values recorded due to low power were omitted from the data analysis. We deleted dissolved oxygen values from Multnomah Falls 3 river during deployment 4 (April 15-April 30). During this time, the stirrer stopped working; because of slow water movement through the piezometer, dissolved oxygen values quickly fell and were not representative of the river.

Water depth influences TDG saturation and, therefore, the physiological effects on sac fry. If the water depth is greater than the compensation depth (water depth at which gas is in equilibrium with hydrostatic, barometric, and water vapor pressure, and saturation level is at 100\%), TDG remains in solution and there are no negative impacts to sac fry. However, if the water depth is less than the compensation depth and TDG levels are elevated, gas bubbles begin to form, with potential negative impacts to sac fry. When this occurs, there is still a percentage reduction in the effective supersaturation in terms of impact to biota, based on the pressure of the water column, but the effective TDG is not fully reduced to $100 \%$. The extent to which it is reduced (and the potential negative impact to sac fry) is a function of the starting TDG concentration and the depth of the water column. We computed the percentage reduction (compensation) in supersaturation based on the pressure of the water column using an equation from Knittel et al. (1980):

$$
\begin{gathered}
\text { Percentage Compensation }=[\text { Water Depth }(\mathrm{cm}) \times 0.740(\mathrm{mmHg} / \mathrm{cm} \text { water })] \\
\text { 100/Barometric Pressure }(\mathrm{mmHg})
\end{gathered}
$$

We assumed that potential impacts to chum salmon sac fry would occur if the resulting dissolved gas levels were greater than 103\% after the percentage compensation was subtracted from the TDG concentration (Wood 1979).

Fluctuations in hyporheic water quality (e.g., temperature and dissolved oxygen) are known to occur in lower Columbia River chum salmon spawning areas, especially within the Ives Island area (Geist et al. 2002, 2008; Arntzen et al. 2007b). To evaluate how these fluctuations affected TDG composition, we used a computer program written by Dawson (1986) that incorporated equations from Bouck (1982) and Colt (1983). The program allowed us to compute the ratio of oxygen to nitrogen, which can affect mortality and symptoms of gas bubble trauma in anadromous sac fry (Nebeker et al. 1979; Krise and Herman 1989). The program required several known quantities to solve for its variables. These included barometric pressure, water temperature, differential dissolved gas pressure, dissolved oxygen, and salinity. 
Water quality results were summarized using functions in Microsoft Excel to calculate the mean, standard error, standard deviation, minimum, and maximum values of uncompensated TDG, depthcompensated TDG, dissolved oxygen, temperature, and specific conductance. Data were summarized from the start of monitoring until emergence (from March 4 through May 15) excluding the data we omitted.

\section{Estimated Exposure of Chum Salmon Redds to Total Dissolved Gas}

The exposure of chum salmon redds to potentially harmful TDG levels is ultimately controlled by the TDG concentration of water surrounding the egg pocket, the extent to which TDG can be depthcompensated (which depends on the elevation of the redd and the water level of the river), and the length of time embryos are exposed to harmful levels of TDG. Operations at Bonneville Dam and chum salmon seining data from the Oregon Department of Fish and Wildlife (ODFW) suggest that incubating fry could be exposed to elevated TDG between March 1 and May 15. The spatial distribution of chum salmon redds was provided by the ODFW for spawning year 2007 (ODFW, unpublished data). To assign vertical elevations to chum salmon redds, we used a bathymetric coverage constructed previously as part of a hydrodynamic model in the Ives Island area (Tiffin et al. 2004). Redd locations were combined with vertical elevations from the bathymetric coverage using ArcMap (Environmental Systems Research Institute, Inc. [ESRI], Redlands, California). A benchmark was created to establish vertical control using a Trimble real-time kinematic GPS receiver (Arntzen et al. 2008b).

We used redd elevations and hourly water surface elevation to estimate the hourly water depth at each redd during incubation year 2008. Our goal was to assess the greatest potential risk to chum salmon fry from elevated TDG. Thus, for each hour, we selected the highest TDG value from a group of sensors simultaneously recording TDG data in the Ives Island area. This TDG value was assumed to be representative of TDG at each redd for that hour and was depth-compensated using the depth of water over each redd. This process was completed first using surface water monitoring TDG sensors, then repeated using hyporheic monitoring TDG sensors. Using both the surface water and hyporheic TDG data allowed us to evaluate whether they each pose an equal risk to chum sac fry. In each case, TDG monitoring results (from either the hyporheic zone or from surface water) were applied to individual redds so that exposure histories over time could be compiled for each redd. The number of hours that depth-compensated TDG exceeded 100\%, 103\%, 105\%, and 108\% were tallied for each redd, allowing for comparisons between redd elevation and exposure time at the various depth-compensated TDG concentrations. During periods of redd dewatering, TDG was not counted toward total exposure time for any of the tested levels. Thus, high-elevation redds could show slightly lower exposure times to given TDG levels due to the increased time they were dewatered.

\section{Results}

\section{Comparison of PNNL Surface Water Total Dissolved Gas Monitoring to Other Columbia River Monitoring Locations}

We compared surface water TDG concentrations obtained from our stations near Ives Island and Multnomah Falls to results obtained by the U.S. Geological Survey (USGS) during the same period at Bonneville Dam, Cascades Island, Warrendale, and Camas/Washougal (Figure 1.4). Surface water TDG 
was generally lower at Bonneville and Ives Island stations compared to that measured at Warrendale and Camas/Washougal (Figure 1.5). Multnomah Falls was the closest to the average of all the sites (excluding Cascades Island). With the exception of Cascades Island, the data from each site remained within $4 \%$ of the average of all the sites. The data did not match as well as they did during the 2007 monitoring season when the data from each site remained within $2 \%$ of the average of all of the sites. The TDG records from all of the sites were very highly correlated with one another (correlation coefficient of at least 0.84) except for Cascades Island, which had a correlation coefficient of between 0.60 and 0.69 when compared to the other locations. Excluding Cascades Island, all correlation coefficients from the 2007 monitoring season were above 0.91 .

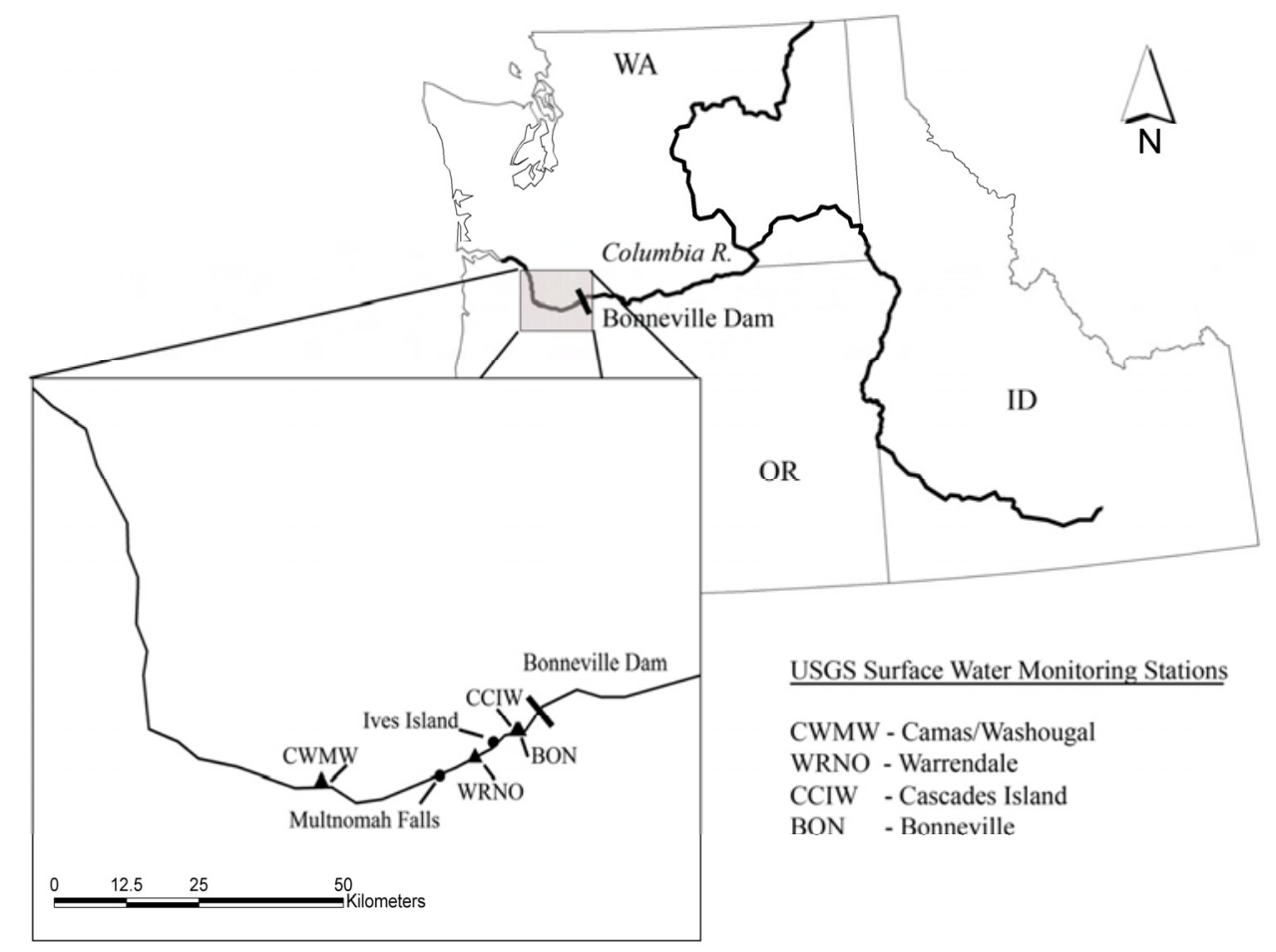

Figure 1.4. Total dissolved gas monitoring stations downstream of Bonneville Dam 


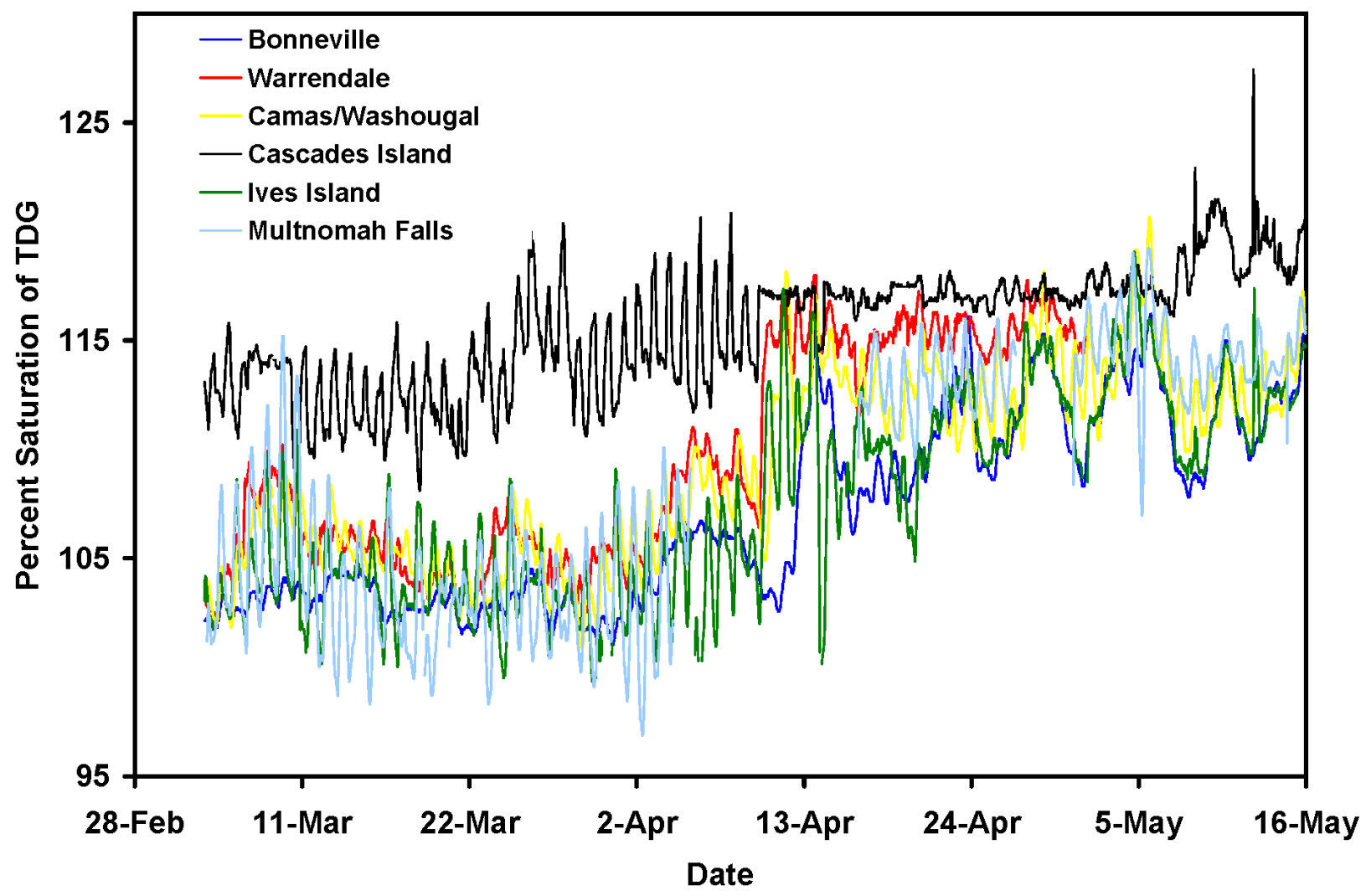

Figure 1.5. Comparison of 2008 total dissolved gas values obtained at PNNL monitoring stations and USGS surface water monitoring stations

\section{Water Quality Monitoring at Ives Island and Multnomah Falls Spawning Locations}

The following sections provide a summary of the water quality data collected at both the Ives Island and Multnomah Falls study sites during the period when spring spill operations occurred during chum sac-fry incubation (March 4 through May 15, 2008; Figure 1.6). All data collected during the monitoring at both sites are presented in Appendix B. 


\begin{tabular}{|c|c|c|}
\hline & March & May \\
\hline Ives 1 River & & \\
\hline Ives 1 Hyporheic & & \\
\hline Ives 2 River & March 4 - May 15 & \\
\hline Ives 2 Hyporheic & March 4 - May 15 & \\
\hline Ives 3 River & & May 1 - 15 \\
\hline Ives 3 Hyporheic & & May 1 - 15 \\
\hline Ives 5 River & & \\
\hline Ives 5 Hyporheic & & \\
\hline MF 1 River & March 4 - May 15 & \\
\hline MF 1 Hyporheic & March 4 - May 15 & \\
\hline MF 3 River & & \\
\hline MF 3 Hyporheic & & \\
\hline
\end{tabular}

Figure 1.6. Deployment periods for water quality sensors in Ives Island and Multnomah Falls area monitoring locations

\section{Ives Island Site}

We monitored water quality including TDG, dissolved oxygen, temperature, specific conductance, and water level at five monitoring stations in the Ives Island area during March 4 through May 15, 2008 (Figure 1.6). Total dissolved gas results for each location are presented in terms of both uncompensated and depth-compensated values at the exact location of each sensor.

\section{Uncompensated Total Dissolved Gas}

Ives Island river TDG levels followed similar trends at all of our sampling pairs (Figure 1.7). Average values $( \pm$ SE) ranged from $106.5 \%( \pm 0.1)$ at Ives 2 river to $112.2 \%( \pm 0.1)$ at Ives 3 river. The maximum hourly value for TDG was $118.5 \%$ at Ives 3 river. Ives Island hyporheic TDG varied between sites (Figure 1.7). The highest TDG values were recorded at Ives 2 hyporheic, and averaged $( \pm \mathrm{SE})$ $105.4 \%$ ( \pm 0.04$)$. The TDG response at Ives 2 hyporheic was most variable during the early part of the record (March 4, 2008, through April 21, 2008), with a range of approximately 18\%, compared to a range of approximately 7\% from April 22 through May 15 (Figure 1.7). TDG was lower at Ives 1 hyporheic and Ives 5 hyporheic, averaging $( \pm$ SE) 102.5\% ( \pm 0.1$)$ and 97.2\% ( \pm 0.1$)$, respectively. Ives 2 had the highest hyporheic TDG value, with a maximum hourly value of $111.1 \%$.

After spring spill started (April 10, 2008), Ives 1 hyporheic average uncompensated TDG percentage saturation values rose (from $101.6 \% \pm 0.1 \%$ to $103.1 \% \pm 0.2 \%$ ). A similar increase occurred at Ives 5 hyporheic, where uncompensated TDG increased following the initiation of spill from $96.3 \%( \pm 0.1)$ to $98.3 \%$ ( \pm 0.1 ). At Ives 2 hyporheic, average TDG values decreased following the onset of spring spill, averaging $106.1 \%( \pm 0.1)$ before spring spill started and $104.6 \%( \pm 0.1)$ afterward. We recorded no data at Ives 3 hyporheic prior to April 10, 2008. 
(A)

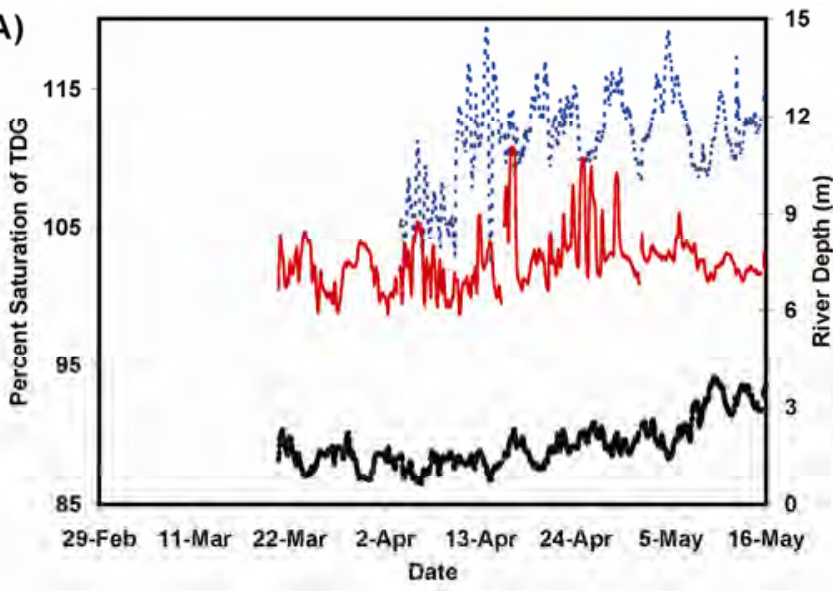

(C)

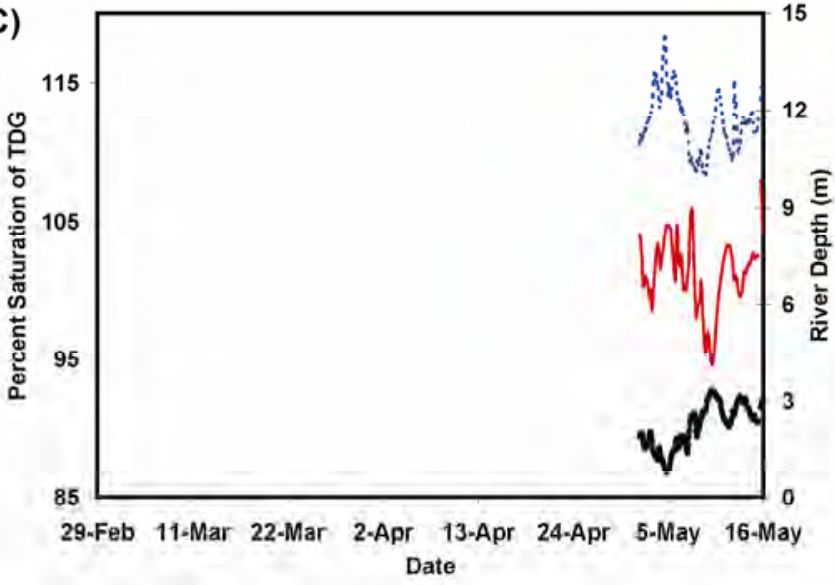

(B)

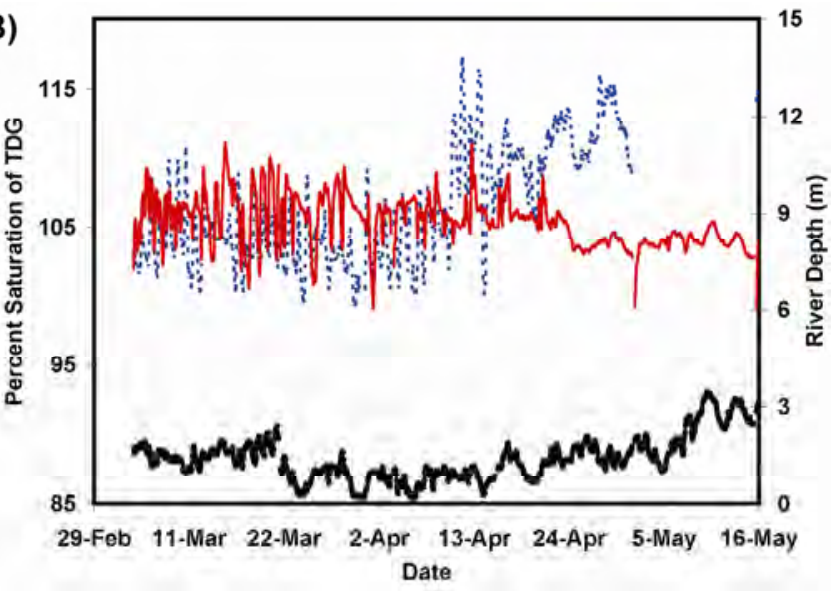

(D)

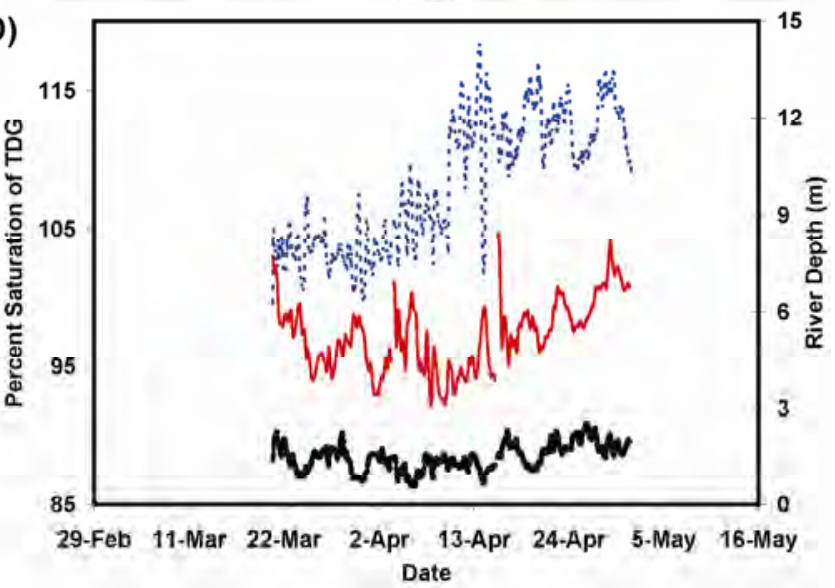

Figure 1.7. Ives Island uncompensated TDG values. (A) Ives pair 1, (B) Ives pair 2, (C) Ives pair 3, and (D) Ives pair 5. Solid red lines represent uncompensated TDG values for hyporheic sensors; dashed blue lines represent uncompensated TDG values for river sensors. Solid black lines represent river depth at the hyporheic sensors.

\section{Depth-Compensated Total Dissolved Gas}

Depth-compensated TDG levels were elevated at our monitoring locations during 2008 compared to previous monitoring years (Figure 1.8). During 2008, depth-compensated TDG levels were above $103.0 \%$ for 334 hours at river monitoring locations and 84 hours at hyporheic monitoring locations. During 2006 and 2007 combined, depth-compensated TDG in the river exceeded 103.0\% for 11 hours, and zero hours were recorded for hyporheic sensors. The difference between 2008 and the other monitoring years was caused primarily by shallower river depths during the spring spill season that year, providing less depth compensation than in 2006-2007. 

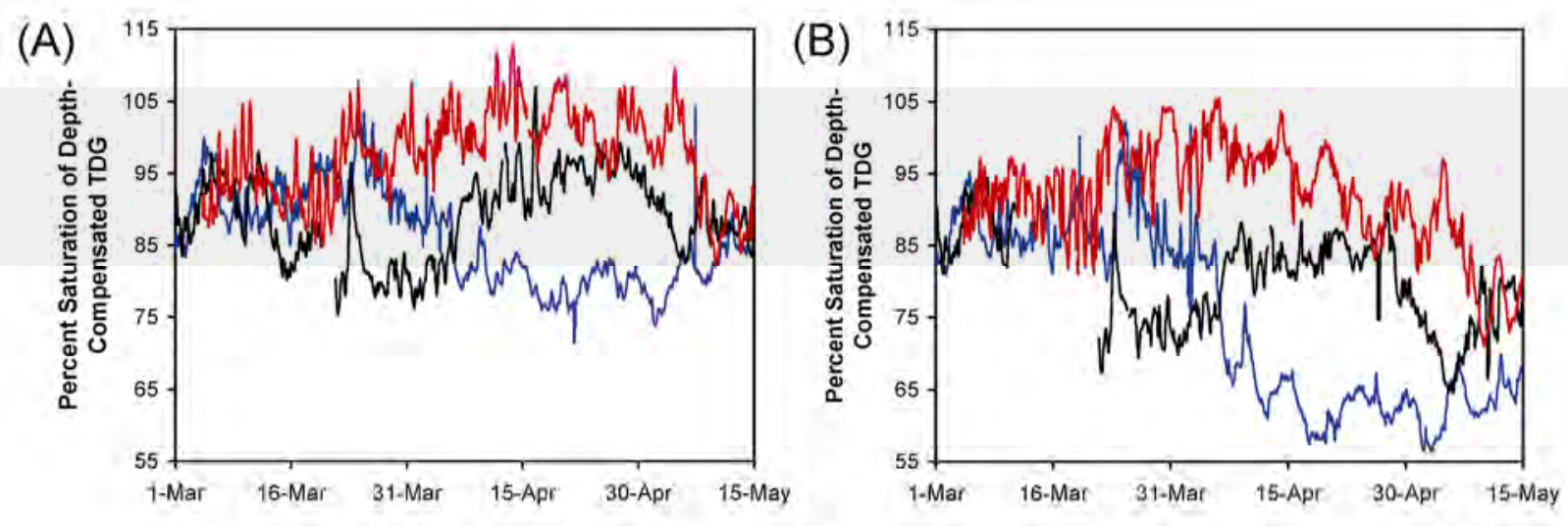

Figure 1.8. Ives Island area depth-compensated TDG values measured in (A) surface water and (B) the hyporheic zone. Blue lines represent 2006, black lines represent 2007, and red lines represent 2008. Data represent the maximum values recorded from all active sensors for each measurement.

\section{Dissolved Oxygen}

Average ( \pm SE) river percentage saturation of dissolved oxygen (DO) remained relatively stable at Ives monitoring locations, ranging from $98.7( \pm 0.6)$ at Ives 3 river to $108.4( \pm 0.2)$ at Ives 5 river. There were frequent diurnal fluctuations, presumably due to photosynthetic activity, that caused the data to fluctuate over an approximately 30\% range (Figure 1.9). The most variability occurred at Ives 2, where percentage saturation of DO had a range of $61.2 \%$. Hyporheic dissolved oxygen levels were generally lower than river levels and much more variable (Figure 1.9). Average ( $\pm \mathrm{SE}$ ) hyporheic values ranged from $23.4 \%( \pm 0.3)$ saturation at Ives 5 hyporheic to $48.7 \%( \pm 0.3)$ at Ives 2 hyporheic. Dissolved oxygen generally remained above 20\% saturation at Ives 1 hyporheic and above 30\% at Ives 2 hyporheic. Minimum DO values were less than 5\% saturation at Ives 5 hyporheic and at Ives 3 hyporheic, where minimum values approached $0.9 \%$. The largest difference between minimum and maximum hyporheic DO-96.8\% — occurred at Ives 3 hyporheic. The smallest difference was 71.3\%, at Ives 5 hyporheic. Fluctuations in dissolved oxygen influenced the ratio of oxygen to nitrogen within Ives Island hyporheic monitoring locations. Average $\mathrm{O}_{2} / \mathrm{N}_{2}$ ranged from 0.19 at Ives 5 hyporheic to 0.41 at Ives 2 hyporheic. Values of $\mathrm{O}_{2} / \mathrm{N}_{2}$ were 0.30 and 0.37 at Ives 3 hyporheic and Ives 1 hyporheic, respectively (see Appendix B for comprehensive $\mathrm{O}_{2} / \mathrm{N}_{2}$ data). 

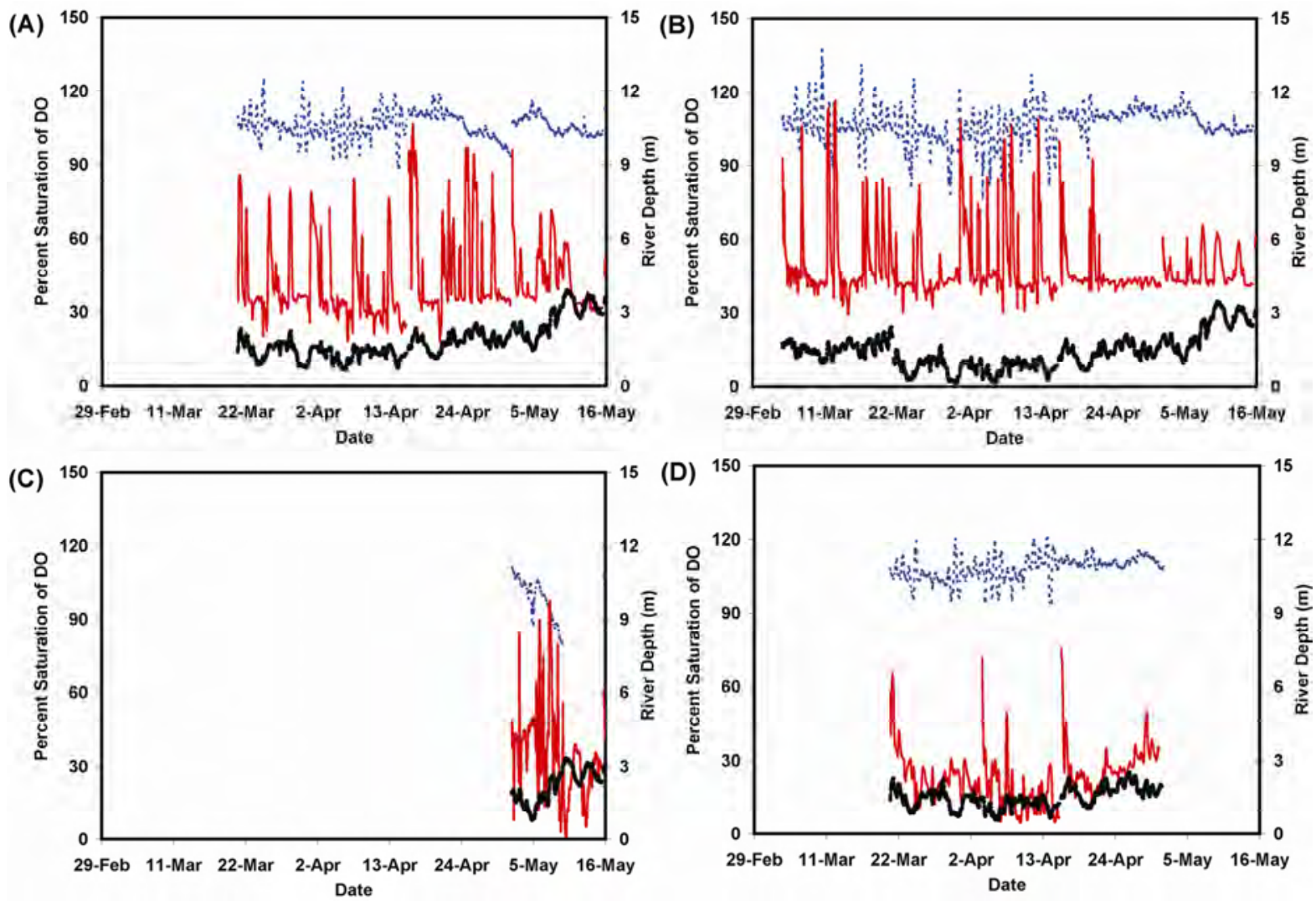

Figure 1.9. Ives Island area dissolved oxygen values. (A) Ives pair 1, (B) Ives pair 2, (C) Ives pair 3, and (D) Ives pair 5. Solid red lines represent dissolved oxygen for hyporheic sensors, and dashed blue lines represent dissolved oxygen for river sensors. Solid black lines represent river depth at the hyporheic sensor.

\section{Temperature}

River temperatures at all four monitoring stations displayed a typical spring warming trend over the sampling period, gradually increasing from February through May, from approximately $4.5^{\circ} \mathrm{C}$ to approximately $12.5^{\circ} \mathrm{C}$ (Figure 1.10). Hyporheic temperature was relatively stable at all sites monitored throughout our study, with only a slight upward trend and a range of approximately $2-3^{\circ} \mathrm{C}$ at Ives 1,3 , and 5 and a range of approximately $5^{\circ} \mathrm{C}$ at Ives 2 hyporheic. Hyporheic water was warmer than river water at the beginning of the record and approached river temperatures as part of seasonal warming trends during mid-April. At the end of the monitoring period, hyporheic water was almost $2^{\circ} \mathrm{C}$ colder than the river (Figure 1.10). Over short time scales (e.g., during the period between March 22 and April 14, 2008), hyporheic temperature data tended to be highly variable and were inversely correlated with river stage at Ives 1 hyporheic $(R=-0.84)$ and Ives 2 hyporheic $(R=-0.67$; Figure 1.11$)$. A similar response had been observed during previous monitoring years at some of the monitoring locations (Arntzen et al. 2008b). However, during longer periods, the trends at all 2008 hyporheic monitoring locations exhibited a relatively stable average hyporheic temperature. The relative stability of mean hyporheic data during 2008 may reflect lower river levels that year as compared to 2006 and 2007, when water levels were higher and hyporheic trends tended to match those of the river more closely (Arntzen et al. 2008b). 

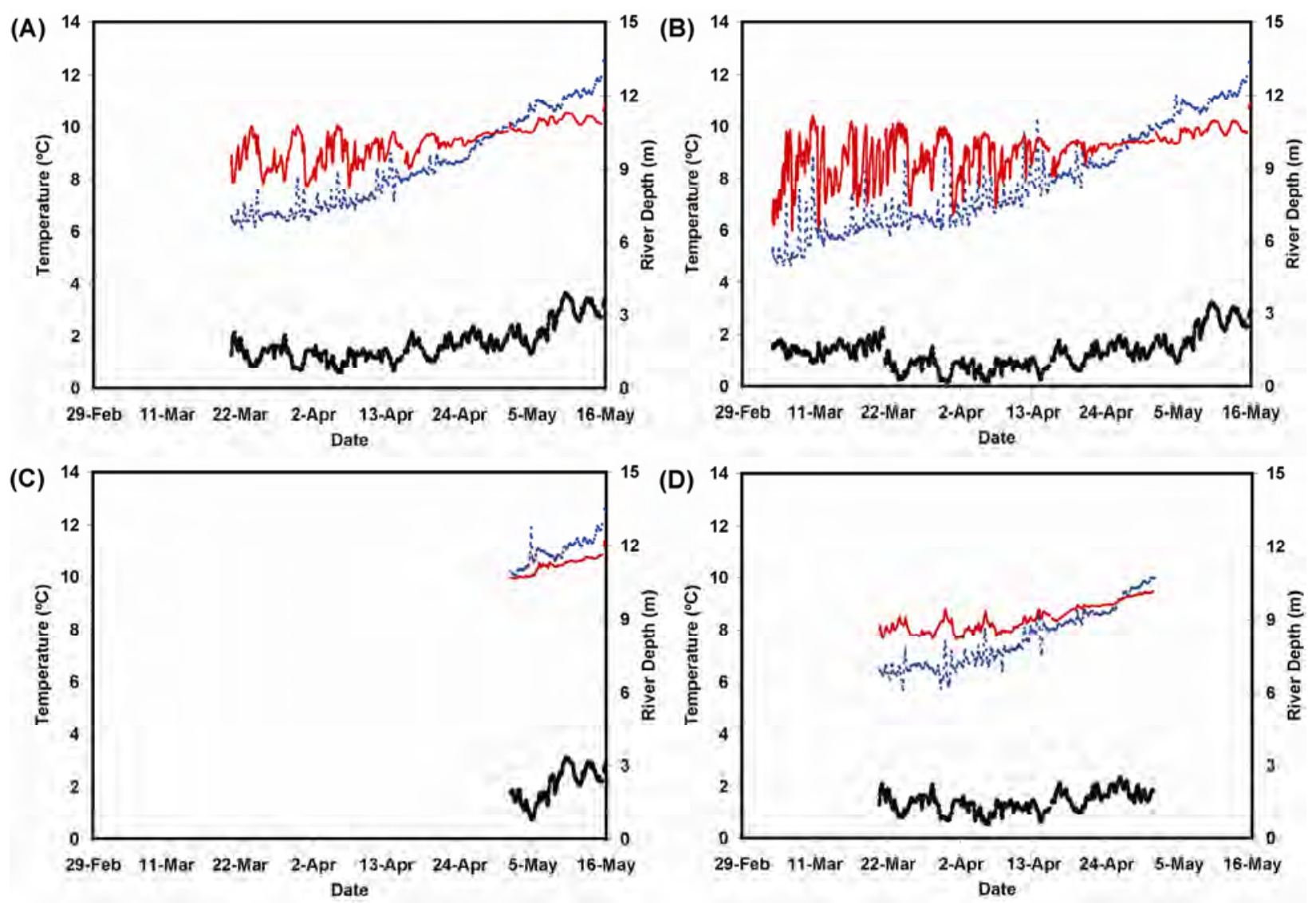

Figure 1.10. Ives Island site temperature values. (A) Ives pair 1, (B) Ives pair 2, (C) Ives pair 3, and (D) Ives pair 5. Solid red lines represent temperature for hyporheic sensors, and dashed blue lines represent temperature for river sensors. Solid black lines represent river depth at the hyporheic sensor.
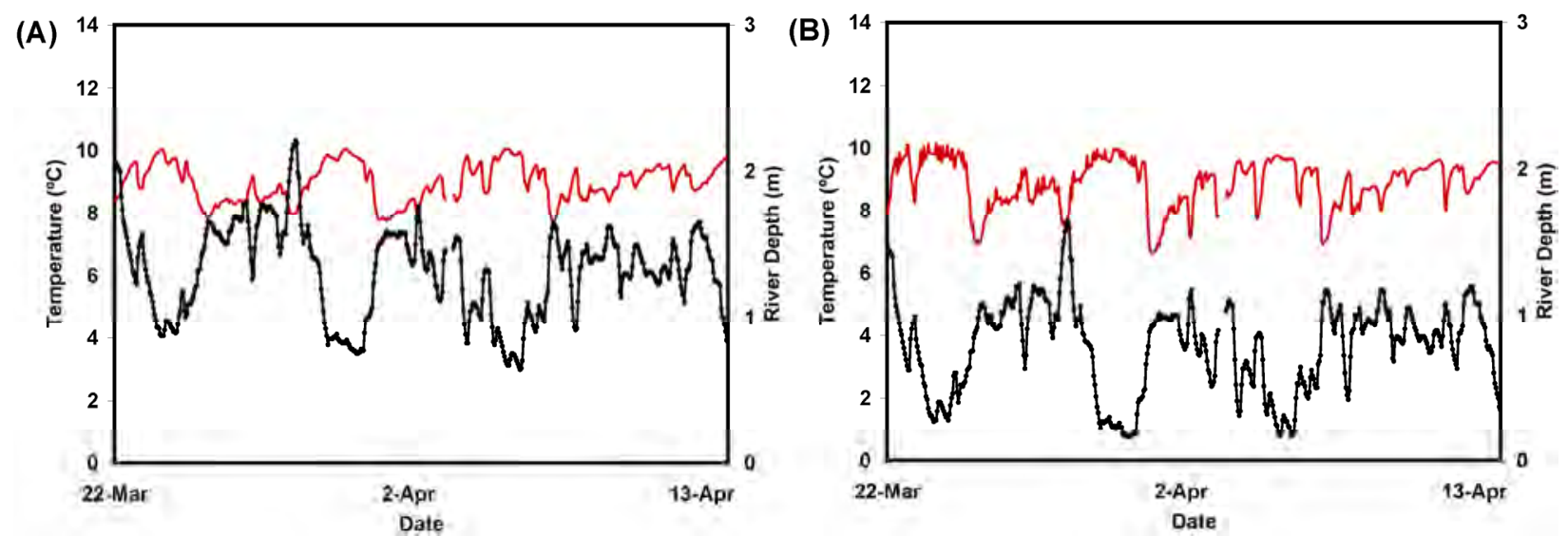

Figure 1.11. Ives Island site hyporheic temperatures, March 22-April 14, 2008. (A) Ives Island pair 1 and (B) Ives Island pair 2. Red lines represent temperature for hyporheic sensors, and black lines represent river depth at hyporheic sensors. 


\section{Specific Conductance}

Specific conductance was higher in the river than in the hyporheic zone (Figure 1.12). Mean specific conductance in the river ranged from $164.3 \mu \mathrm{S} / \mathrm{cm}( \pm 0.4 \mu \mathrm{S} / \mathrm{cm})$ at Ives 3 river to $180.1 \mu \mathrm{S} / \mathrm{cm}$ $( \pm 0.6 \mu \mathrm{S} / \mathrm{cm})$ at Ives 5 river. Mean hyporheic values ranged from $141.1 \mu \mathrm{S} / \mathrm{cm}( \pm 0.4 \mu \mathrm{S} / \mathrm{cm})$ at Ives 3 hyporheic to $148.8 \mu \mathrm{S} / \mathrm{cm}( \pm 0.2 \mu \mathrm{S} / \mathrm{cm})$ at Ives 1 hyporheic. Specific conductance fluctuated more throughout the monitoring period within the hyporheic zone than it did in the river (Figure 1.12).

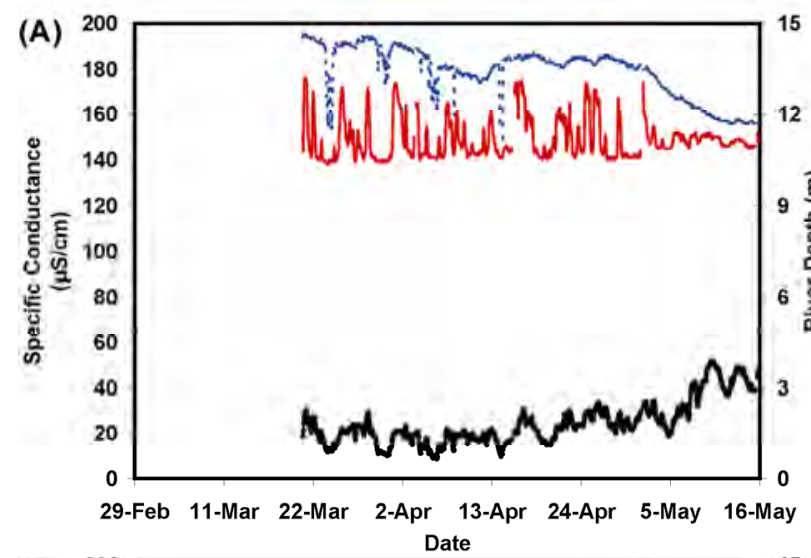

(B)
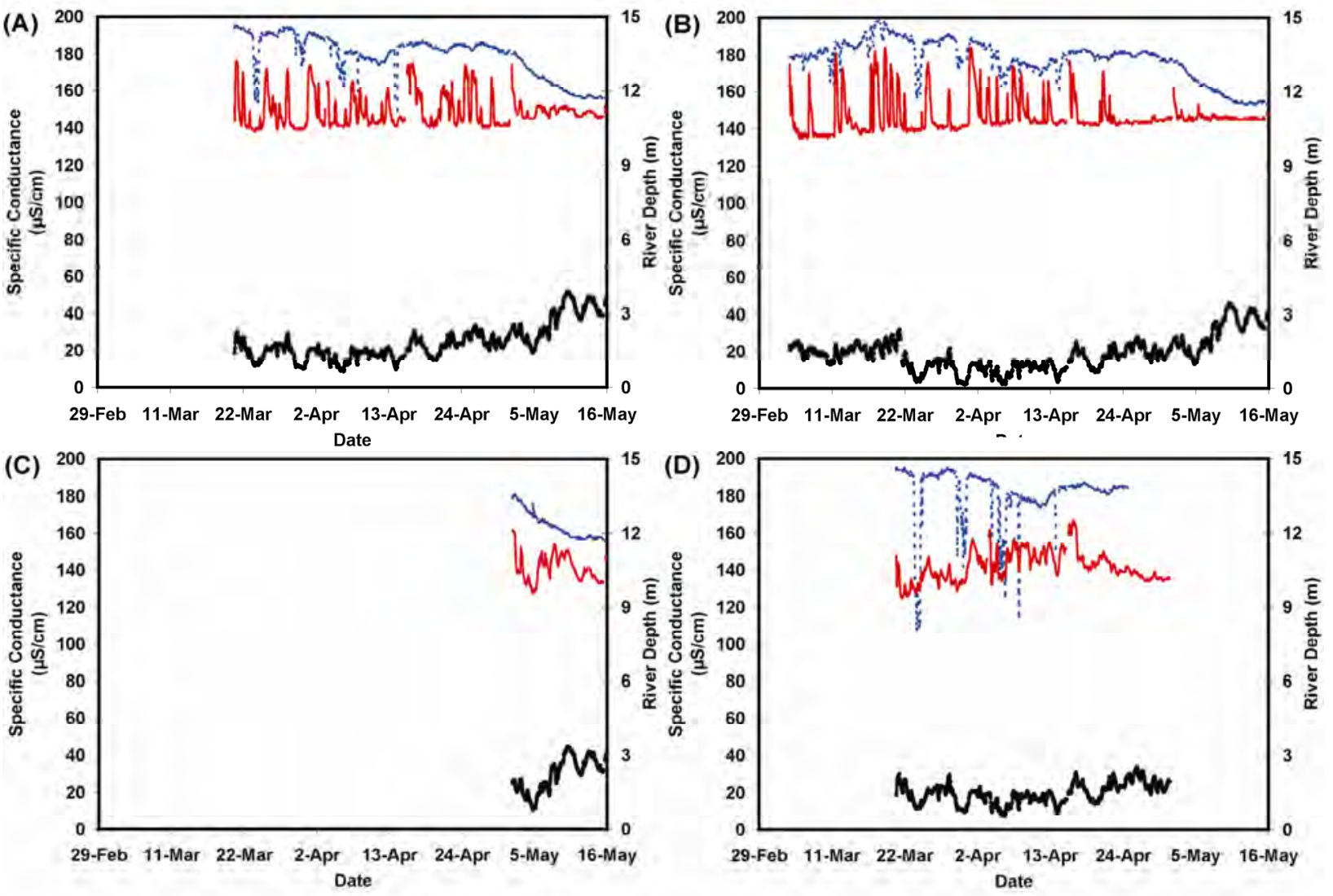

Figure 1.12. Ives Island site specific conductance values. (A) Ives pair 1, (B) Ives pair 2, (C) Ives pair 3, and (D) Ives pair 5. Solid red lines represent specific conductance for hyporheic sensors, and dashed blue lines represent specific conductance for river sensors. Solid black lines represent river depth at the hyporheic sensor.

\section{Multnomah Falls Site}

We monitored water quality at Multnomah Falls locations pair 1 and Multnomah Falls pair 3 at various times during the period from March 4 through May 15, 2008. Data availability from each Multnomah Falls monitoring location was summarized in Figure 1.6. 


\section{Uncompensated Total Dissolved Gas}

Mean uncompensated TDG was $107.3 \%( \pm 0.2)$ at Multnomah Falls 1 river and $113.9 \%( \pm 0.1)$ at Multnomah Falls 3 river (Figure 1.13). The higher average at Multnomah Falls 3 river was a function of the period during which monitoring was conducted there; monitoring was conducted only after the onset of spring spill (April 10, 2008) at Multnomah Falls 3, when TDG concentrations were elevated. At Multnomah Falls 1 river, TDG increased by approximately 10\% following the start of spring spill (Figure 1.13). Hyporheic TDG ranged from 100.7\% ( \pm 0.02 ) at Multnomah Falls 1 hyporheic to 102.3\% $( \pm 0.04)$ at Multnomah Falls 3 hyporheic (Figure 1.13). Total dissolved gas was more variable at Multnomah Falls 3 hyporheic than at Multnomah Falls 1 hyporheic, where the overall ranges in TDG were $9.7 \%$ and 3.7\%, respectively. Increased variability at Multnomah Falls 3 hyporheic suggests the location was in greater contact with surface water than was Multnomah Falls 1 hyporheic.
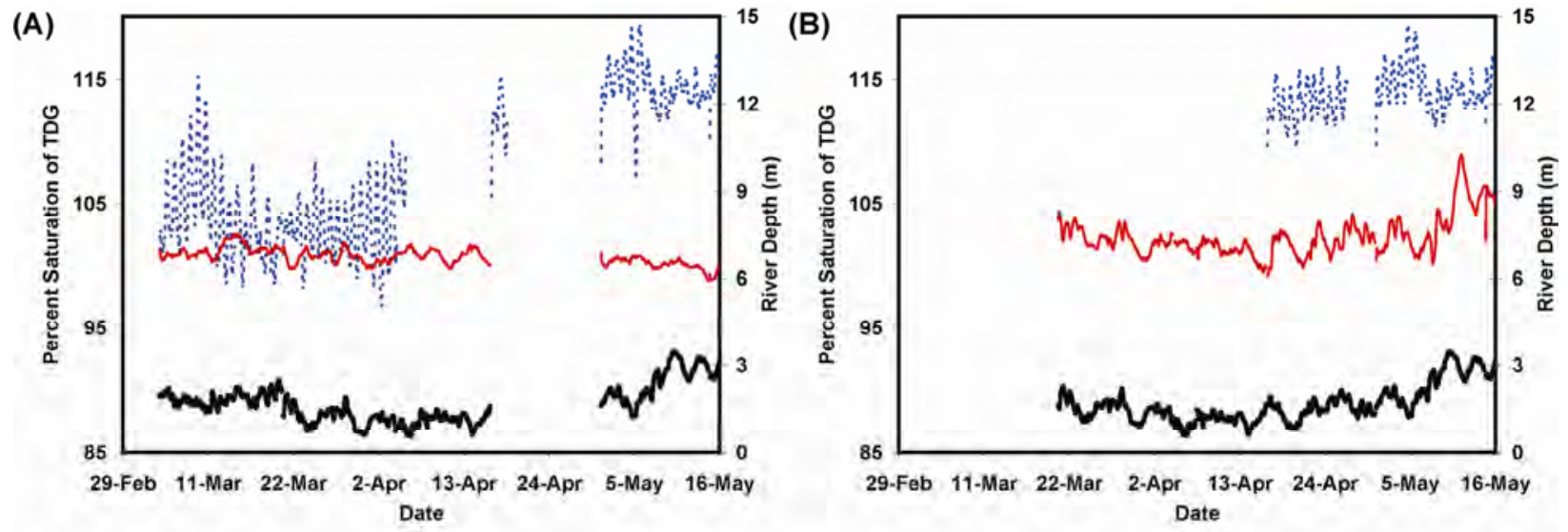

Figure 1.13. Multnomah Falls total dissolved gas values. (A) Multnomah Falls pair 1 and (B) Multnomah Falls pair 3. Solid red lines represent uncompensated TDG values for hyporheic sensors, and dashed blue lines represent uncompensated TDG values for river sensors. Solid black lines represent river depth at the hyporheic sensor.

\section{Depth-Compensated Total Dissolved Gas}

During 2008, less depth compensation was available compared to monitoring years 2006-2007. Depth-compensated TDG within the hyporheic zone at Multnomah Falls still remained below 100\%. However, at Multnomah Falls river monitoring locations, depth-compensated TDG frequently exceeded 103\%. During 2008, depth-compensated TDG at Multnomah Falls 1 river exceeded $100.0 \%$ for 133 hours and exceeded $103.0 \%$ for 43 hours. At Multnomah Falls 3 river, TDG exceeded $100.0 \%$ for 182 hours and exceeded $103.0 \%$ for 93 hours. Peak depth-compensated TDG values exceeded 109.0\% at both Multnomah Falls river monitoring locations. Values at Multnomah Falls 1 river were elevated above 105.0\% three times - once each during early March, early April, and early May (Figure 1.14). At Multnomah Falls 3 river, monitoring began after the onset of spring spill, and depth-compensated TDG approached $110 \%$ twice during that period, once during mid-April and again during early May (Figure 1.14). 

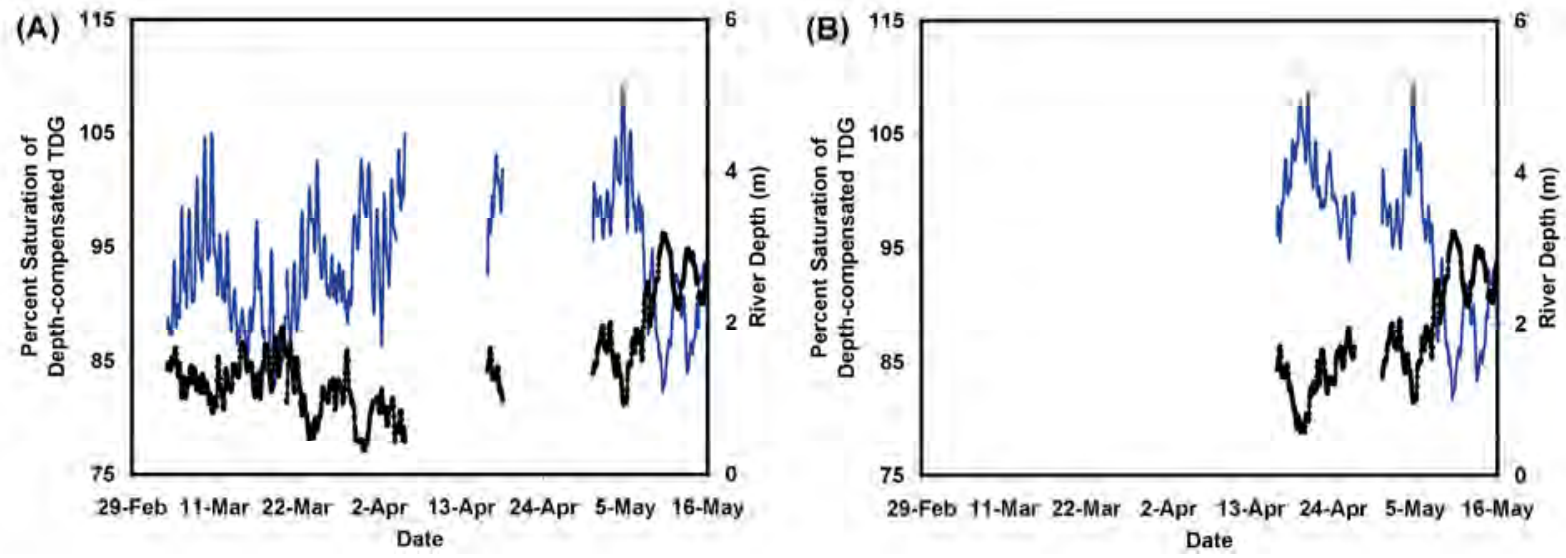

Figure 1.14. Multnomah Falls depth-compensated total dissolved gas. (A) Multnomah Falls pair 1 and (B) Multnomah Falls pair 3. Solid blue lines represent depth-compensated TDG values for river sensors, and black lines represent river depth.

\section{Dissolved Oxygen}

River DO values were highly variable over short time scales (e.g., days), especially prior to spring spill, a result noted not only in the Ives area during 2008 but also during previous monitoring years at Multnomah Falls (Arntzen et al. 2008b). During 2008, Multnomah Falls river DO saturation ranged from approximately $60 \%$ to $150 \%$ (Figure 1.15 ). Dissolved oxygen levels stabilized following the start of spring spill, generally ranging only $10 \%-15 \%$. Mean river DO was similar to that recorded in the Ives Island area, with values of $101.4 \%( \pm 0.4)$ and $110.4 \%( \pm 0.2)$ at Multnomah Falls 1 and 3 river, respectively. In contrast to hyporheic DO in the Ives Island area, Multnomah Falls hyporheic DO values were stable throughout the study and were quite a bit higher than in the Ives Island area; mean values were $86.0 \%( \pm 0.1)$ and $76.5 \%( \pm 0.1)$ at Multnomah Falls 1 and 3 hyporheic, respectively (Figure 1.15). Similarly, the ratio of oxygen to nitrogen was higher within Multnomah Falls hyporheic sensors than in Ives Island hyporheic sensors. The $\mathrm{O}_{2} / \mathrm{N}_{2}$ ranged from 0.70 at Multnomah Falls 3 hyporheic to 0.82 at Multnomah Falls 1 hyporheic (see Appendix B for comprehensive $\mathrm{O}_{2} / \mathrm{N}_{2}$ data). 

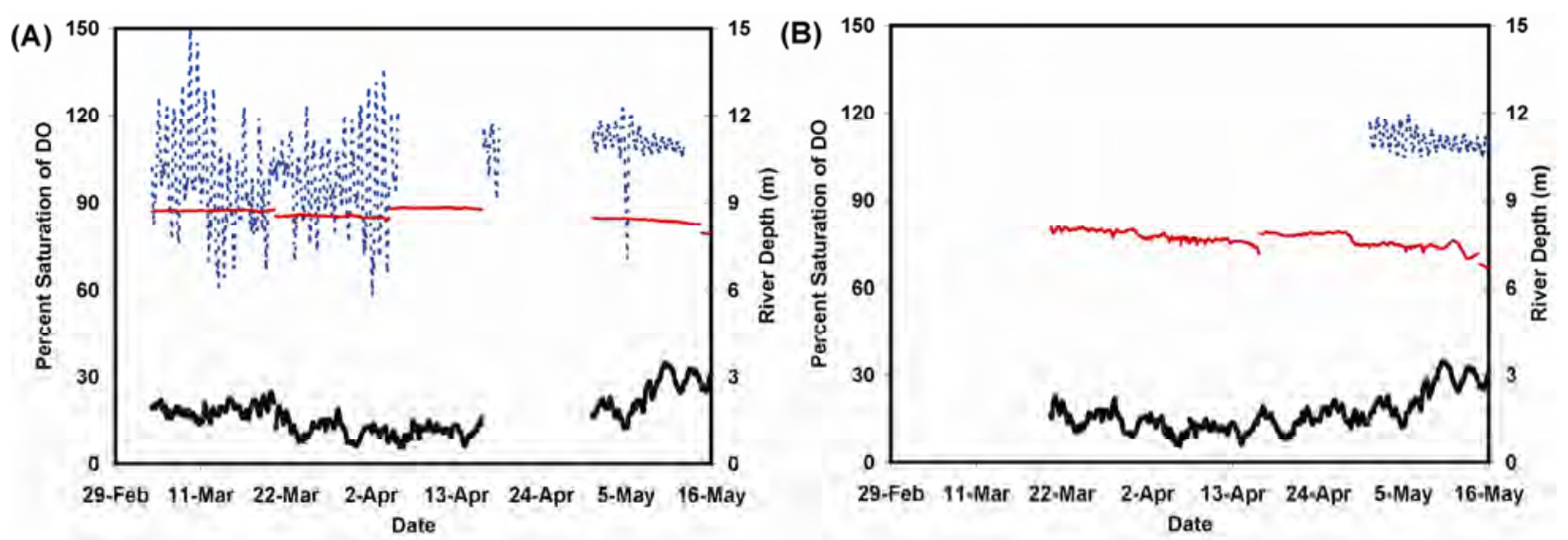

Figure 1.15. Multnomah Falls dissolved oxygen. (A) Multnomah Falls pair 1 and (B) Multnomah Falls pair 3. Solid red lines represent dissolved oxygen values for hyporheic sensors, and dashed blue lines represent dissolved oxygen for river sensors. Solid black lines represent river depth at the hyporheic sensor.

\section{Temperature}

Temperature patterns at Multnomah Falls 1 and Multnomah Falls 3 locations during 2008 were very similar to 2007 monitoring results (Arntzen et al. 2008b). During 2008, river temperature at both sites displayed a typical spring warming trend, gradually increasing from February through May, starting at approximately $5^{\circ} \mathrm{C}$ and rising to $12.5^{\circ} \mathrm{C}$ (Figure 1.16). Hyporheic temperatures were very stable throughout the study period (Figure 1.16). Similar to 2007 monitoring results, during 2008 Multnomah Falls 1 hyporheic was warmer than Multnomah Falls 3 hyporheic, with an average of $7.3^{\circ} \mathrm{C}$ compared to $5.6^{\circ} \mathrm{C}$, respectively. The stable nature of hyporheic temperatures and apparent lack of influence of surface water in the Multnomah Falls area suggest relatively constant water discharge through the hyporheic zone there (Shepherd et al. 1986; Crisp 1990).
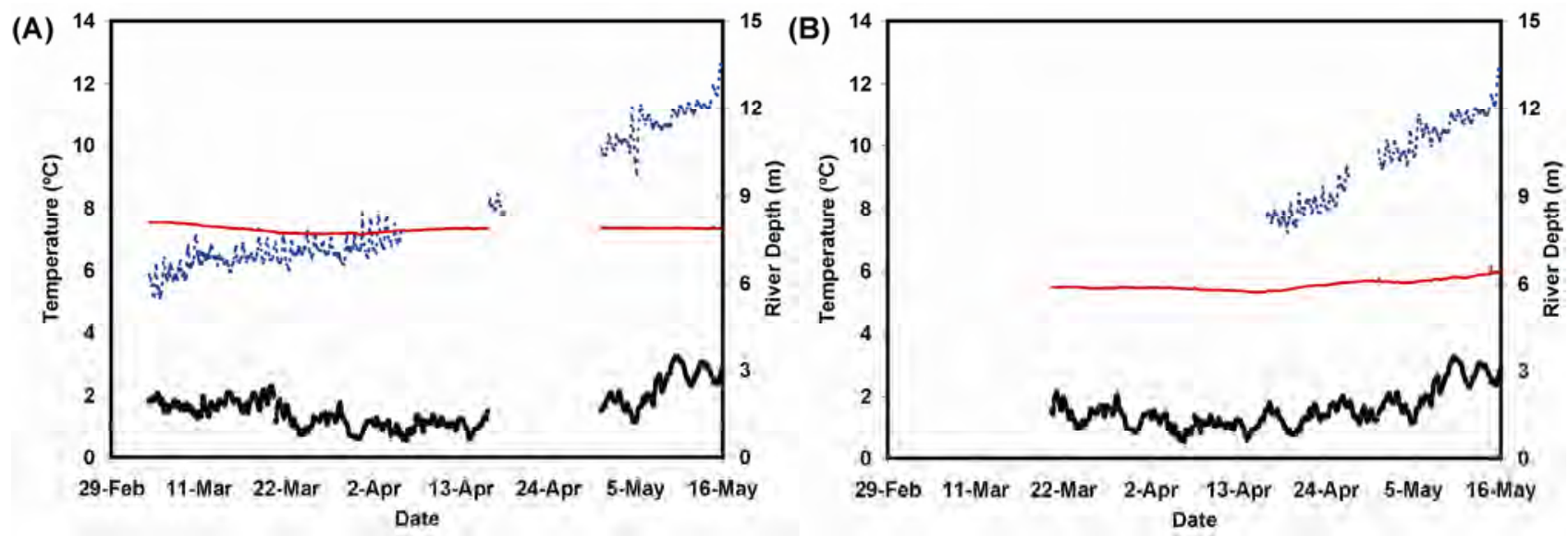

Figure 1.16. Multnomah Falls temperature values. (A) Multnomah Falls pair 1 and (B) Multnomah Falls pair 3. Solid red lines represent temperature values for hyporheic sensors, and dashed blue lines represent temperature values for river sensors. Solid black lines represent river depth at the hyporheic sensor. 


\section{Specific Conductance}

Specific conductance values measured by the river piezometers were more variable early during the monitoring period than later after spring spill started (Figure 1.17). This was true also during previous specific conductance monitoring in 2007 and may be caused by the influence of low-conductivity hyporheic water discharging from the hyporheic zone into the river during periods of low river stage early in the monitoring season. Later in the season, when river stage was higher, specific conductance in the river was higher and probably less influenced by discharging hyporheic water. Hyporheic specific conductance values were much lower and more stable than those recorded in the river, averaging $40.3 \mu \mathrm{S} / \mathrm{cm}$ and $32.5 \mu \mathrm{S} / \mathrm{cm}$ at Multnomah Falls 1 hyporheic and Multnomah Falls 3 hyporheic, respectively (Figure 1.17). Multnomah Falls 3 hyporheic was more variable than Multnomah Falls 1 hyporheic, with an overall range of $9 \mu \mathrm{S} / \mathrm{cm}$ compared to a range of $4 \mu \mathrm{S} / \mathrm{cm}$ at Multnomah Falls 1 hyporheic. However, both of these sites were very stable compared to the hyporheic zone at Ives Island, where the minimum range was $34 \mu \mathrm{S} / \mathrm{cm}$. Similar to Multnomah Falls temperature data, the stable nature of the specific conductance response is indicative of an environment where groundwater discharges into the river and the hyporheic water quality is not significantly affected by fluctuations in river stage.
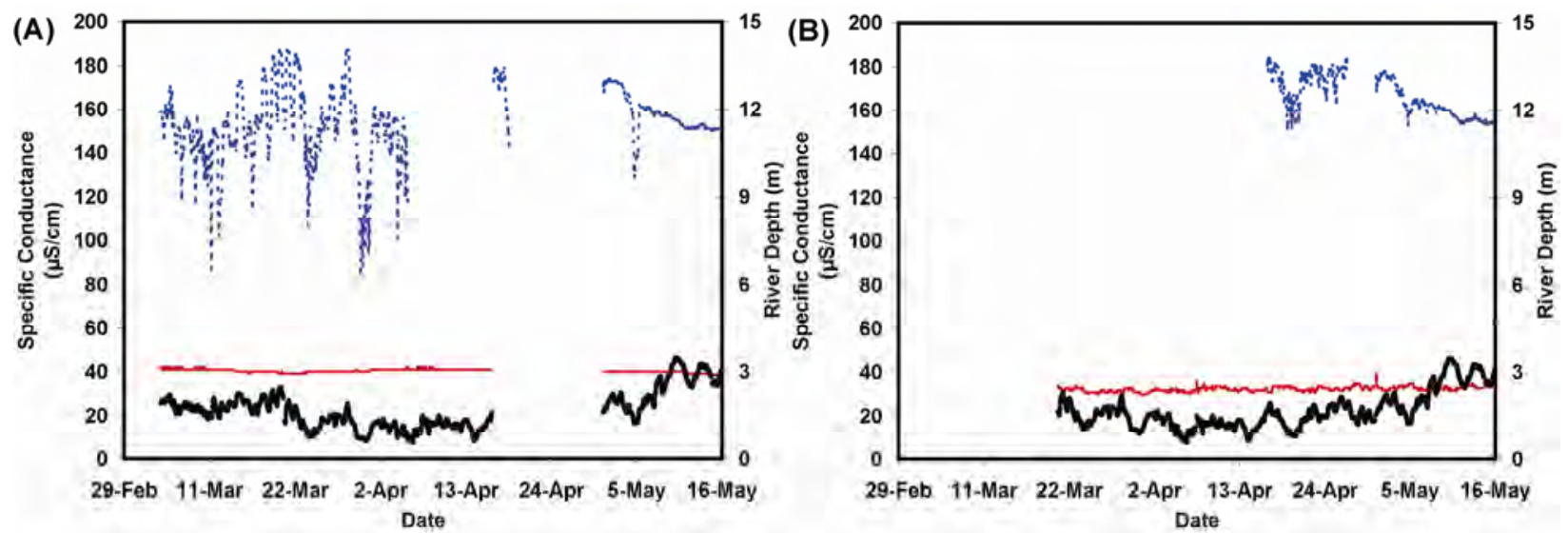

Figure 1.17. Multnomah Falls specific conductance values. (A) Multnomah Falls pair 1 and (B) Multnomah Falls pair 3. Solid red lines represent temperature values for hyporheic sensors, and dashed blue lines represent temperature values for river sensors. Solid black lines represent river depth at the hyporheic sensor.

\section{Estimated Exposure of Chum Salmon Redds to Total Dissolved Gas}

The extent to which chum salmon redds are exposed to potentially toxic depth-compensated TDG concentrations is controlled largely by the concentration of TDG in the water surrounding the egg pocket and the depth of the water column above the egg pocket that is available to provide depth compensation. The amount of water available to provide depth compensation was reduced during the 2008 incubation year compared to most of the previous five years, especially monitoring years 2006-2007 (Figure 1.18).

Redds constructed at relatively shallow riverbed elevations are provided less depth compensation than redds constructed at deeper riverbed elevations. To estimate chum salmon redd exposure to TDG in the Ives Island and Multnomah Falls areas, we evaluated the elevation distribution of the redds constructed there during the 2007 spawning year. 


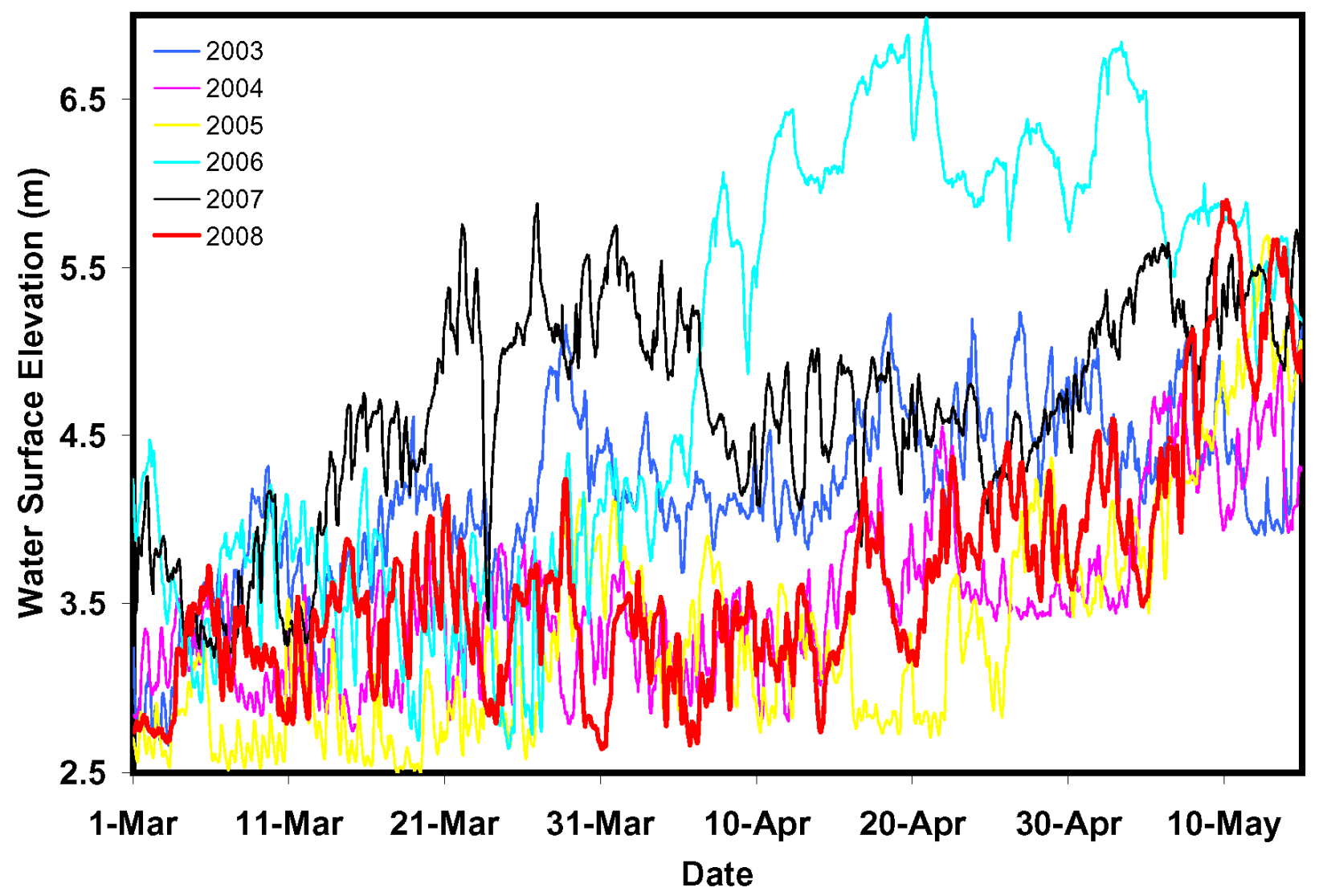

Figure 1.18. Water surface elevations during chum emergence (our study period) for the Ives Island area, 2003-2008

Within the Multnomah Falls area, 33 chum salmon redds were mapped during 2007. The redds were generally constructed at elevations equivalent to our monitoring locations. However, individual chum salmon redd elevations were not recorded relative to our sensors in the Multnomah Falls area. During subsequent incubation in 2008, Multnomah Falls hyporheic depth-compensated TDG never exceeded $100 \%$ saturation of TDG at the depth of our sensors. However, monitoring results from river sensors (depth-compensated using water depth above the river sensor) exhibited higher TDG levels (Figure 1.14). We estimated TDG exposure using the river monitoring results by first assuming an additional $25 \mathrm{~cm}$ of water were located between the river sensors and egg pocket depth, thus providing additional depth compensation. Subsequent exposure estimates showed that chum salmon redds in the Multnomah Falls area could have been exposed to depth-compensated TDG above $100 \%$ for more than 100 hours and depth-compensated TDG above 103\% for more than 30 hours (Table 1.2). 
Table 1.2. Exposure estimates of Multnomah Falls area chum salmon redds to depth-compensated TDG based on 2008 river monitoring results

\begin{tabular}{ccc}
\hline $\begin{array}{c}\text { Depth-compensated TDG } \\
\text { (saturation, \%) }\end{array}$ & $\begin{array}{c}\text { Hours of exceedance at egg pocket } \\
\text { depth based on Multnomah Falls 1 } \\
\text { river monitoring }\end{array}$ & $\begin{array}{c}\text { Hours of exceedance at egg pocket } \\
\text { depth based on Multnomah Falls 3 } \\
\text { river monitoring }\end{array}$ \\
\hline 100 & 60 & 115 \\
103 & 10 & 31 \\
105 & 6 & 18 \\
108 & 0 & 0 \\
\hline
\end{tabular}

We evaluated the elevation distribution of 2007 Ives area chum salmon redds by comparing their locations (as determined by the ODFW) to a digital elevation model constructed by the USGS (Tiffan et al. 2004). Comparison of the 2007 chum redd elevation distribution to our sensor pairs shows that most 2007 redds were constructed at lower elevations than our monitoring locations (Table 1.3). The elevation distribution of 2007 redds was similar to that of 2005. During 2006, redds were distributed at much higher elevations (Table 1.3).

Table 1.3. Percentage of chum salmon redds constructed at riverbed elevations higher than Ives Island area monitoring locations for total dissolved gas, 2005-2007 spawning years

\begin{tabular}{ccccc}
\hline $\begin{array}{c}\text { Monitoring } \\
\text { location }\end{array}$ & $\begin{array}{c}\text { Elevation } \\
\text { (NGVD 29 m) }\end{array}$ & $\begin{array}{c}2007 \text { chum redds } \\
\text { at a higher elevation (\%) }\end{array}$ & $\begin{array}{c}2006 \text { chum redds } \\
\text { at a higher elevation (\%) }\end{array}$ & $\begin{array}{c}2005 \text { chum redds } \\
\text { at a higher elevation (\%) }\end{array}$ \\
\hline Pair 1 & 2.50 & 37 & 99 & 25 \\
Pair 2 & 2.80 & 2 & 92 & 4 \\
Pair 3 & 2.90 & 0 & 91 & 0 \\
Pair 5 & 2.47 & 47 & 99 & NA $^{(\text {a) }}$ \\
\hline
\end{tabular}

(a) Pair 5 was installed during 2006.

During the 2007 spawning year, only 32 redds were mapped within our Ives Island assessment area (Figure 1.19). The redds were distributed at elevations ranging from $2.0 \mathrm{~m}$ to $2.8 \mathrm{~m}$ above mean sea level (MSL; NGVD 29). Of those 32 redds, 50\% were at an elevation below $2.5 \mathrm{~m}$ MSL, and 80\% were below $2.6 \mathrm{~m}$ MSL. At the highest riverbed elevations, there was little difference in risk estimates made using the river and hyporheic monitoring results. At lower elevations, surface monitoring resulted in longer exposure estimates. 

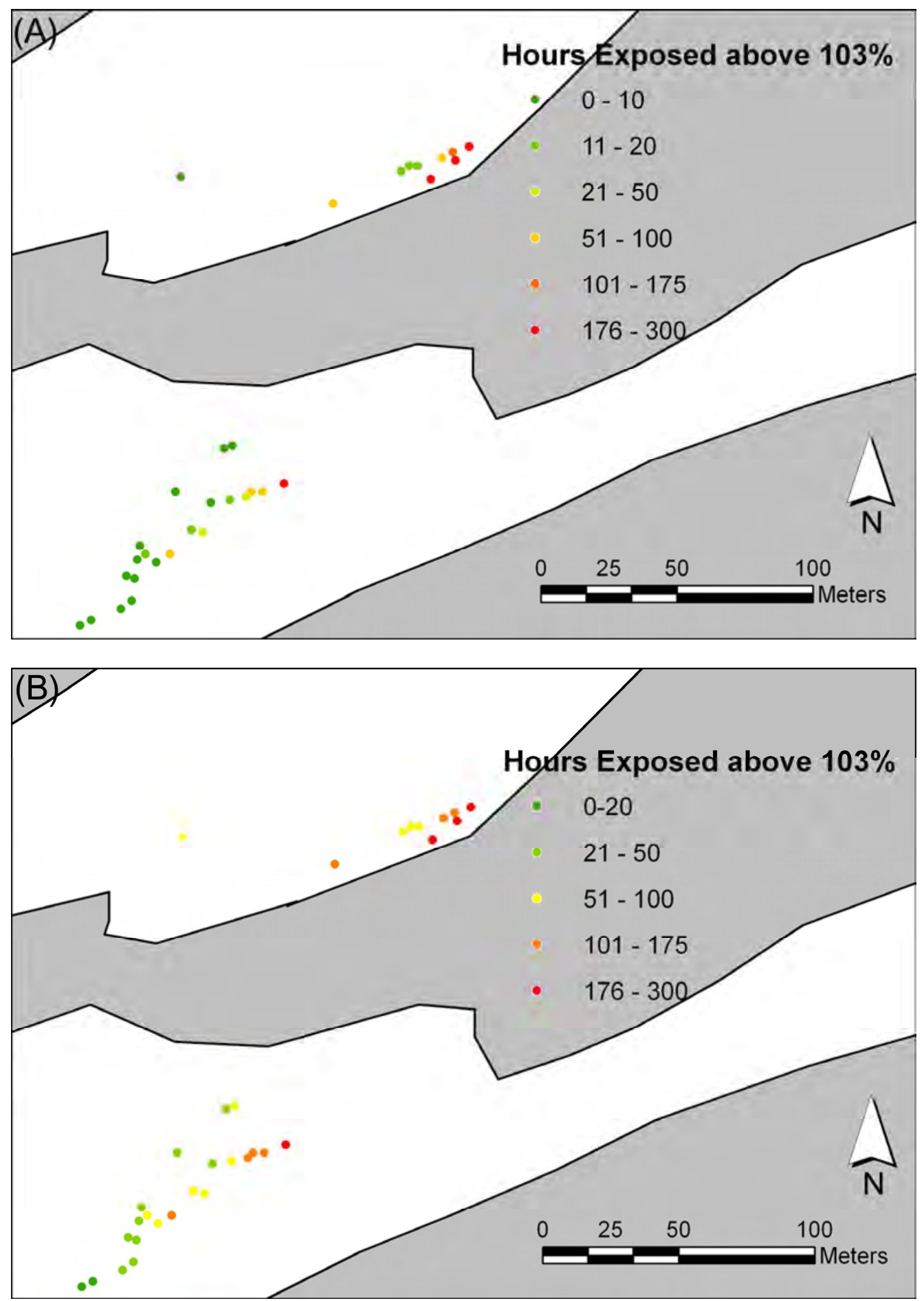

Figure 1.19. Estimated TDG exposure to chum salmon sac fry. (A) Incubation year 2008 hyporheic water monitoring results; (B) incubation year 2008 surface water results. 
At the shallowest redd in the distribution, estimated exposure time to depth-compensated TDG greater than $100 \%$ was 634 hours based on hyporheic monitoring TDG and 652 hours based on surface water TDG. Hyporheic monitoring results suggest that at this elevation, redds were exposed to TDG greater than 105\% for more than 100 hours and to TDG greater than 103\% for more than 200 hours. These durations represent approximately $4 \%$ and $8 \%$ of the total chum salmon incubation period, respectively. At slightely deeper riverbed elevations (e.g., the 80th elevation distribution percentile), exposure times based on hyporheic results were 323 hours at 100\% TDG, 87 hours at 103\% TDG, and 4 hours at 105\% TDG (Figure 1.20). Similar estimates based on surface water TDG monitoring were obtained; exposure times were 340 hours at 100\% TDG, 127 hours at 103\% TDG, and 53 hours at 105\% TDG (Figure 1.21). Hyporheic monitoring estimates suggest redds at the 50th elevation percentile were exposed to depth-compensated TDG greater than 100\% for 209 hours (Figure 1.20). Hyporheic estimates for exposure times to TDG levels of 103\% and 105\% were 14 hours and zero hours, respectively.

Exposure times based on surface water TDG monitoring and estimated for the 50th depth percentile were 219 hours at 100\% TDG, 70 hours at 103\% TDG, and 38 hours at 105\% TDG (Figure 1.21). Only three redds were dewatered during incubation year 2008, for a period ranging from 2 hours to 24 hours.

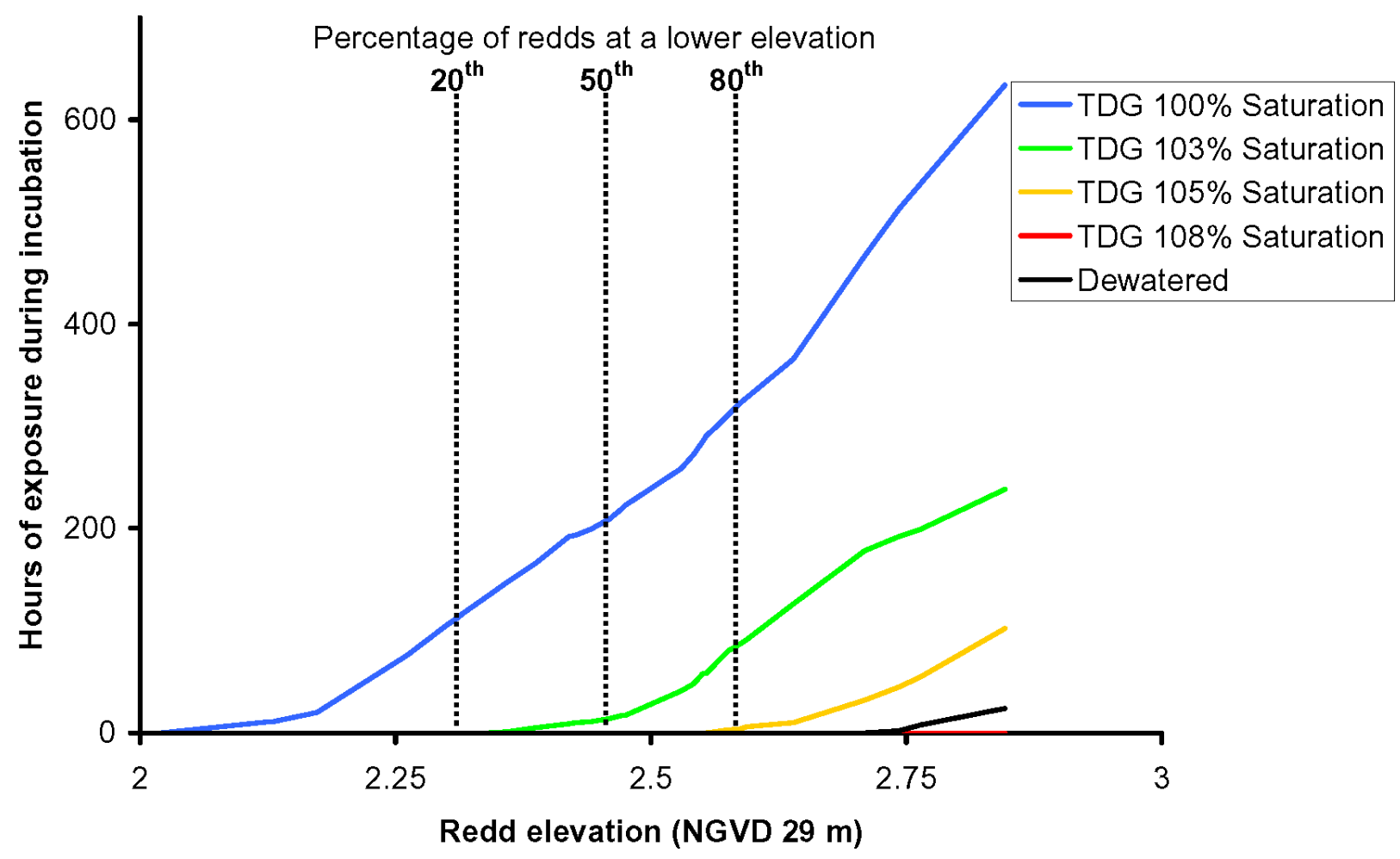

Figure 1.20. Estimated hours of TDG exposure and dewatering to chum salmon sac fry based on hyporheic results from incubation year 2008. Dashed lines show the 2007 chum salmon redd elevation distribution percentiles. 


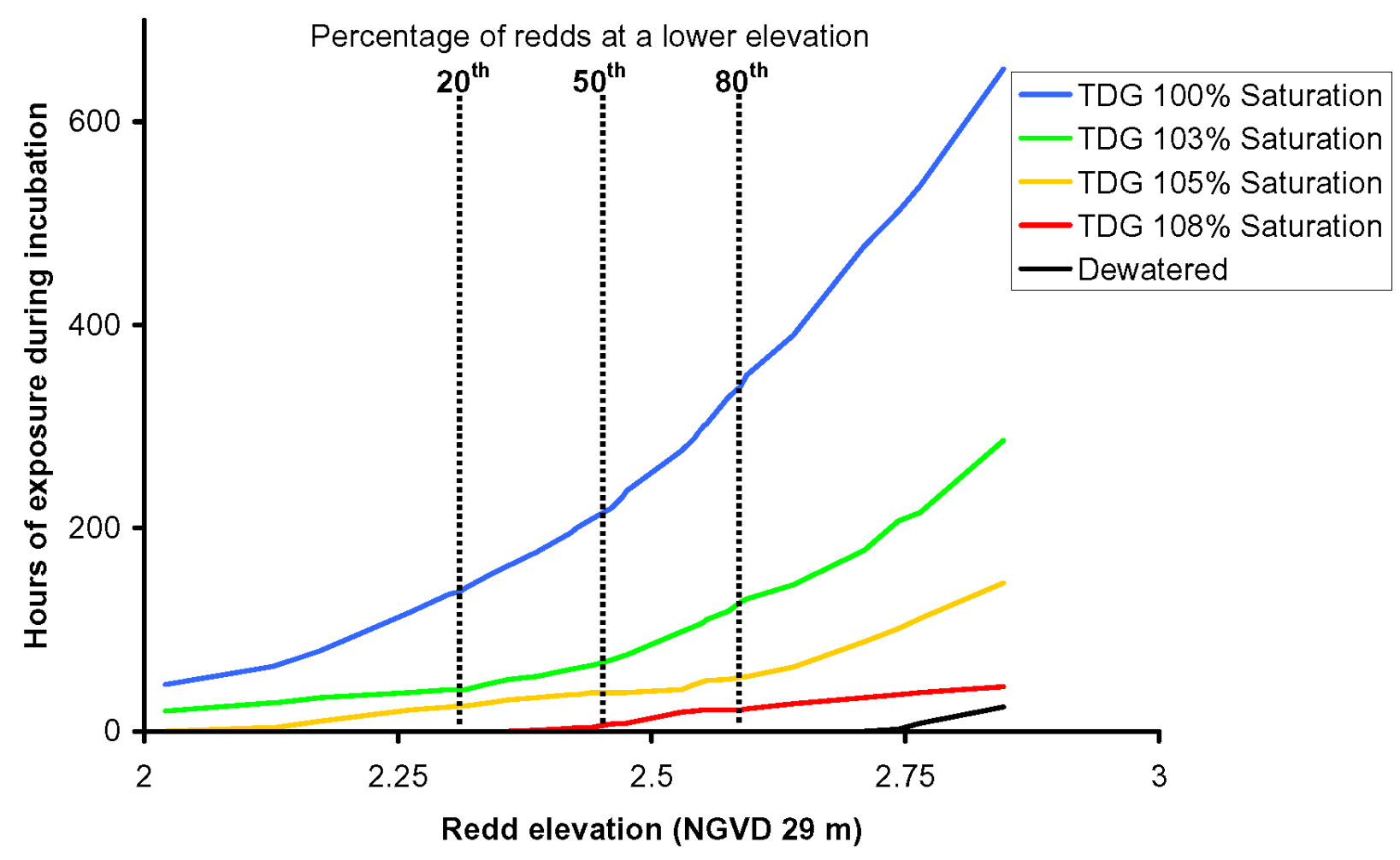

Figure 1.21. Estimated hours of TDG exposure and dewatering to chum salmon sac fry based on surface water results from incubation year 2008. Dashed lines show the 2007 chum salmon redd elevation distribution percentiles.

The timing of exposure of elevated TDG to incubating chum salmon in the Ives Island area varied widely during our three-year study. TDG was elevated in surface water due to corner collector operation and spring spill operations all three years. However, tailwater elevations and chum salmon redd elevation distributions were substantially different each year. These differences caused exposure timing to vary during chum salmon incubation each year from 2006 through 2008. During 2006, there was very little exposure to elevated TDG (Arntzen et al. 2007a). During 2007, exposure occurred both prior to and after the onset of spring spill (Figure 1.22). During 2008, most of the exposure occurred prior to the start of spring spill (Figure 1.22). For the shallowest redd in the distribution, there were 21 instances during 2007 and 39 instances during 2008 when depth-compensated TDG became elevated above 103\%. The median exposure duration above 103\% TDG at this elevation was 4 hours during 2007 and 5 hours during 2008. For a given TDG concentration, the number of exposures, median exposure duration, and maximum exposure duration increased with increasing redd elevation (redds in shallower water received less depth compensation; Table 1.4). 

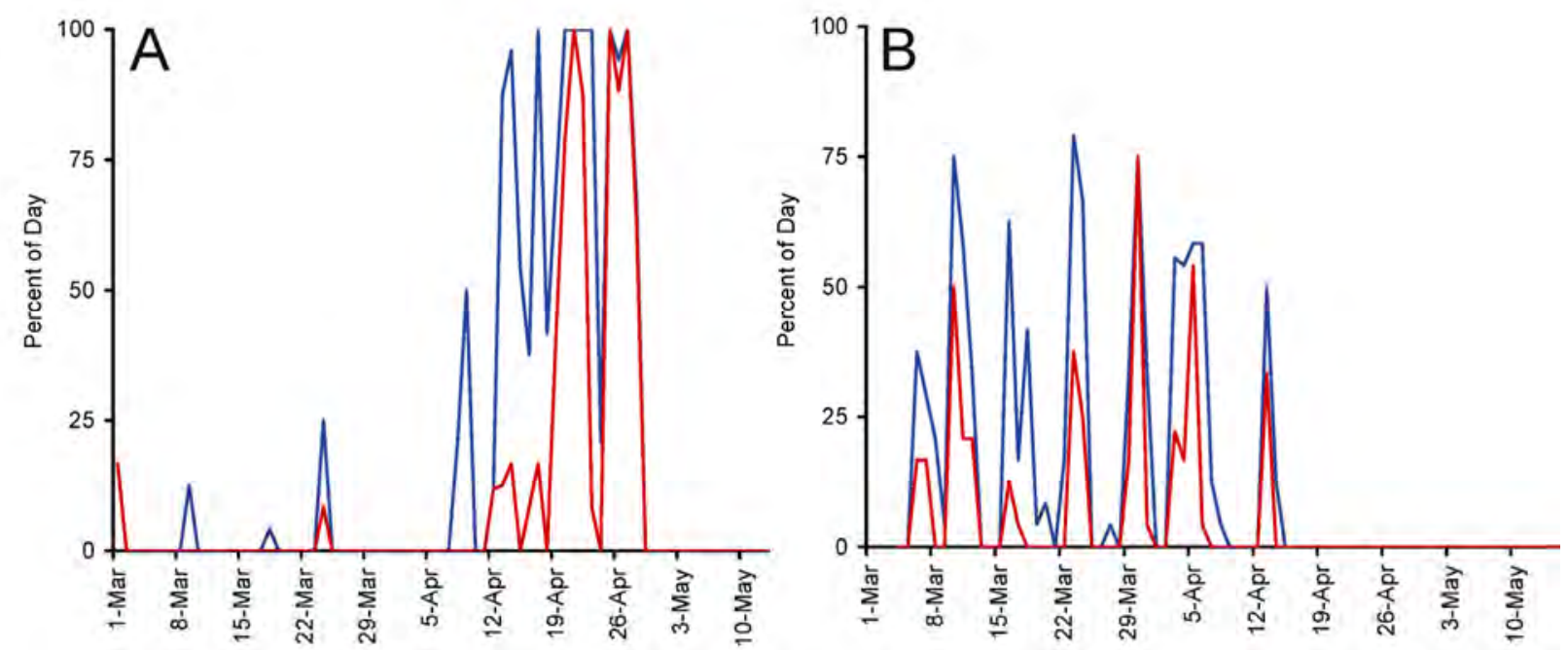

Figure 1.22. Temporal distribution of chum salmon sac fry exposure to elevated TDG during (A) 2007 and (B) 2008. Exposures were estimated for the shallowest redd constructed within our study area during 2007 and 2008, respectively. Blue lines represent exposure to TDG greater than $103 \%$. Red lines represent exposure to TDG greater than $105 \%$.

Table 1.4. Frequency and duration of TDG exposure to incubating chum salmon, 2007-2008

\begin{tabular}{cccccccc}
\hline & \multicolumn{9}{c}{2007} & & \multicolumn{2}{c}{2008} \\
\hline $\begin{array}{c}\text { TDG } \\
\begin{array}{c}\text { Toncentration } \\
(\%)\end{array}\end{array}$ & $\begin{array}{c}\text { Redd } \\
\text { Elevation }^{(\text {a) }}\end{array}$ & Number & $\begin{array}{c}\text { Median } \\
\text { (h) }\end{array}$ & $\begin{array}{c}\text { Maximum } \\
\text { (h) }\end{array}$ & $\begin{array}{c}\text { Number } \\
\text { (h) }\end{array}$ & $\begin{array}{c}\text { Maximum } \\
\text { (h) }\end{array}$ \\
\hline 103 & 50th & 8 & 5.5 & 50 & 2 & 7 & 8 \\
103 & 80th & 9 & 6 & 40 & 11 & 6 & 24 \\
103 & Shallowest & 21 & 4 & 113 & 39 & 5 & 19 \\
105 & 50th & 4 & 17 & 46 & 0 & 0 & 0 \\
105 & 80th & 7 & 3 & 23 & 2 & 2 & 2 \\
105 & Shallowest & 14 & 4 & 57 & 22 & 4 & 18 \\
\hline
\end{tabular}

(a) Redd elevations are shown using elevation distribution percentiles. Elevation distribution percentiles show the percentage of redds that are shallower (e.g., the 80th elevation distribution percentile is at an elevation higher than $80 \%$ of the redds).

\section{Discussion}

During 2008, involuntary spill (in excess of the USACE target of $100 \mathrm{kcfs}$ spill discharge) occurred on three occasions during the period between the onset of spring spill (April 10, 2008) and the end of chum salmon emergence (May 15, 2008). On these occasions, spill discharge ranged up to approximately $150 \mathrm{kcfs}$ and remained above $100 \mathrm{kcfs}$ for up to 7 hours. Depth-compensated TDG remained below $100 \%$ saturation at all river and hyporheic monitoring stations within the Ives Island and Multnomah Falls areas on all three occasions.

The response of water quality to fluctuation in river stage was significantly different at the Ives Island site compared to the Multnomah Falls site. At Multnomah Falls, hyporheic responses were relatively 
stable despite substantial fluctuation in river water quality (Figures 1.13, 1.15, 1.16, and 1.17). In contrast, Ives hyporheic values fluctuated more than river values in response to daily changes in river stage (Figures 1.7, 1.9, 1.10, and 1.12). A similar difference in the response of hyporheic water quality to river stage fluctuation was noted during previous monitoring years (Arntzen et al. 2007a, 2008b). Stable water quality responses at Multnomah Falls indicate there may be a fairly constant source of subsurface water discharging through the hyporheic zone from groundwater or spring water (Shepherd et al. 1986; Crisp 1990). It is possible that such a water source originates from Multnomah Creek, entering the subsurface upgradient from our study site and later upwelling into the Columbia River through the hyporheic zone. This idea is supported by similarities between the water chemistry of Multnomah Creek upstream from our study site and the hyporheic zone at our study site (Arntzen et al. 2007a). In contrast, the relative instability of hyporheic water quality near Ives Island suggests that the direction of flux between hyporheic water and the river is reversed with river stage fluctuations. This condition has been observed before in the Columbia River associated with large and frequent fluctuations in river stage (Arntzen et al. 2006; Geist et al. 2008). The hyporheic response to river stage changes in the Ives area varied by location, with the most variable results obtained from Ives 1 hyporheic and Ives 2 hyporheic. These monitoring locations were installed in an area where chum salmon are known to spawn and where previous water quality monitoring has shown large differences between the hyporheic zone and the river (Geist et al. 2002).

Temperature affects dissolved gas solubility. At higher temperatures, total dissolved gas levels increase. Elevated hyporheic temperatures in the Ives Island area may thus contribute toward elevated hyporheic TDG levels found within the Ives study site early in the season and may also affect TDG concentrations during fluctuations in hyporheic temperature when the river stage fluctuates. There was an inverse relationship between temperature and river stage at Ives Island locations 1 and 2 (Figure 1.11). This pattern suggests that surface water fluctuations are affecting the interaction between hyporheic water and river water. The extent of riverbed permeability at these locations could control this pattern of interaction. For example, if the riverbed is highly permeable there, river water easily could be forced below the riverbed surface into the hyporheic zone, especially when the river stage is higher (Vaux 1968; White 1993; Arntzen et al. 2006). The location of groundwater upwelling areas may also affect the response of water quality to river stage changes in the Ives Island area. There is quite a bit of geothermal activity near North Bonneville, Washington, including developed hot springs northeast of North Bonneville (Moffetts Hot Springs) and east of Carson (St. Martin's Hot Springs). These hot springs are thought to occur along a northeast-trending lineament that is defined by the pre-Bonneville landslide Columbia River shoreline (Nielson and Moran 1980; Korosec 1983). There are also locations southeast of this line, especially near the current shoreline of the Columbia River, where hot springs are known to occur or where anecdotal accounts suggest evidence of geothermal activity. It is generally thought that these locations occur along northwest-trending lineaments or faults that intersect the previously mentioned northeast-trending lineament (Nielson and Moran 1980; Korosec 1983). Shipherds Hot Springs near the mouth of the Wind River and Collins Hot Springs (now submerged by the Bonneville Dam pool) are examples of such locations (Korosec 1983). Nielson and Moran (1983) discuss anecdotal evidence of warm water encountered during the replacement of the Highway 14 bridge over Hamilton Creek in North Bonneville, as well as of warm water $\left(60^{\circ} \mathrm{F}\right.$ compared to $20^{\circ} \mathrm{F}$ ambient temperature) encountered on the Washington shoreline during Bonneville Dam construction. These locations are particularly close to our field site at Ives Island, and it is possible that the warm water encountered within chum salmon spawning areas north of Ives Island is related to geothermal activity. Water chemistry could be used to determine whether this is true. Korosec et al. (1983) presented water chemistry analyses 
of Moffetts Hot Springs and also of water from a test well drilled by the city of North Bonneville. The geothermal waters are chemically distinct, most notably by high $\mathrm{pH}$ values, which were well above 9 at both locations. We have not tested the $\mathrm{pH}$ of water extracted from chum salmon spawning locations near Ives Island or evaluated other analytes that would allow us to determine whether the water is chemically similar to nearby hot springs.

Hyporheic dissolved oxygen fluctuations in the Ives Island area (see Figure 1.9) have the potential to affect chum alevin negatively, both directly by lowering dissolved oxygen levels below thresholds that cause harm and indirectly by altering the ratio of oxygen to dinitrogen $\left(\mathrm{O}_{2} / \mathrm{N}_{2}\right)$, which can increase mortality during periods of elevated TDG (Rucker 1975). Dissolved oxygen was generally lower at Ives hyporheic monitoring locations during 2008 compared to 2007. This may be due to lower river water levels during 2008, which may have reduced river flow into the hyporheic zone compared to previous monitoring years when river levels were higher. It is generally thought that DO levels above $5 \mathrm{mg} / \mathrm{L}$ are sufficient to incubate salmon embryos (Bjornn and Reiser 1991). There are examples in which DO above $5 \mathrm{mg} / \mathrm{L}$ negatively impacted salmonid survival. Malcolm et al. (2003) found a substantial negative impact on survival of Atlantic salmon at DO concentrations above $6.2 \mathrm{mg} / \mathrm{L}$. Not surprisingly, chum salmon have a very low rate of survival to emergence when dissolved oxygen is less than $1.67 \mathrm{mg} / \mathrm{L}$ (Wickett 1954). During 2008, we measured DO levels below $1.67 \mathrm{mg} / \mathrm{L}$ at the Ives 3 hyporheic and Ives 5 hyporheic locations. During 2008 at Ives 3 hyporheic, average DO was $3.97 \mathrm{mg} / \mathrm{L}$ and DO levels were less than $1.67 \mathrm{mg} / \mathrm{L}$ for 45 hours. At Ives 5 hyporheic, dissolved oxygen averaged $2.75 \mathrm{mg} / \mathrm{L}$ and was less than $1.67 \mathrm{mg} / \mathrm{L}$ for a total of 164 hours. Low dissolved oxygen for that extended length of time is a concern for the redds near Ives 5 , which is in the vicinity of chum salmon redds (Figure 1.2). The ratio of $\mathrm{O}_{2}$ to $\mathrm{N}_{2}$ becomes very important when TDG supersaturation is high and $\mathrm{O}_{2} / \mathrm{N}_{2}$ ratios are low, raising the lethality of total dissolved gas (Rucker 1975). Although most of the areas in which we have sampled TDG can be depth-compensated to safe levels, we are concerned that very low $\mathrm{O}_{2} / \mathrm{N}_{2}$ occurs where groundwater-surface-water interaction occurs in the Ives area, and that shallow redds at elevations well above our monitoring stations could be exposed to dangerously low $\mathrm{O}_{2}$ or $\mathrm{O}_{2} / \mathrm{N}_{2}$. Nebeker et al. (1979) demonstrated a significant decrease in mortality when the ratio of oxygen to nitrogen was increased while holding the total percentage saturation constant. After 71 hours at 120\% TDG, 50\% of the fish died when the $\mathrm{O}_{2} / \mathrm{N}_{2}$ ratio was 0.966 . Only $7 \%$ of the fish died after 167 hours when the $\mathrm{O}_{2} / \mathrm{N}_{2}$ ratio was changed to 1.593. During 2008, we estimated average ratios in the Ives area from 0.19 at Ives 5 hyporheic to 0.41 at Ives 2 hyporheic (see Appendix B for comprehensive $\mathrm{O}_{2} / \mathrm{N}_{2}$ data). Similar lows were recorded during 2007 at Ives 3 hyporheic (0.18), but the highest average ratio that year was 0.7 at Ives 1 hyporheic, substantially higher than during 2008. During 2008, at Multnomah Falls hyporheic 1 and 3, average $\mathrm{O}_{2} / \mathrm{N}_{2}$ ranged from 0.82 to 0.7 , respectively. Although $\mathrm{O}_{2} / \mathrm{N}_{2}$ was highly variable within the hyporheic zone, average ratios we measured are typical of those found in groundwater. Mookherji et al. (2003) performed a dissolved gas analysis in a riparian wetland with nested piezometers in upwelling regions and found ratios ranging from 0.038 to 0.444 . Blicher-Mathiesen et al. (1998) measured denitrification and degassing in groundwater in a Danish riparian wetland. They sampled groundwater from four piezometers and found ratios ranging from 0.011 to 0.125 . The variability of $\mathrm{O}_{2} / \mathrm{N}_{2}$ at our study site likely was controlled by frequent changes in hyporheic DO. Changes in DO likely were caused by frequent surface water fluctuations, which influenced the mixture of surface water and hyporheic water. It also is likely that photosynthetic activity and biological respiration contributed to changes in DO and thus altered $\mathrm{O}_{2} / \mathrm{N}_{2}$ (Nebeker et al. 1979). 

Final Report

\title{
Chapter 2
}

\section{Bioassays on the Formation of Gas Bubble Disease in Chum Salmon Fry at Total Dissolved Gas Levels Ranging up to $129 \%$ Saturation}

\author{
K.D. Hand, K.M. Carter, D.R. Geist, V.I. Cullinan, R.A. Elston
}

\section{Introduction}

Prior to our study of the effect of total dissolved gas (TDG) on chum salmon (Oncorhynchus keta) survival and development, other dissolved gas toxicity studies had not been conducted on this species. Results from 2007, the first year of our 2-year laboratory study, showed that direct mortality and body size at emergence were not influenced by TDG levels ranging up to 113\% (Hand et al. 2008). However, the presence of moderate epithelial hypertrophy and moderate epithelial separation and swelling of secondary gill lamellae were related to the concentration of TDG; a larger proportion of the fish exposed to $108 \%$ and $113 \%$ TDG exhibited these symptoms than would be expected due to chance (Hand et al. 2008). Similar histological findings have been observed with fingerling Chinook salmon (O. tshawytscha) (Pauley and Nakatani 1967) and other salmonids (Wright and McLean 1985; Krise and Meade 1988). However, previous studies have shown a reduction in survival usually accompanies histological aberrations when exposures are of sufficient duration. In a long-term study on lake trout (Salvelinus namaycush), Krise (1993) showed that mortality did not increase at $110 \%$ TDG until after day 28. That survival was not significantly different between our groups of juvenile chum salmon from the 2007 study suggested the disease was chronic and that the period of exposure to TDG may not have been long enough to elicit a survival response.

It is possible that newly hatched chum salmon sac fry in the Columbia River downstream from Bonneville Dam are exposed to elevated dissolved gas that could result in reductions in survival. Arntzen et al. (2008b) showed that dissolved gas in riverbed gravels exceeds 103\% TDG as early as March 1. It is conceivable that without adequate water depths over chum salmon redds, dissolved gas concentrations could reach levels early in the development that would create sublethal concentrations of dissolved gas that eventually could reduce overall survival. Understanding the relationship between these dissolved gas thresholds and histological aberrations is needed.

We evaluated lethal and sublethal effects of both static and incrementally increasing levels of elevated TDG on chum salmon embryos and alevin in order to complete three objectives. Our first two objectives exposed fish to static levels of TDG up to 113\% saturation for two separate exposure periods. The first exposure period began approximately 4 weeks before emergence, replicating work done in 2007. The second group was exposed starting at an earlier development stage, approximately 6 weeks before emergence, to examine the effects of chronic elevated gas exposure during a longer portion of the development period between hatch and emergence. Our third objective involved exposing chum salmon alevin to incremental increases in TDG from 101\% to 129\% to determine the concentration at which external gas bubble disease symptoms become apparent. 


\section{Methods}

\section{Static Exposure to Supersaturated Total Dissolved Gas Levels up to $113 \%$}

We examined the effects of 48- and 34-day exposures to untreated (95\% TDG) water and 103, 108, and $113 \%$ TDG supersaturation at a constant water temperature of $9.8^{\circ} \mathrm{C}$ on direct mortality, sublethal tissue damage, delayed mortality, and abnormal behavior. Alevin were sampled periodically throughout the experiment (immediately prior to exposure, three weeks pre-emergence and emergence for the long exposure, one week pre-emergence and emergence for the short exposure, and 30 days after the end of the exposures) for histopathological examination. Incubating alevin were monitored daily during the exposures to document mortality and developmental differences between treatments.

\section{Egg Source, Egg and Alevin Incubation}

For this task, approximately 18,500 fertilized chum salmon eggs were obtained in two lots from the Washington Department of Fish and Wildlife Minter Creek Hatchery, Gig Harbor, Washington. The eggs were spawned on December 4, 2007. The first lot of 17,000 eggs was transferred to the PNNL Aquatic Research Laboratory on January 15, 2008, at a development stage of 395 accumulated thermal units (ATU). The eggs were placed in incubation trays at approximately $10^{\circ} \mathrm{C}$. A water quality problem in the incubation trays resulted in higher than normal egg mortality so a second lot of 1,500 eggs was transferred to PNNL on January 23 at a development stage of 461 ATU to ensure an adequate number of fish for the experiment. The eggs were maintained in incubation trays at approximately $10^{\circ} \mathrm{C}$ through hatching and until the alevin were transferred to the exposure troughs.

\section{Supersaturated Gas and Temperature Control}

Gas supersaturated water was produced by a gas supersaturation column. The 9-ft-high x 6-in.diameter PVC pipe column has inflow hoses for both gas and water. A centrifugal pump maintains inflow water pressure. Water enters at the top of the column; a gate valve controls flow rate. Compressed air is injected to either the top or bottom of the column. A sight glass at the side of the column has a proximity meter that can be adjusted up or down to control the injected air supply. Outflow occurs from the bottom of the column. The desired saturation level produced by the column can be maintained by manipulating the combination of water inflow, water outflow, and column water level.

The exposure to three levels of gas supersaturation took place in three of four stainless steel troughs ( $30 \times 305 \times 13 \mathrm{~cm}$ ) arranged side by side on an elevated platform. The fourth trough housed fish for the untreated water, or control group. The gas supersaturation column provided water to head tanks supplying three of the troughs (Figure 2.1). In the head tanks, supersaturated and control water were mixed via both manual and computerized solenoid valves to achieve the 103, 108, and $113 \%$ exposure levels. Water was piped by gravity flow from the head tanks into PVC manifolds. Ball valves on the manifolds were used to adjust flow volume. From each manifold, 24 individual sections of 1/8-in.-inside diameter tubing supplied water to emergence tubes and egg cups. Water flow through the tubing to each container was approximately $600 \mathrm{~mL} / \mathrm{min}$. The emergence tubes received treated water directly in a closed system. The egg cups received a smaller percentage directly; the remaining water in the trough supplying the egg cups came from the outflow of the emergence tubes. Due to gas loss at the exposed water surface of the trough and egg cups, the TDG levels in the water in the egg cups for the 103, 108, 
and $113 \%$ TDG levels averaged $0.7 \%-0.9 \%$ less than in the emergence tubes. Gas levels were monitored in-line using TDG sensors (Model T507, In-Situ Inc., Fort Collins, Colorado) that were connected to a data logger (Model CR1000 datalogger, Campbell Scientific, Inc., Logan, Utah) and a personal computer. Chilled well water with a 95\% TDG concentration and no gas level manipulations supplied the control trough.

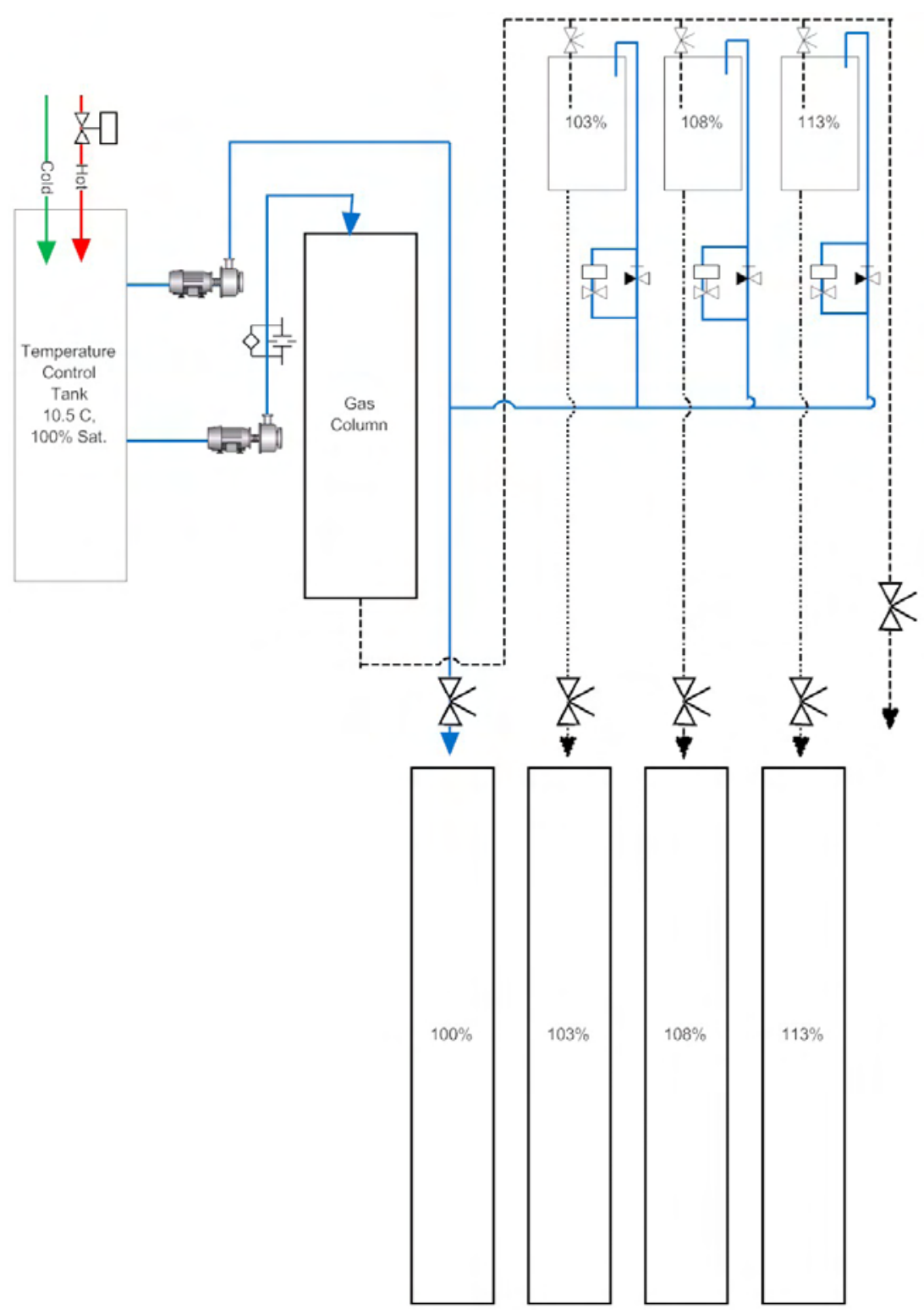

Figure 2.1. Total dissolved gas experimental system

Daily adjustments were made to the gas column during periods of unstable weather to decrease or increase percentage saturation of output as needed to maintain 103, 108, and 113\% TDG treatment water. Water temperature was maintained at an average of $9.8^{\circ} \mathrm{C}$ during the exposure period. Temperature control was achieved using the chilled water system supplying the PNNL Aquatic Research Laboratory. 


\section{Alevin Exposure to Supersaturated Gas}

For the exposure, alevin were housed in both egg cups and emergence tubes. Egg cups were constructed of 15-cm sections of 10-cm-diameter PVC pipe that was screened on the bottom and slotted (4 banks of 11 horizontal grooves, each $2.5 \mathrm{~mm} \times 5 \mathrm{~cm}$ ) and screened on the sides. The sides were screened to prevent chum salmon alevin from escaping through the slots. Alevin in the egg cups were accessible for daily monitoring of abnormal behavior, mortality, and histology sampling throughout the entire exposure period. Emergence tubes consisted of a light and dark chamber connected to each other via a clear tube. They were constructed of $17-\mathrm{cm}$-long sections of 5-cm-diameter white and 6.5-cmdiameter clear PVC pipe. Water flow (approximately $600 \mathrm{~mL} / \mathrm{min}$ ) was directed such that it upwelled through gravel in the bottom of the dark (white) chamber, across the clear tube, and into the light (clear) chamber. Fry emergence occurred when the alevin followed the flow of water toward the light and moved across to the clear chamber of the emergence tube. In the emergence tubes, until alevin emerged, they were not accessible for daily monitoring or sampling; these alevin were used to determine survival and timing to emergence and for the emergence histology sampling.

On February 6, alevin were randomly assigned to one of two exposure periods and divided into treatment groups, and the long exposure was started. For the long exposure, approximately 200 alevin (measured volumetrically at approximately 200 alevin per $70 \mathrm{~mL}$ ) were placed into each of 24 egg cups and 100 alevin (counted) were placed into each of 24 emergence tubes. Six replicate egg cups and six replicate emergence tubes were distributed among each of the four troughs (the 103, 108, and 113\% TDG treatment troughs and the 95\% TDG untreated control trough).

Also on February 6, the alevin for the short exposure were divided into treatment groups but were kept in the control trough until the short exposure began. In this case, approximately 300 alevin (measured volumetrically at approximately 300 alevin per $105 \mathrm{~mL}$ ) were placed into each of 24 egg cups in the control trough. On February 20, the short exposure was started. On this day, 100 alevin (counted) were taken from each egg cup (leaving approximately 200 per egg cup) and placed into corresponding emergence tubes. Six replicate egg cups and their corresponding emergence tubes were then distributed among each of the four troughs.

The long exposure period lasted 48 days, and the short exposure period lasted 34 days. Both exposure periods ended on March 25, 2008.

\section{Survival and Development}

The date of 50\% hatch was January 28 and was determined from daily observations of the eggs in the incubation trays. On the day of 50\% hatch, a sample of 200 alevin was taken from the population, euthanized, measured for weight and length, and preserved in a $10 \%$ solution of neutral buffered formalin (NBF). A small sample of 20 alevin was measured for weight and fork length on the day treatments were assigned and distributed (February 6 ) and preserved in 10\% NBF.

Throughout the exposure periods, alevin in the egg cups and the clear portion of the emergence tubes were monitored daily. Dead alevin and emergent fry were counted and removed.

Alevin that moved to the clear side of the emergence tubes within 24 hours of being placed there were removed and eliminated from the trial. After 24 hours, alevin found in the clear tube were recorded as 
emerged for purposes of documenting the dates of first, $50 \%$, and $100 \%$ emergence. Within \pm 1 day of $50 \%$ emergence, 15 emergent fry from each emergence tube were euthanized, measured for weight and fork length, and preserved in $10 \% \mathrm{NBF}$.

The various wet weight and fork length data were used to compare alevin and emergent fry size and to calculate growth curves and a developmental index. The development index $\left(k_{\mathrm{D}}\right)$ was calculated as described in Bams (1970) using Equation (2.1):

$$
k_{\mathrm{D}}=\frac{10 \sqrt[3]{\text { wet weight in } \mathrm{mg}}}{\text { fork length in } \mathrm{mm}}
$$

Samples from hatch and emergence were analyzed further for dry weight. After at least 80 days in $10 \% \mathrm{NBF}$, the preserved samples from 50\% hatch and 50\% emergence were processed for dry weight ratios of body tissue and yolk. The body tissue and yolk tissue were dissected, combined according to treatment and replicate, and dried in an oven at $60^{\circ} \mathrm{C}$ for 48 hours. After drying, the body tissue and yolk tissue of each group were weighed and ratios were calculated.

Near the time of 50\% emergence, a subsample of alevin remaining in the egg cups was transferred to a Living Stream system (Frigid Units Inc., Toledo, Ohio; 60 x 274 x 55 cm; 700-L capacity) supplied with control water for a 30-day observation period. Fifty fish per replicate were combined by treatment and exposure to form eight groups of 300 fish each. The fish were placed into one of eight mesh pens within the Living Stream tank. Fish were fed size \#0 crumb BioVita Starter (Bio-Oregon, Longview, Washington) four to six times daily using automatic feeders. Minimum daily feed amounts were calculated to allow for a $4.4 \%$ daily weight gain. Fish were observed daily for abnormal behavior and mortality. At the end of the holding period, five fish per group were euthanized, measured for weight and length, and preserved in Bouin's solution. The remaining fish were euthanized and disposed.

\section{Necropsy and Histology}

Samples of alevin were euthanized and preserved prior to exposure (baseline), twice during exposure for each exposure period, and at the end of the post-exposure period for histological analysis. Baseline samples were taken on February 6, 2008 and preserved in 10\% NBF. For the long exposure, samples were taken on February 21, 2008 (approximately 3 weeks pre-emergence) and on March 11-12 (50\% emergence). For the short exposure, samples were taken on March 4 (approximately one week preemergence) and on March 11-12 (50\% emergence). The pre-emergence samples included alevin preserved in Bouin's solution and in 10\% NBF; all emergence samples were preserved in Bouin's solution. Samples were taken also at the end of the 30-day post-exposure holding period on April 16 and preserved in Bouin's solution. These samples were stored in fixative at the Aquatic Research Laboratory until they were submitted to Dr. Ralph Elston, AquaTechnics, Inc. (Sequim, Washington), for histological examination.

\section{Necropsy}

The sample fish were received at AquaTechnics on June 9 and assigned case number AQ08 138. Upon receipt, each preserved fish was placed whole into separate coded histology cassettes. The fish were oriented so that sagittal (longitudinal or anterior to posterior) histology sections would result. Thus, the cut fish sections are viewed from the side from anterior to posterior. The cassettes containing fish 
were then re-immersed in fixative. A spreadsheet was created that referenced the PNNL inventory code and histology cassette identity for each fish.

\section{Histology Processing}

Histology processing was performed by a subcontractor to AquaTechnics, Inc. Routine methods of dehydration, embedding, sectioning, and staining tissue sections with hematoxylin and eosin were used (Luna 1968). A set of subcontractor histology processing protocols approved by AquaTechnics is on file at AquaTechnics. The cassettes and resulting histology blocks and slides carried the coded case number unique to each specimen and histology cassette. The coded identification information did not contain any reference to the specific treatment the specimen received during the experiment that produced the fish. The resulting embedded tissue block for each fish was cut at nine approximately evenly spaced levels, utilizing about $75 \%$ of the thickness of each fish. Each of the nine levels was numbered sequentially; each section was cut at approximately 5 - $\mu$ m thicknesses. Thus, each fish resulted in nine tissue sections that, in total, represented a range of the organs and tissues present in each fish. The objective was to obtain all types of organs or tissue that were thought to be potentially affected by gas supersaturation.

\section{Histology Interpretation}

The histology sections were examined by light microscopy using an Olympus BX40 microscope equipped with 4x, 10x, 20x, 40x, and 100x objective lenses. The sections were examined without knowledge of the treatment group to which the specimen belonged. Each organ of interest was examined, and lesions were recorded in an Excel spreadsheet. Because the first reading of all slides indicated that significant lesions in the gill tissues occurred at an apparent high prevalence, the gill tissues were reexamined and results added to the spreadsheet. Lesions in the secondary lamellae of the gills were graded as follows: grade $0=$ lesion not present; grade 1 = very rare/very mild; grade 2 = few/mild; grade 3 = many/moderate; and grade 4 = too many to count/severe.

\section{Special Stains}

Due to the finding of an unknown structure (apparently a protistan parasite) in epithelium of the gills and adjacent tissues, special staining studies were conducted to attempt to elucidate the nature of this structure. To implement these special staining studies, the sections were recut from several representative blocks containing the unknown structures and stained with the following special stains: periodic acidSchiff, Giemsa, Gomori methenamine silver, Gram, and mucicarmen (Luna 1968).

\section{Statistical Analysis}

Descriptive statistics, including the coefficient of variation and histograms, were used to evaluate the variability in exposure concentrations and water temperature. Analysis of variance (ANOVA) was used to compare average water temperature, ATU, and fish response among exposure concentrations. The nonparametric alternative, the Kruskal-Wallis test, was used when sample sizes were small or when transformation of the response variable did not satisfy parametric assumptions.

The severity of each type and the sum of all gill lesions were analyzed to test the null hypothesis of equal proportional occurrence among TDG level percentages for each sampling stage (pre-emergence and emergence). When expected frequencies were too low to meet the assumptions of a chi-square analysis, a binomial exact test of goodness-of-fit was used if moderate lesions were observed in the higher 
concentrations of TDG. The rankings of gill lesion severity $(0=$ no lesion and 1 to 4 indicating increasing severity) were pooled into two categories (low $=0+1$ and moderate $=2+3+4$ ) to meet the assumptions of both the chi-square and the binomial exact goodness-of-fit test using the marginal frequencies of occurrence as the expected proportions. When the data exhibited a dose-response, a probit analysis was conducted on the proportion of moderate lesions as a function of TDG. An effective concentration that causes 50\% response (EC50) and the 95\% confidence limits were calculated when appropriate. Because of the small number of doses (four), a simple linear regression also was employed. A generalized linear model on the proportion of moderate lesions was used to compare sampling scenario (a combination of the age sampled and the number of days exposed) and TDG exposure levels. The age sampled and the number of days exposed also were evaluated as covariates.

The maximum number and proportional occurrence of parasites in the tissues of the thymus and skin also were evaluated. A full generalized linear model was used to evaluate the main effects of sampling scenario (a combination of the age sampled and the number of days exposed) and TDG exposure levels.

\section{Incremental Exposure to Supersaturated Total Dissolved Gas Levels up to $129 \%$}

\section{Fish Source}

Wild chum salmon were obtained as eggs from Washougal Hatchery (Washougal, Washington) and incubated in our laboratory to serve as a control group for the artificial redd study (Chapter 3, this report). Extra alevin not needed for that task were utilized for this study. On March 20, 60 alevin were divided into two equal groups and placed into one of two exposure cups housed within a 5-gal aquarium. Exposure cups A and B were identical to those used for the static exposure experiment in our laboratory. The alevin were 93 days post-fertilization and had 613 ATU when placed in the exposure cups. Each sac fry still retained a large portion of yolk distending from the ventral side (Figure 2.2).

On March 21, 27 of the 30 alevin escaped from cup A. Eight of these fish were recovered. The other 19 fish were not found. Because of the limited number of alevin available to us, we placed the 8 recovered fish back into cup A along with an additional 13 excess alevin from the control group for the artificial redd study. Cup A contained 24 fish, all of which remained in the cup until removed for examination or mortality. No fish escaped from cup B.

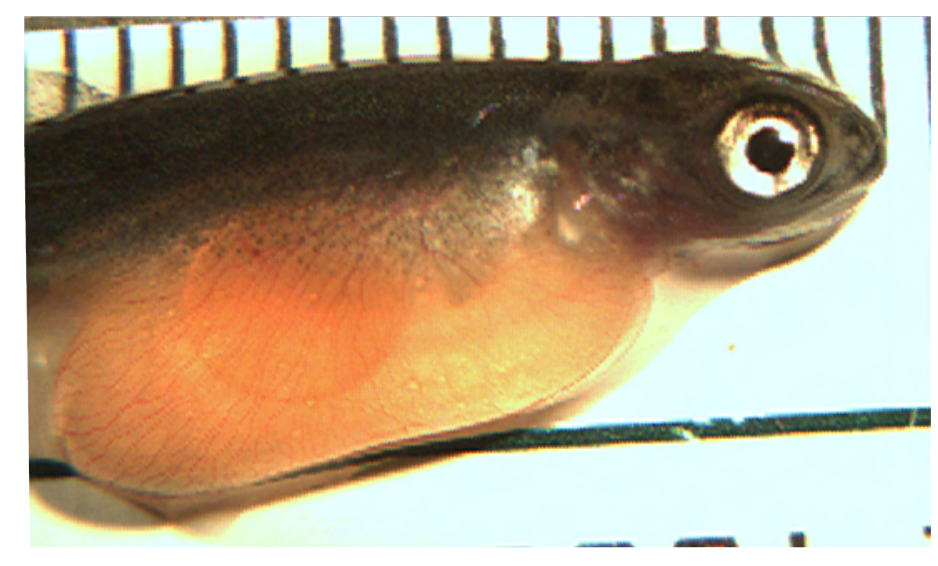

Figure 2.2. Alevin retained large yolk sacs when placed in the exposure cups 


\section{Supersaturated Gas and Temperature Control}

Gas supersaturated water was produced using a gas superaturation column, similar to that used for the static exposure study. Well water was pumped into a gas supersaturation column where it was mixed with compressed air. The level of supersaturation was controlled by adjusting the water pressure within the gas column. Higher water pressures allowed for higher supersaturation levels. On the initial day of the experiment, TDG levels were set at $101.8 \%$. For the remainder of the study, we increased TDG levels approximately $2 \%$ every other day. Actual dissolved gas levels varied slightly from the experimental target of 2\% every other day. Changes to the water pressure in the supersaturating gas column did not always bring predictable results, and several adjustments over a period of hours sometimes were needed to achieve the desired level of supersaturation. Changes in barometric pressure also added variability to the TDG percentage.

Supersaturated water was pumped from the gas column to a head tank for distribution to the exposure cups. Water was piped by gravity flow from the head tank to each of the two egg cups containing fish. The head tank was situated $12 \mathrm{ft}$ above the aquarium, which maintained head pressure adequate to keep the water supersaturated until reaching the egg cups. Gas levels were measured in-line just prior to the exposure cups using the same equipment as used for the static exposure study.

Water temperature ranged from $6.25^{\circ} \mathrm{C}$ to $9.9^{\circ} \mathrm{C}$ throughout the study. Although the temperature of the water was controlled within the laboratory, the experimental head tank was located outside and was subject to some environmental conditions that caused the temperature to fluctuate during the experiment.

\section{Gross Examination and Histology}

Fish in each exposure cup were monitored daily for mortality, abnormal behavior, and anatomical signs of gas bubble disease. Dead fish were examined upon discovery. In addition, a detailed gross examination on one fish from cup A was performed every other day. The live fish were euthanized with $250 \mathrm{mg}$ of MS-222/L of water prior to examination. Fish were examined for external bubbles in the nares, mouth, fins, yolk sac, and eyes and for internal bubbles in the gills, swim bladder, and intestinal tract. Three fish also were submitted for histological examination, once gas bubble disease became grossly apparent. These examinations were performed as described for the static exposure study. Fish in cup B were monitored only for mortality and examined only if mortality occurred. No live fish were removed for examination.

\section{Results}

\section{Static Exposure to Supersaturated Total Dissolved Gas Levels up to $113 \%$}

\section{Gas and Temperature Levels}

Actual dissolved gas levels followed very closely the experimental targets (Table 2.1) and varied little. The coefficient of variation (CV) values for all treatments were less than $1 \%$; the largest variability $(\mathrm{CV}=0.59 \%)$ occurred in the control group (Figure 2.3 ). 
Table 2.1. Total dissolved gas levels used in the exposure experiments and expressed as daily means between February 6 and March 25, 2008

\begin{tabular}{ccccccc}
\hline Treatment & $N$ & Mean & Median & $\begin{array}{c}\text { Standard } \\
\text { Deviation }\end{array}$ & Minimum & Maximum \\
\hline Control & 42 & $94.9 \%$ & $95.97 \%$ & 0.558 & $93.27 \%$ & $95.87 \%$ \\
$103 \%$ & 48 & $103.0 \%$ & $103.06 \%$ & 0.367 & $101.76 \%$ & $103.58 \%$ \\
$108 \%$ & 48 & $108.0 \%$ & $107.97 \%$ & 0.254 & $107.47 \%$ & $108.75 \%$ \\
$113 \%$ & 48 & $113.0 \%$ & $112.92 \%$ & 0.309 & $112.43 \%$ & $113.71 \%$ \\
\hline
\end{tabular}

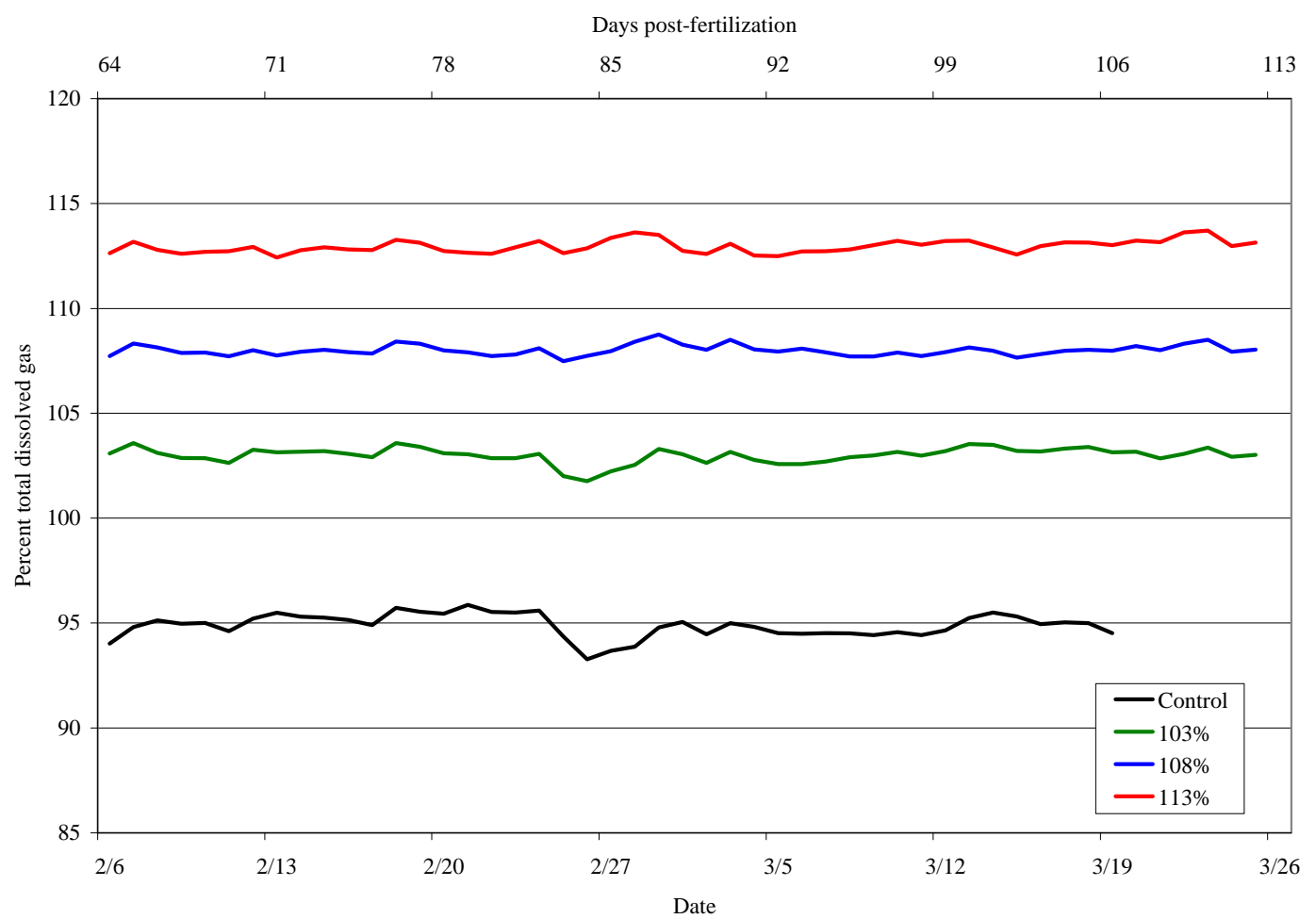

Figure 2.3. Daily mean total dissolved gas levels for the exposure period

The average daily water temperature over the study period from hatching (January 28) until termination (April 16) ranged from $10.2^{\circ} \mathrm{C}$ to $7.7^{\circ} \mathrm{C}$ (Figure 2.4). During the exposure periods, mean daily water temperatures in the control and three treatment groups were very stable, ranging from a low of $9.7^{\circ} \mathrm{C}$ in the $113 \%$ TDG group to a high of $9.9^{\circ} \mathrm{C}$ in the control group (Table 2.2). During the 30-day post-exposure holding period, the average temperature decreased approximately $2^{\circ} \mathrm{C}$ (from $9.5^{\circ} \mathrm{C}$ to $7.7^{\circ} \mathrm{C}$ ). This change occurred because the chilled water source supplying both the laboratory and this experiment was adjusted to meet the needs of other research projects. 


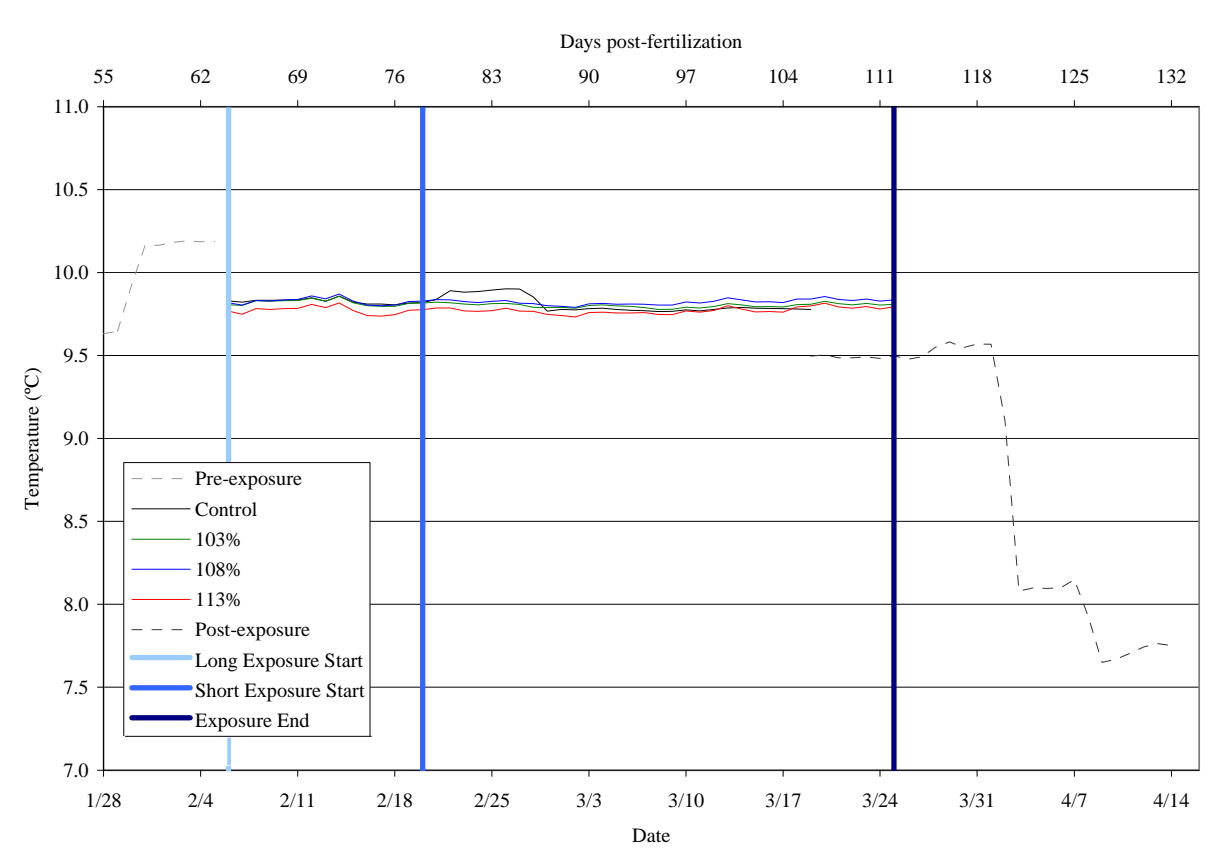

Figure 2.4. Daily mean temperatures for the study period

Table 2.2. Mean daily temperature during the 48-day exposure period

\begin{tabular}{llccccc}
\hline \multicolumn{1}{c}{ Treatment } & $N$ & $\begin{array}{c}\text { Mean } \\
\left({ }^{\circ} \mathrm{C}\right)\end{array}$ & $\begin{array}{c}\text { Median } \\
\left({ }^{\circ} \mathrm{C}\right)\end{array}$ & $\begin{array}{c}\text { Standard } \\
\text { Deviation }\end{array}$ & $\begin{array}{c}\text { Minimum } \\
\left({ }^{\circ} \mathrm{C}\right)\end{array}$ & $\begin{array}{c}\text { Maximum } \\
\left({ }^{\circ} \mathrm{C}\right)\end{array}$ \\
\hline Control & 42 & 9.81 & 9.81 & 0.042 & 9.77 & 9.90 \\
$103 \%$ TDG & 48 & 9.81 & 9.81 & 0.016 & 9.78 & 9.86 \\
$108 \%$ TDG & 48 & 9.82 & 9.83 & 0.017 & 9.79 & 9.87 \\
$113 \%$ TDG & 48 & 9.77 & 9.77 & 0.020 & 9.73 & 9.82 \\
\hline
\end{tabular}

\section{Survival and Development}

Survival from hatch to emergence equaled or exceeded 98.8\% in all treatments (Table 2.3). The proportion that survived to emergence did not differ among the treatment groups in either the long (48-day) or short (34-day) exposures (ANOVA: $F=0.96$; $\mathrm{df}=3,40 ; P=0.421$; Figure 2.5). Survival also did not differ between the two exposure periods (ANOVA: $F=0.19$; $\mathrm{df}=1,40 ; \mathrm{p}=0.662$; Table 2.3). No substantial mortalities or abnormal behavior were noted during the 30-day post-exposure holding period.

The average dates of 50\% emergence occurred from March 10 (97 days post-fertilization [DPF]) to March 12 (99 DPF) for treatments in both exposure periods (Figure 2.6). Timing of emergence did not differ among treatments within each exposure period (ANOVA: $F=0.881$; $\mathrm{df}=3,40 ; \mathrm{p}=0.459$ ) but did differ slightly between exposure periods. The long-exposure group emerged one day earlier, on average, than did the short-exposure group. Though this was statistically significant (ANOVA: $F=4.52 ; \mathrm{df}=1$, $40 ; p=0.040$ ) it is not biologically significant. The thermal units accumulated at the time of $50 \%$ emergence ranged from 913 to 925 ATU for the long exposure and from 921 to 930 for the short exposure (Table 2.3). The thermal units accumulated at the time of 50\% emergence did not differ among treatments within each exposure period (ANOVA: $F=1.01 ; \mathrm{df}=3,40 ; \mathrm{p}=0.399$ ). Between the two exposure periods, however, the thermal units accumulated at $50 \%$ emergence were significantly different. 
The long-exposure group had significantly fewer ATU than the short-exposure group (ANOVA: $F=$ 4.73; $\mathrm{df}=1,40 ; \mathrm{p}=0.036$ ).

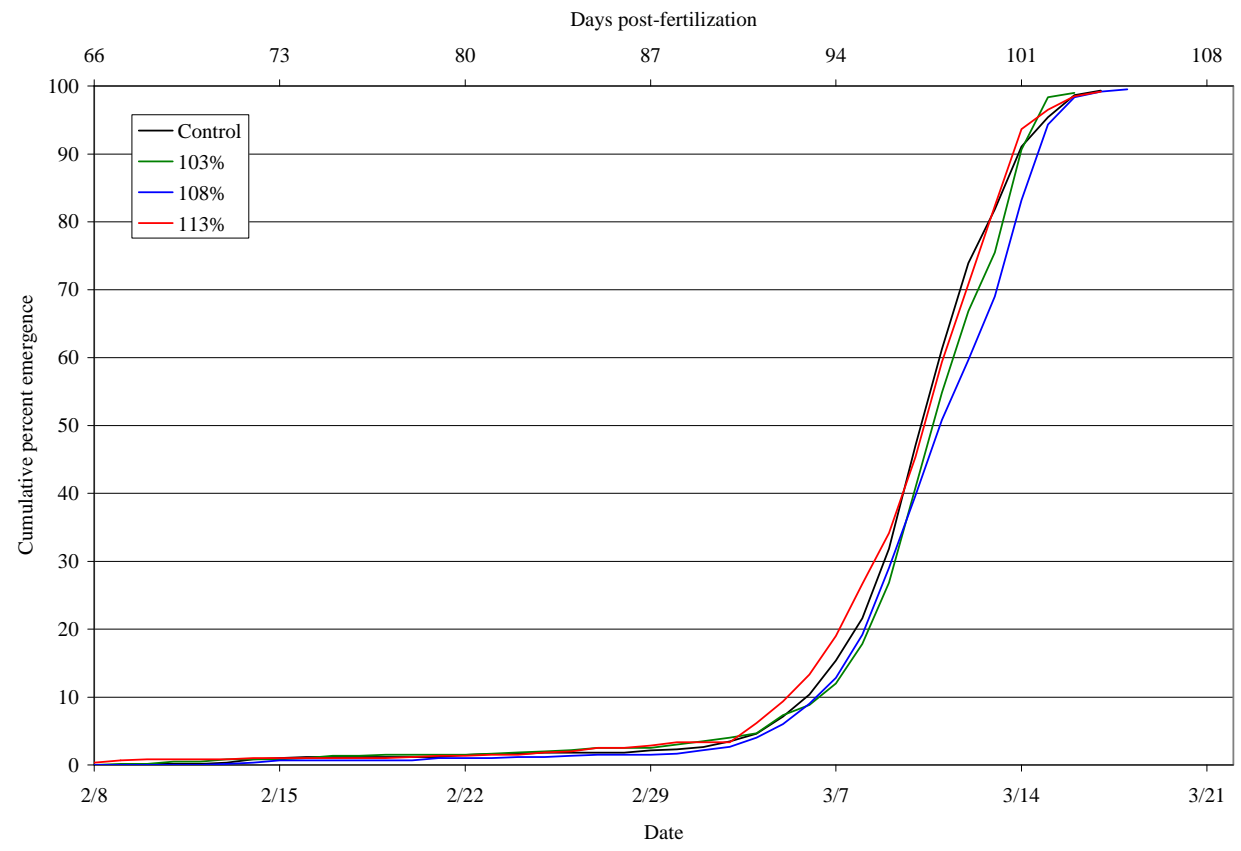

(a) Long-exposure (48-day) treatment group

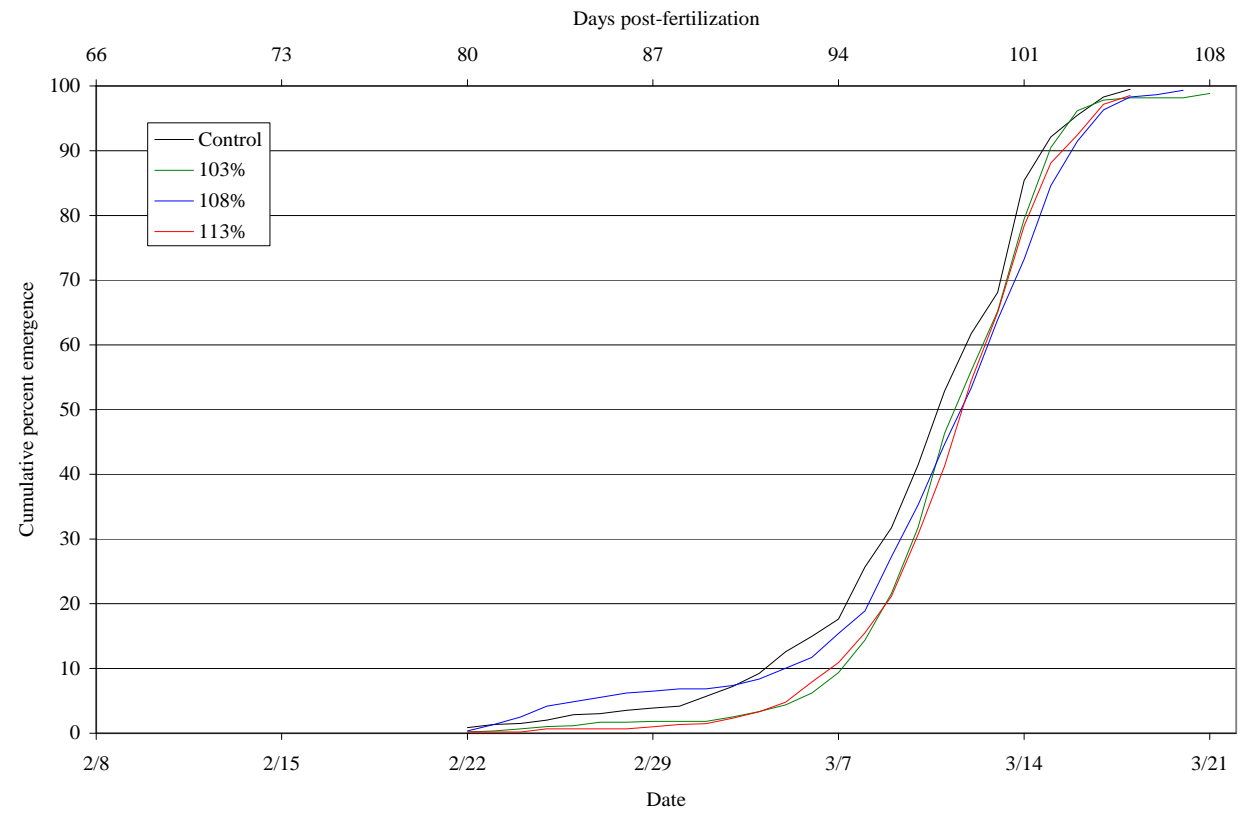

(b) Short-exposure (34-day) treatment group

Figure 2.5. Number of days to $50 \%$ and $100 \%$ emergence for each treatment group 


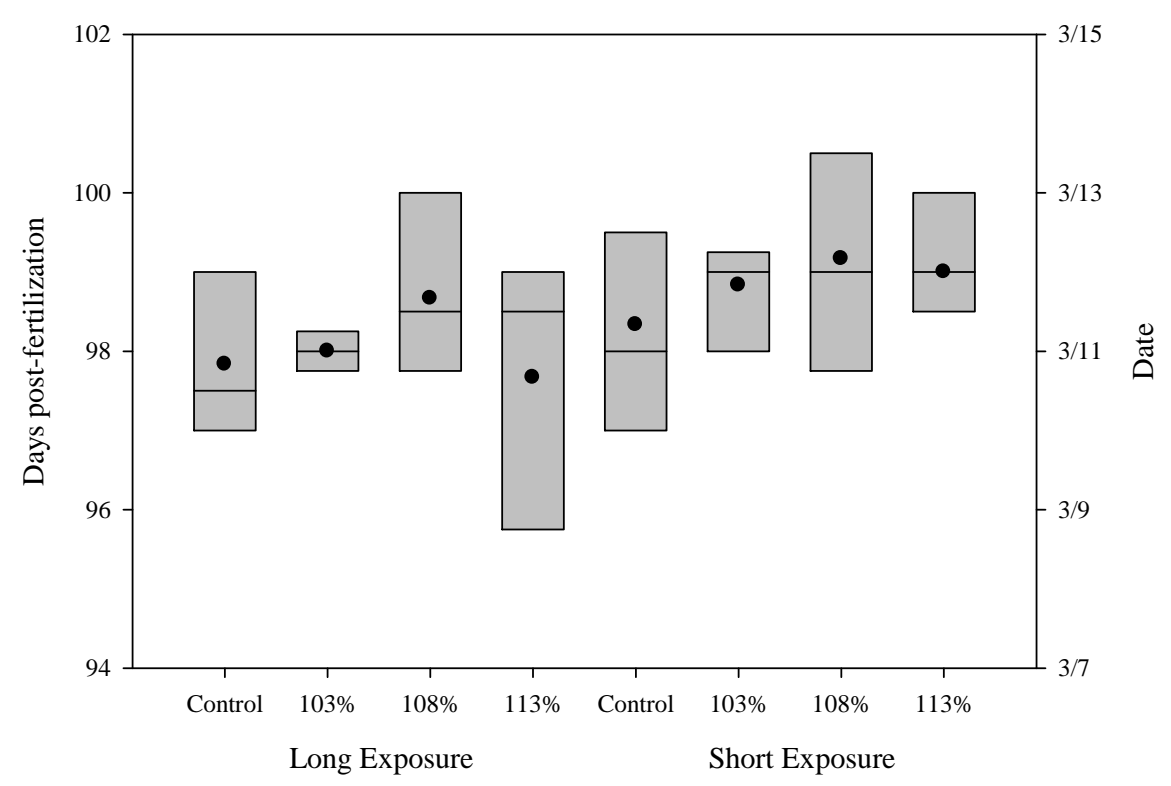

Figure 2.6. Number of days post-fertilization at 50\% emergence for each exposure period and treatment. The first and third quartiles are represented by the lower and upper bounds of the box, respectively; median values are represented by a horizontal line within the box; and mean values are represented by a black solid circle.

Table 2.3. Mean (and range) survival, days post-fertilization (DPF), date, and accumulated thermal units (ATU) at $50 \%$ emergence

\begin{tabular}{|c|c|c|c|c|c|}
\hline Exposure Period & Treatment & Survival & DPF & Date & ATU \\
\hline \multirow{4}{*}{$\begin{array}{c}\text { Long } \\
\text { (48 days) }\end{array}$} & Control & $\begin{array}{c}99.3 \% \\
(98-100 \%)\end{array}$ & $\begin{array}{c}96 \\
(96-98)\end{array}$ & $\begin{array}{c}3 / 10 \\
(3 / 10-12)\end{array}$ & $\begin{array}{c}917 \\
(908-928)\end{array}$ \\
\hline & $103 \%$ TDG & $\begin{array}{c}99.0 \\
(98-100 \%)\end{array}$ & $\begin{array}{c}97 \\
(96-98)\end{array}$ & $\begin{array}{c}3 / 11 \\
(3 / 10-12)\end{array}$ & $\begin{array}{c}918 \\
(908-928)\end{array}$ \\
\hline & $108 \%$ TDG & $\begin{array}{c}99.5 \\
(98-100 \%)\end{array}$ & $\begin{array}{c}97 \\
(96-99)\end{array}$ & $\begin{array}{c}3 / 11 \\
(3 / 10-13)\end{array}$ & $\begin{array}{c}925 \\
(908-938)\end{array}$ \\
\hline & $113 \%$ TDG & $\begin{array}{c}99.2 \\
(98-100 \%)\end{array}$ & $\begin{array}{c}97 \\
(94-98)\end{array}$ & $\begin{array}{c}3 / 11 \\
(3 / 8-12)\end{array}$ & $\begin{array}{c}913 \\
(887-926)\end{array}$ \\
\hline \multirow{4}{*}{$\begin{array}{c}\text { Short } \\
\text { (34 days) }\end{array}$} & Control & $\begin{array}{c}99.5 \% \\
(98-100 \%)\end{array}$ & $\begin{array}{c}97 \\
(96-100)\end{array}$ & $\begin{array}{c}3 / 11 \\
(3 / 10-14)\end{array}$ & $\begin{array}{c}921 \\
(908-948)\end{array}$ \\
\hline & $103 \%$ TDG & $\begin{array}{c}98.8 \% \\
(97-100 \%)\end{array}$ & $\begin{array}{c}97 \\
(97-99)\end{array}$ & $\begin{array}{c}3 / 11 \\
(3 / 11-13)\end{array}$ & $\begin{array}{c}926 \\
(918-937)\end{array}$ \\
\hline & $108 \%$ TDG & $\begin{array}{c}99.3 \% \\
(97-100 \%)\end{array}$ & $\begin{array}{c}98 \\
(96-101)\end{array}$ & $\begin{array}{c}3 / 12 \\
(3 / 10-15)\end{array}$ & $\begin{array}{c}930 \\
(908-957)\end{array}$ \\
\hline & $113 \%$ TDG & $\begin{array}{c}99.8 \% \\
\text { (99-100\%) }\end{array}$ & $\begin{array}{c}98 \\
(96-99)\end{array}$ & $\begin{array}{c}3 / 12 \\
(3 / 10-13)\end{array}$ & $\begin{array}{c}927 \\
(907-937)\end{array}$ \\
\hline
\end{tabular}




\section{Alevin and Fry Size}

The mean wet weight of alevin at 50\% hatch (January 28, 2008) was $216.4 \mathrm{mg}$, while the mean fork length was $23.1 \mathrm{~mm}$ (Table 2.4). At the time the alevin were transferred to the emergence tubes (and the long exposure was initiated) on February 6, their average wet weight had increased to $236 \mathrm{mg}$ and their mean fork length had increased to $27.9 \mathrm{~mm}$ (Table 2.4).

Table 2.4. Size of chum salmon sampled at $50 \%$ hatch (January 28, 2008) and at time of transfer to emergence tubes (February 6, 2008)

\begin{tabular}{cccccccc}
\hline $\begin{array}{c}\text { Development } \\
\text { Stage }\end{array}$ & Variable & N & Mean & Median & $\begin{array}{c}\text { Standard } \\
\text { Deviation }\end{array}$ & Minimum & Maximum \\
\hline \multirow{2}{*}{$50 \%$ hatch } & Wet weight (mg) & 200 & 216 & 209 & 26 & 158 & 298 \\
& Fork length (mm) & 200 & 23.1 & 23.0 & 0.8 & 21.0 & 25.0 \\
\multirow{2}{*}{$\begin{array}{c}\text { Transfer to } \\
\text { emergence tubes }\end{array}$} & Wet weight (mg) & 20 & 236 & 224 & 32 & 190 & 310 \\
& Fork length (mm) & 20 & 27.9 & 28.0 & 1.6 & 25.0 & 31.0 \\
\hline
\end{tabular}

The mean wet weight of alevin at 50\% emergence ranged from $286 \mathrm{mg}$ in the short-exposure control group to $312 \mathrm{mg}$ in both the short- and long-exposure 113\% TDG treatment groups, a range of $26 \mathrm{mg}$. Differences in wet weight were statistically significant among exposure periods (ANOVA: $F=6.18$; $\mathrm{df}=$ 1,40; $\mathrm{p}=0.017$ ) and treatments (ANOVA: $F=4.24 ; \mathrm{df}=3 ; \mathrm{p}=0.011$ ) but not significant for the interaction of exposure period and treatment (ANOVA: $F=1.33$; $\mathrm{df}=3,40 ; \mathrm{p}=0.277$ ). These differences may be due in part to the difficulty in obtaining accurate and consistent wet weight measurements due to differences in water retention on the surface of the samples. The mean fork length ranged from $36.4 \mathrm{~mm}$ in the short-exposure control group to $37.0 \mathrm{~mm}$ in the long-exposure $113 \%$ TDG treatment group (Table 2.5). Lengths did not differ among exposure periods (ANOVA: $F=3.54$; $\mathrm{df}=$ 1,$40 ; \mathrm{p}=0.067$ ) or treatments (ANOVA: $F=2.35$; $\mathrm{df}=3,40 ; \mathrm{p}=0.087$ ).

The mean development index $\left(k_{\mathrm{D}}\right)$ ranged from 1.81 to 1.84 and was significantly different among the treatments (ANOVA: $F=7.84$; $\mathrm{df}=3,40 ; \mathrm{p}=0.0003$ ) and exposure periods (ANOVA: $F=5.45$; $\mathrm{df}$ $=1,40 ; p=0.025)$. The range is small (0.03) and is likely not biologically significant. These differences also may be related to variabilities in wet weight measurements. 
Table 2.5. Size of chum salmon sampled at 50\% emergence

\begin{tabular}{|c|c|c|c|c|c|c|c|c|}
\hline Exposure & Variable & Treatment & $N$ & Mean & Median & $\begin{array}{l}\text { Standard } \\
\text { Deviation }\end{array}$ & Minimum & Maximum \\
\hline \multirow{12}{*}{$\begin{array}{c}\text { Long } \\
\text { (48 days) }\end{array}$} & \multirow{4}{*}{$\begin{array}{l}\text { Wet weight } \\
\text { (mg) }\end{array}$} & Control & 90 & 303 & 297 & 34 & 233 & 409 \\
\hline & & $103 \%$ & 90 & 311 & 299 & 40 & 237 & 434 \\
\hline & & $108 \%$ & 90 & 306 & 297 & 35 & 263 & 462 \\
\hline & & $113 \%$ & 90 & 312 & 301 & 34 & 247 & 463 \\
\hline & \multirow{4}{*}{$\begin{array}{l}\text { Fork length } \\
\quad(\mathrm{mm})\end{array}$} & Control & 90 & 36.8 & 37.0 & 0.96 & 35.0 & 39.0 \\
\hline & & $103 \%$ & 90 & 36.7 & 36.5 & 1.18 & 34.0 & 41.0 \\
\hline & & $108 \%$ & 90 & 36.9 & 37.0 & 0.90 & 35.0 & 40.0 \\
\hline & & $113 \%$ & 90 & 37.0 & 37.0 & 1.08 & 34.0 & 41.0 \\
\hline & \multirow{4}{*}{$\begin{array}{l}\text { Development } \\
\text { index }\left(\mathrm{k}_{\mathrm{D}}\right)\end{array}$} & Control & 90 & 1.82 & 1.82 & 0.04 & 1.70 & 1.99 \\
\hline & & $103 \%$ & 90 & 1.84 & 1.83 & 0.06 & 1.77 & 2.05 \\
\hline & & $108 \%$ & 90 & 1.82 & 1.82 & 0.04 & 1.74 & 2.01 \\
\hline & & $113 \%$ & 90 & 1.83 & 1.83 & 0.03 & 1.75 & 1.91 \\
\hline \multirow{12}{*}{$\begin{array}{c}\text { Short } \\
\text { (34 days) }\end{array}$} & \multirow{4}{*}{$\begin{array}{l}\text { Wet weight } \\
\text { (mg) }\end{array}$} & Control & 90 & 286 & 285 & 32 & 192 & 401 \\
\hline & & $103 \%$ & 90 & 297 & 290 & 31 & 225 & 390 \\
\hline & & $108 \%$ & 90 & 302 & 296.5 & 33 & 222 & 422 \\
\hline & & $113 \%$ & 90 & 312 & 302 & 30 & 242 & 294 \\
\hline & \multirow{4}{*}{$\begin{array}{l}\text { Fork length } \\
\quad(\mathrm{mm})\end{array}$} & Control & 90 & 36.4 & 36.0 & 1.10 & 34.0 & 40.5 \\
\hline & & $103 \%$ & 90 & 36.6 & 36.5 & 0.95 & 34.0 & 39.0 \\
\hline & & $108 \%$ & 90 & 36.8 & 37.0 & 1.01 & 34.0 & 41.0 \\
\hline & & $113 \%$ & 90 & 36.9 & 37.0 & 0.94 & 34.0 & 39.0 \\
\hline & \multirow{4}{*}{$\begin{array}{l}\text { Development } \\
\text { index }\left(\mathrm{k}_{\mathrm{D}}\right)\end{array}$} & Control & 90 & 1.81 & 1.81 & 0.04 & 1.70 & 2.02 \\
\hline & & $103 \%$ & 90 & 1.82 & 1.82 & 0.04 & 1.73 & 1.97 \\
\hline & & $108 \%$ & 90 & 1.82 & 1.82 & 0.04 & 1.68 & 1.88 \\
\hline & & $113 \%$ & 90 & 1.84 & 1.84 & 0.04 & 1.76 & 1.93 \\
\hline
\end{tabular}

On average, alevin gained weight at approximately $2 \mathrm{mg} / \mathrm{d}$ (Figure 2.7) and length at approximately $0.32 \mathrm{~mm} / \mathrm{d}$ (Figure 2.8) from hatch to emergence and followed a growth curve typical of salmonid alevin. The weight gain did not differ among treatment groups and was related more to days post-fertilization. Both weight and length could be modeled as a second-order polynomial function of days post-fertilization $\left(R^{2}=0.98\right)$. The regression equation for weight was

$$
\text { Weight }=76.44+2.84(\mathrm{DPF})-0.0053\left(\mathrm{DPF}^{2}\right)
$$

where DPF was days post-fertilization.

The length gains of the fish were represented by

$$
\text { Length }=-28.64+1.29(\mathrm{DPF})-0.00637\left(\mathrm{DPF}^{2}\right)
$$




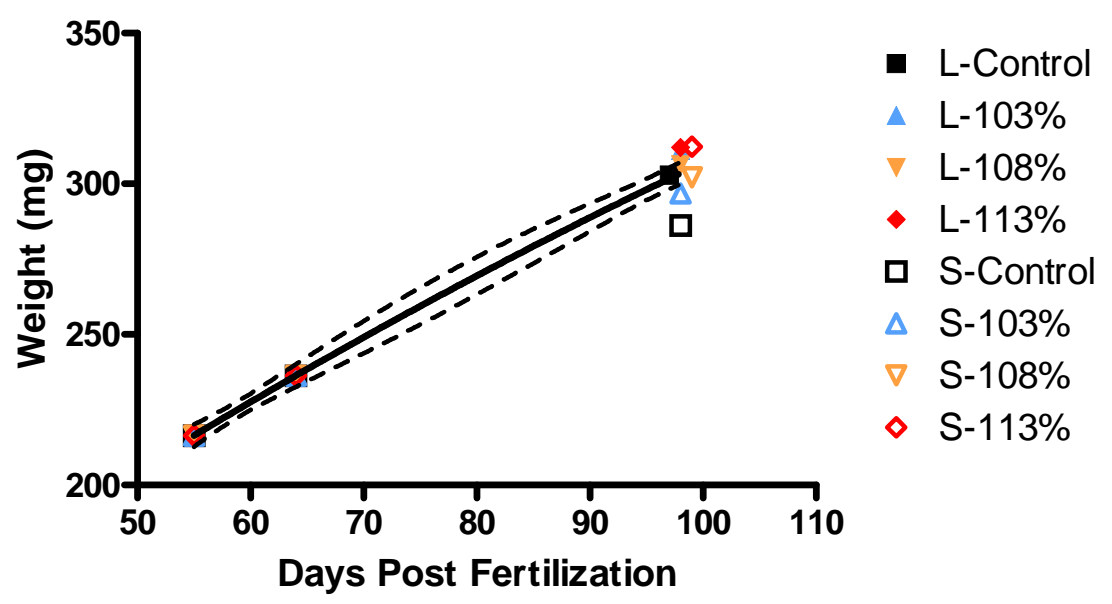

Figure 2.7. Average daily weight gain (mg/d) from $50 \%$ hatch to $50 \%$ emergence. Long (48-day) exposure represented by closed symbols (L); short (34-day) exposure represented by open symbols (S).

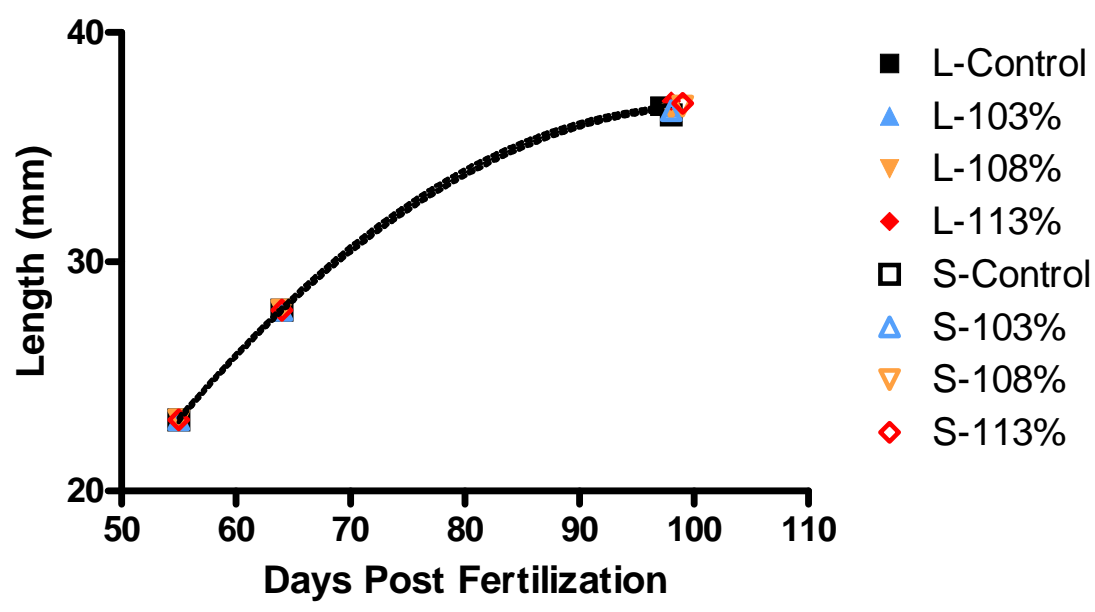

Figure 2.8. Average daily length gain ( $\mathrm{mm} / \mathrm{d}$ ) from $50 \%$ hatch to $50 \%$ emergence. Long (48-day) exposure represented by closed symbols (L); short (34-day) exposure represented by open symbols (S).

The mean dry tissue weight of alevin at 50\% hatch was $12.6 \mathrm{mg}$ (range 11.3-15.3 mg). At the time of $50 \%$ emergence, the mean dry tissue weight across the treatments ranged from a low of $51.1 \mathrm{mg}$ in the short-exposure control group to a high of $55.8 \mathrm{mg}$ in the short-exposure 113\% TDG treatment group (Table 2.6). The differences in dry tissue weight among the treatment groups were nearly significant (ANOVA: $F=2.69 ; \mathrm{df}=3,40 ; \mathrm{p}=0.059$ ), as were differences between exposures (ANOVA: $F=4.01$; $\mathrm{df}=3,40 ; \mathrm{p}=0.052$ ). The dry tissue weights for the short exposure were more variable than those for the long exposure. The mean dry yolk weight of alevin at 50\% hatch was $77.0 \mathrm{mg}$ (range $71.2-83.4 \mathrm{mg}$ ). At $50 \%$ emergence, the mean dry yolk weight across treatment groups ranged from a low of $2.5 \mathrm{mg}$ in the short-exposure control group to $4.3 \mathrm{mg}$ in the short-exposure 113\% TDG treatment group (Table 2.6). There were no significant differences in dry yolk weight among treatments within each exposure at 50\% emergence (ANOVA: $F=1.09 ; \mathrm{df}=3,40 ; \mathrm{p}=0.363$ ) or between exposures (ANOVA: $F=0.34$; $\mathrm{df}=$ 3,$40 ; p=0.564$ ). Again, the short-exposure alevin exhibited more variability. Finally, the total dry weight of alevin at 50\% emergence ranged from a low of $53.6 \mathrm{mg}$ in the short-exposure control group to 
$60.1 \mathrm{mg}$ in the short-exposure 113\% TDG treatment group (Table 2.6); with more variability among the short-exposure alevin.

Table 2.6. Tissue, yolk, and total dry weights of emergent fry

\begin{tabular}{|c|c|c|c|c|c|c|c|c|}
\hline Exposure & Variable & Treatment & $N$ & Mean & Median & $\begin{array}{c}\text { Standard } \\
\text { Deviation }\end{array}$ & Minimum & Maximum \\
\hline \multirow{12}{*}{$\begin{array}{c}\text { Long } \\
\text { (48 days) }\end{array}$} & \multirow{4}{*}{$\begin{array}{l}\text { Tissue dry } \\
\text { wt (mg) }\end{array}$} & Control & 6 & 54.6 & 54.7 & 1.4 & 52.8 & 56.3 \\
\hline & & $103 \%$ & 6 & 54.9 & 54.8 & 2.0 & 52.0 & 57.1 \\
\hline & & $108 \%$ & 6 & 54.7 & 54.6 & 3.1 & 49.7 & 59.1 \\
\hline & & $113 \%$ & 6 & 55.4 & 54.9 & 2.3 & 52.3 & 58.1 \\
\hline & \multirow{4}{*}{$\begin{array}{l}\text { Yolk dry } \\
\text { wt (mg) }\end{array}$} & Control & 6 & 3.9 & 3.6 & 0.84 & 3.0 & 5.2 \\
\hline & & $103 \%$ & 6 & 3.1 & 3.0 & 0.43 & 2.6 & 3.8 \\
\hline & & $108 \%$ & 6 & 3.3 & 3.3 & 0.66 & 2.5 & 4.2 \\
\hline & & $113 \%$ & 6 & 3.7 & 3.8 & 0.91 & 2.6 & 5.1 \\
\hline & \multirow{4}{*}{$\begin{array}{l}\text { Total dry } \\
\text { wt (mg) }\end{array}$} & Control & 6 & 58.5 & 58.8 & 2.0 & 55.8 & 60.9 \\
\hline & & $103 \%$ & 6 & 58.0 & 57.5 & 1.8 & 55.8 & 60.5 \\
\hline & & $108 \%$ & 6 & 58.0 & 57.2 & 3.3 & 53.4 & 63.3 \\
\hline & & $113 \%$ & 6 & 59.1 & 58.9 & 2.7 & 54.9 & 62.2 \\
\hline \multirow{12}{*}{$\begin{array}{c}\text { Short } \\
\text { (34 days) }\end{array}$} & \multirow{4}{*}{$\begin{array}{l}\text { Tissue dry } \\
\text { wt (mg) }\end{array}$} & Control & 6 & 51.1 & 50.8 & 2.6 & 48.2 & 55.5 \\
\hline & & $103 \%$ & 6 & 51.9 & 52.1 & 3.0 & 48.3 & 56.3 \\
\hline & & $108 \%$ & 6 & 54.0 & 53.8 & 3.9 & 48.6 & 58.3 \\
\hline & & $113 \%$ & 6 & 55.8 & 56.0 & 1.7 & 53.7 & 57.7 \\
\hline & \multirow{4}{*}{$\begin{array}{l}\text { Yolk dry } \\
\text { wt (mg) }\end{array}$} & Control & 6 & 2.5 & 2.6 & 0.79 & 1.4 & 3.7 \\
\hline & & $103 \%$ & 6 & 3.9 & 3.6 & 2.32 & 1.0 & 7.8 \\
\hline & & $108 \%$ & 6 & 4.0 & 4.1 & 0.87 & 2.6 & 5.1 \\
\hline & & $113 \%$ & 6 & 4.3 & 4.2 & 0.81 & 3.5 & 5.7 \\
\hline & \multirow{4}{*}{$\begin{array}{l}\text { Total dry } \\
\text { wt (mg) }\end{array}$} & Control & 6 & 53.6 & 53.0 & 2.9 & 51.0 & 59.2 \\
\hline & & $103 \%$ & 6 & 55.8 & 55.4 & 2.0 & 53.7 & 58.7 \\
\hline & & $108 \%$ & 6 & 57.9 & 58.3 & 4.5 & 52.2 & 62.8 \\
\hline & & $113 \%$ & 6 & 60.1 & 60.9 & 1.6 & 57.8 & 61.5 \\
\hline
\end{tabular}

\section{Histology}

The most significant histologic findings were present in the secondary lamellae of fish. The findings included crenated erythrocytes, dilated lamellar tips, epithelial hypertrophy, epithelial cell separation, and distal gill arch epithelization. For lesions of moderate severity or greater (grades 2, 3, and 4), only epithelial hypertrophy (Figure 2.9) and epithelial separation were present in substantive numbers of the pre-emergence and emergence samples (Figure 2.10). Other findings included hepatic glycogen depletion and an infection with a presumed protozoan parasite. 


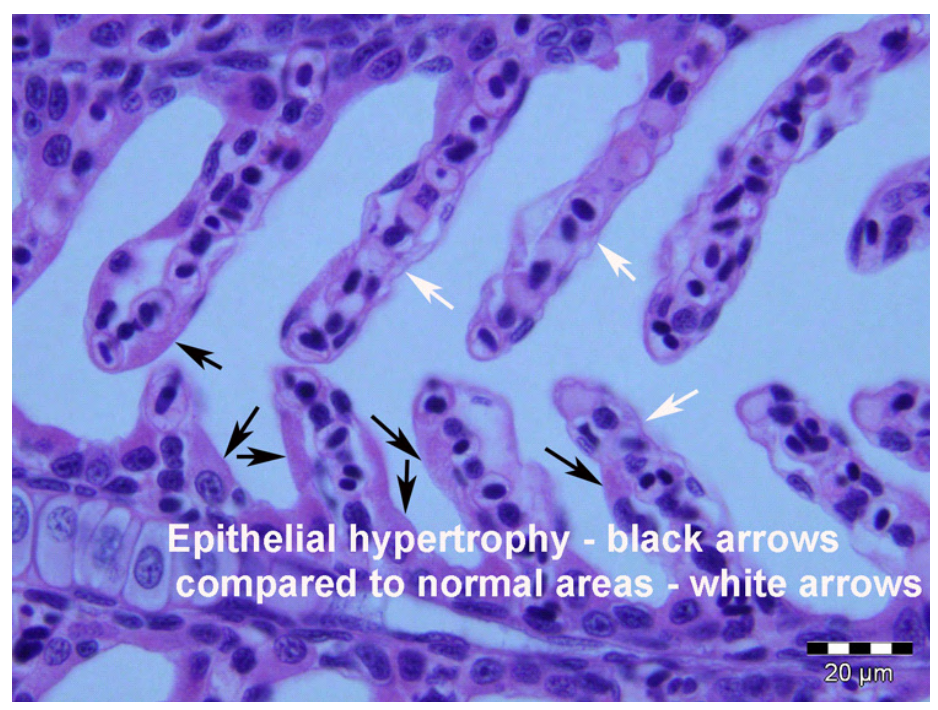

Figure 2.9. Epithelial hypertrophy appears as a thickening of the outer layer, or epithelium of the secondary lamellae (black arrows). Normal gill epithelium (white arrows) should appear as a thin layer around the lamellae.

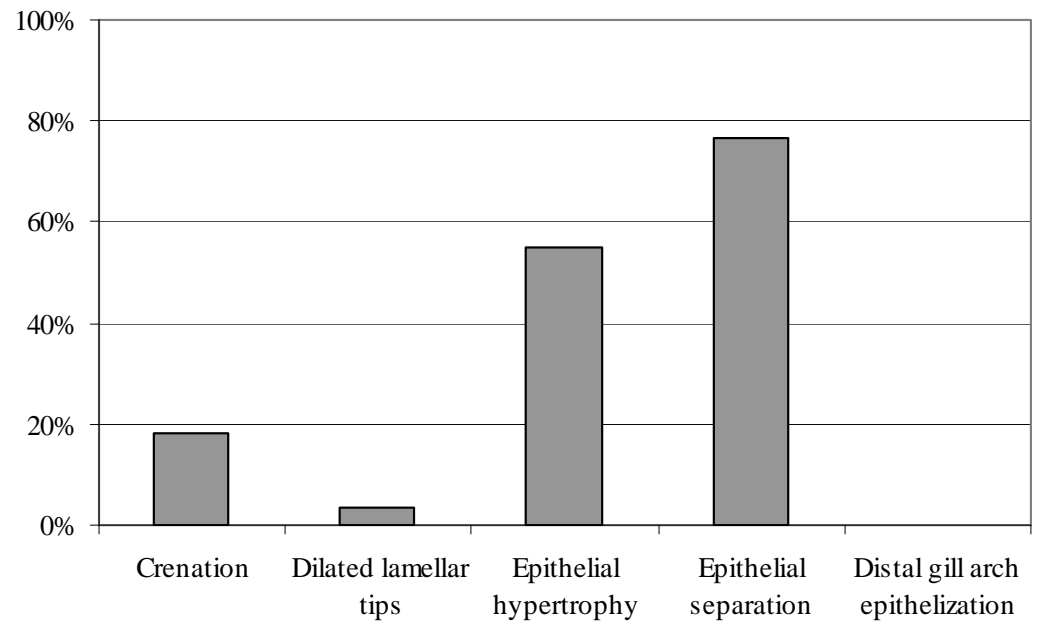

Figure 2.10. Percentage occurrence of moderate severity or greater gill lesions in the overall preemergence and emergence samples from the long and short exposures $(n=120)$

Crenated erythrocytes of moderate severity or greater were present in $18.3 \%$ of fish sampled during the exposure periods (Figure 2.10). The proportions of these lesions within each exposure period and percent TDG treatment group are shown in Figure 2.11. This lesion was limited to the capillaries in the secondary lamellae and could be an artifact of fixation or euthanasia. For the long exposure, no moderate lesions occurred in the pre-emergence sample; at emergence, the rates had increased significantly based on all pair-wise comparisons (Tukey simultaneous test: $T=4.03$; $\mathrm{df}=15 ; \mathrm{p}=0.011$ ), although they were not significantly different across percent TDG treatments (chi-square test: $p=0.72$ ). For the short exposure, the rate of moderate lesions was not significantly different across percent TDG levels in the 
pre-emergence sample (binomial exact test: $\mathrm{p}>0.19$ ); at emergence, there were slightly more moderate lesions than expected in the control group (chi-square test: $\mathrm{p}=0.046$ ).

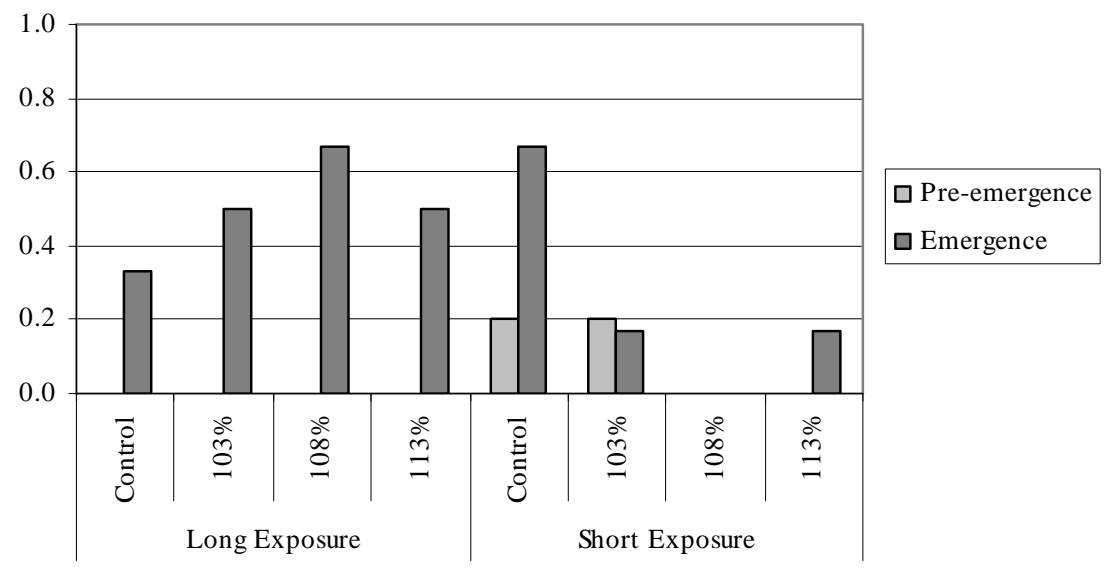

Figure 2.11. Proportions of fish sampled by exposure and treatment that exhibited crenated erythrocytes of moderate severity or greater in the secondary gill lamellae

Dilation of secondary lamellar tips and mild epithelization of gill arch tips was present at mild severity in most fish. Dilated lamellar tips appeared to be a terminal event and may have been related to stress at euthanasia; this lesion was present at moderate or greater severity in only $3.3 \%$ of fish sampled during the exposure periods (Figure 2.10). For the long exposure, no moderate dilated lamellar tip lesions occurred in the pre-emergence or emergence samples. For the short exposure, the rate of moderate dilated lamellar tip lesions was not significantly different across percent TDG levels in the preemergence samples (binomial exact test: $\mathrm{p}>0.32$ ). Epithelial hypertrophy also was present in many fish; $55 \%$ sampled had moderate severity or greater overall (Figure 2.10). For the long exposure at preemergence, slightly more moderate epithelial hypertrophy lesions occurred in the control group (binomial exact test: $p=0.06$ ). At emergence, the rates across treatments were significantly higher based on all pair-wise comparisons (Tukey simultaneous test: $T=5.765$; $\mathrm{df}=15 ; \mathrm{p}<0.001$ ); nearly all of the fish sampled had moderate lesions. For the short exposure at pre-emergence, slightly more lesions occurred than expected in the 113\% TDG treatment group (binomial exact test: $\mathrm{p}<0.1$ ). However, at emergence, the rate of moderate lesions was not significantly different across percent TDG groups (chi-square test: $p$ $>0.1$ ). The proportions of dilated lamellar tips and epithelial hypertrophy within each exposure period and percent TDG treatment group are shown in Figures 2.12 and 2.13. No fish sampled had distal gill arch epithelization of moderate severity or greater. The mild distal gill arch epithelialization coupled with the epithelial hypertrophy could be the result of poor water quality. However, epithelial hyperplasia was not present to indicate a severe water quality problem. 


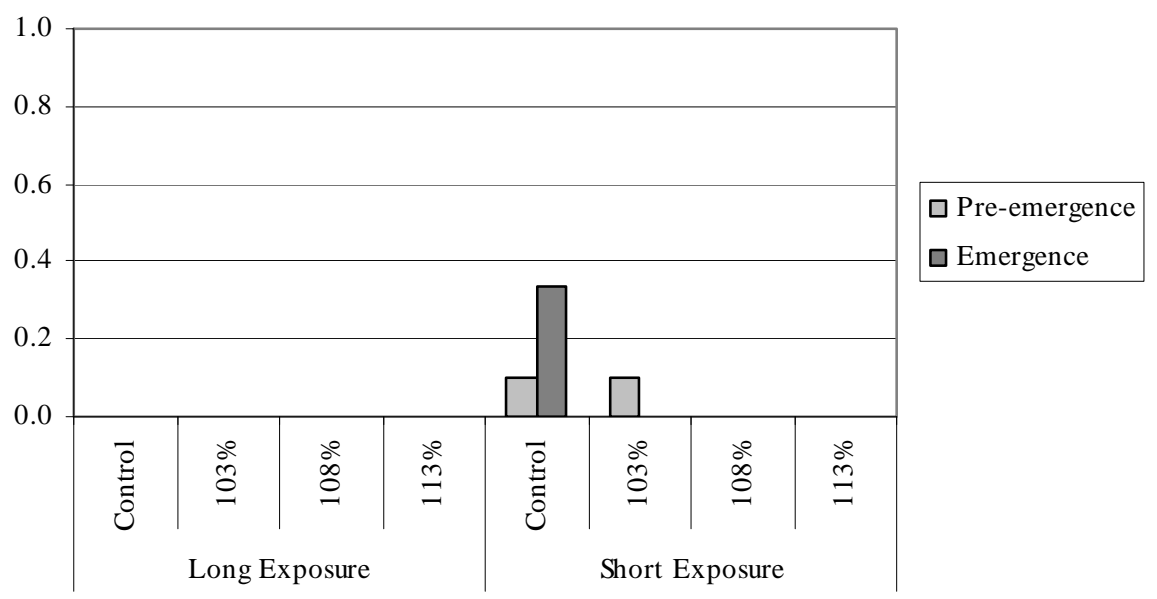

Figure 2.12. Proportions of fish sampled by exposure and treatment that exhibited dilated lamellar tips of moderate severity or greater

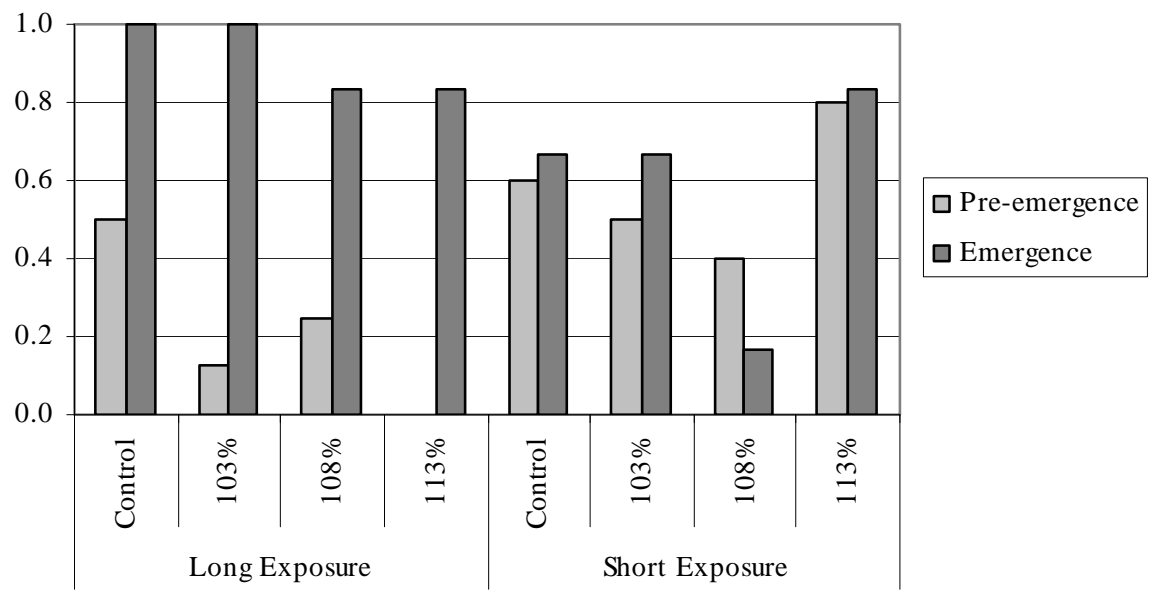

Figure 2.13. Proportions of fish sampled by exposure and treatment that exhibited epithelial hypertrophy of moderate severity or greater

Epithelial cell separation and vacuolar swelling and/or fragmentation with possible separation of the basement membrane from the pillar cell cytoplasm were observed at moderate severity or greater in $76.7 \%$ of fish sampled during the exposure periods (Figure 2.10). This was characterized by observation of a clear empty space between the epithelial cell and basement membrane or cytoplasm of the pillar cell. In the most severe cases (grade 4), a separation of approximately 5 to $6 \mu$ was noted. The separation was so severe that the pillar cell cytoplasm that forms the lamellar blood channels was clearly isolated from the epithelium. This gave the impression of a tube within a blood-filled tube. This is a unique lesion and most probably represents edema. The proportions of epithelial cell separation within each exposure period and percent TDG treatment group are shown in Figure 2.14. The rate of moderate epithelial cell separation was not significantly different across percent TDG levels for either the long or short exposures 
at pre-emergence (binomial exact test: $\mathrm{p}<0.21$ and $\mathrm{p}<0.3$, respectively). At emergence, the rates of lesions were not different across percent TDG groups for either the long or short exposures. The occurrence of lesions had increased from the pre-emergence period for the long exposure; this increase was significant based on all pair-wise comparisons (Tukey simultaneous test: $T=8.08$; $\mathrm{df}=15$; $\mathrm{p}<$ 0.001).



Figure 2.14. Proportions of fish sampled by exposure and treatment that exhibited epithelial cell separation of moderate severity or greater

Hepatic glycogen depletion was present at mild severity in $42.5 \%$ and at moderate severity or greater in $18.3 \%$ of fish sampled during the exposure periods. The proportions of hepatic glycogen depletion at moderate severity or greater within each exposure period and percent TDG treatment group are shown in Figure 2.15. The proportions of hepatic glycogen depletion were significantly different between the preemergence and emergence samples (ANOVA: $F=6.19$; $\mathrm{df}=1,7 ; \mathrm{p}=0.042$ ) but not significantly different among percent TDG treatments (ANOVA: $F=6.19$; $\mathrm{df}=7,7 ; \mathrm{p}=0.409$ ). Correlations between moderate hepatic glycogen depletion and moderate gill lesions were not consistent across exposures or treatments. 


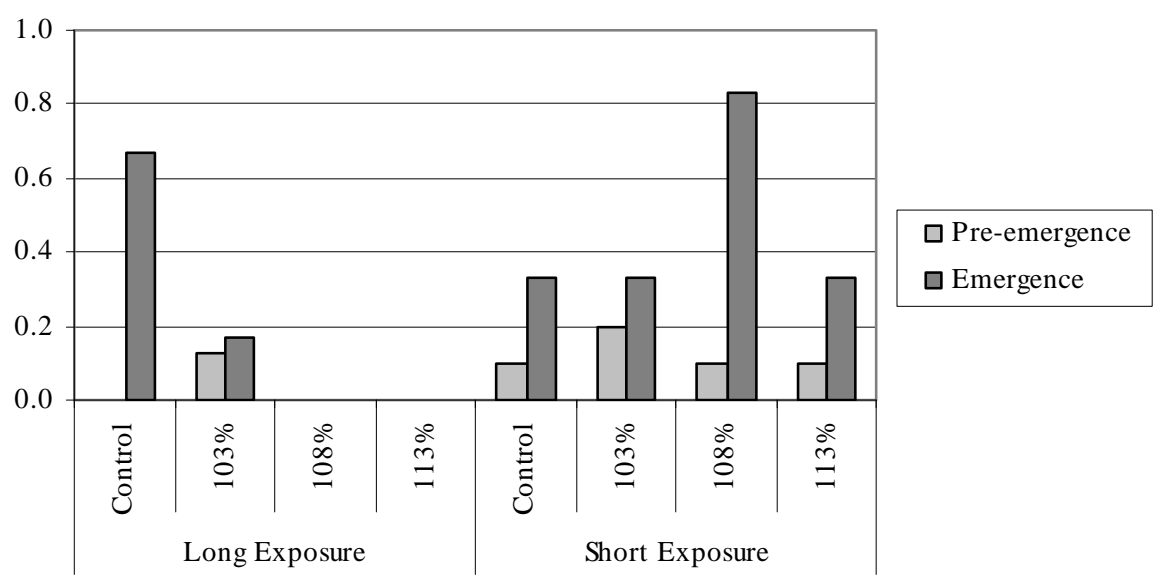

Figure 2.15. Proportions of fish sampled by exposure and treatment that exhibited hepatic glycogen depletion of moderate severity or greater

Of the fish examined during pre-emergence and emergence, 25\% overall were infected with an unidentified presumed protozoan parasite on the thymus, gills, and/or skin. Most occurrences were graded only mild severity, and the skin generally contained more parasites than either the thymus or gills. All fish exhibiting parasites were from the pre-emergence samples (of which $41.7 \%$ had parasites); no fish from the emergence samples were infected. Figure 2.16 shows the distribution of parasite infection of mild and moderate severity within each exposure period and treatment. The proportions of moderate parasite infections was not significantly different by exposure (ANOVA: $F=0.08$; $\mathrm{df}=1,3 ; \mathrm{p}=0.8$ ) or percent TDG treatment (ANOVA: $F=1.0 ; \mathrm{df}=3,3 ; \mathrm{p}=0.5$ ). This infection did not appear to correlate with the lesions in the secondary lamellae. Special stains for the parasitic wall and/or for internal structures were negative, including the PAS, GMS, Geimsa, and stain for mucin. The presumed "zoites" in the protozoan could be best visualized with the mucin stain due to the yellow background. The zoites were negative for the red-staining mucin. The results did indicate the presumed round intra-cytoplasmic structures were protozoan and not intracellular mucous-containing cysts. Mucus in the epithelial cells was positive with all four special stains. The special stains also helped to differentiate the protozoan from smaller intracellular apoptotic cells (phagocytized dead cellular debris in a vacuole). 




Figure 2.16. Proportions by treatment of fish sampled at pre-emergence that exhibited protozoan parasite infection of mild or moderate severity in the skin

\section{Incremental Exposure to Supersaturated Total Dissolved Gas Levels up to 129\%}

\section{Gross Examinations}

Total dissolved gas levels increased throughout the study from a low of $101.8 \%$ at the beginning of the experiment to a high of $129.1 \%$ on April 12 (Figure 2.17). Alevin in this study exhibited signs of gas bubble trauma when exposed to supersaturated gas levels of 121\% TDG and higher. Symptoms first appeared as small bubbles in the pupil and along the lateral line (Figure 2.18). Mortality occurred at $124.6 \%$ TDG and above. Bubbles were observed in the eye, jaw, and operculum of dead fish but not in living fish. The most prevalent symptom was the formation of bubbles in the vitelline membrane. These bubbles caused changes in behavior, as fish were noted to first swim tail-up, then float at the surface, and finally swim upside down. 


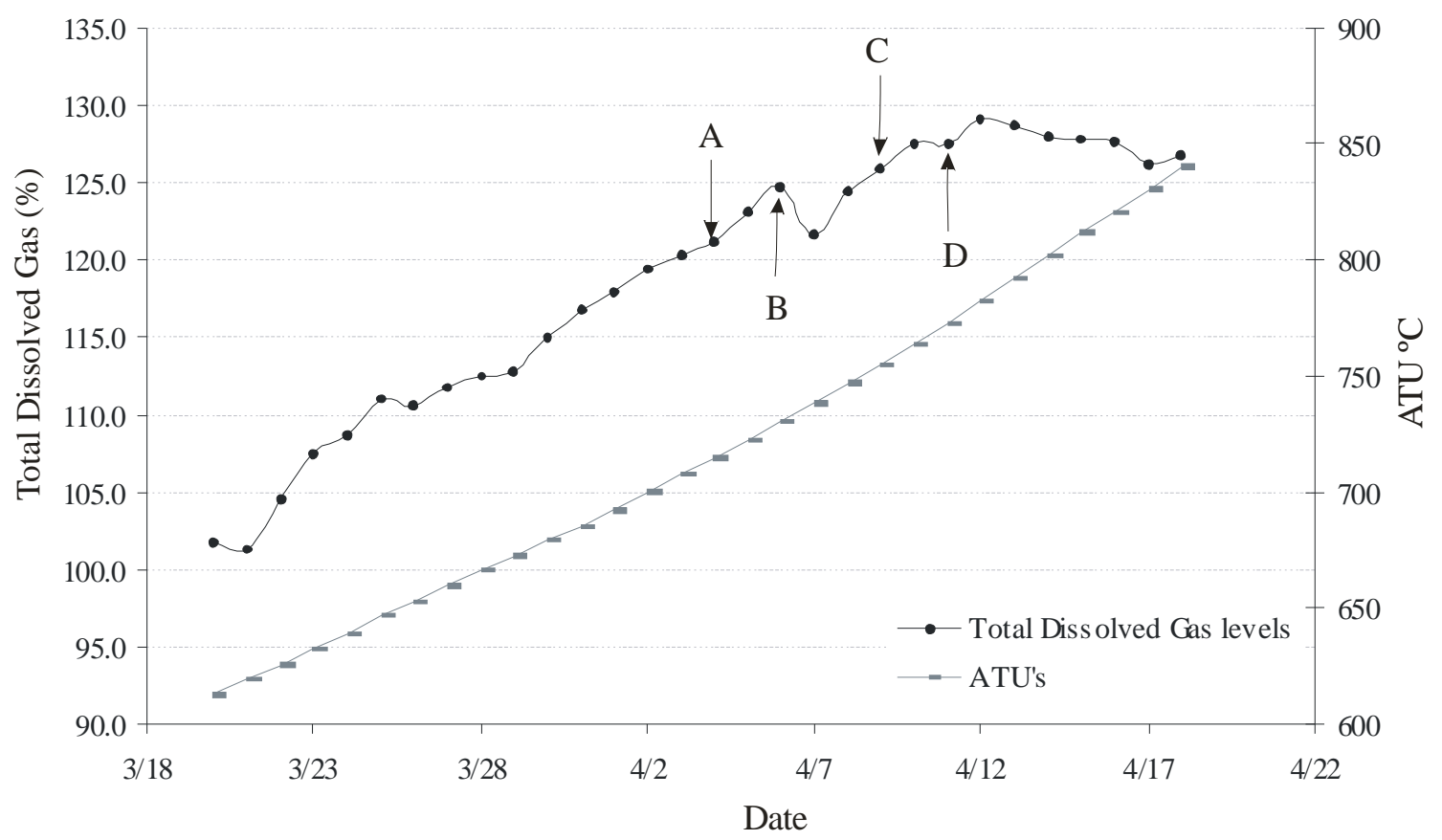

Figure 2.17. General increase in total dissolved gas levels over the study period (black line). All fish were found in the substrate with tails up at 121\% TDG (A). Bubbles in the pupil and lateral line also were noted. Mortality began at $124.6 \%$ TDG (B) and continued throughout the study. Fish were found swimming at the surface of the water at $125.9 \%$ TDG (C). Large bubbles in the vitelline membrane formed causing fish to swim upside down at $127.5 \%$ TDG (D). The first signs of gas bubble disease occurred when fish reached 715 ATU (grey line).

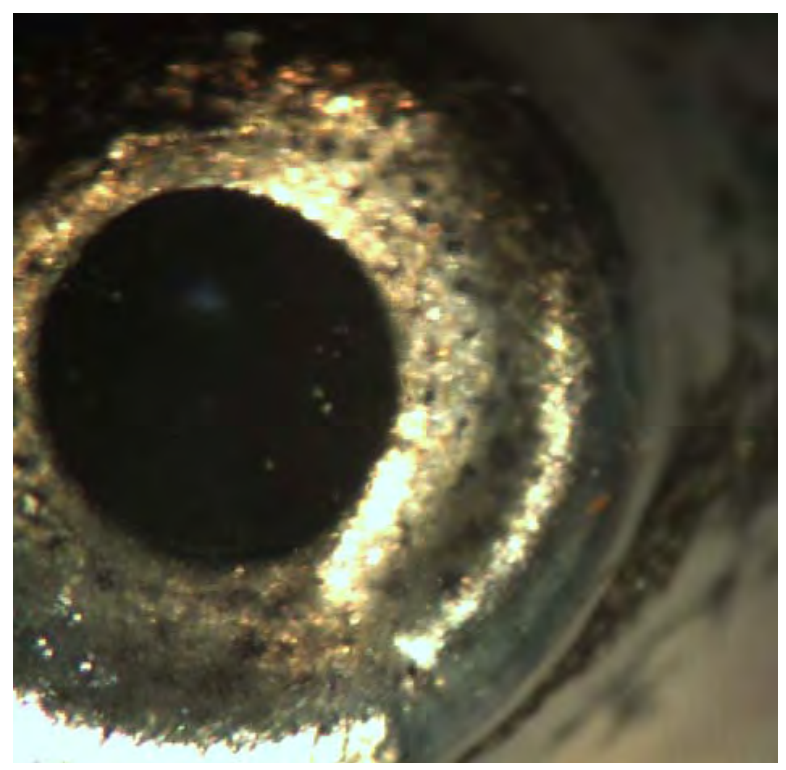

Figure 2.18. Small clusters of bubbles observed in the pupil of fish exposed to 121\% TDG and above 
As shown in Figure 2.19, the water temperature ranged from 6.25 to $9.9^{\circ} \mathrm{C}$ over the duration of the incremental exposure study.

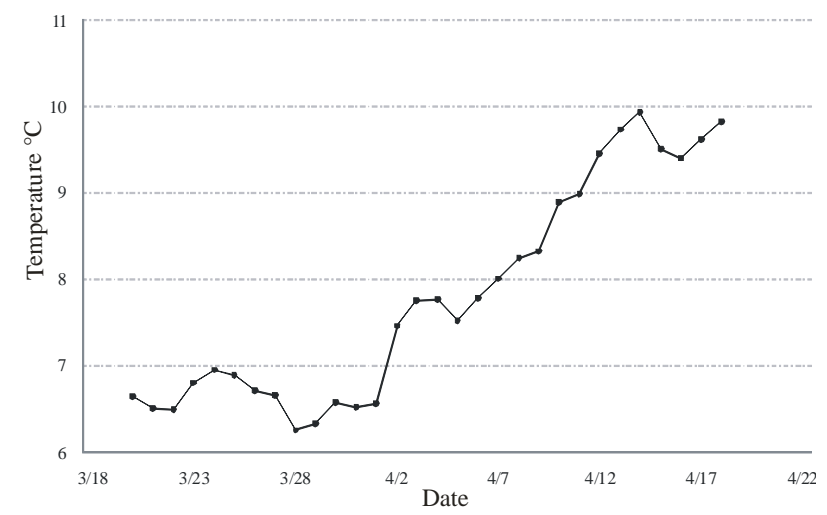

Figure 2.19. Temperature range during incremental exposure study

The first mortality occurred on April 6 when gas levels reached $124.6 \%$. This fish was too decomposed to examine, and the cause of death could not be determined. An additional fish examined on this day was noted to have bubbles in the intestine and stomach. The yolk was beginning to coagulate and turn an opaque orange-white (Figure 2.20). Small white patches were observed on the gills. We could not determine if the patches were a result of emboli in the filaments. No other fish examined during the study were observed with abnormalities in the gills.

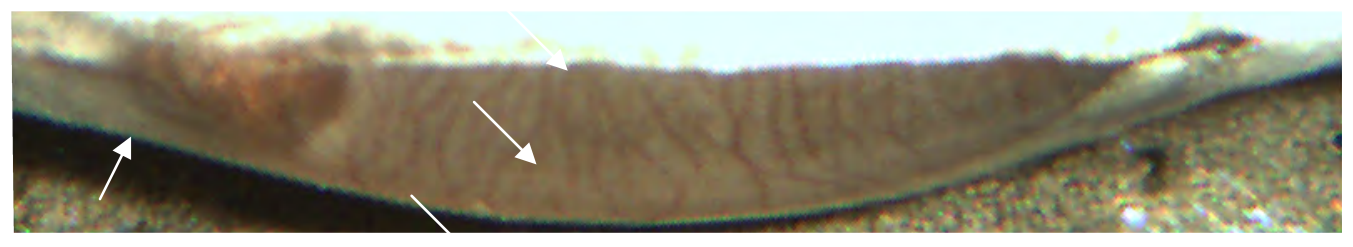

Figure 2.20. Coagulated yolk in fish exposed to $124.6 \%$ total dissolved gas and above. Note the bright orange color of the residual normal yolk (arrow) for comparison to the coagulated portion.

A second mortality occurred on April 9 when TDG levels reached $125.9 \%$. This fish had several large bubbles around the eyes, head, and jaw, and cranial swelling (Figure 2.21). Cohorts did not show any apparent signs of bubbles or other abnormalities other than bubbles in the pupil, lateral line, and intestines. However, several fish were observed floating at the surface of the water. Fish not at the surface floated to the surface if the substrate was removed. 


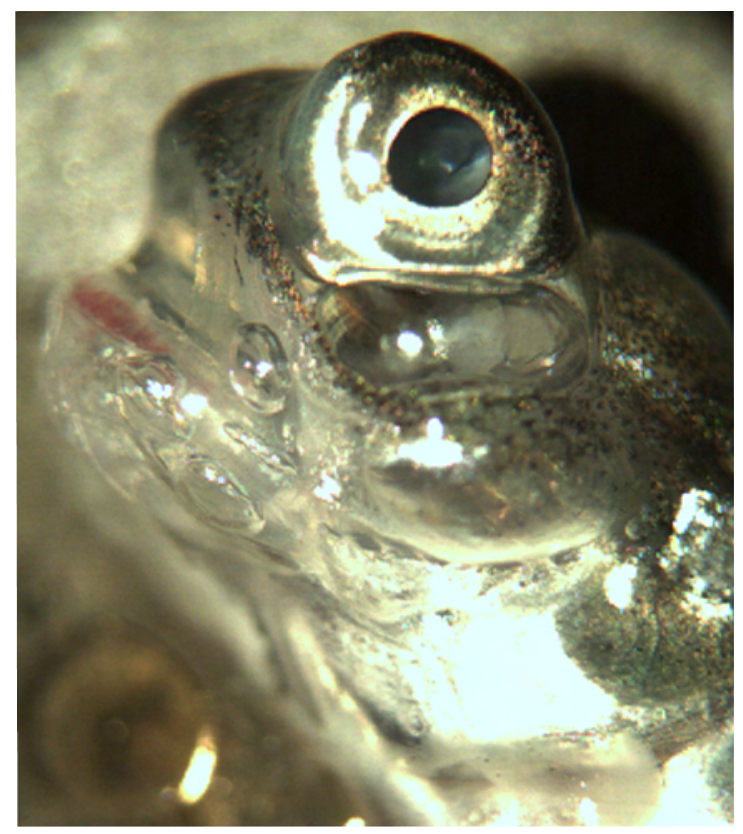

Figure 2.21. Mortality found when total dissolved gas levels reached $125.9 \%$ was observed with numerous large bubbles on the head, eyes, and jaw.

As TDG levels reached $127.5 \%$ on April 11, all fish were swimming erratically and some fish were ventral side up due to a large bubble within the vitelline membrane (Figure 2.22). A necropsy on one of these fish showed large bubbles in the intestines and behind the eyes as well as the bubble in the vitelline membrane. Mortalities found on April 12 exhibited large bubbles covering the face, jaw, and opercula and in the intestines. The eyes were exophthalmic due to bubbles behind and around the orbs. In two fish, the vitelline membrane had burst.

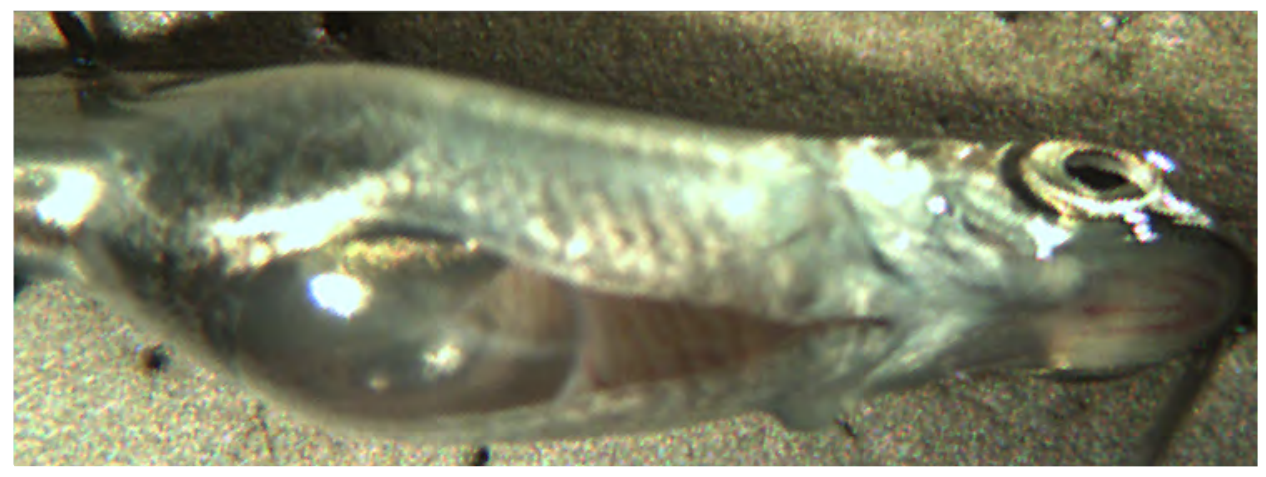

Figure 2.22. A very large bubble in the vitelline membrane of a fish exposed to $127.5 \%$ total dissolved gas. Note how the bubble is displacing the yolk.

No additional symptoms were noted between April 12 and the end of the exposure period on April 18. The majority of fish remaining had developed a large bubble in the vitelline membrane. Mortalities were seen in 26\% of fish in cup A and 17\% of fish in cup B (Figure 2.23). Interestingly, only mortalities exhibited bubbles in the jaw and opercula. All mortalities had bubbles in the eye. Only one sacrificed fish was noted with bubbles in the eye causing exophthalmia. 


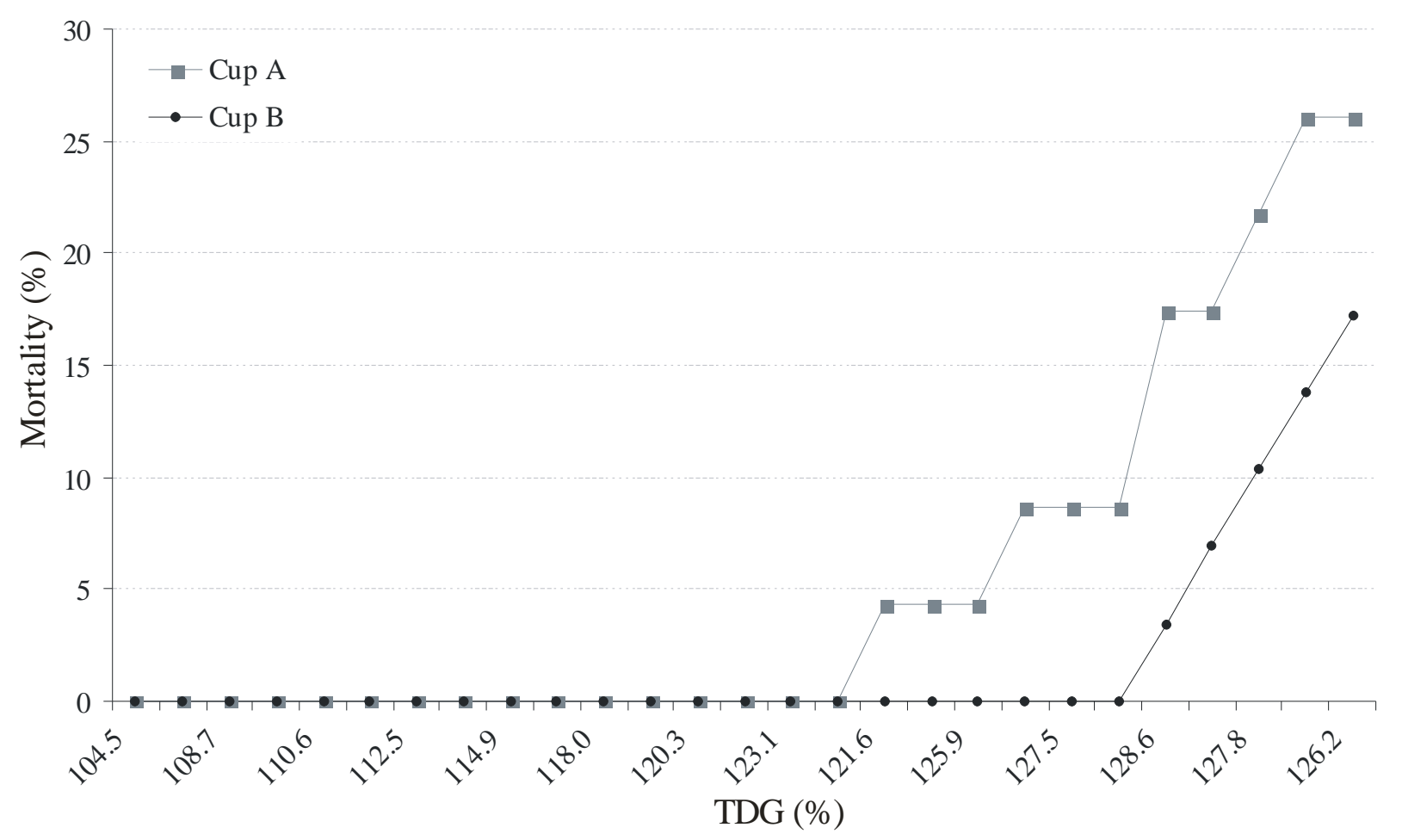

Figure 2.23. Percentage of fish experiencing mortalities with increasing total dissolved gas levels in both cup A (grey line - squares) and cup B(black line - circles).

\section{Histology}

Three fish were removed from the incubation cups for histological analysis between April 15 and 18 . Moderate amounts of epithelial hypertrophy and epithelial separation or swelling were found in the gills of two of the fish. One of the fish had low levels of these lesions. All three fish showed moderate to severe levels of glycogen/lipid depletion. All other organs appeared normal.

\section{Discussion}

This study demonstrated that survival to emergence of developing chum salmon alevin was not influenced by exposure to supersaturated gas levels up to $113 \%$ but that alevin did show signs of gas bubble trauma at gas levels of $121 \%$ and above. Alevin size and timing at emergence were not affected and not biologically different between the different exposure lengths and supersaturation levels up to $113 \%$. Histological analysis found incidence of gill and organ lesions, but frequency and severity of these lesions failed to correlate with exposure to increasing levels of gas supersaturation.

The high survival rates for this study (>98\%) compared similarly to those of last year ( $>99 \%$ for control through 108\% TDG and 95\% for 113\% TDG; Hand et al. 2008). Beacham and Murray (1990) reported a survival rate of greater than $90 \%$ for chum alevin raised at $10^{\circ} \mathrm{C}$. These high rates of survival in both the 48-day and 34-day exposure periods demonstrate that incubating chum salmon alevin are not detrimentally affected by exposure up to $113 \%$ TDG. The nationwide water quality standard for TDG 
(established in 1972 and still in effect) is 110\% (EPA 1987). Results from this study indicate that this level may be adequate to protect chum salmon incubating in the Columbia River. .

The size of chum salmon fry at emergence and the timing to emergence for this study compare well with other researchers' findings. Bams (1970) reported chum salmon fry raised in hatchery conditions had an average length of $36.15 \mathrm{~mm}$ at emergence, compared to 36.4 to $37.0 \mathrm{~mm}$ in our study. The average weight of $367.9 \mathrm{mg}$ reported by Bams (1970) was higher than our results of 286 to $312 \mathrm{mg}$. This difference could be due to different methods of determining emergence and because egg size (from population and species variation) is a major factor in alevin weight (Beacham and Murray 1990). The number of days to emergence in our study ( 97 to 99 days post-fertilization) are consistent with the observed and predicted times reported by Beacham and Murray (1990). That the values from our study correspond well with known parameters further indicates that the development of chum salmon alevin was not influenced by gas concentrations up to $113 \%$.

Histological analysis of the gills and other organs showed several types of lesions in fish from most treatment groups in this study. The most significant histological lesions consisted of epithelial separation and vacuolar swelling in the gills and epithelial hypertrophy, similar to those seen in the 2007 laboratory study (Hand et al. 2008). Unlike that study, the frequency or severity of the gill lesions this year did not correlate with increasing TDG levels. Alevin in the static study (up to 113\% TDG) showed histological lesions but no gross physical effects or decreased survival, indicating that factors other than TDG level may be involved.

Because the apparent dose response of moderate epithelial hypertrophy observed in 2007 (Hand et al. 2008) was not seen this year, the cause of the 2007 lesion increase was questioned. We reexamined the data to identify other variables that may have differed proportionally with TDG level. We found that the power outage that occurred in 2007 could have affected the experimental results more than initially thought and is a possible cause of the dose-related increase in this lesion. The disruption of power altered flow rates, water temperatures, and possibly oxygen levels. Although epithelial hypertrophy could be expected from chronic gas supersaturation exposure, it is also a lesion that results from excess un-ionized ammonia, which could have increased with increased water temperature. Because the temperature effect was correlated directlywith TDG level, it is likely the cause of the observed increase in epithelial hypertrophy from the control through the 113\% TDG treatment levels in 2007.

This year, fish exposed to less than 100\% TDG (control) often had as high as, or higher than, levels of gill lesions of fish exposed to supersaturated waters. Where differences were evident, the time of exposure was generally the significant factor; longer exposure times generally resulted in increased occurrence and severity of lesions. This finding, in addition to the lack of other signs of gas bubble trauma in the static exposure study, suggests that elevated TDG levels above $100 \%$ are not the sole mechanism for these lesions. Ultrastructural studies have noted similar gill lesions in fish exposed to toxins and overly turbid waters (Camargo and Martinez 2007; Sutherland and Meyer 2007). This study used filtered well water that is not known to contain contaminants, although testing would be necessary to rule out water quality problems. It is also possible that stress (i.e., poor water flow and quality) during the egg stage could have weakened some of the fish and contributed to the development of gill lesions. In conclusion, there does not appear to be an obvious explanation for the varying levels of observed histological lesions, especially in the control group, in 2008. 
Due to small sample sizes, statistical analysis could not be performed on the incremental study fish samples. However, the few fish from the incremental study that were examined histologically did not exhibit obviously higher frequency or severity of gill lesions than did the static study samples. One reason for this may be that gas bubble trauma that results in gross physical symptoms is an acute disease and changes at the cellular level may not have time to develop. Rucker and Kangas (1974) did not note any histological abnormalities in mortalities in Chinook and coho alevin with grossly visible bubbles in the vitelline membrane.

Alevin in this study showed increased levels of lipid or glycogen depletion in the liver over the chum salmon alevin in the 2007 laboratory study also exposed to supersaturated water up to 113\% TDG (Hand et al. 2008). Glycogen plays a role in energy metabolism and can vary widely in fish. The differences in the amount of glycogen depletion were related more to length of exposure than to supersaturated gas levels, which indicates that experimental treatments were not the cause.

The infection by a presumed protozoan parasite was mild and did not appear to affect alevin survival or susceptibility to gas bubble trauma. It is unusual that alevin at pre-emergence were infected but alevin later at emergence were not because, in 2007, the parasite infection increased with length of exposure (Hand et al. 2008). Fish were not medicated or treated for disease during the study period. Examination by electron microscopy would be required to identify the protozoan before its significance can be evaluated.

In the incremental study, direct alevin mortality began at 124.6\% TDG. Before direct mortality occurred, alevin were observed with positive buoyancy, unable to stay down in the gravel. Due to this abnormal swimming behavior, in a natural system mortality through predation most likely would occur before direct mortality.

The gross physical symptoms we witnessed in the incremental exposure study are similar to those seen in other studies examining the effects of supersaturated gas on sac-fry salmonids. Embody (1934), Rucker and Kangas (1974), Adams and Towle (1974), Stroud et al. (1975), and Wood (1979) all report bubbles in the vitelline membrane to be the most pronounced symptom of gas supersaturated water exposure. In our study, dead fish had symptoms; live fish did not have symptoms. This may be due to changes in permeability in skin and membranes after death.

The development stage of the fish in this study may have influenced the onset of the symptoms. The study fish were 108 days post-fertilization, 715 ATU, and close to buttoned-up when symptoms appeared at $121 \%$ TDG. Onset of gas bubble disease in the later portion of incubation has been noted in sac fry of Chinook salmon and coho salmon (Rucker and Kangas 1974). It is possible that symptoms may have occurred at lower TDG levels in our study if fish had been exposed during later development stages. Results from the static exposure study suggest that if the onset of gas bubble disease will occur at lower levels, it likely will be at a level above 113\% TDG.

Decreased tolerance to supersaturation may arise as fish develop from the larval to juvenile life stage, as several features of the young alevin's physiology and anatomy could protect the fish from gas bubble formation. Young salmonid alevin respiration is accomplished through passive diffusion of gasses across the skin and, to some extent, the yolk, rather than the gills. This mode of respiration persists until gills are developed and surface-to-mass ratios become too great to make this mechanism feasible (Wells and Pinder 1996a, 1996b; Rombough 1999). Symptoms of gas bubble disease have been documented in sturgeon soon after conversion to gill respiration (Counihan et al. 1998). The time at which fry will 
convert to gill respiration will depend on the size and the ratio of surface area to volume of the fish, which will vary with species.

Changes in skin and membrane permeability also occur as fish approach emergence (Talbot et al. 1982), which also may affect gas permeability. Finally, the large yolk content of young alevin may act as a sink for nitrogen and protect the fish from bubble formation. Body fat influences gas bubble development in humans after rapid decompression due to the greater solubility of nitrogen in lipids versus other tissues (Philip and Gowdey 1964). However, further testing would need to be done to confirm this concept.

In conclusion, gas supersaturation up to $113 \%$ did not affect chum salmon survival through emergence, but behavior and mortality were affected detrimentally at levels of $121 \%$ and above. A fullscale study of the effects on survival, behavior, and histological changes of levels above $113 \%$ TDG would be valuable to further understand this topic. 

Final Report

\title{
Chapter 3
}

\section{Field Analysis of Incubating Chum Salmon Sac Fry Exposed to In-River Total Dissolved Gas Levels Downstream of Bonneville Dam}

\author{
K. M. Carter, E. V. Arntzen, D. R. Geist, E. M. Dawley
}

\section{Introduction}

During FY 2007, we examined the effects of TDG levels up to $113 \%$ on the sac fry of chum salmon (Oncorhynchus keta) in a laboratory setting. However, laboratory conditions differ from natural redd conditions, and hydropower project management agencies and Native American tribes have questioned whether controlled laboratory studies are representative of TDG exposure in the Columbia River. Their concern led to the recommendation to sample pre-emergent chum salmon fry incubating in the river environment. Consequently, as part of our study in FY 2007, live alevin were captured from wild redds in the Ives Island location. This sampling coincided with a period of elevated TDG-in fact, depthcompensated TDG exceeded 105\% while sampling was conducted. Field examination showed potential signs of gas bubble trauma, such as bubbles in the nares and intestinal tract and hemorrhaging in fins. However, assessments were qualitative, and survival could not be calculated by sampling naturally occurring redds.

To assess negative impacts to field sac fry and quantify their survival, we executed an egg tube study during FY 2008. We placed eight artificial incubation tubes in an artificial redd near Ives Island to study the effects of elevated TDG as would be experienced by pre-emergent wild chum salmon sac fry. The area chosen was adjacent to areas sampled during FY 2007, as well as close to known wild chum salmon redds. Unlike FY 2007, our study design allowed for quantitative estimates of survival and physiological impacts to chum salmon.

\section{Study Site}

We built one artificial redd downstream from Bonneville Dam at rkm 230. The artificial redd was located north of Ives Island, between Ives pair 1 and Ives pair 2 monitoring stations (see Figure 1.2). Chum salmon are known to spawn at this location; they may experience elevated TDG when water is spilled at Bonneville Dam and adequate compensation depths are not available. 


\section{Methods}

\section{Artificial Redd}

On the day of egg tube deployment, eyed wild chum salmon eggs were obtained from the Washougal Hatchery (Washougal, Washington) and transported to the Ives Island location. At deployment, eggs were at 449 accumulated thermal units (ATU). Egg tubes (Figure 3.1) were filled with washed gravel ranging in size from $4 \mathrm{~mm}$ to $62 \mathrm{~mm}$. The gravel was transported to the field using two different mixtures, which were divided by hand into each egg tube using approximately equal quantities. By weight, one gravel mixture contained $64 \%$ material in the 16 - to $31-\mathrm{mm}$ size class and $36 \%$ gravel in the 32- to 62-mm size class. The other gravel mixture contained (by weight) $5 \%$ gravel in the 4- to 7-mm size class, 36\% 16- to 31-mm size class, and 59\% in the 8- to 15-mm size class. One hundred eggs were placed within each tube. Eight tubes were placed in the redd, for a total of 800 eggs. Each tube also contained a temperature logger (DST milli-T [archival temperature logger], Star-Oddi, Reykjavik, Iceland). Unused eggs were transported to the PNNL Aquatics Research Laboratory in Richland, Washington, for incubation and use as an experimental control group.

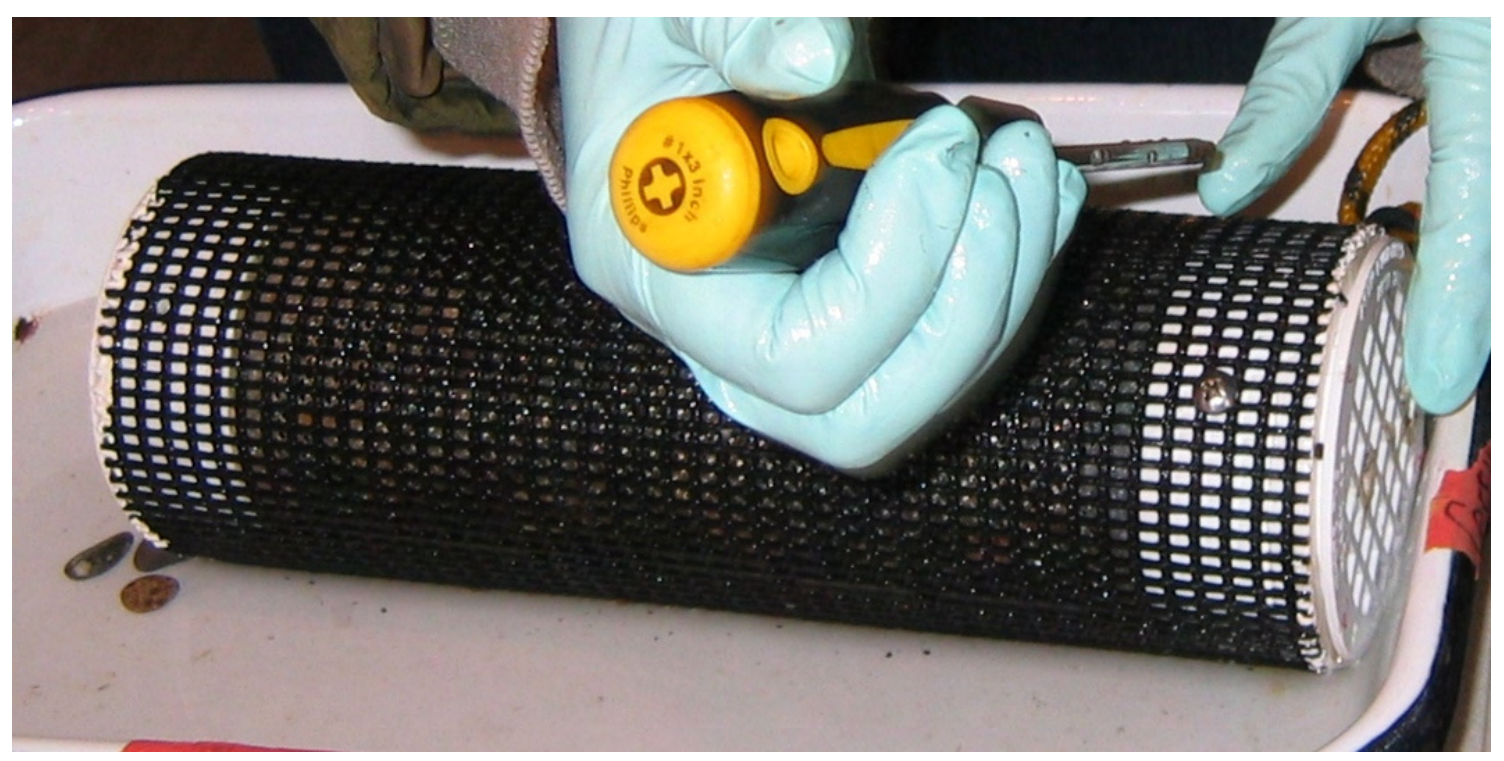

Figure 3.1. Egg tube to house wild chum salmon eggs and alevin while in the artificial redd

The artificial redd was constructed near existing monitoring piezometers in the Ives Island area (refer to Figure 1.2 in Chapter 1). We used hand shovels to excavate the redd to total depth of $30 \mathrm{~cm}$ below the surrounding undisturbed gravel (Figure 3.2A). This depth allowed our 9-cm-diameter egg tubes to be covered by approximately $21 \mathrm{~cm}$ of gravel, closely simulating the geometry of a natural chum salmon redd. Spawning chum salmon typically excavate redds to a depth of up to $30 \mathrm{~cm}$ and create an egg pocket with a ceiling approximately $20 \mathrm{~cm}$ below the surrounding riverbed (Peterson and Quinn 1996). Redds were excavated to measure approximately $60 \mathrm{~cm}$ at the bottom, in a direction parallel to river flow, and approximately $150 \mathrm{~cm}$ perpendicular to flow (Figure 3.2B). 


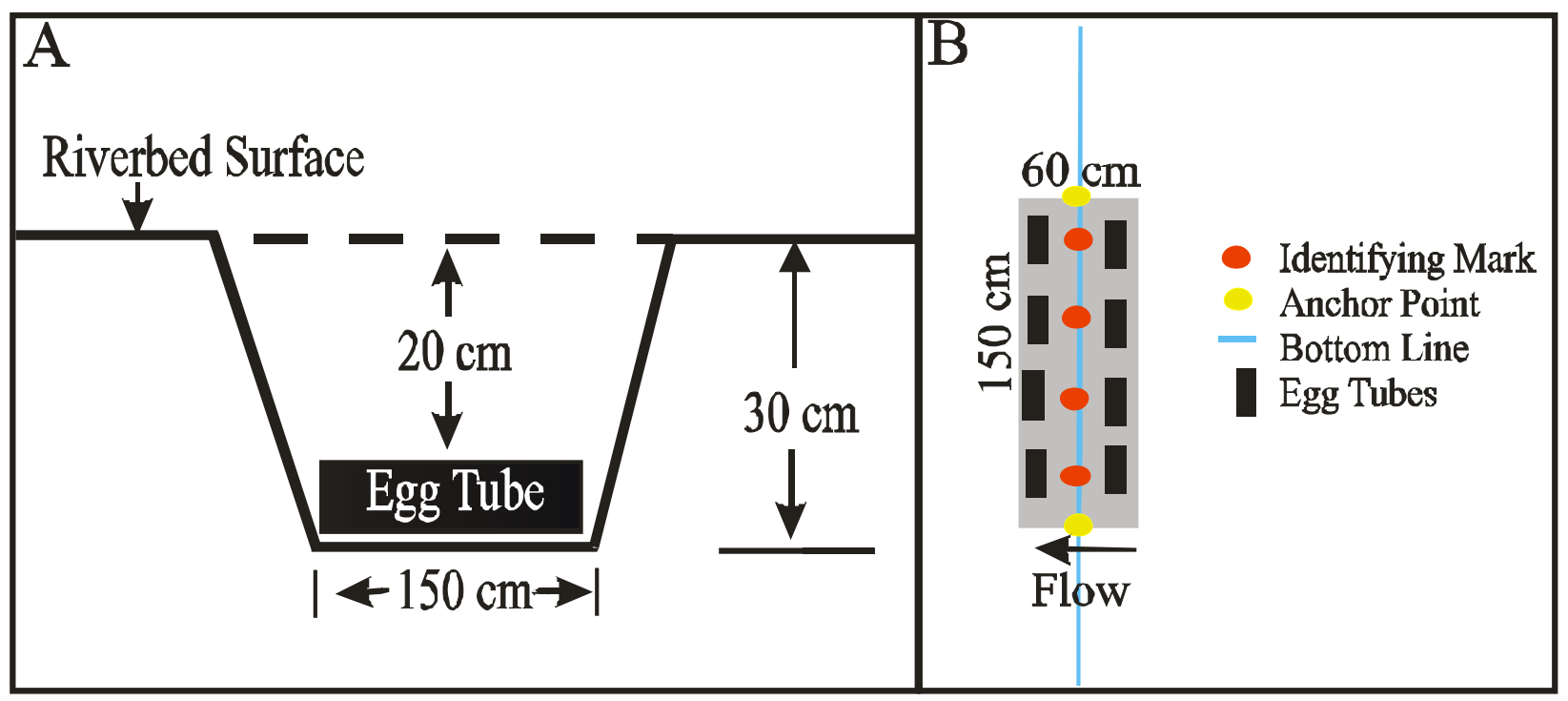

Figure 3.2. Artificial redd (A) and egg tube (B) configuration (drawings not to scale)

Eight egg incubation tubes (Figure 3.1) were deployed within the redd. The tubes were placed perpendicular to flow in two rows of four (Figure 3.2B). Each tube had a rope extending above the river surface so it could later be located. Tailings from redd excavation were placed on top of the egg tubes until the substrate was above the elevation of the surrounding riverbed. Once the artificial redd was constructed, the fixed diver line was placed at a known location relative to the redd.

\section{Sampling}

Sampling occurred on five days during March and April 2008 (Table 3.1). The sampling dates corresponded to times of dewatering in which little to no depth compensation was available. On each of the five sampling dates, divers retrieved one egg tube, transferred it to a water-filled bucket, and transported it directly to a mobile laboratory trailer located at the Pierce National Wildlife Refuge. The laboratory was equipped with a dissecting scope and associated tools (Figure 3.3). On dates on which more than one egg tube was examined, divers did not retrieve subsequent egg tubes until the previous examination was finished.

Table 3.1. Egg tube sampling dates

\begin{tabular}{cc}
\hline Egg Tube & Sampling Date \\
\hline 1 & March 4, 2008 \\
2 & March 21, 2008 \\
3,4 & April 3, 2008 \\
$5,6,7$ & April 15, 2008 \\
8 & April 16, 2008 \\
\hline
\end{tabular}




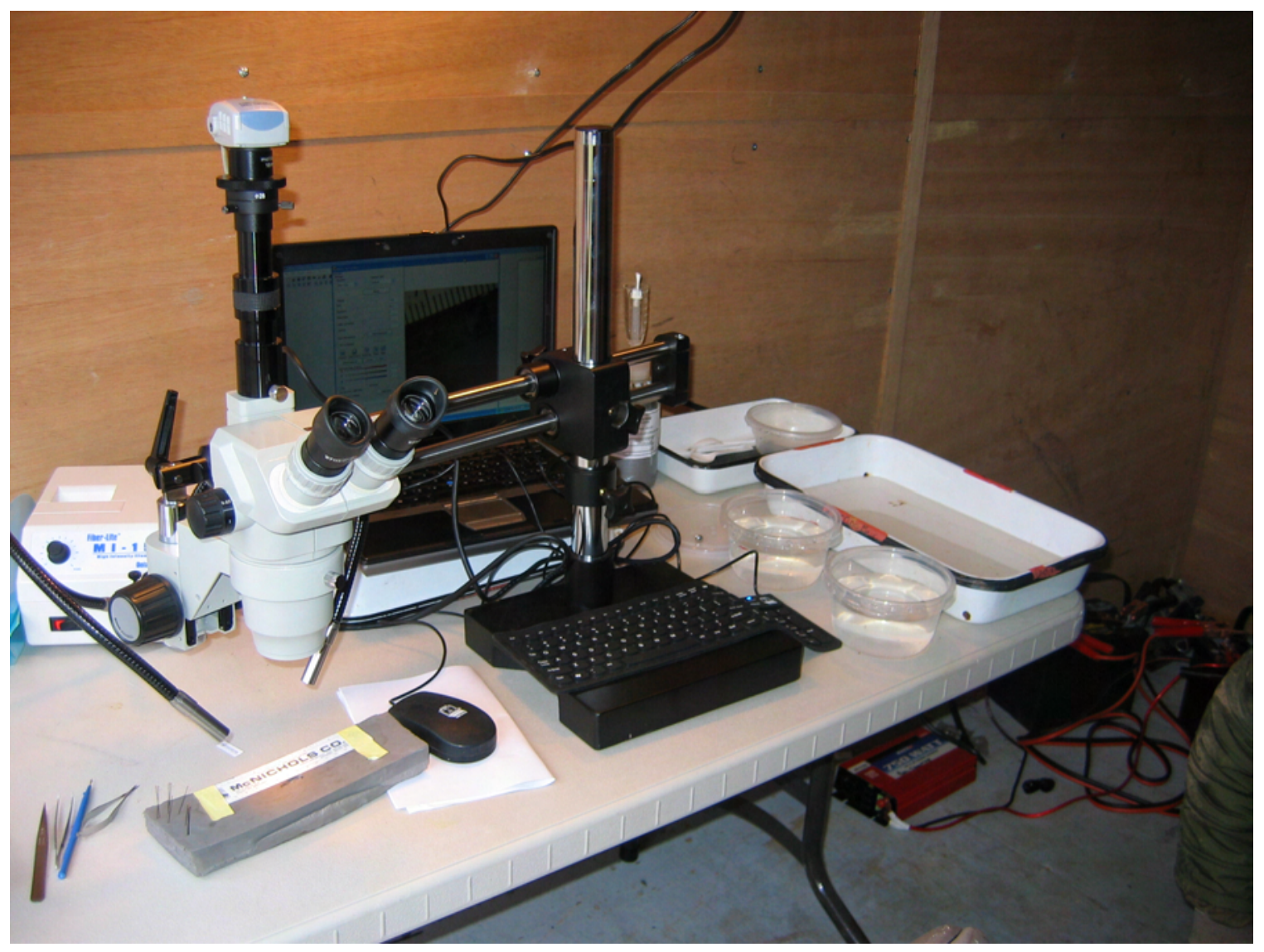

Figure 3.3. Mobile laboratory and equipment used to examine chum salmon sac fry

Alevin were removed from the incubation tube by removing one of the end screens and gently tipping the tube to empty it into a shallow water-filled pan (Figure 3.4). Once out of the tube, alevin were allowed to shelter in the substrate until removed for examination. While they were in the pan, we observed living alevin for abnormal behaviors, such as erratic swimming or floating head or abdomen up—signs of gas bubble disease (Harvey and Cooper 1962). Dead eggs and alevin contained in the tube were counted along with living alevin. 


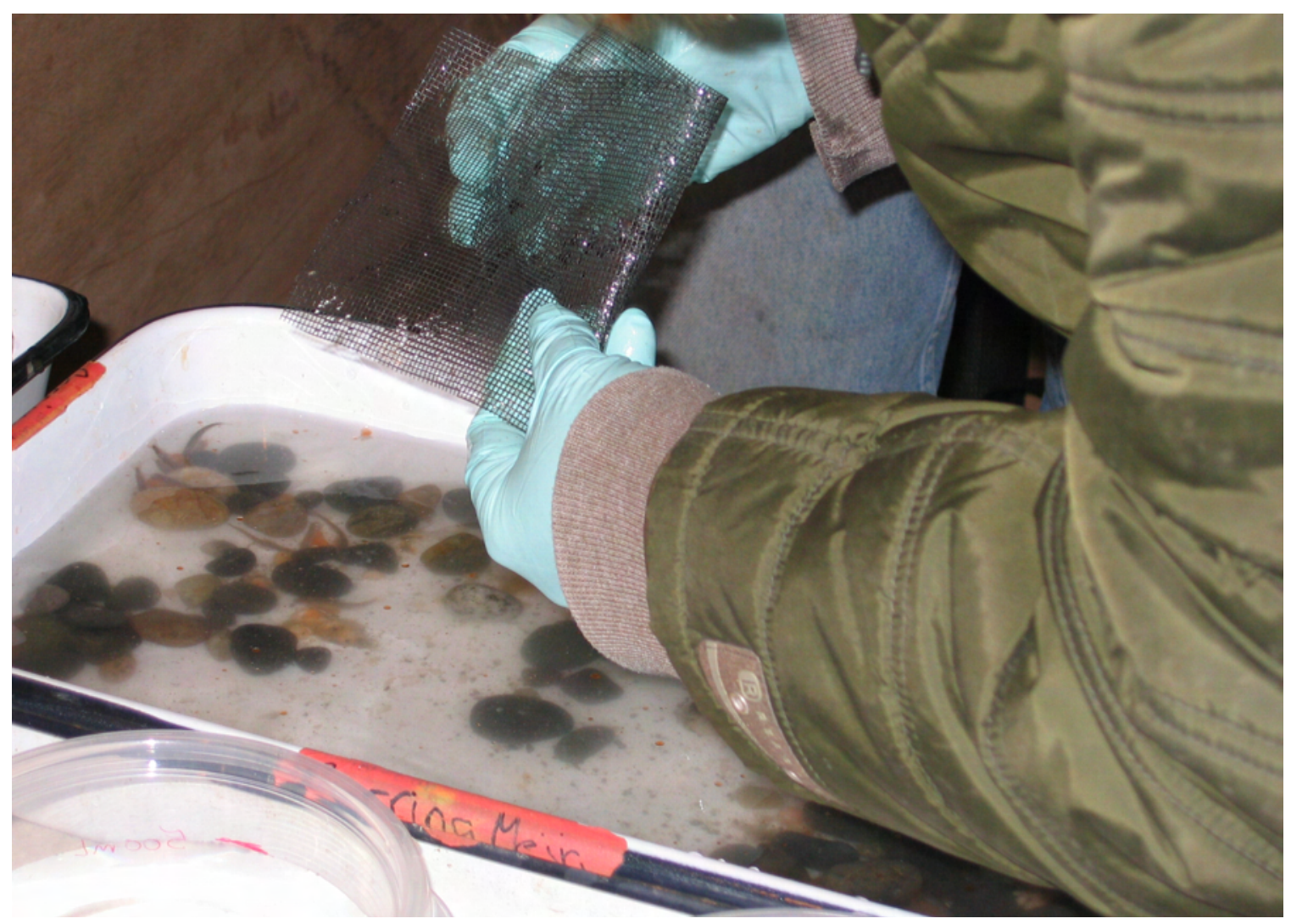

Figure 3.4. Alevin were removed from the egg tube and placed into a shallow pan with the tube substrate

Evidence suggests that signs of gas bubble disease are apparent for at least 1 hour after removal from supersaturated conditions (Hans et al. 1999). We ensured that our detailed examinations were completed within this timeframe. Alevin were examined using a Bausch \& Lomb StereoZoom 7 variable magnification (7x-70x) dissecting microscope (Bausch \& Lomb, Inc., Rochester, New York). Histological samples were quickly euthanized with $250 \mathrm{mg}$ of buffered MS-222/L of water and transferred into Bouin's fixative solution for later examination. Remaining alevin were removed from the pan and euthanized 1 at a time. We observed fish for external signs of gas bubble disease, including air bubbles in the yolk sac or between the yolk sac and perivitelline membrane (Shirahata 1966), in the mouth (Peterson 1971), or on the body surface (Shirahata 1966), fins, caudal peduncle, and yolk sac. Hemorrhaging in fins and eyes also were noted, as this may be a delayed sign of gas bubble disease (Stroud et al 1975). We also noted internal signs such as bubbles in the stomach and intestines (Dannevig and Dannevig 1950; Henly 1952) and hyperinflation of the air bladder (Krise and Herman 1989). When possible, we examined the fish for bubbles in the stomach and intestines. If inflated, the size of the swim bladder was recorded.

Alevin continued to be examined for 1 hour after removal from the redd. During this time, as many alevin as possible were examined for signs of gas bubble disease. This equated to 5 to 25 fish per egg tube. During subsequent examination dates, examination became more time-consuming as the alevin developed. Older fish had larger and more discernable organs. Younger fish were small and had undeveloped organs, so detailed internal examination was difficult and therefore not attempted. This resulted in far fewer fish being examined during later sampling dates. At the end of the hour, the 
remainder of alevin were euthanized and counted, weighed, and measured. Detailed examinations of these fish were not attempted. Histology processing was similar to that described in Chapter 2.

\section{Results}

Water levels fluctuated over the sampling period from March through April 2008, resulting in variable depth compensation. Early sampling dates in March and early April occurred when water levels were high enough to provide depth-compensated TDG levels below 100\% around the artificial redd. Lower tailwaters around April 14 resulted in depth-compensated TDG reaching 105\% to 110\% (Figure 3.5).

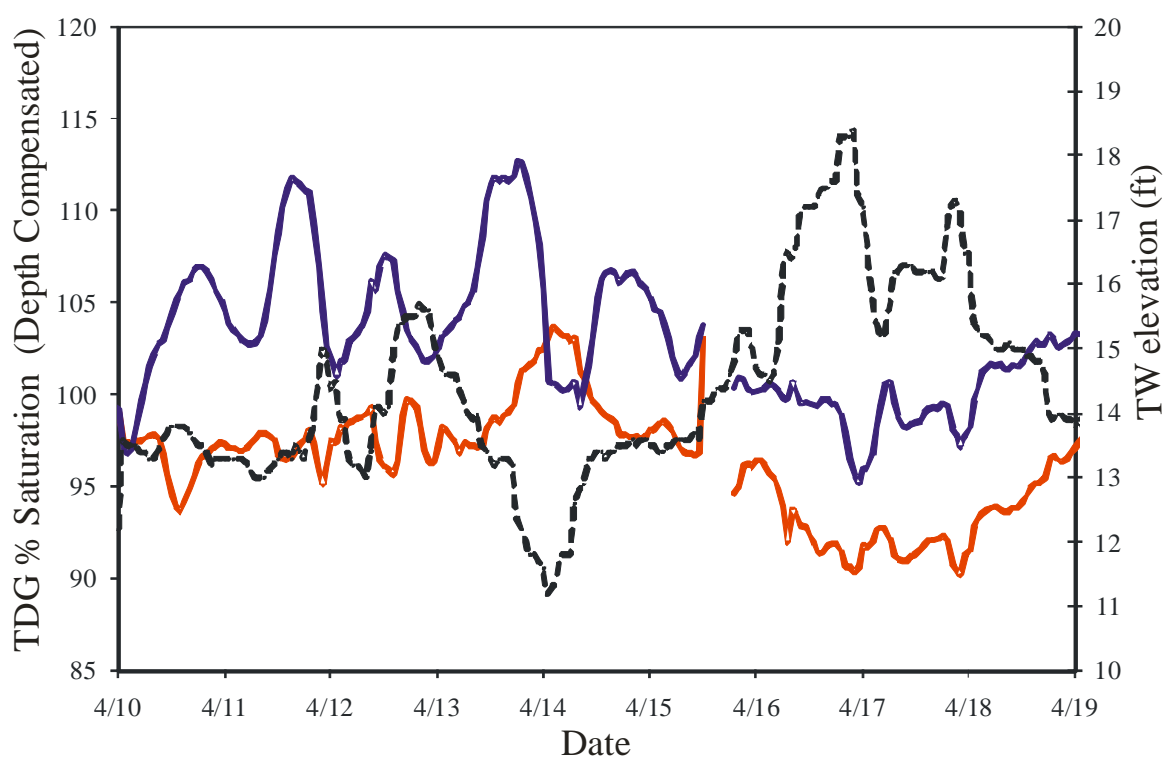

Figure 3.5. Total dissolved gas levels over the sampling period. Depth-compensated values are given for the Ives 2 (red line) hyporheic and (blue line) river sensors. The dashed black line represent river depth at the hyporheic sensor. Routine sensor servicing on 4/15 corresponds with the lapse in the TDG monitoring seen in the graph.

The alevin survival for the eight egg tubes pulled from the artificial redd during March and April 2008 ranged from $0 \%$ (tube 6) to $89 \%$ (tube 3) to $0 \%$ (tube 6). Dead eggs comprised the majority of mortality in five of the tubes. Tubes 3 and 5 had a higher mortality of hatchlings compared to eggs. The ratio of dead fish and eggs was not quantified in tube 6 . The fish in tube 6 were found covered in fungus and decaying, as evidenced by the soft and friable condition of the tissue. It was not possible to determine the number of fish and eggs present in this tube. We did note the alevin had large yolk sacs at the time of death, unlike those in the other tubes pulled at the same time (Figure 3.6), suggesting the alevin from tube 6 died 3 to 4 weeks prior to sampling. Eggs incubated at PNNL had 98\% survival. Of the 100 eggs housed at our facility, only 2 failed to hatch. No alevin died after hatching. 


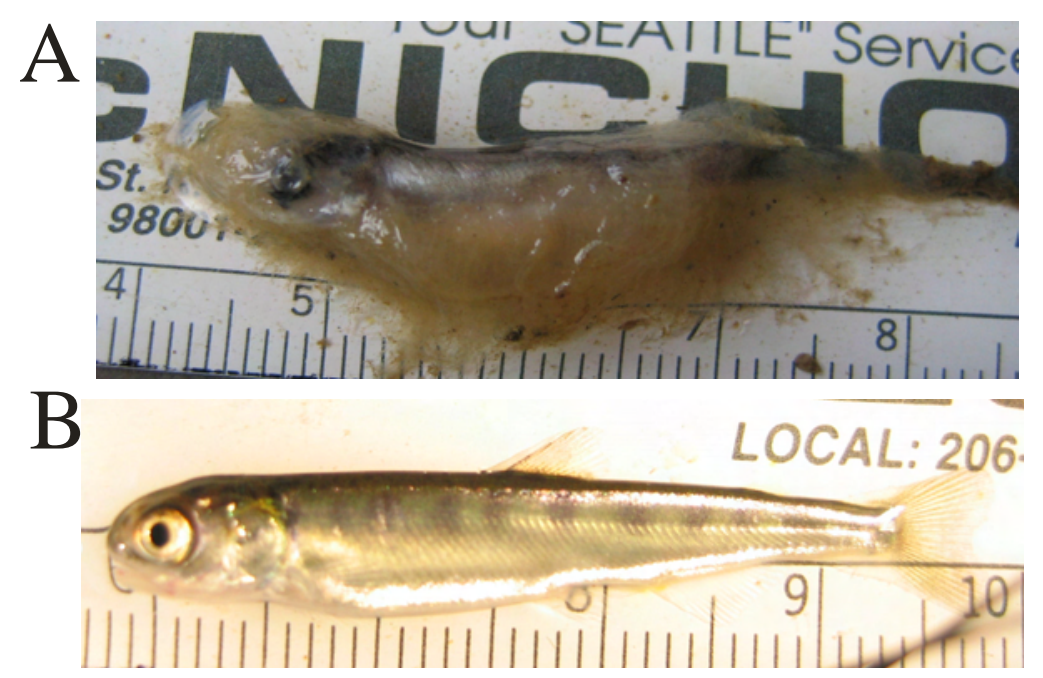

Figure 3.6. Comparison of fish from (A) egg tube 6 to fish from (B) egg tube 8. Note the large yolk sac on the fish from egg tube 6.

The number of fish grossly examined from each tube during the 1-hour gas bubble disease observation period varied from 25 to 5, depending on the developmental stage of the fish (Table 3.2). The number of fish examined decreased with subsequent sampling dates. Younger fish had underdeveloped or nonexistent swim bladders compared to older fish and were not measured. Therefore, the examinations took less time to complete for younger fish. No fish from tube 6 were examined due to their state of decay.

Hemorrhaging fins was the most common ailment noted in 15\% of all fish (Table 3.3), although no fish from tubes 2 and 5 were found with hemorrhaging fins. Hemorrhaging eyes was the next most common aliment. Fish from tubes 5, 7, and 8 had very small clusters of bubbles visible in the pupil of the eye. No fish had bubbles in the cornea, the more commonly cited area of bubble formation in fish eyes (Rucker and Kangas 1974; Weitkamp and Katz 1980). Fish from tubes 5, 7, and 8 also had small bubbles occluding $5 \%$ to $15 \%$ of the lateral line. The bubbles were very small and visible only by turning the fish from side to side and noting a small sparkle of a bubble along the line. One fish from tube 4 had a very small bubble in the roof of the mouth. No fish were found with bubbles in the fins, nares, or yolk sacs. No bubbles were found in the gills; however, they were more difficult to examine grossly due to their small size, even with the aid of the dissecting scope. Internal examinations revealed bubbles in the stomach and hindgut of some fish in tubes 4 and 8 . Fish were found with inflated swim bladders in tubes 3 through 8. No swim bladders appeared to be overinflated. 
Table 3.2. Mortality and survival in egg tubes held in the artificial redd

\begin{tabular}{clcccc}
\hline Egg Tube & $\begin{array}{c}\text { Sampling } \\
\text { Date } \\
(2008)\end{array}$ & $\begin{array}{c}\text { Survival } \\
(\%)\end{array}$ & $\begin{array}{c}\text { Number of Dead Eggs } \\
\text { Number of Dead } \\
\text { Alevin }\end{array}$ & $\begin{array}{c}\text { Number of Fish } \\
\text { Examined }^{(\text {a })}\end{array}$ \\
\hline 1 & March 4 & 70 & 30 & 0 & 25 \\
2 & March 21 & 44 & 29 & 27 & 10 \\
3 & April 3 & 89 & 2 & 9 & 7 \\
4 & April 3 & 86 & 11 & 3 & 8 \\
5 & April 15 & 61 & 10 & 29 & 5 \\
6 & April 15 & 0 & $---^{(\text {b) }}$ & $--^{(b)}$ & 5 \\
7 & April 15 & 58 & 28 & 14 & 5 \\
8 & April 16 & 78 & 13 & 9 & 0 \\
\hline
\end{tabular}

(a) Examinations occurred for 1 hour after removal from the artificial redd. Older alevin were more difficult to examine and fewer examinations were possible in that time.

(b) Did not count due to level of tissue degradation. However, the majority were alevin with large yolk sacs.

Table 3.3. Results of gross examinations of sac fry housed in the eight egg tubes inside the artificial redd

\begin{tabular}{|c|c|c|c|c|c|c|c|c|}
\hline \multirow[b]{2}{*}{ Examination Points } & \multicolumn{8}{|c|}{ Egg Tube Number and Sampling Date } \\
\hline & $\begin{array}{c}1 \\
3 / 4\end{array}$ & $\begin{array}{c}2 \\
3 / 21\end{array}$ & $\begin{array}{c}3 \\
4 / 3\end{array}$ & $\begin{array}{c}4 \\
4 / 3\end{array}$ & $\begin{array}{c}5 \\
4 / 15\end{array}$ & $\begin{array}{c}6 \\
4 / 15\end{array}$ & $\begin{array}{c}7 \\
4 / 15\end{array}$ & $\begin{array}{c}8 \\
4 / 16\end{array}$ \\
\hline Number Examined & 25 & 10 & 7 & 8 & 5 & 0 & 5 & 5 \\
\hline Bubbles on eyes & 0 & 0 & 0 & 0 & 3 & \multirow{15}{*}{ 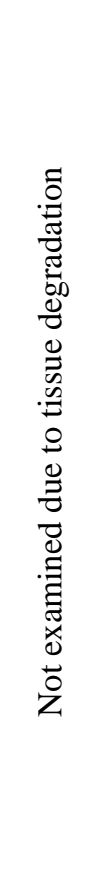 } & 1 & 1 \\
\hline Bubbles in nares & 0 & 0 & 0 & 0 & 0 & & 0 & 0 \\
\hline Bubbles in mouth & 0 & 0 & 0 & 1 & 0 & & 0 & 0 \\
\hline Bubbles in fins & 0 & 0 & 0 & 0 & 0 & & 0 & 0 \\
\hline Bubbles in caudal fin & 0 & 0 & 0 & 0 & 0 & & 0 & 0 \\
\hline Bubbles in yolk sac & 0 & 0 & 0 & 0 & 0 & & 0 & 0 \\
\hline Bubbles in lateral line & 0 & 0 & 0 & 0 & 2 & & 3 & 3 \\
\hline Hemorrhaging in eyes & 0 & 3 & 1 & 2 & 1 & & 1 & 0 \\
\hline Hemorrhaging in fins & 1 & 0 & 2 & 2 & 0 & & 1 & 4 \\
\hline Gills & 0 & 0 & 0 & 0 & 0 & & 0 & 0 \\
\hline Inflated swim bladder & No & No & 4 of 7 & 6 of 8 & 5 of 5 & & 5 of 5 & 5 of 5 \\
\hline Bubbles in stomach & 0 & 0 & 0 & 3 & 0 & & 0 & 1 \\
\hline Bubbles in hindgut & 0 & 0 & 0 & 3 & 0 & & 0 & 1 \\
\hline Swim bladder length (mm) & NA & NA & 4.3 & 4.1 & 4.8 & & 5.4 & 5 \\
\hline Swim bladder width (mm) & NA & NA & 1.4 & 0.8 & 1.6 & & 1.5 & 1.5 \\
\hline
\end{tabular}




\section{Discussion}

We observed potential but subtle signs of gas bubble disease in the chum salmon fry incubated in the artificial redd. The potential symptoms were more prevalent in fish during sampling periods on April 15 and 16 after depth-compensated TDG levels rose to 105\%. The rise in TDG levels was a result of a drop in river levels near the artificial redd. The lowest levels occurred on April 14.

Mortality varied from $11 \%$ to $100 \%$ in the eight incubation tubes. Failure to hatch was the cause of the majority of this mortality as noted by the number of eggs remaining in the incubation tube. The control eggs incubated at our facility had a higher survival rate than those incubated in the field. Dissolved oxygen levels can vary dramatically within small spatial ranges and impact egg and alevin survival (Malcom et al. 2003). The percentage of fines in the redd substrate has been shown to decrease embryo survival as a result of decreased dissolved oxygen (Shirazi et al. 1981). It is possible that the egg and alevin mortality could have been due to sediment infiltration.

The bubbles in the eyes were the most surprising symptom noted. Their appearance corresponded with times when uncompensated TDG levels reached over 105\%. To our knowledge, bubbles in the pupil have not been reported in the literature and may or may not be a symptom of gas bubble disease. The bubbles in the eyes of these fish were very small and isolated to the pupil only. The composition of these bubbles is unknown; they could be filled with gas or lipid. They appeared to be gas-filled, but no tests were done to confirm this observation. These small bubbles were observed also in chum salmon sac fry exposed to 121\% TDG and above in the laboratory portion of this study (Chapter 2). These bubbles were unlike the bubbles found in the epithelial tissue surrounding the eye cited by others (Rucker and Kangas 1974; Weitkamp and Katz 1980). These more commonly mentioned epithelial bubbles were noted also in the chum sac fry in this study (Chapter 2) but did not appear until TDG levels reached 124\%.

Susceptibility to GBD may change with environmental conditions. The water level fluctuations caused intermittent rather than constant exposure to elevated TDG. In general, intermittent exposure reduces total exposure time and thus decreases symptoms of GBD as compared to constant exposure (Antcliffe 2002). During intermittent exposure, a cumulative effect has been observed in which fish resistance to GBD decreased with subsequent exposures (White et al. 1991). The cumulative effects of GBD during intermittent exposure cannot equate to those during a constant exposure, however they may reduce the expected benefits of providing intermittent depth compensation.

We noted bubbles in the lateral line, intestines, and stomach, as well as hemorrhaging fins and eyes. These symptoms may be a sign of gas bubble disease. Fish residing in unsaturated conditions also have shown some signs of gas bubble disease, such as bubbles along the lateral line (Dawley et al. 1976), gasfilled intestines (Hand et al. 2008), and hemorrhaging eyes and fins. Presence of these symptoms in this study may indicate effects from elevated TDG levels, but also could be a result of other disease processes or simply a normal occurrence.

Inflated swim bladders were observed in some fish examined from tubes 3 and 4 and all fish examined in tubes 5, 7, and 8 . Some evidence suggests that even low supersaturation can result in overinflation of the swim bladder (Fidler 1988; Shrimpton et al. 1990). Fish noted with inflated swim bladders had been exposed to uncompensated TDG levels over 105\%. However, the swim bladders did not appear to be overinflated or strained. Although inflation may be due to exposure to elevated TDG, it 
also may be a result of the fish's developmental state (Hoar 1937), as swim bladder inflation usually occurs close to yolk absorption.

Histological analysis showed moderate levels of epithelial hypertrophy and epithelial separation and swelling in the gill. Similar lesions in chum salmon sac fry have been attributed to edema in the gills because of exposure to supersaturated conditions up to 113\% TDG (Hand et al. 2008). However, our 2008 laboratory study (Chapter 2) did not find a correlation between gill lesions and TDG levels up to $113 \%$, although severe gill lesions were noted in many fish, including those exposed to $100 \%$ TDG. Similar gill lesions can be caused by toxins (Woodward et al. 1989), usually accompanied by epithelial hyperplasia, and by lamellae fusion, which was not noted in our study fish. 


\section{Chapter 4}

\section{Literature Cited}

Adams ES and FG Towle. 1974. Use of a compression chamber to alleviate gas-bubble disease in coho sac-fry. The Progressive Fish-Culturist 36(1):41.

Arntzen EV, DR Geist, and PE Dressel. 2006. Effects of fluctuating river flow on groundwater/surface water mixing in the hyporheic zone of a regulated, large cobble bed river. River Research and Applications 22(8):937-946.

Arntzen EV, JL Panther, DR Geist, and EM Dawley. 2007a. Total Dissolved Gas Monitoring in Chum Salmon Spawning Gravels Below Bonneville Dam. PNNL-16200, Pacific Northwest National Laboratory, Richland, Washington.

Arntzen EV, RP Mueller, CJ Murray, Y-J Bott, JL Panther, DR Geist, and TP Hanrahan. 2007b. Evaluation of Salmon Spawning Below Bonneville Dam - Annual Report - October 2005September 2006. DOE/BP-00000652-35, Bonneville Power Administration, Portland, Oregon.

Arntzen EV, KD Hand, DR Geist, KJ Murray, JL Panther, VI Cullinan, EM Dawley, and RA Elston. 2008a. Effects of Total Dissolved Gas on Chum Salmon Fry Incubating in the Lower Columbia River. PNNL-17132, Pacific Northwest National Laboratory, Richland, Washington.

Arntzen EV, KJ Murray, JL Panther, DR Geist, and EM Dawley. 2008b. Assessment of total dissolved gas within chum salmon spawning areas in the Columbia River downstream of Bonneville Dam. Chapter 1 in Effects of Total Dissolved Gas on Chum Salmon Fry Incubating in the Lower Columbia River, EV Arntzen, KD Hand, DR Geist, KJ Murray, JL Panther, VI Cullinan, EM Dawley, and RA Elston, PNNL17132, pp. 1.1-1.38. Pacific Northwest National Laboratory, Richland, Washington.

Backman TWH and AF Evans. 2002. Gas bubble trauma incidence in adult salmonids in the Columbia River Basin. North American Journal of Fisheries Management 22:579-584.

Backman TWH, AF Evans, MS Robertson, and MA Hawbecker. 2002. Gas bubble trauma incidence in juvenile salmonids in the lower Columbia and Snake Rivers. North American Journal of Fisheries Management 22:965-972.

Bams RA. 1970. Evaluation of a revised hatchery method tested on pink and chum salmon fry. Journal of the Fisheries Research Board of Canada 27:1429-1452.

Beacham TD and CB Murray. 1990. Temperature, egg size, and development of embryos and alevins of five species of Pacific salmon: A comparative analysis. Transactions of the American Fisheries Society 119(6):927-945.

Beiningen KT and WJ Ebel. 1970. Effect of John Day Dam on dissolved nitrogen concentrations and salmon in the Columbia River. Transactions of the American Fisheries Society 99:664-671.

Beiningen KT and WJ Ebel. 1971. Dissolved Nitrogen, Dissolved Oxygen, and Related Water Temperatures in the Columbia and Lower Snake Rivers, 1965-69. Data Report No. 56, National Marine Fisheries Service, Seattle, Washington. 
Blicher-Mathiesen G, GW McCarty, and LP Nielsen. 1998. Denitrification and degassing in groundwater estimated from dissolved dinitrogen and argon. Journal of Hydrology 208:16-24.

Bouck GR. 1982. Gasometer: An inexpensive device for continuous monitoring of dissolved gases and supersaturation. Transactions of the American Fisheries Society 111:505-516.

Camargo MMP and CBR Martinez. 2007. Histopathology of giills, kidney and liver of a Neotropical fish caged in an urban stream. Ichthyology 5(3):327-336.

Colt J. 1983. The computation and reporting of dissolved gas levels. Water Research 17:841-849.

Counihan TD, AI Miller, MG Mesa, and MJ Parsley. 1998. The effects of dissolved gas supersaturation on white sturgeon larvae. Transactions of the American Fisheries Society 127:316-322.

Crisp DT. 1990. Water temperatures in a stream gravel bed and implications for salmonid incubation. Freshwater Biology 23:601-602.

Dannevig A and G Dannevig. 1950. Factors affecting the survival of fish larvae. Journal du Conseil International pour l'Exploration de la Mer 15:277-283.

Dawley EM, M Schiewe, and B Monk. 1976. Effects of long-term exposure to supersaturation of dissolved atmospheric gases on juvenile chinook salmon and steelhead trout in deep and shallow tank tests. In Gas Bubble Disease, DH Fickeisen and MJ Schneider (eds), pp. 1-10. ERDA CONF741033, National Technical Information Service, Springfield, Virginia.

Dawson DK. 1986. Computer program calculation of gas supersaturation in water. The Progressive Fish-Culturist 48:142-146.

Ebel WJ. 1969. Supersaturation of nitrogen in the Columbia River and its effect on salmon and steelhead trout. Fisheries Bulletin 68(1):1-11.

Ebel W and H Raymond. 1976. Effects of atmosphere gas saturation on salmon and steelhead trout of the Snake and Columbia Rivers. Marine Fisheries Review 38(7):1-14.

Embody GC. 1934. Relation of temperature to the incubation period of eggs of four species of trout. Transactions of the American Fisheries Society 64:281-292.

EPA (U.S. Environmental Protection Agency). 1987. Quality Criteria for Water 1986. EPA 440/5-86001, U.S. Environmental Protection Agency, Washington, D.C.

Fidler LE. 1988. Gas bubble trauma in fish. Doctoral dissertation, University of British Columbia, Vancouver, Canada.

Geist DR, TP Hanrahan, EV Arntzen, GA McMichael, CJ Murray, and Y-J Chien. 2002.

Physicochemical characteristics of the hyporheic zone affect redd site selection by chum salmon and fall Chinook salmon in the Columbia River. North American Journal of Fisheries Management 22:10771085.

Geist DR, EV Arntzen, CJ Murray, KE McGrath, Y-J Bott, and TP Hanrahan. 2008. Influence of river level on temperature and hydraulic gradients in chum and fall Chinook salmon spawning areas 
downstream of Bonneville Dam, Columbia River. North American Journal of Fisheries Management 27:30-41.

Hach Environmental. 2006. Hydrolab DS5X, DS5, and MS5 Water Quality Multiprobes - User Manual - February 2006, Edition 3. Hach Environmental, Loveland, Colorado.

Hand KD, DR Geist, VI Cullinan, and RA Elston. 2008. Bioassays on the formation of gas bubble disease in chum salmon fry at total dissolved gas levels ranging up to $113 \%$ saturation. Chapter 2 in Effects of Total Dissolved Gas on Chum Salmon Fry Incubating in the Lower Columbia River, EV Arntzen, KD Hand, DR Geist, KJ Murray, JL Panther, VI Cullinan, EM Dawley, and RA Elston, PNNL17132, pp. 2.1-2.20. Pacific Northwest National Laboratory, Richland, Washington.

Hans KM, MG Mesa, and AG Maule. 1999. Rate of disappearance of gas bubble trauma signs in juvenile salmonids. Journal of Aquatic Animal Health 11:383-390.

Harvey HH and AC Cooper. 1962. Origin and Treatment of a Supersaturated River Water. Progress Report 9, International Pacific Salmon Fisheries Commission, New Westminster, British Columbia, Canada.

Henly E. 1952. The influence of the gas content of sea-water on fish and fish larvae. Rapports et Proces-verbaux des Reunions, Conseil International pour l'Exploration de la Mer 131(3):24-27.

Hoar WS. 1937. The development of the swim bladder of the Atlantic salmon. Journal of Morphology 61:309-319.

Knittel MD, GA Chapman, and RR Garton. 1980. Effects of hydrostatic pressure on steelhead survival in air-supersaturated water. Transactions of the American Fisheries Society 109:755-759.

Korosec MA, WM Phillips, and JE Schuster. 1983. The 1980-1982 Geothermal Resource Assessment Program in Washington. DOE/ET/27014-T6, National Technical Information Service, Springfield, Virginia.

Krise WF. 1993. Effects of one-year exposures to gas supersaturation on lake trout. The Progressive Fish-Culturist 55:159-176.

Krise WF and RL Herman. 1989. Tolerance of lake trout (Salvelinus namaycush Walbaum) sac fry to dissolved gas supersaturation. Journal of Fish Diseases 12:269-273.

Krise WF and JW Meade. 1988. Effects of low-level gas supersaturation on lake trout (Salvelinus namaycush). Canadian Journal of Fisheries and Aquatic Sciences 45:666-674.

Luna LG (ed). 1968. Manual of Histologic Staining Methods of the Armed Forces Institute of Pathology. 3rd edition. McGraw-Hill Book Company, New York.

Malcolm IA, AF Youngson, and C Soulsby. 2003. Survival of salmonid eggs in a degraded gravel-bed stream: effects of groundwater-surface water interactions. River Research and Applications 19(4):303316.

McGrath K, EM Dawley, and DR Geist. 2006. Total Dissolved Gas Effects on Fishes of the Lower Columbia River. PNNL-15525, Pacific Northwest National Laboratory, Richland, Washington. 
Meekin TK and RL Allen. 1974. Summer Chinook and sockeye salmon mortality in the upper Columbia River and its relationship to nitrogen supersaturation. In Nitrogen Supersaturation Investigations in the Mid-Columbia, Washington Department of Fisheries Technical Report 12, pp. 127-153. Washington Department of Fisheries, Olympia.

Mookherji S, GW McCarty, and JT Angier. 2003. Dissolved gas analysis for assessing the fate of nitrate in wetlands. Journal of the American Water Resources Association 39:381-387.

NAS/NAE (National Academy of Sciences/National Academy of Engineering). 1973. Water Quality Criteria 1972. EPA-R3-73033, U.S. Environmental Protection Agency, Washington, D.C.

Nebeker AV, AK Hauck, and FD Baker. 1979. Temperature and oxygen-nitrogen gas ratios affect fish survival in air-supersaturated water. Water Research 13:299-303.

Nielson DL and MR Moran. 1980. Geologic Interpretation of the Geothermal Potential of the North Bonneville Area. Earth Science Laboratory, University of Utah Research Institute, Salt Lake City.

NMFS (National Marine Fisheries Service). 1999. Listing Endangered and Threatened Species and Designating Critical Habitat: Petition to List Eighteen Species of Marine Fishes in Puget Sound, Washington. Federal Register, 21 June 1999, 64(118):33037-33040.

NOAA (National Oceanographic and Atmospheric Administration). 1995. Item 2. Pages 104-110 in: Endangered Species Act - Section 7 Consultation, Biological Opinion, Federal Columbia River Power System (FCRPS). National Oceanic and Atmospheric Administration, National Marine Fisheries Service, Northwest Regional Office, Seattle, Washington.

NOAA (National Oceanographic and Atmospheric Administration). 2000. Risk Assessment for Spill Program Described in 2000 Draft Biological Opinion. Appendix E in Endangered Species Act - Section 7, Biological Opinion on the Reinitiation of Consultation on Operation of the Federal Columbia River Power System, Including the Juvenile Fish Transportation Program, and 19 Bureau of Reclamation Projects in the Columbia Basin. National Oceanic and Atmospheric Administration, National Marine Fisheries Service, Northwest Regional Office, Seattle, Washington.

Pauley GB and RE Nakatani. 1967. Histopathology of "gas-bubble" disease in salmon fingerlings. Journal of the Fisheries Research Board of Canada 24(4):867-871.

Peterson H. 1971. Smolt rearing methods, equipment and techniques used successfully in Sweden. In Atlantic Salmon Workshop, WM Carter (ed), Atlantic Salmon Foundation Special Publication Series 2(1), pp. 32-62. International Atlantic Salmon Foundation, Fredericton, Nova Scotia, Canada.

Peterson NP and TP Quinn. 1996. Persistence of egg pocket architecture in redds of chum salmon, Oncorhynchus keta. Environmental Biology of Fishes 46:243-253.

Philip RB and CW Gowdey. 1964. Experimental analysis of the relation between body fat and susceptibility to decompression sickness. Aerospace Medicine 35:351-356.

Rombough PJ. 1999. The gill of fish larvae. Is it primarily a respiratory or an ionoregulatory structure? Journal of Fish Biology 55(SUP A):186-204. 
Rucker RR. 1975. Gas-bubble disease: mortalities of coho salmon, Oncorhynchus kisutch, in water with constant total gas pressure and different oxygen-nitrogen ratios. Fishery Bulletin 73:915-918.

Rucker RR and PM Kangas. 1974. Effect of nitrogen supersaturated water on coho and Chinook salmon. The Progressive Fish-Culturist 36(3):152-156.

Ryan BA and EM Dawley. 1998. Effects of Dissolved Gas Supersaturation on Fish Residing in the Snake and Columbia Rivers, 1997. Bonneville Power Administration, Portland, Oregon. Available at http://pisces.bpa.gov/release/documents/documentviewer.aspx?doc=93605-2 (November 2008).

Ryan BA, EM Dawley, and RA Nelson. 2000. Modeling the effects of dissolved gas supersaturation on resident aquatic biota in the mainstem Snake and Columbia Rivers. North American Journal of Fisheries Management 20:192-204.

Shepherd BG, GF Hartman, and WJ Wilson. 1986. Relationships between stream and intra-gravel temperatures in coastal drainages, and some implications for fisheries workers. Canadian Journal of Fisheries and Aquatic Sciences 43:1818-1822.

Shirahata S. 1966. Experiments on nitrogen gas disease with rainbow trout fry. Bulletin of the Freshwater Fisheries Research Laboratory (Tokyo) 15:197-211.

Shirazi MA, WK Seim, and DH Lewis. 1981. Characterization of spawning gravel and stream system evaluation. In Salmon-Spawning Gravel: A Renewable Resource in the Pacific Northwest? State of Washington Water Research Center, Pullman.

Shrimpton JM, DJ Randall, and LE Fidler. 1990. Factors affecting swim bladder volume in rainbow trout (Oncorhyncus mykiss) held in gas supersaturated water. Canadian Journal of Zoology 68:962-968.

Stroud RK, GR Bouck, and AV Nebeker. 1975. Pathology of acute and chronic exposure of salmonid fishes to supersaturated water. In Chemistry and Physics of Aqueous Gas Solutions, WA Adams (ed), pp. 435 - 449. The Electrochemical Society, Princeton, New Jersey.

Sutherland AB and JL Meyer. 2007. Effects of increased suspended sediment on frowth rate and gill conditions of two southern Appalachian minnows. Environmental Biology of Fishes 80:389-402.

Talbot C, FB Eddy, and J Johnston. 1982. Osmoregulation in salmon and sea trout alevins. Journal of Experimental Biology 101:61-70.

Tanner DQ and MW Johnston. 2001. Data-Collection Methods, Quality-Assurance Data, and Site Considerations for Total Dissolved Gas Monitoring, Lower Columbia River, Oregon and Washington, 2000. Water Resources Investigations Report 01-4005, U.S. Geological Survey, Portland, Oregon.

Tiffin K, R Garland, D Rondorf, and J Skalicky. 2004. Juvenile and Adult Fall Chinook and Chum Salmon habitat Studies below Bonneville Dam on the Columbia River - 2002-2003 Annual Report. DOE/BP-00004701-2, Bonneville Power Administration, Portland, Oregon.

Toner MA and EM Dawley. 1995. Evaluation of the Effects of Dissolved Gas Supersaturation on Fish and Invertebrates Downstream from Bonneville Dam, 1993. U.S. Army Corps of Engineers, Portland District, Portland, Oregon. 
USACE (U.S. Army Corps of Engineers), U.S. Bureau of Reclamation, and Bonneville Power Administration. 2004. Final Updated Proposed Action for the FCRPS Biological Opinion Remand. November 24, 2004. Available at http://www.salmonrecovery.gov/biological_Opinions/FCRPS/biop_remand_2004/update (November 2008).

Vaux WG. 1968. Intragravel flow and interchange of water in a streambed. U.S. Fish and Wildlife Service Fishery Bulletin 66:479-489.

Weitkamp DE and M Katz. 1980. A review of dissolved gas supersaturation literature. Transactions of the American Fisheries Society 109:659-702.

Weitkamp DE, RD Sullivan, T Swant, and J DosSantos. 2003. Gas bubble disease in resident fish of the Lower Clark Fork River. Transactions of the American Fisheries Society 132:865-876.

Wells PR and AW Pinder. 1996a. The respiratory development of Atlantic salmon - I. Morphometry of gills, yolk sac and body surface. The Journal of Experimental Biology 199:2725-2736.

Wells PR and AW Pinder. 1996b. The respiratory development of Atlantic salmon - II. Partitioning of oxygen uptake among gills, yolk sac and body surfaces. The Journal of Experimental Biology 199:27372744.

White RG, G Phillips, G Liknes, J Brammer, W Connor, L Fidler, T Williams, and WP Dwyer. 1991. Effects of Supersaturation of Dissolved Gases on the Fishery of the Bighorn River Downstream of the Yellowtail Afterbay Dam. Montana Cooperative Fishery Unit, Montana State University, Bozeman.

Wickett P. 1954. The oxygen supply to salmon eggs in spawning beds. Journal of the Fisheries Research Board of Canada 116:933-953.

Wood JW. 1979. Diseases of Pacific Salmon, Their Prevention and Treatment. 3rd edition. Washington Department of Fisheries, Hatchery Division, Olympia, Washington.

Woodward DF, AM Farag, ME Mueller, KK Little, and FA Vertucci. 1989. Sensitivity of endemic Snake River cutthroat trout to acidity and elevated aluminum. Transactions of the American Fisheries Society 118(6):630-643.

Wright PB and WE McLean. 1985. The effects of aeration on the rearing of summer Chinook fry (Onchorhunchus tshawytscha) at the Puntledge Hatchery. Canadian Technical Report of Fisheries and Aquatic Sciences 1390. 


\section{Appendixes}

Supplemental information is included in the following appendixes, which are on the CD that accompanies this report:

Appendix A - Membrane Tests

Appendix B - Water Quality Data 
Appendix A

Membrane Tests 


\section{Appendix A}

\section{Membrane Tests}

The following graphs represent membrane tests done before and after deployments. Dates listed for each membrane are the dates during which sensors collected data. The attachment tests show the pressure increase as the membrane was attached to a data-logging sensor, followed by a reduction in pressure toward atmospheric equilibrium over time. The soda tests show the response when the sensor tip was inserted into a beaker of soda water. A functioning membrane would show a rapid increase in pressure well above barometric pressure, followed by a gradual return to barometric pressure. The steeper decrease in pressure corresponds to the time at which the tester removed the membrane from the soda water (after approximately 10 minutes). Post-deployment testing was performed to establish whether the data we collected were reliable. Following quality testing to confirm that the integrity of the membranes was fully functional, many were reused in additional deployments.

\section{Pre-Deployment}

All membranes were tested prior to use. 

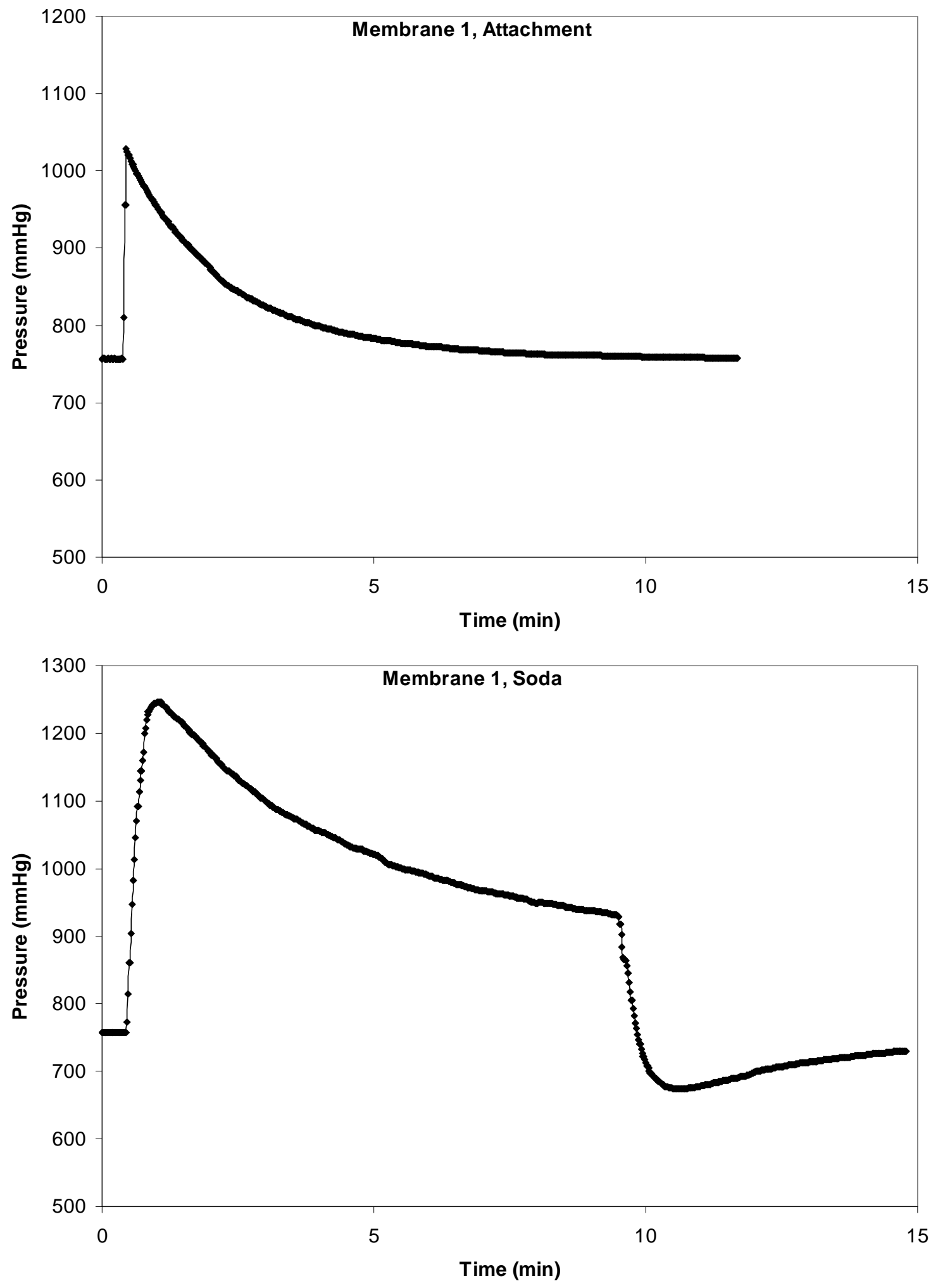

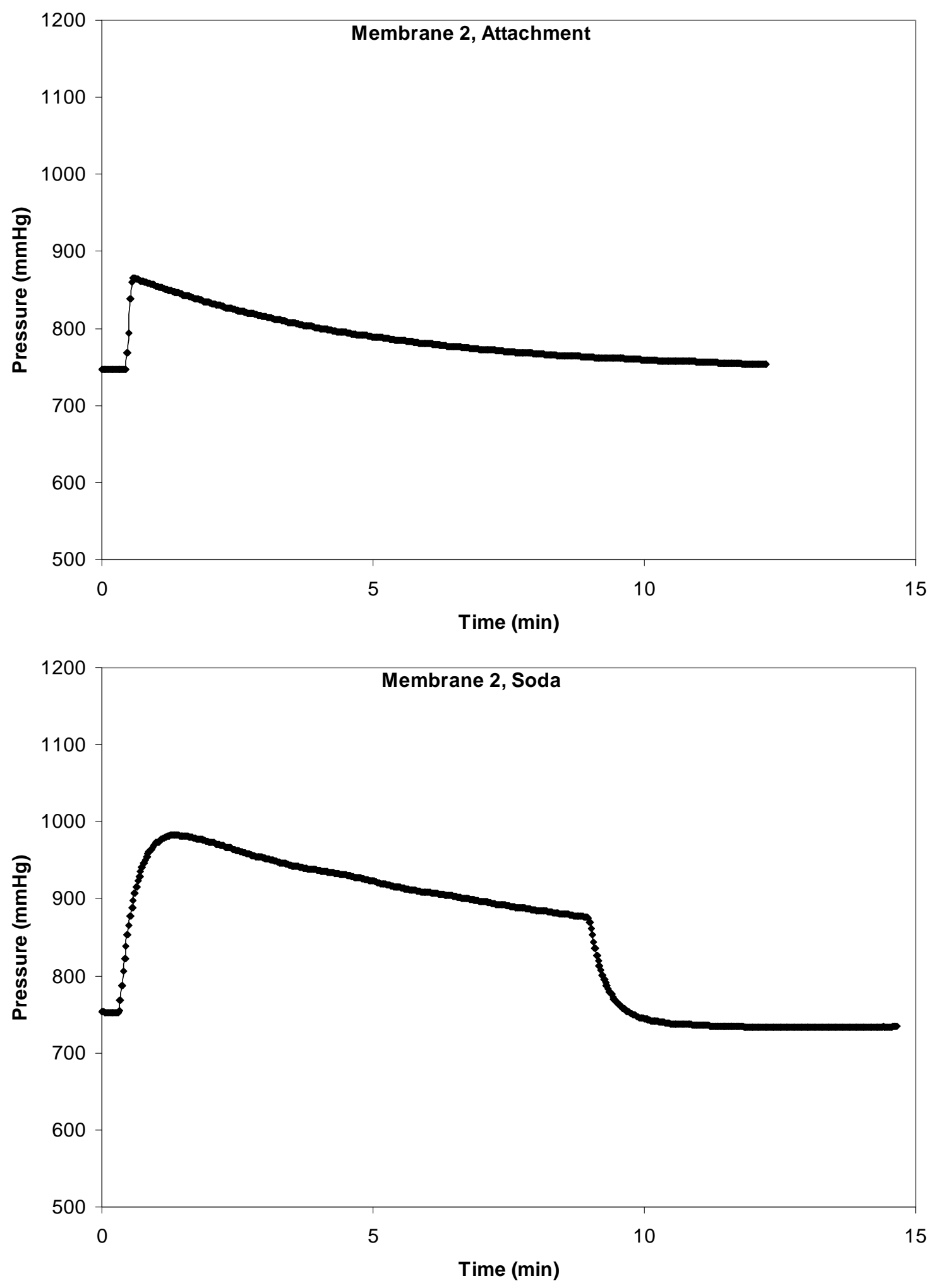

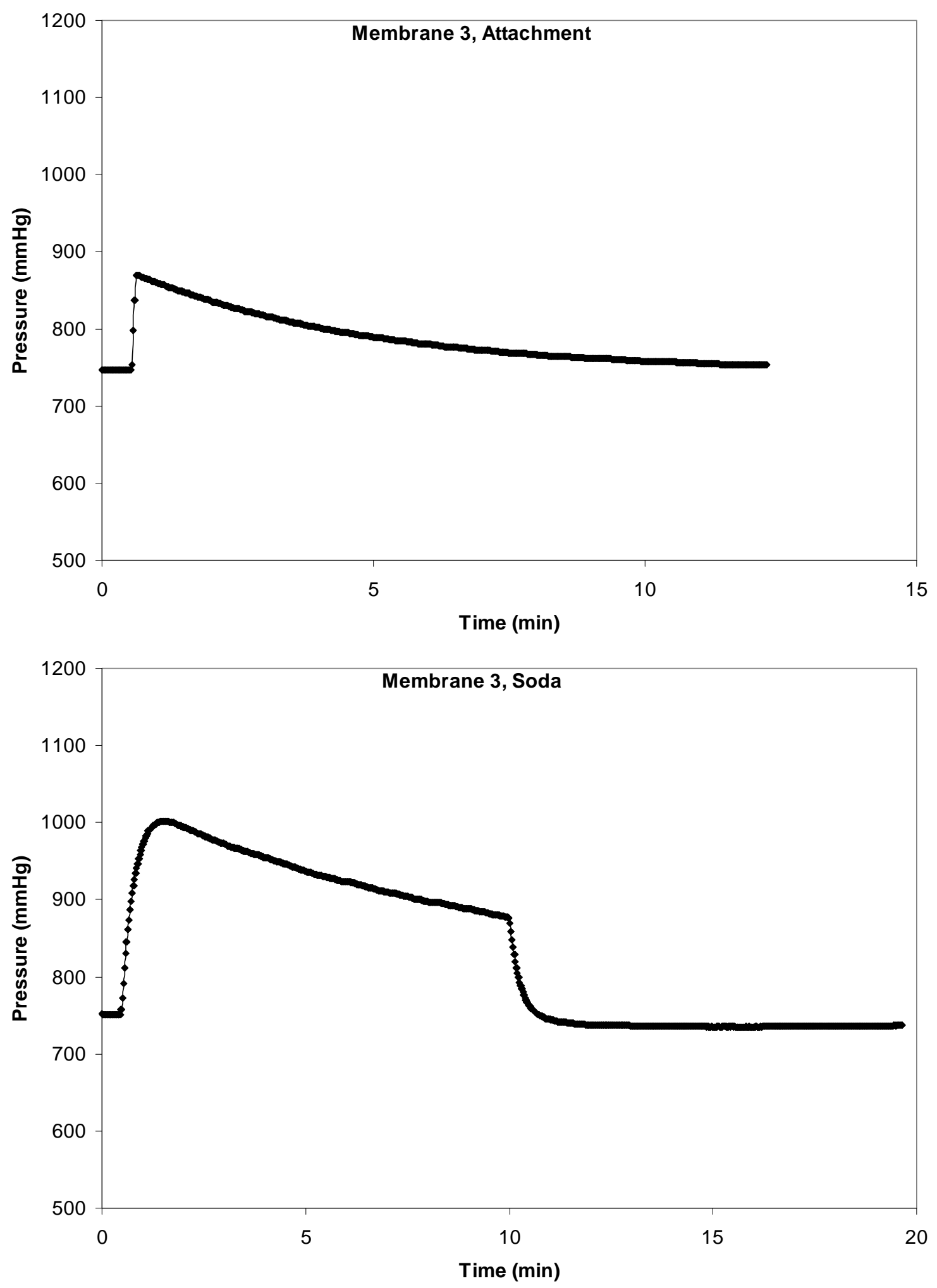

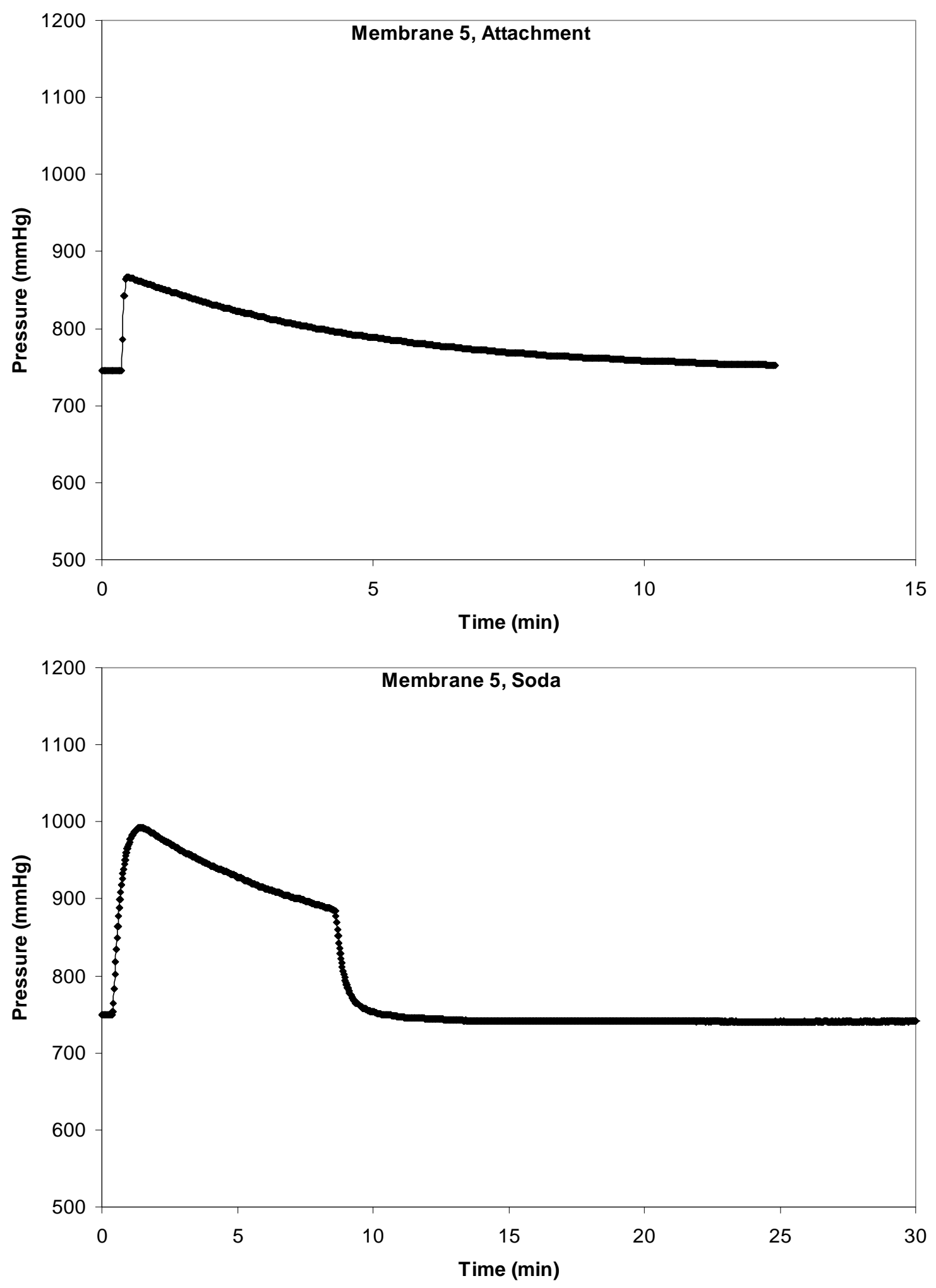

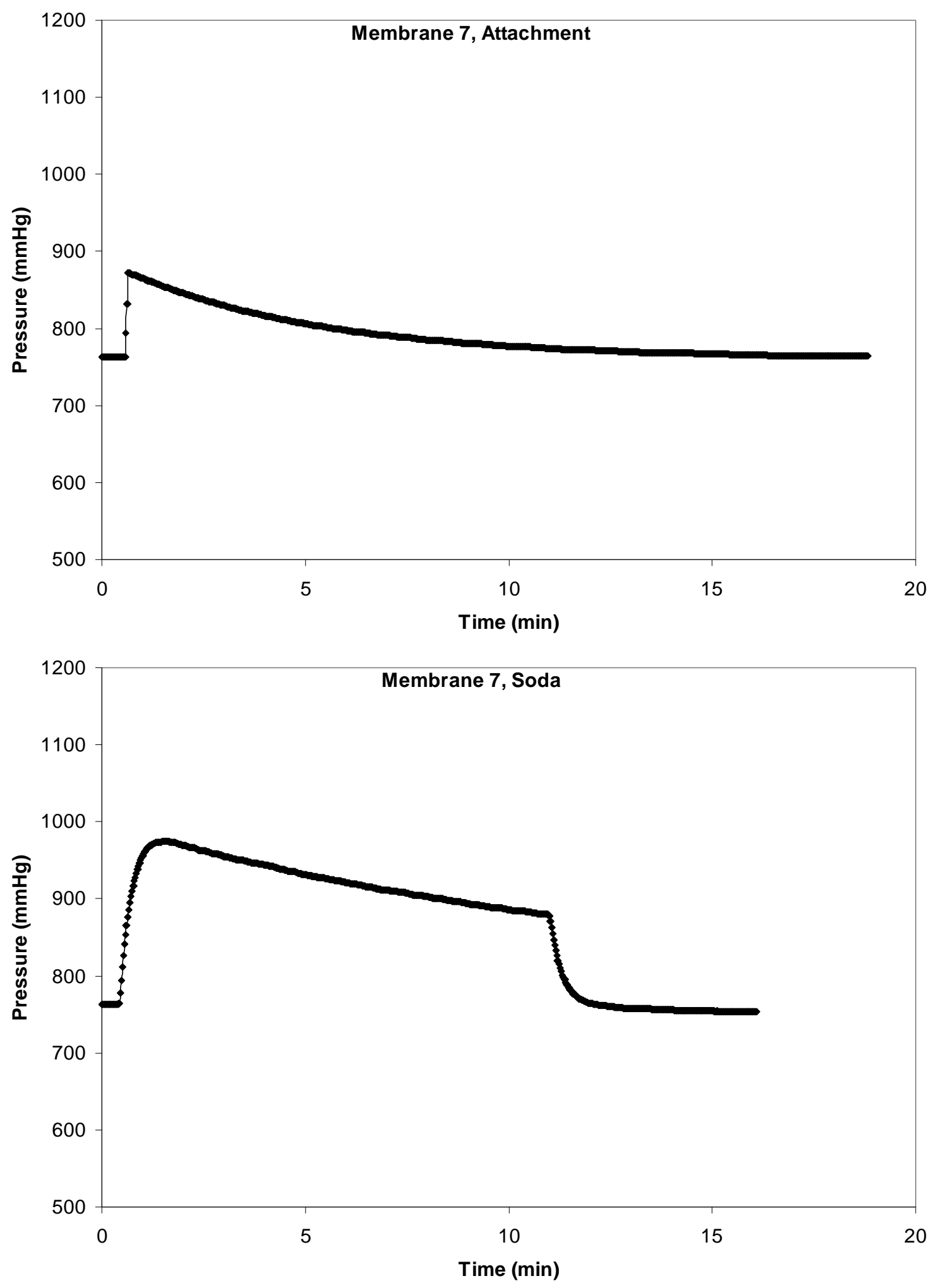

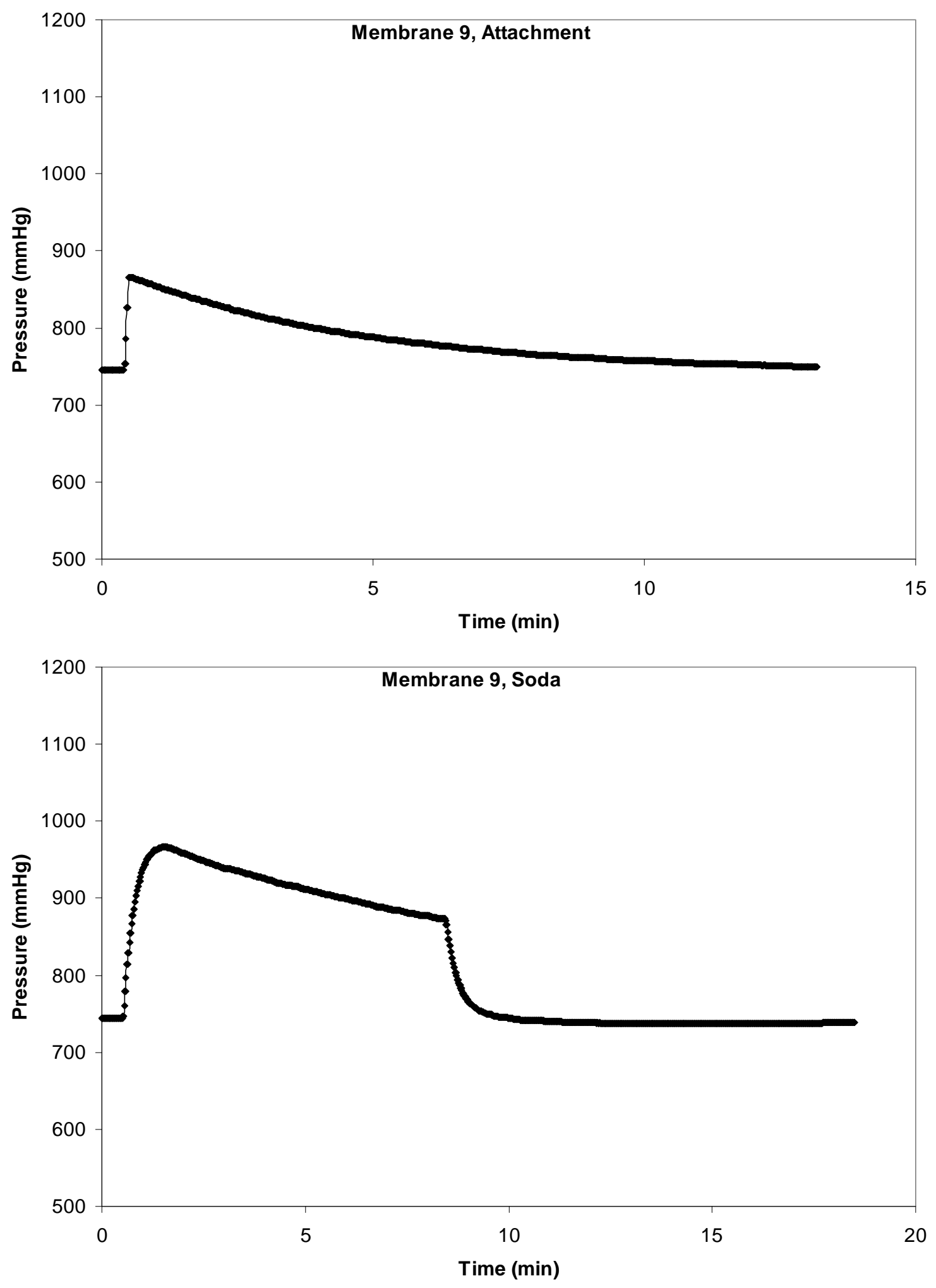

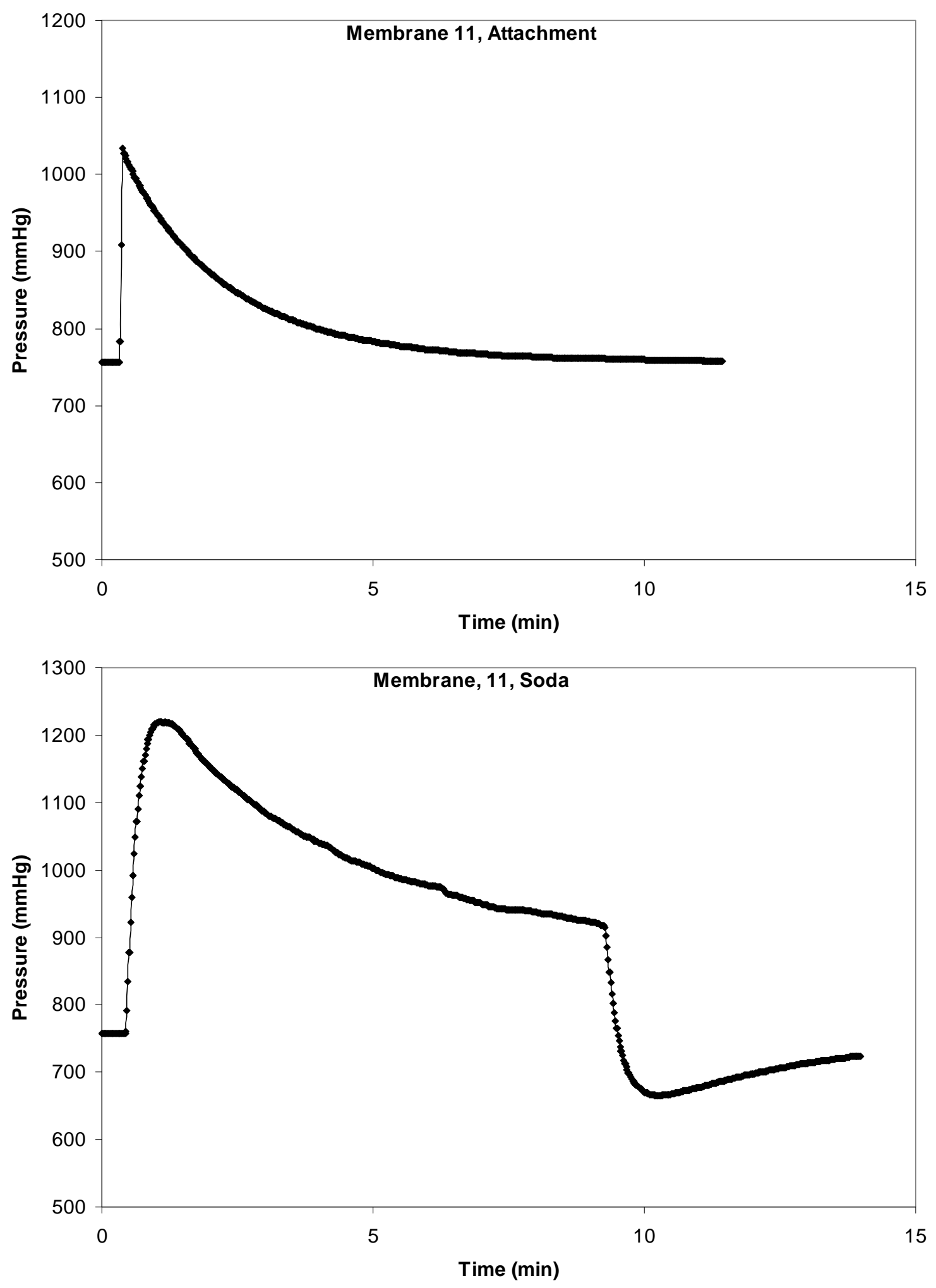

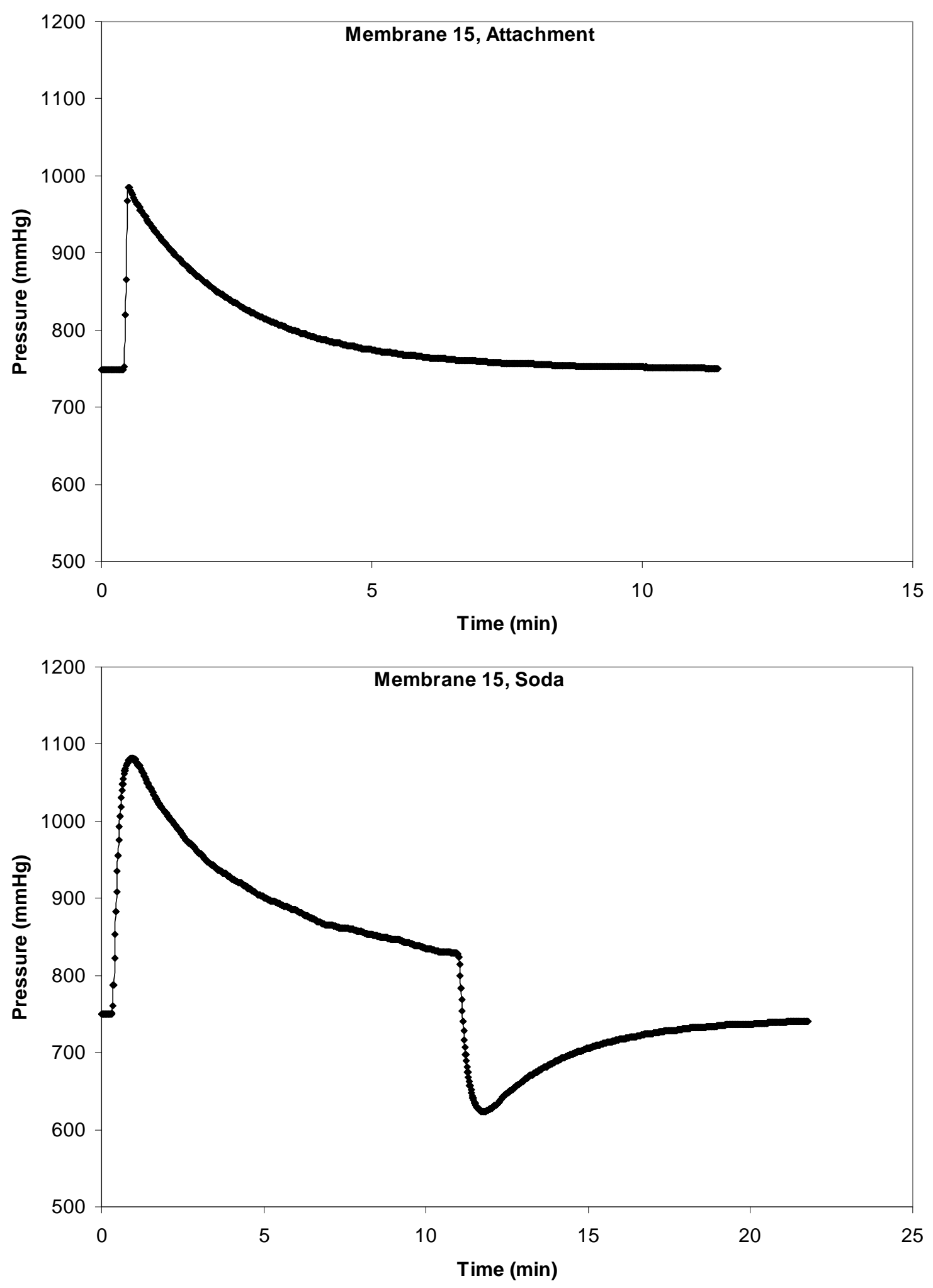

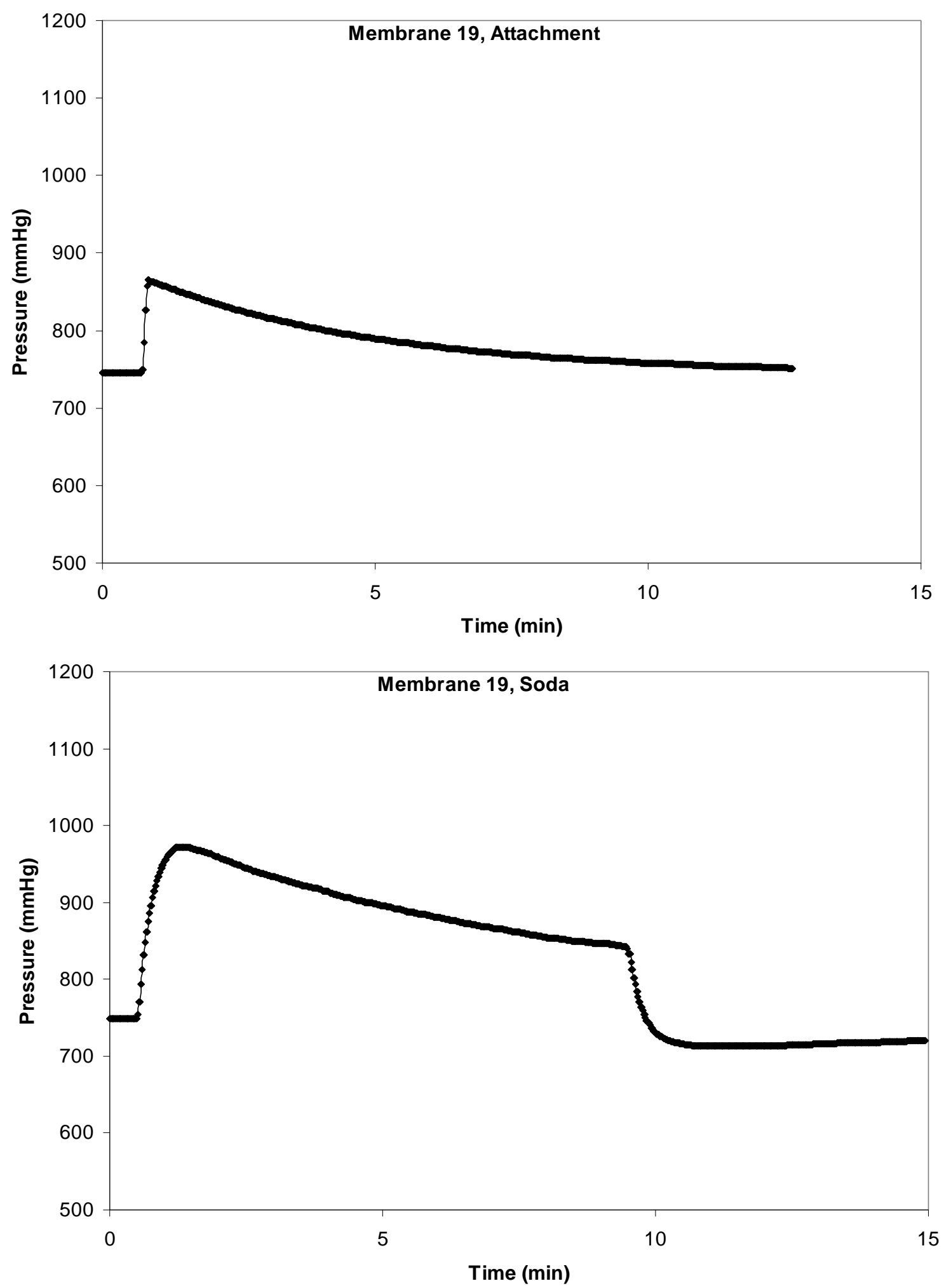

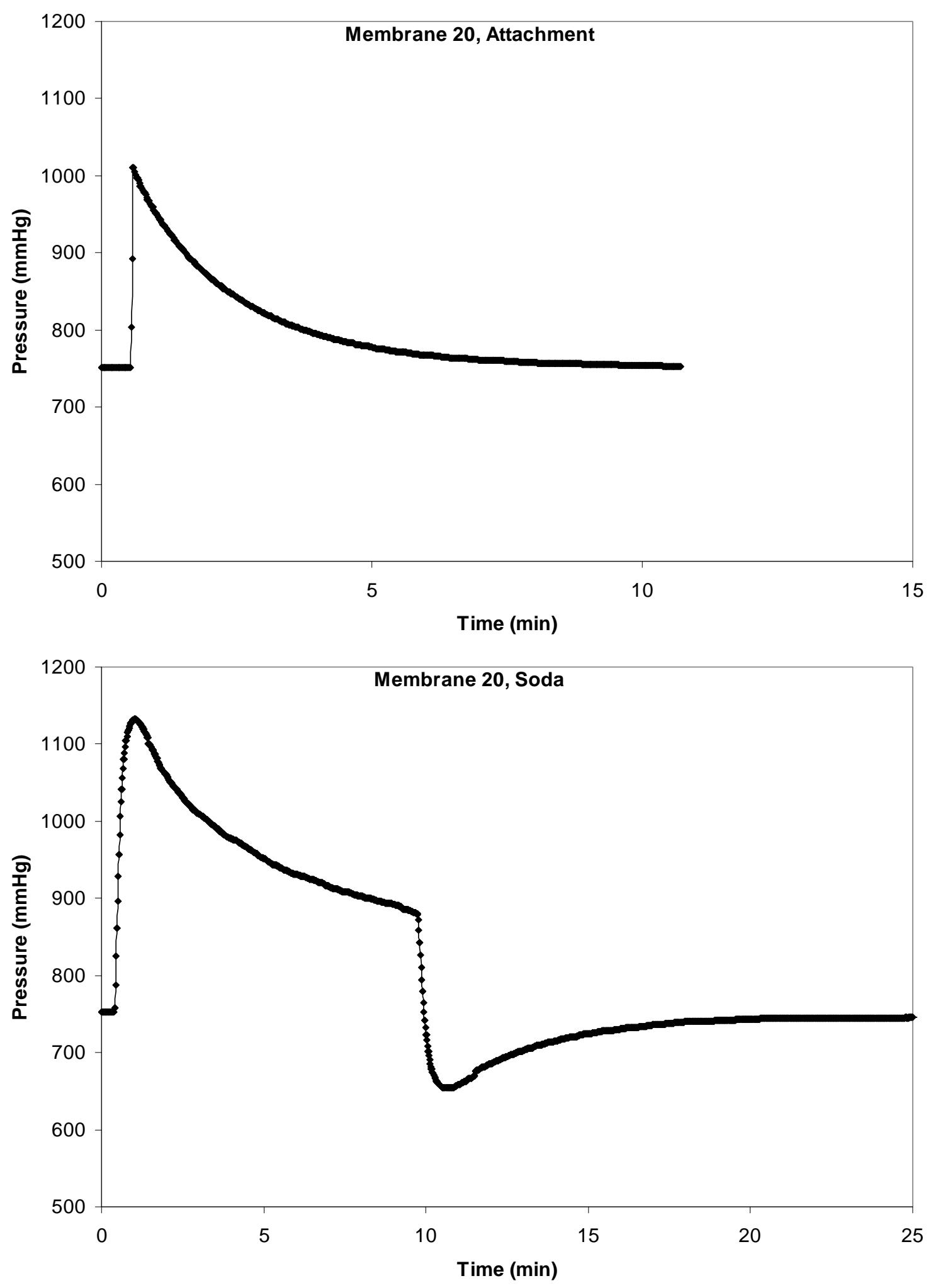

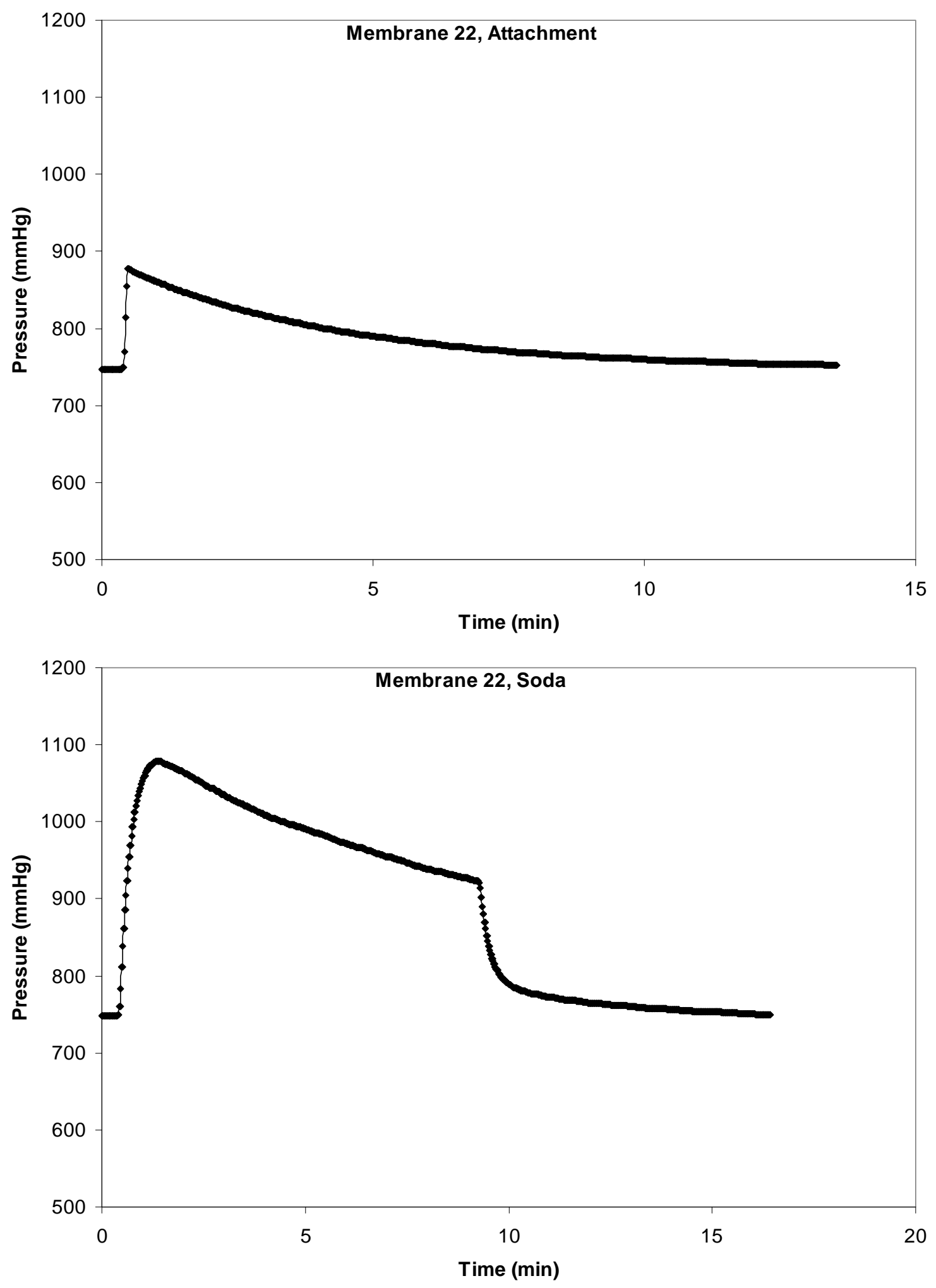

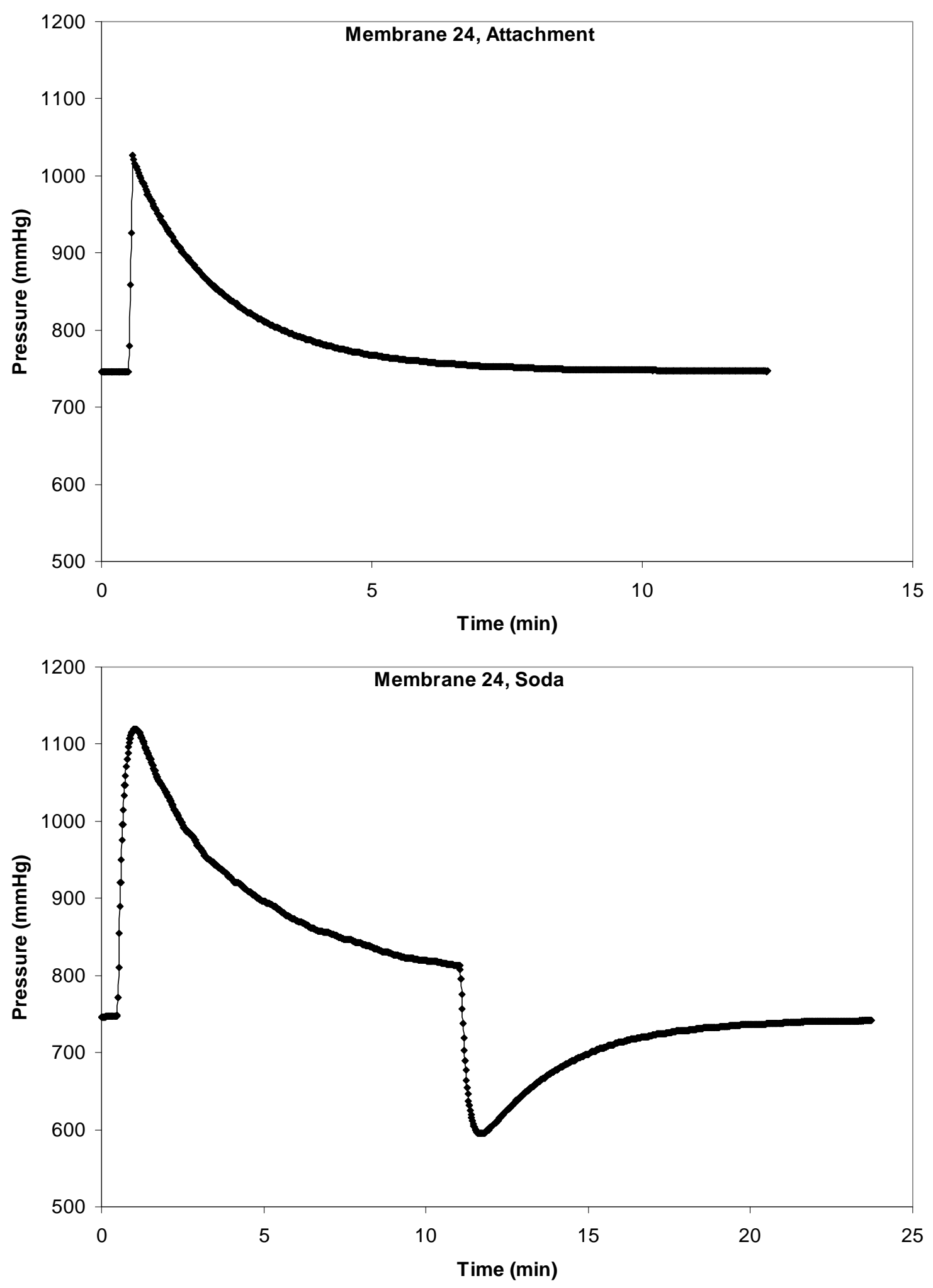

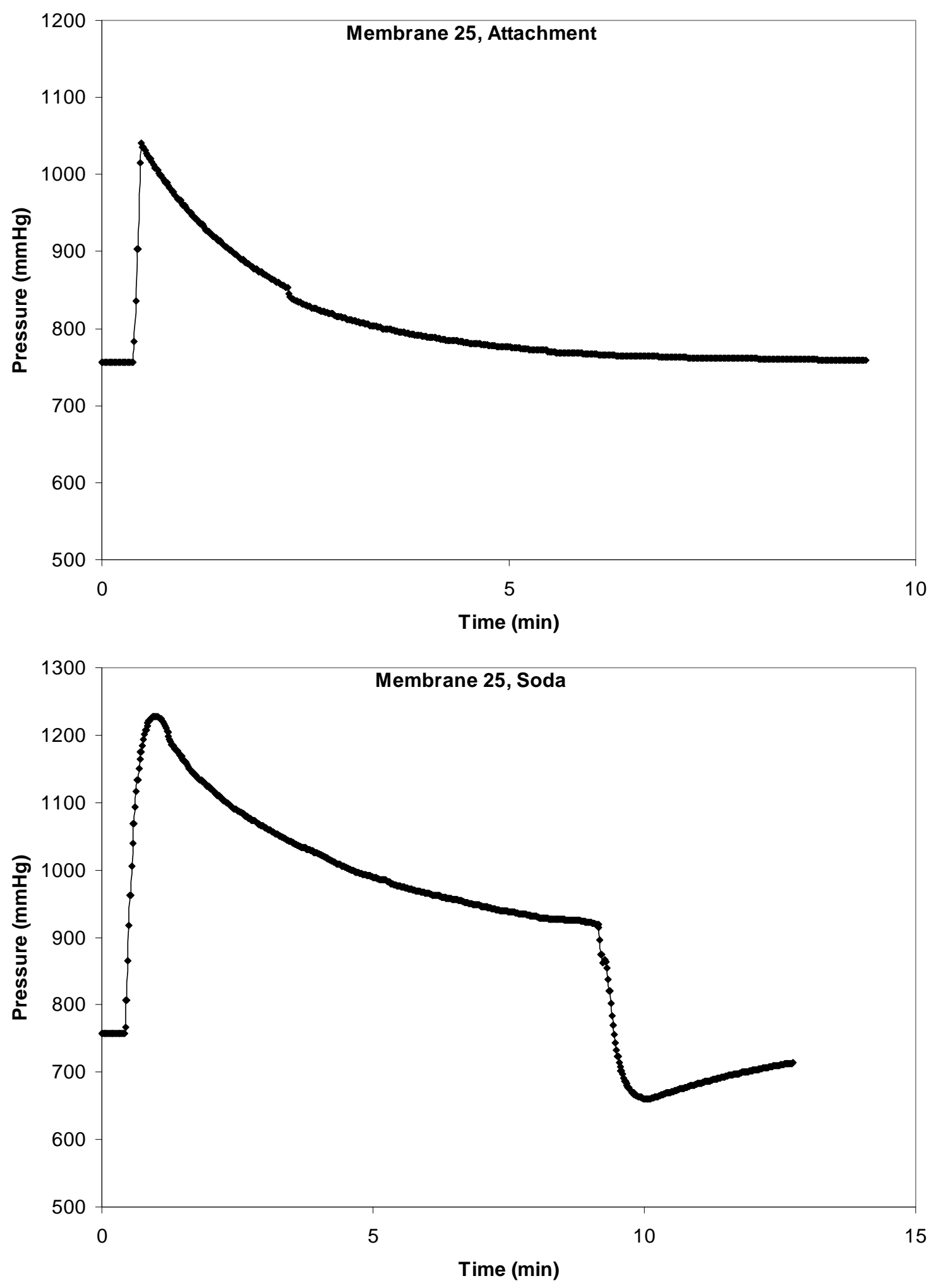

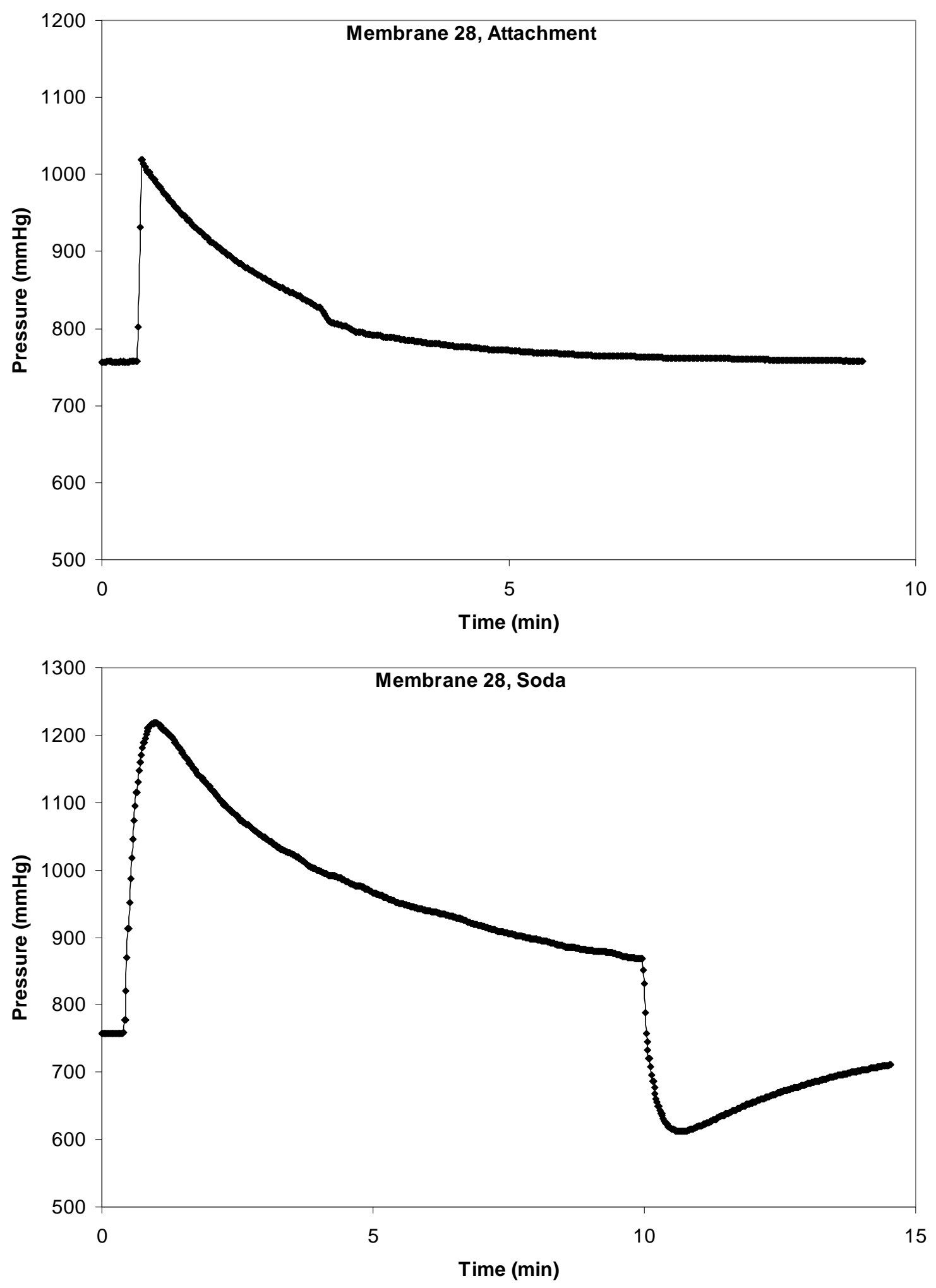

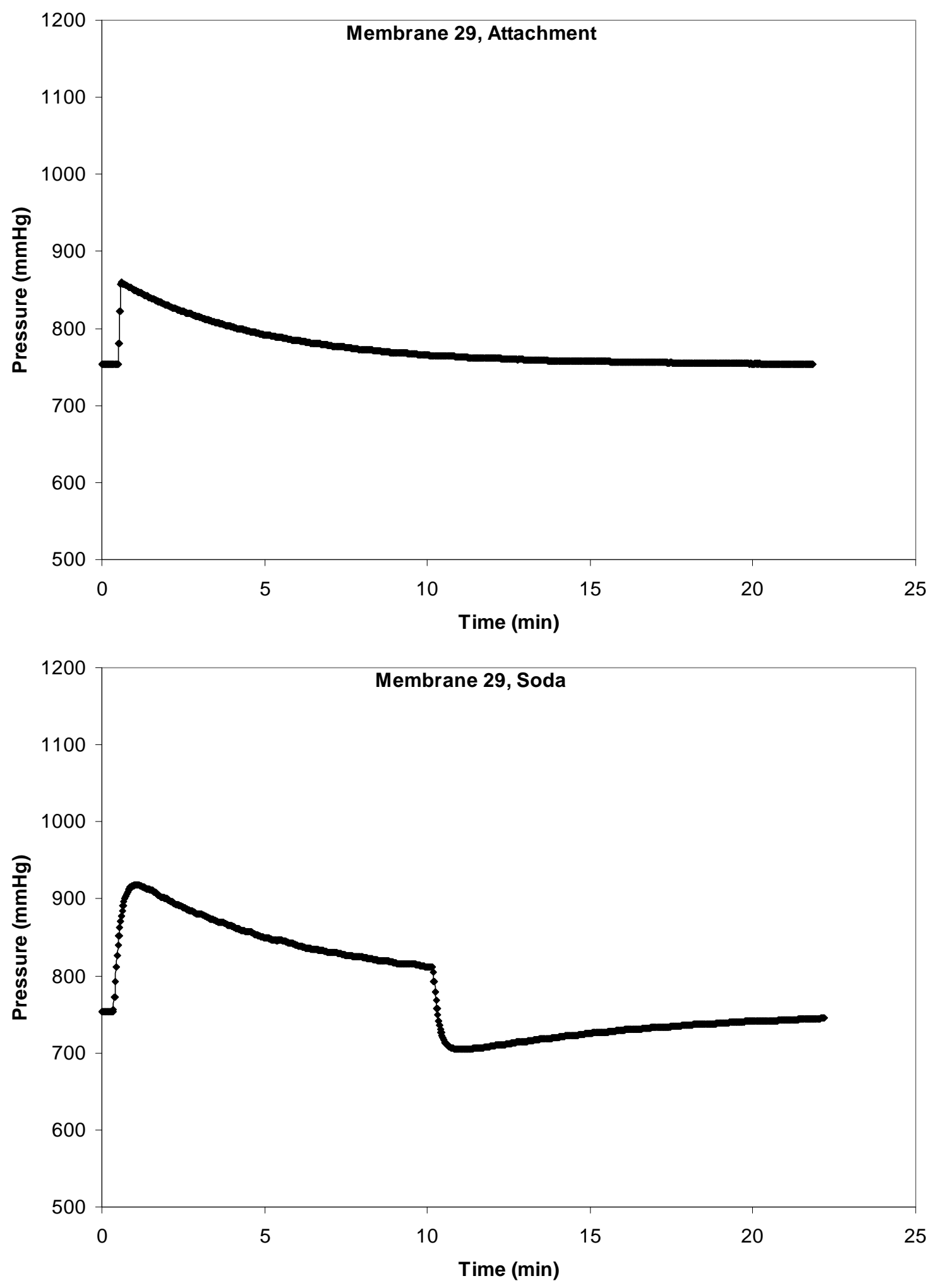

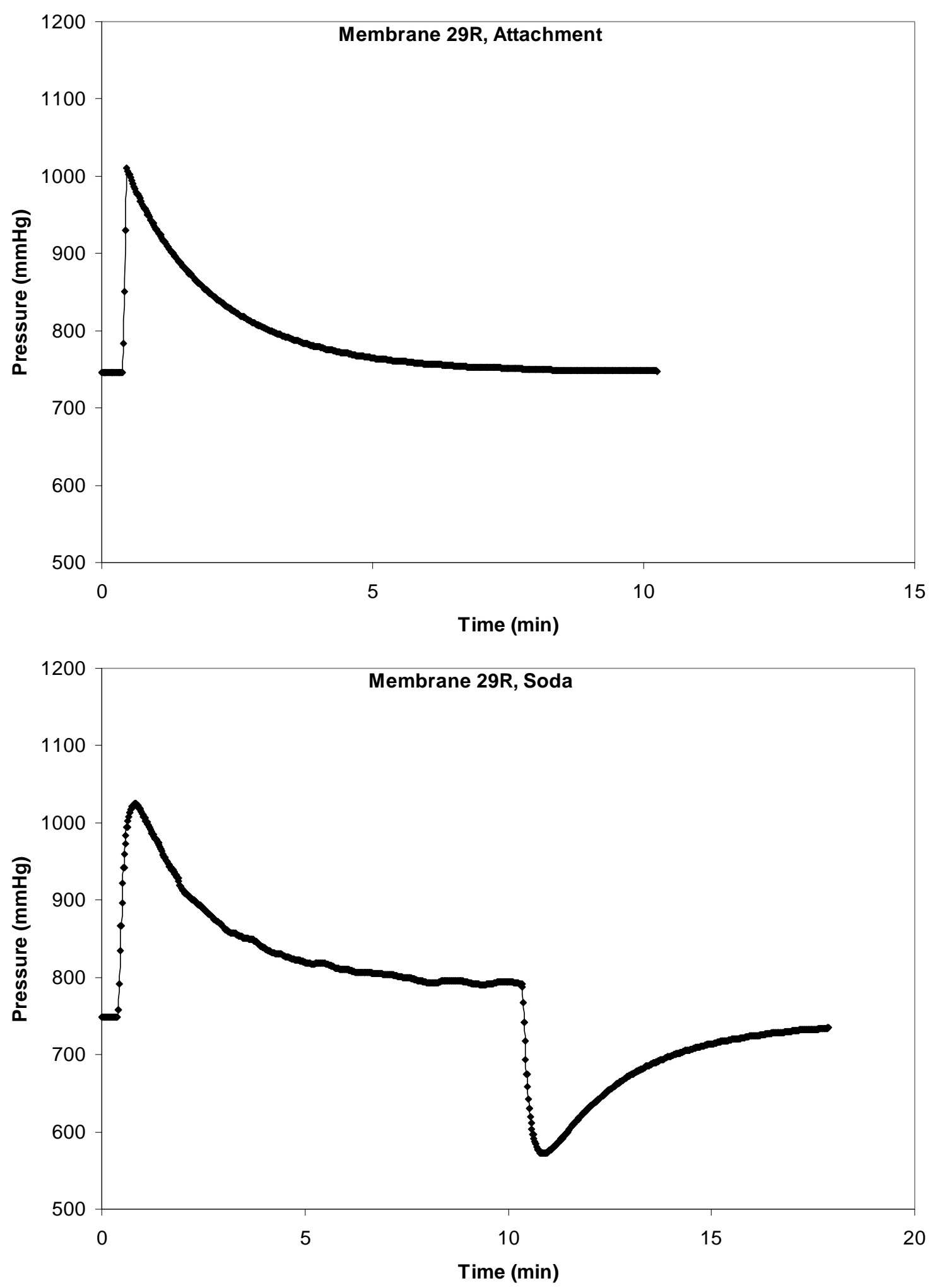

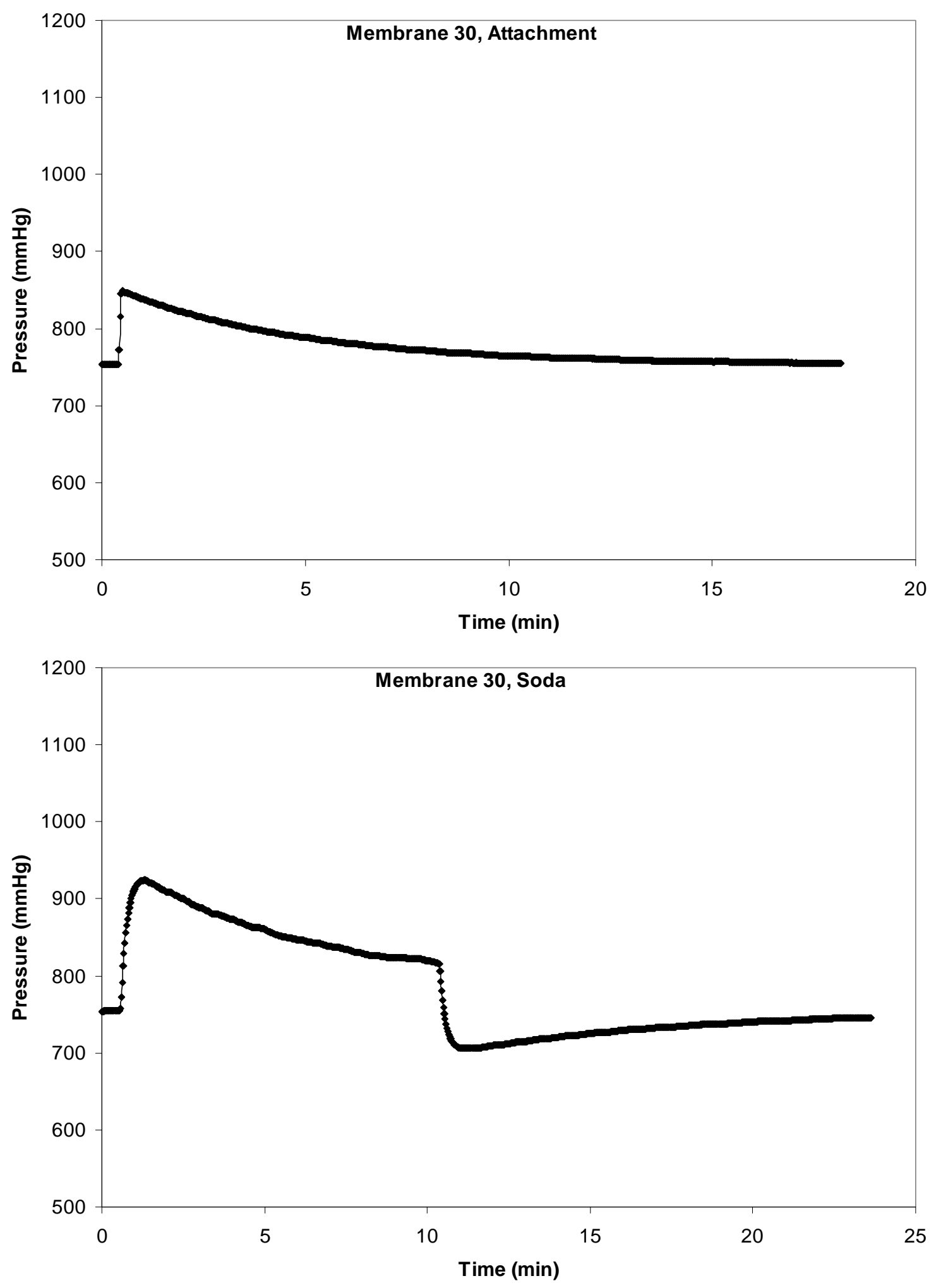

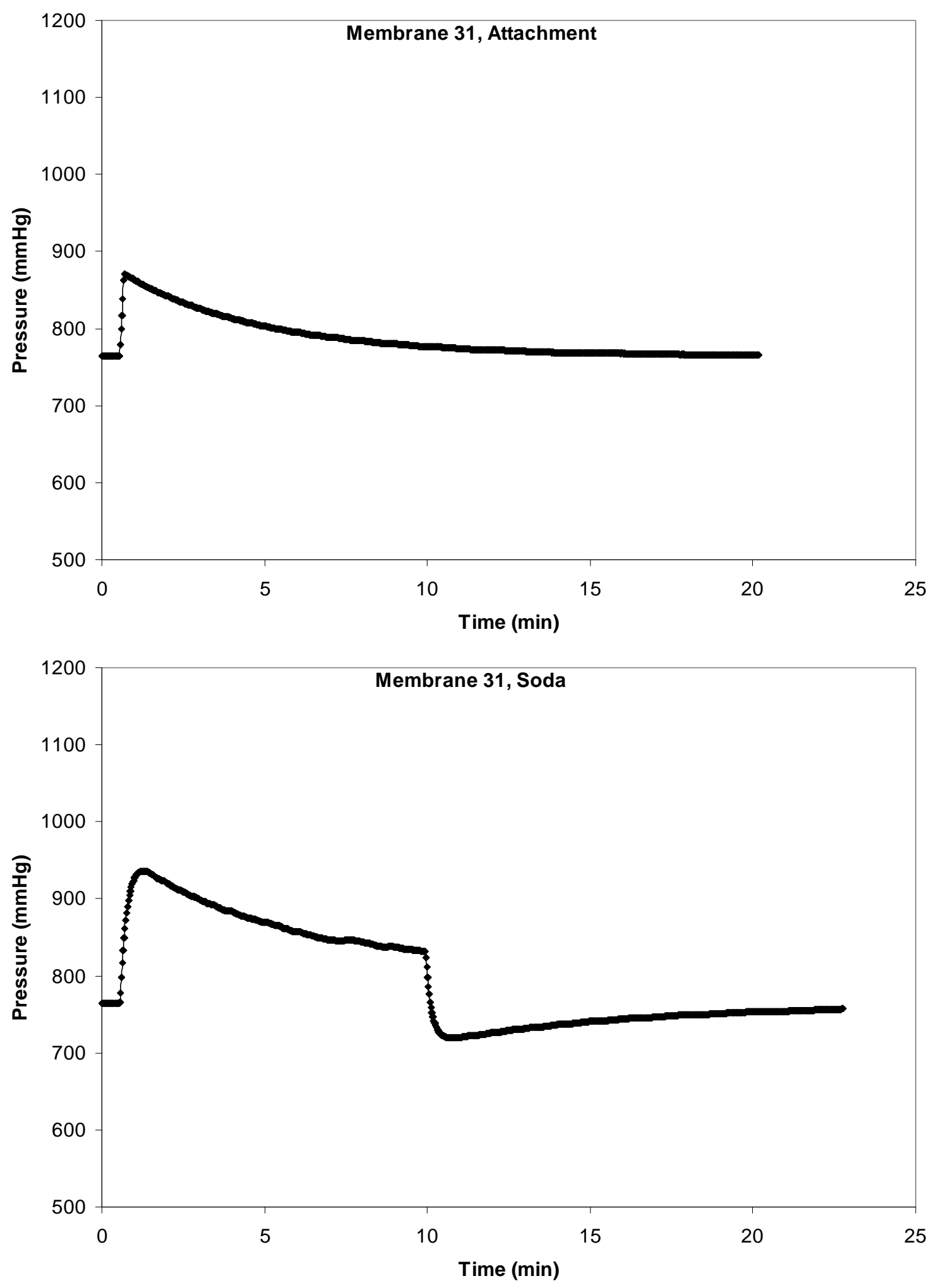

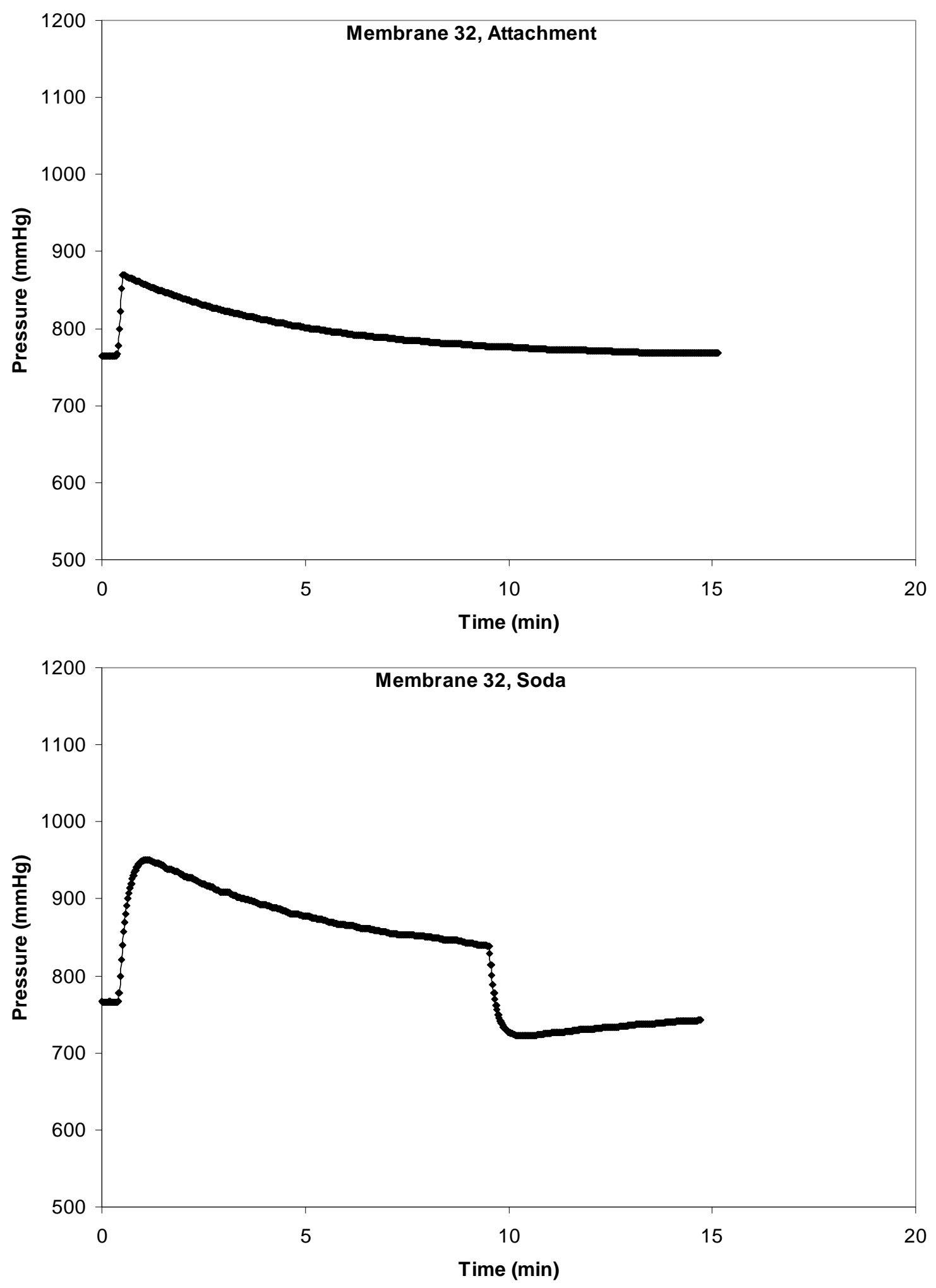

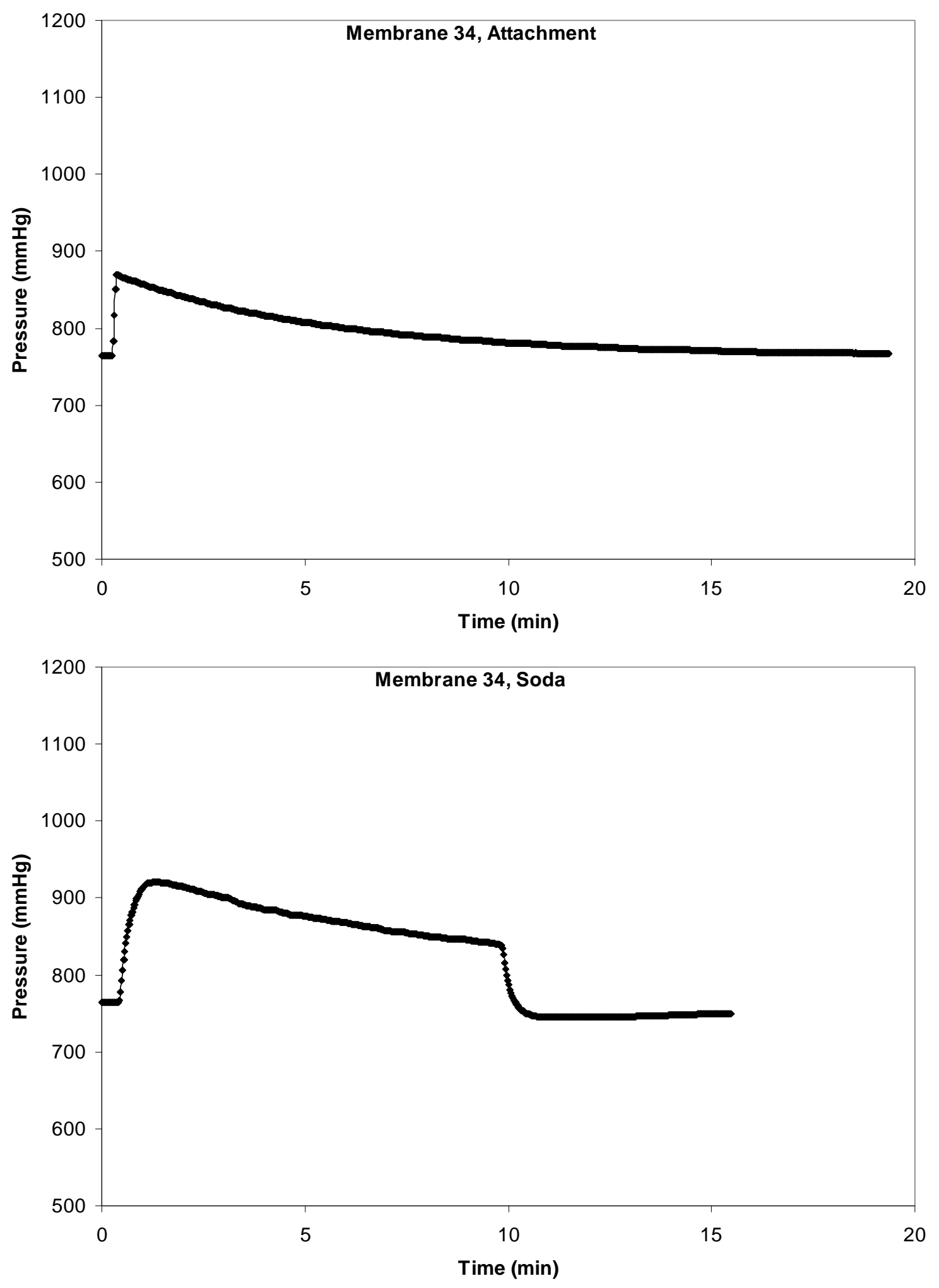

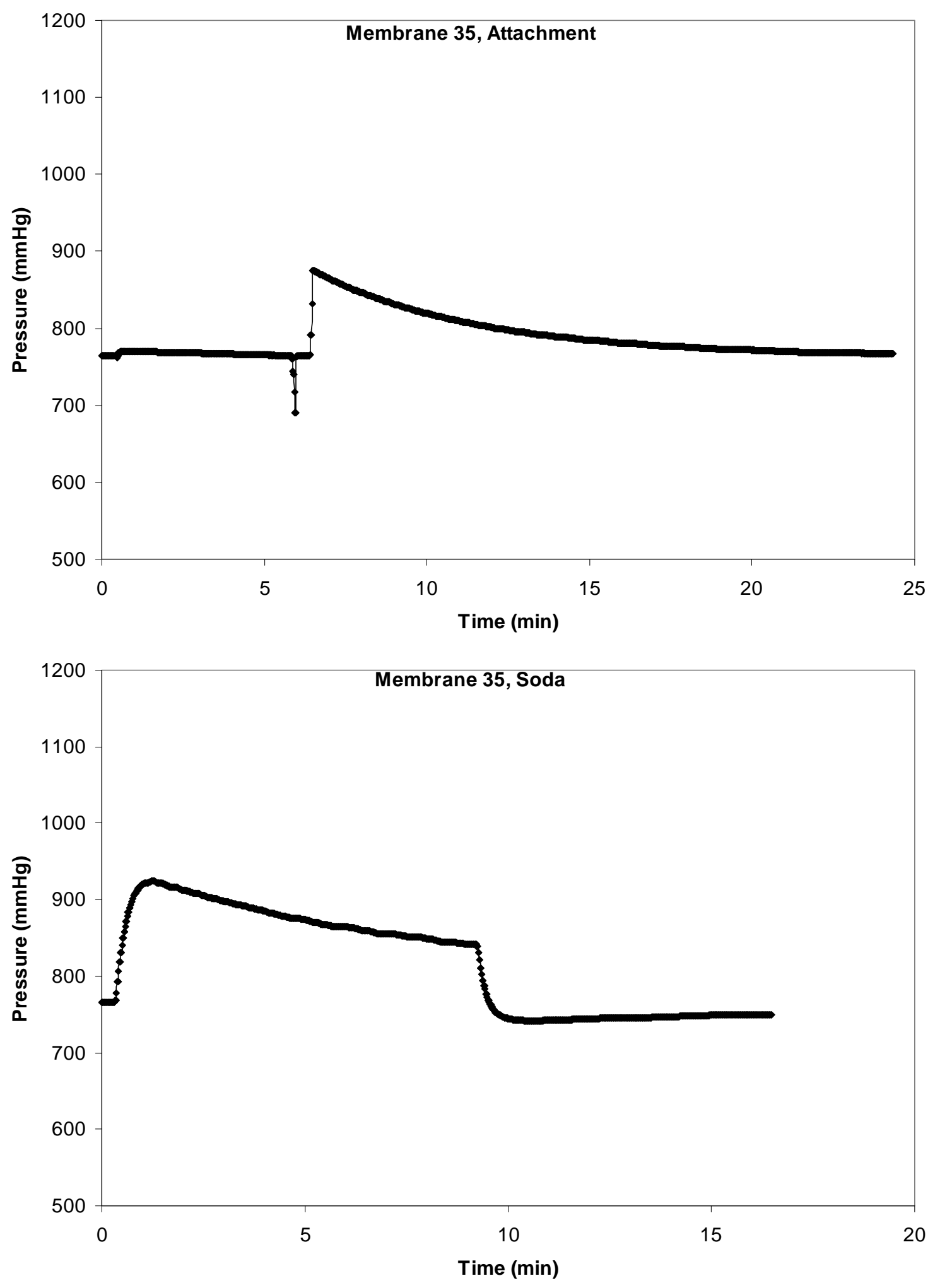

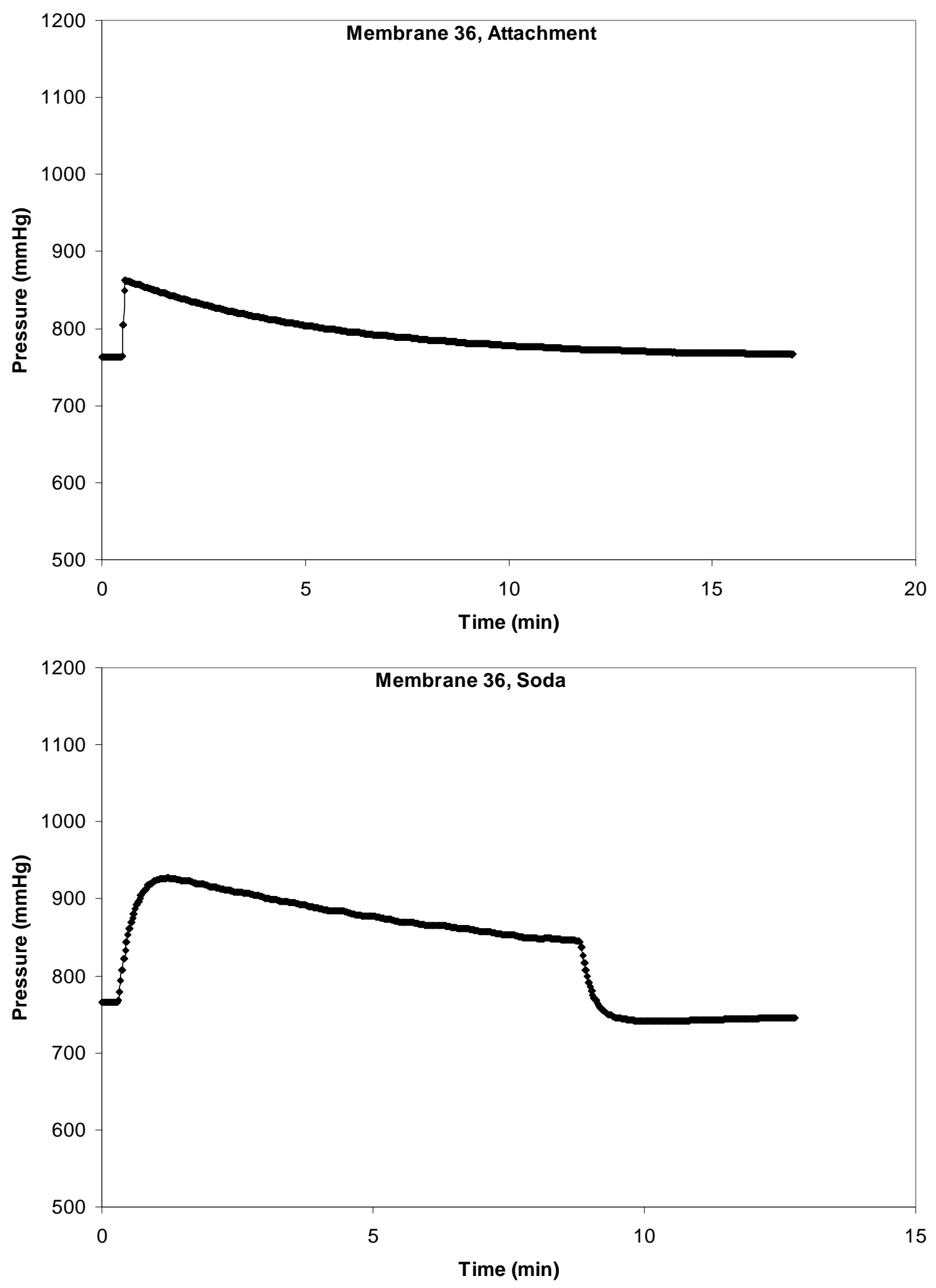

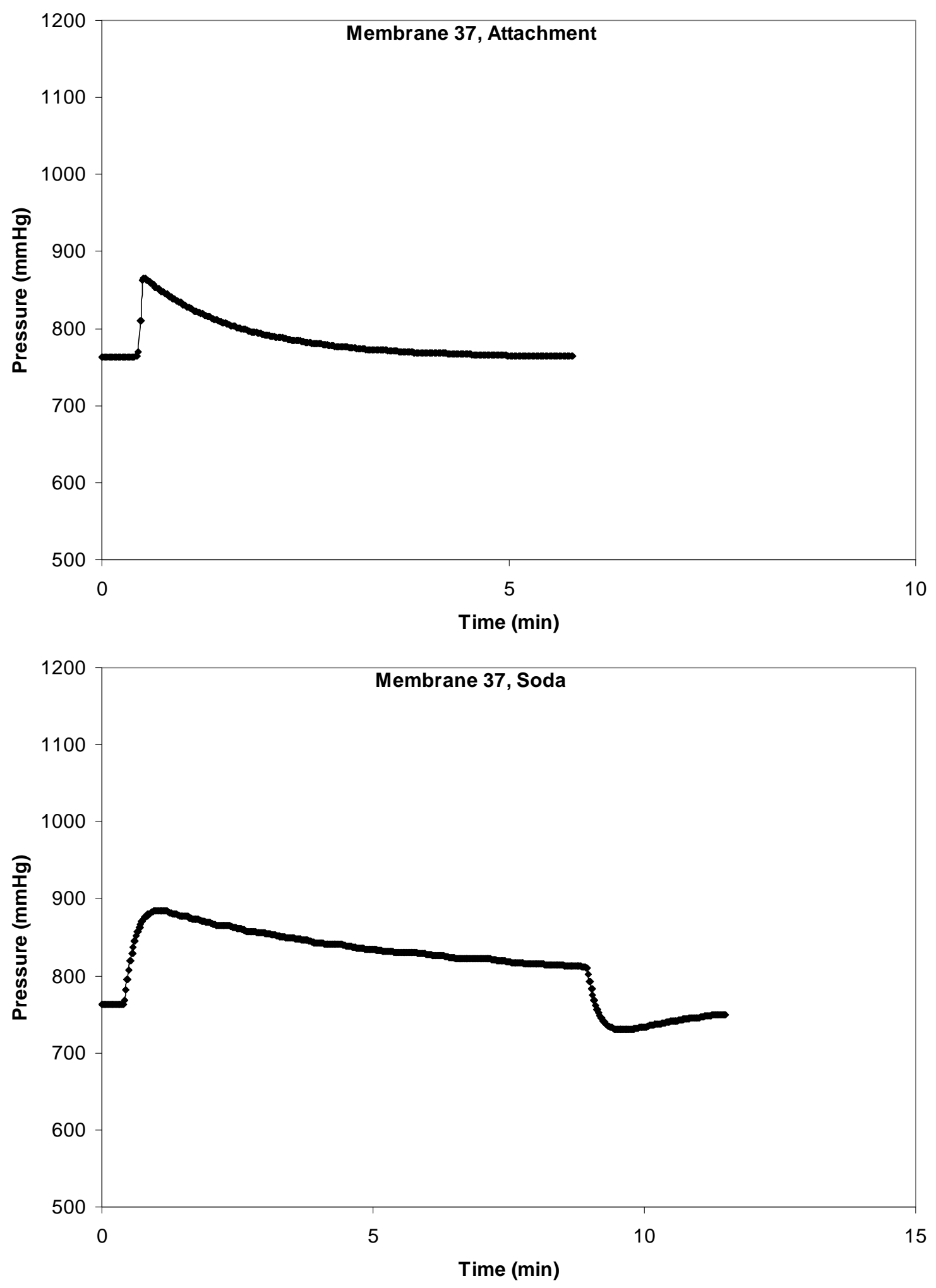

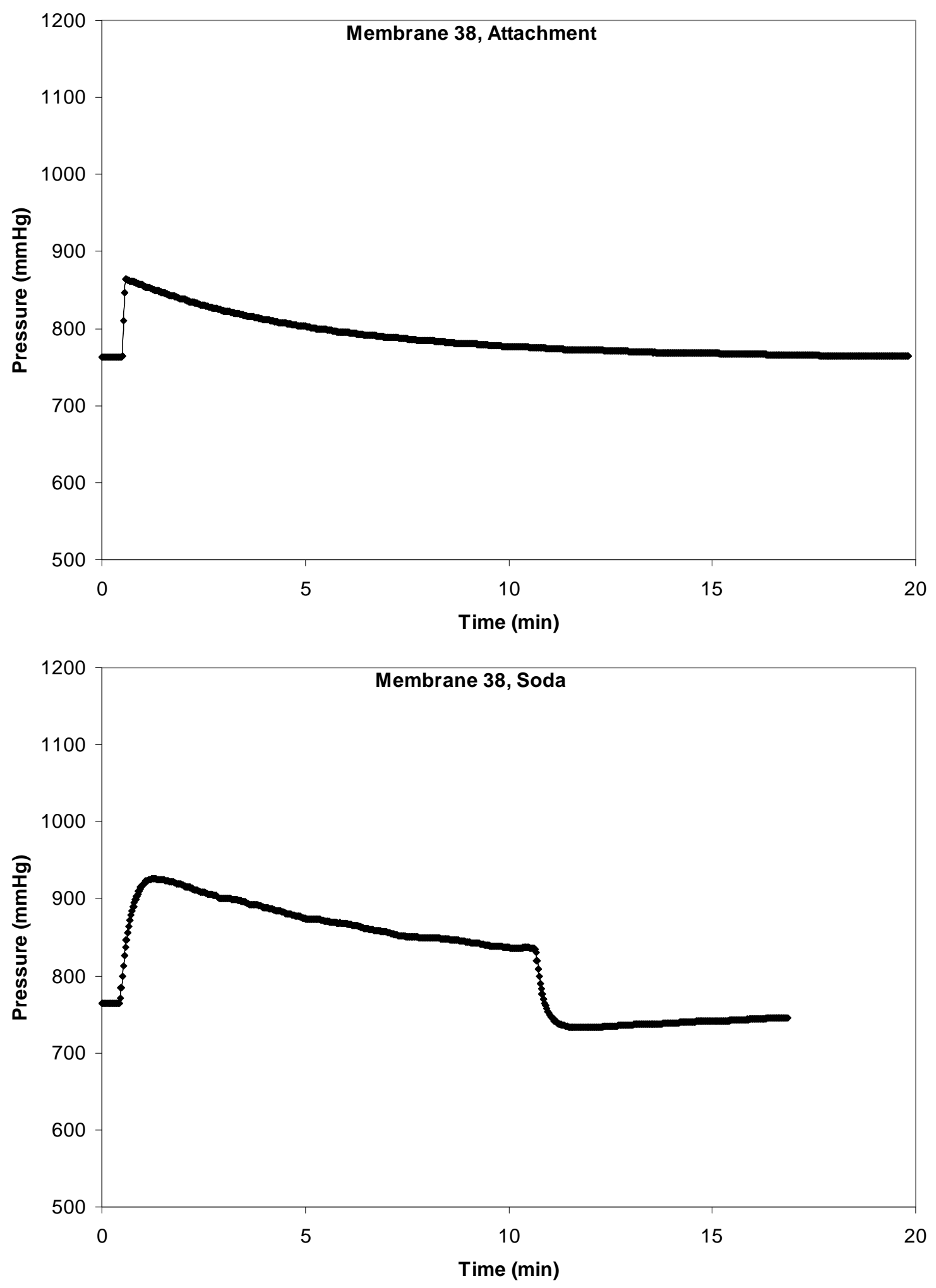


\section{Post Deployment 1}

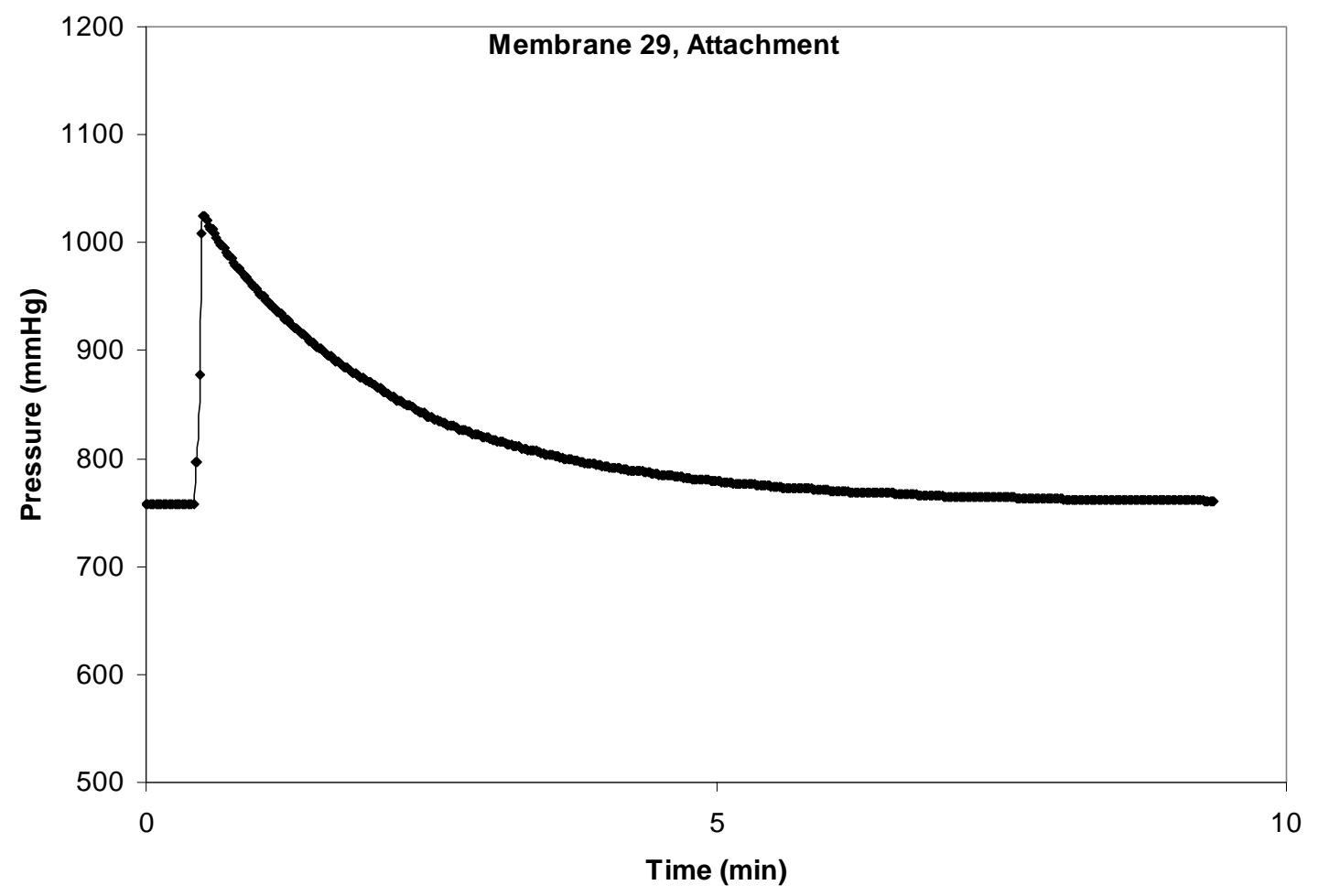

Membrane 29 was used at Multnomah Falls 1 river from 3/4/2008 to 3/20/2008 with MiniSonde 44927.

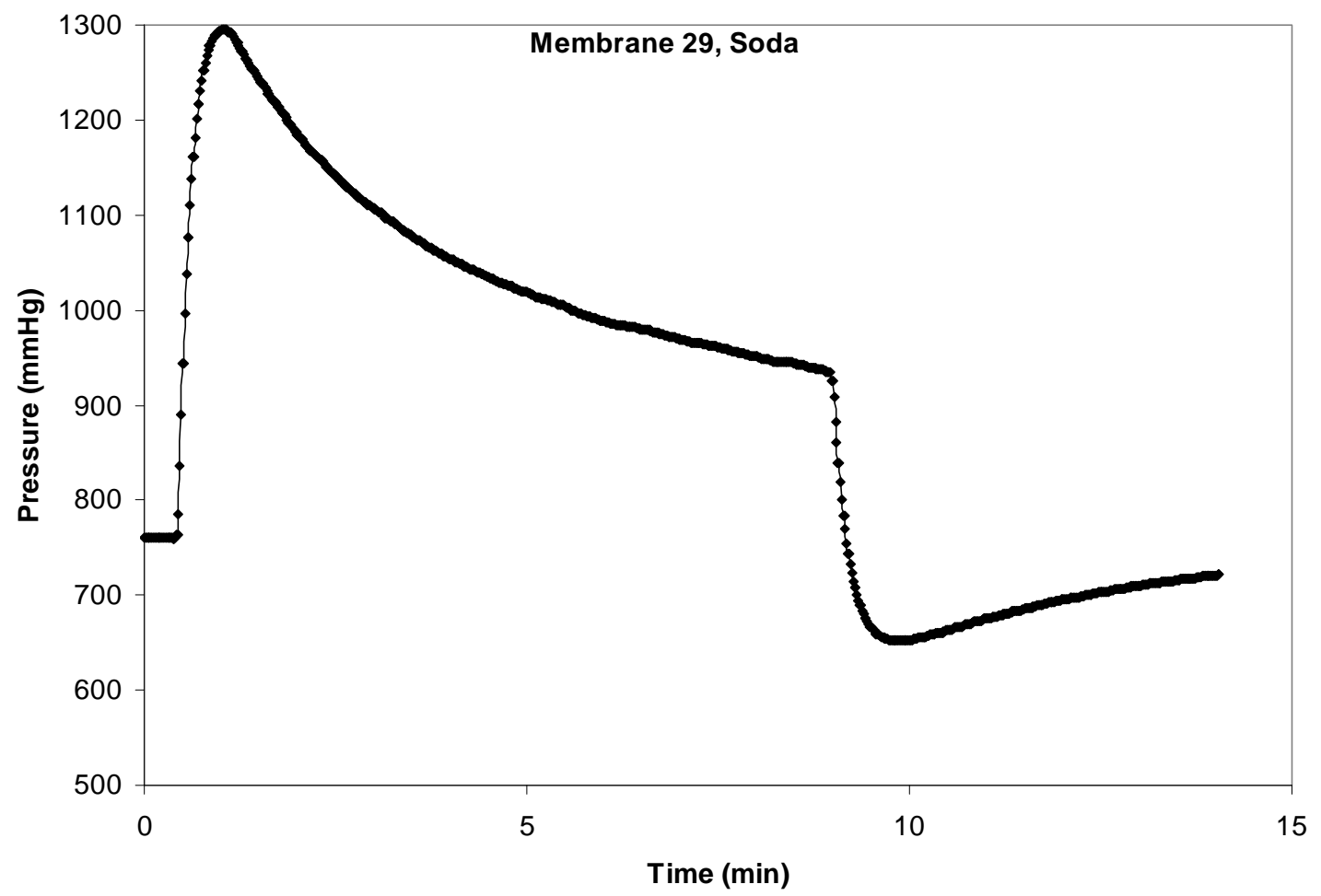




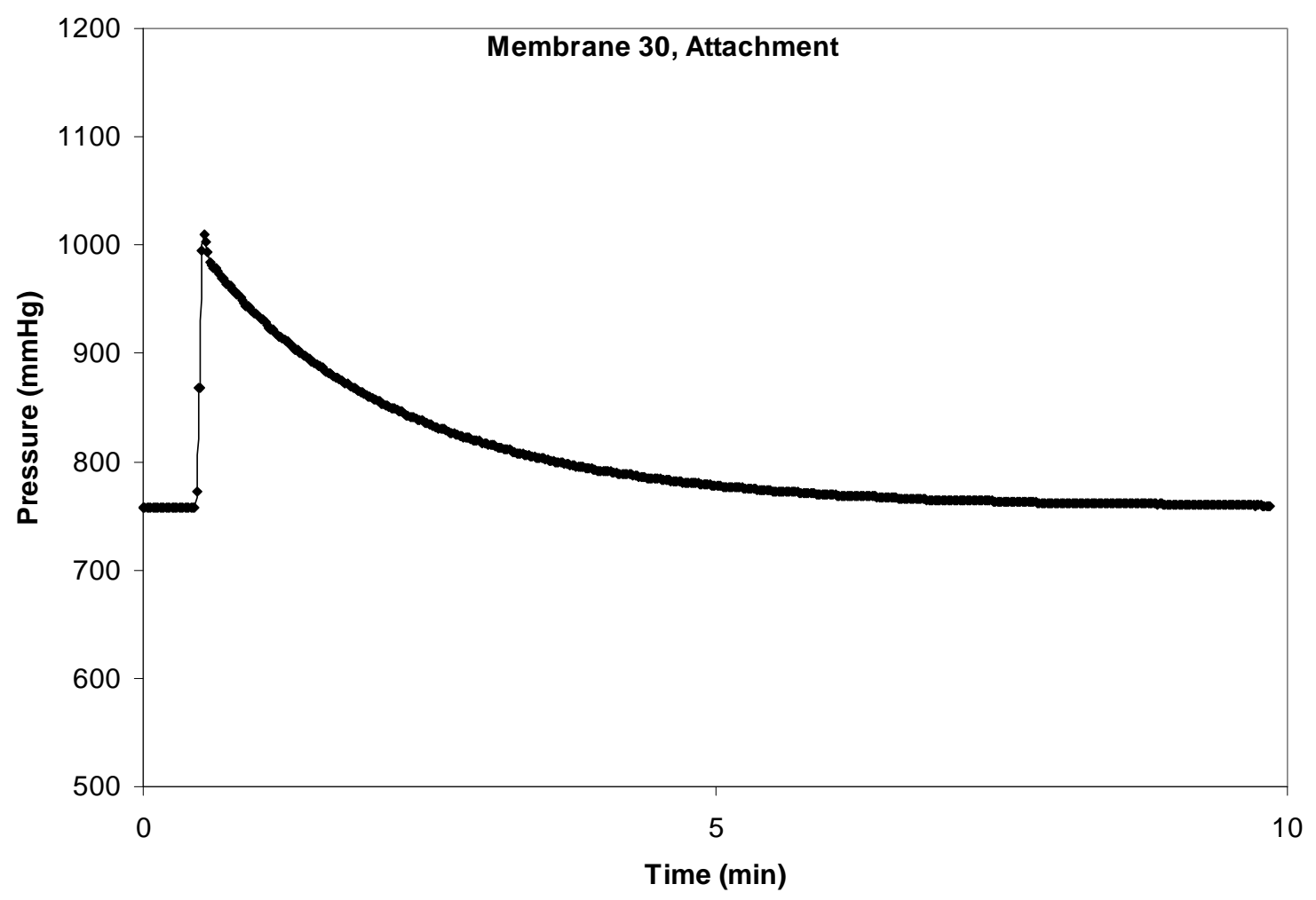

Membrane 30 was used at Multnomah Falls 1 hyporheic from 3/4/2008 to 3/20/2008 with MiniSonde 44945.

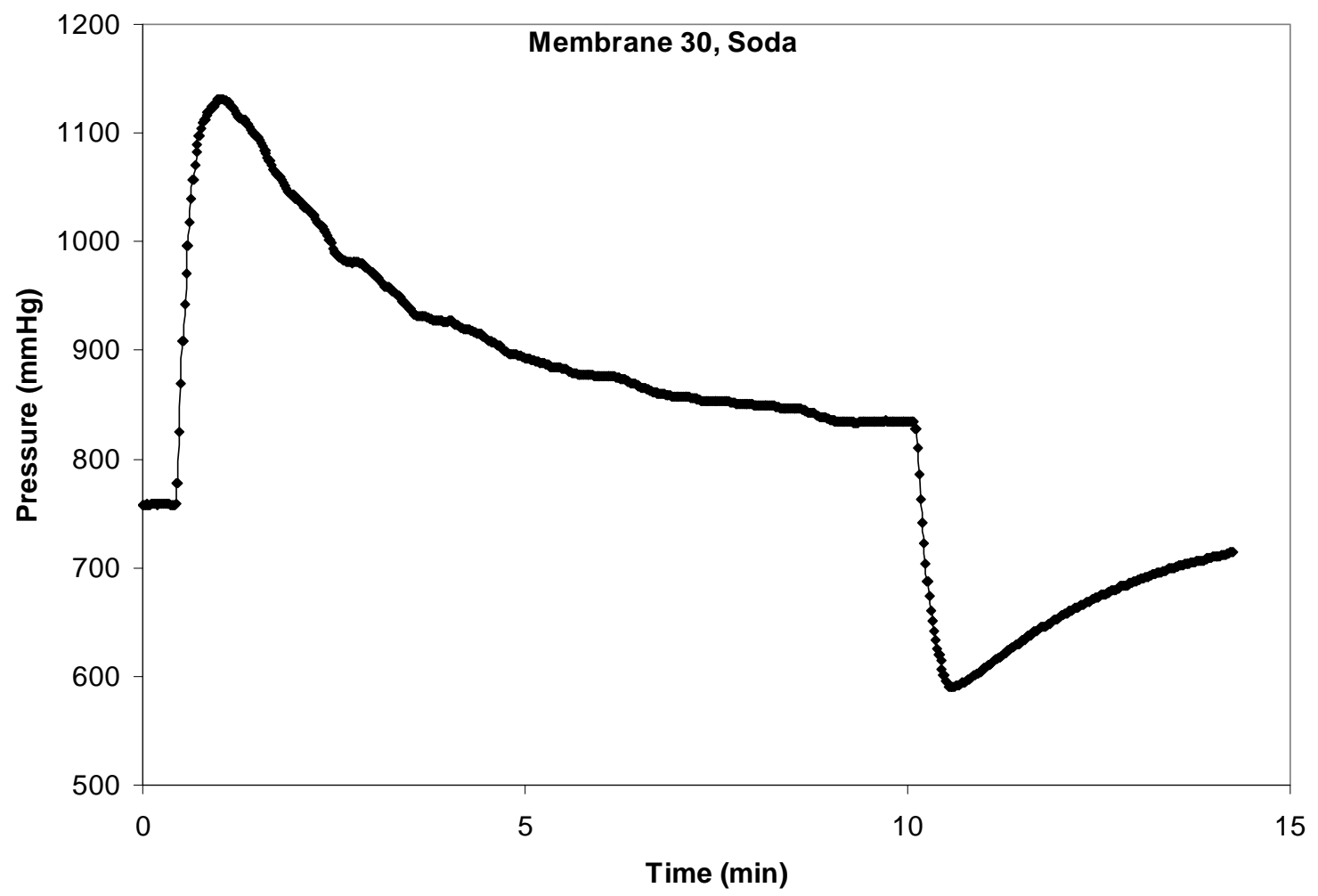




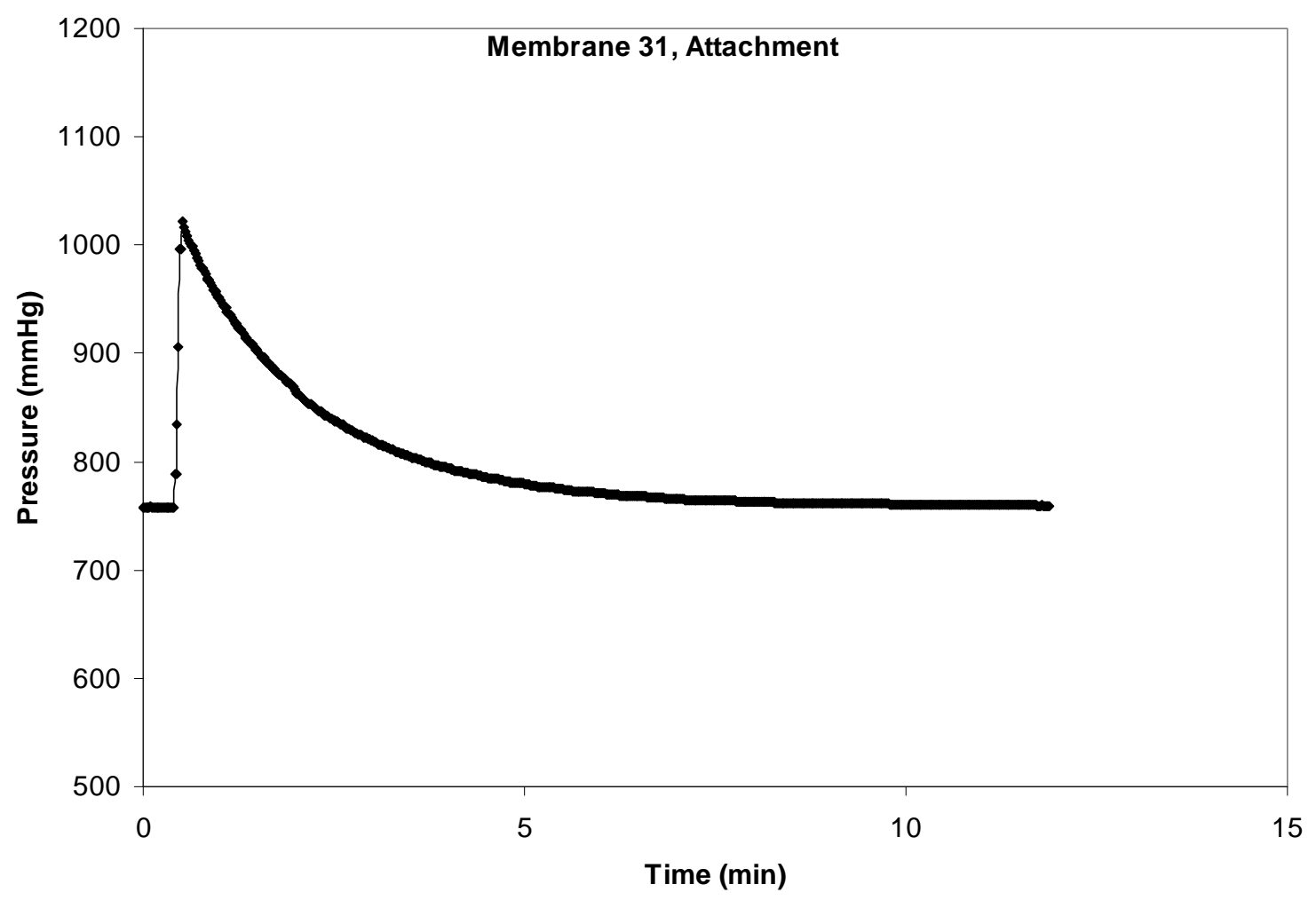

Membrane 31 was used at Ives 2 river from 3/4/2008 to 3/20/2008 with MiniSonde 44946.

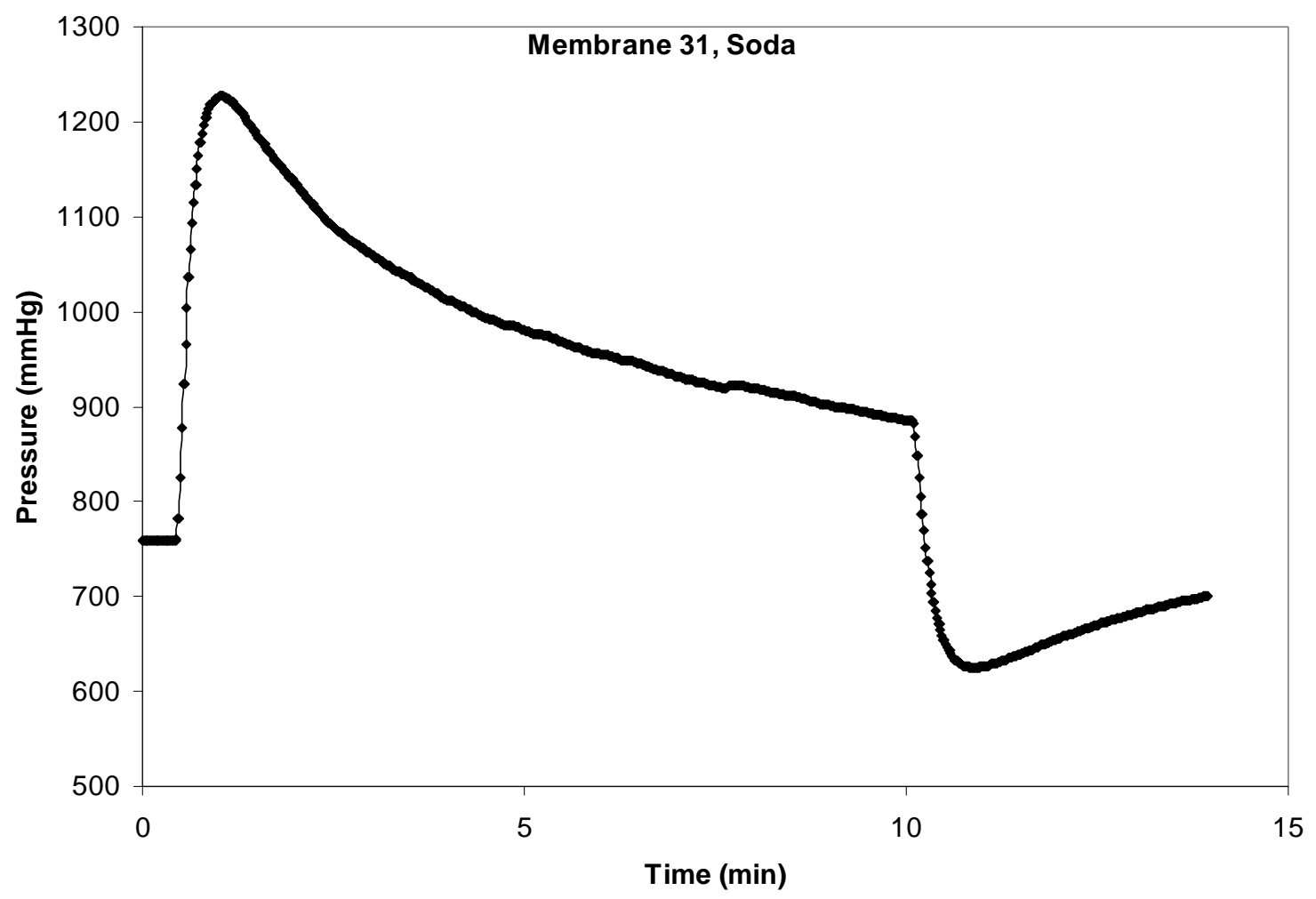




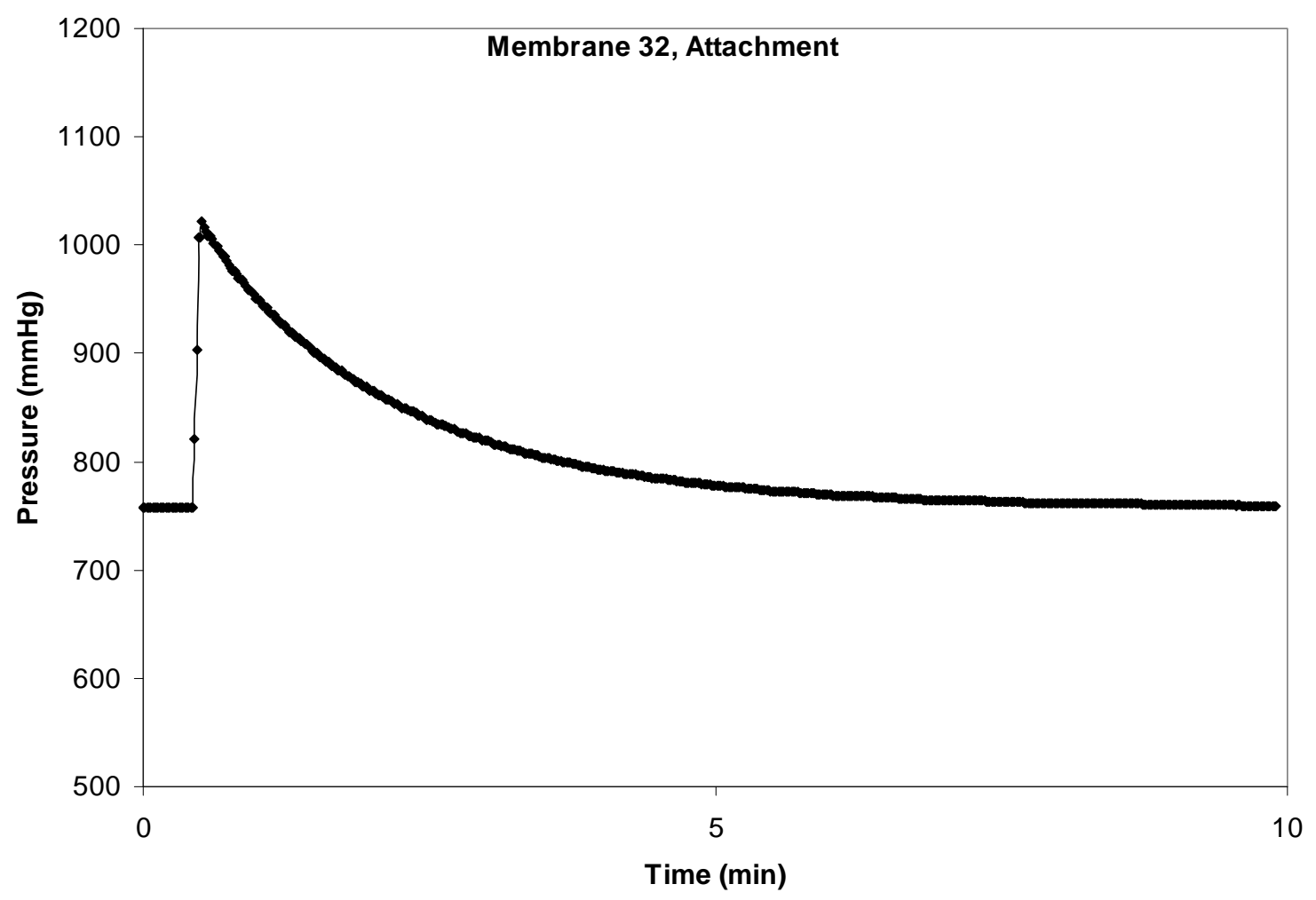

Membrane 32 was used at Ives 2 hyporheic from 3/4/2008 to 3/20/2008 with MiniSonde 44947.

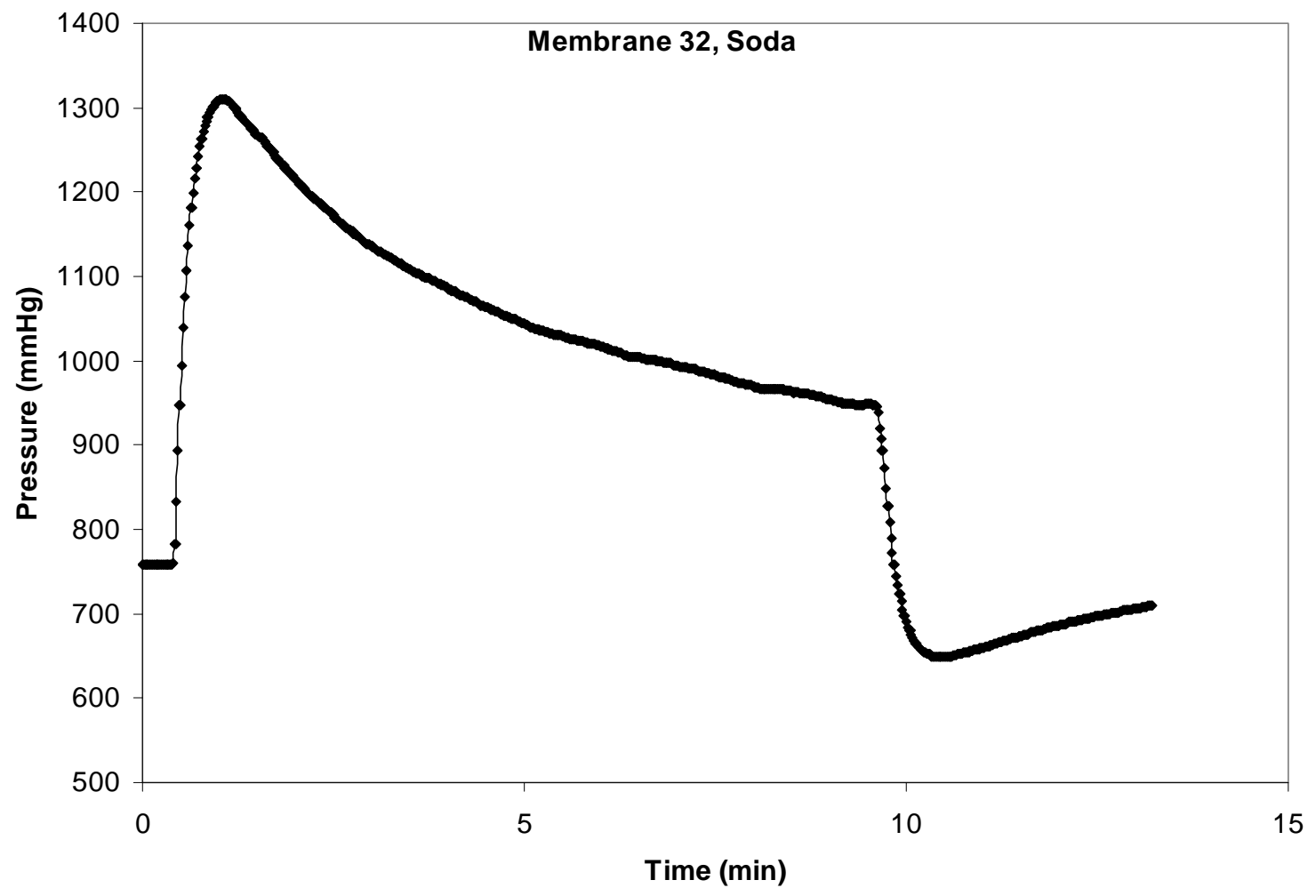




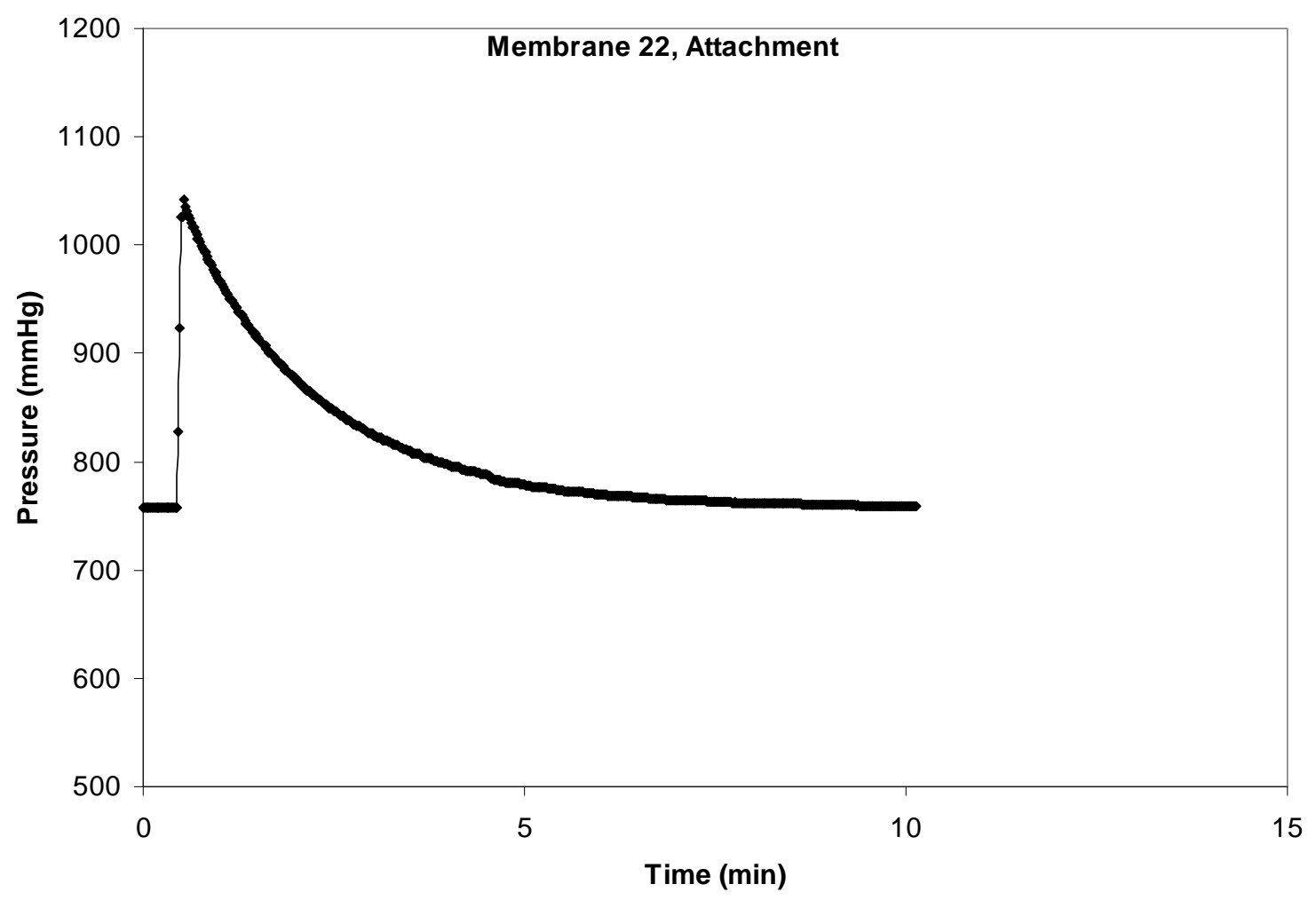

Membrane 22 was used as the control for the side-by-side after deployment 1 with MiniSonde 40347.

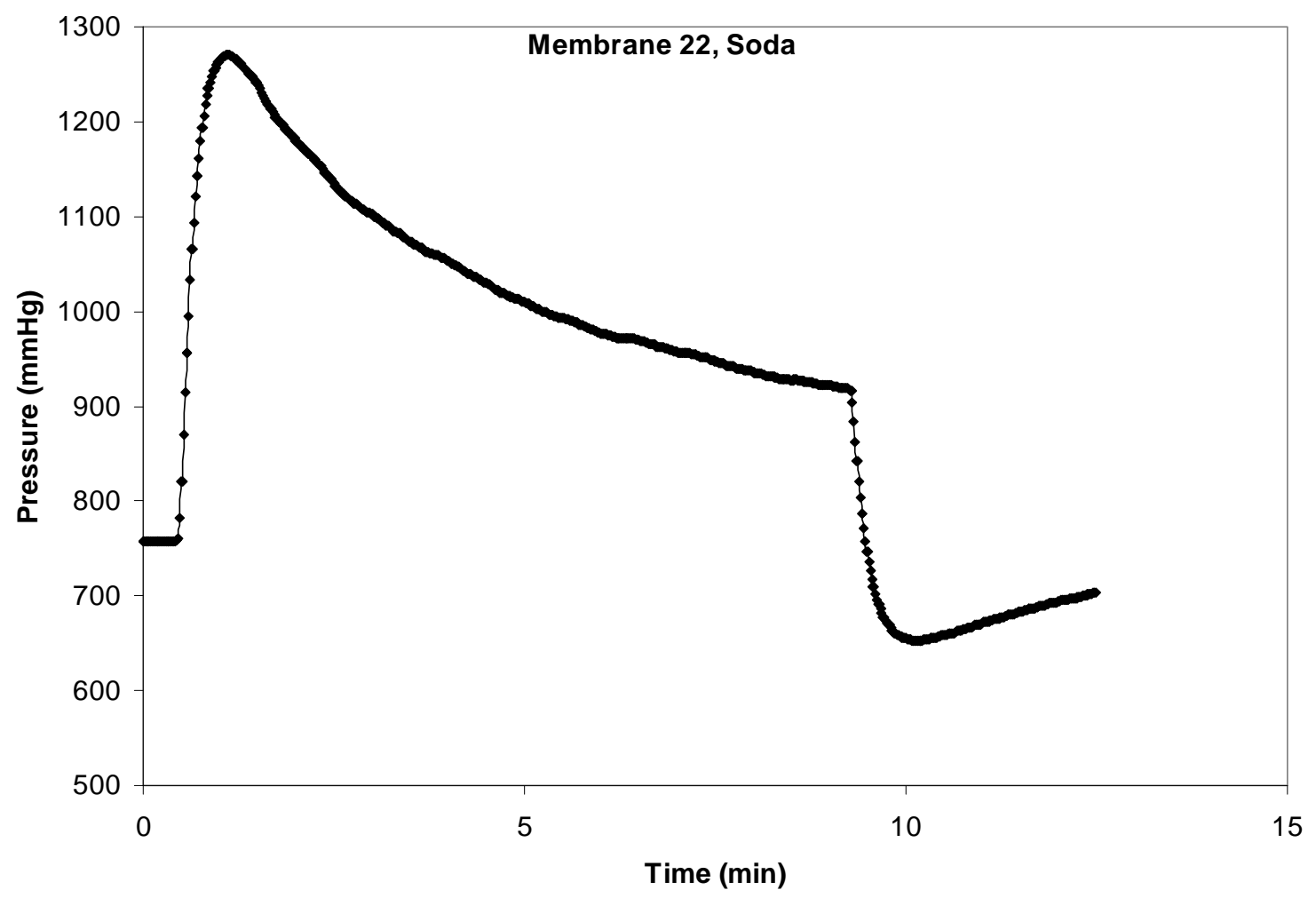




\section{Post Deployment 2}

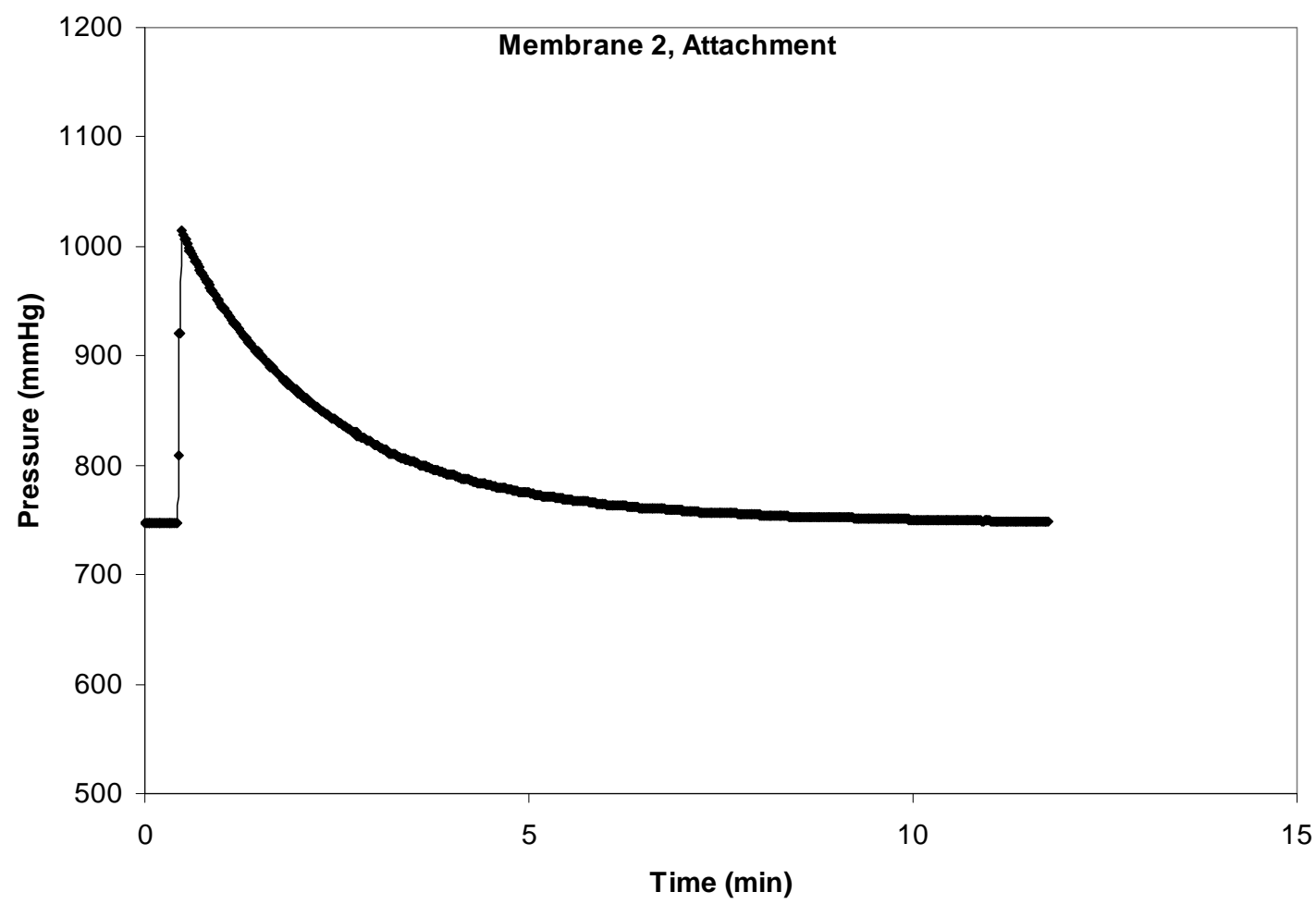

Membrane 2 was used at Multnomah Falls 1 river from 3/20/2008 to 4/3/2008 with MiniSonde 44927.

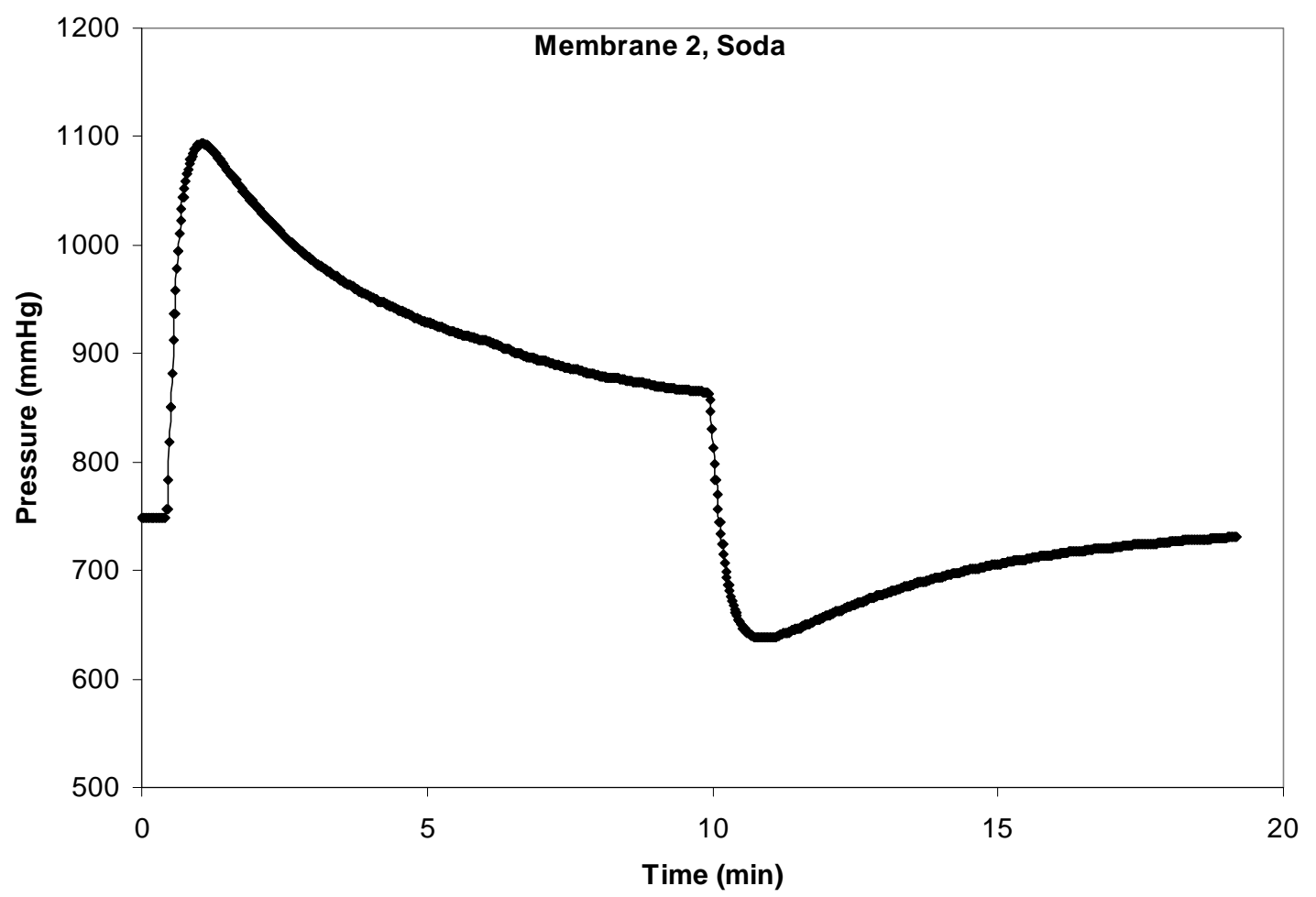






Membrane 3 was used at Multnomah Falls 1 hyporheic from 3/20/2008 to 4/3/2008 with MiniSonde 44945.

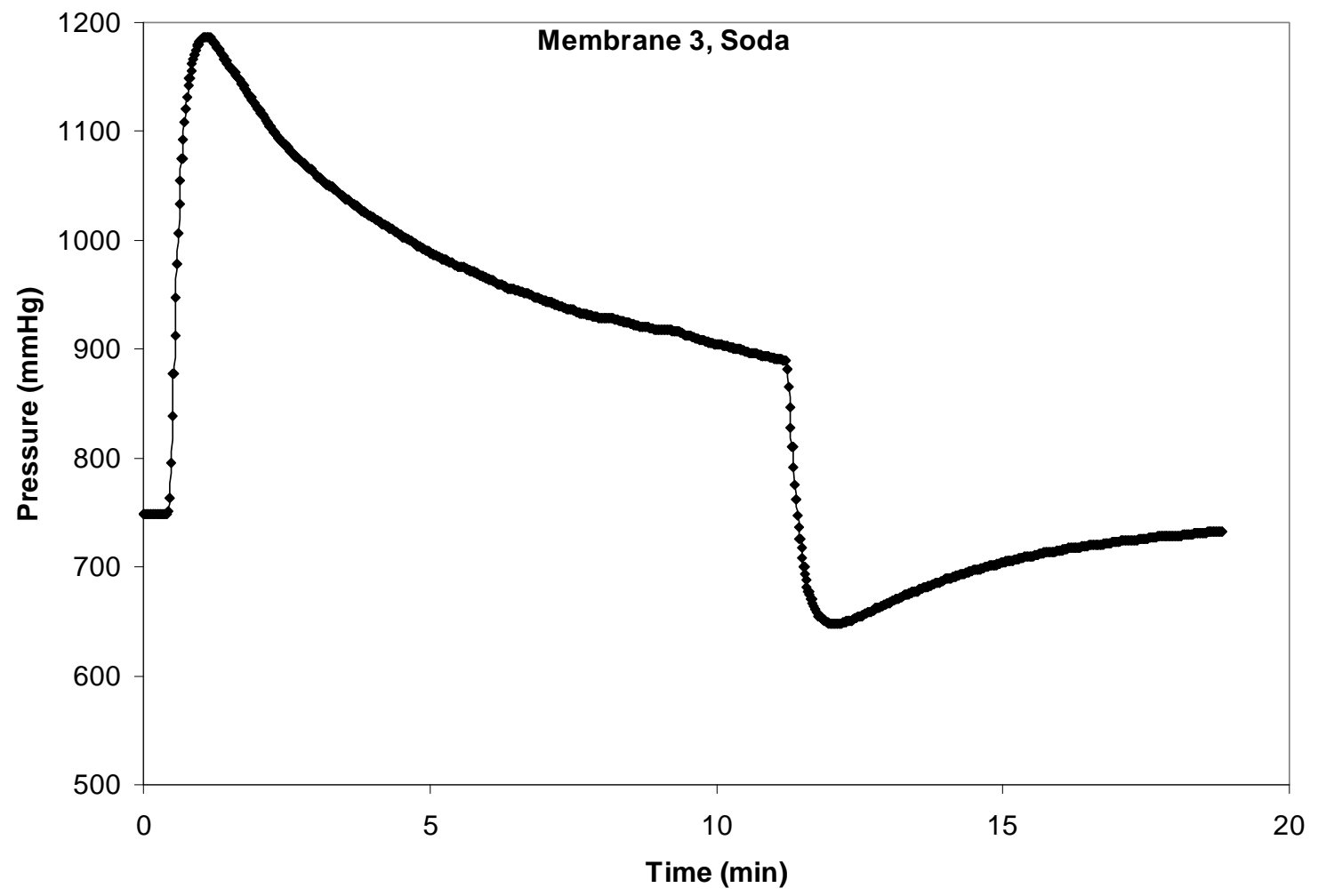




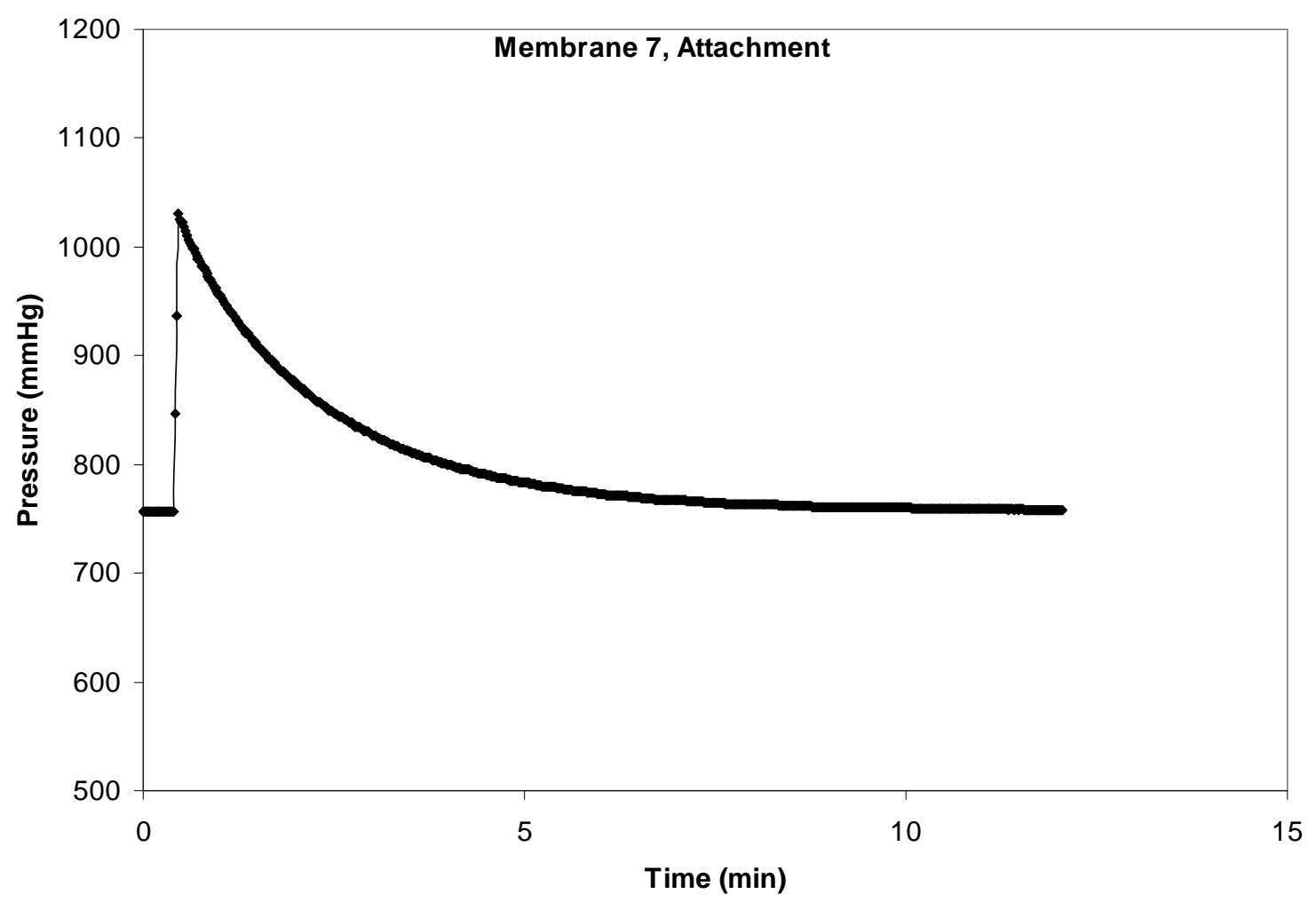

Membrane 7 was used at Ives 2 hyporheic from 3/20/2008 to 4/3/2008 with MiniSonde 44947.

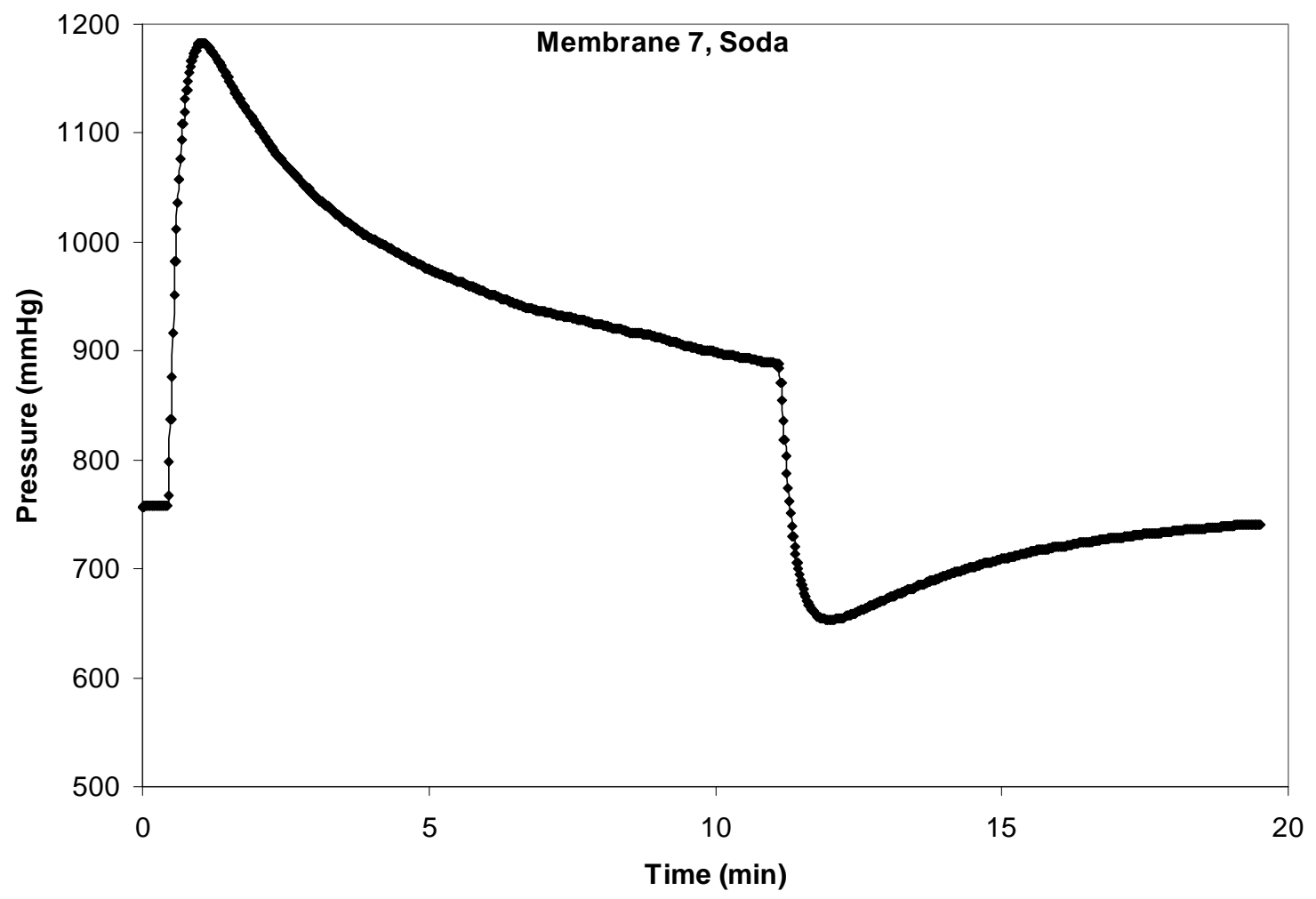




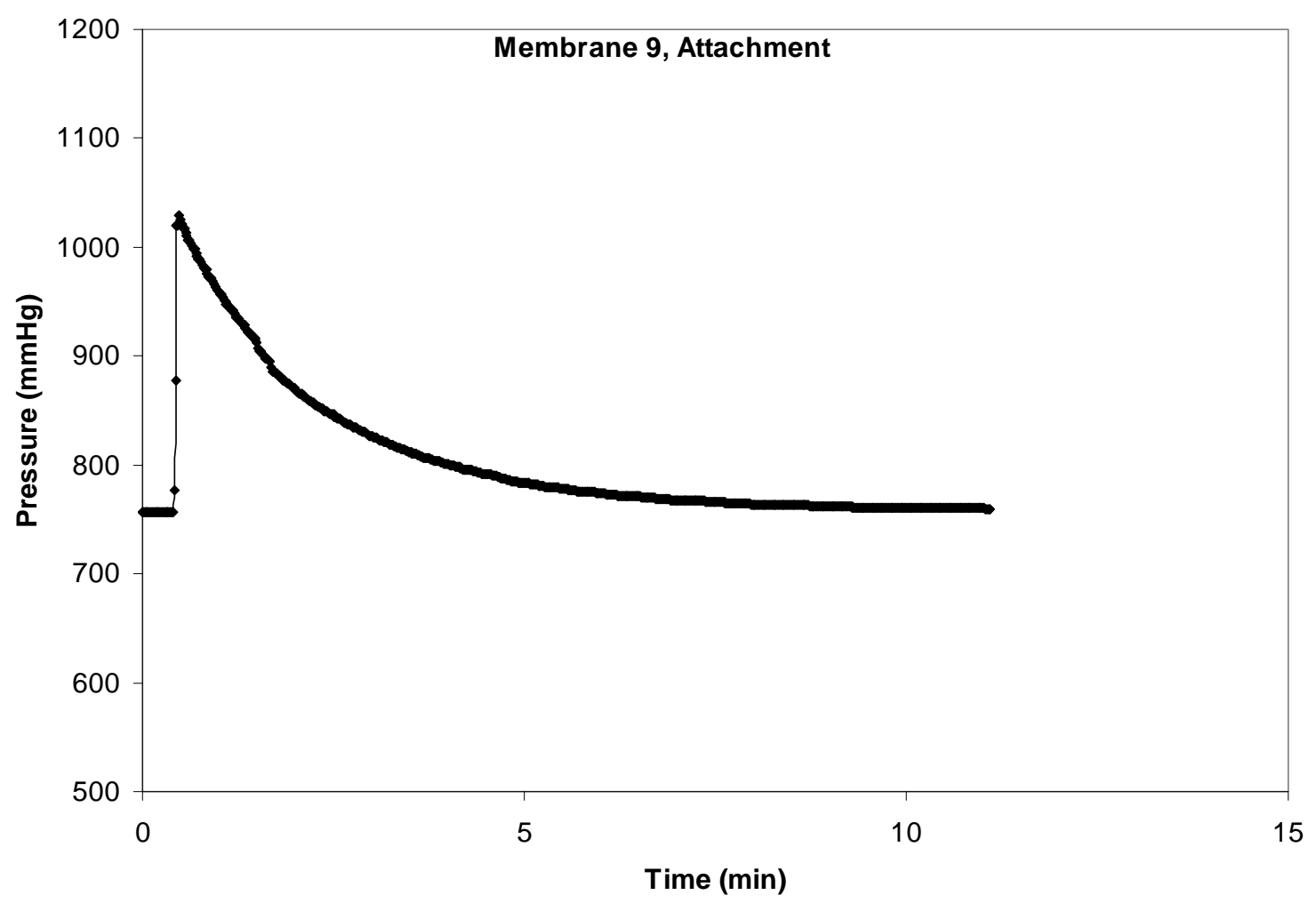

Membrane 9 was used at Ives 2 river from 3/20/2008 to 4/3/2008 with MiniSonde 44946.

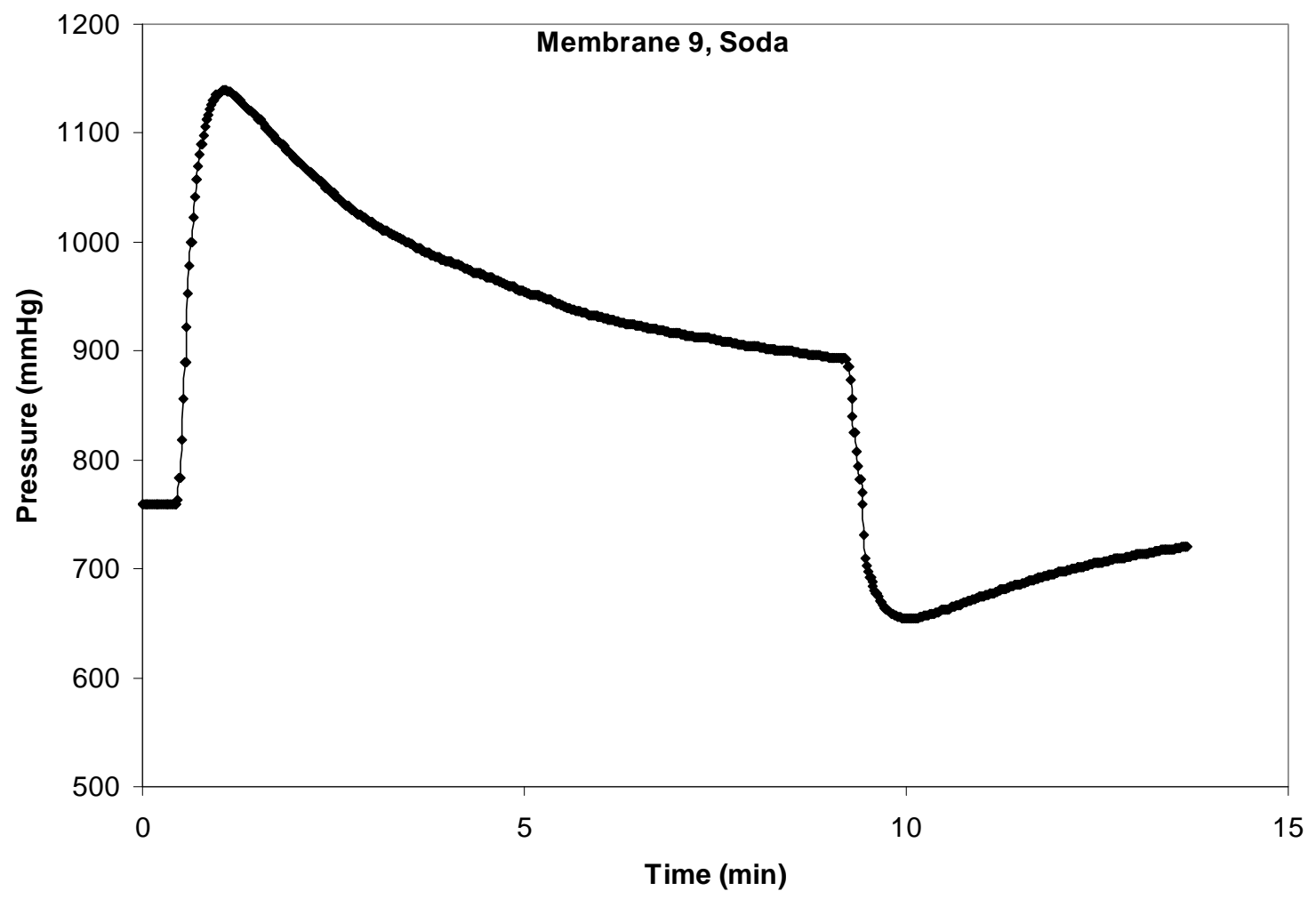




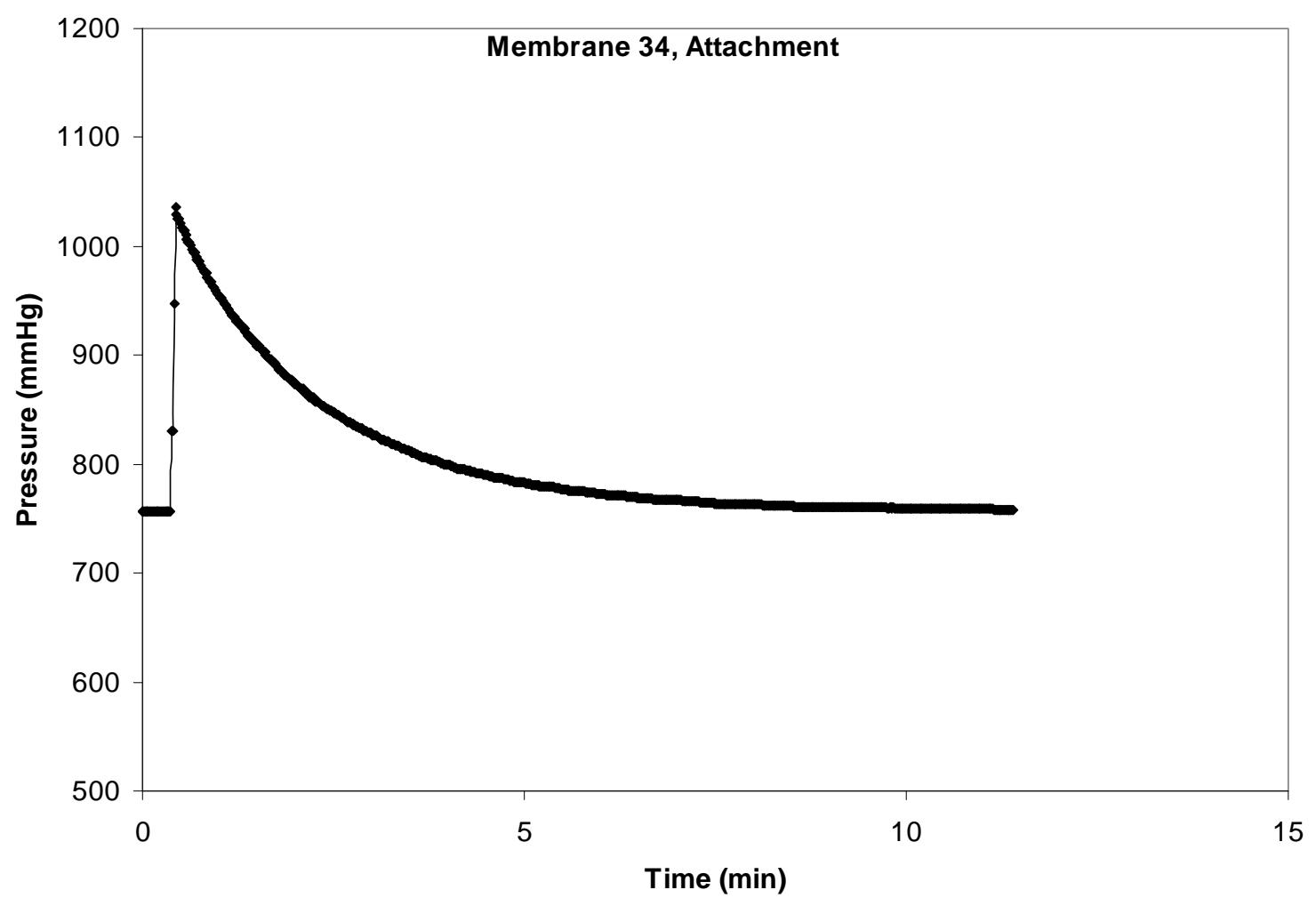

Membrane 34 was used at Ives 5 river from 3/20/2008 to 4/3/2008 with MiniSonde 43639.

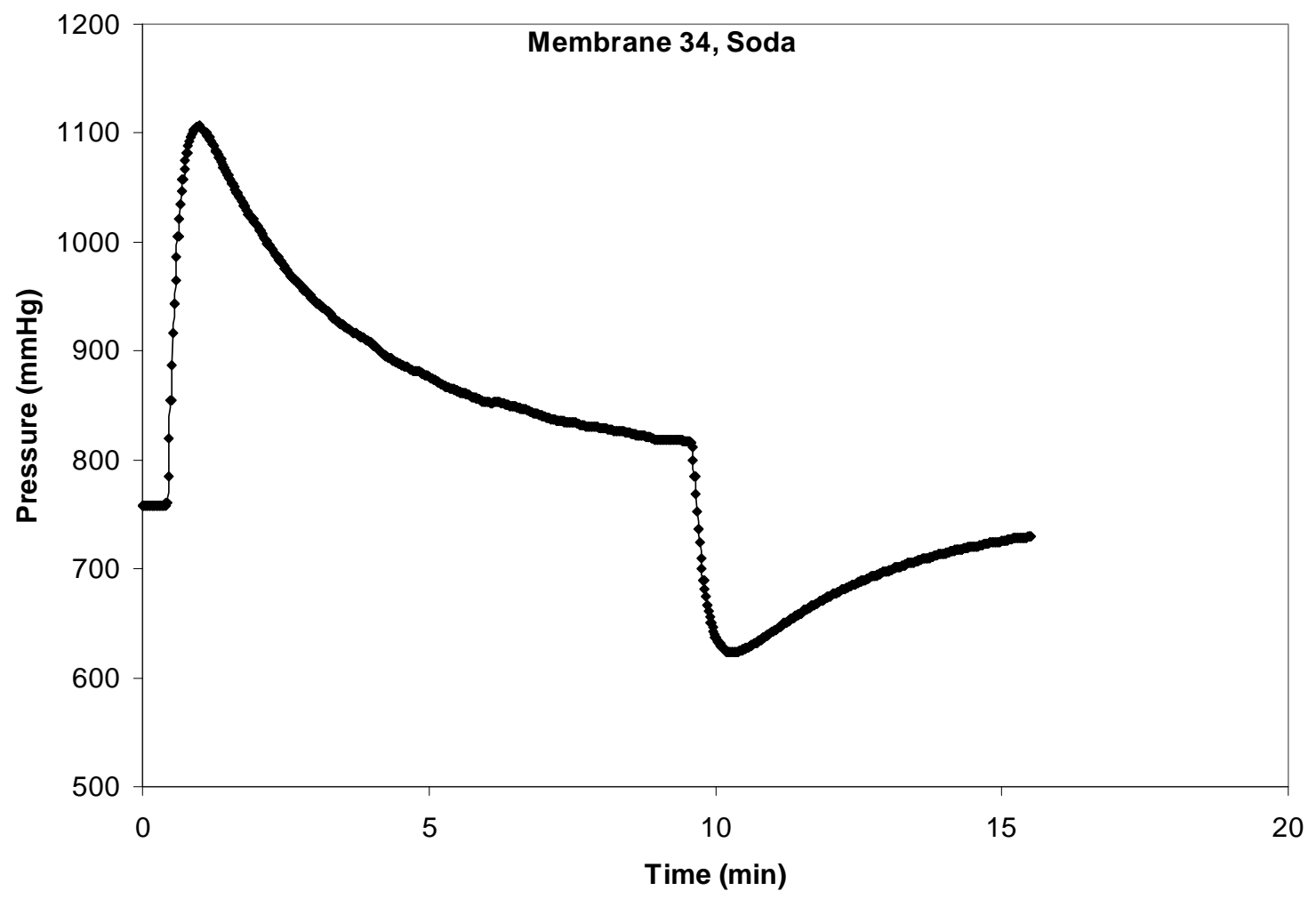




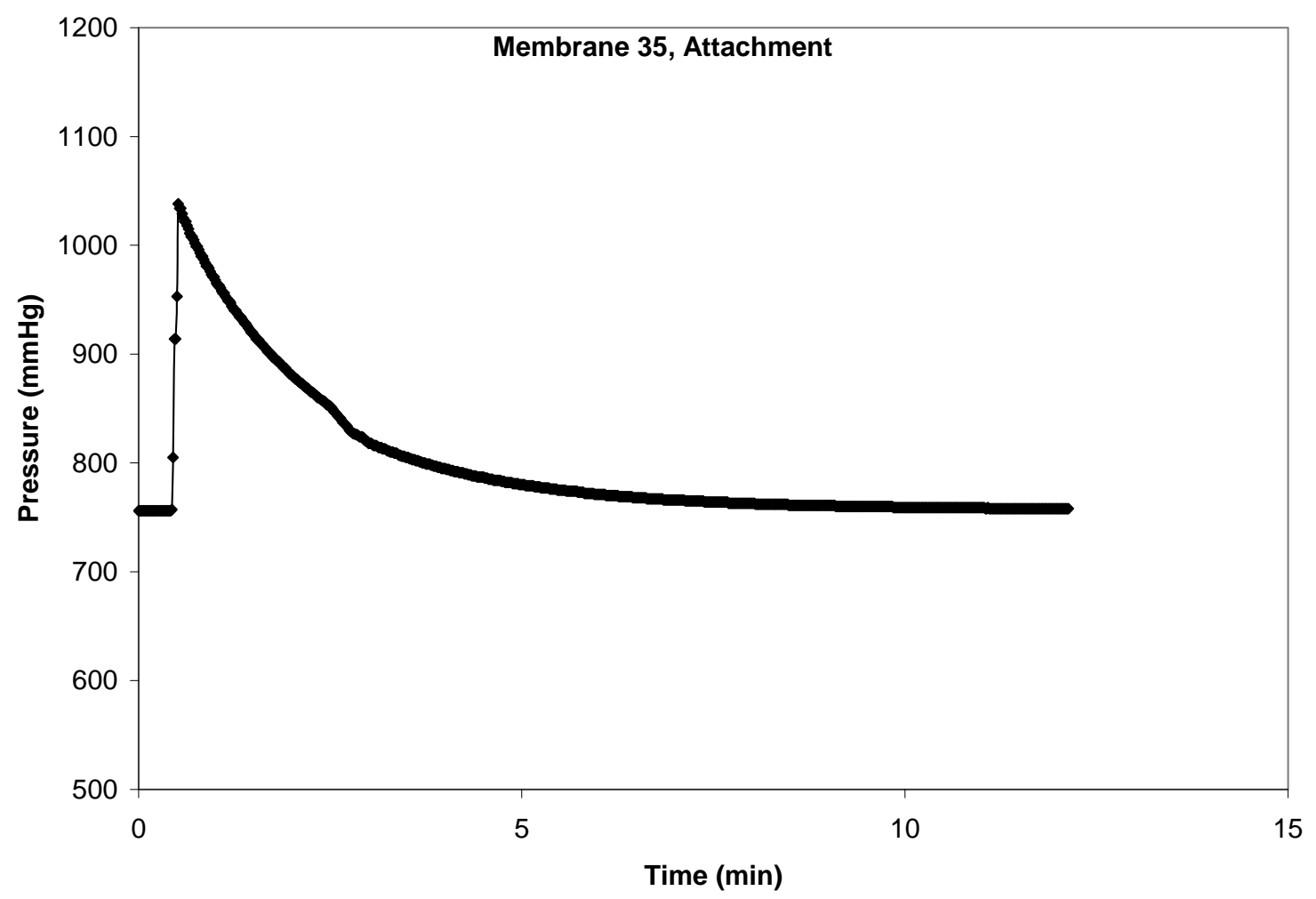

Membrane 35 was used at Multnomah Falls 3 hyporheic from 3/20/2008 to 4/3/2008 with MiniSonde 43656.

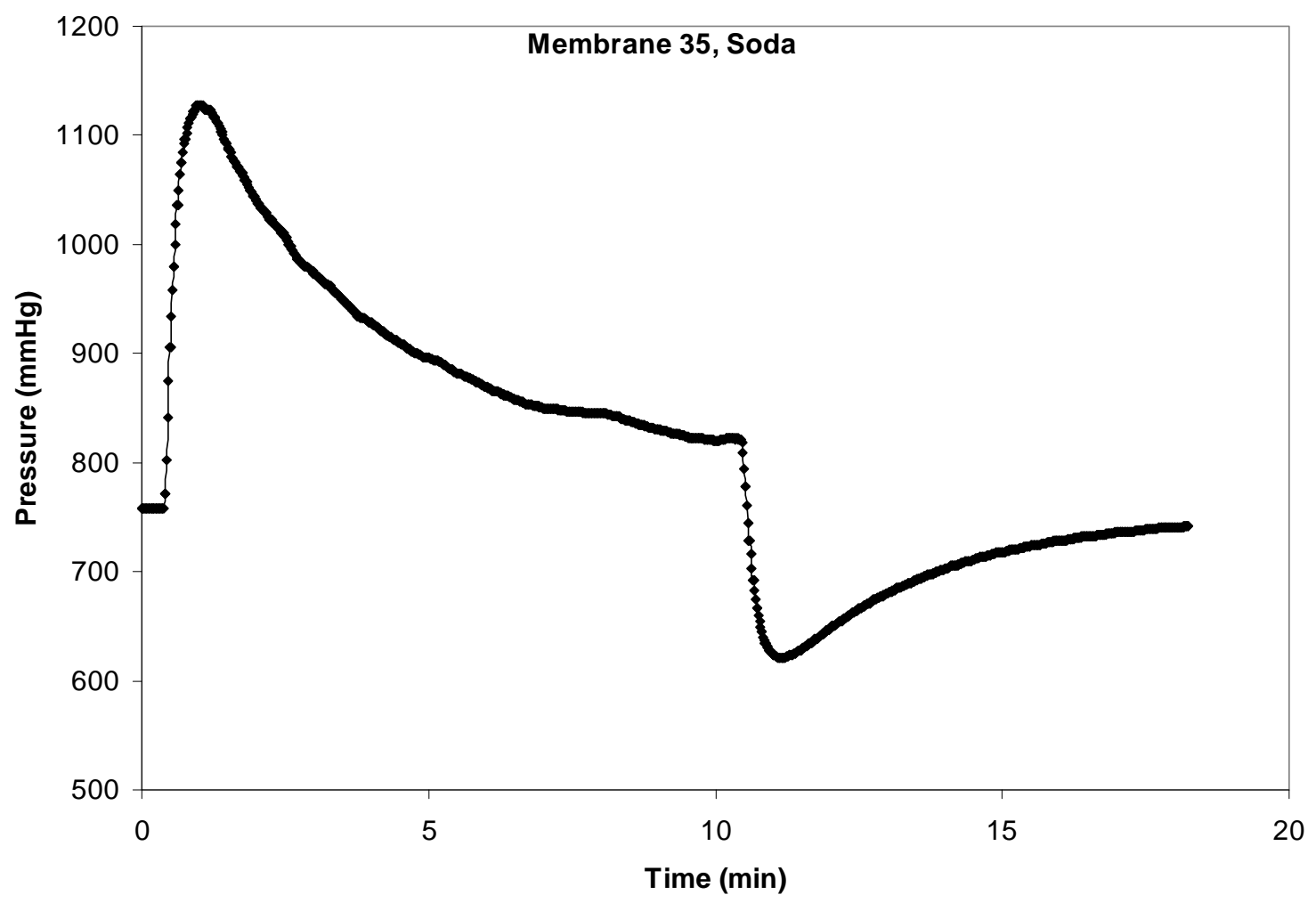




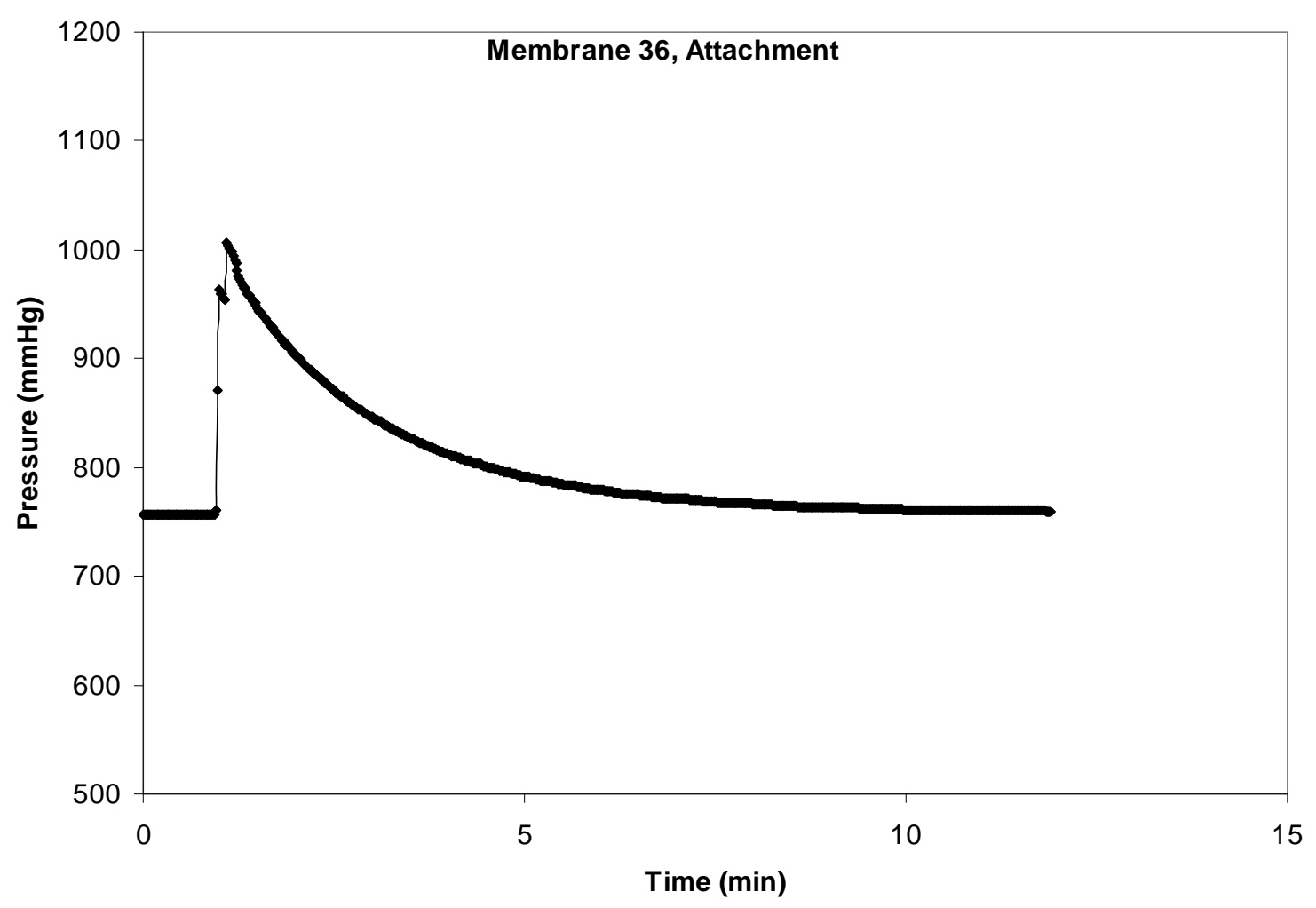

Membrane 36 was used at Ives 1 hyporheic from 3/20/2008 to 4/3/2008 with MiniSonde 43659.

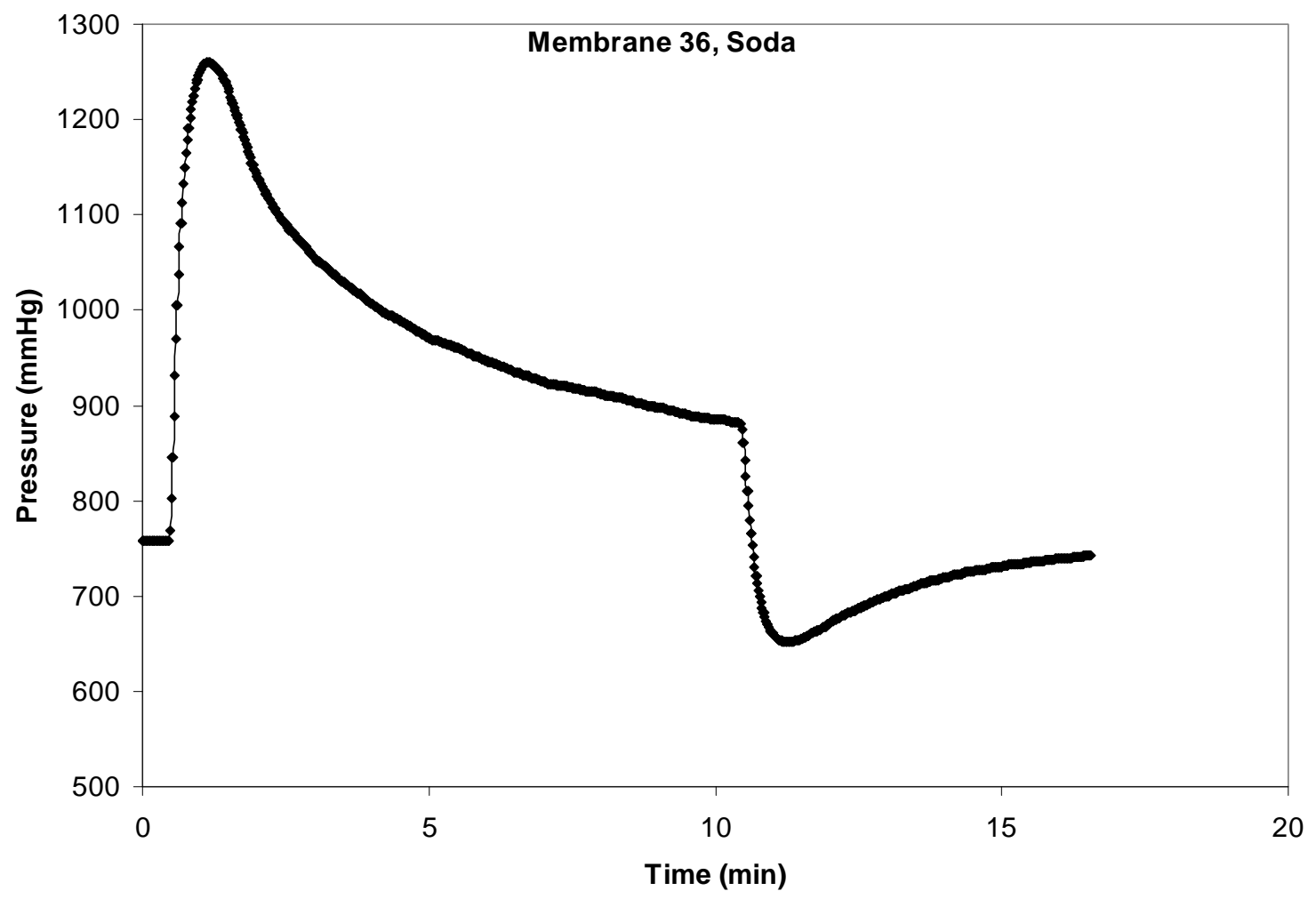




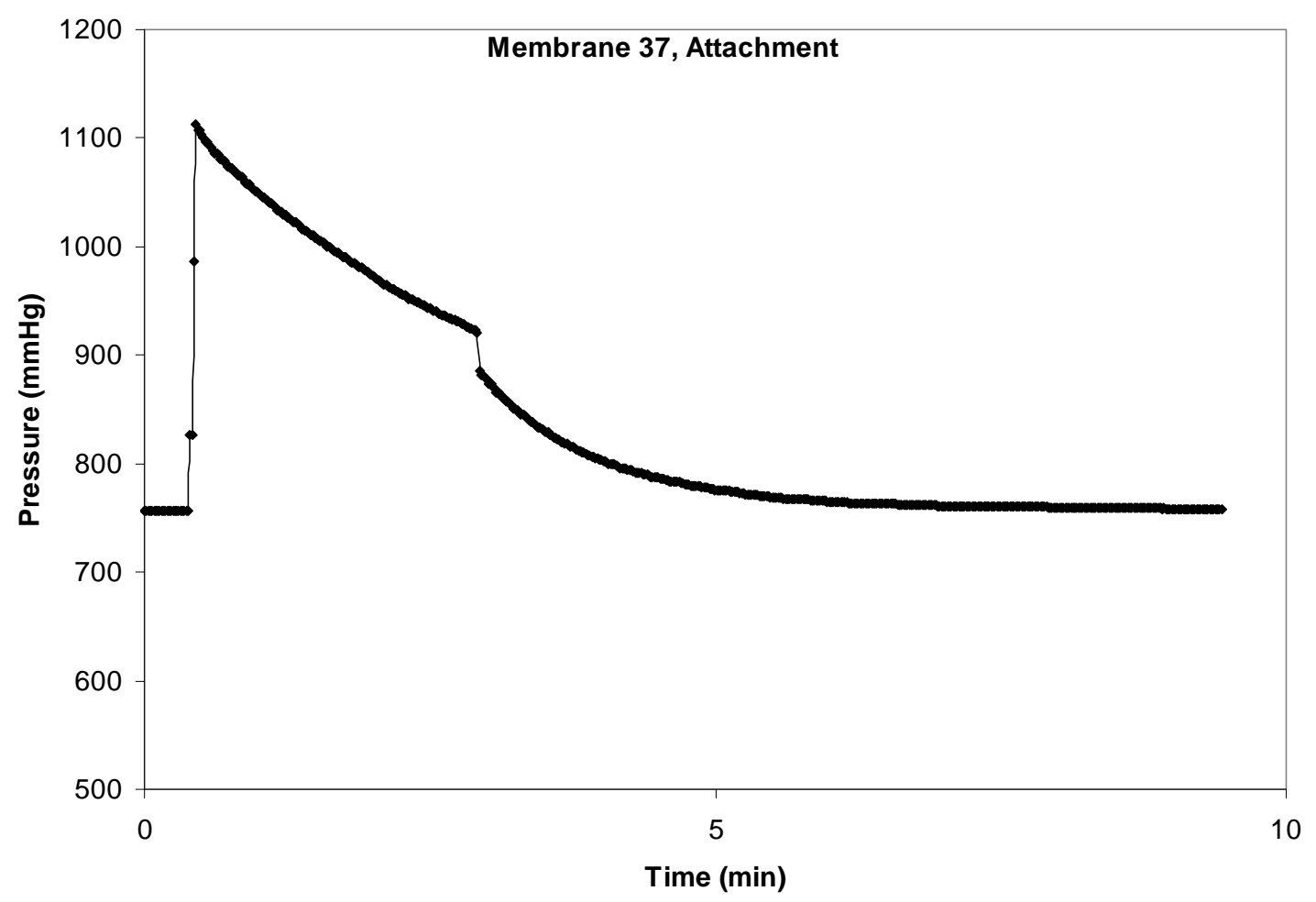

Membrane 37 was used at Ives 1 river from 3/20/2008 to 4/3/2008 with MiniSonde 43655. This membrane did not have a definitive "bad" test, but its side-by-side data was questionable also, so these data were thrown out.

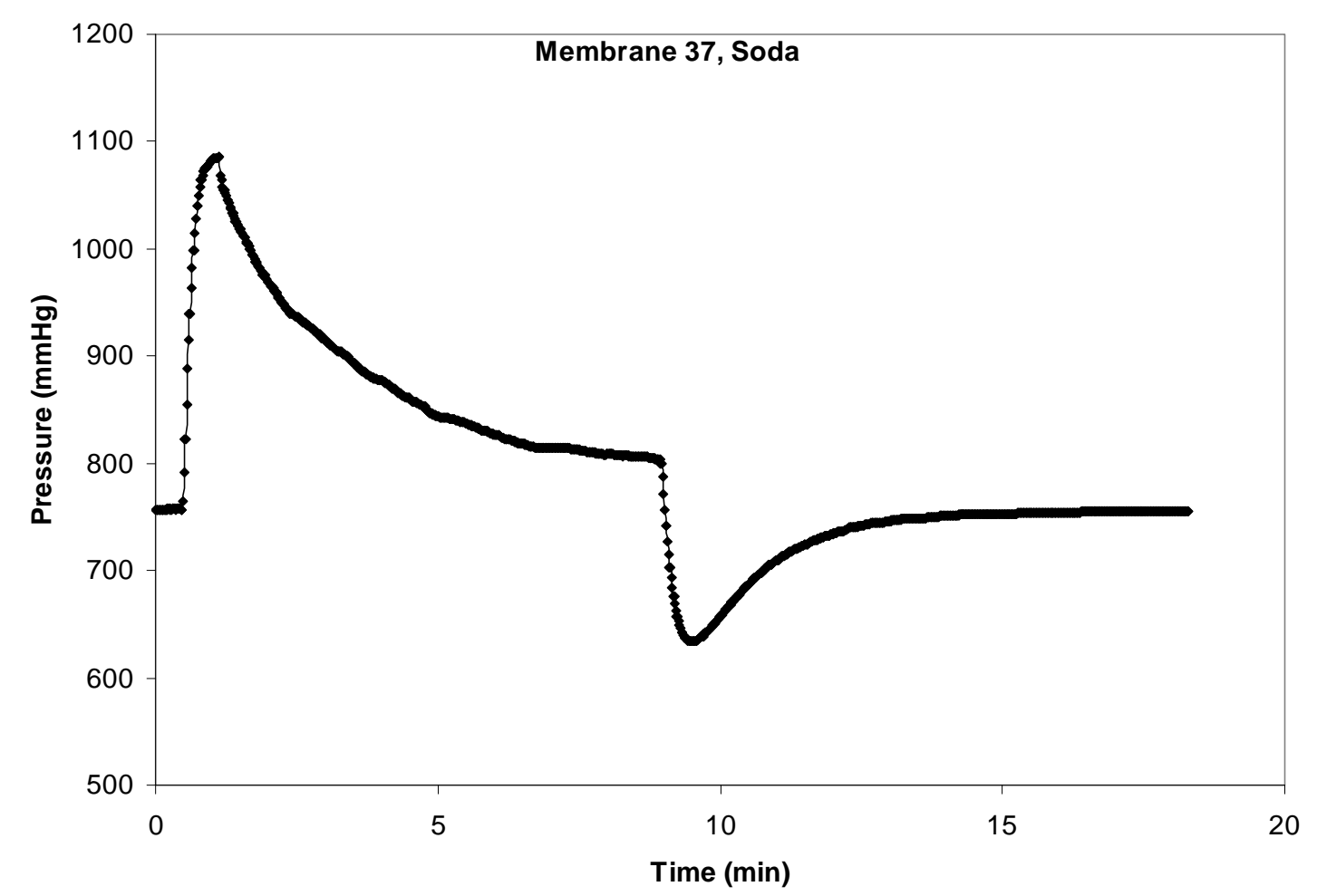




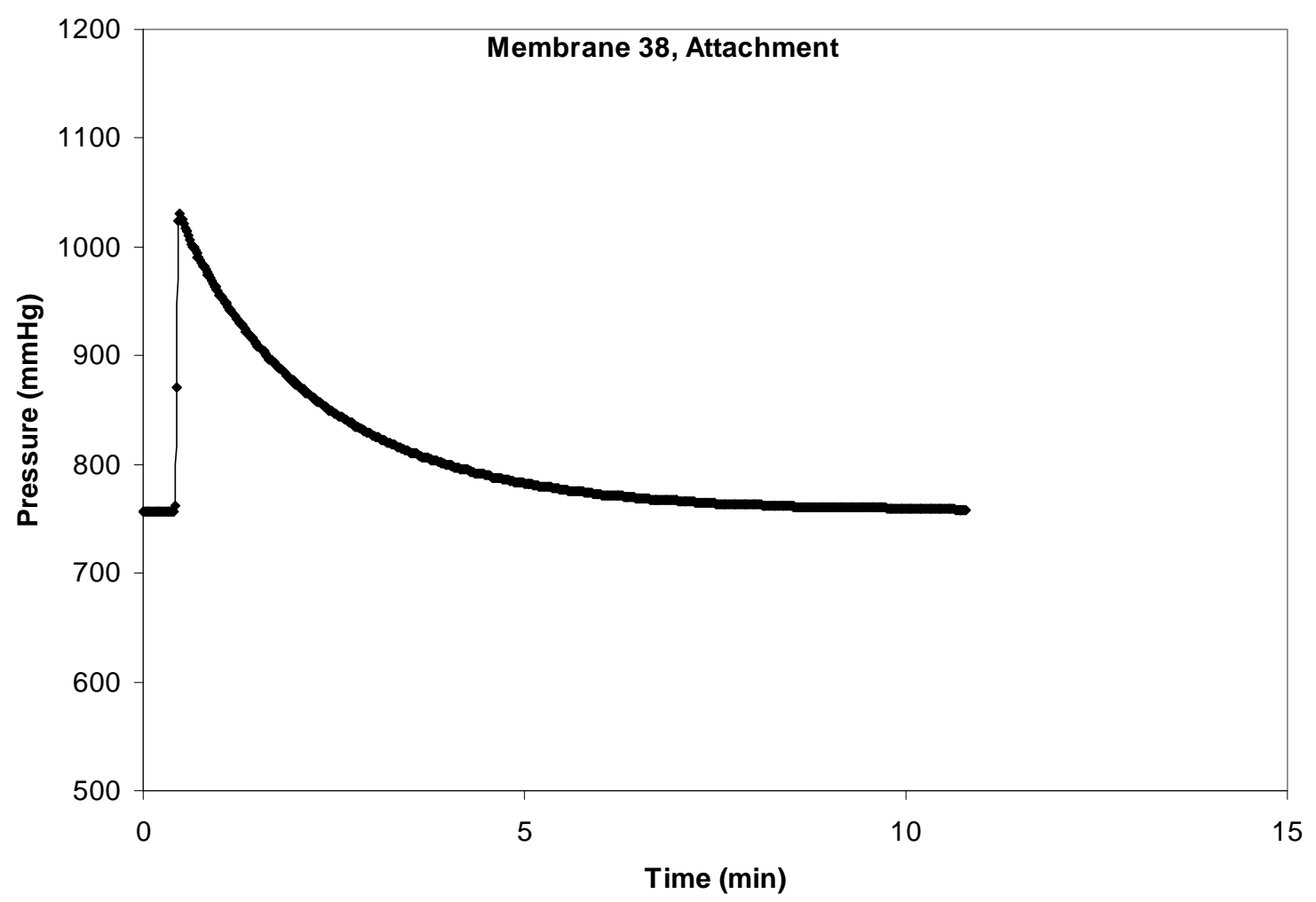

Membrane 38 was used at Ives 5 hyporheic from 3/20/2008 to 4/3/2008 with MiniSonde 45451.






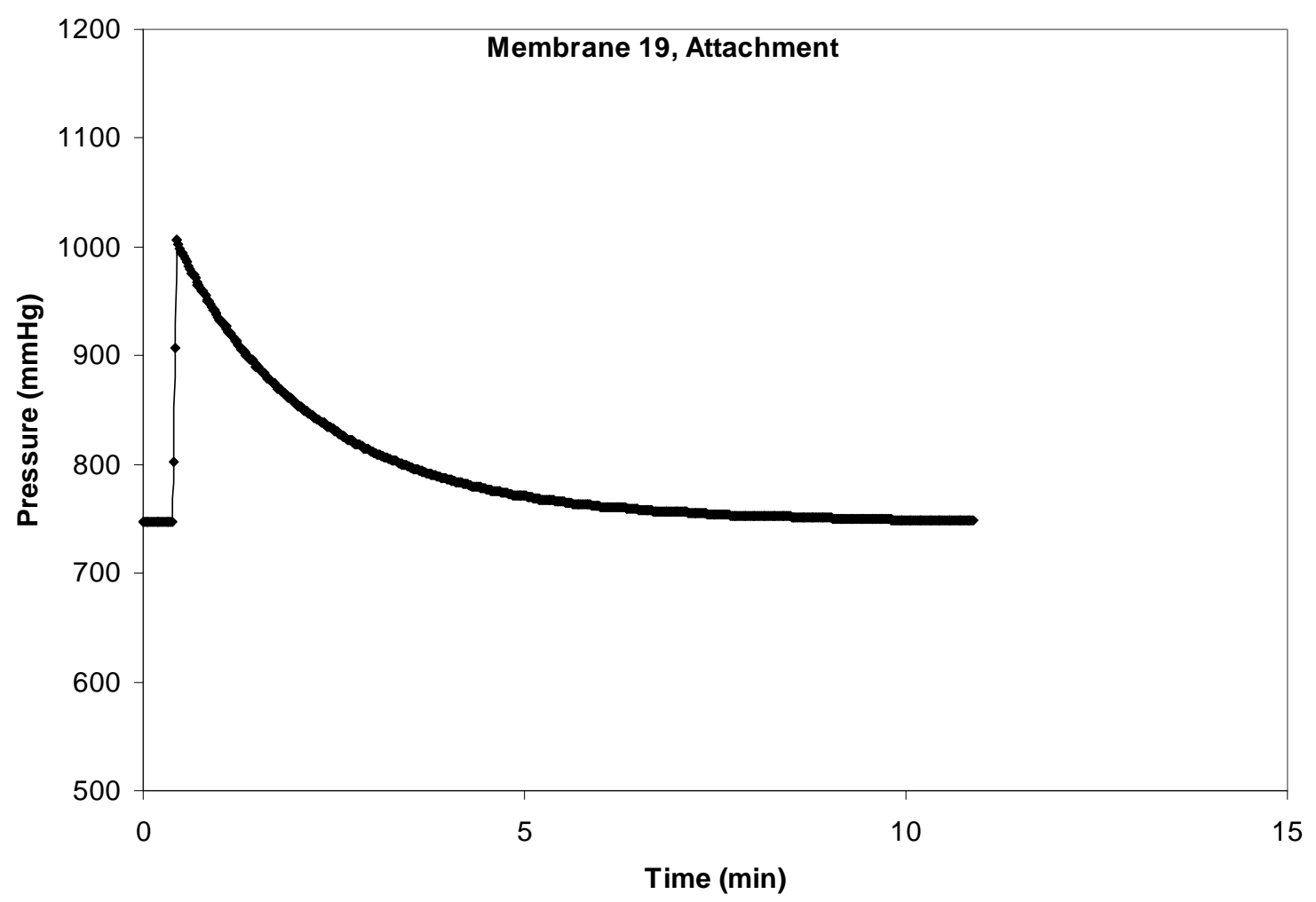

Membrane 19 was used as the control for the side-by-side after deployment 2 with MiniSonde 40347.

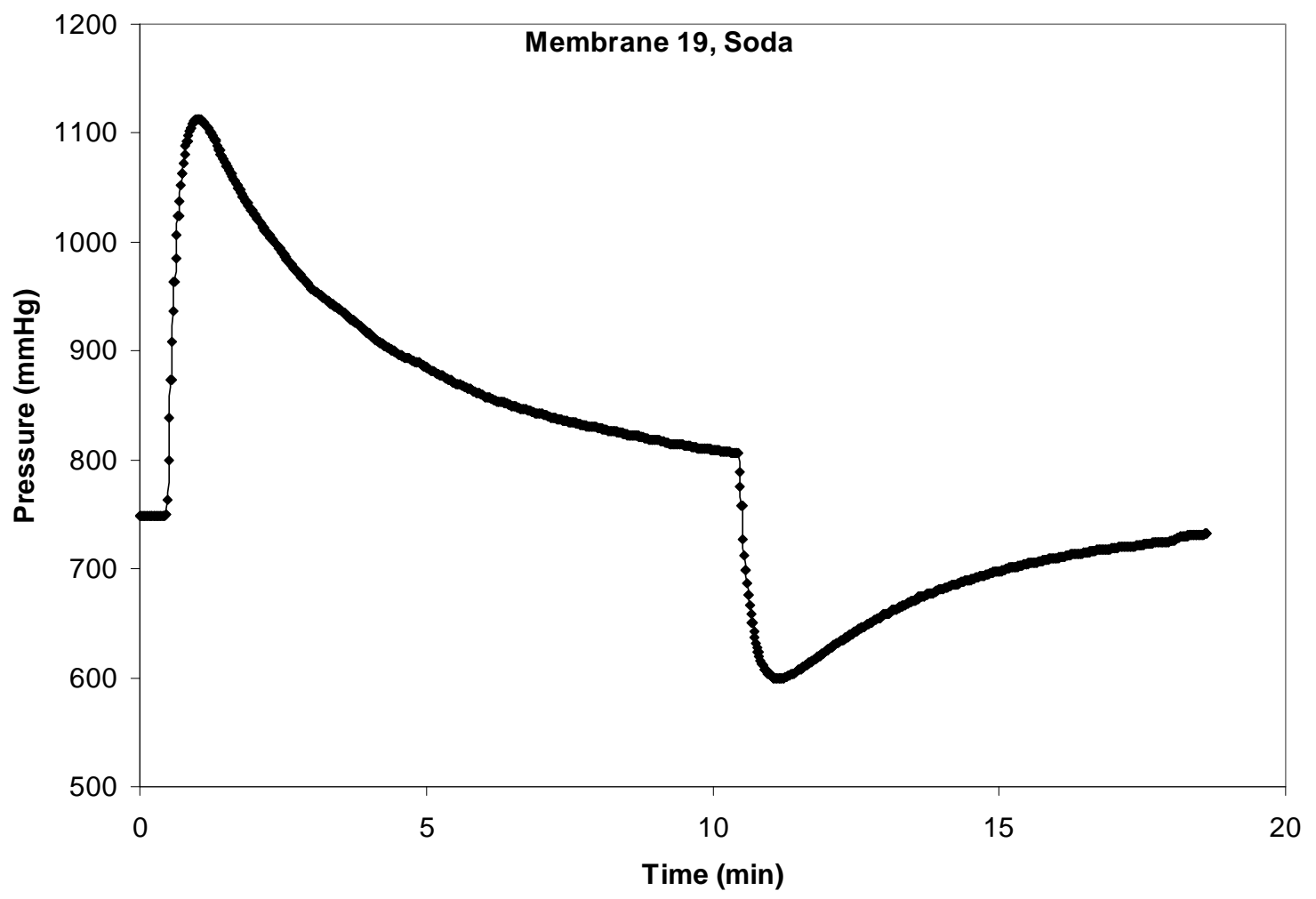




\section{Post Deployment 3}

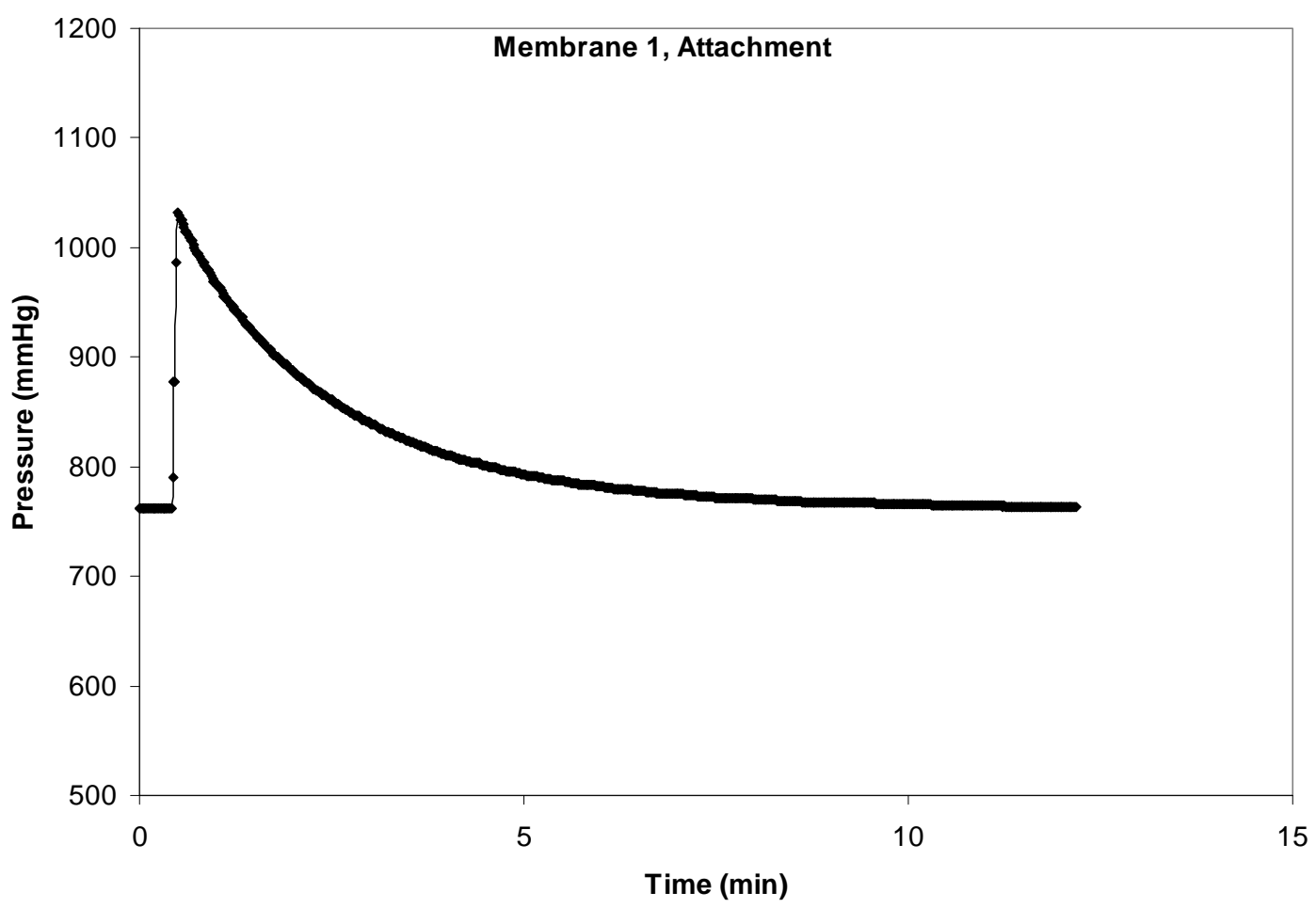

Membrane 1 was used at Multnomah Falls 1 hyporheic from 4/3/2008 to 4/15/2008 with MiniSonde 44945.

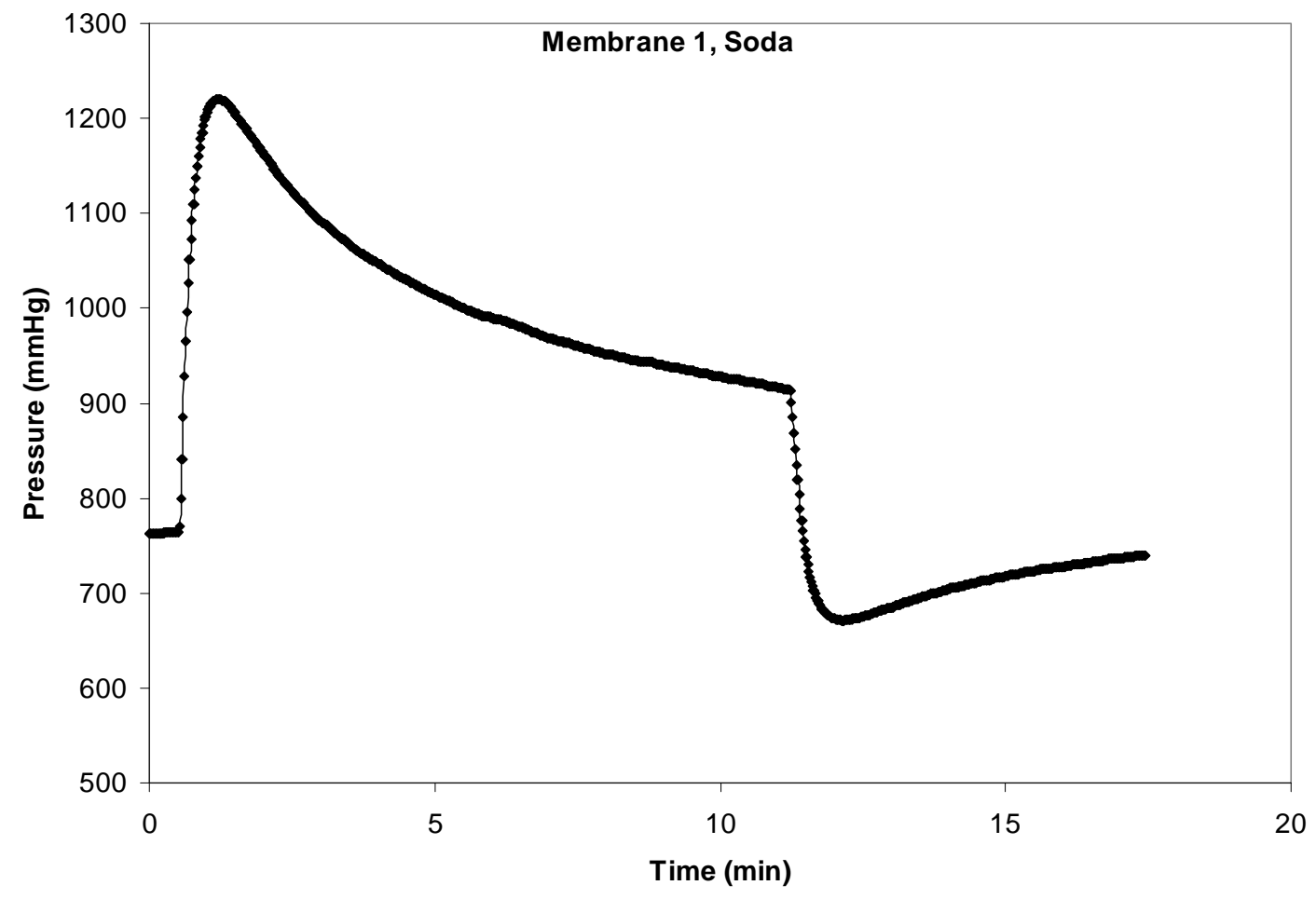




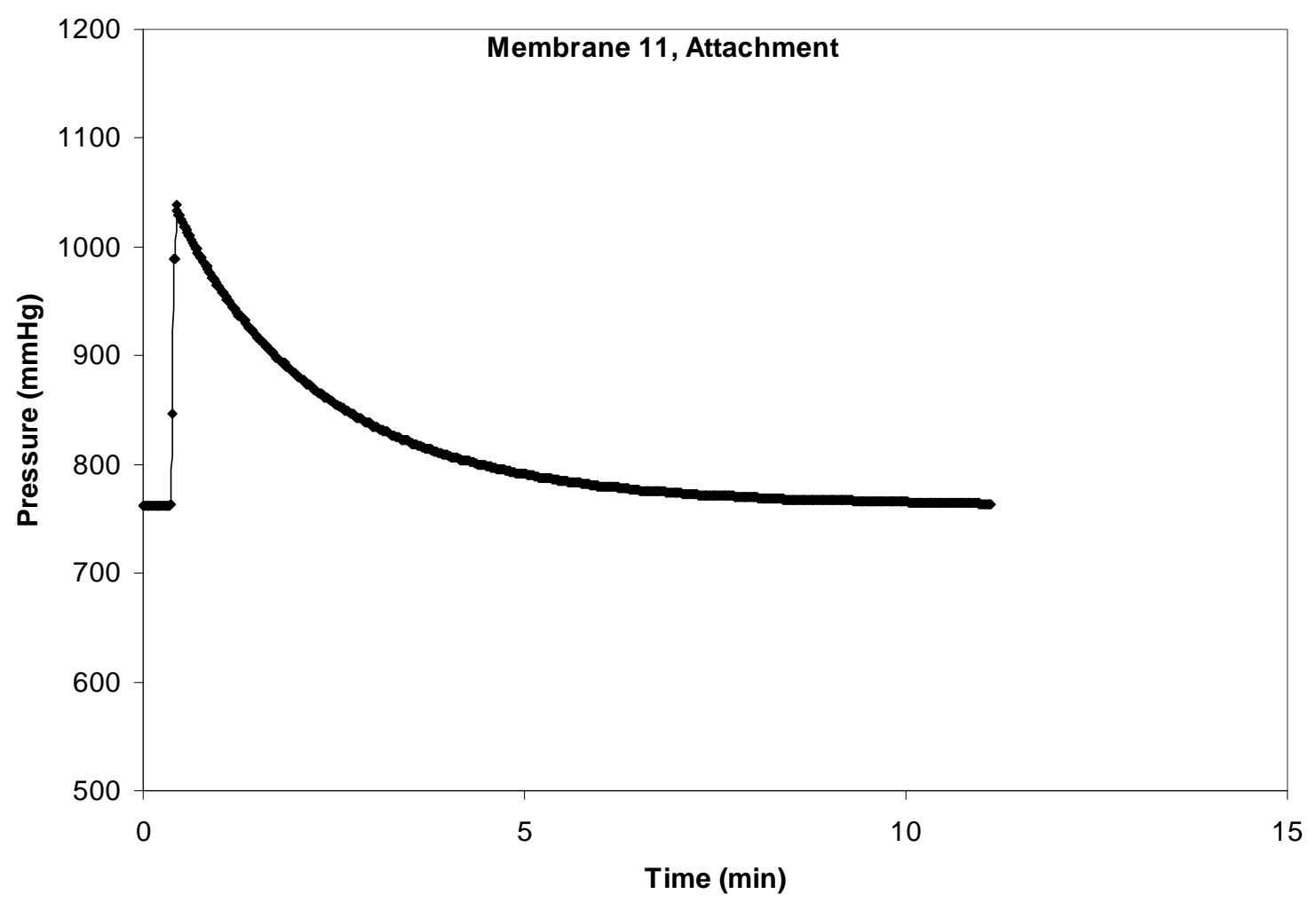

Membrane 11 was used at Multnomah Falls 1 river from 4/3/2008 to 4/15/2008 with MiniSonde 44927.

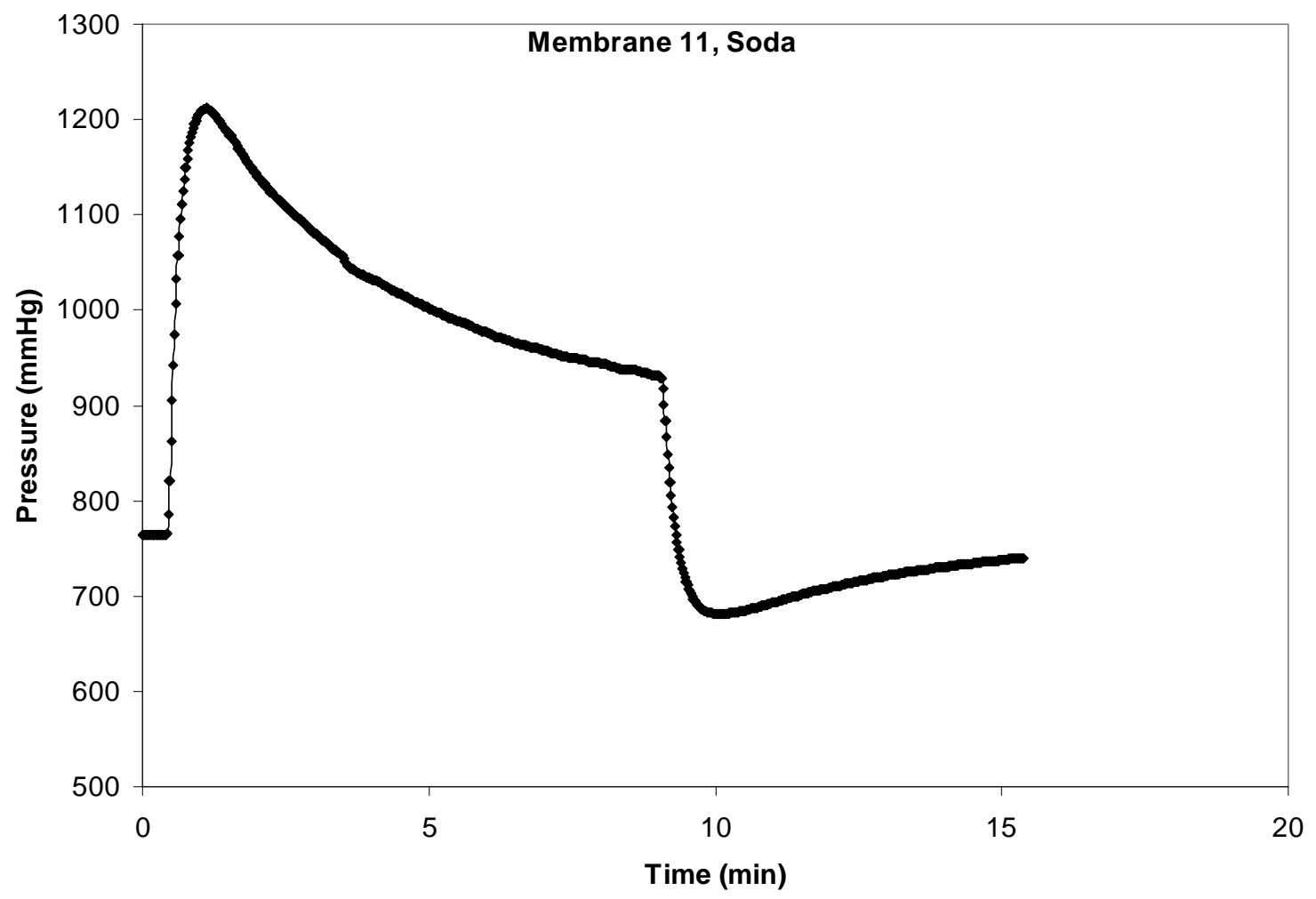




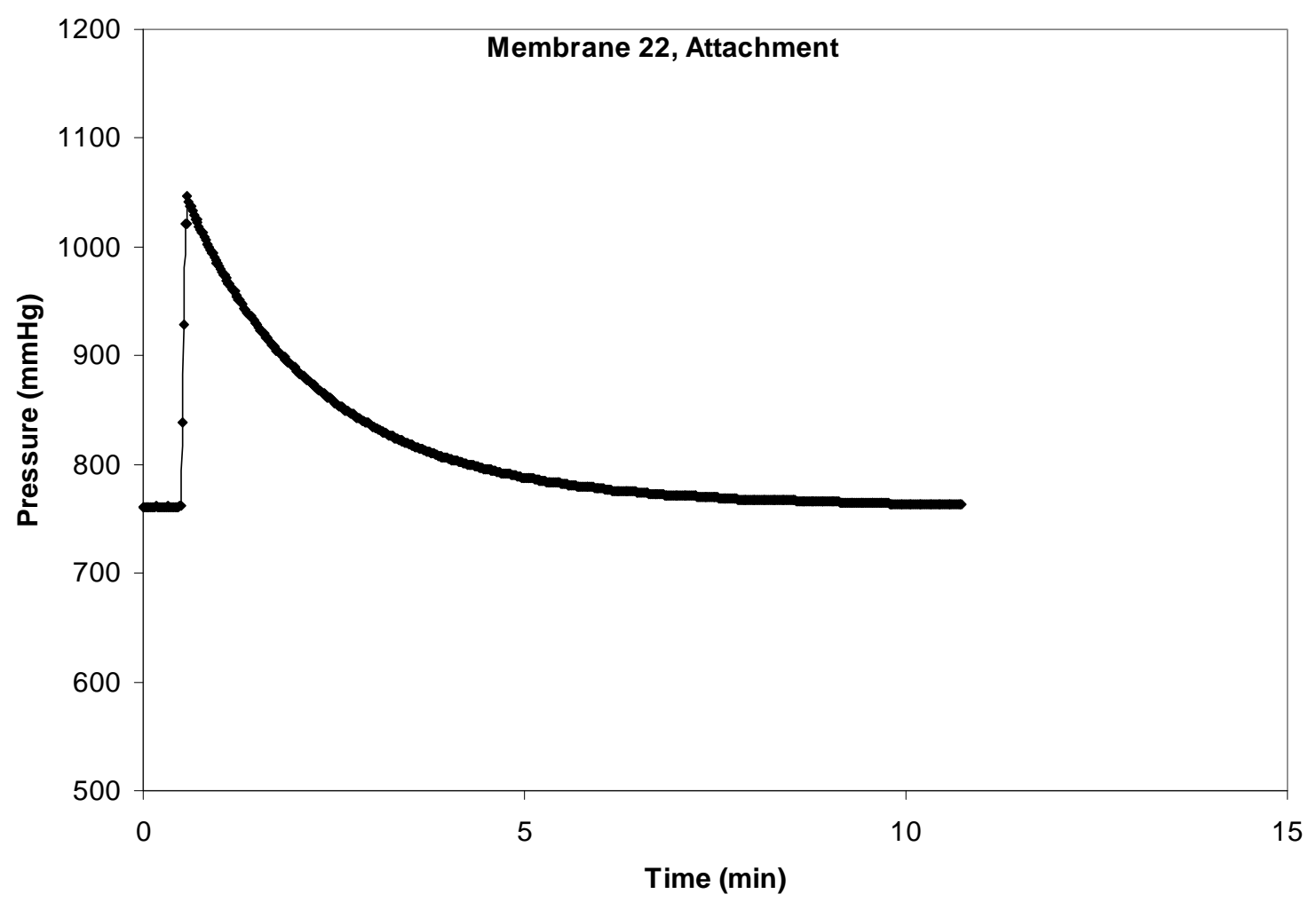

Membrane 22 was used at Ives 5 hyporheic from 4/3/2008 to 4/15/2008 with MiniSonde 45451.

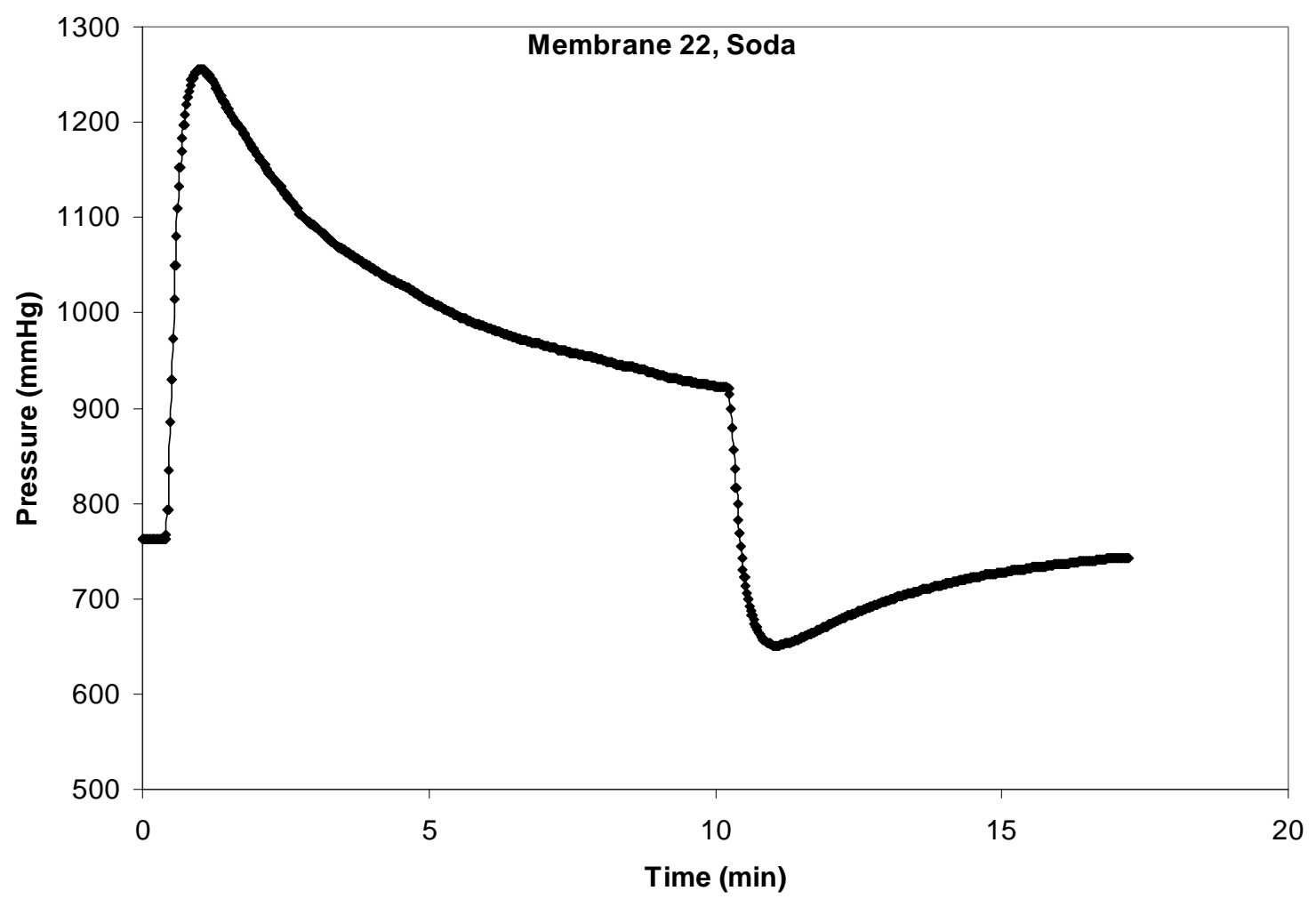




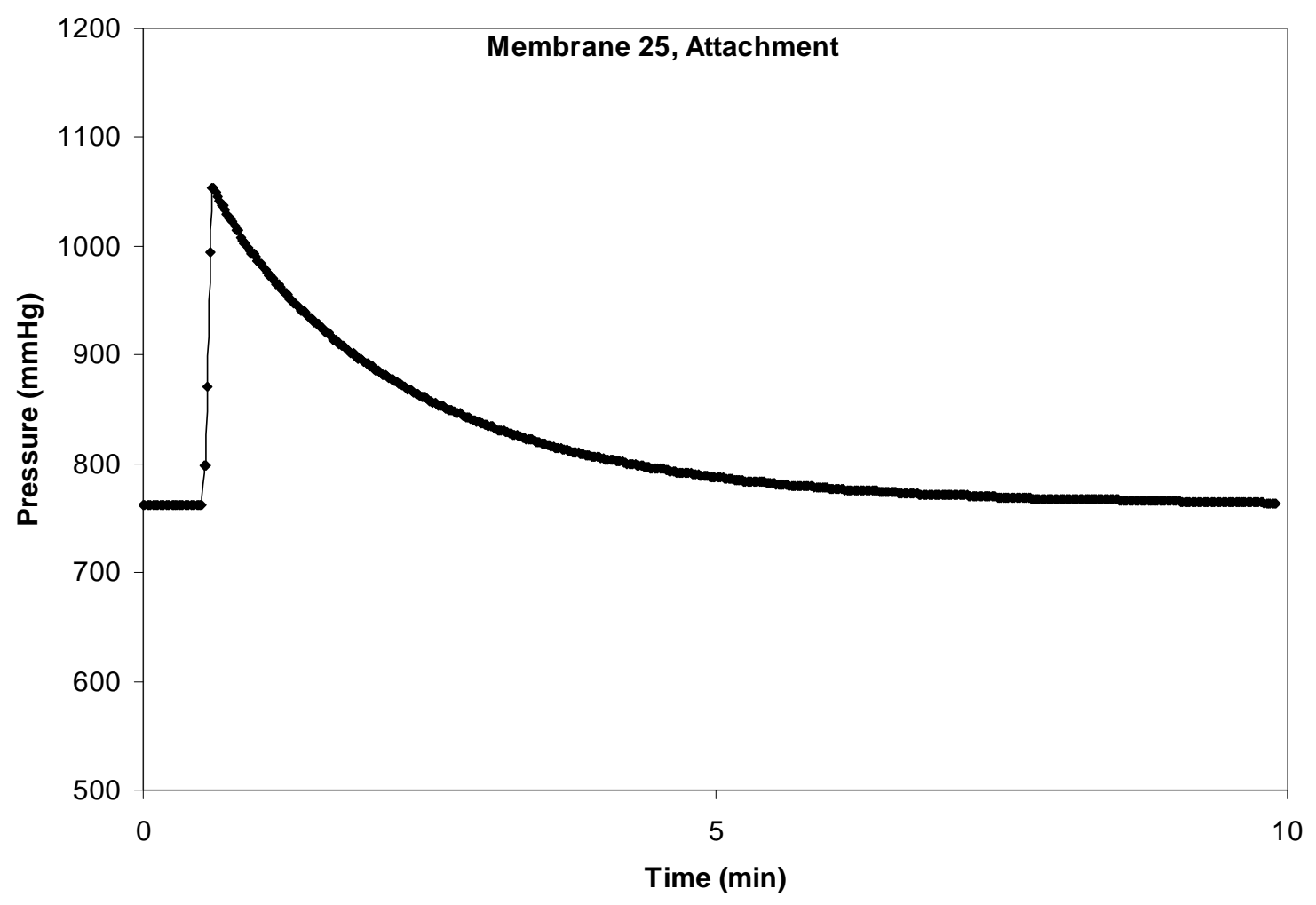

Membrane 25 was used at Ives 2 hyporheic from 4/3/2008 to 4/15/2008 with MiniSonde 44947.

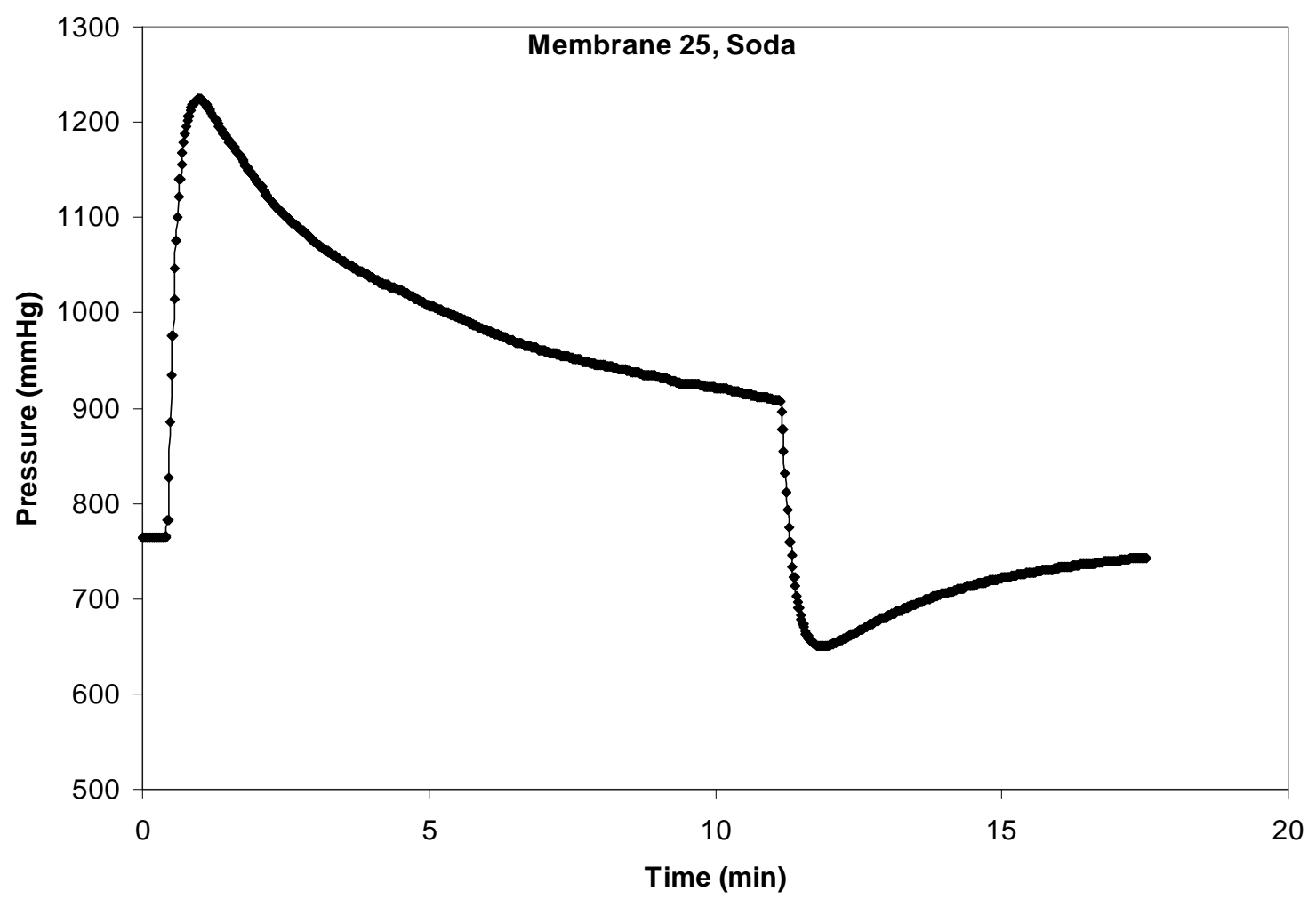




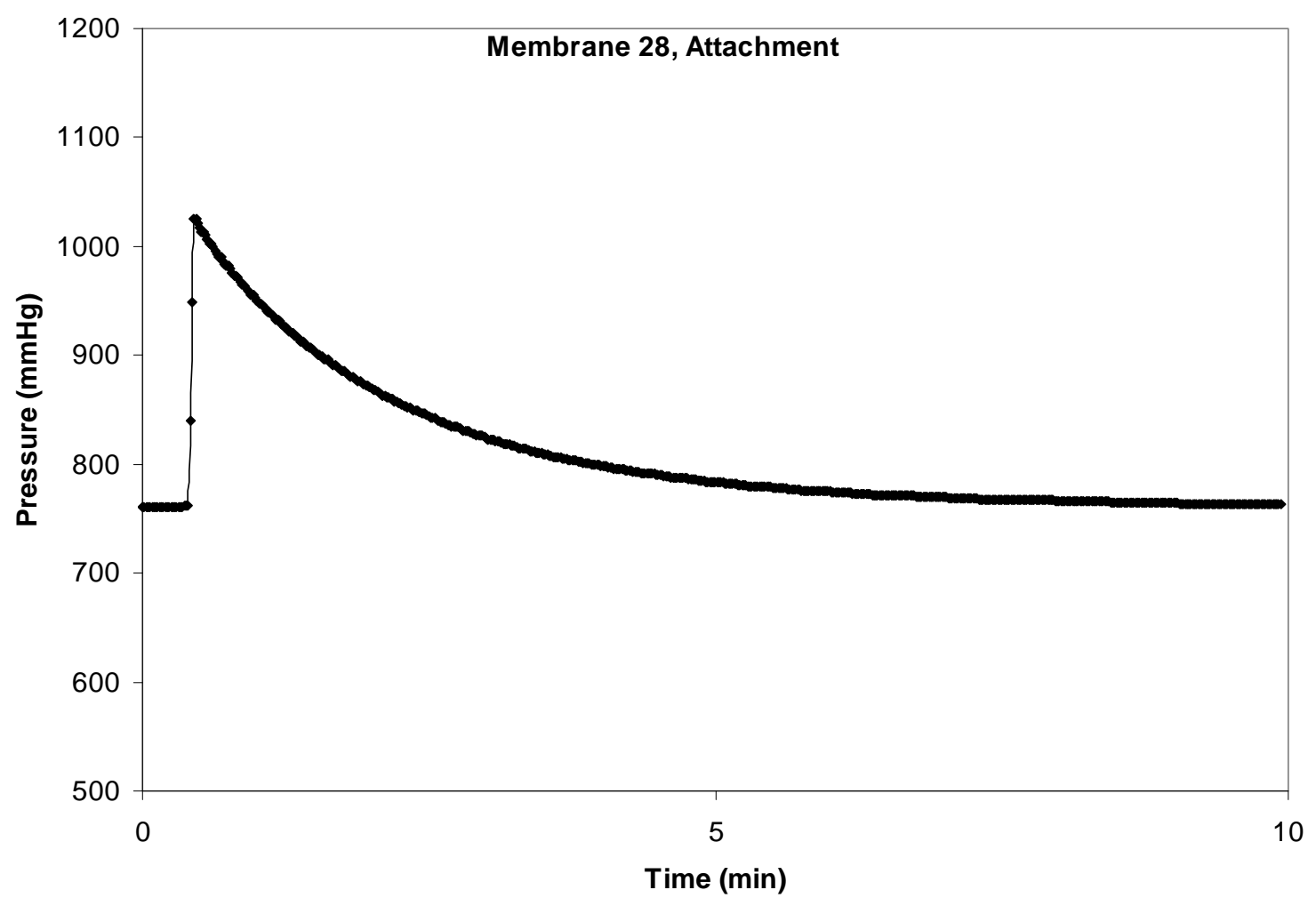

Membrane 28 was used at Ives 2 river from 4/3/2008 to 4/15/2008 with MiniSonde 44946.

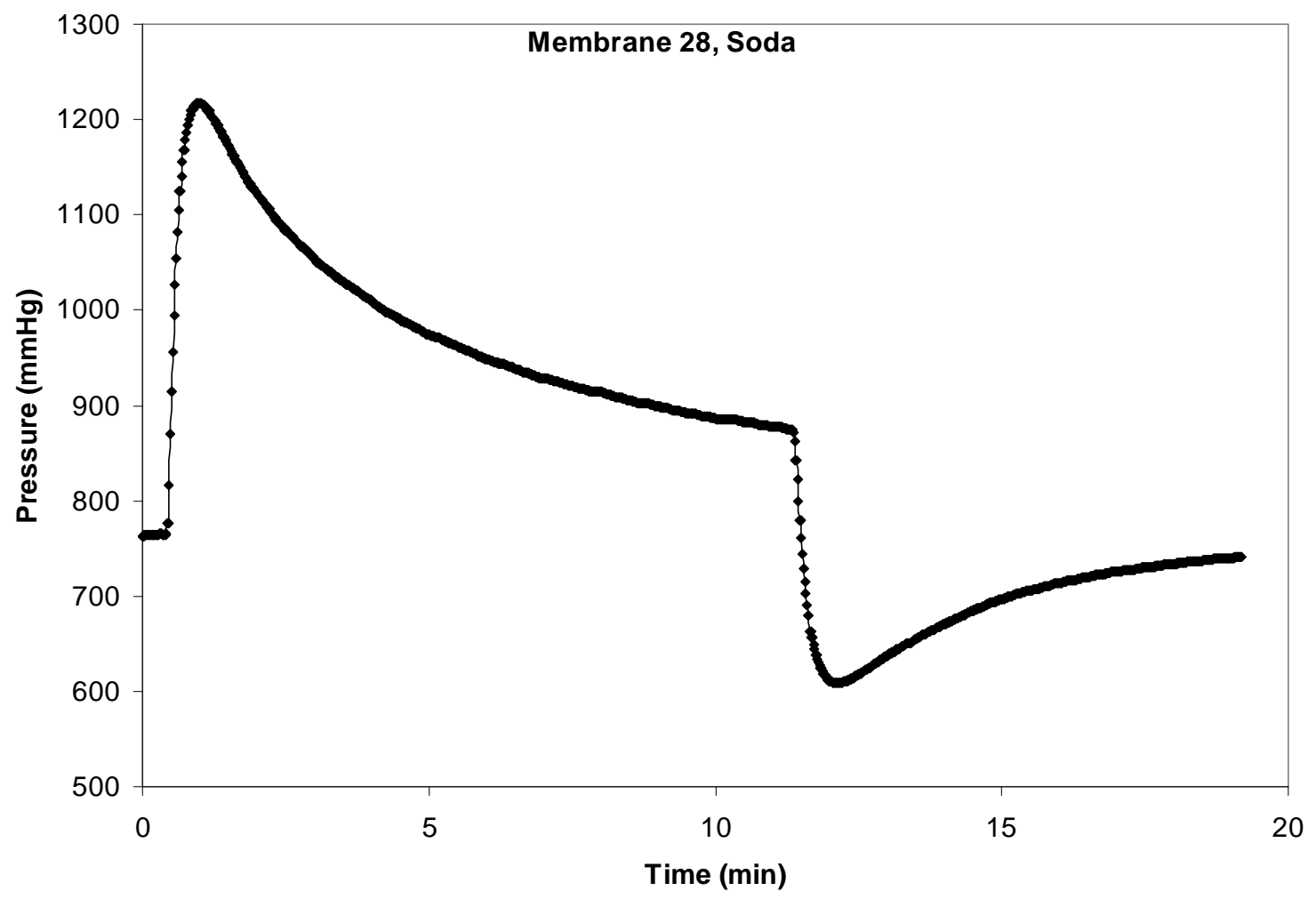




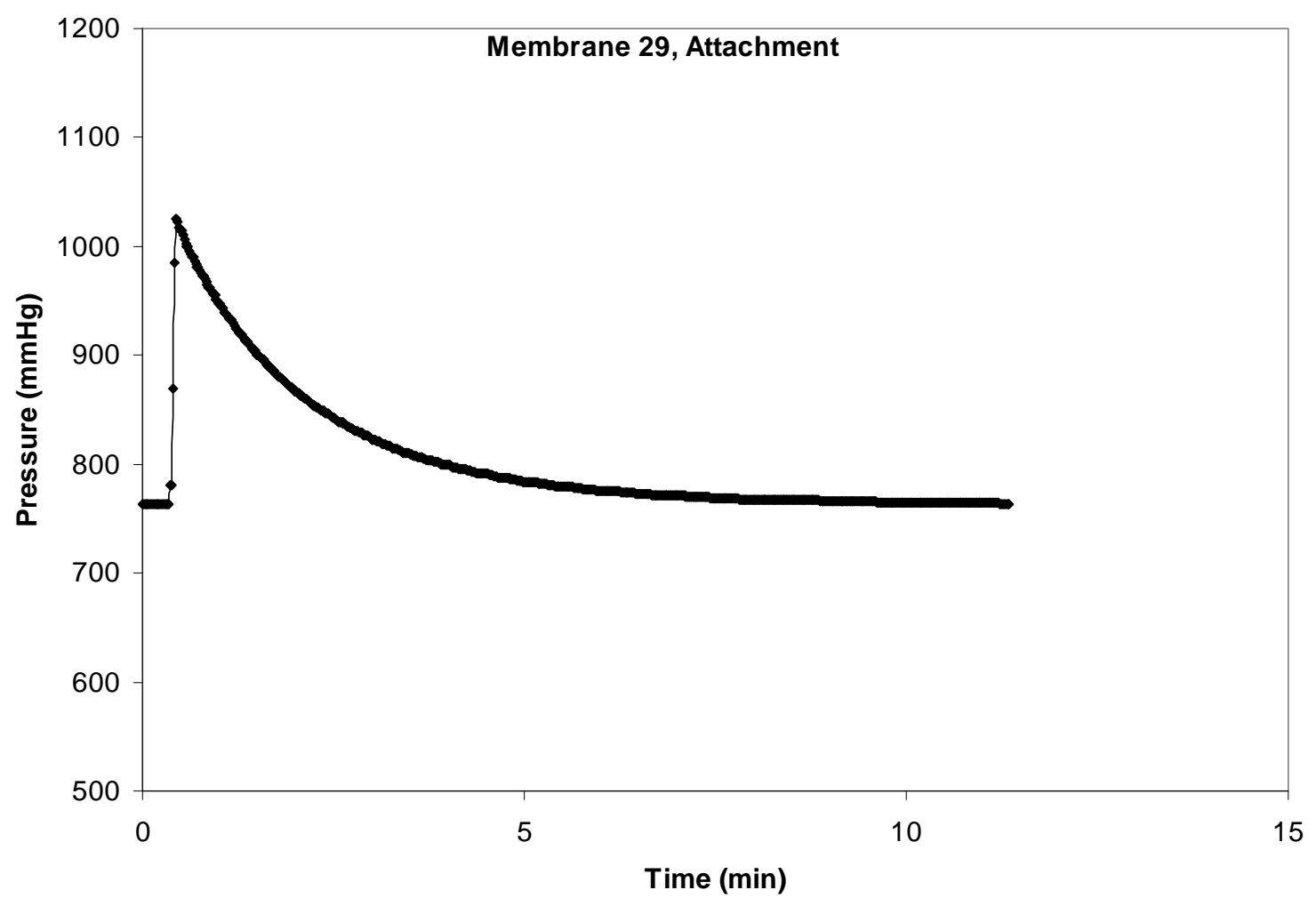

Membrane 29 was used at Multnomah Falls 3 hyporheic from 4/3/2008 to 4/15/2008 with MiniSonde 43656.

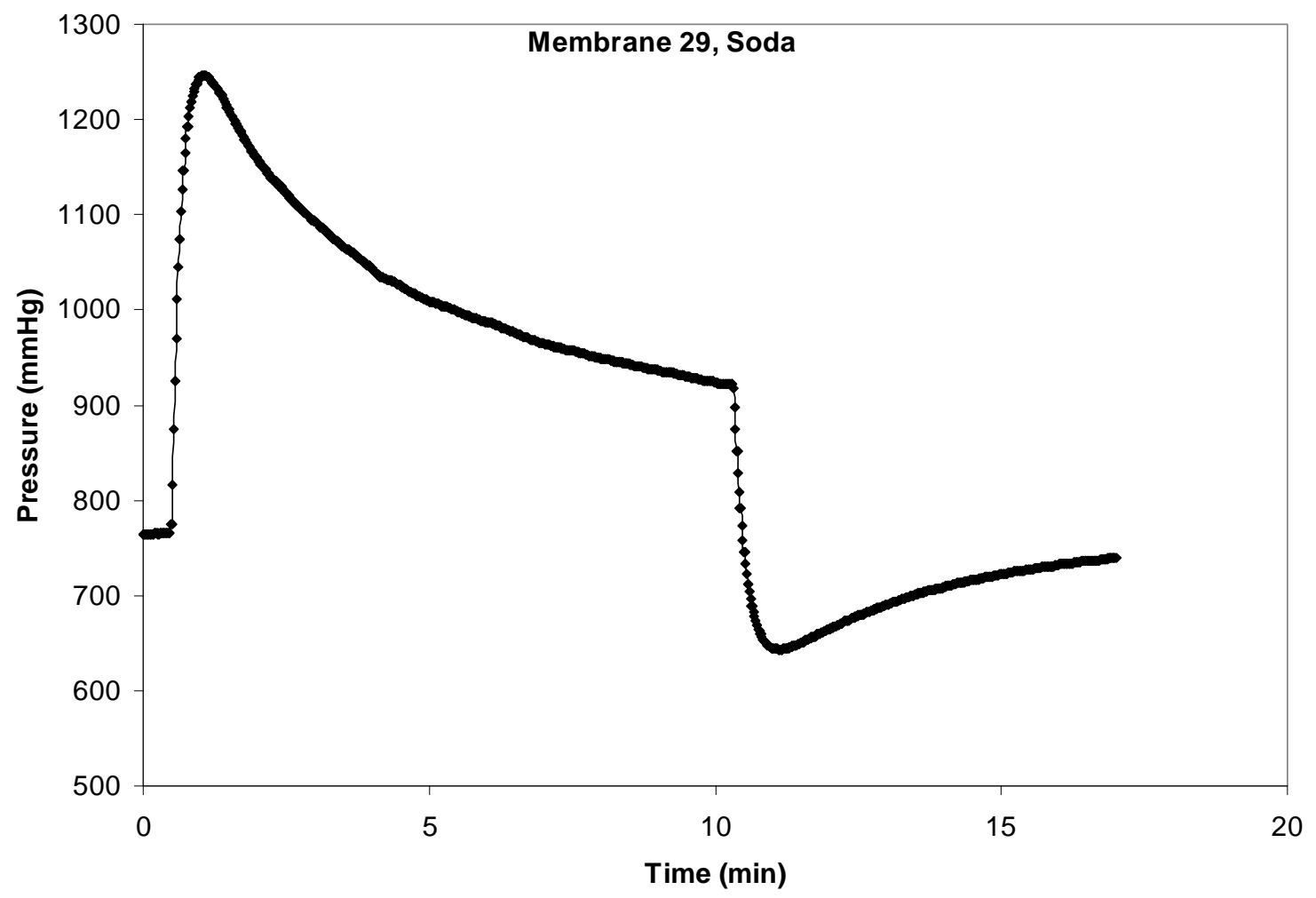




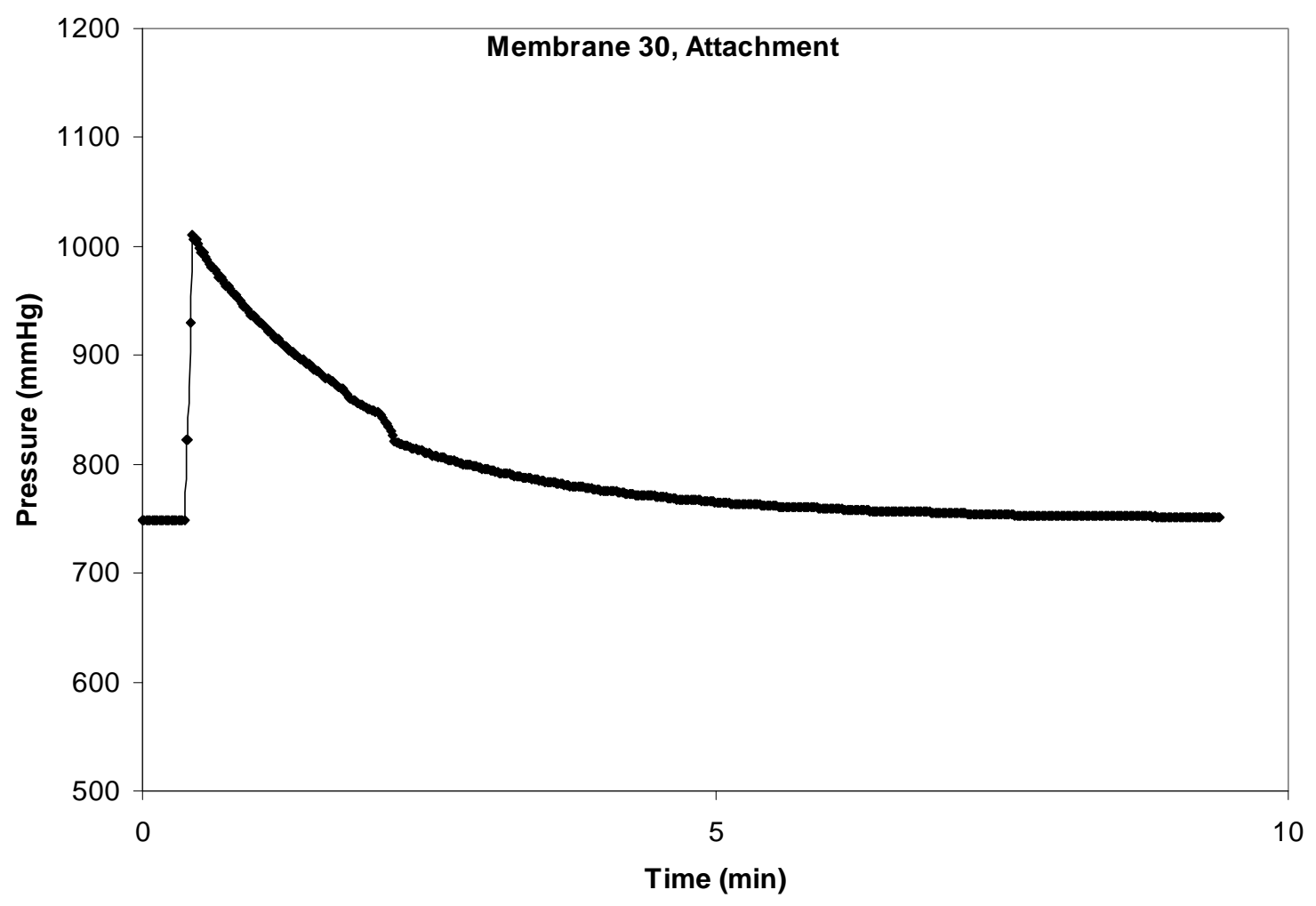

Membrane 30 was used at Ives 5 river from 4/3/2008 to 4/15/2008 with MiniSonde 43639.

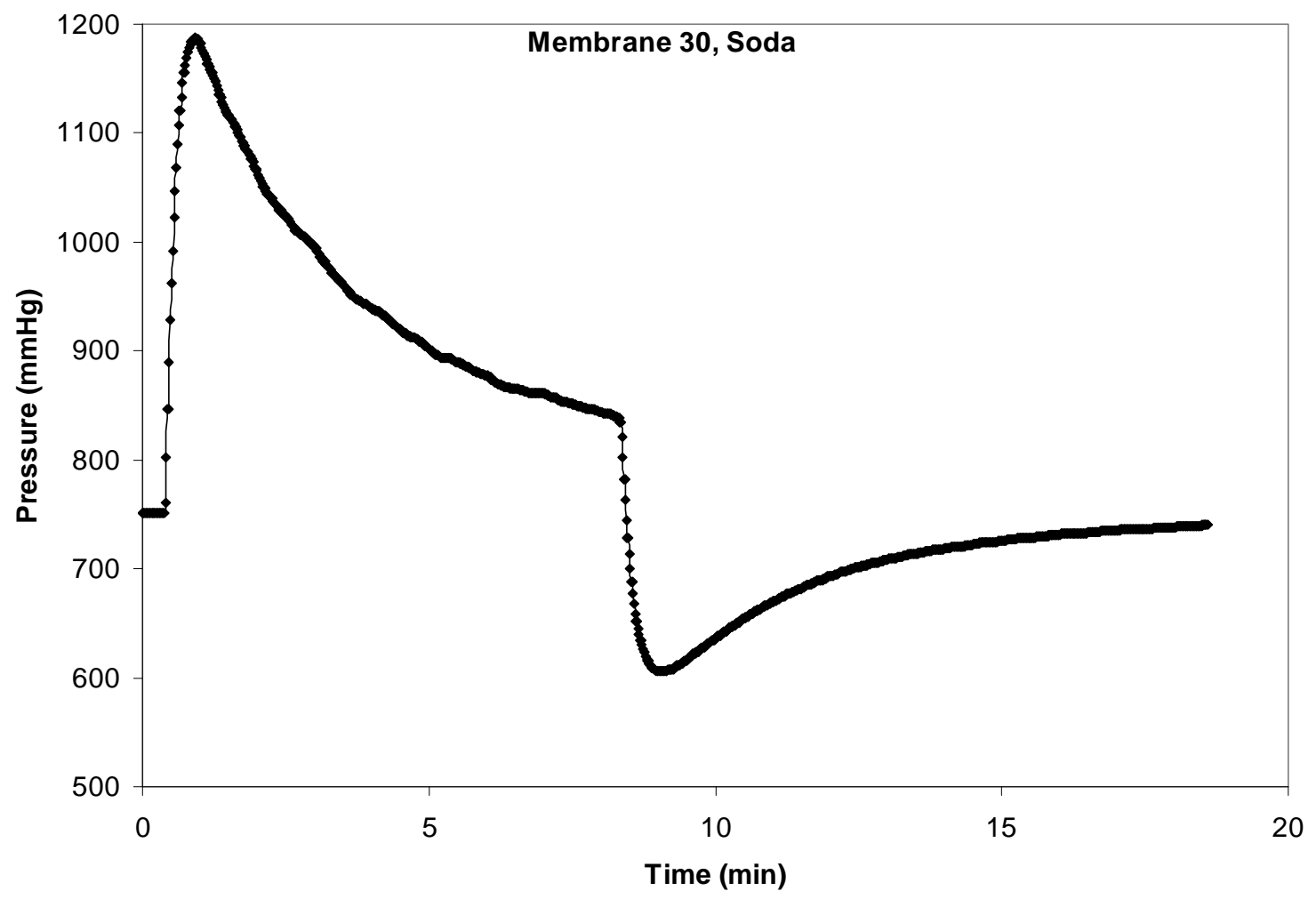




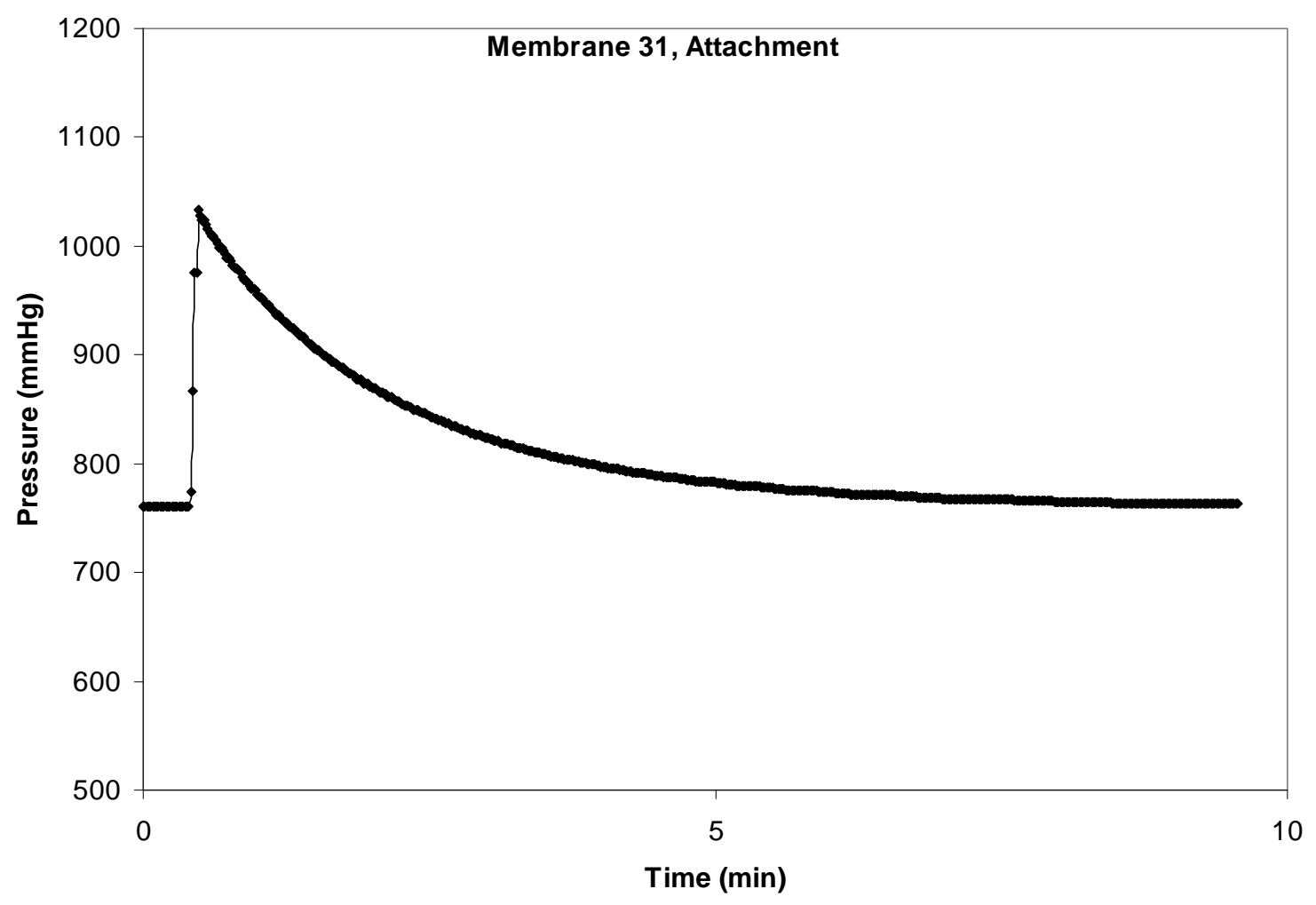

Membrane 31 was used at Ives 1 river from 4/3/2008 to 4/15/2008 with MiniSonde 43655.

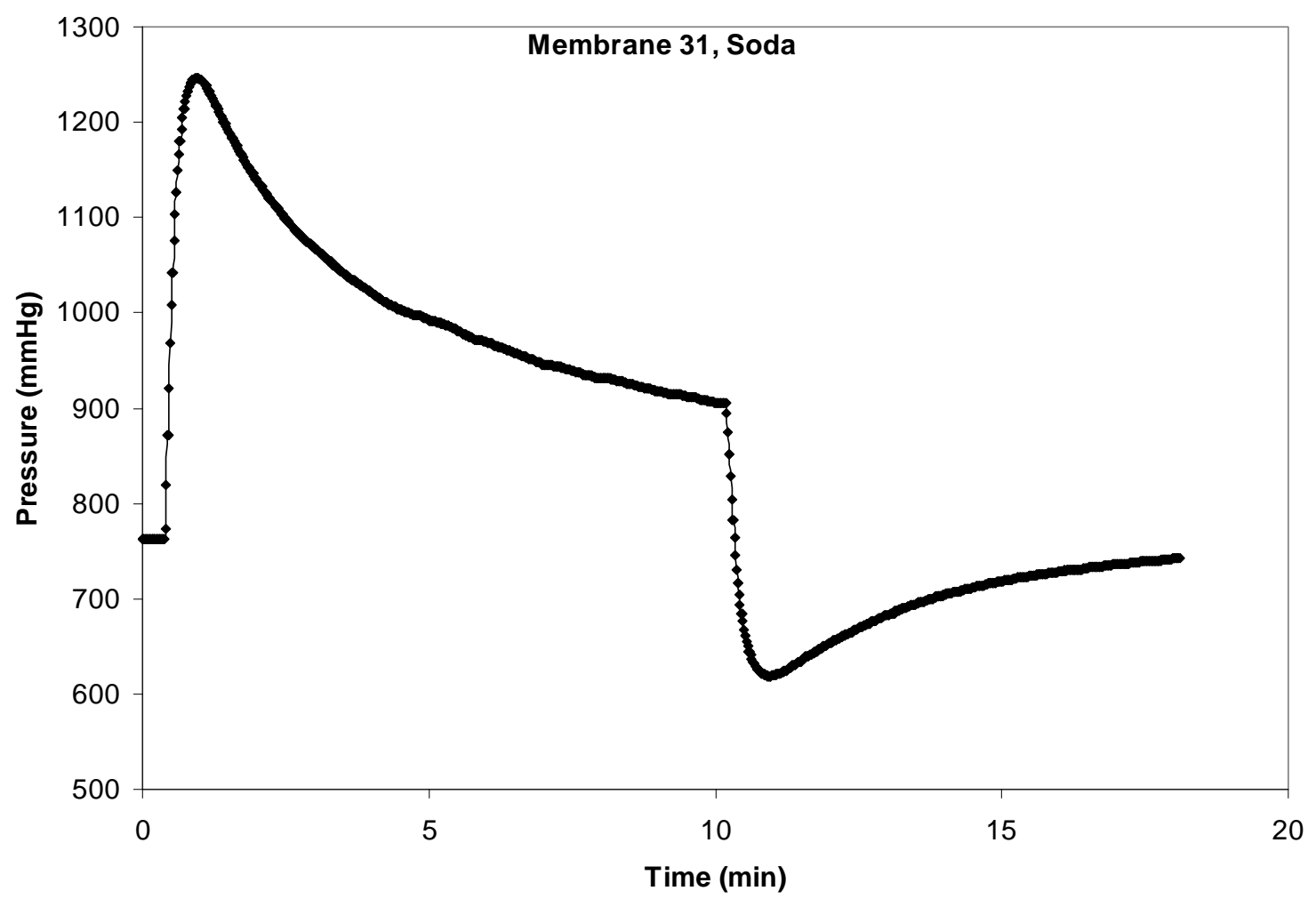






Membrane 32 was used at Ives 1 hyporheic from 4/3/2008 to 4/15/2008 with MiniSonde 43659.

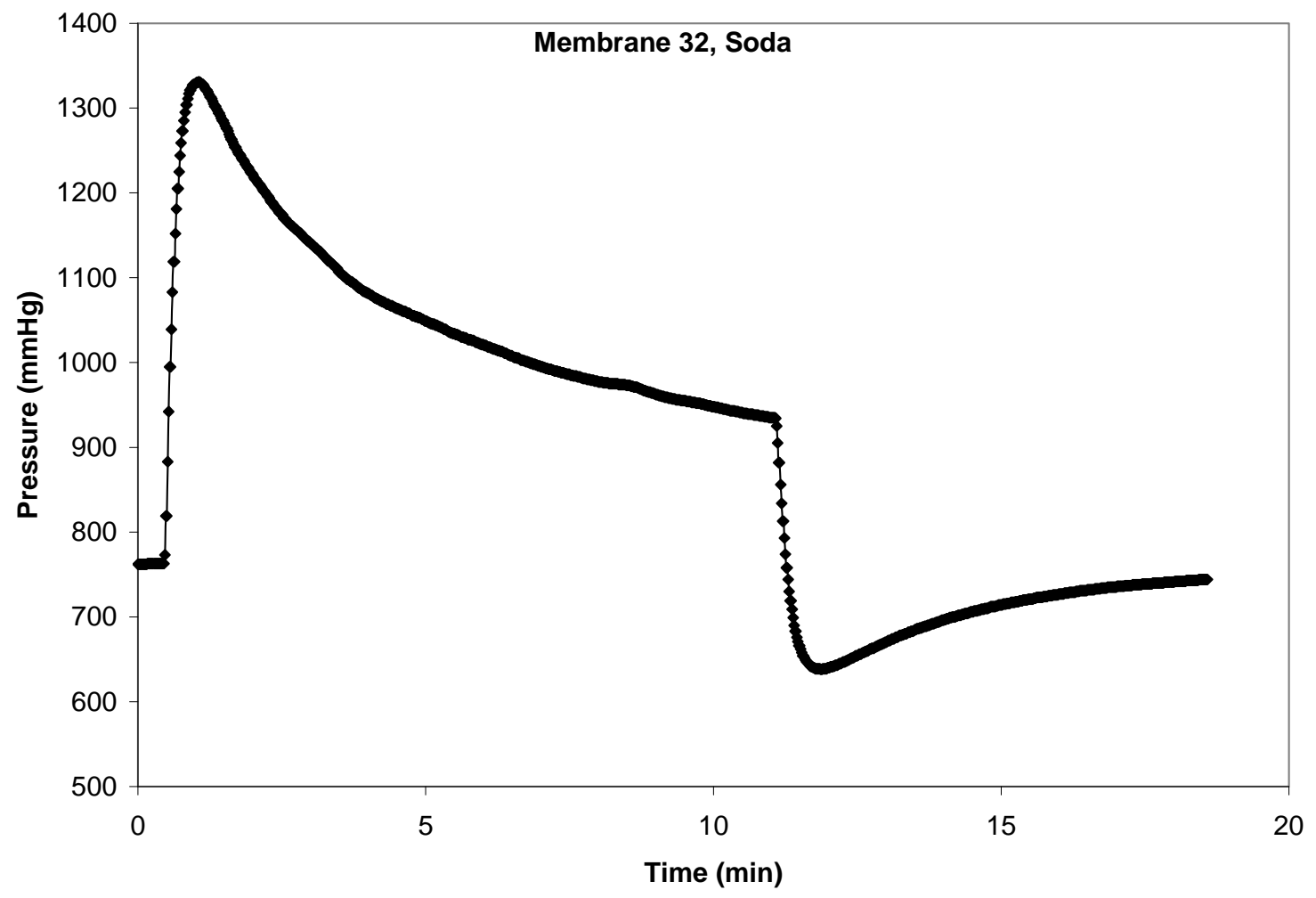




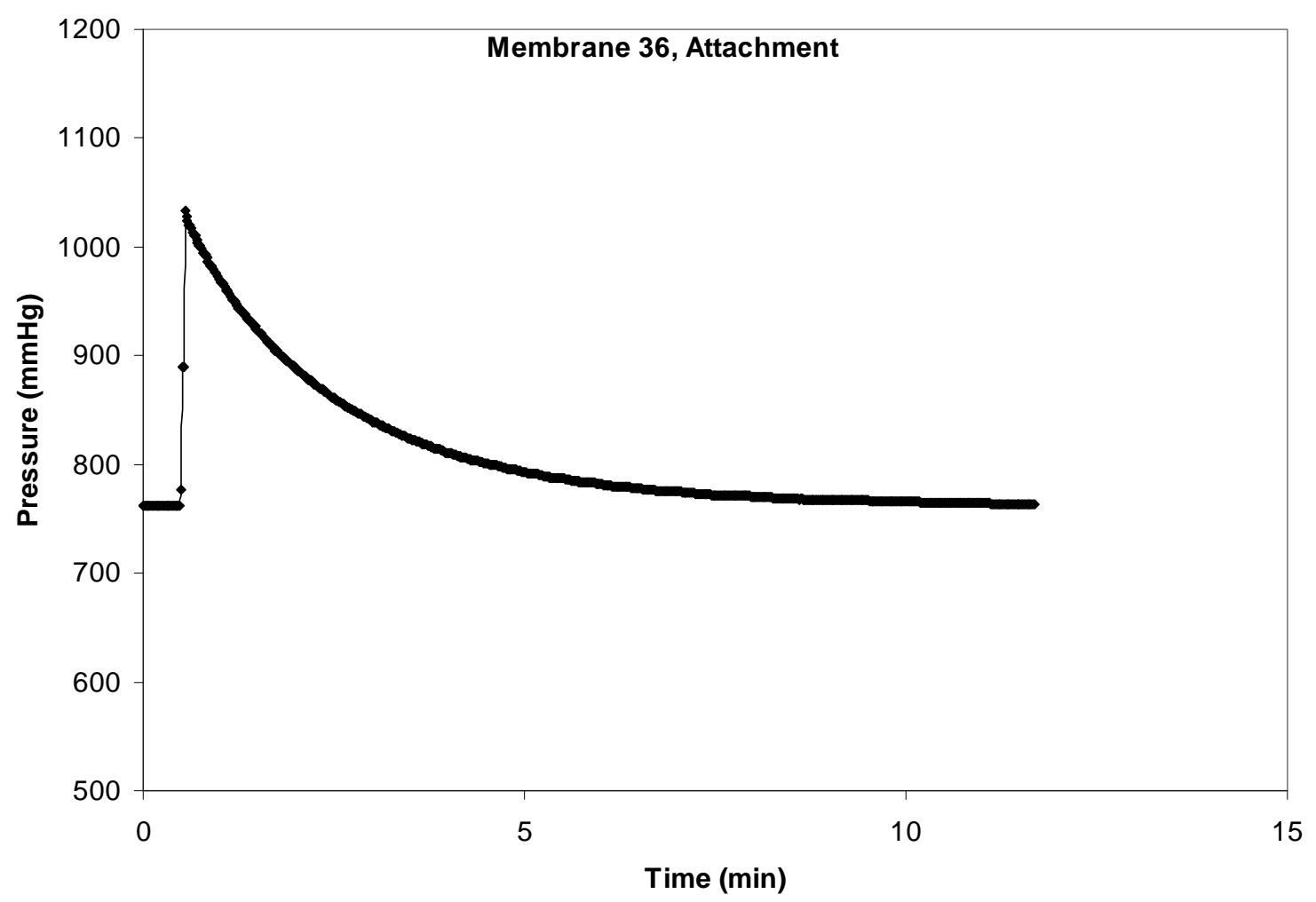

Membrane 36 was used as the control for the side-by-side after deployment 3 with MiniSonde 40347.






\section{Post Deployment 4}

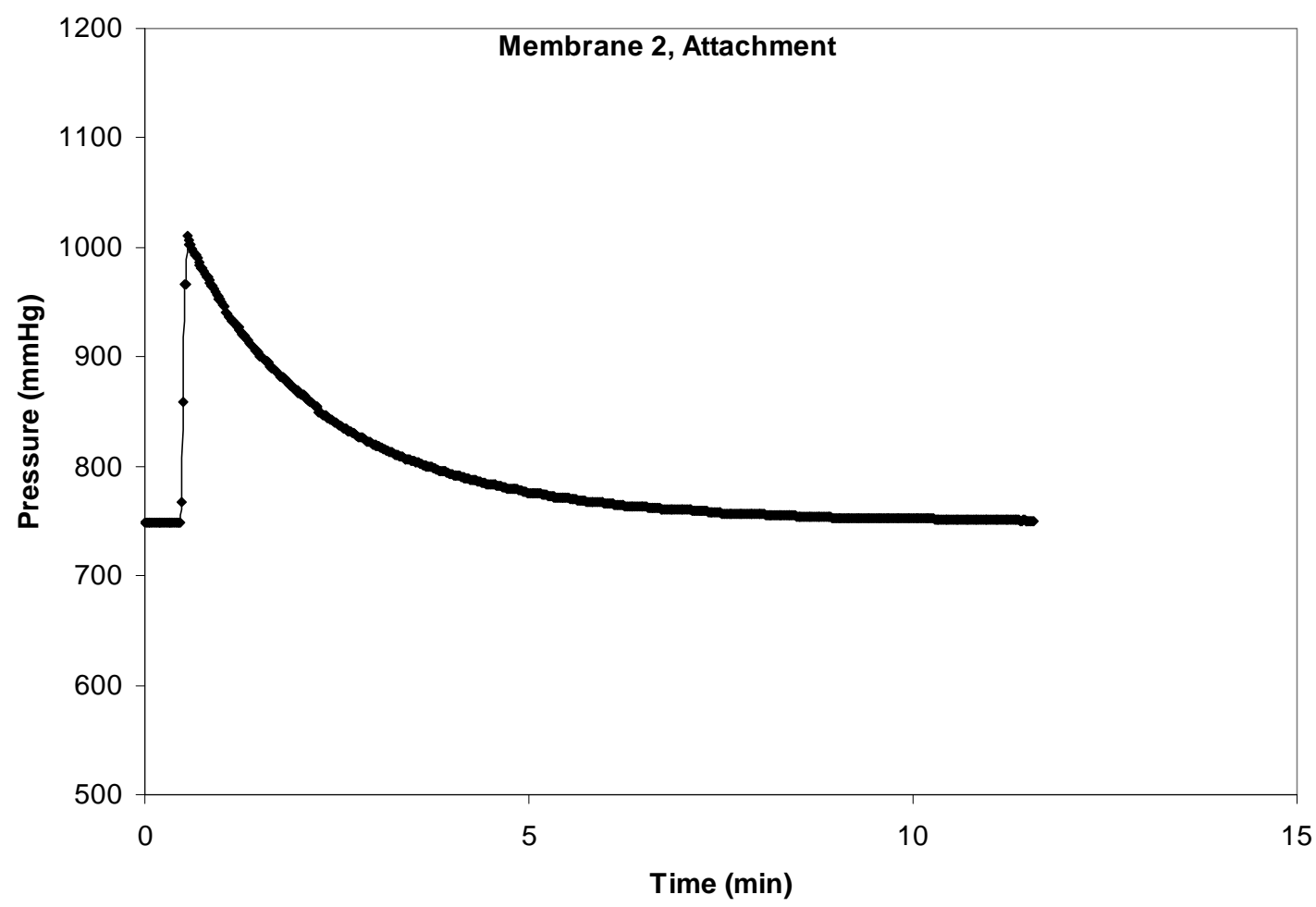

Membrane 2 was used at Ives 5 river from 4/15/2008 to 4/30/2008 with MiniSonde 43639.

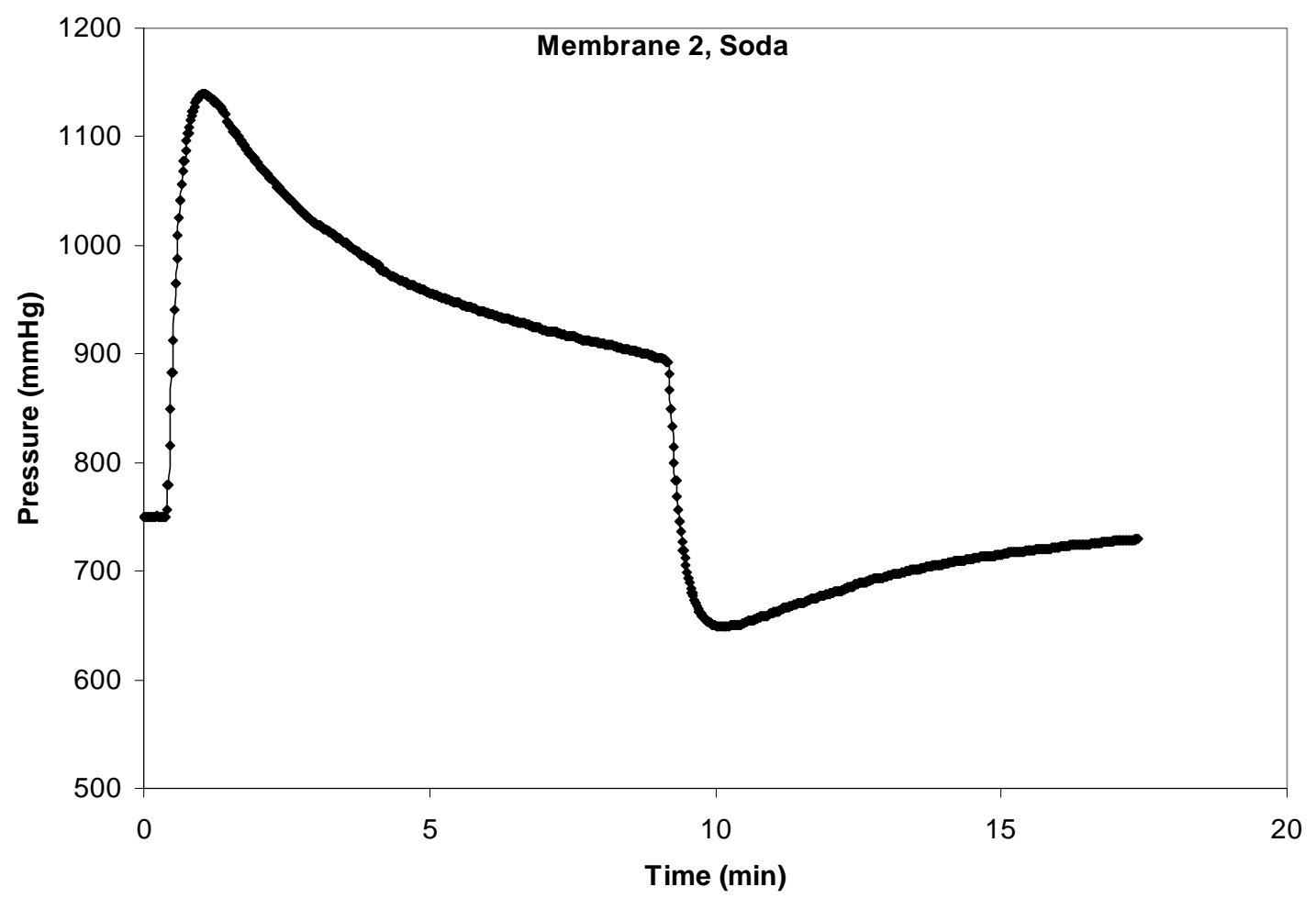




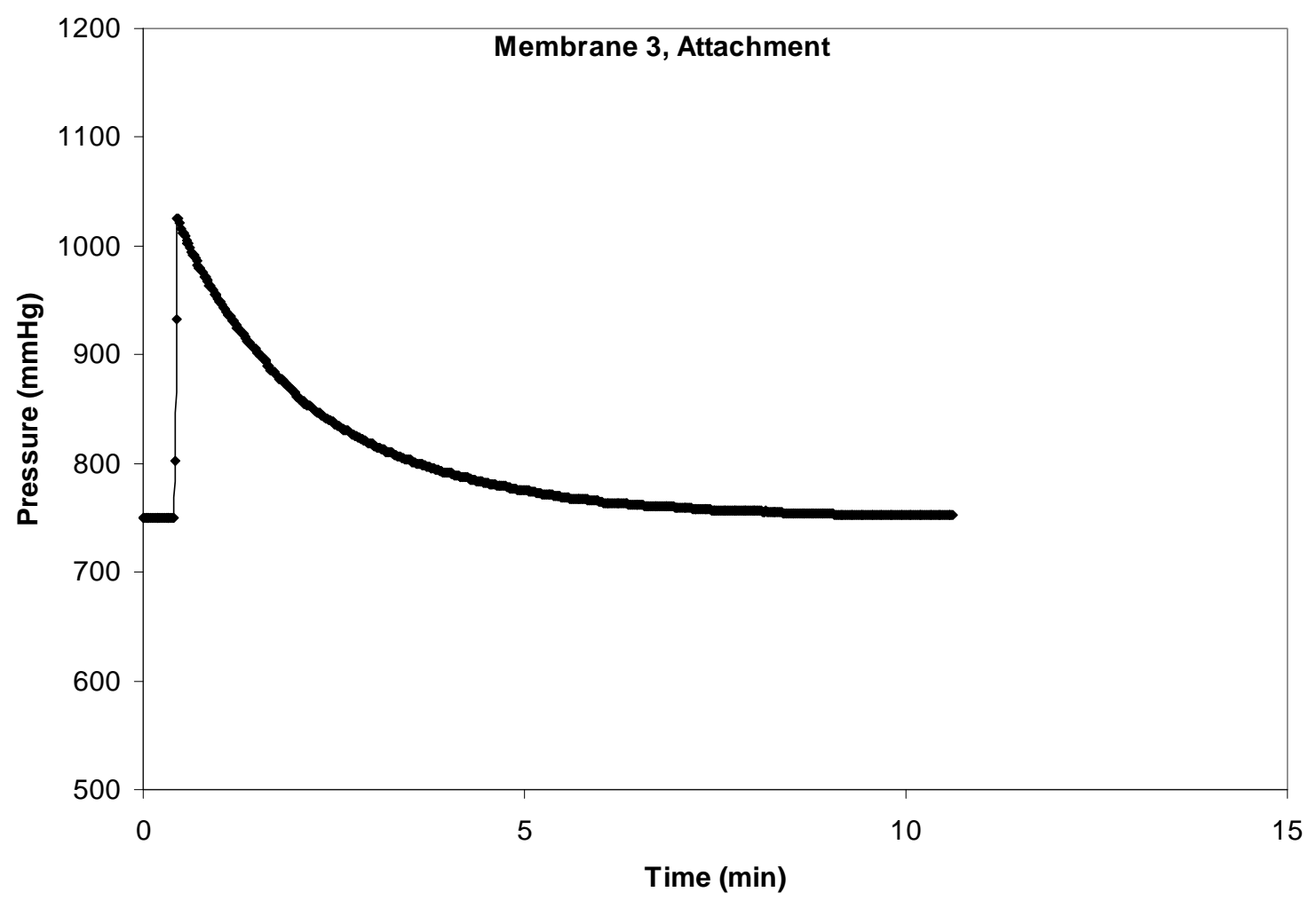

Membrane 3 was used at Multnomah Falls 3 river from 4/15/2008 to 4/30/2008 with MiniSonde 44948.

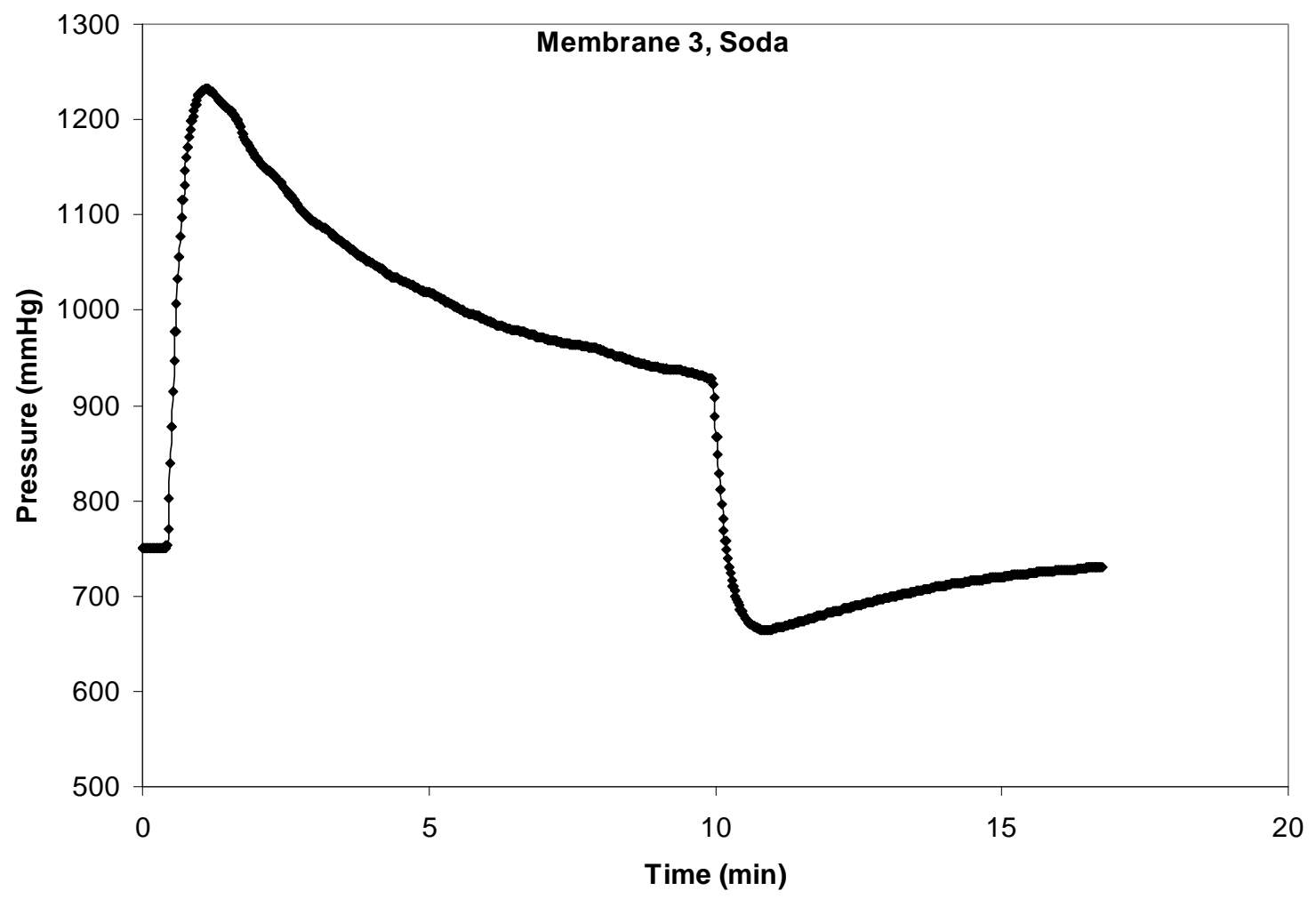




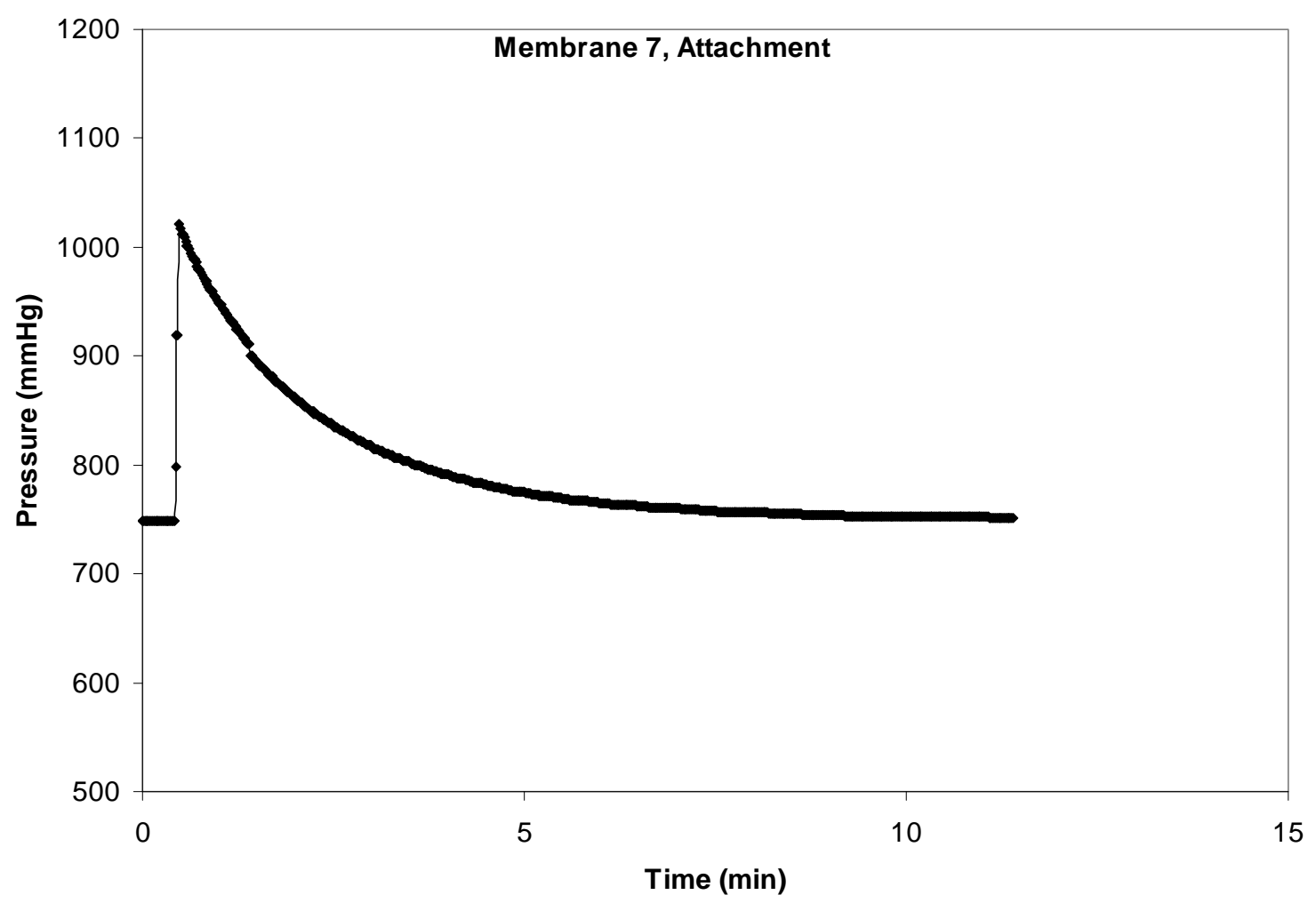

Membrane 7 was used at Ives 5 hyporheic from 4/15/2008 to 4/30/2008 with MiniSonde 45451.

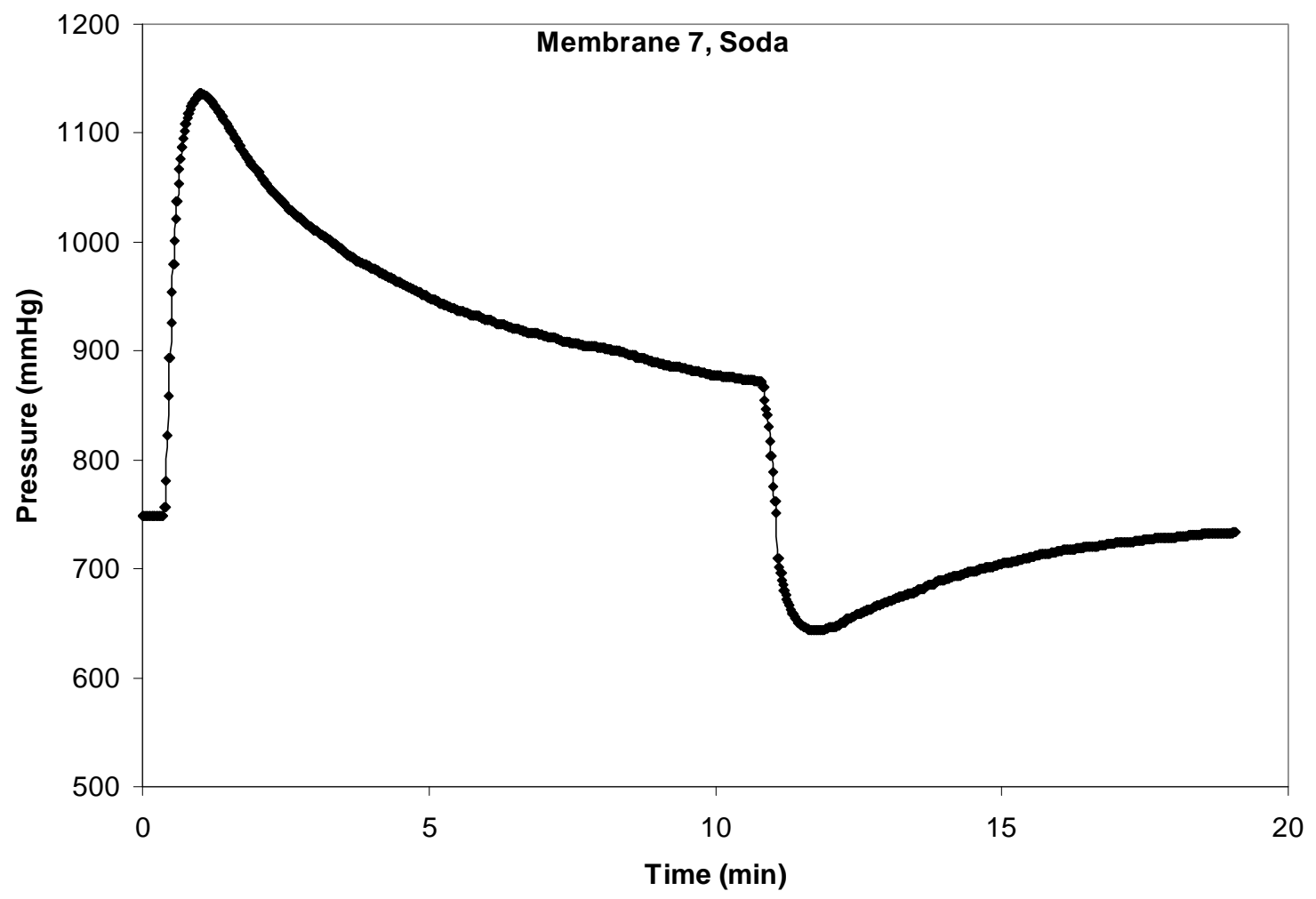




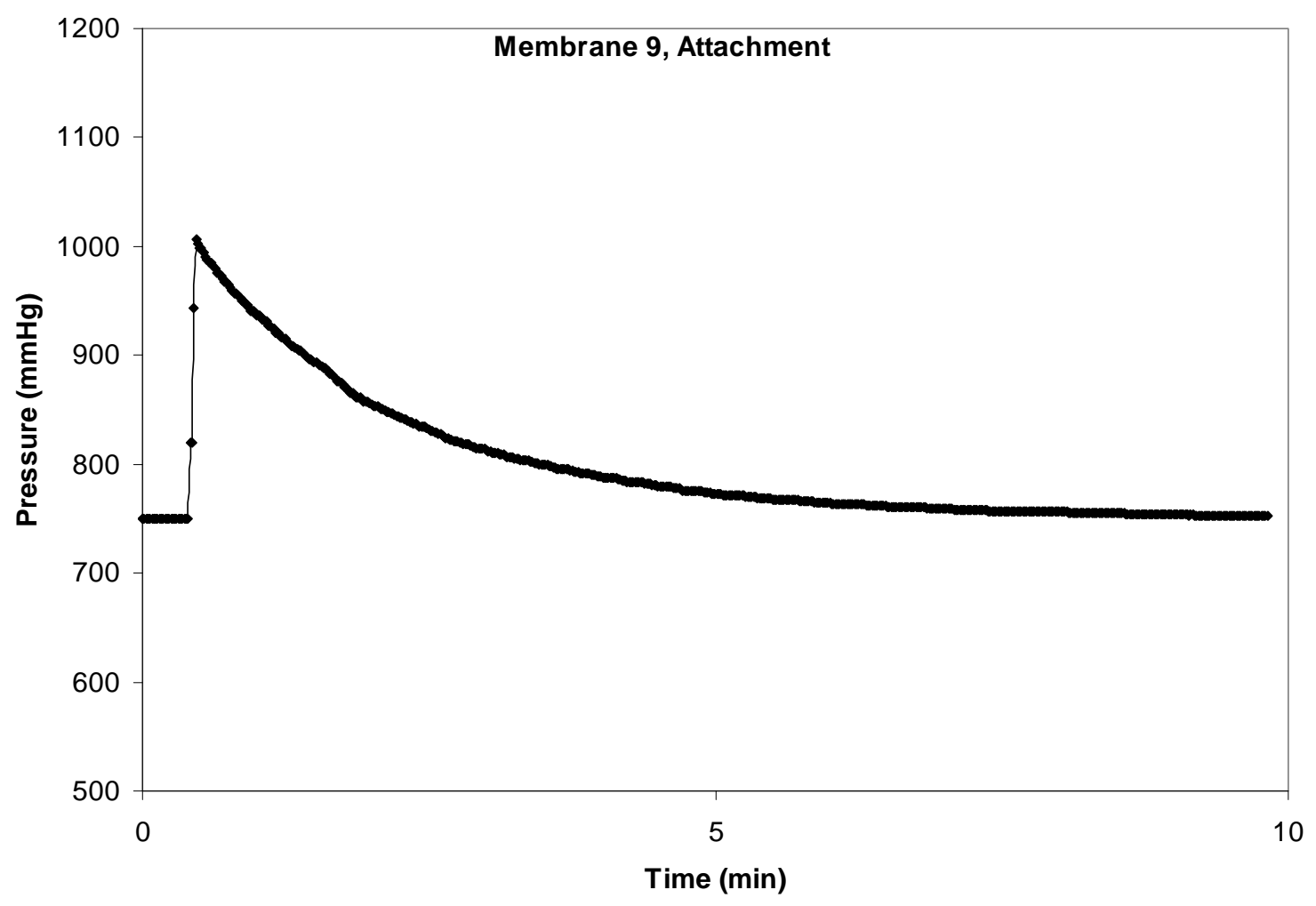

Membrane 9 was used at Multnomah Falls 3 hyporheic from 4/15/2008 to 4/30/2008 with MiniSonde 43656.

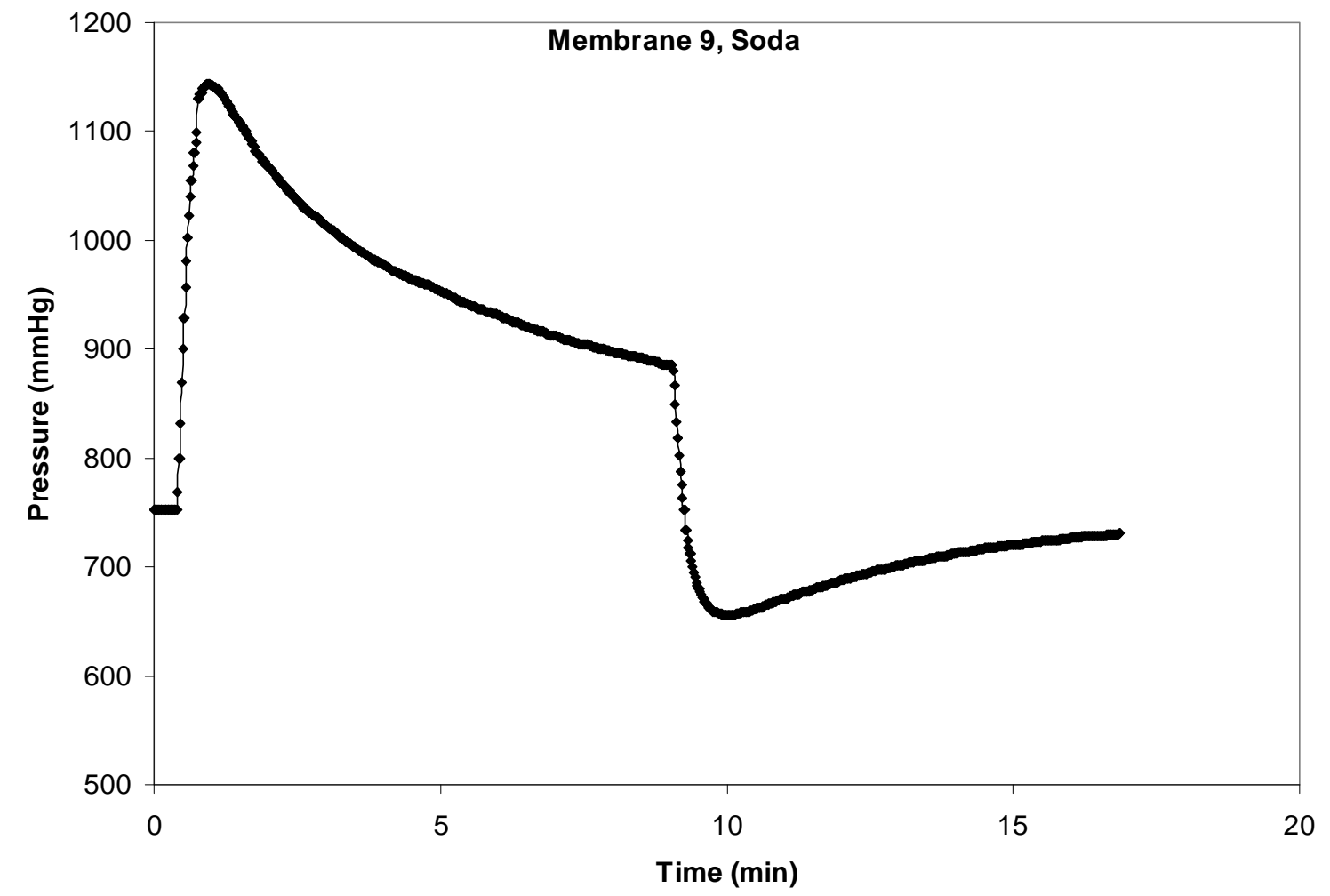




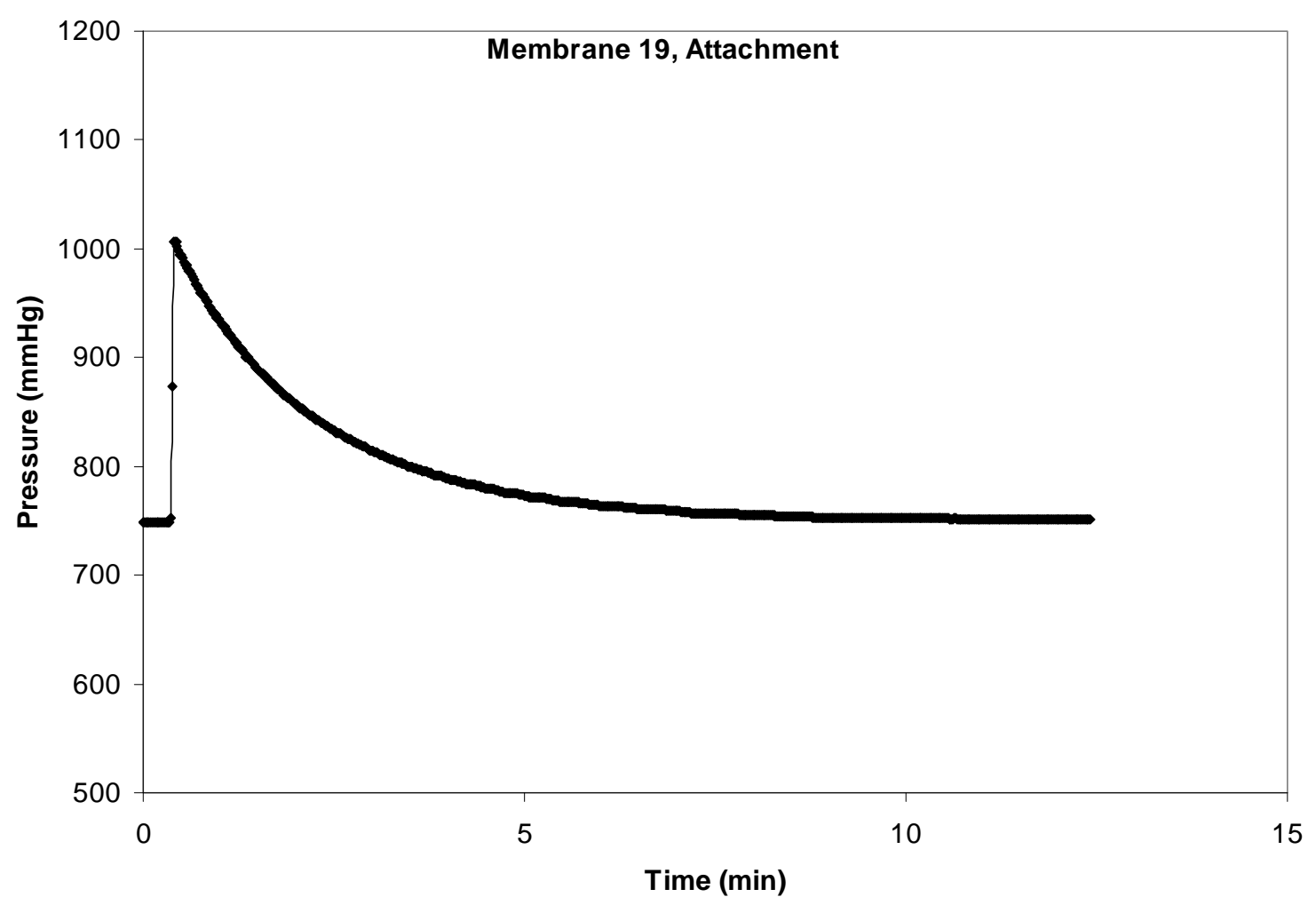

Membrane 19 was used at Ives 2 hyporheic from 4/15/2008 to 4/30/2008 with MiniSonde 44947.

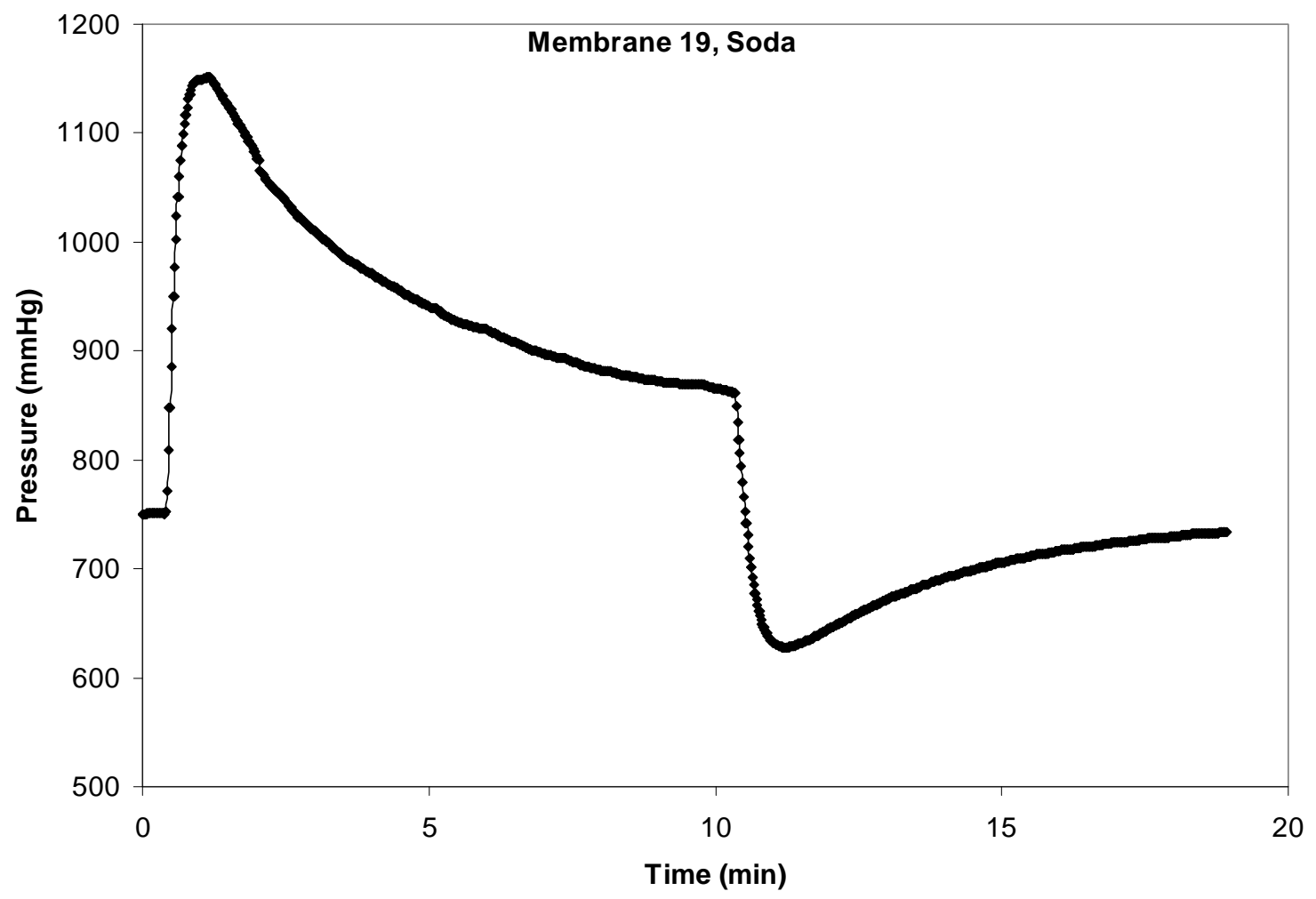




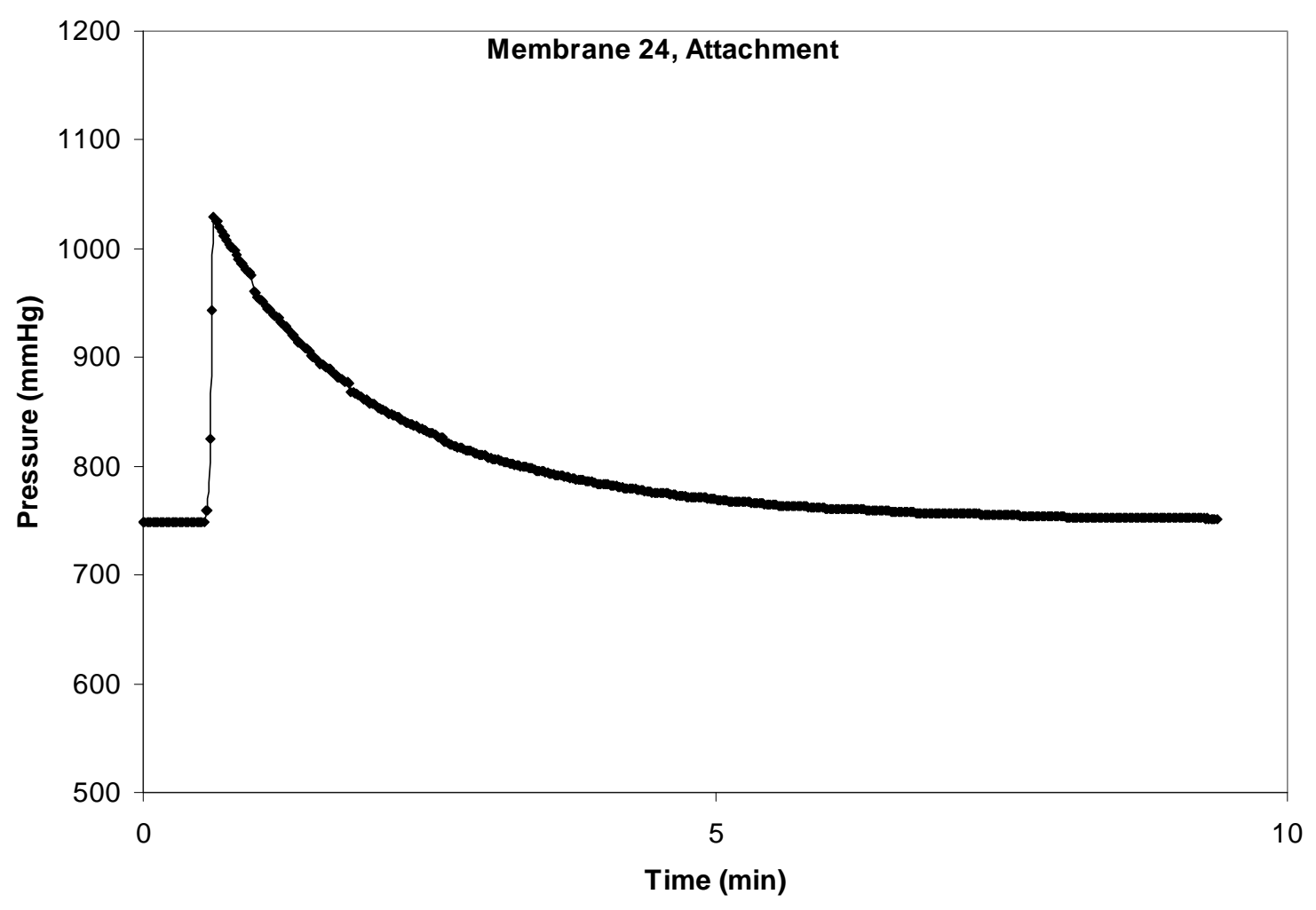

Membrane 24 was used at Ives 1 river from 4/15/2008 to 4/30/2008 with MiniSonde 43655.

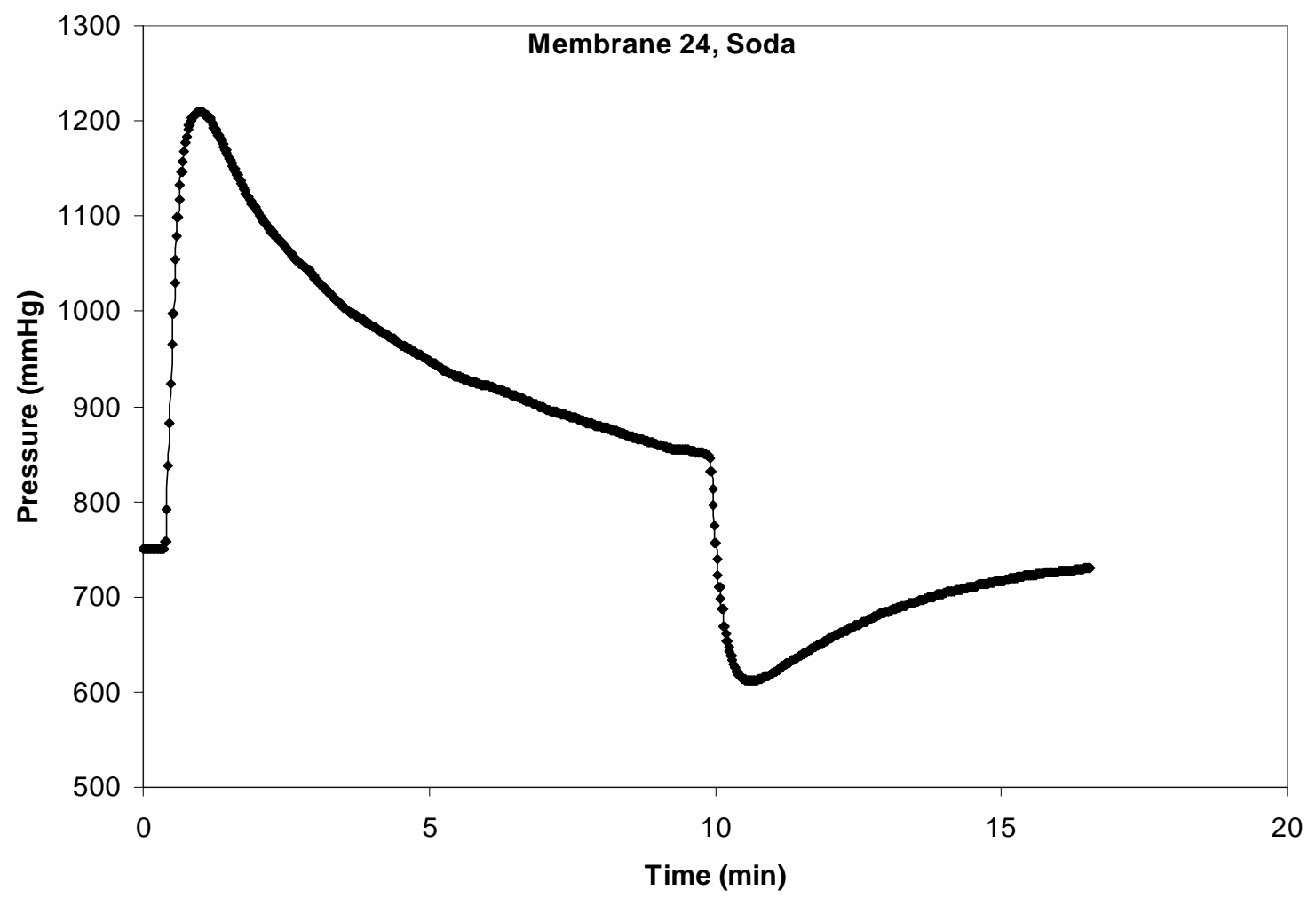




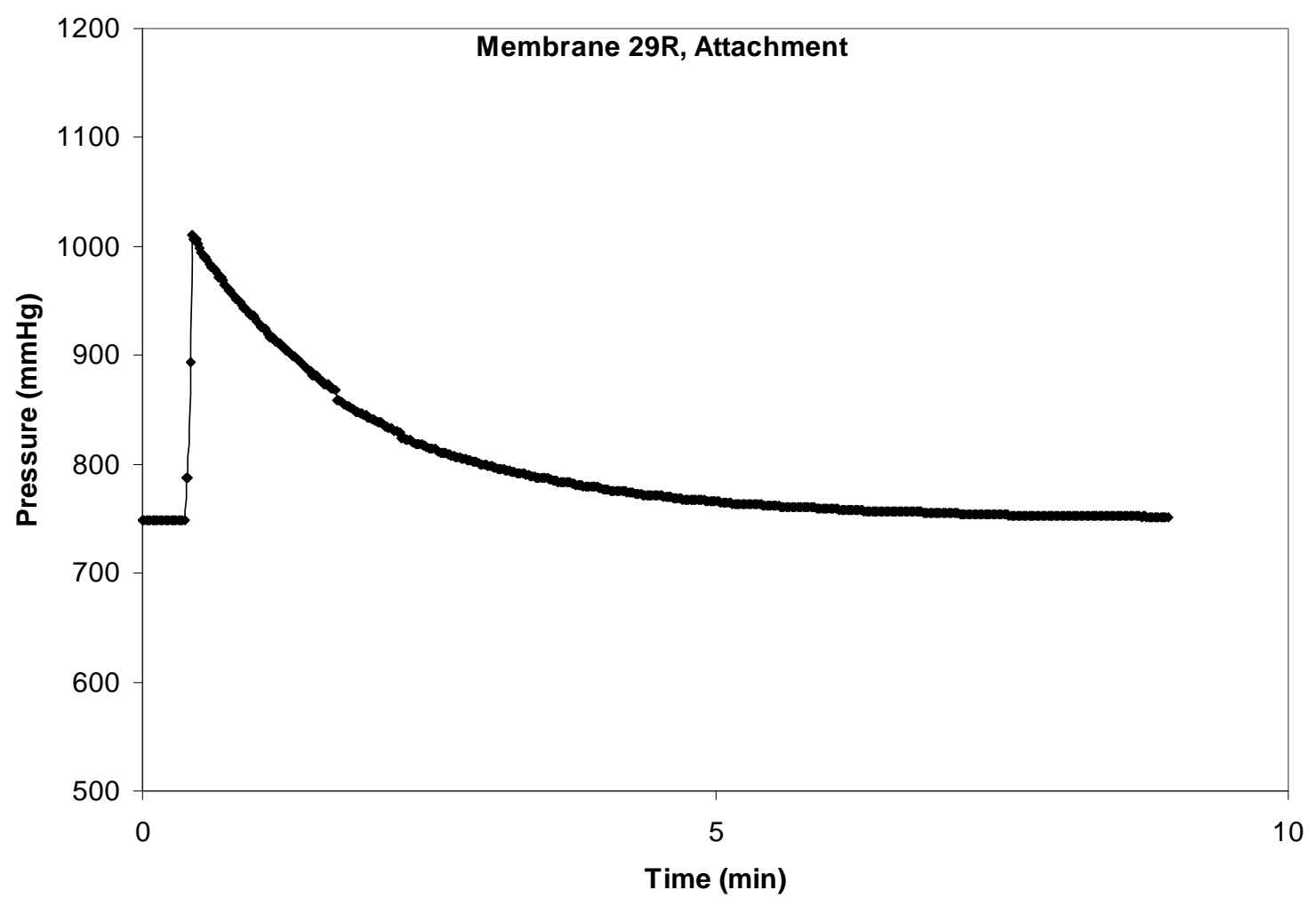

Membrane 29R was used at Ives 2 river from 4/15/2008 to 4/30/2008 with MiniSonde 44946.






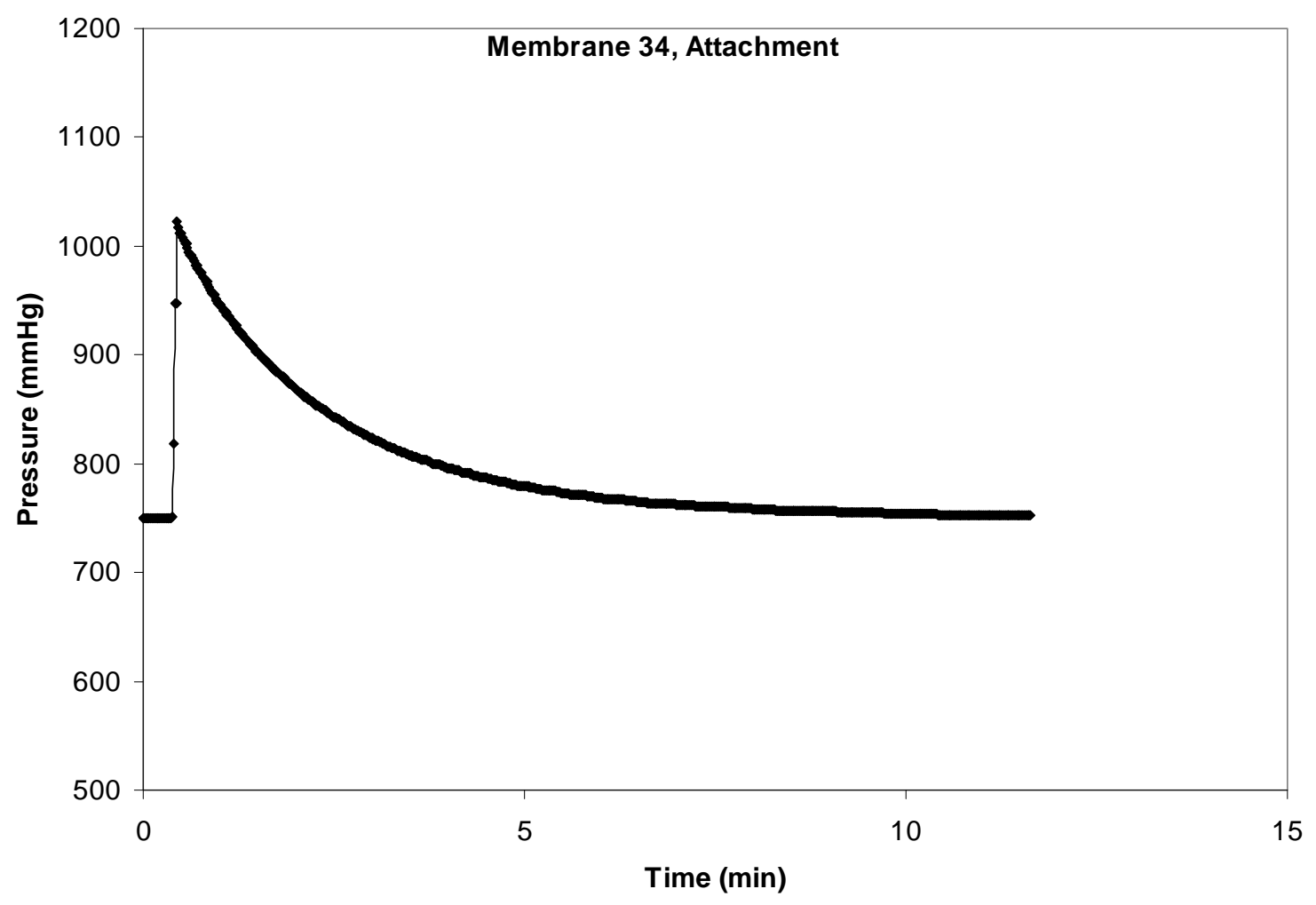

Membrane 34 was used at Multnomah Falls 1 hyporheic from 4/15/2008 to 4/30/2008 with MiniSonde 44945.

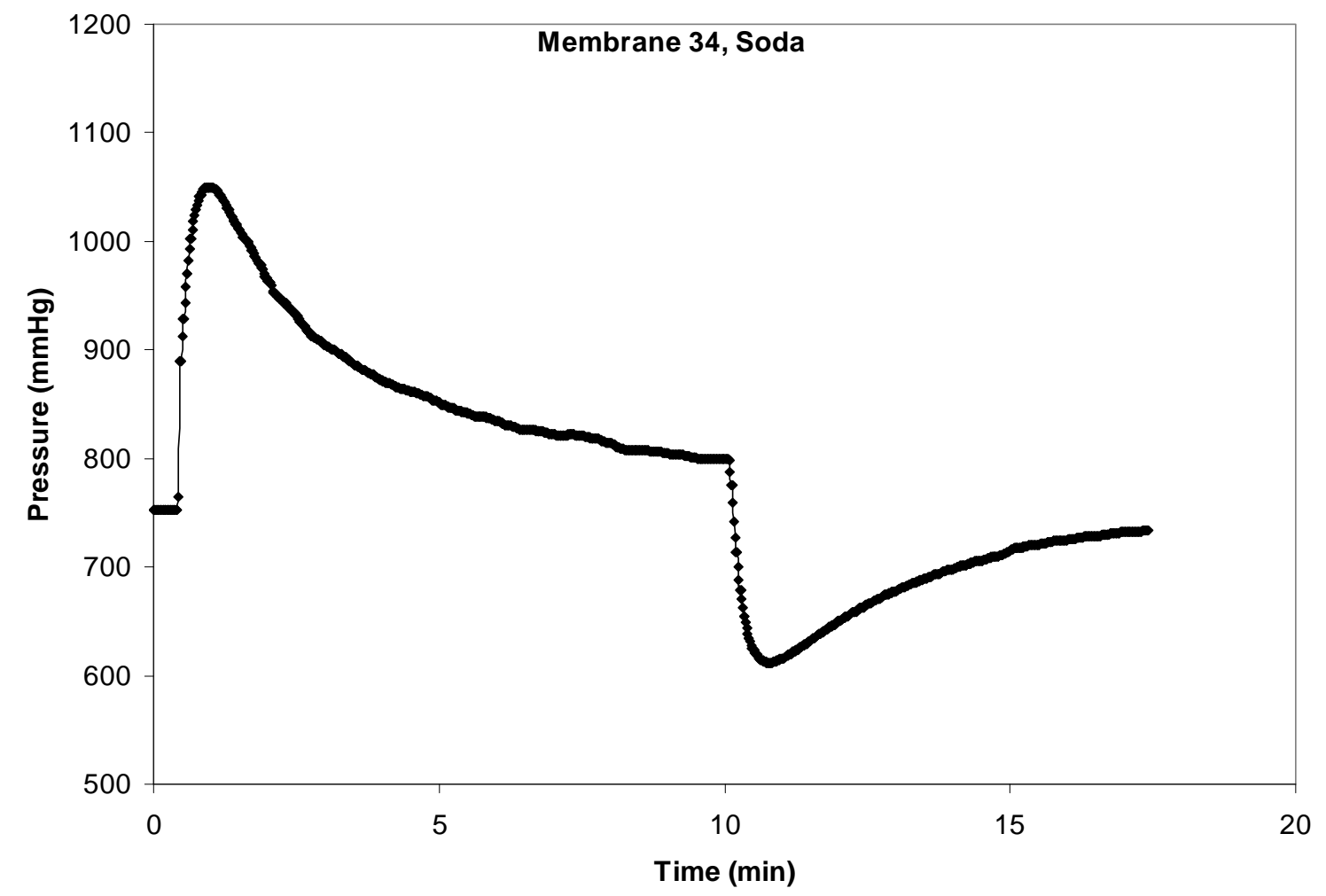




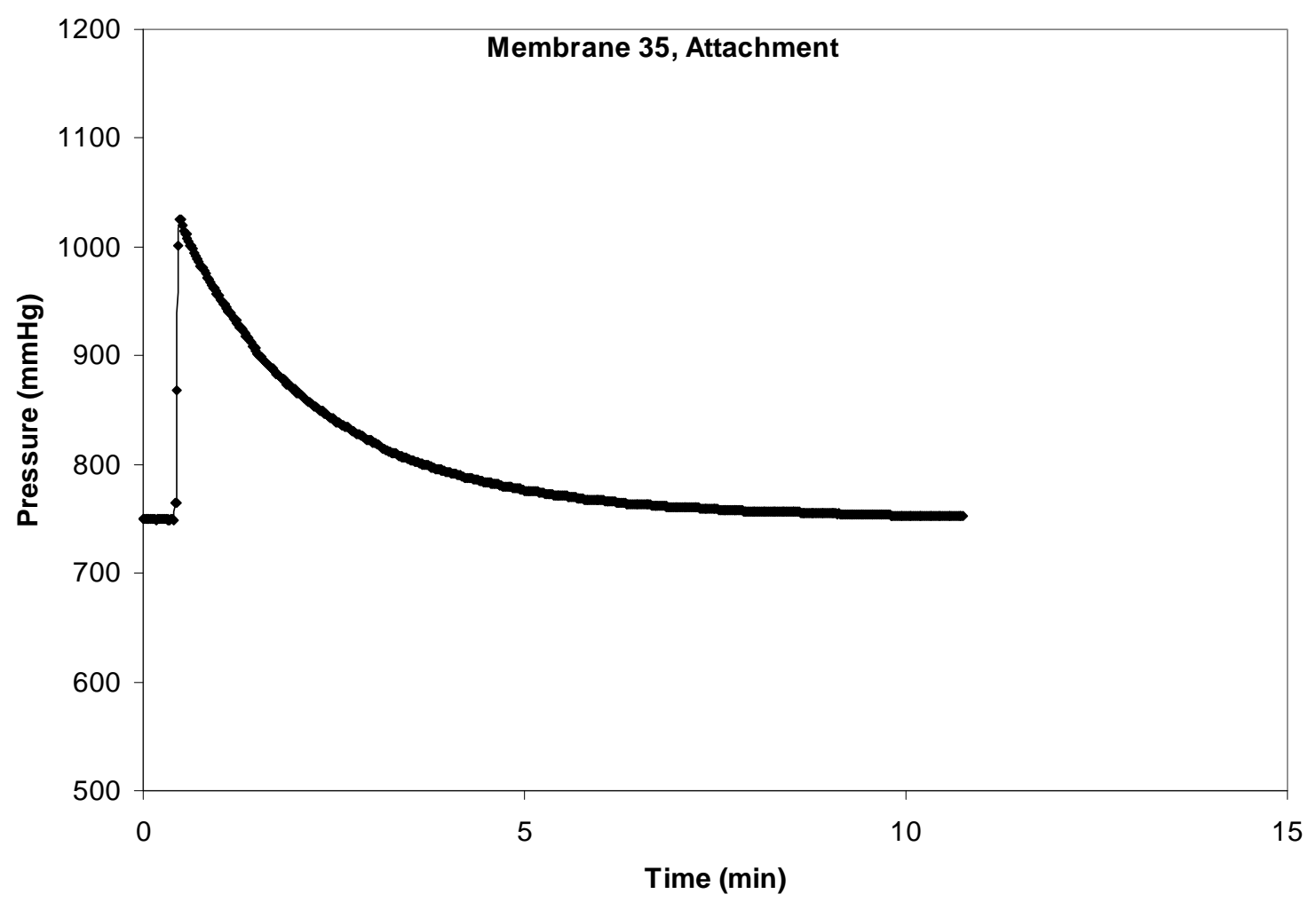

Membrane 35 was used at Ives 1 hyporheic from 4/15/2008 to 4/30/2008 with MiniSonde 43659.

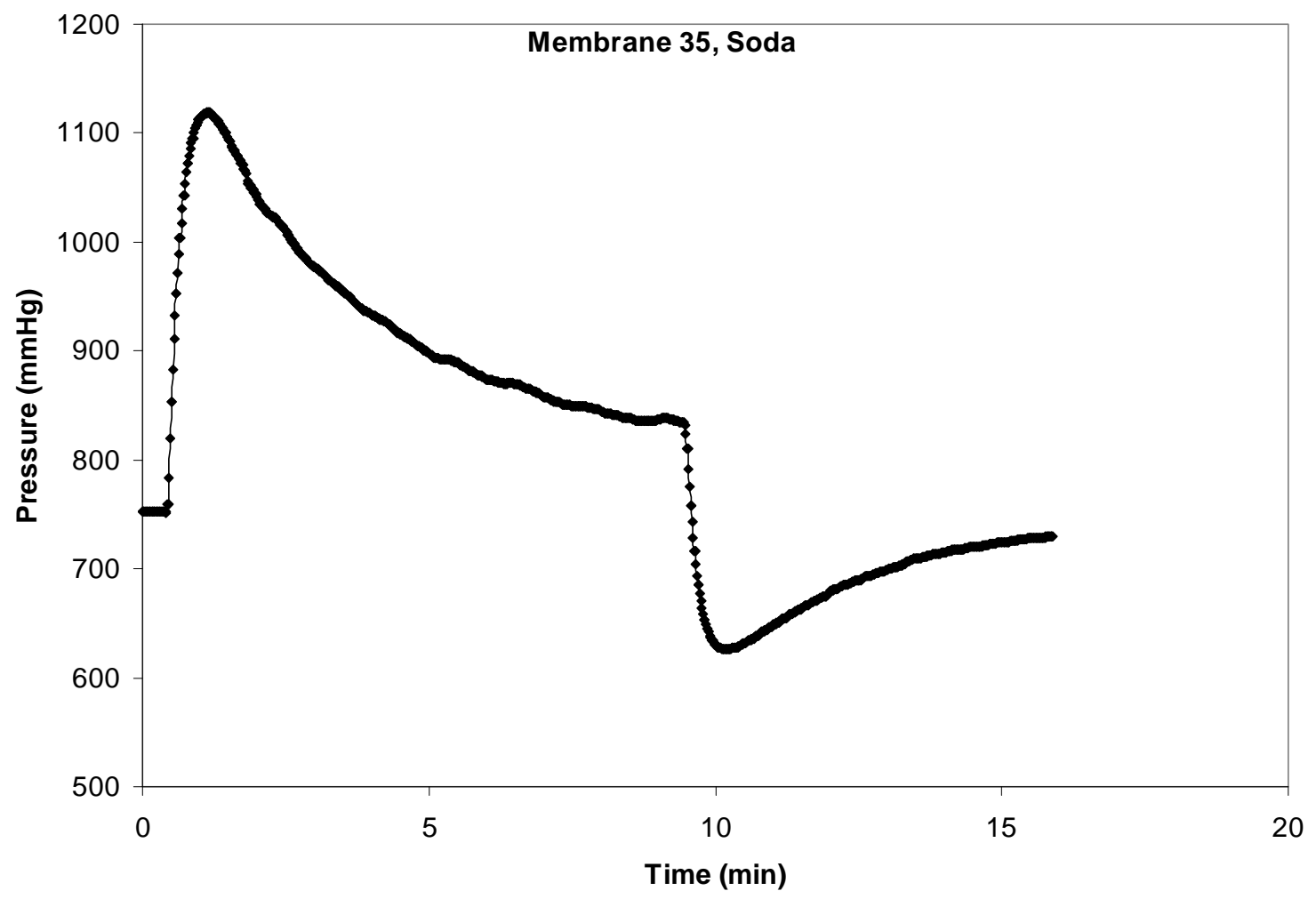




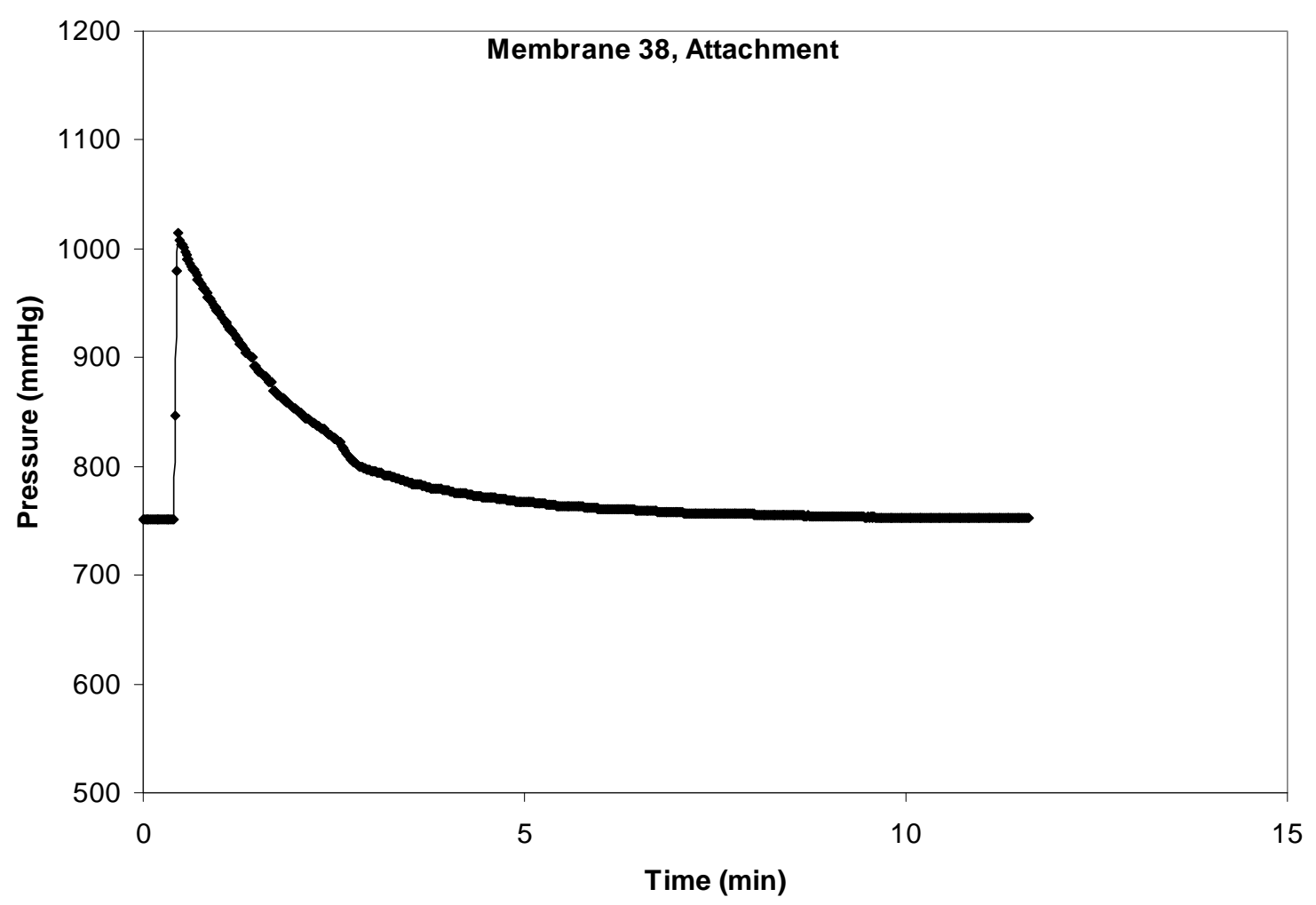

Membrane 38 was used at Multnomah Falls 1 river from 4/15/2008 to 4/30/2008 with MiniSonde 44927.

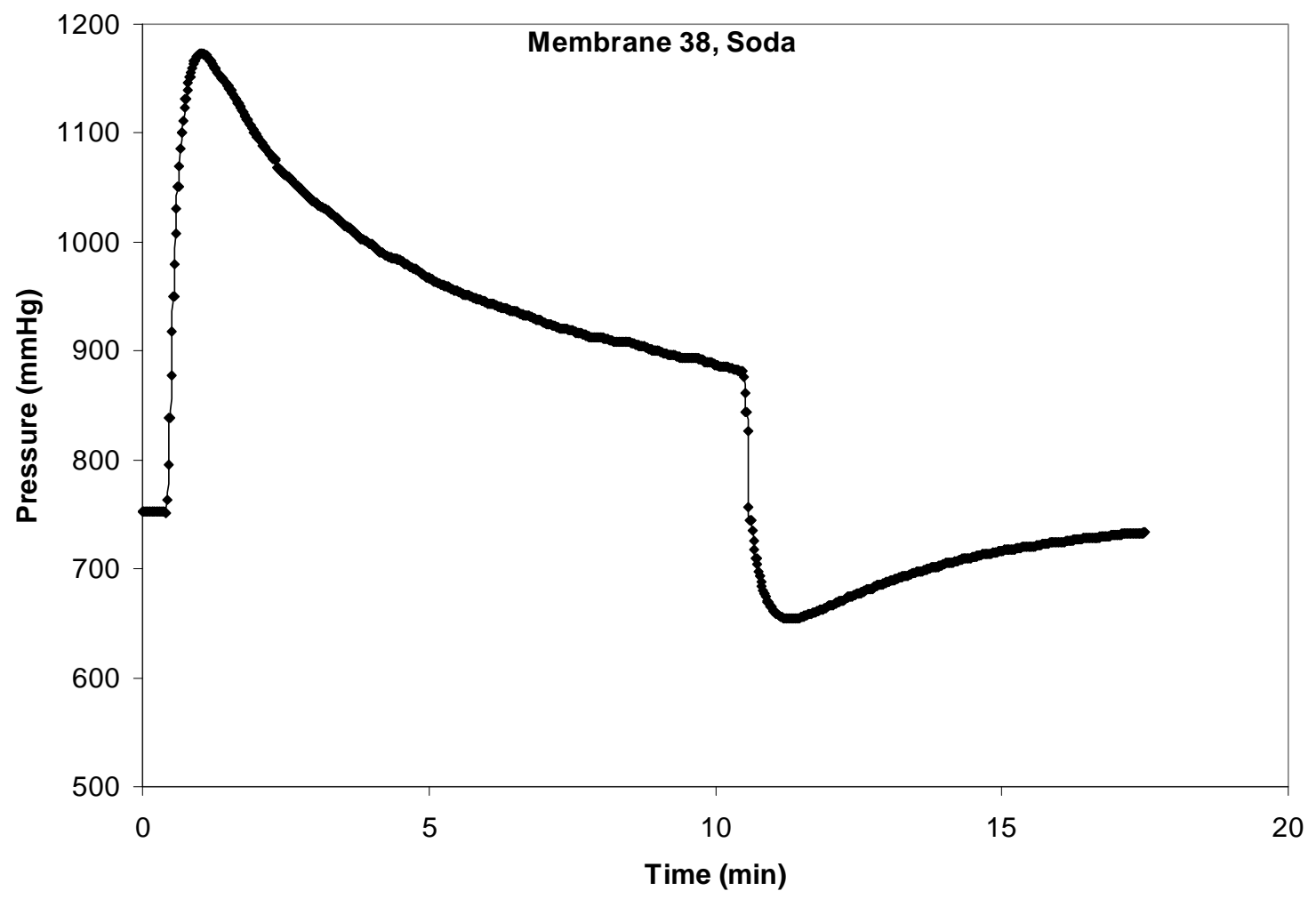




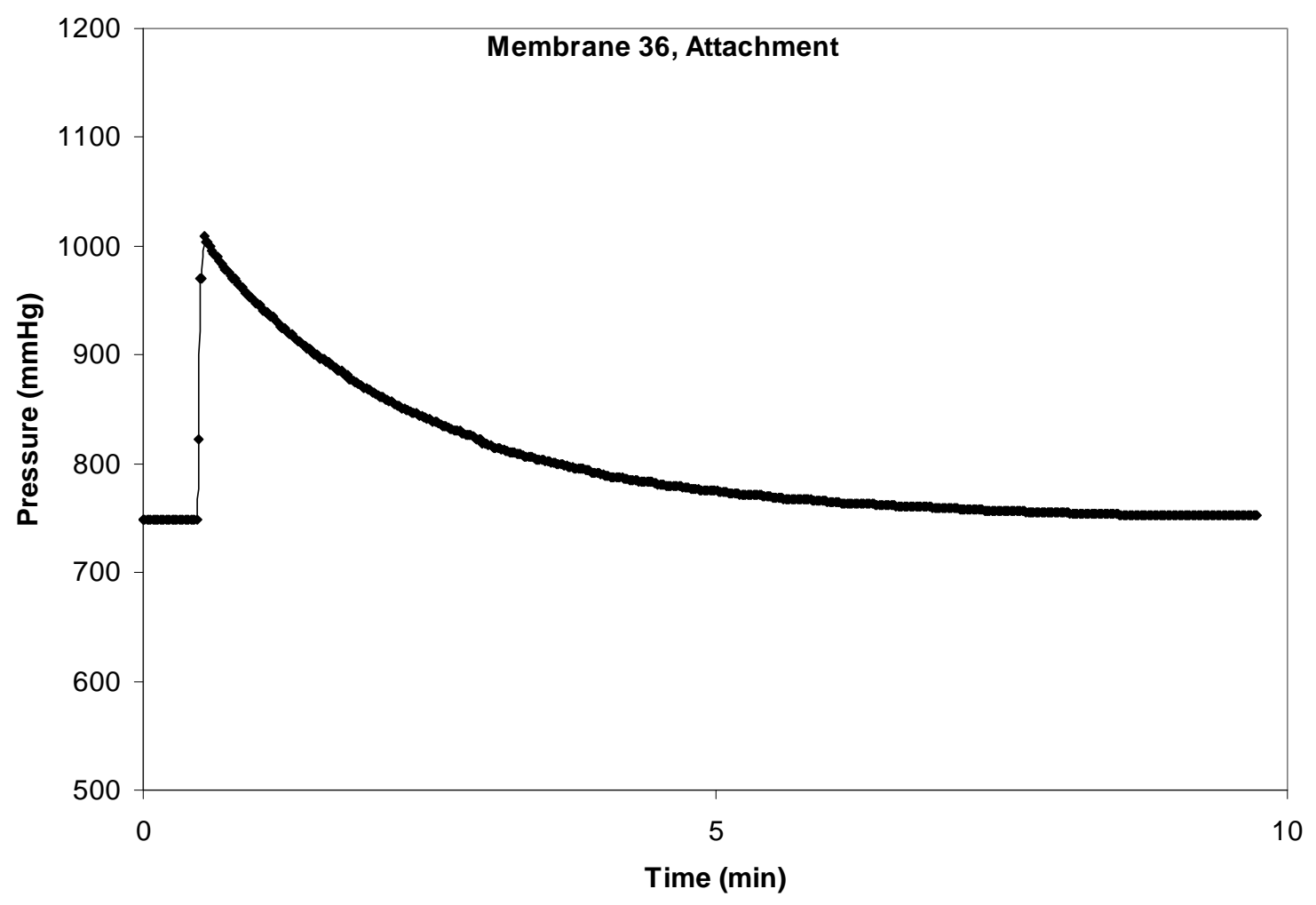

Membrane 36 was used as the control for the side-by-side after deployment 4 with MiniSonde 40347.

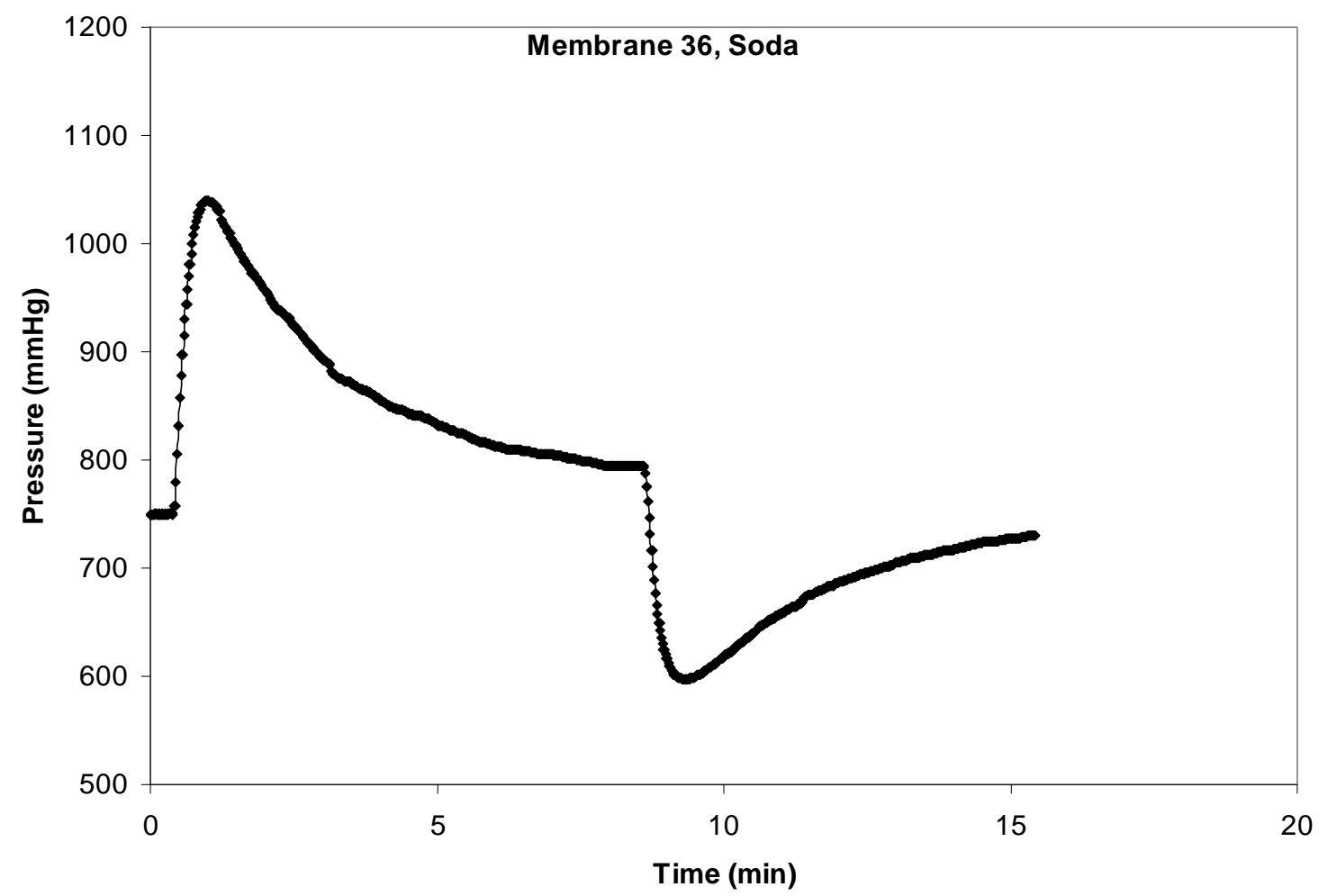




\section{Post Deployment 5}

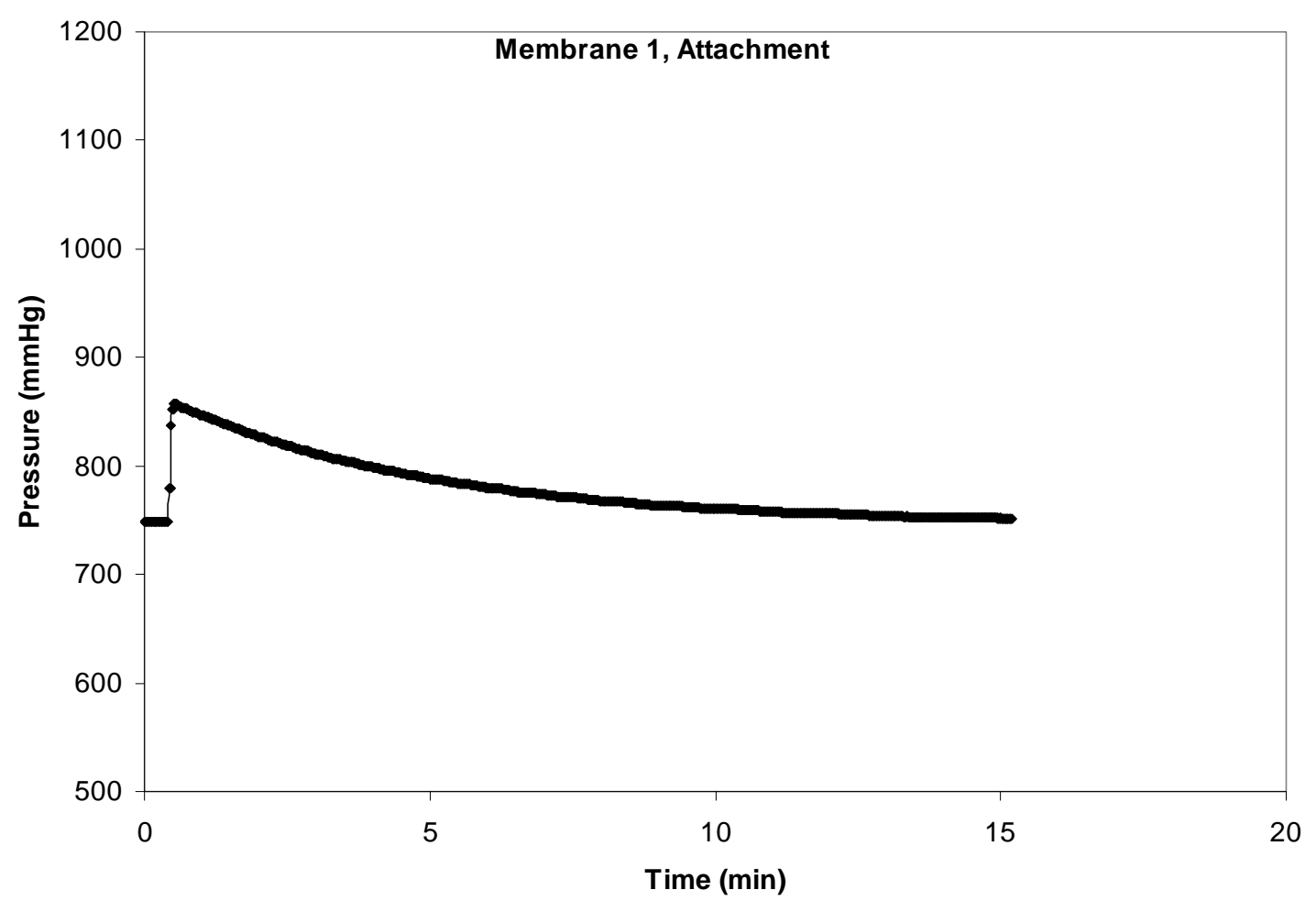

Membrane 1 was used at Ives 5 hyporheic from 4/30/2008 to 5/14/2008 with MiniSonde 45451.

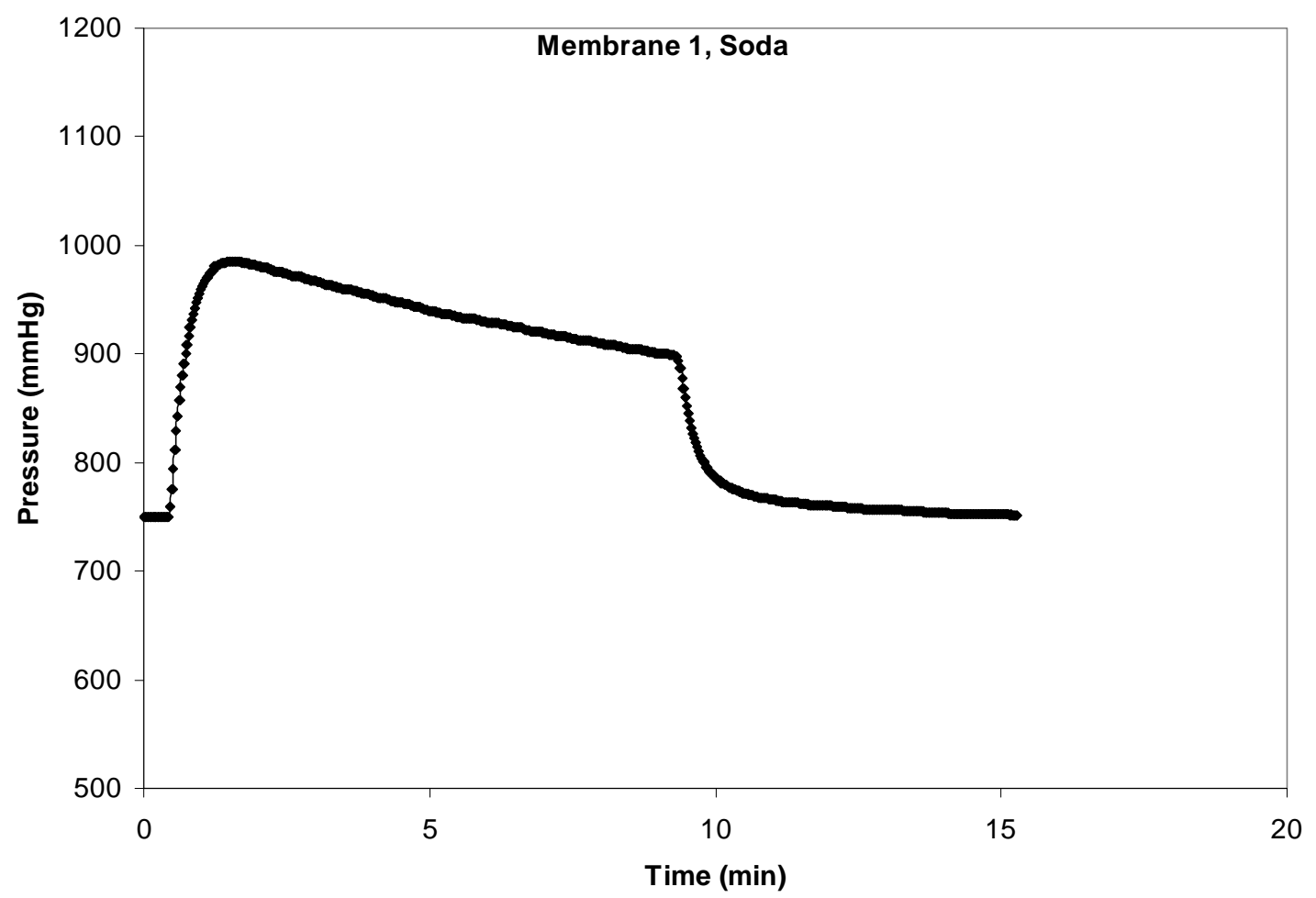




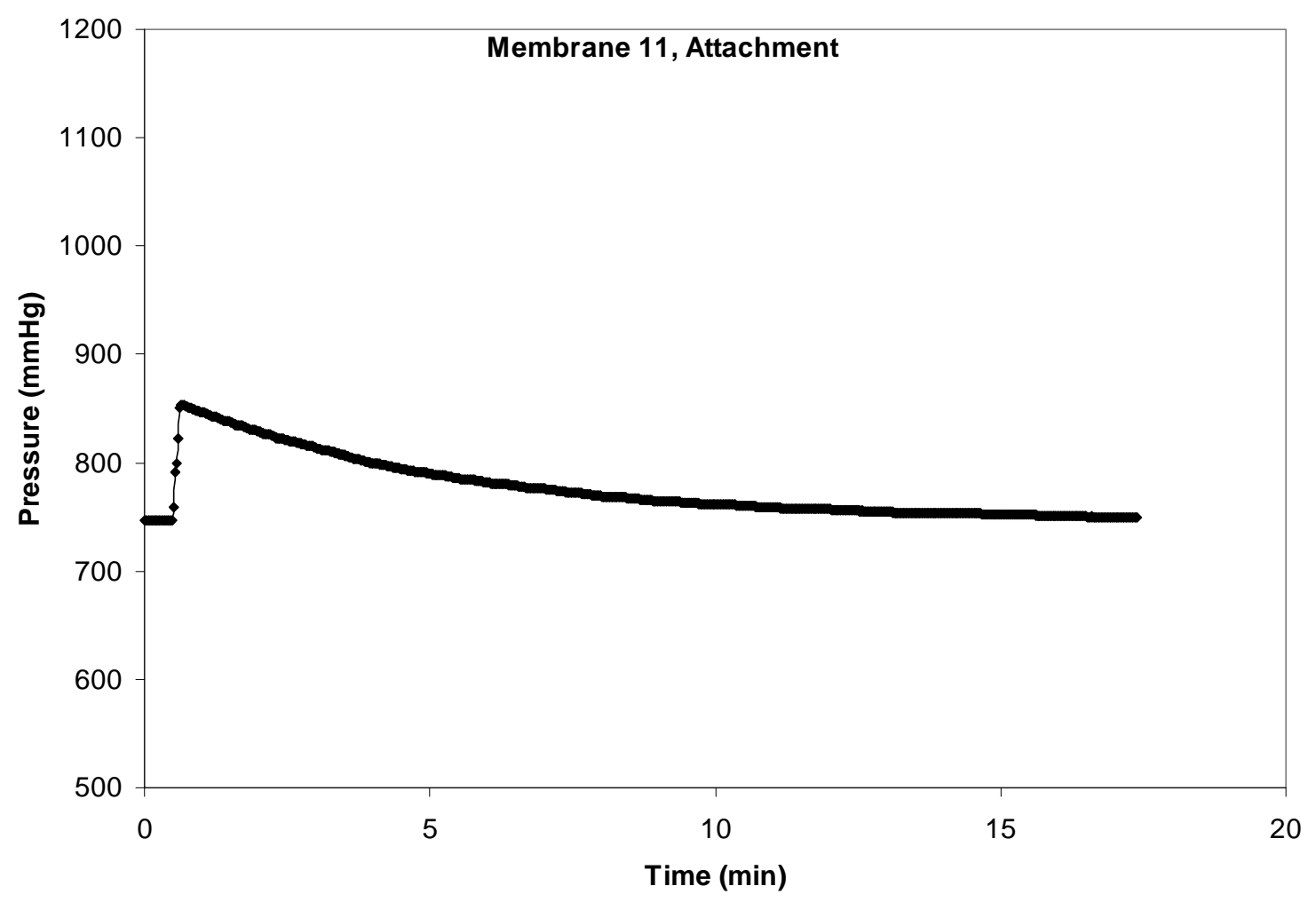

Membrane 11 was used at Multnomah Falls 3 river from 4/30/2008 to 5/14/2008 with MiniSonde 44948.

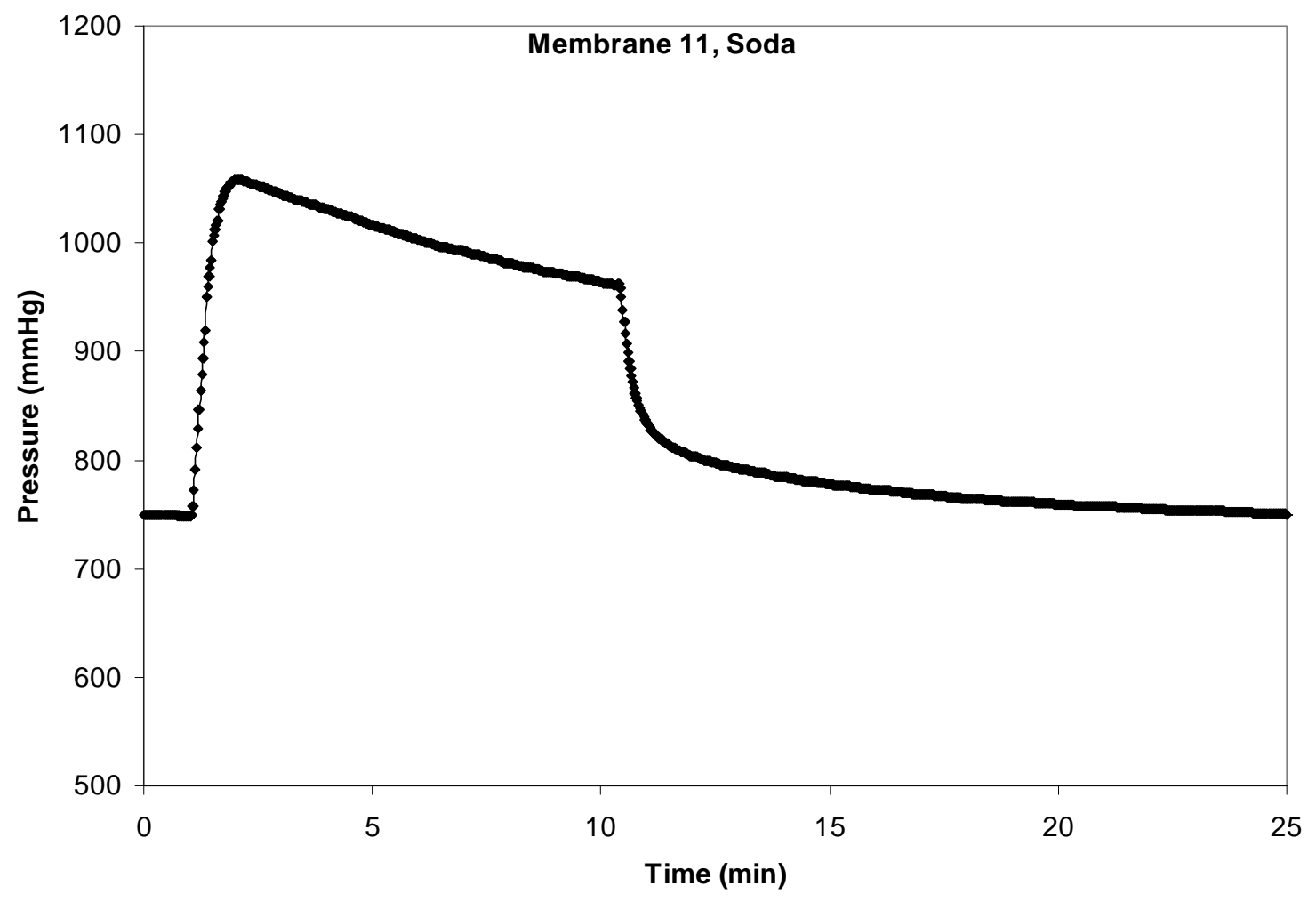




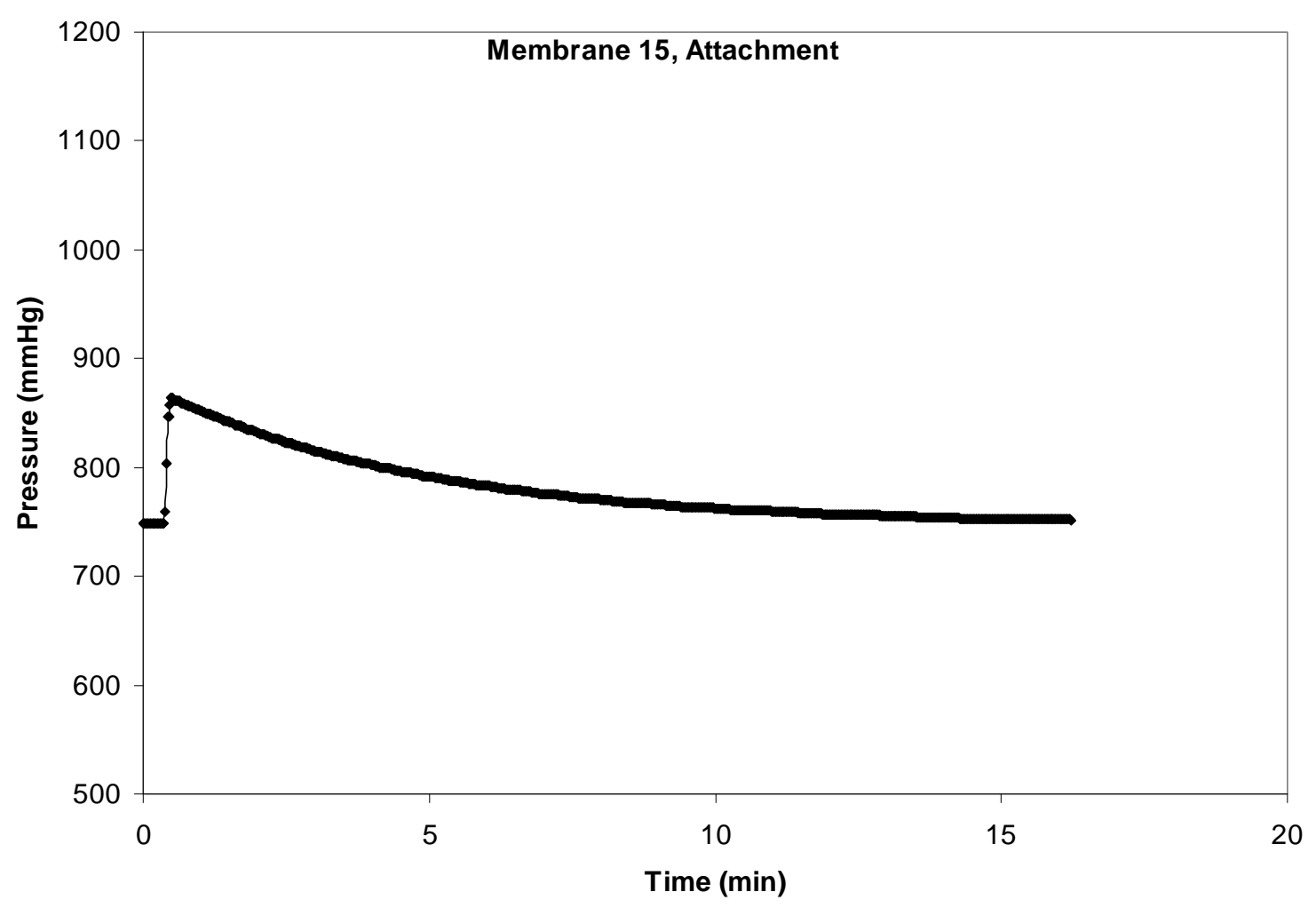

Membrane 15 was used at Ives 1 hyporheic from 4/30/2008 to 5/14/2008 with MiniSonde 43659.

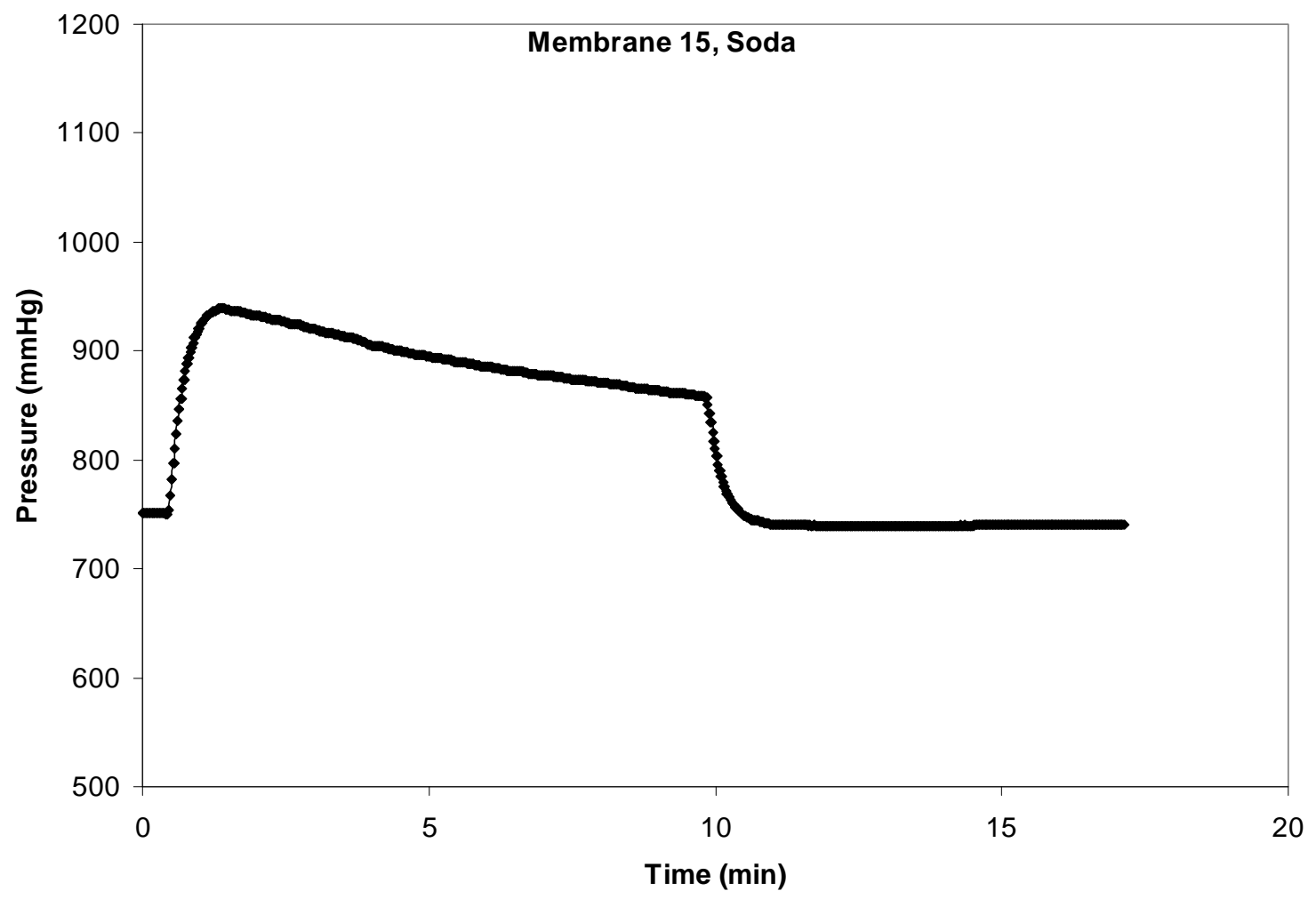




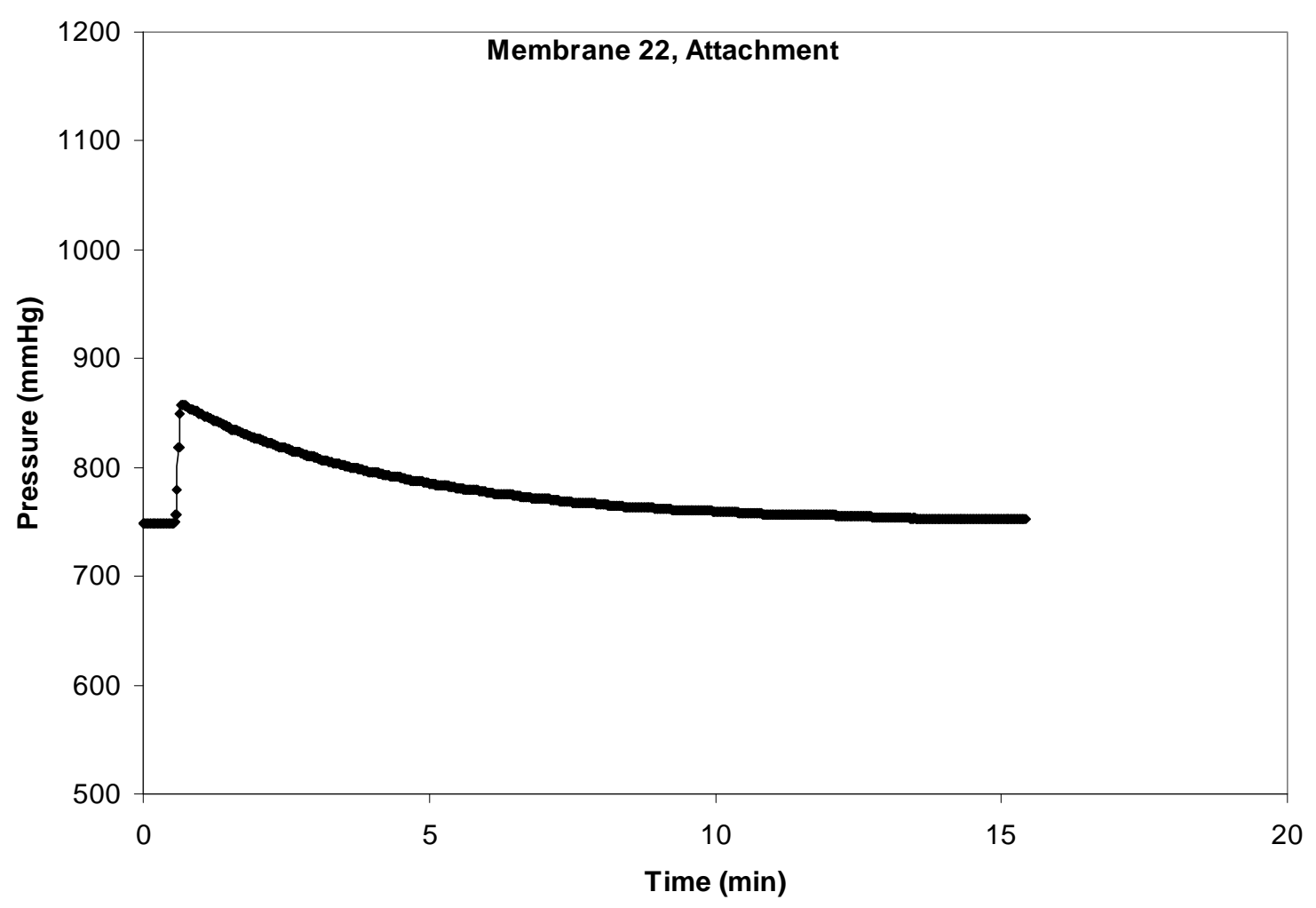

Membrane 22 was used at Multnomah Falls 1 hyporheic from 4/30/2008 to 5/15/2008 with MiniSonde 44945.

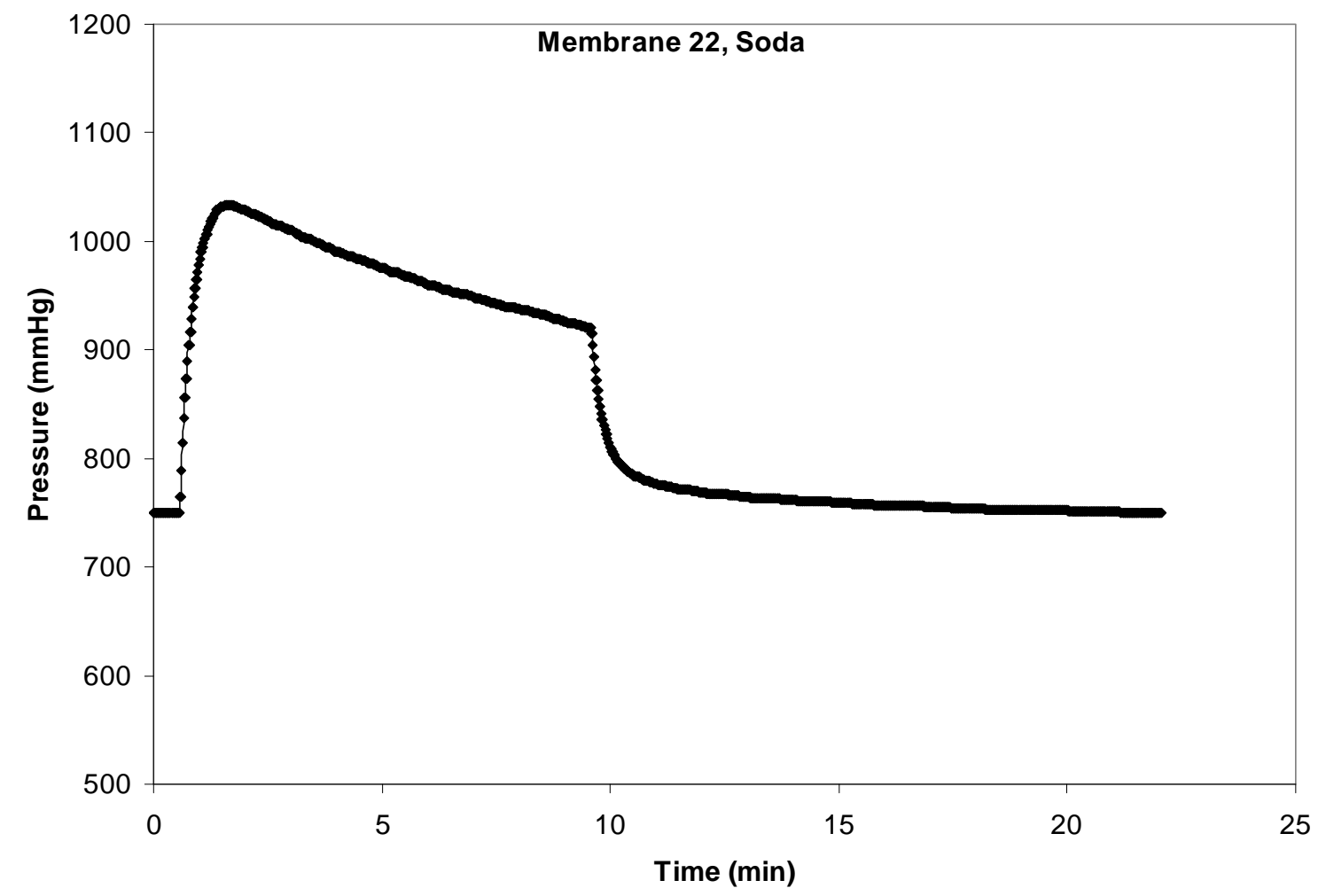




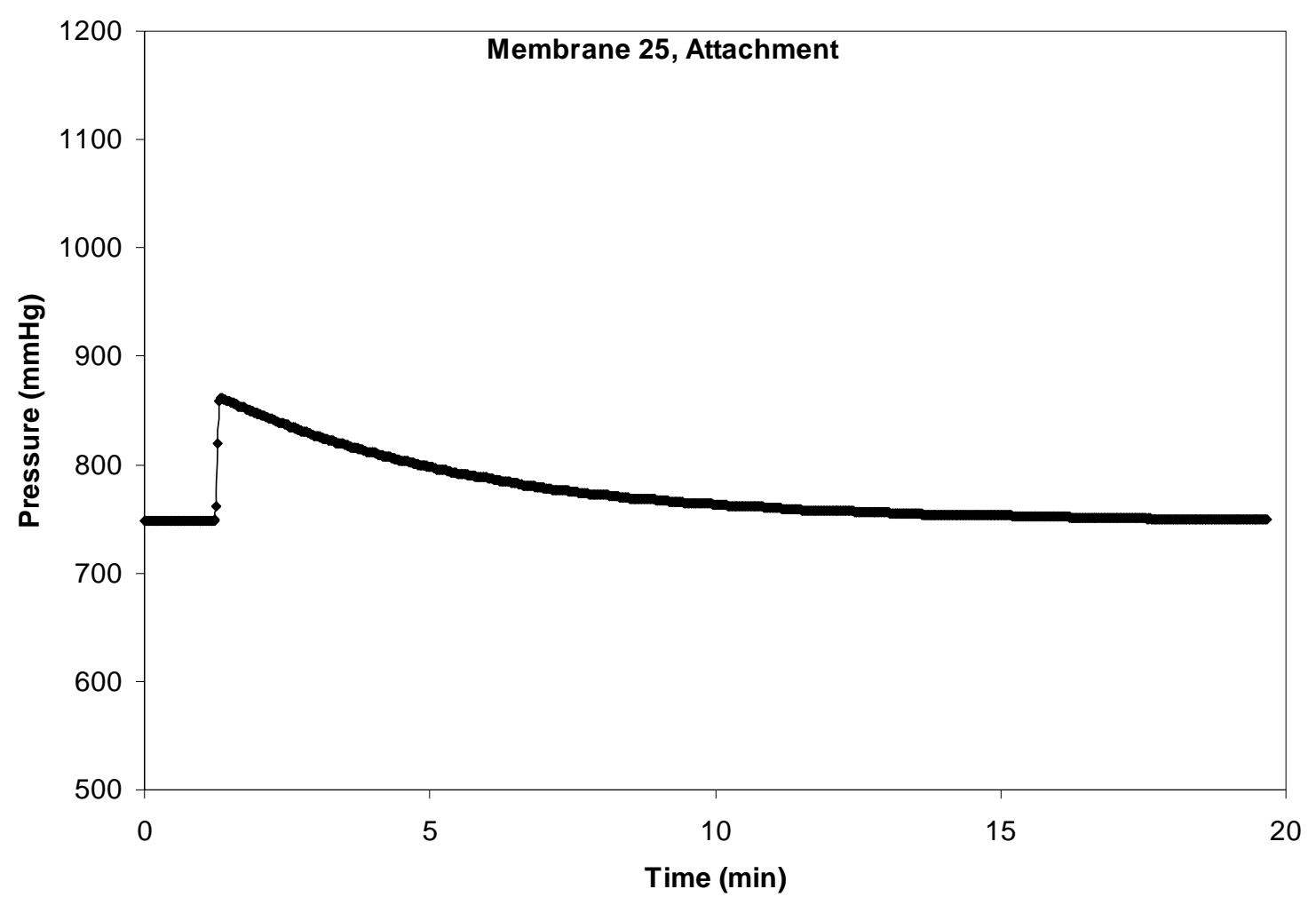

Membrane 25 was used at Multnomah Falls 3 hyporheic from 4/30/2008 to 5/14/2008 with MiniSonde 43656.

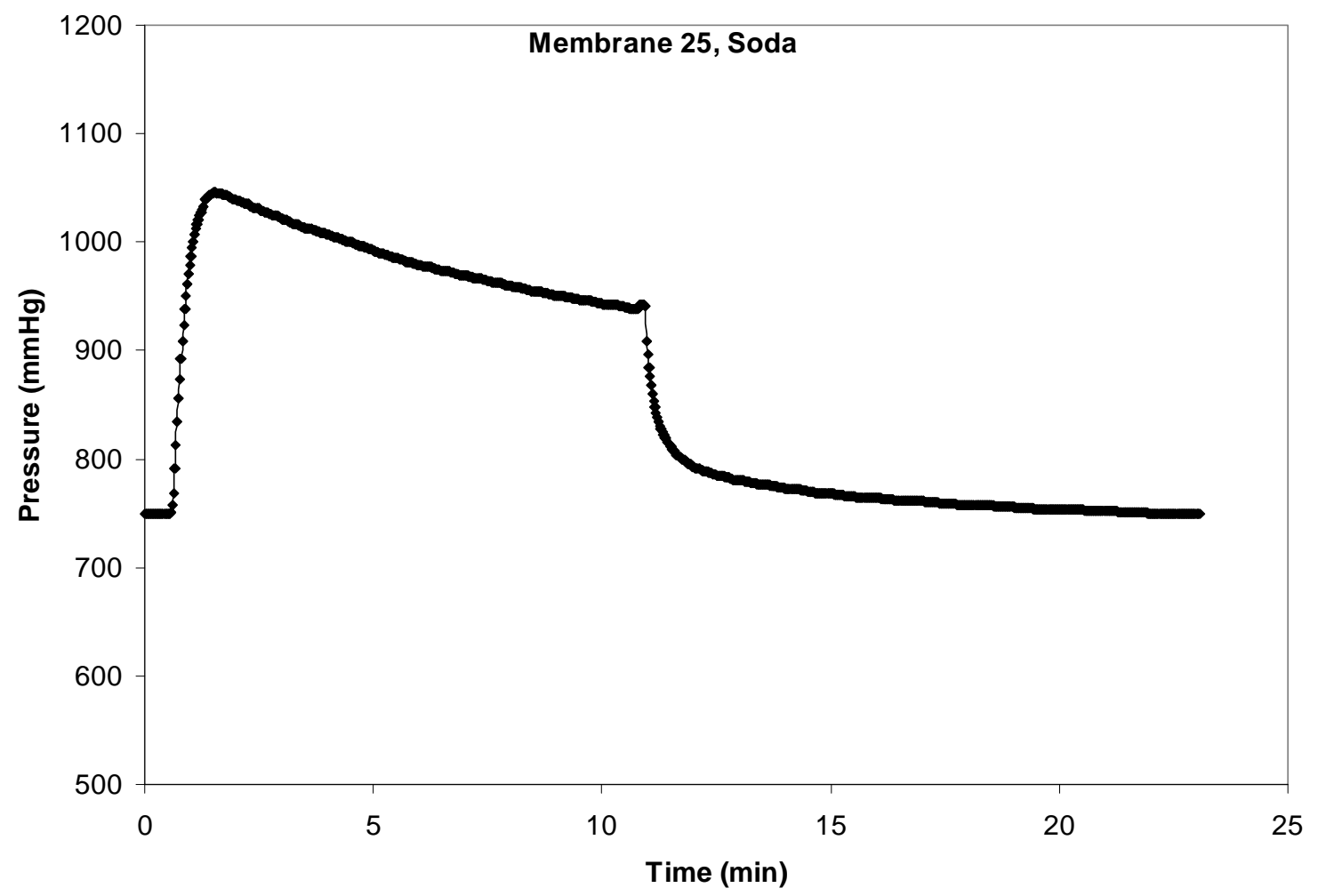




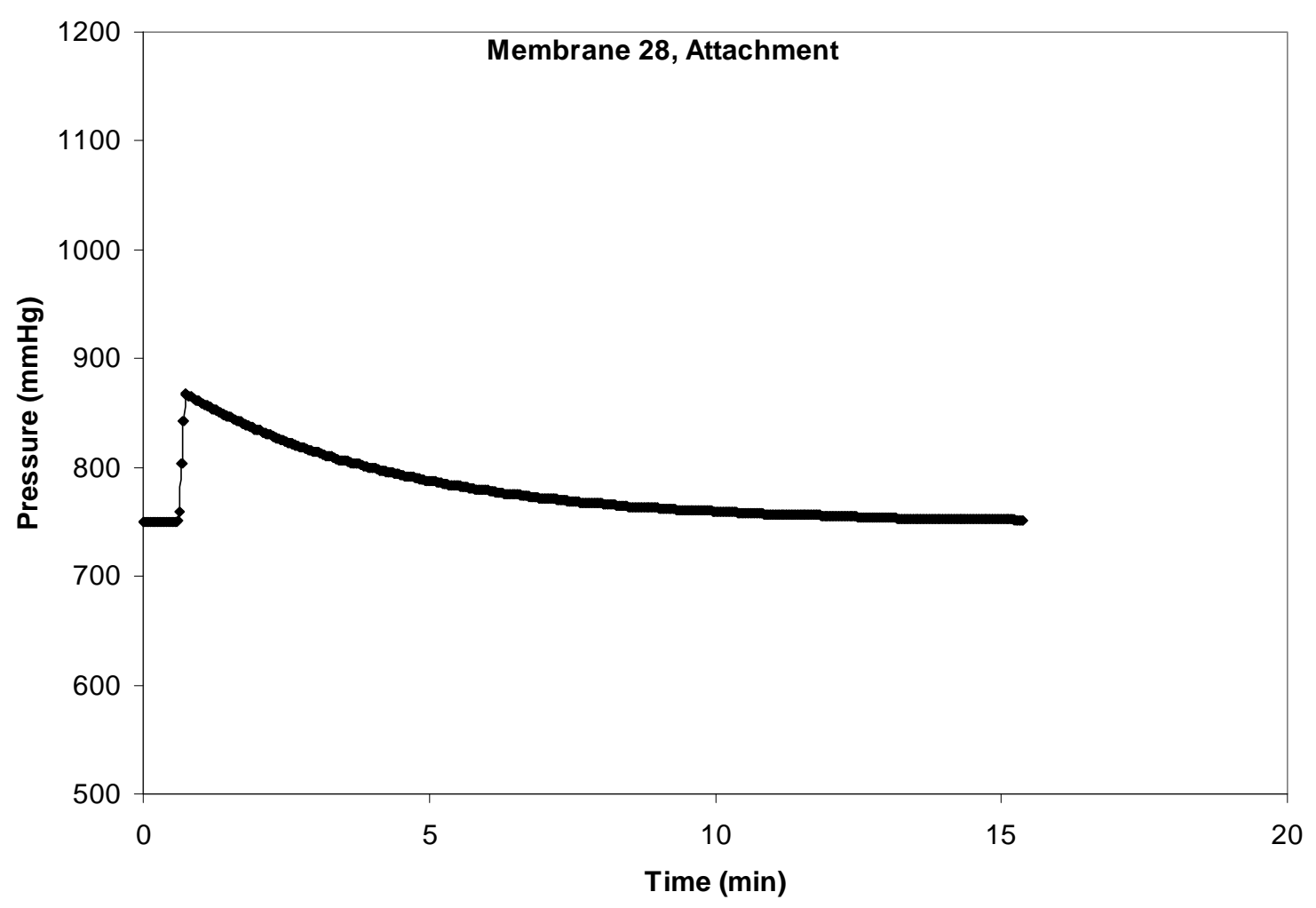

Membrane 28 was used at Ives 5 river from 4/30/2008 to 5/14/2008 with MiniSonde 43639.

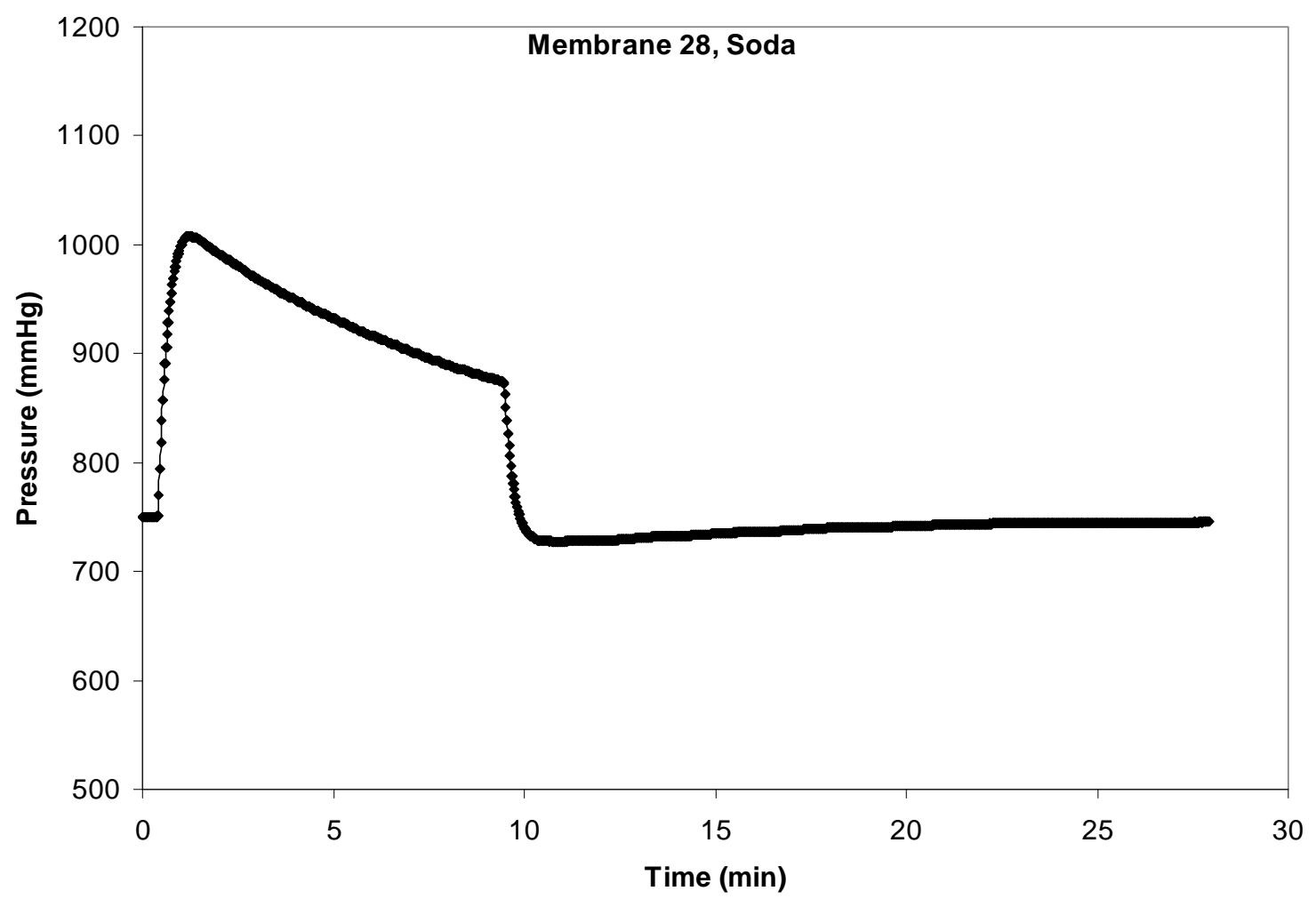




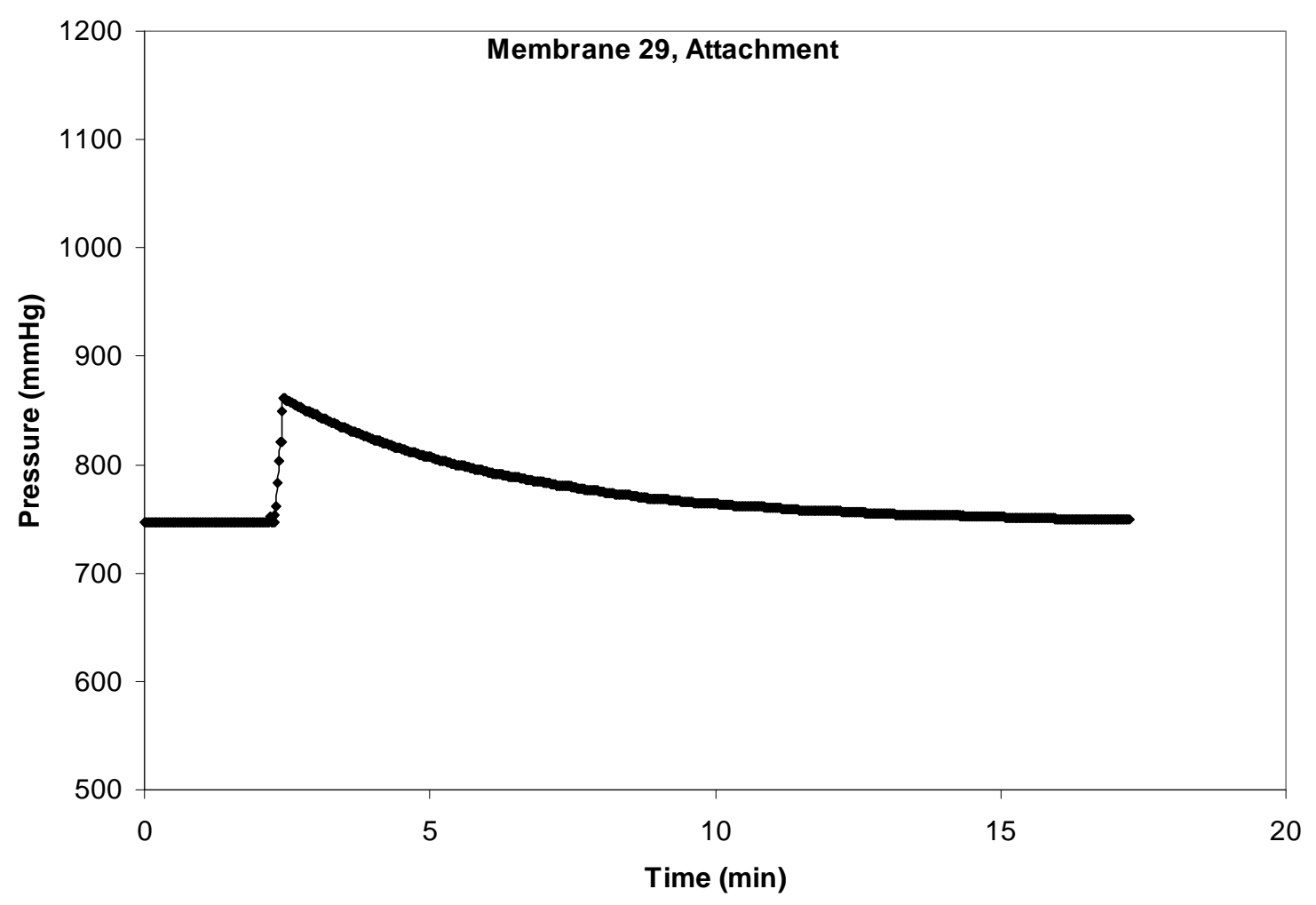

Membrane 29 was used at Multnomah Falls 1 river from 4/30/2008 to 5/14/2008 with MiniSonde 44927.

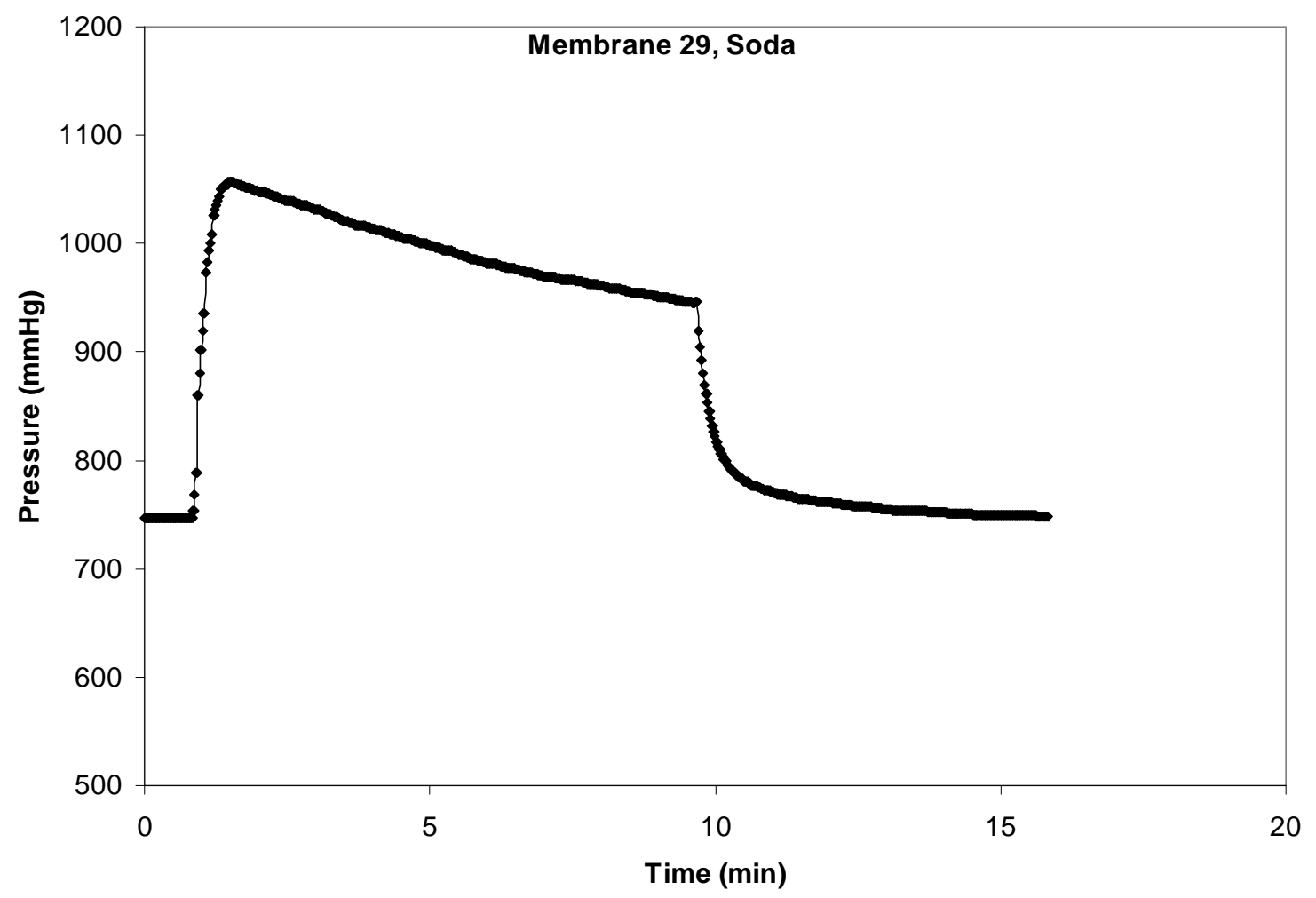




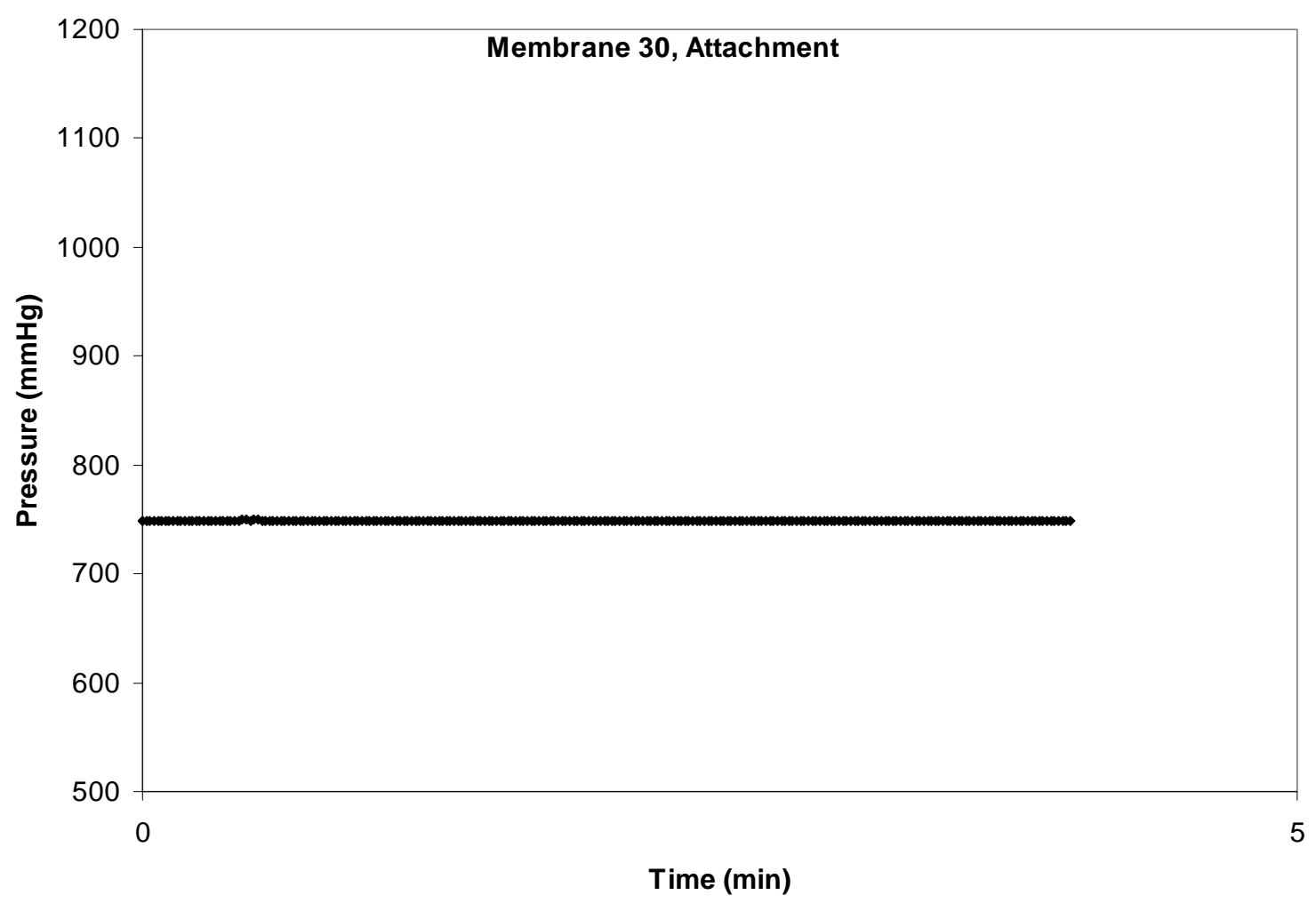

Membrane 30 was used at Ives 2 river from 4/30/2008 to 5/14/2008 with MiniSonde 44946. This membrane tested badly so these data were thrown out.

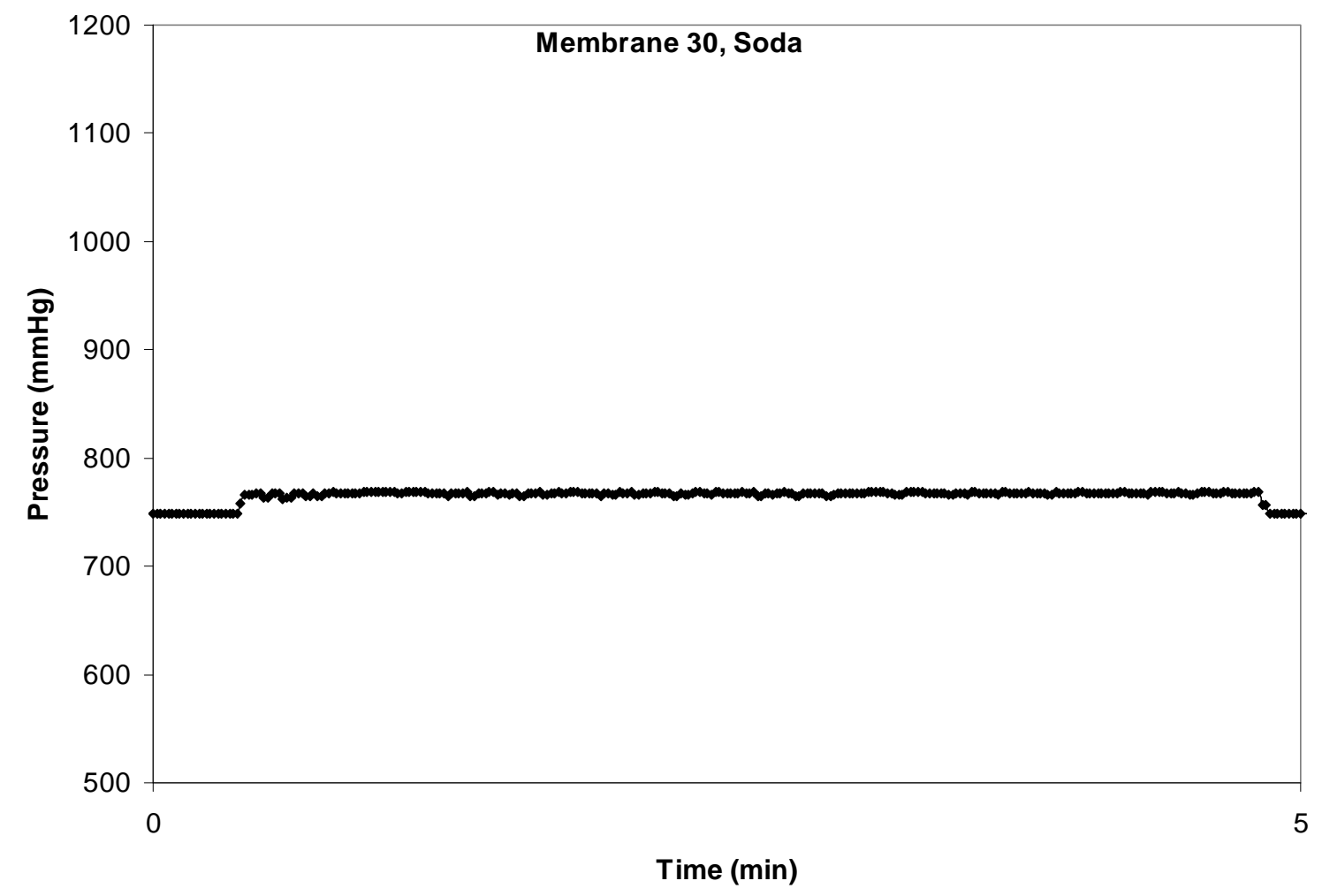




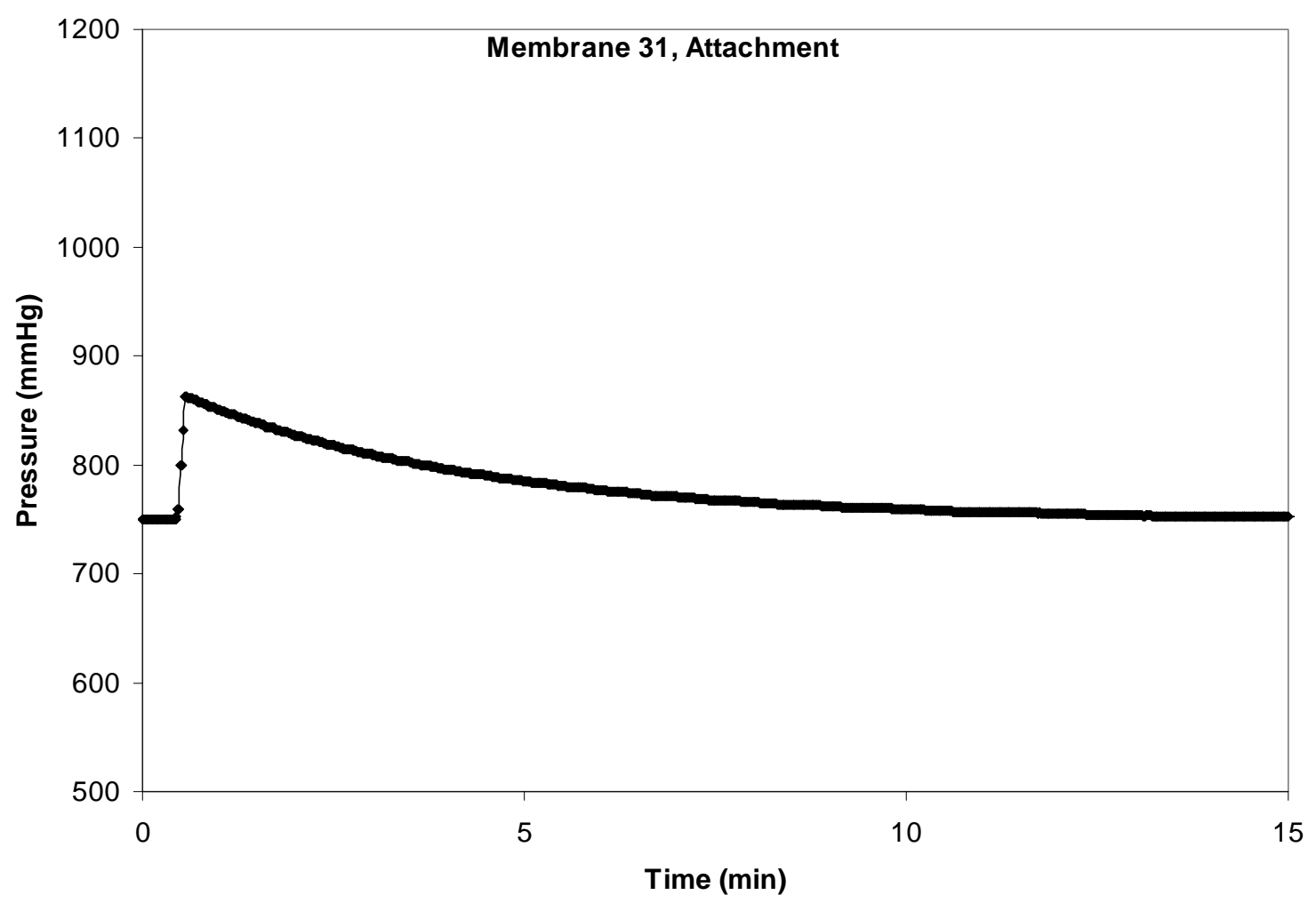

Membrane 31 was used at Ives 2 hyporheic from 4/30/2008 to 5/14/2008 with MiniSonde 44947.

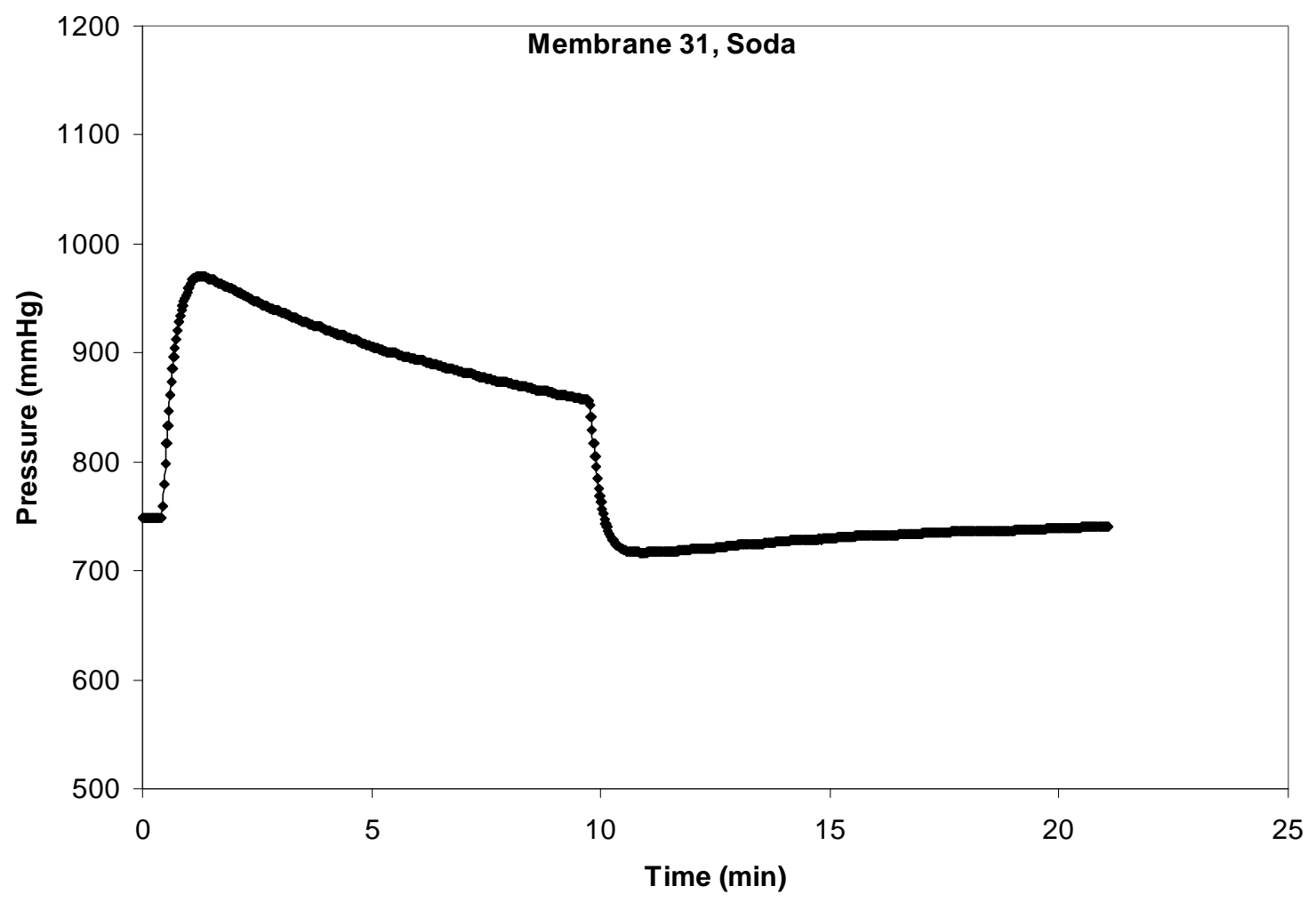




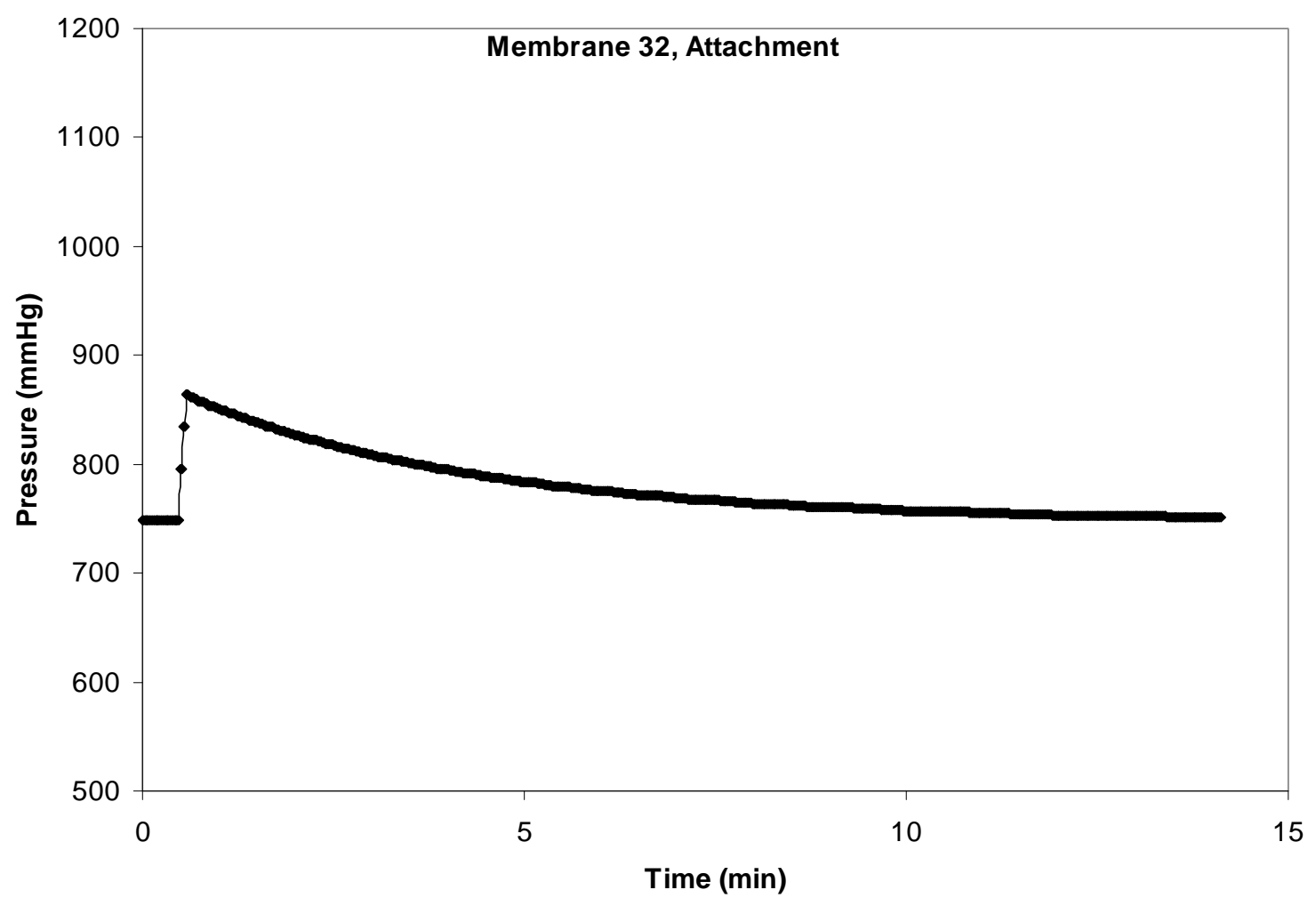

Membrane 32 was used at Ives 1 river from 4/30/2008 to 5/14/2008 with MiniSonde 43655.

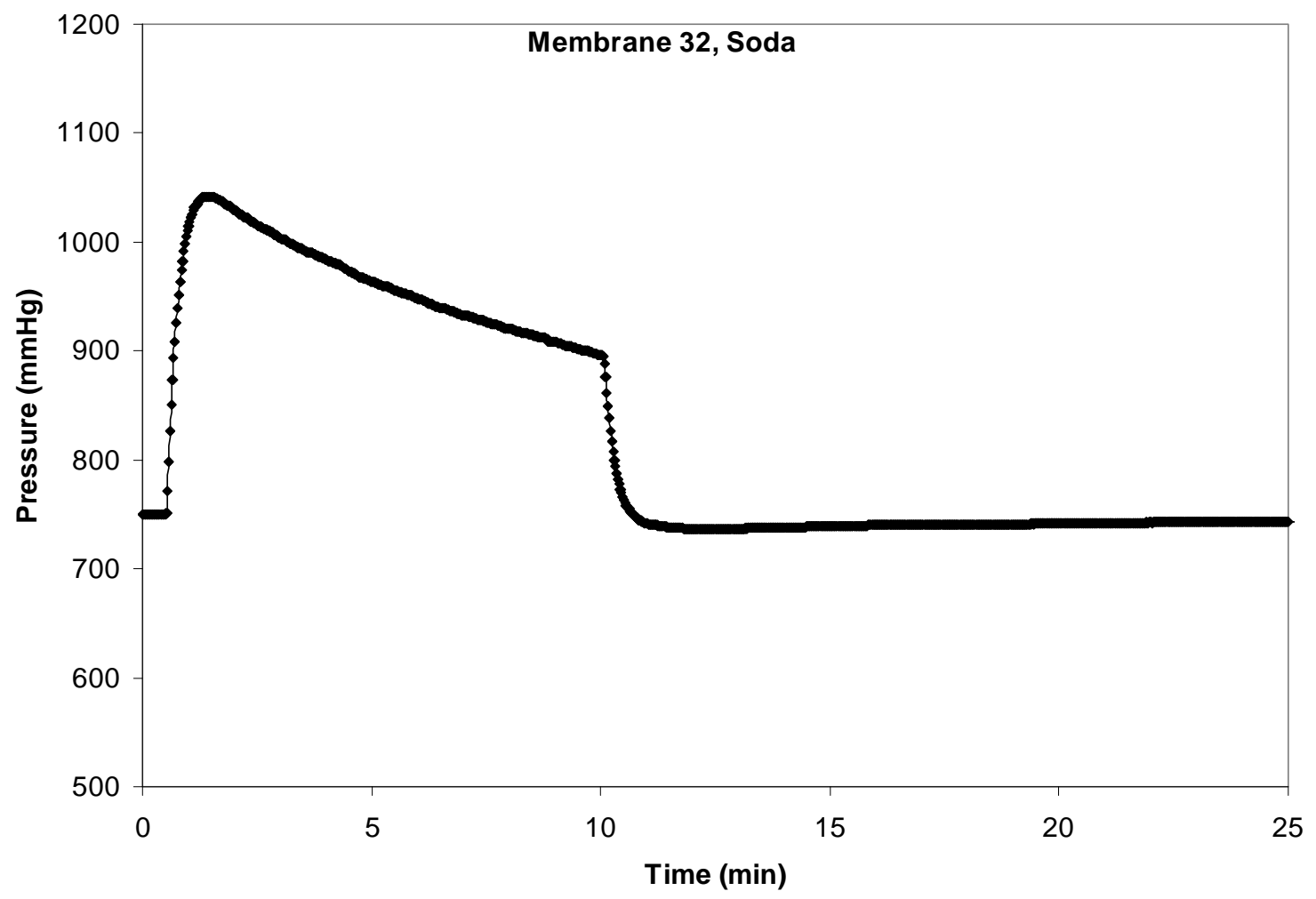




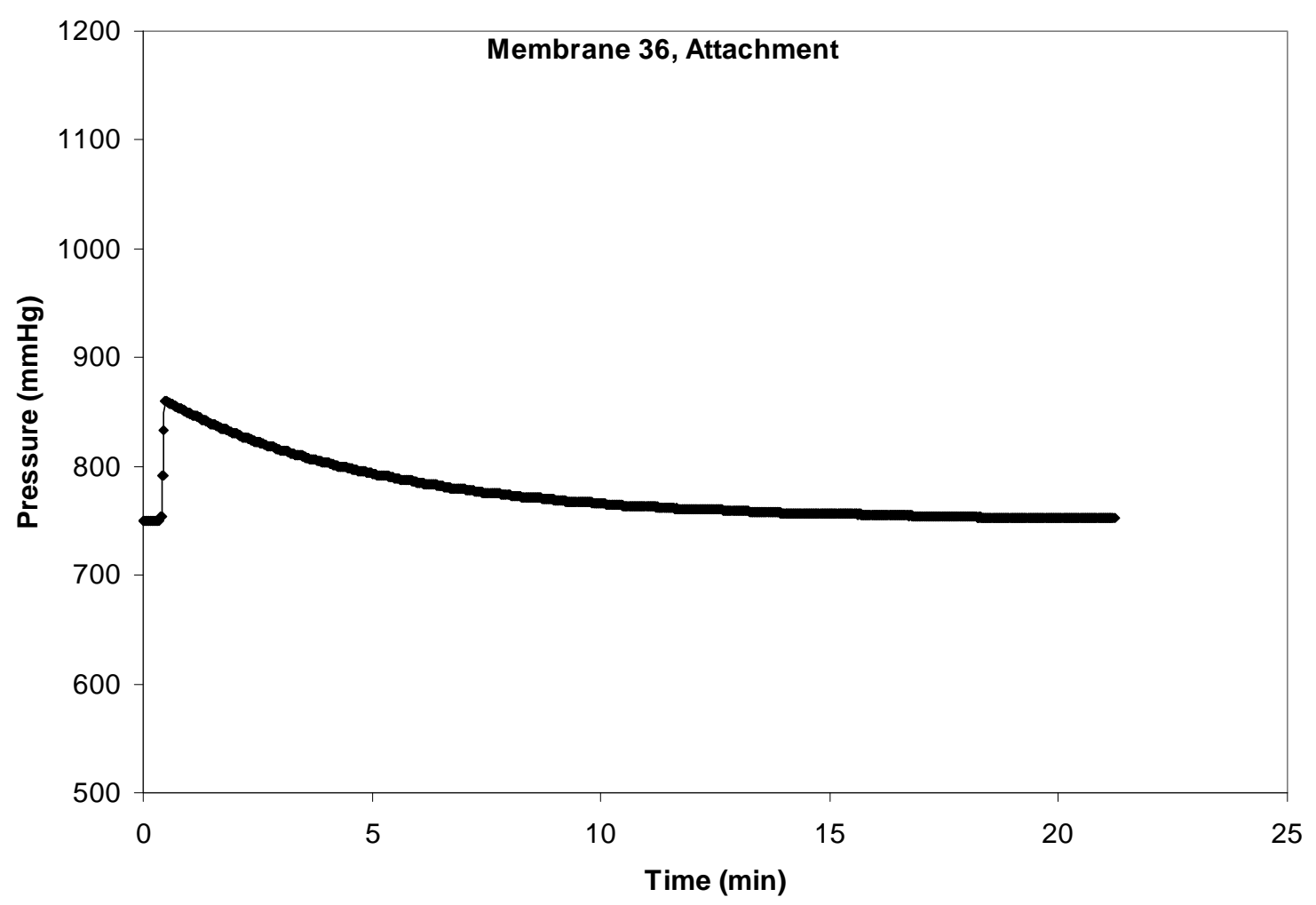

Membrane 36 was used as the control for the side-by-side after deployment 5 with MiniSonde 40347.

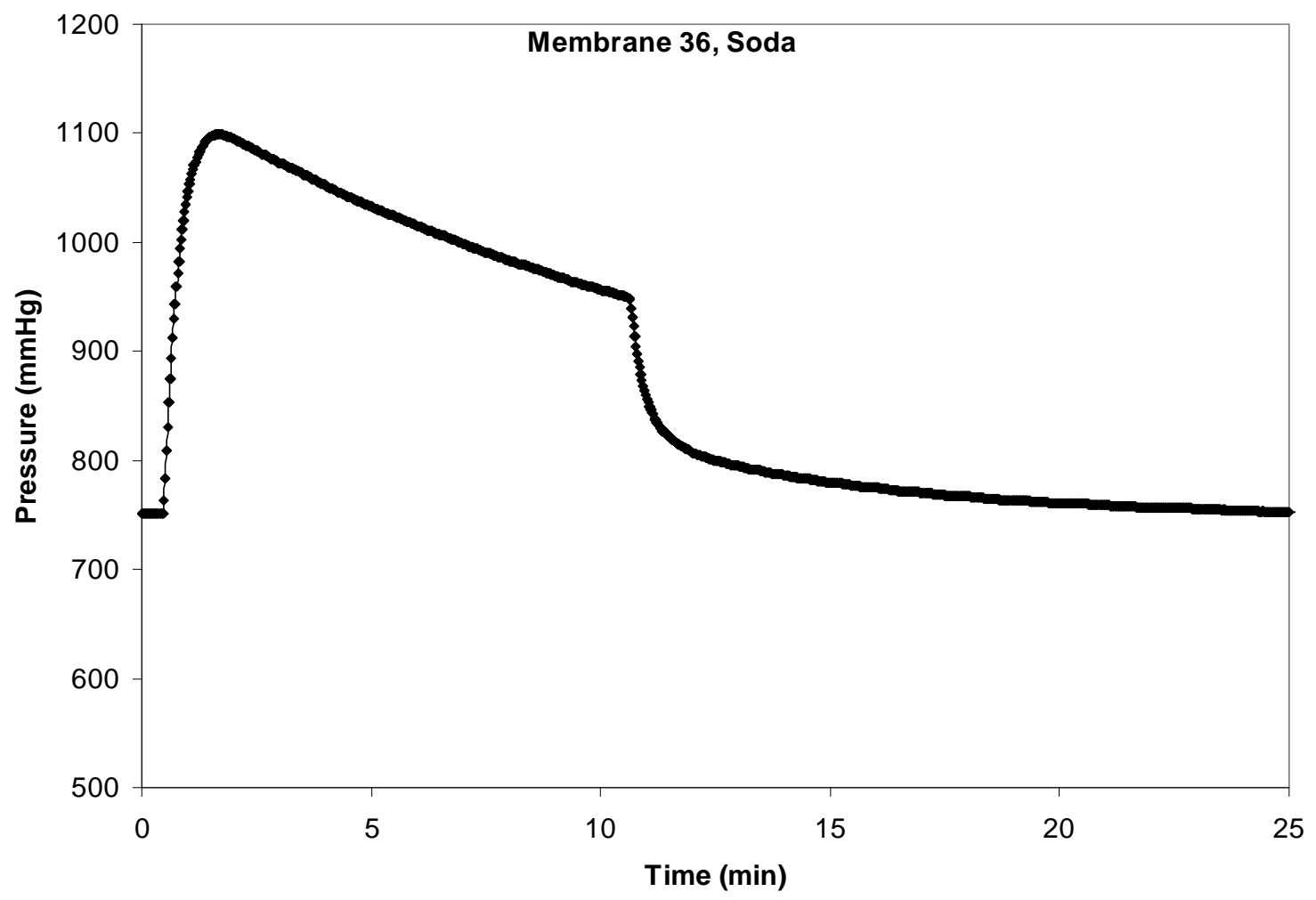




\section{Post Deployment 6}



Membrane 2 was used at Ives 2 river from 5/14/2008 to 5/15/2008 with MiniSonde 44946.

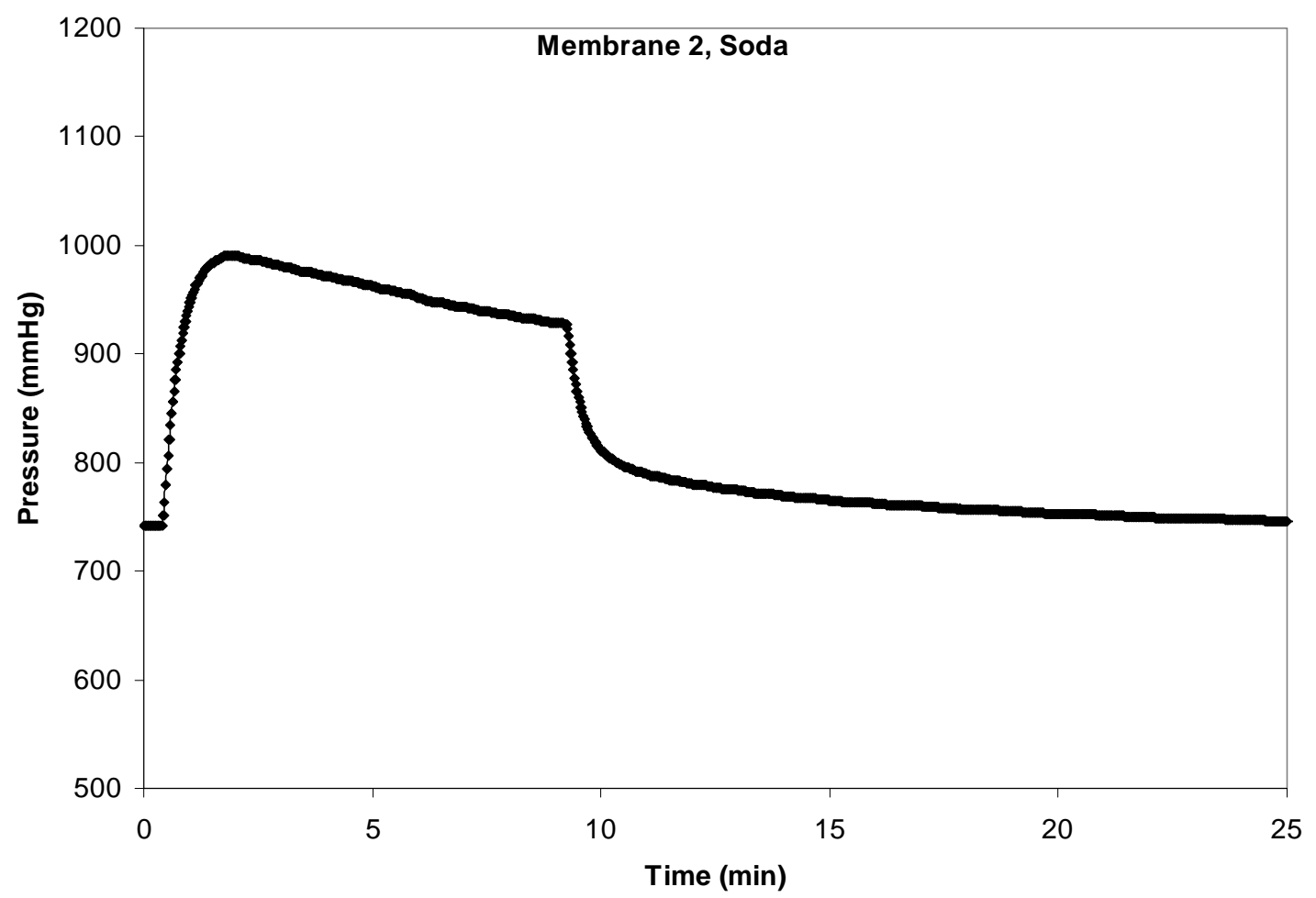




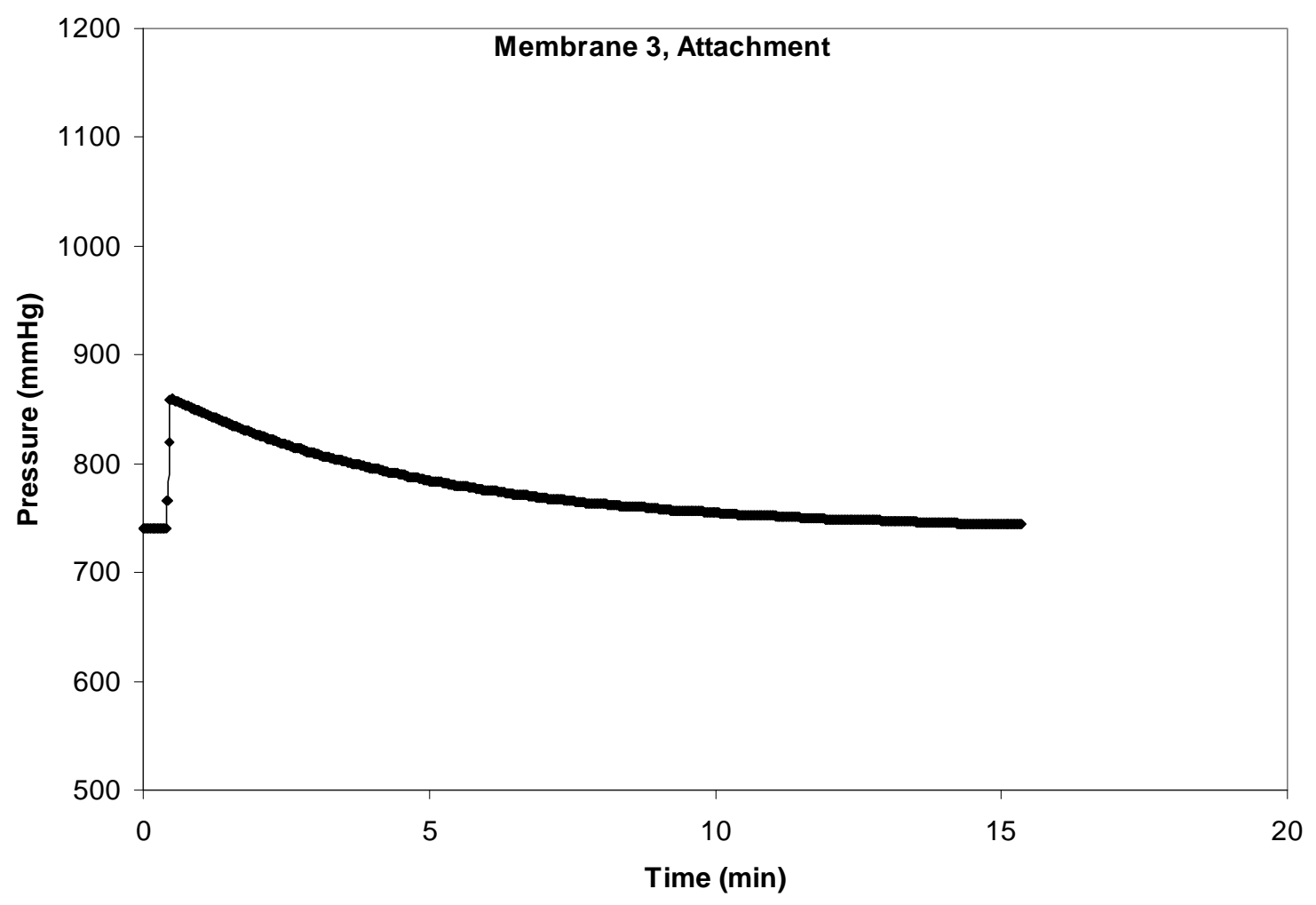

Membrane 3 was used at Multnomah Falls 1 hyporheic from 5/14/2008 to 5/15/2008 with MiniSonde 44945.






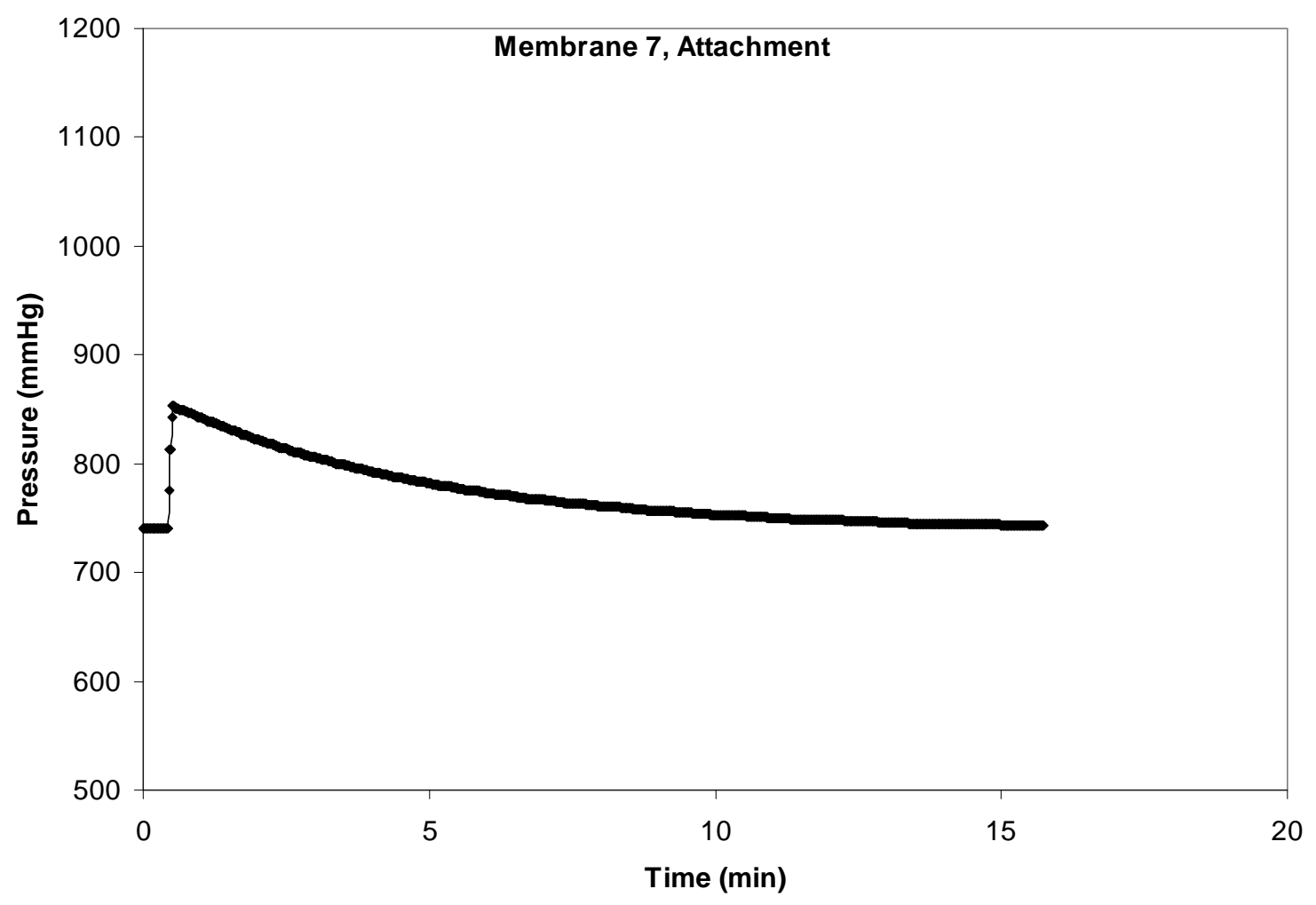

Membrane 7 was used at Ives 1 hyporheic from 5/14/2008 to 5/15/2008 with MiniSonde 43659.

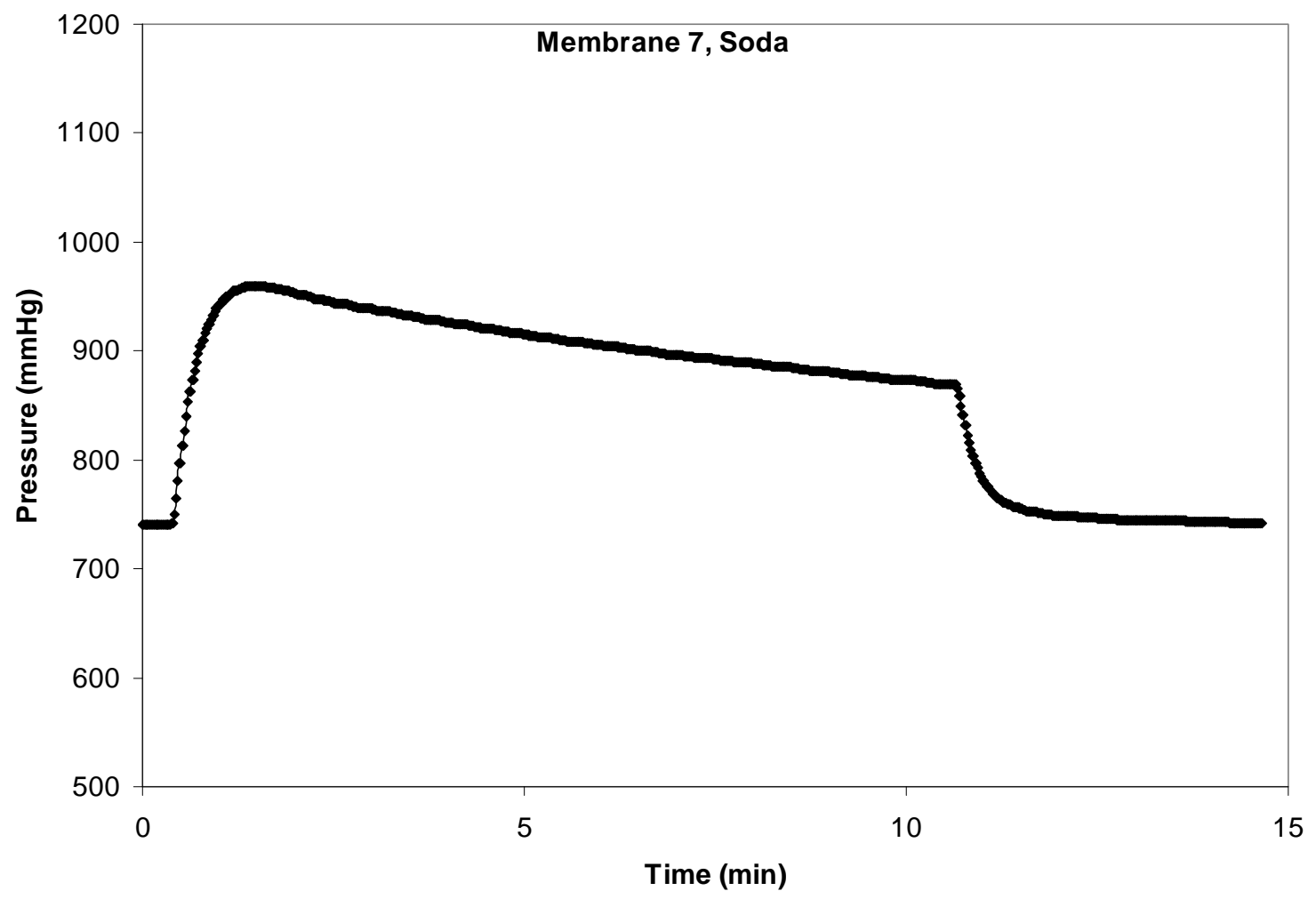




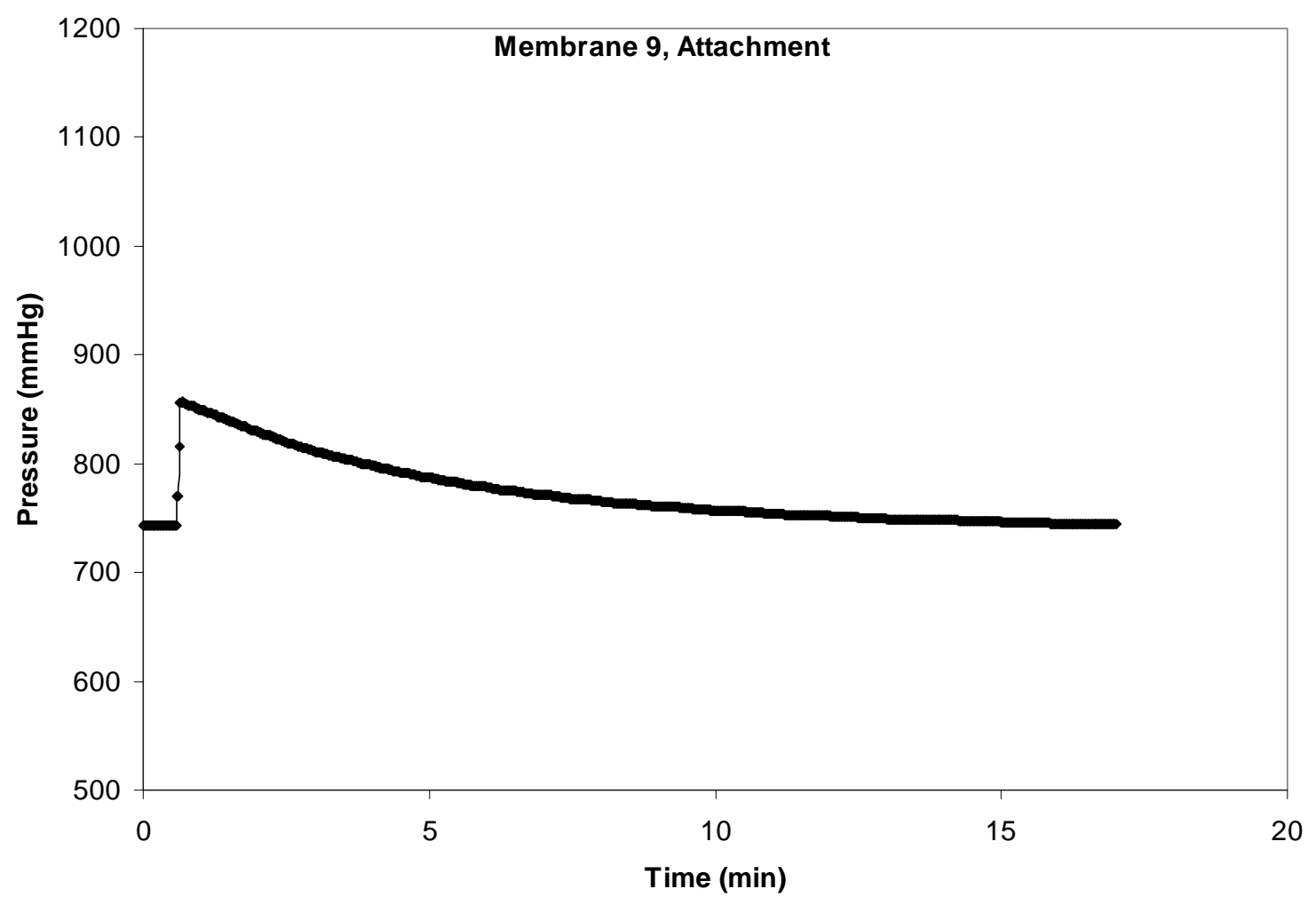

Membrane 9 was used at Multnomah Falls 3 hyporheic from 5/14/2008 to 5/15/2008 with MiniSonde 43656.

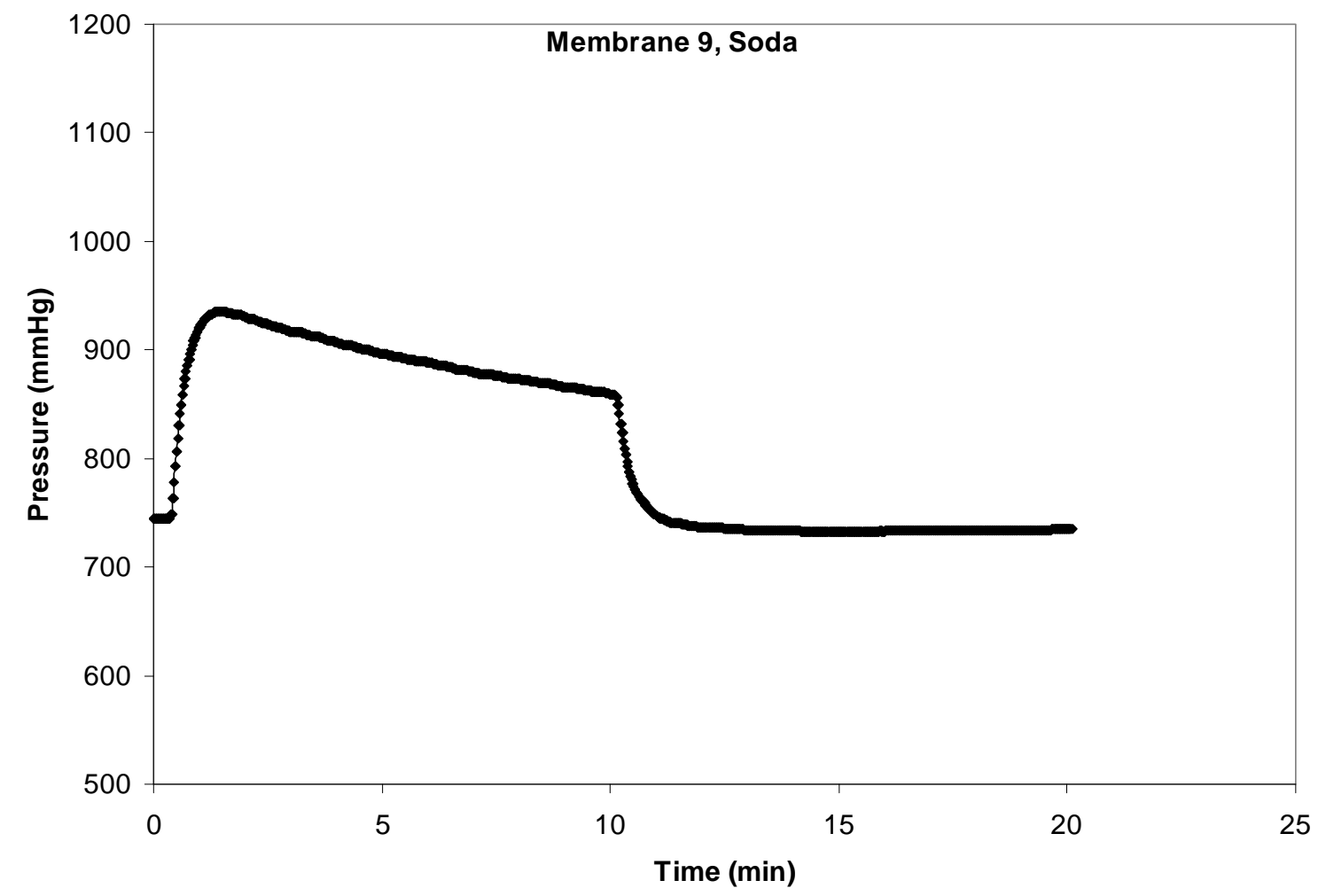




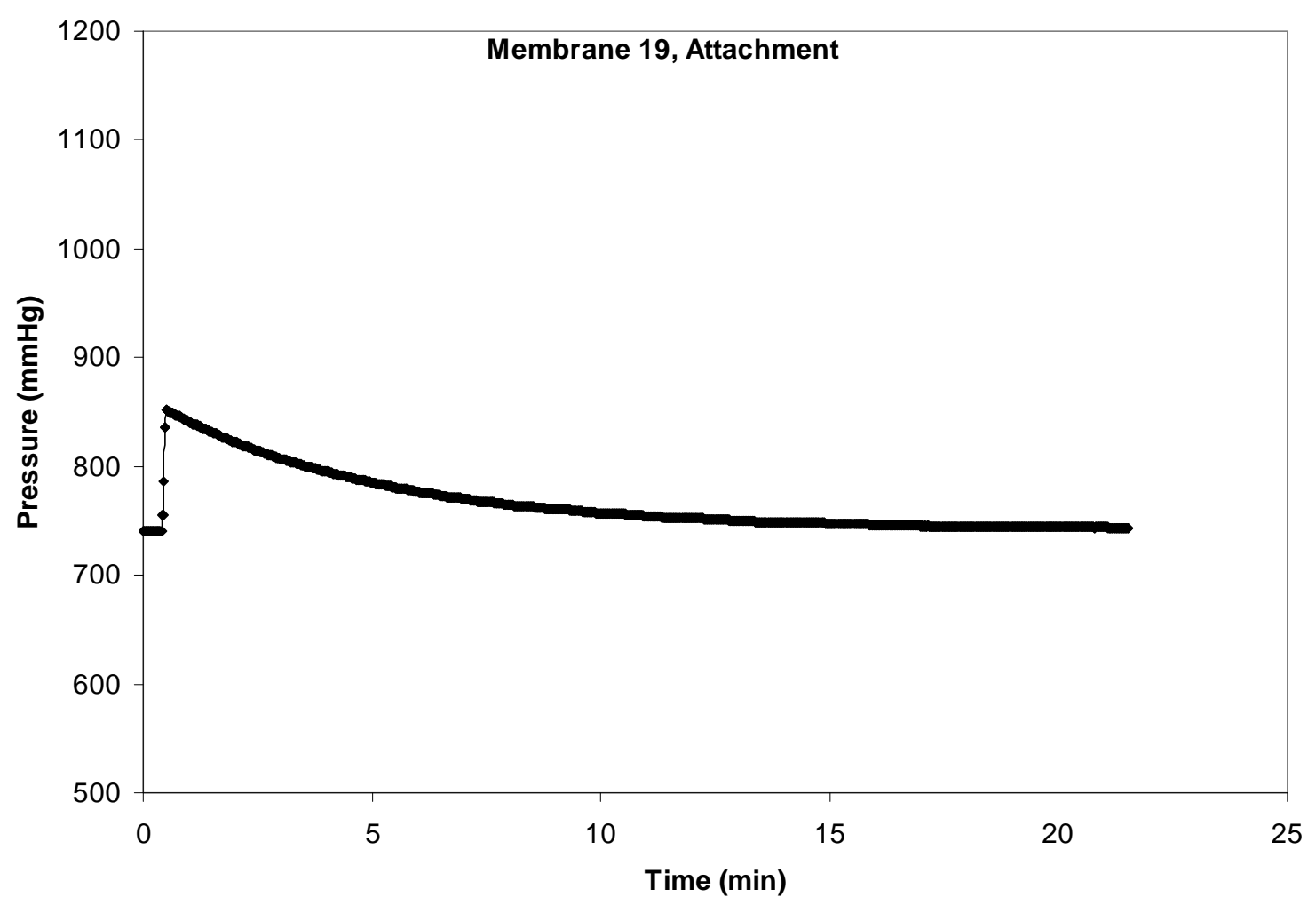

Membrane 19 was used at Ives 2 hyporheic from 5/14/2008 to 5/15/2008 with MiniSonde 44947.

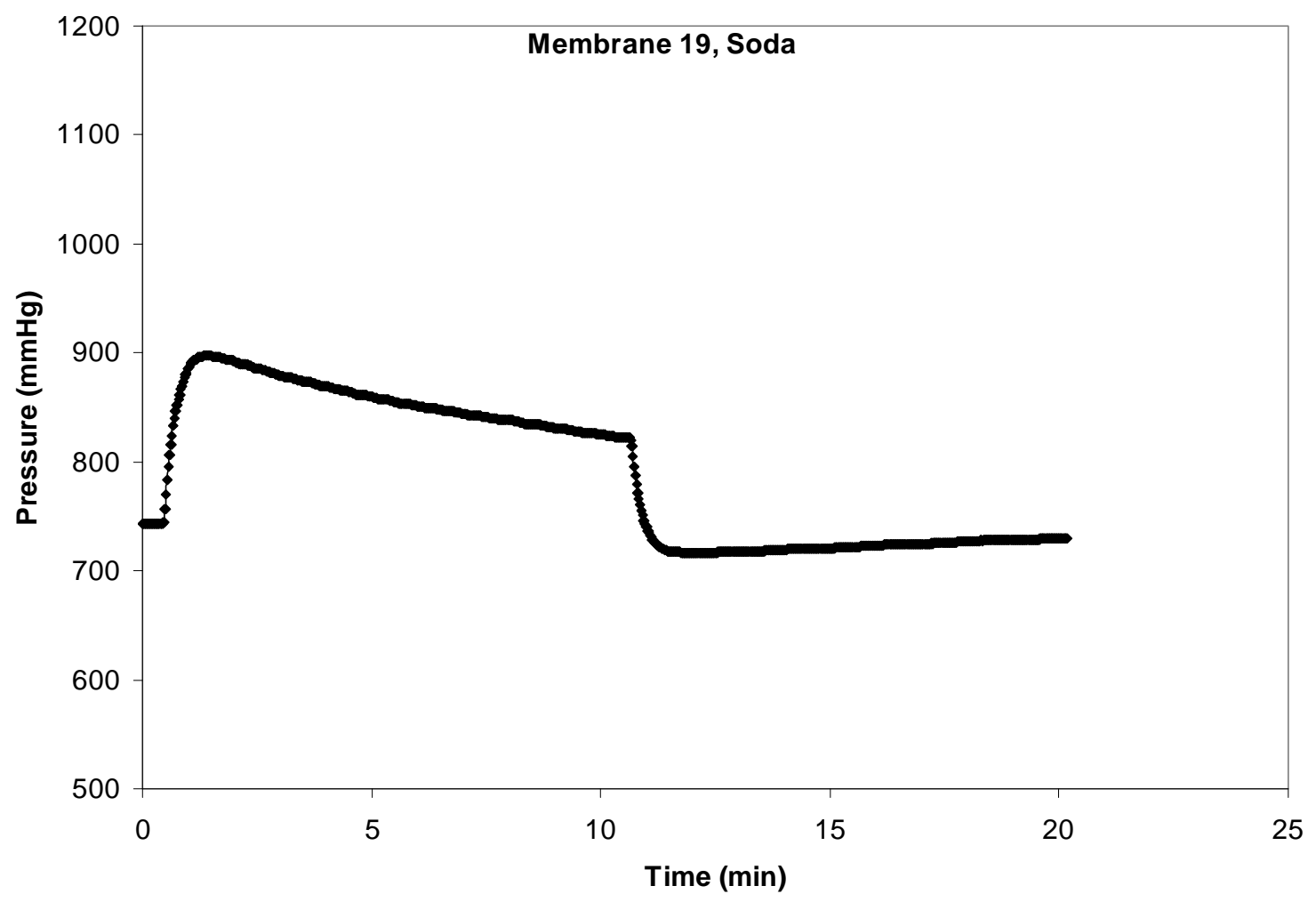




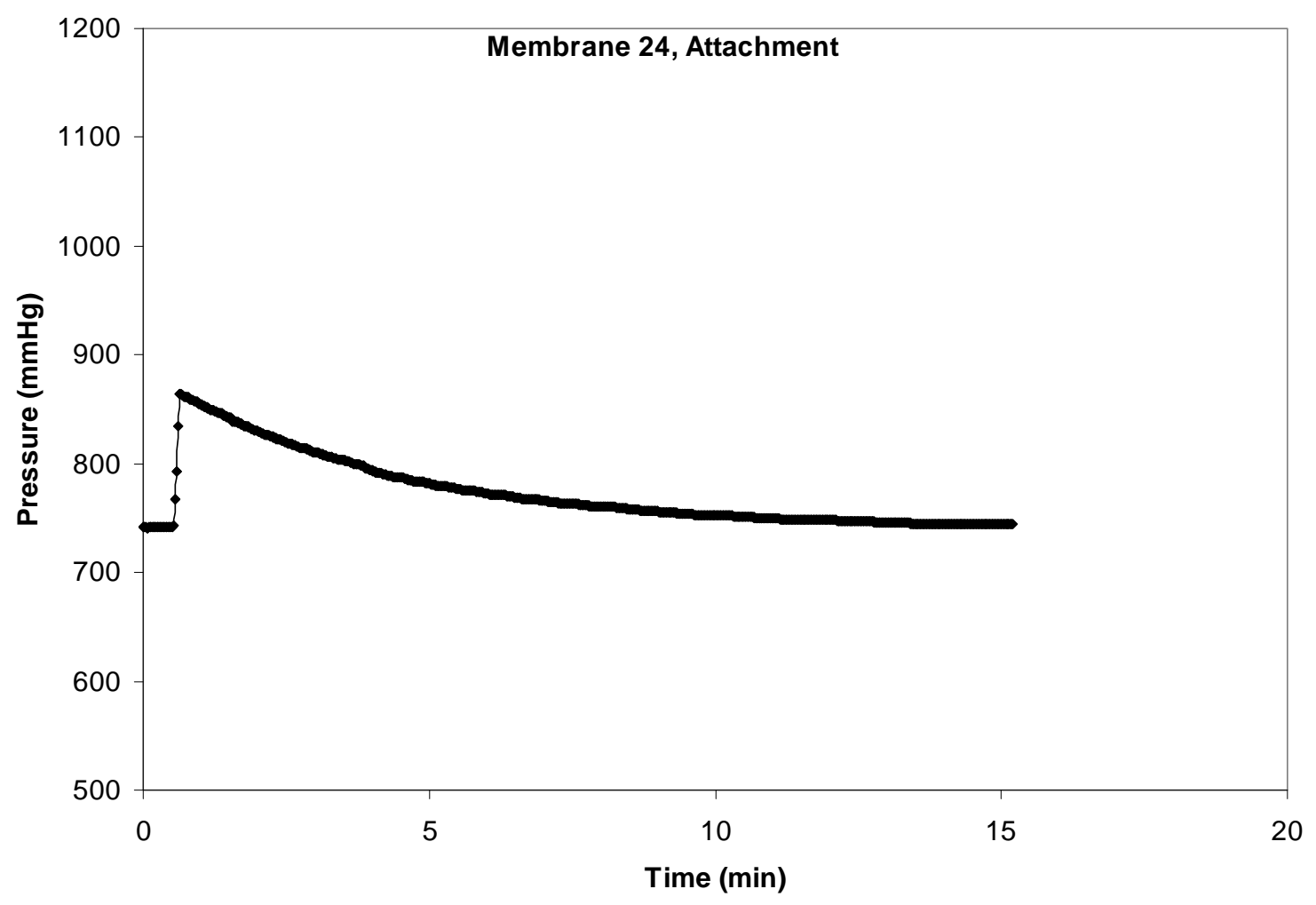

Membrane 24 was used at Ives 3 hyporheic from 5/14/2008 to 5/15/2008 with MiniSonde 45451.

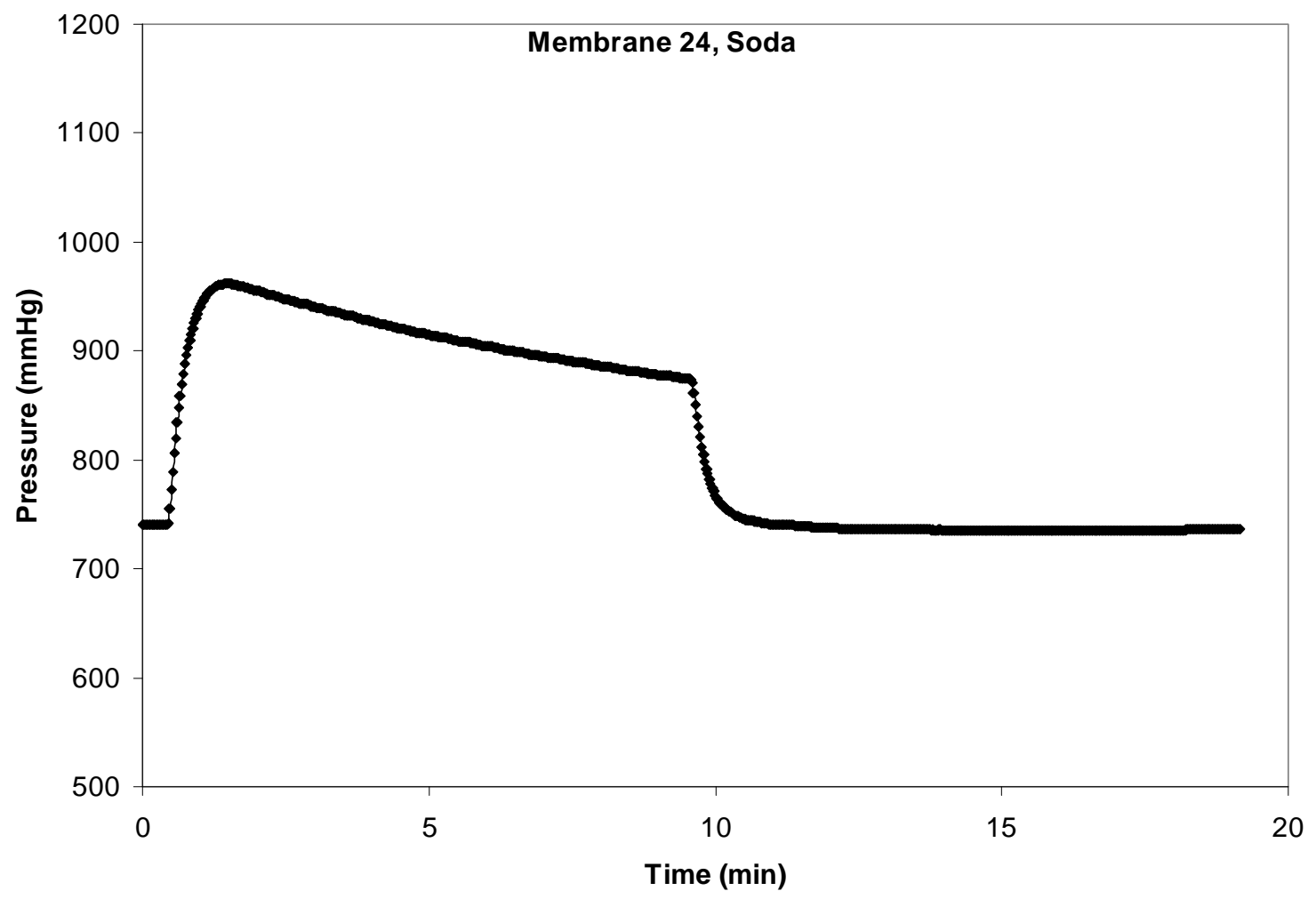




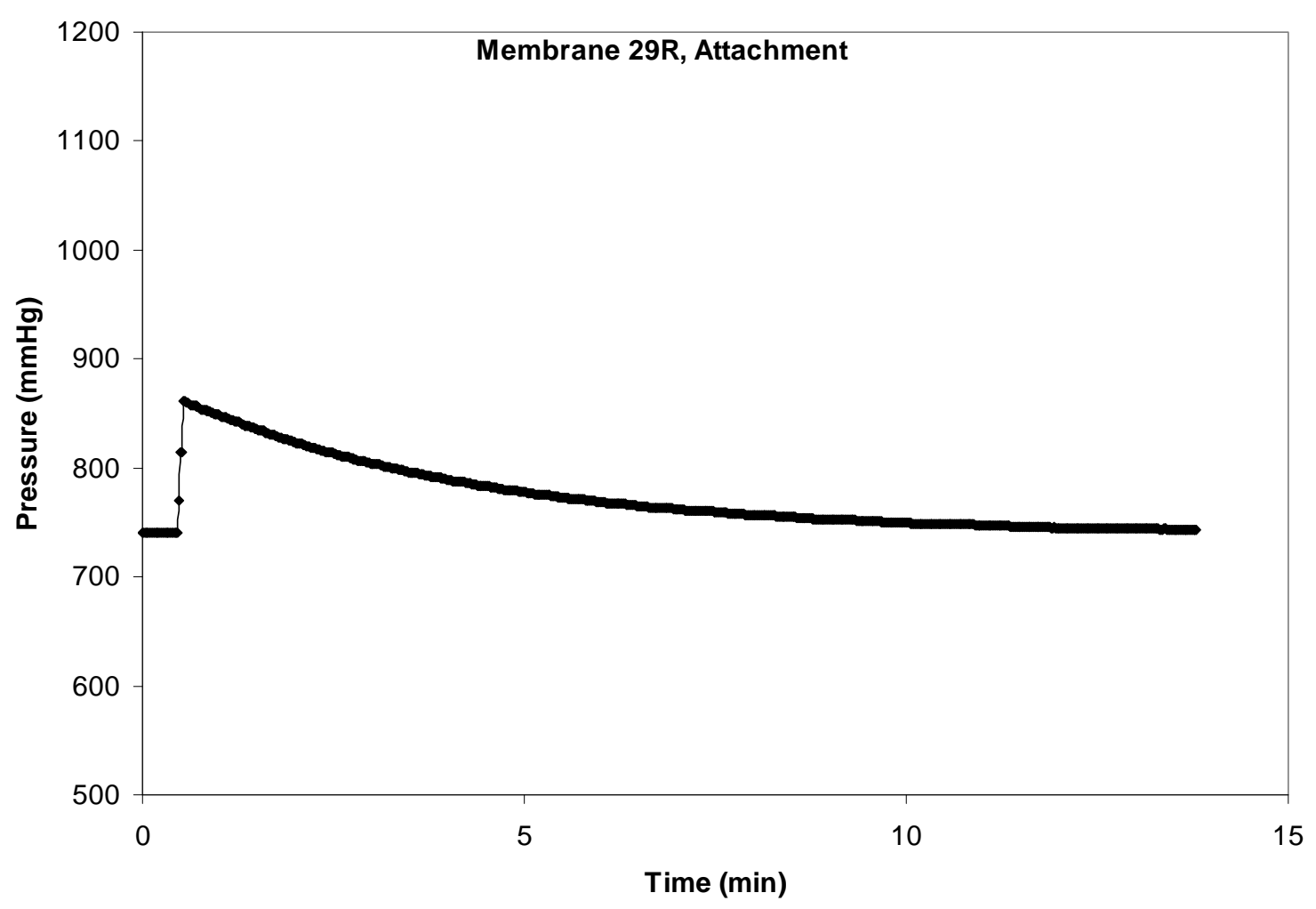

Membrane 29R was used at Ives 1 river from 5/14/2008 to 5/15/2008 with MiniSonde 43655.

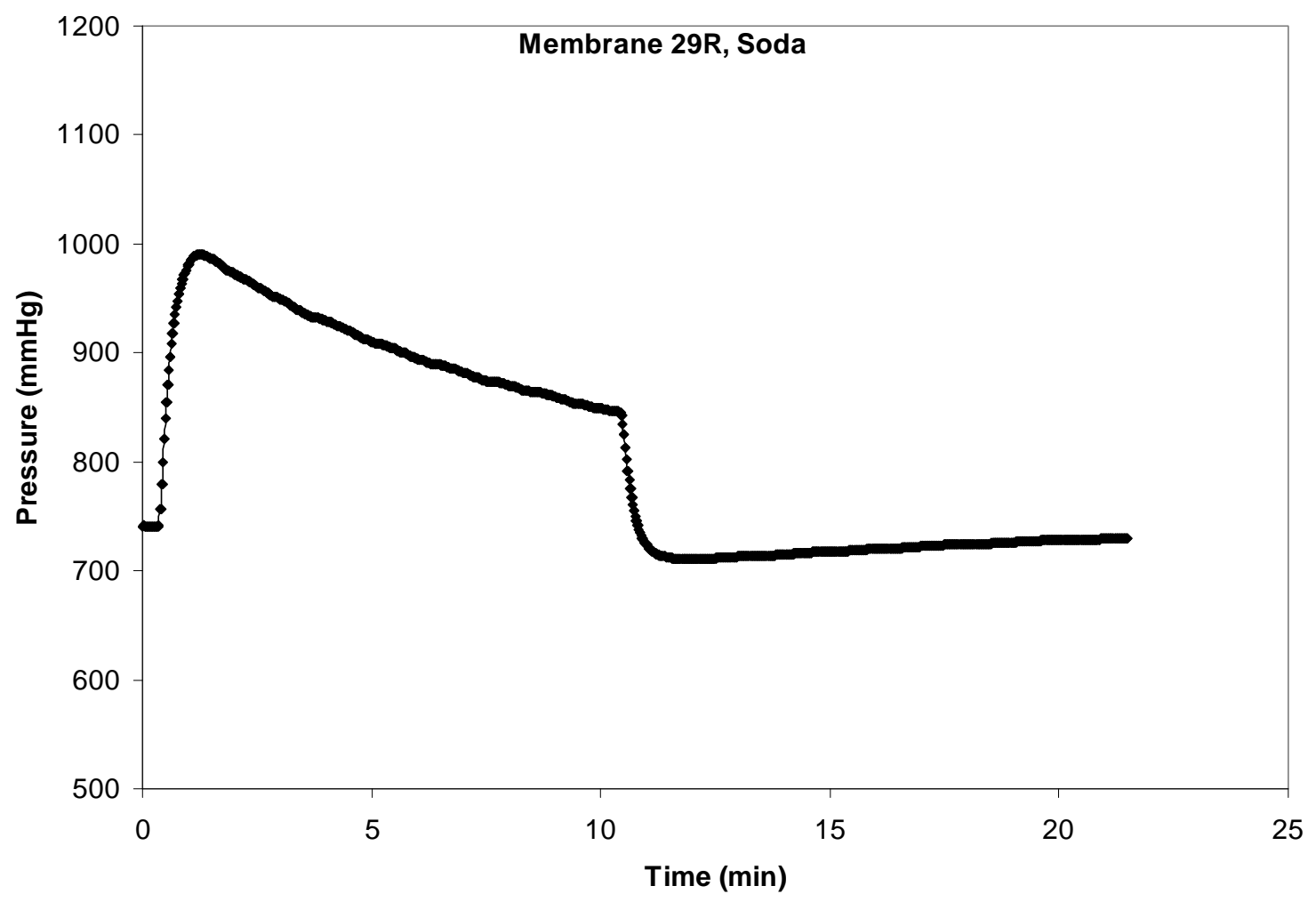




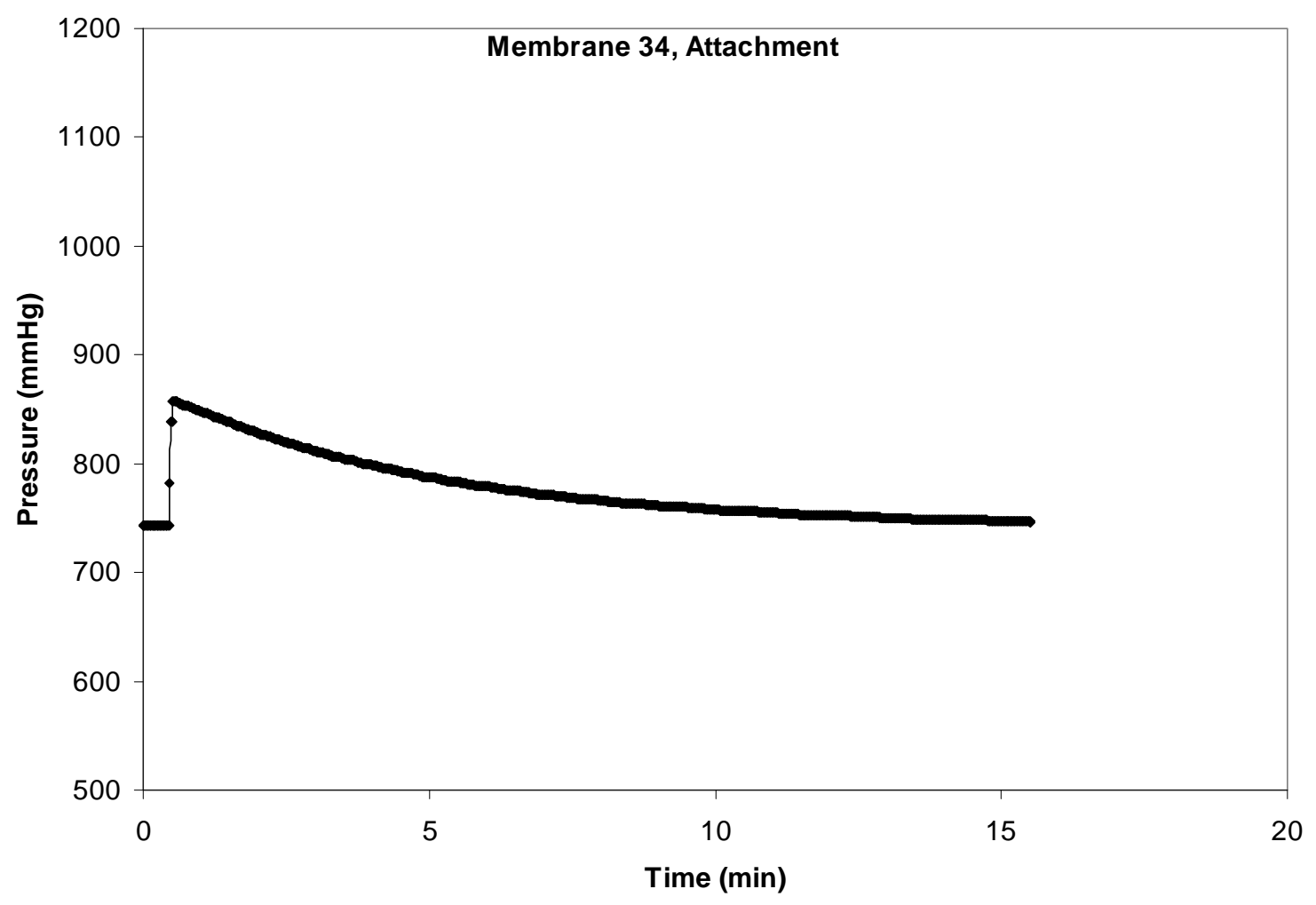

Membrane 34 was used at Multnomah Falls 3 river from 5/14/2008 to 5/15/2008 with MiniSonde 44948.

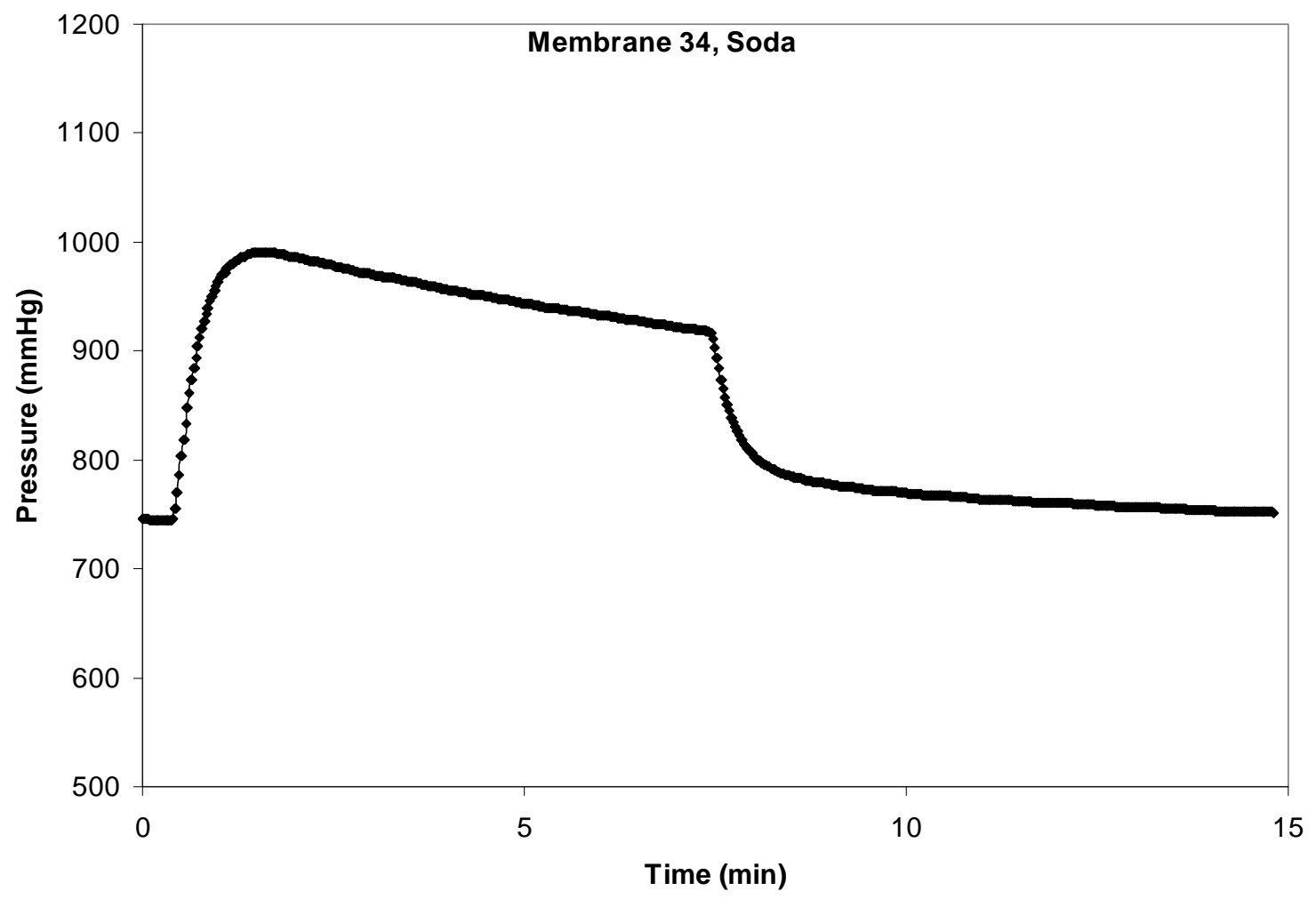




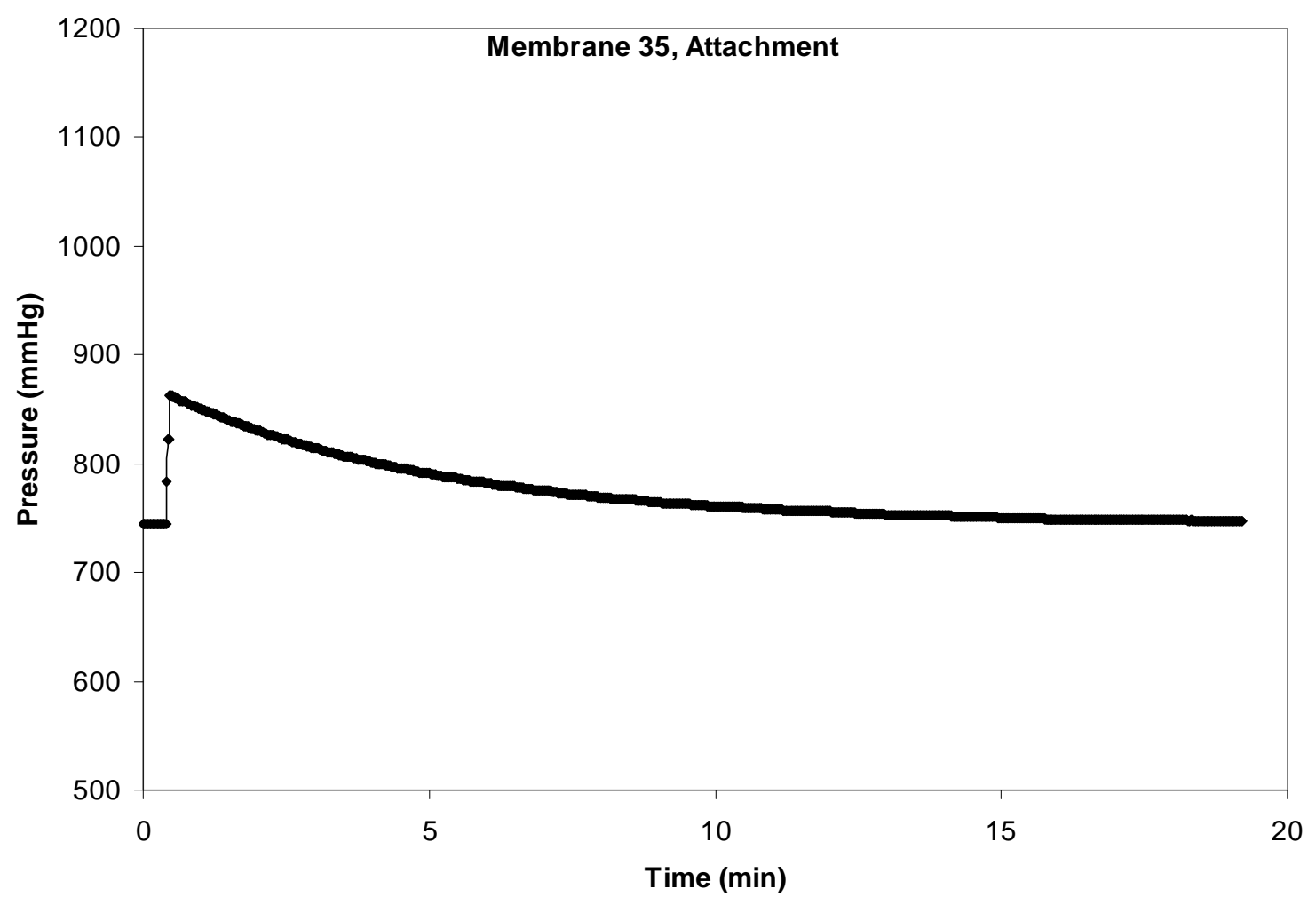

Membrane 35 was used at Multnomah Falls 1 river from 5/14/2008 to 5/15/2008 with MiniSonde 44927.

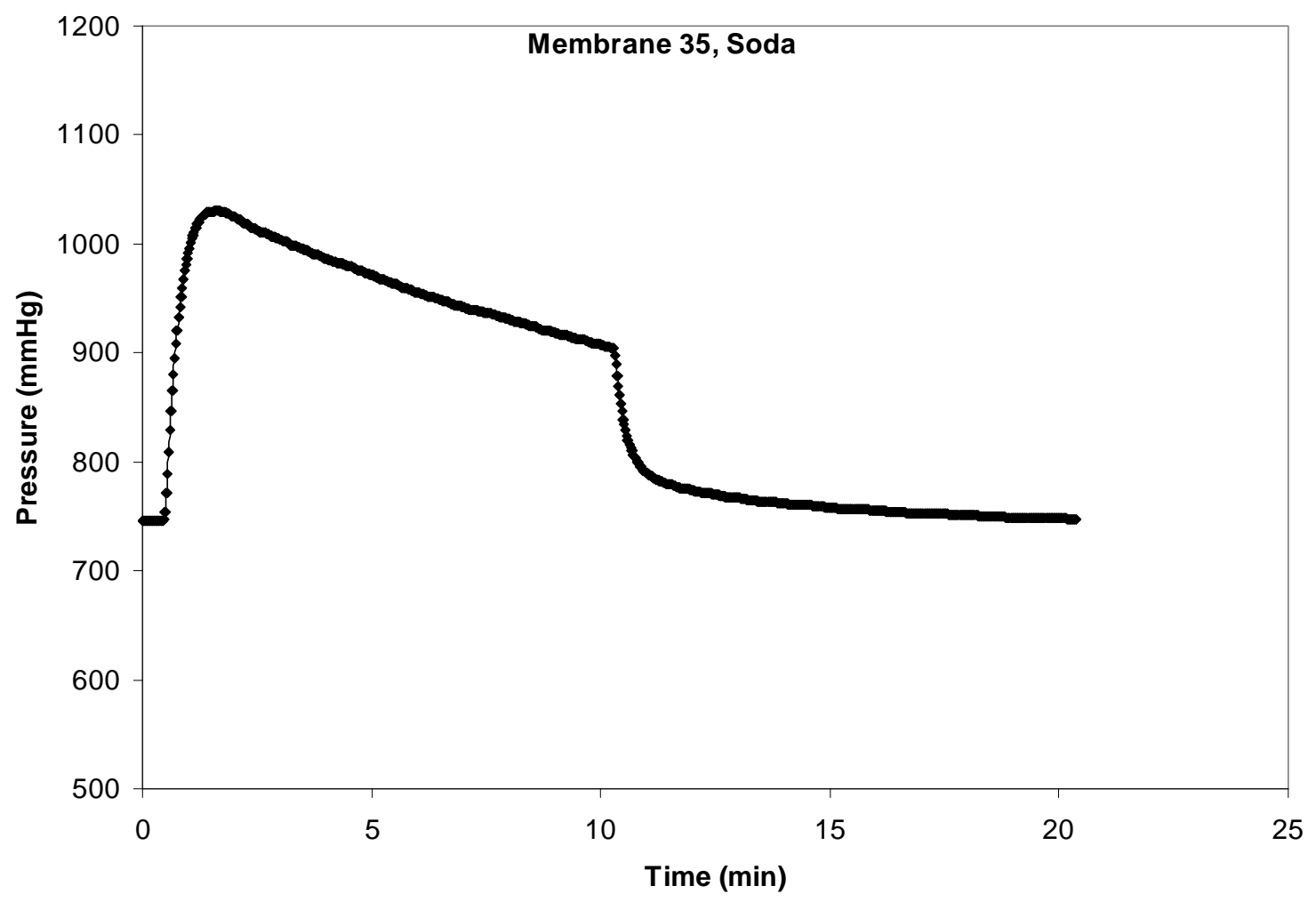




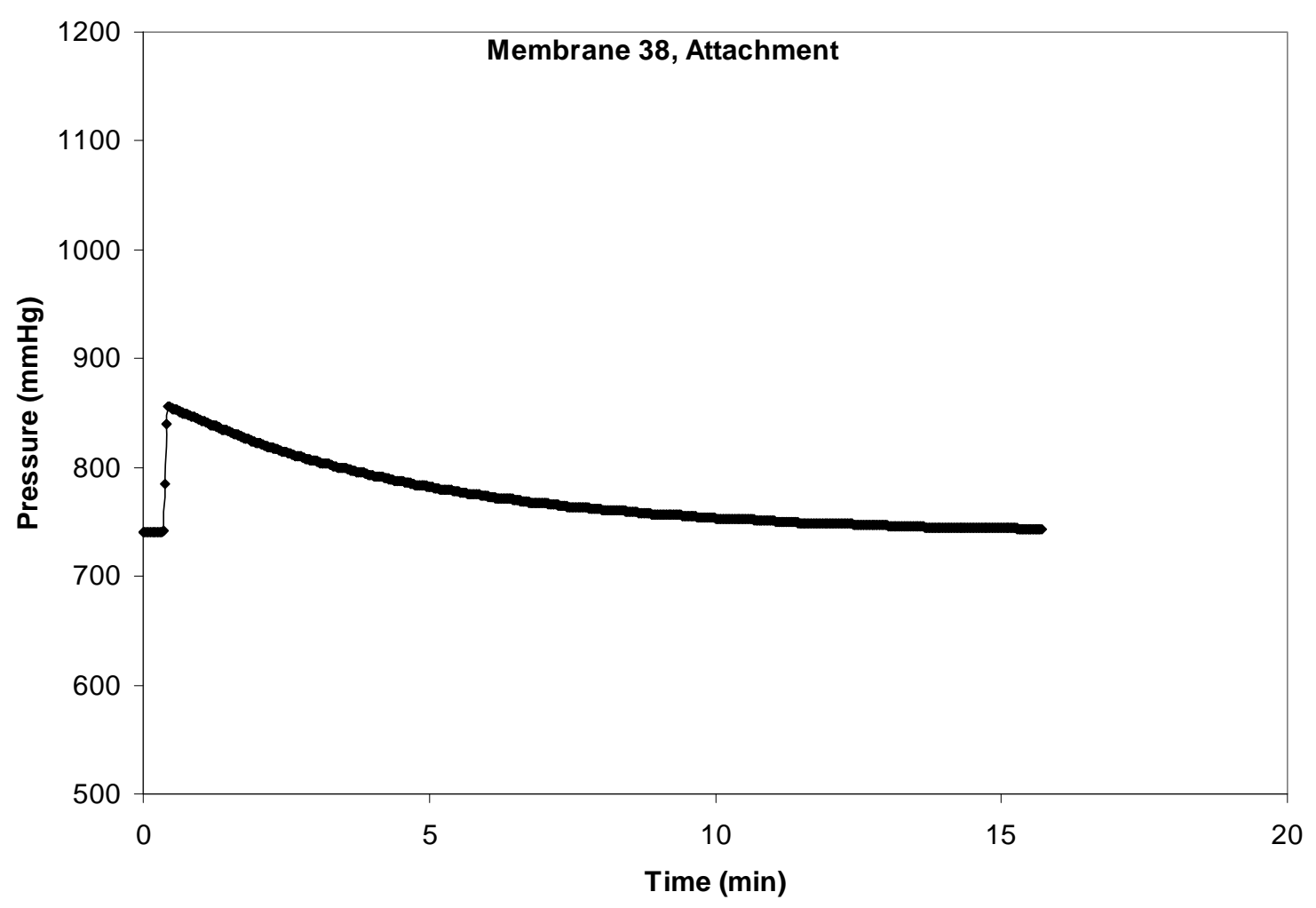

Membrane 38 was used at Ives 3 river from 5/14/2008 to 5/15/2008 with MiniSonde 43639.

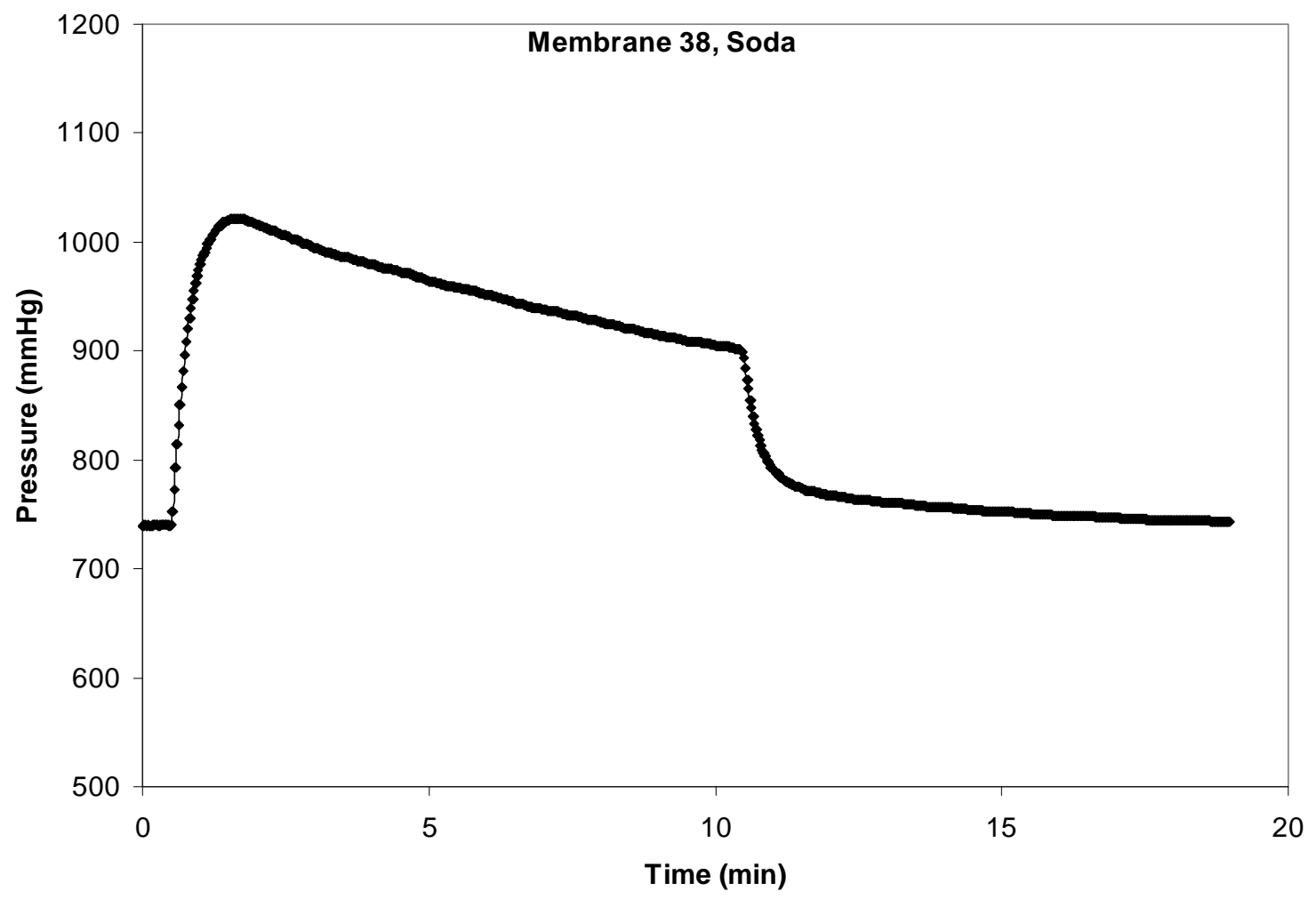




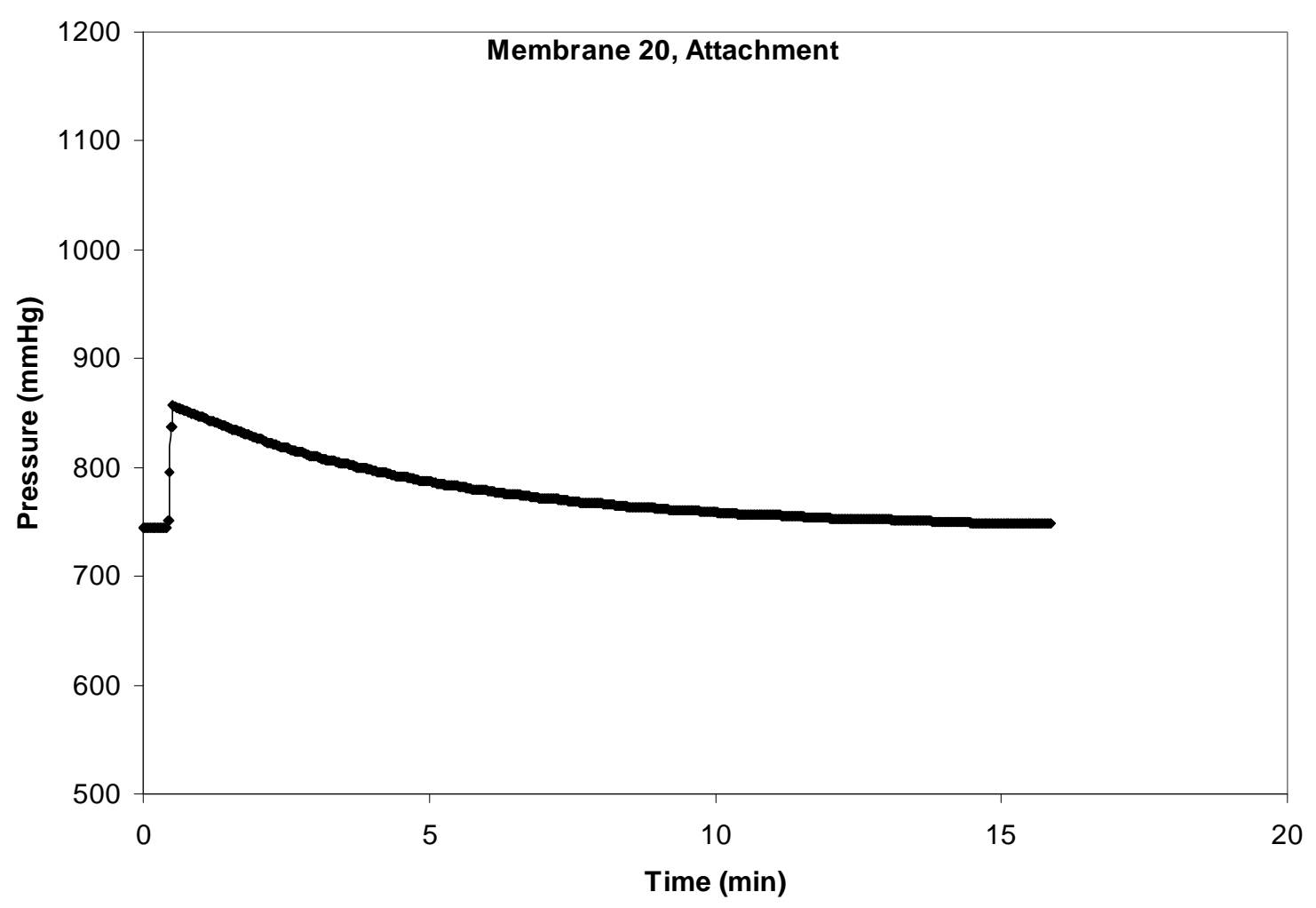

Membrane 20 was used as the control for the side-by-side after deployment 6 . It was used with MiniSonde 40347.

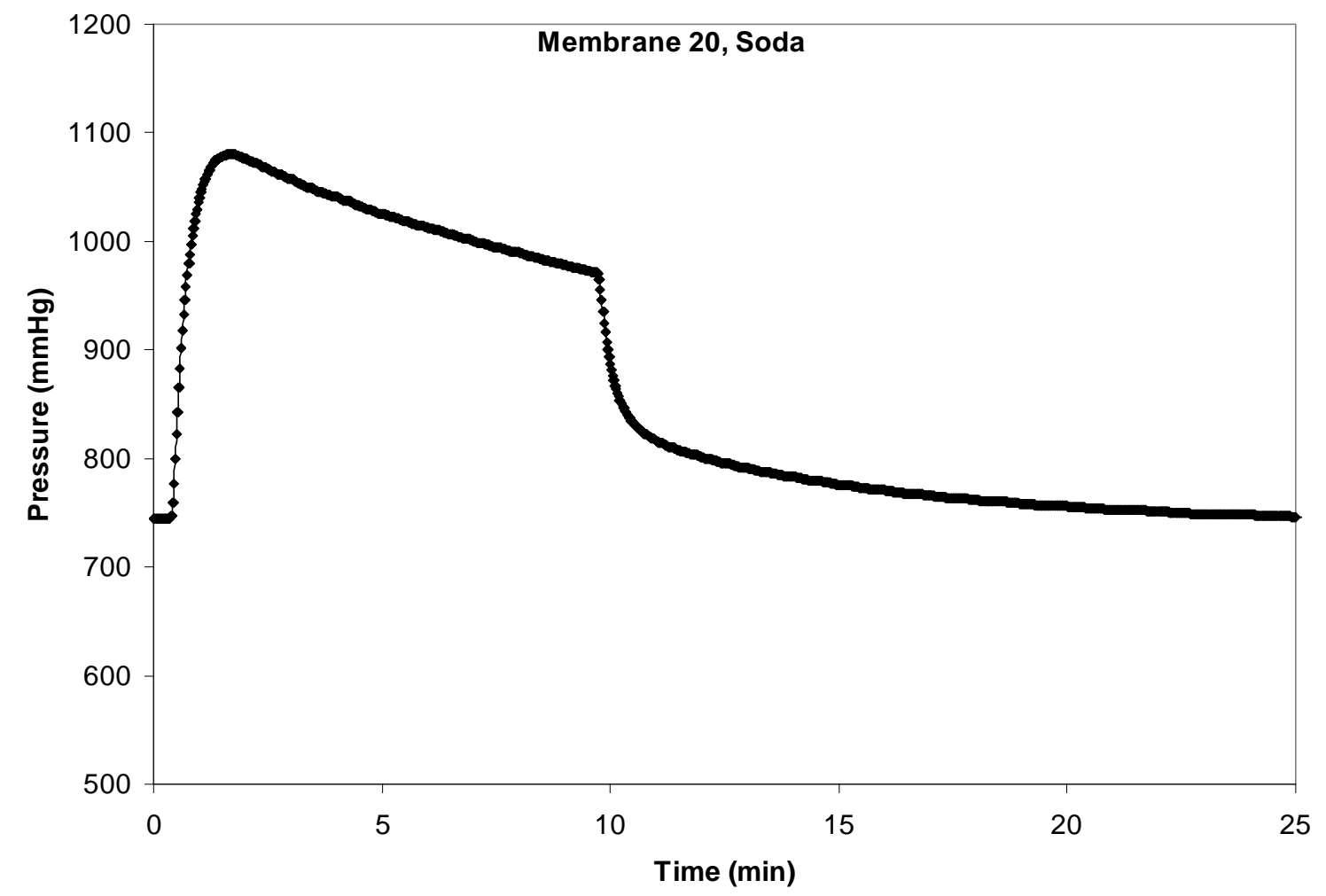


Bonneville

Date/Time Total Gas Pressure (mmHG)

3/4/08 14:00

3/4/08 16:00

$3 / 4 / 0817: 00$

$3 / 4 / 0818: 00$

$3 / 4 / 0819: 00$

$3 / 4 / 0820: 00$

$3 / 4 / 0821: 00$

$3 / 4 / 0822: 00$

$3 / 4 / 0823: 00$

$3 / 5 / 08$ 0:00

$3 / 5 / 081: 00$

3/5/08 2:00

3/5/08 3:00

$3 / 5 / 08$ 4:00

$3 / 5 / 085: 00$

$3 / 5 / 08$ 6:00

$3 / 5 / 087: 00$

$3 / 5 / 088: 00$

3/5/08 9:00

$3 / 5 / 0810: 00$

$3 / 5 / 0811: 00$

$3 / 5 / 0812: 00$

$3 / 5 / 0813: 00$

$3 / 5 / 08$ 14:00

3/5/08 15:00

3/5/08 16:00

3/5/08 17:00

3/5/08 18:00

3/5/08 19:00

3/5/08 20:00

3/5/08 21:00

3/5/08 22:00

3/5/08 23:00

3/6/08 0:00

3/6/08 1:00

3/6/08 2:00

3/6/08 3:00

3/6/08 4:00

3/6/08 5:00

3/6/08 6:00

3/6/08 7:00

3/6/08 8:00

3/6/08 9:00

3/6/08 10:00

3/6/08 11:00

$3 / 6 / 08$ 12:00

3/6/08 13:00

3/6/08 14:00

3/6/08 15:00

$\begin{array}{ll}785 & 102.1 \\ 785 & 102.1 \\ 785 & 102.1 \\ 786 & 102.2 \\ 786 & 102.2 \\ 786 & 102.1 \\ 786 & 102.2 \\ 787 & 102.2 \\ 786 & 102.1 \\ 786 & 102.1 \\ 785 & 101.9 \\ 785 & 101.9 \\ 784 & 101.8\end{array}$

$\begin{array}{rr}784 & 101.8 \\ 784 & 102\end{array}$

$\begin{array}{ll}783 & 101.7\end{array}$

$\begin{array}{ll}783 & 101.7\end{array}$

$\begin{array}{ll}783 & 101.7\end{array}$

$\begin{array}{ll}783 & 101.7\end{array}$

$\begin{array}{ll}784 & 101.8\end{array}$

$\begin{array}{ll}784 & 101.8\end{array}$

$\begin{array}{ll}784 & 101.8\end{array}$

$\begin{array}{ll}785 & 102.1\end{array}$

$\begin{array}{ll}785 & 102.1\end{array}$

$\begin{array}{ll}786 & 102.3\end{array}$

$\begin{array}{ll}787 & 102.6\end{array}$

$\begin{array}{ll}788 & 102.7\end{array}$

$\begin{array}{ll}789 & 102.9\end{array}$

$\begin{array}{lll}790 & 103.1\end{array}$

$\begin{array}{ll}791 & 103.3\end{array}$

$\begin{array}{ll}792 & 103.3\end{array}$

$\begin{array}{ll}792 & 103.3\end{array}$

$\begin{array}{ll}791 & 103.1\end{array}$

$791 \quad 103.1$

$791 \quad 103.1$

$\begin{array}{ll}790 & 103\end{array}$

$\begin{array}{ll}789 & 102.7\end{array}$

$\begin{array}{ll}789 & 102.9\end{array}$

$\begin{array}{ll}788 & 102.7\end{array}$

\begin{tabular}{ll}
787 & 102.6 \\
\hline
\end{tabular}

$\begin{array}{ll}786 & 102.3\end{array}$

$\begin{array}{ll}786 & 102.3\end{array}$

$\begin{array}{ll}786 & 102.3\end{array}$

$\begin{array}{ll}785 & 102.1\end{array}$

$\begin{array}{ll}786 & 102.2\end{array}$

$\begin{array}{ll}786 & 102.3\end{array}$

$\begin{array}{ll}786 & 102.3\end{array}$

$\begin{array}{ll}786 & 102.3\end{array}$

\begin{tabular}{ll}
787 & 102.5 \\
\hline
\end{tabular}

$\begin{array}{ll}787 & 102.6\end{array}$

$787 \quad 102.6$
TDG \% Sat

CFS) Warrendale Washougal Cascades

\section{$2.4 \quad 103.1$}

$2.4 \quad 103.2$

$2.4 \quad 103.2$

$2.4 \quad 102.8$

$2.4 \quad 103$

$2.4 \quad 102.7$

$0.8 \quad 102.7$

102.6

102.7

102.6

102.6

102.5

102.6

102.5

102.5

102.3

102.2

102.2

102.2

102.3

102.5

102.9

103.2

103.5

104.2

104.2

104.2

104.2

104

104.3

104.3

104.3

104.3

104.3

104.3

104.3

104.3

104.7

104.4

104.5

104.4

104.2

104.3

104

104.3

104.4

104.2

104.7

104.8

105.1
103.5

$103.6 \quad 112.8$

$103.8 \quad 112.5$

$103.8 \quad 112.1$

$104 \quad 111.8$

$103.9 \quad 111.4$

$103.9 \quad 110.9$

$103.8 \quad 111.3$

$103.5 \quad 112.3$

$103.2 \quad 112.7$

$103.1 \quad 113.4$

$102.8 \quad 113.6$

$102.6 \quad 113.7$

$102.5 \quad 113.9$

$102.3 \quad 114.1$

$102.2 \quad 114.4$

$102.1 \quad 114$

$101.9 \quad 112.8$

$101.8 \quad 112.6$

$101.8 \quad 112.7$

$102.1 \quad 112.7$

$102.2 \quad 112.7$

$102.6 \quad 112.6$

$103.1 \quad 112.6$

$103.6 \quad 112.5$

$104.2 \quad 112.2$

$104.4 \quad 112.2$

$104.6 \quad 112$

$104.6 \quad 111.7$

$104.6 \quad 111.5$

$104.3 \quad 111.8$

$104.2 \quad 113$

$103.8 \quad 113$

$103.4 \quad 113.8$

$103 \quad 114.2$

$102.9 \quad 114.6$

$102.7 \quad 115.1$

$102.6 \quad 115.4$

$102.5 \quad 115.8$

$102.2 \quad 115.6$

$102.1 \quad 115.6$

$102 \quad 114.2$

$101.8 \quad 113.4$

$101.9 \quad 112.9$

$102.2 \quad 112.9$

$102.3 \quad 111.9$

$102.7 \quad 111.6$

$103.4 \quad 111.8$

$103.9 \quad 111.6$

$104.3 \quad 111.2$ 


\begin{tabular}{|c|}
\hline 3/6/08 16:00 \\
\hline 3/6/08 17:00 \\
\hline 3/6/08 18:00 \\
\hline 3/6/08 19:00 \\
\hline 3/6/08 20:00 \\
\hline 3/6/08 21:00 \\
\hline 3/6/08 22:00 \\
\hline 3/6/08 23:00 \\
\hline 3/7/08 0:00 \\
\hline 3/7/08 1:00 \\
\hline 3/7/08 2:00 \\
\hline 3/7/08 3:00 \\
\hline 3/7/08 4:00 \\
\hline 3/7/08 5:00 \\
\hline 3/7/08 6:00 \\
\hline 3/7/08 7:00 \\
\hline 3/7/08 8:00 \\
\hline 3/7/08 9:00 \\
\hline 3/7/08 10:00 \\
\hline 3/7/08 11:00 \\
\hline 3/7/08 12:00 \\
\hline 3/7/08 13:00 \\
\hline 3/7/08 14:00 \\
\hline 3/7/08 15:00 \\
\hline 3/7/08 16:00 \\
\hline 3/7/08 17:00 \\
\hline 3/7/08 18:00 \\
\hline 3/7/08 19:00 \\
\hline 3/7/08 20:00 \\
\hline 3/7/08 21:00 \\
\hline 3/7/08 22:00 \\
\hline 3/7/08 23:00 \\
\hline 3/8/08 0:00 \\
\hline 3/8/08 1:00 \\
\hline 3/8/08 2:00 \\
\hline 3/8/08 3:00 \\
\hline 3/8/08 4:00 \\
\hline 3/8/08 5:00 \\
\hline 3/8/08 6:00 \\
\hline 3/8/08 7:00 \\
\hline 3/8/08 8:00 \\
\hline 3/8/08 9:00 \\
\hline 3/8/08 10:00 \\
\hline 3/8/08 11:00 \\
\hline 3/8/08 12:00 \\
\hline 3/8/08 13:00 \\
\hline 3/8/08 14:00 \\
\hline 3/8/08 15:00 \\
\hline 3/8/08 16:00 \\
\hline 3/8/08 17:00 \\
\hline 3/8/08 18:00 \\
\hline 3/8/08 19:00 \\
\hline
\end{tabular}

$\begin{array}{rrrrrr}788 & 102.7 & 2.5 & 105.6 & 104.8 & 110.9 \\ 788 & 102.7 & 2.4 & 106.1 & 105.2 & 110.9 \\ 788 & 102.7 & 2.4 & 106.1 & 105.5 & 111.1 \\ 788 & 102.6 & 2.4 & 106 & 105.6 & 110.5 \\ 788 & 102.6 & 0 & 106 & 105.7 & 111.1 \\ 788 & 102.6 & 0 & 105.7 & 105.7 & 111.4 \\ 788 & 102.6 & 0 & 105.5 & 105.8 & 112.4 \\ 787 & 102.5 & 0 & 105.2 & 105.7 & 112.7 \\ 787 & 102.5 & 0.5 & 105.1 & 105.6 & 113.5 \\ 788 & 102.6 & 34.8 & 104.9 & 105.3 & 113.7 \\ 787 & 102.5 & 35.7 & 104.9 & 104.9 & 113.9 \\ 787 & 102.6 & 35.7 & 105.2 & 104.7 & 113.9 \\ 786 & 102.5 & 35.6 & 106.5 & 104.5 & 113.8 \\ 786 & 102.5 & 35.6 & 107.4 & 104.5 & 114 \\ 785 & 102.3 & 37 & 108.6 & 104.7 & 113.8 \\ 785 & 102.3 & 38 & 108.3 & 104.7 & 113.5 \\ 786 & 102.5 & 38 & 108.4 & 104.8 & 112.9 \\ 786 & 102.5 & 38.2 & 108.6 & 105.1 & 113.2 \\ 787 & 102.6 & 38.2 & 108.7 & 105.2 & 112.8 \\ 788 & 102.7 & 38.1 & 109 & 105.3 & 113.9 \\ 789 & 103 & 38.1 & 109.2 & 105.5 & 114.3 \\ 789 & 103.1 & 38.1 & 109.4 & 105.7 & 114.5 \\ 790 & 103.3 & 38.1 & 108.2 & 105.9 & 114.4 \\ 790 & 103.4 & 38.1 & 108.2 & 106.3 & 114.2 \\ 790 & 103.4 & 38 & 108.1 & 106.4 & 114.2 \\ 790 & 103.4 & 38 & 108.1 & 106.4 & 114.1 \\ 790 & 103.4 & 38 & 108 & 106.6 & 114.1 \\ 790 & 103.4 & 38 & 107.8 & 107 & 114.2 \\ 790 & 103.5 & 36.2 & 108 & 107.4 & 114.5 \\ 790 & 103.4 & 35.5 & 108 & 107.8 & 114.5 \\ 790 & 103.4 & 35.5 & 107.8 & 107.8 & 114.5 \\ 790 & 103.4 & 35.5 & 107.6 & 107.8 & 114.6 \\ 789 & 103.1 & 35.6 & 107.6 & 107.8 & 114.8 \\ 789 & 103.1 & 35.6 & 107.3 & 107.7 & 114.6 \\ 789 & 103.1 & 35.6 & 107.4 & 107.4 & 114.5 \\ 788 & 103 & 35.6 & 107.4 & 107.4 & 114.3 \\ 788 & 102.9 & 35.6 & 107.4 & 107.2 & 114.2 \\ 788 & 102.9 & 35.5 & 107.4 & 106.9 & 114.1 \\ 788 & 102.7 & 36.9 & 108.2 & 106.6 & 113.9 \\ 788 & 102.7 & 37.9 & 108.2 & 106.5 & 113.5 \\ 788 & 102.6 & 37.9 & 108.1 & 106.4 & 113.6 \\ 788 & 102.6 & 37.8 & 108.2 & 106.5 & 114 \\ 789 & 102.6 & 38 & 108.4 & 106.6 & 113.9 \\ 790 & 102.9 & 38 & 108.4 & 106.9 & 114 \\ 790 & 102.9 & 38 & 108.7 & 107 & 114 \\ 792 & 103.1 & 38 & 109.1 & 107.3 & 113.9 \\ 793 & 103.3 & 38 & 109.1 & 107.9 & 114 \\ 794 & 103.4 & 37.9 & 109.7 & 108.2 & 114 \\ 795 & 103.7 & 37.9 & 109.9 & 108.4 & 113.9 \\ 795 & 103.7 & 37.9 & 109.9 & 108.6 & 113.9 \\ 795 & 103.7 & 37.9 & 109.8 & 108.7 & 113.8 \\ & 103.7 & 37.9 & 109.5 & 108.7 & 113.8\end{array}$






$\begin{array}{rrrrrr}795 & 103.7 & 35.6 & 109.4 & 108.5 & 114.2 \\ 795 & 103.7 & 35.7 & 109.1 & 108.5 & 114.3 \\ 795 & 103.7 & 35.7 & 109 & 108.5 & 114.2 \\ 795 & 103.7 & 35.8 & 108.7 & 108.3 & 114.3 \\ 794 & 103.5 & 35.8 & 109 & 108.1 & 114.3 \\ 793 & 103.5 & 35.8 & 109.2 & 107.8 & 114.3 \\ 792 & 103.3 & 35.8 & 109 & 107.4 & 114.1 \\ 792 & 103.3 & 35.8 & 109 & 107.3 & 114.1 \\ 791 & 103.1 & 35.7 & 109.1 & 107 & 114.1 \\ 790 & 103.1 & 35.7 & 108.8 & 106.9 & 114.1 \\ 789 & 102.9 & 37.7 & 108.8 & 106.6 & 113.8 \\ 789 & 102.9 & 38 & 108.8 & 106.6 & 113.8 \\ 789 & 102.9 & 37.9 & 108.7 & 106.4 & 113.7 \\ 789 & 102.9 & 37.8 & 108.6 & 106.5 & 113.7 \\ 789 & 102.7 & 37.9 & 108.3 & 106.4 & 113.8 \\ 790 & 103 & 37.8 & 109.1 & 106.4 & 113.7 \\ 791 & 103.3 & 37.7 & 109 & 106.5 & 113.8 \\ 791 & 103.3 & 37.7 & 109.2 & 106.8 & 114 \\ 792 & 103.5 & 37.6 & 109.6 & 107.2 & 113.7 \\ 793 & 103.7 & 37.4 & 110 & 107.6 & 113.8 \\ 794 & 103.9 & 37.3 & 110.2 & 108.1 & 113.7 \\ 794 & 103.9 & 37.2 & 110.1 & 108.4 & 113.9 \\ 795 & 104.1 & 37.1 & 109.7 & 108.6 & 113.9 \\ 795 & 104.1 & 35 & 109.4 & 108.7 & 114.1 \\ 795 & 103.9 & 34.9 & 108.7 & 108.9 & 114 \\ 796 & 104.1 & 34.9 & 108.6 & 108.9 & 114.1 \\ 796 & 104.1 & 35 & 108.3 & 108.7 & 114 \\ 795 & 103.9 & 35 & 108.2 & 108.7 & 114.2 \\ 795 & 103.9 & 34.9 & 108.2 & 108.6 & 114 \\ 794 & 103.8 & 34.9 & 108.2 & 108.1 & 114 \\ 793 & 103.7 & 34.8 & 108 & 107.7 & 114 \\ 792 & 103.7 & 34.7 & 108.4 & 107.5 & 114.1 \\ 791 & 103.5 & 34.6 & 108.2 & 107.2 & 114.1 \\ 790 & 103.4 & 35.8 & 108.2 & 106.9 & 113.9 \\ 790 & 103.4 & 6.3 & 108 & 106.9 & 113.6 \\ 789 & 103.3 & 2.6 & 107.7 & 106.8 & 111.9 \\ 789 & 103.3 & 2.4 & 107.7 & 106.4 & 110.7 \\ 789 & 103.1 & 2.4 & 107.6 & 106.5 & 110.1 \\ 789 & 103.1 & 2.4 & 107.7 & 106.7 & 109.5 \\ 790 & 103.4 & 2.4 & 107.6 & 106.9 & 109.1 \\ 790 & 103.4 & 2.4 & 107.6 & 106.9 & 109.3 \\ 791 & 103.7 & 2.4 & 107.7 & 107.1 & 109.3 \\ 791 & 103.7 & 2.4 & 108.5 & 107.2 & 109.7 \\ 791 & 103.7 & 2.4 & 107.7 & 107.3 & 109.7 \\ 792 & 103.9 & 2.4 & 108.1 & 107.7 & 109.7 \\ 792 & 103.9 & 2.4 & 107.9 & 108 & 109.7 \\ 793 & 103.9 & 2.3 & 107.6 & 108.1 & 109.4 \\ 792 & 103.8 & 0 & 106.9 & 108.2 & 110.1 \\ 793 & 103.8 & 0 & 106.5 & 108.2 & 111.5 \\ 793 & 103.7 & 0 & 106 & 108.1 & 112.7 \\ 793 & 103.5 & 0 & 105.9 & 107.8 & 113.4\end{array}$




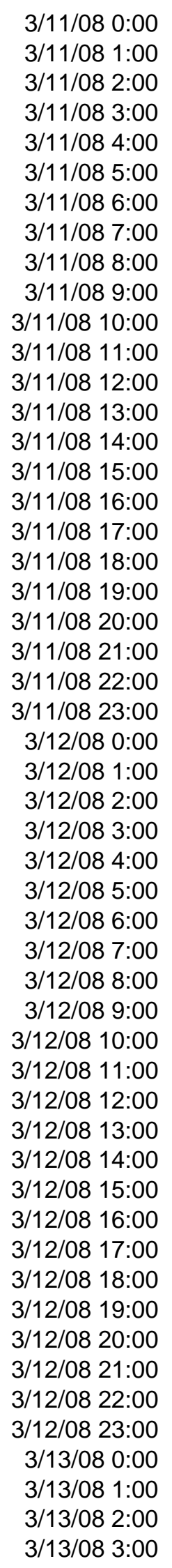

\begin{tabular}{|c|c|c|c|c|c|}
\hline 793 & 103.5 & 0 & 105.6 & 107.8 & 113.7 \\
\hline 793 & 103.4 & 0 & 105.9 & 107.7 & 113.9 \\
\hline 792 & 103.4 & 0 & 106 & 107.3 & 114.2 \\
\hline 792 & 103.3 & 0 & 105.9 & 107 & 114.5 \\
\hline 793 & 103.4 & 0 & 106.2 & 106.8 & 114.4 \\
\hline 792 & 103.3 & 0 & 106.2 & 106.4 & 114.6 \\
\hline 792 & 103.1 & 1.4 & 106.2 & 106.1 & 114.7 \\
\hline 792 & 103.1 & 2.4 & 105.7 & 105.7 & 112.9 \\
\hline 791 & 102.9 & 2.4 & 105.7 & 105.6 & 111.4 \\
\hline 791 & 102.9 & 2.4 & 105.3 & 105.4 & 110.8 \\
\hline 791 & 102.7 & 2.4 & 105.4 & 105.3 & 110.4 \\
\hline 790 & 102.6 & 2.5 & 105 & 105.6 & 110 \\
\hline 790 & 102.5 & 2.5 & 104.8 & 105.7 & 109.8 \\
\hline 791 & 102.7 & 2.4 & 104.9 & 105.7 & 109.8 \\
\hline 791 & 102.7 & 2.4 & 104.7 & 105.7 & 110 \\
\hline 791 & 102.7 & 2.4 & 104.8 & 106 & 109.8 \\
\hline 792 & 103 & 2.4 & 104.8 & 106.2 & 110 \\
\hline 792 & 103 & 2.4 & 104.8 & 106.3 & 109.9 \\
\hline 792 & 103 & 2.4 & 105.1 & 106.5 & 110 \\
\hline 793 & 103.1 & 2.3 & 104.7 & 106.5 & 109.6 \\
\hline 793 & 103.1 & 0 & 104.9 & 106.5 & 110.1 \\
\hline 792 & 103 & 0 & 104.9 & 106.4 & 111.3 \\
\hline 792 & 103 & 0 & 105.1 & 106.4 & 111.9 \\
\hline 792 & 103 & 0 & 105.1 & 106.2 & 112.5 \\
\hline 792 & 103.1 & 0 & 104.7 & 106 & 112.6 \\
\hline 792 & 103.1 & 0 & 105.2 & 105.8 & 113 \\
\hline 791 & 103 & 0 & 105.3 & 105.6 & 113.1 \\
\hline 791 & 103.1 & 0 & 105.3 & 105.6 & 113.4 \\
\hline 791 & 103.3 & 0 & 106 & 105.5 & 113.7 \\
\hline 791 & 103.3 & 0 & 106.4 & 105.2 & 114.1 \\
\hline 790 & 103.1 & 1.4 & 106 & 104.9 & 113.2 \\
\hline 789 & 103 & 2.4 & 106.2 & 104.7 & 112.1 \\
\hline 789 & 103.1 & 2.4 & 106.4 & 104.7 & 111.6 \\
\hline 789 & 103.1 & 2.4 & 106.5 & 104.4 & 111.1 \\
\hline 789 & 103.1 & 2.4 & 106.2 & 104.6 & 110.7 \\
\hline 789 & 103.3 & 2.4 & 106.7 & 104.7 & 110.4 \\
\hline 790 & 103.4 & 2.4 & 106.1 & 105.4 & 110.4 \\
\hline 790 & 103.5 & 2.4 & 106.4 & 105.6 & 110.6 \\
\hline 791 & 103.7 & 2.4 & 105.9 & 105.9 & 110.9 \\
\hline 791 & 103.8 & 2.4 & 106.4 & 106.4 & 110.9 \\
\hline 792 & 103.9 & 2.4 & 106.3 & 107.1 & 110.9 \\
\hline 792 & 104.1 & 2.4 & 106 & 107.7 & 110.9 \\
\hline 792 & 104.1 & 2.4 & 106.3 & 108 & 110.9 \\
\hline 793 & 104.2 & 2.4 & 106 & 108.3 & 110.5 \\
\hline 792 & 104.1 & 0 & 105.9 & 108.4 & 111 \\
\hline 792 & 104.2 & 0 & 105.8 & 108.4 & 112.2 \\
\hline 793 & 104.3 & 0 & 105.9 & 108.3 & 112.7 \\
\hline 792 & 104.3 & 0 & 105.8 & 108.1 & 113.6 \\
\hline 792 & 104.3 & 0 & 106 & 107.9 & 113.6 \\
\hline 792 & 104.3 & 0 & 106.3 & 107.6 & 113.8 \\
\hline 791 & 104.4 & 0 & 106.4 & 107.2 & 114.1 \\
\hline 790 & 104.4 & 0 & 106.5 & 107.1 & 114.4 \\
\hline
\end{tabular}




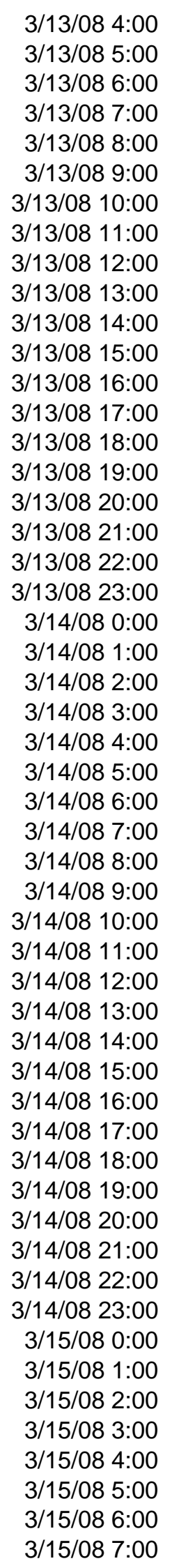

\begin{tabular}{rr}
790 & 104.4 \\
790 & 104.5 \\
789 & 104.4 \\
789 & 104.4 \\
789 & 104.4 \\
789 & 104.4 \\
789 & 104.2 \\
789 & 104.2 \\
789 & 104.2 \\
789 & 104.2 \\
789 & 104.2 \\
789 & 104.2 \\
789 & 104.2 \\
789 & 104.2 \\
789 & 104.2 \\
789 & 104.2 \\
789 & 104.2 \\
789 & 104.2 \\
789 & 104.2 \\
788 & 104.1 \\
789 & 104.4 \\
788 & 104.2 \\
788 & 104.2 \\
787 & 104.1 \\
787 & 104.2 \\
786 & 104.1 \\
786 & 104.1 \\
786 & 104.1 \\
786 & 104.1 \\
786 & 104 \\
786 & 104 \\
786 & 104 \\
786 & 104 \\
786 & 104 \\
787 & 104.1 \\
787 & 104.2 \\
787 & 104.1 \\
788 & 104.2 \\
789 & 104.4 \\
790 & 104.5 \\
790 & 104.5 \\
789 & 104.4 \\
790 & 104.4 \\
789 & 104.2 \\
789 & 104.2 \\
789 & 104.2 \\
788 & 104.1 \\
788 & 104.1 \\
788 & 104.1 \\
788 & 104 \\
788 & 104 \\
788 & 103.8 \\
\hline &
\end{tabular}

\begin{tabular}{rrrr}
0 & 106.5 & 106.9 & 114.6 \\
0 & 106.3 & 106.6 & 114.5 \\
1.1 & 106.3 & 106.3 & 113.9 \\
2.4 & 106.1 & 106.1 & 112.5 \\
2.4 & 106.1 & 105.8 & 112.3 \\
2.4 & 105.8 & 105.5 & 111.7 \\
2.4 & 105.7 & 105.3 & 111.2 \\
2.4 & 105.5 & 105.4 & 110.9 \\
2.4 & 105.5 & 105.5 & 110.7 \\
2.4 & 105.7 & 105.7 & 110.7 \\
2.4 & 105.7 & 105.8 & 110.7 \\
2.5 & 105.8 & 105.9 & 110.5 \\
2.4 & 105.5 & 106.1 & 109.9 \\
2.4 & 105.4 & 106.2 & 110.3 \\
2.4 & 105.3 & 106.4 & 110.3 \\
2.4 & 105.3 & 106.7 & 110.4 \\
0.1 & 105.4 & 106.7 & 110.5 \\
0 & 105.5 & 106.6 & 111.3 \\
0 & 105.5 & 106.3 & 112 \\
0 & 105.5 & 106.1 & 112.5 \\
0 & 105.7 & 105.8 & 113.1 \\
0 & 105.7 & 105.5 & 113.6 \\
0 & 105.9 & 105.4 & 113.9 \\
0 & 106.3 & 105.4 & 114 \\
0 & 106.3 & 105.3 & 114.4 \\
0 & 106.5 & 105.3 & 114.4 \\
1.2 & 106.3 & 105.3 & 113.6 \\
2.4 & 106.2 & 105.1 & 112.4 \\
2.4 & 106.3 & 105 & 112 \\
2.4 & 106.1 & 104.9 & 112 \\
2.4 & 106.1 & 104.9 & 111.5 \\
2.4 & 105.9 & 105 & 111.3 \\
2.4 & 105.9 & 105 & 111.2 \\
2.4 & 105.8 & 105.3 & 111.1 \\
2.4 & 105.8 & 105.5 & 111.1 \\
2.4 & 105.9 & 105.8 & 111.2 \\
2.4 & 105.7 & 106.1 & 111.1 \\
2.4 & 105.7 & 106.3 & 111.1 \\
2.4 & 105.7 & 106.6 & 111.1 \\
2.4 & 105.7 & 106.7 & 110.9 \\
0 & 105.5 & 106.7 & 110.9 \\
0 & 105.4 & 106.6 & 111.1 \\
0 & 105.5 & 106.3 & 111.5 \\
0 & 105.5 & 106.1 & 111.3 \\
0 & 105.5 & 105.7 & 111.6 \\
0 & 105.5 & 105.4 & 113.2 \\
0 & 105.5 & 105.1 & 113.4 \\
0 & 105.4 & 104.9 & 113.6 \\
0 & 105.4 & 104.9 & 113.8 \\
\hline 4 & 105.3 & 104.7 & 113.8 \\
\hline & 105.3 & 104.5 & 113.2 \\
\hline .3 & 105.4 & 104.3 & 112 \\
\hline & & &
\end{tabular}




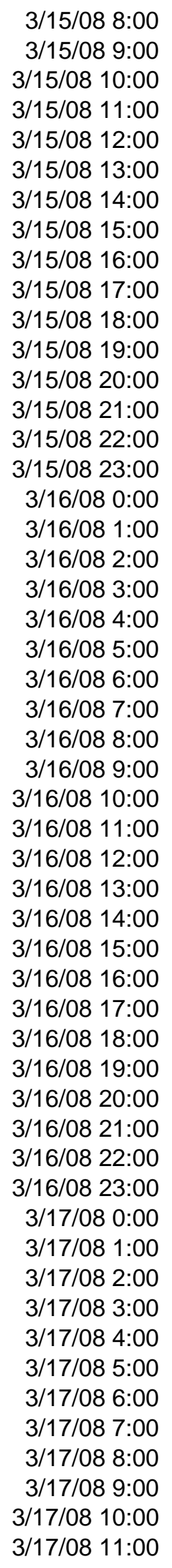

\begin{tabular}{rr}
788 & 103.8 \\
788 & 103.7 \\
788 & 103.7 \\
788 & 103.5 \\
789 & 103.7 \\
789 & 103.7 \\
790 & 103.8 \\
791 & 103.9 \\
791 & 103.9 \\
792 & 104.1 \\
792 & 104.1 \\
792 & 103.9 \\
792 & 103.9 \\
792 & 103.8 \\
791 & 103.7 \\
791 & 103.7 \\
791 & 103.5 \\
790 & 103.4 \\
789 & 103.1 \\
788 & 103 \\
787 & 102.9 \\
787 & 102.7 \\
787 & 102.7 \\
785 & 102.3 \\
784 & 102.2 \\
784 & 102.1 \\
784 & 102.1 \\
784 & 102 \\
784 & 102 \\
784 & 102 \\
785 & 102.1 \\
785 & 102.1 \\
786 & 102.2 \\
786 & 102.3 \\
786 & 102.3 \\
786 & 102.3 \\
787 & 102.5 \\
787 & 102.5 \\
787 & 102.5 \\
787 & 102.5 \\
787 & 102.6 \\
786 & 102.5 \\
786 & 102.5 \\
785 & 102.3 \\
785 & 102.3 \\
784 & 102.2 \\
783 & 102.2 \\
782 & 102.1 \\
782 & 102.1 \\
782 & 102.1 \\
782 & 102.1 \\
782 & 102.1 \\
\hline &
\end{tabular}

$\begin{array}{rr}2.4 & 105.4 \\ 2.4 & 105.6 \\ 2.4 & 105.8 \\ 2.4 & 106 \\ 2.4 & 106.2 \\ 2.4 & 106.3 \\ 2.4 & 106.4 \\ 2.4 & 106.7 \\ 2.4 & 106.7 \\ 2.4 & 106.7 \\ 2.4 & 106.4 \\ 2.4 & 106.3 \\ 0.2 & 106 \\ 0 & 106 \\ 0 & 105 .\end{array}$

105.7

105.9

105.9

105.5

105.3

105.1

104.8

104.7

104.9

105.1

104.8

105.3

105.8

106.2

106.6

106.6

106.7

106.9

106.6

106.5

106.5

106.4

106.1

105.8

105.2

104.8

104.7

104.5

104.5

104.5

104.7

105.2

105.1

105.9

105.9

105.7

105.5

104.4

$\begin{array}{rr}104.2 & 111.6 \\ 104.1 & 111.2 \\ 104.1 & 110.8 \\ 104.2 & 110.8 \\ 104.3 & 110.6 \\ 104.6 & 110.6 \\ 104.7 & 110.6 \\ 105.2 & 110.7 \\ 105.6 & 110.7 \\ 105.9 & 110.4 \\ 106 & 110.2 \\ 105.9 & 110.2 \\ 105.9 & 110.9 \\ 105.7 & 111.8 \\ 105.6 & 112.4 \\ 105.5 & 112.4 \\ 105.1 & 112.7 \\ 105.1 & 112.5 \\ 104.8 & 112.5 \\ 104.8 & 112.8 \\ 104.8 & 113.2 \\ 104.7 & 113.4 \\ 104.6 & 113.5 \\ 104.6 & 112.8 \\ 104.4 & 111.1 \\ 104.5 & 110.3 \\ 104.4 & 109.5 \\ 104.5 & 109.5 \\ 104.8 & 109.7 \\ 104.9 & 110.2 \\ 105.2 & 110.4 \\ 105.4 & 110.6 \\ 105.6 & 110.9 \\ 105.7 & 110.6 \\ 105.8 & 110.9 \\ 105.8 & 111.2 \\ 105.8 & 111.6 \\ 105.8 & 111.8 \\ 105.7 & 112.9 \\ 105.6 & 113.4 \\ 105.4 & 113.9 \\ 105.5 & 114 \\ 105.3 & 114.5 \\ 105.3 & 114.6 \\ 105.3 & 115.1 \\ 105.5 & 115.4 \\ 105.3 & 115.8 \\ 105.3 & 114.5 \\ 105.2 & 113.7 \\ 105.2 & 113 \\ 105.1 & 112.8 \\ 105.1 & 112.4\end{array}$




\begin{tabular}{|c|}
\hline 3/17/08 12:00 \\
\hline 3/17/08 13:00 \\
\hline 3/17/08 14:00 \\
\hline 3/17/08 15:00 \\
\hline 3/17/08 16:00 \\
\hline 3/17/08 17:00 \\
\hline 3/17/08 18:00 \\
\hline 3/17/08 19:00 \\
\hline 3/17/08 20:00 \\
\hline 3/17/08 21:00 \\
\hline 3/17/08 22:00 \\
\hline 3/17/08 23:00 \\
\hline 3/18/08 0:00 \\
\hline 3/18/08 1:00 \\
\hline $3 / 18 / 08$ 2:00 \\
\hline 3/18/08 3:00 \\
\hline 3/18/08 4:00 \\
\hline 3/18/08 5:00 \\
\hline $3 / 18 / 086: 00$ \\
\hline 3/18/08 7:00 \\
\hline 3/18/08 8:00 \\
\hline 3/18/08 9:00 \\
\hline 3/18/08 10:00 \\
\hline 3/18/08 11:00 \\
\hline 3/18/08 12:00 \\
\hline 3/18/08 13:00 \\
\hline 3/18/08 14:00 \\
\hline 3/18/08 15:00 \\
\hline 3/18/08 16:00 \\
\hline 3/18/08 17:00 \\
\hline 3/18/08 18:00 \\
\hline 3/18/08 19:00 \\
\hline 3/18/08 20:00 \\
\hline 3/18/08 21:00 \\
\hline 3/18/08 22:00 \\
\hline 3/18/08 23:00 \\
\hline 3/19/08 0:00 \\
\hline 3/19/08 1:00 \\
\hline 3/19/08 2:00 \\
\hline 3/19/08 3:00 \\
\hline $3 / 19 / 084: 00$ \\
\hline 3/19/08 5:00 \\
\hline $3 / 19 / 086: 00$ \\
\hline 3/19/08 7:00 \\
\hline 3/19/08 8:00 \\
\hline 3/19/08 9:00 \\
\hline 3/19/08 10:00 \\
\hline 3/19/08 11:00 \\
\hline 3/19/08 12:00 \\
\hline 3/19/08 13:00 \\
\hline 3/19/08 14:00 \\
\hline חم. 15 10/019 \\
\hline
\end{tabular}

\begin{tabular}{|c|c|c|c|c|c|}
\hline 782 & 102.1 & 2.4 & 104.3 & 105.1 & 112.4 \\
\hline 782 & 102.1 & 2.4 & 104.2 & 105.1 & 112.3 \\
\hline 782 & 102.2 & 2.4 & 104.2 & 105.1 & 112.3 \\
\hline 783 & 102.4 & 2.4 & 104.3 & 105.2 & 112.1 \\
\hline 783 & 102.4 & 2.4 & 104.4 & 105.5 & 112 \\
\hline 783 & 102.4 & 2.4 & 104.4 & 105.5 & 112.3 \\
\hline 784 & 102.6 & 2.4 & 104.6 & 105.7 & 112 \\
\hline 784 & 102.6 & 2.4 & 104.6 & 105.9 & 111.9 \\
\hline 784 & 102.8 & 2.4 & 104.3 & 106.1 & 111.8 \\
\hline 784 & 102.8 & 0 & 104.2 & 106.3 & 111.1 \\
\hline 784 & 102.8 & 0 & 104 & 106.1 & 110.8 \\
\hline 784 & 102.6 & 0 & 103.9 & 106 & 111.8 \\
\hline 784 & 102.6 & 0 & 103.9 & 105.6 & 112.4 \\
\hline 784 & 102.8 & 0 & 103.8 & 105.1 & 112.7 \\
\hline 784 & 102.8 & 0 & 103.9 & 104.7 & 112.8 \\
\hline 784 & 102.8 & 0 & 103.9 & 104.4 & 112.9 \\
\hline 783 & 102.6 & 0 & 103.9 & 104.4 & 113 \\
\hline 783 & 102.8 & 0 & 103.9 & 104.3 & 113.2 \\
\hline 783 & 102.8 & 1.9 & 103.8 & 104.3 & 113.4 \\
\hline 783 & 102.8 & 2.4 & 103.7 & 104.3 & 114 \\
\hline 782 & 102.6 & 2.4 & 103.7 & 104.3 & 113.5 \\
\hline 783 & 102.8 & 2.4 & 103.7 & 104.2 & 113 \\
\hline 783 & 102.8 & 2.4 & 103.9 & 104.2 & 112.3 \\
\hline 783 & 102.8 & 2.4 & 104.2 & 104.2 & 111.3 \\
\hline 783 & 102.8 & 2.4 & 104.6 & 104.4 & 110.6 \\
\hline 783 & 102.6 & 2.4 & 104.6 & 104.6 & 110.1 \\
\hline 783 & 102.6 & 2.4 & 103.7 & 104.6 & 109.7 \\
\hline 784 & 102.6 & 2.4 & 103.5 & 104.6 & 108.7 \\
\hline 784 & 102.5 & 2.4 & 103.6 & 104.6 & 108.5 \\
\hline 784 & 102.5 & 2.4 & 103.9 & 104.7 & 108.2 \\
\hline 785 & 102.6 & 2.4 & 103.5 & 104.8 & 108.1 \\
\hline 785 & 102.6 & 2.4 & 103.8 & 104.8 & 108.5 \\
\hline 786 & 102.6 & 0.4 & 103.5 & 104.8 & 110.7 \\
\hline 786 & 102.6 & 0 & 103.5 & 104.7 & 111.6 \\
\hline 786 & 102.6 & 0 & 104.2 & 104.7 & 112.1 \\
\hline 787 & 102.7 & 0 & 104.4 & 104.4 & 111.9 \\
\hline 786 & & 0 & 104.3 & 104.4 & 111.9 \\
\hline 786 & 102.6 & 0 & 104 & 104 & 112.9 \\
\hline 786 & 102.7 & 0 & 103.9 & 103.9 & 113.4 \\
\hline 784 & 102.5 & 0 & 103.7 & 103.7 & 113.4 \\
\hline 784 & 102.5 & 0 & 103.5 & 103.5 & 114.2 \\
\hline 783 & 102.5 & 0 & 103.5 & 103.5 & 114.5 \\
\hline 783 & 102.5 & 1 & 103.3 & 103.4 & 114.9 \\
\hline 784 & 102.6 & 2.4 & 103.1 & 103.3 & 113.5 \\
\hline 784 & 102.6 & 2.4 & 103.4 & 103.1 & 113.1 \\
\hline 784 & 102.8 & 2.4 & 103.4 & 103.1 & 113.3 \\
\hline 784 & 102.6 & 2.4 & 103.8 & 103.1 & 113.1 \\
\hline 784 & 102.8 & 2.4 & 103.7 & 103.4 & 112.4 \\
\hline 784 & 102.8 & 2.4 & 103.9 & 103.8 & 111.8 \\
\hline 784 & 102.8 & 2.4 & 103.8 & 104.4 & 111.6 \\
\hline 785 & 103 & 2.4 & 104.2 & 104.8 & 111.9 \\
\hline 785 & 103 & 2.4 & 104.3 & 105.1 & 111.9 \\
\hline
\end{tabular}




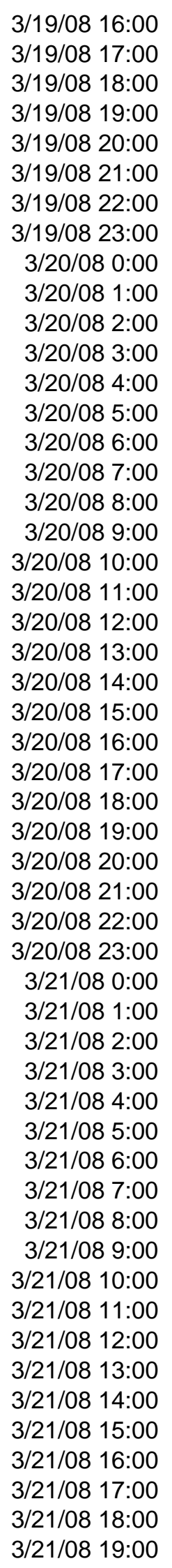

\begin{tabular}{|c|c|c|c|c|c|}
\hline 785 & 103 & 2.4 & 104.3 & 105.4 & 112.1 \\
\hline 785 & 103.2 & 2.4 & 104.3 & 105.6 & 111.5 \\
\hline 787 & 103.3 & 2.4 & 104.3 & 105.8 & 111.1 \\
\hline 787 & 103.3 & 2.4 & 104.1 & 105.6 & 111.7 \\
\hline 789 & 103.5 & 0 & 104.2 & 105.5 & 111.7 \\
\hline 789 & 103.5 & 0 & 104.6 & 105.4 & 111.8 \\
\hline 788 & 103.4 & 0 & 104.4 & 105 & 111.3 \\
\hline 789 & 103.4 & 0 & 104.4 & 104.6 & 111.4 \\
\hline 789 & 103.4 & 0 & 104.4 & 104.2 & 111.3 \\
\hline 789 & 103.4 & 0 & 104.3 & 103.8 & 111.3 \\
\hline 787 & 103.1 & 0 & 104.2 & 103.7 & 110.7 \\
\hline 787 & 103.1 & 0 & 104.2 & 103.7 & 111 \\
\hline 786 & 103 & 0 & 103.8 & 103.7 & 111.6 \\
\hline 786 & 102.9 & 0 & 103.7 & 103.5 & 113.2 \\
\hline 786 & 102.9 & 1.3 & 103.7 & 103.4 & 113.9 \\
\hline 786 & 102.9 & 2.4 & 103.5 & 103.3 & 112.9 \\
\hline 786 & 102.9 & 2.4 & 103.5 & 103.1 & 114.1 \\
\hline 786 & 102.9 & 2.4 & 103.4 & 103.1 & 113.7 \\
\hline 786 & 102.7 & 2.4 & 103.8 & 103.3 & 113.3 \\
\hline 787 & 102.9 & 2.4 & 104 & 103.5 & 112.9 \\
\hline 787 & 102.9 & 2.4 & 104.2 & 104 & 112.3 \\
\hline 787 & 103 & 2.4 & 104.2 & 104.3 & 111.6 \\
\hline 788 & 103.1 & 2.4 & 104.4 & 104.8 & 111 \\
\hline 788 & 103.1 & 2.4 & 104.6 & 105.2 & 111 \\
\hline 789 & 103.3 & 2.4 & 104.6 & 105.5 & 111.1 \\
\hline 790 & 103.4 & 2.4 & 105 & 105.5 & 111.1 \\
\hline 790 & 103.4 & 2.4 & 104.6 & 105.6 & 110.5 \\
\hline 792 & 103.8 & 2.4 & 104.6 & 105.6 & 111.1 \\
\hline 792 & 103.8 & 0 & 104.4 & 105.4 & 112 \\
\hline 792 & 103.5 & 0 & 104.4 & 105 & 111.9 \\
\hline 792 & 103.4 & 0 & 104.4 & 104.6 & 111.1 \\
\hline 792 & 103.3 & 0 & 104.3 & 104.2 & 110.2 \\
\hline 792 & 103.3 & 0 & 104 & 103.8 & 110.4 \\
\hline 791 & 103 & 0 & 103.8 & 103.2 & 110.3 \\
\hline 790 & 102.7 & 0 & 103.5 & 102.8 & 110.1 \\
\hline 789 & 102.6 & 0 & 103.4 & 102.7 & 110 \\
\hline 788 & 102.3 & 0 & 103.1 & 102.6 & 109.7 \\
\hline 788 & 102.2 & 0 & 102.8 & 102.6 & 109.6 \\
\hline 787 & 102.1 & 1.2 & 102.6 & 102.3 & 109.6 \\
\hline 787 & 101.9 & 2.4 & 102.3 & 102.1 & 111.6 \\
\hline 787 & 101.8 & 2.4 & 102.3 & 102.1 & 112.1 \\
\hline 787 & 101.8 & 2.4 & 102.3 & 102.1 & 112.3 \\
\hline 787 & 101.7 & 2.4 & 102.6 & 102.2 & 111.9 \\
\hline 787 & 101.7 & 2.4 & 102.7 & 102.3 & 111.3 \\
\hline 787 & 101.5 & 2.4 & 102.8 & 102.8 & 110.6 \\
\hline 788 & 101.7 & 2.4 & 103.1 & 103.2 & 109.9 \\
\hline 788 & 101.7 & 2.4 & 103.2 & 103.5 & 109.8 \\
\hline 788 & 101.7 & 2.4 & 103.3 & 103.7 & 109.9 \\
\hline 788 & 101.7 & 2.4 & 103.6 & 104 & 109.7 \\
\hline 789 & 101.8 & 2.4 & 103.6 & 104.2 & 109.8 \\
\hline 789 & 101.8 & 2.4 & 103.7 & 104.4 & 109.7 \\
\hline 789 & 101.8 & 2.4 & 103.6 & 104.5 & 109.8 \\
\hline
\end{tabular}




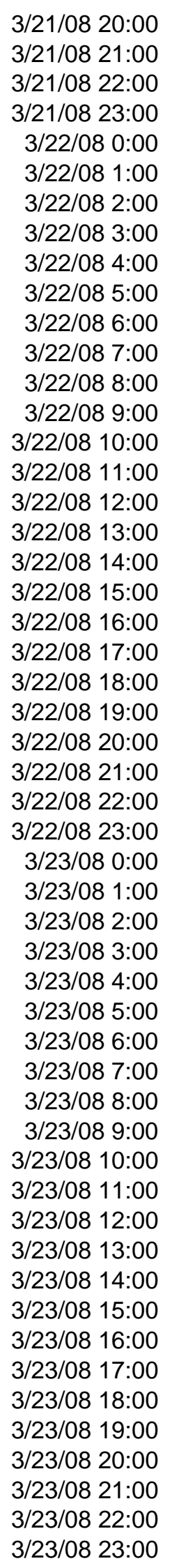

\begin{tabular}{|c|c|c|c|c|c|}
\hline 790 & 101.9 & 1.2 & 103.3 & 104.4 & 110.7 \\
\hline 789 & 101.8 & 0.1 & 103 & 104.2 & 112.1 \\
\hline 790 & 101.9 & 0 & 103.5 & 104 & 112.6 \\
\hline 789 & 101.8 & 0 & 103.6 & 103.9 & 113.5 \\
\hline 789 & 101.8 & 0 & 103.3 & 103.9 & 114 \\
\hline 789 & 101.8 & 0 & 103.2 & 103.5 & 114.4 \\
\hline 788 & 101.7 & 0 & 103.1 & 103.1 & 114.4 \\
\hline 787 & 101.7 & 0 & 103 & 103 & 114.7 \\
\hline 787 & 101.7 & 0 & 102.8 & 102.8 & 115.2 \\
\hline 786 & 101.6 & 0 & 102.8 & 102.6 & 115.4 \\
\hline 785 & 101.6 & 1.3 & 102.8 & 102.6 & 115.2 \\
\hline 785 & 101.6 & 2.5 & 102.7 & 102.3 & 114.5 \\
\hline 785 & 101.6 & 2.4 & 102.6 & 102.2 & 113.7 \\
\hline 785 & 101.6 & 2.4 & 102.7 & 102.2 & 114.2 \\
\hline 785 & 101.6 & 2.4 & 102.7 & 102.2 & 114.2 \\
\hline 786 & 101.8 & 2.4 & 103 & 102.5 & 114.1 \\
\hline 786 & 101.8 & 2.4 & 103.1 & 102.7 & 114 \\
\hline 787 & 102.1 & 2.4 & 103.4 & 103.4 & 113.6 \\
\hline 787 & 102.2 & 2.4 & 103.8 & 103.9 & 113.6 \\
\hline 788 & 102.5 & 2.4 & 104.2 & 104.2 & 113.6 \\
\hline 788 & 102.5 & 2.4 & 104 & 104.4 & 113.1 \\
\hline 788 & 102.6 & 2.4 & 103.9 & 104.7 & 113 \\
\hline 788 & 102.7 & 2.4 & 103.6 & 104.7 & 113 \\
\hline 789 & 102.9 & 2.4 & 103.6 & 104.7 & 112.8 \\
\hline 788 & 102.7 & 0 & 103.5 & 104.6 & 112.2 \\
\hline 789 & 102.9 & 0 & 103.4 & 104.2 & 112.2 \\
\hline 789 & 102.9 & 0 & 103.3 & 103.9 & 113.2 \\
\hline 788 & 102.7 & 0 & 103.8 & 103.6 & 113.3 \\
\hline 789 & 103 & 0 & 104 & 103.4 & 114.3 \\
\hline 788 & 102.9 & 0 & 104.2 & 103.1 & 114.7 \\
\hline 787 & 102.7 & 0 & 104.3 & 103 & 115.3 \\
\hline 787 & 102.7 & 0 & 104.3 & 102.7 & 116 \\
\hline 787 & 102.9 & 0 & 104.4 & 102.9 & 116 \\
\hline 786 & 102.7 & 0 & 104.4 & 102.9 & 116.6 \\
\hline 786 & 102.9 & 1.3 & 104.7 & 103 & 116.7 \\
\hline 786 & 102.9 & 2.4 & 104.7 & 103 & 115 \\
\hline 786 & 102.7 & 2.4 & 105 & 103 & 113.8 \\
\hline 786 & 102.9 & 2.4 & 105 & 103 & 114 \\
\hline 786 & 102.9 & 2.4 & 105.2 & 103.1 & 113.5 \\
\hline 786 & 103 & 2.4 & 105.4 & 103.1 & 112.8 \\
\hline 786 & 103 & 2.4 & 105.6 & 103 & 112.2 \\
\hline 786 & 103.1 & 2.4 & 106.1 & 103.1 & 111.6 \\
\hline 787 & 103.3 & 2.4 & 106.5 & 103.4 & 111.3 \\
\hline 787 & 103.4 & 2.4 & 107.1 & 103.7 & 110.7 \\
\hline 787 & 103.4 & 2.4 & 107.2 & 103.9 & 110.7 \\
\hline 788 & 103.4 & 2.4 & 107.3 & 103.9 & 110.6 \\
\hline 788 & 103.4 & 2.4 & 107.3 & 104.3 & 110.6 \\
\hline 788 & 103.3 & 2.4 & 107 & 104.4 & 110.3 \\
\hline 787 & 103.1 & 0 & 106.8 & 104.3 & 110.5 \\
\hline 786 & 102.9 & 0 & 106.6 & 104.3 & 111.6 \\
\hline 786 & 102.7 & 0 & 106.4 & 104.2 & 112.4 \\
\hline 786 & 102.7 & 0 & 106.4 & 104.2 & 112.9 \\
\hline
\end{tabular}




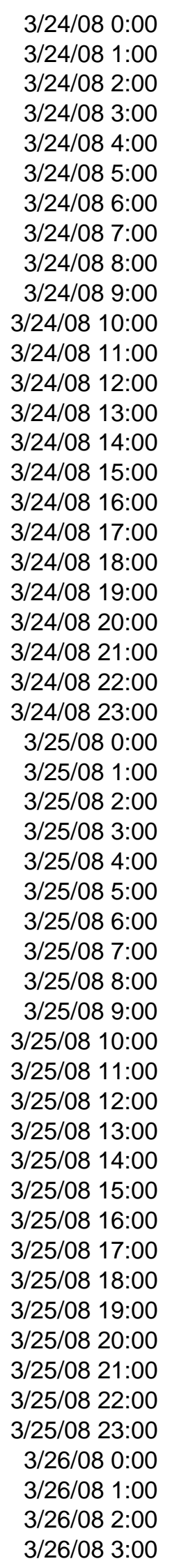

$\begin{array}{ll}785 & 102.6 \\ 785 & 102.6 \\ 788 & 102.9 \\ 787 & 102.7 \\ 787 & 102.7 \\ 786 & 102.6 \\ 786 & 102.5 \\ 786 & 102.5 \\ 786 & 102.5 \\ 786 & 102.5 \\ 785 & 102.3 \\ 787 & 102.6 \\ 787 & 102.6 \\ 787 & 102.7 \\ 788 & 102.9 \\ 789 & 103.1 \\ 789 & 103.1 \\ 790 & 103.3 \\ 790 & 103.3 \\ 791 & 103.4 \\ 791 & 103.4 \\ 791 & 103.4 \\ 791 & 103.4 \\ 792 & 103.5 \\ 792 & 103.5 \\ 792 & 103.5 \\ 792 & 103.5 \\ 791 & 103.4 \\ 791 & 103.4 \\ 790 & 103.3 \\ 790 & 103.3 \\ 789 & 103.1 \\ 789 & 103.1 \\ 789 & 103.1 \\ 789 & 103.1 \\ 789 & 103.1 \\ 790 & 103.4 \\ 790 & 103.4 \\ 790 & 103.4 \\ 791 & 103.7 \\ 792 & 103.8 \\ 793 & 103.9 \\ 793 & 104.1 \\ 794 & 104.2 \\ 794 & 104.2 \\ 795 & 104.3 \\ 795 & 104.3 \\ 795 & 104.5 \\ 795 & 104.5 \\ 794 & 104.3 \\ 794 & 104.5 \\ 794 & 104.5\end{array}$

\begin{tabular}{rrr}
106.1 & 104.2 & 113.3 \\
106.1 & 104.2 & 113.7 \\
106.1 & 103.9 & 113.6 \\
106.2 & 103.6 & 113.5 \\
106.2 & 103.6 & 113.8 \\
106.4 & 103.8 & 114.1 \\
106.4 & 103.8 & 114.6 \\
106.4 & 103.9 & 113.8 \\
106.4 & 103.9 & 113.5 \\
106.5 & 103.9 & 112.9 \\
106.8 & 104.4 & 112.2 \\
107 & 104.9 & 111.6 \\
107.4 & 105.3 & 111.3 \\
107.8 & 105.6 & 111.5 \\
107.5 & 106 & 111.2 \\
107.6 & 106.5 & 111.7 \\
107 & 107.2 & 112 \\
107.2 & 107.7 & 112.1 \\
107.3 & 108 & 111.9 \\
107 & 108.1 & 112.1 \\
107 & 108.1 & 112.7 \\
106.9 & 108.1 & 114 \\
106.6 & 108 & 114.5 \\
106.5 & 107.8 & 114.5 \\
106.4 & 107.6 & 115 \\
106.4 & 107.3 & 115.8 \\
106.2 & 107 & 116.6 \\
106.1 & 106.6 & 117.1 \\
106.4 & 106.4 & 117.5 \\
106.3 & 106.1 & 118 \\
105.9 & 106 & 117.4 \\
105.7 & 105.6 & 117.2 \\
105.6 & 105.3 & 117 \\
105.5 & 105.2 & 116.4 \\
105.5 & 105.3 & 115.9 \\
105.5 & 105.5 & 115.5 \\
105.5 & 105.5 & 115.4 \\
105.9 & 105.7 & 115 \\
106 & 106 & 114.4 \\
106 & 106.5 & 114.5 \\
106.1 & 107.1 & 114.7 \\
106 & 107.3 & 114.7 \\
106 & 107.7 & 114.7 \\
105.9 & 107.7 & 114.7 \\
106 & 107.6 & 114.9 \\
106 & 107.3 & 115.7 \\
106 & 107.2 & 119.8 \\
105.9 & 106.9 & 121.4 \\
105.9 & 106.7 & 121 \\
106 & 106.4 & 119.9 \\
106.2 & 106.2 & 118.9 \\
\hline & 105.9 & 119.1 \\
\hline
\end{tabular}




$$
\begin{aligned}
& \text { 3/26/08 4:00 } \\
& 3 / 26 / 08 \text { 5:00 } \\
& 3 / 26 / 08 \text { 6:00 } \\
& 3 / 26 / 08 \text { 7:00 } \\
& 3 / 26 / 08 \text { 8:00 } \\
& 3 / 26 / 089: 00 \\
& \text { 3/26/08 10:00 } \\
& 3 / 26 / 08 \text { 11:00 } \\
& 3 / 26 / 08 \text { 12:00 } \\
& 3 / 26 / 08 \text { 13:00 } \\
& 3 / 26 / 08 \text { 14:00 } \\
& 3 / 26 / 08 \text { 15:00 } \\
& \text { 3/26/08 16:00 } \\
& 3 / 26 / 08 \text { 17:00 } \\
& \text { 3/26/08 18:00 } \\
& \text { 3/26/08 19:00 } \\
& 3 / 26 / 08 \text { 20:00 } \\
& 3 / 26 / 08 \text { 21:00 } \\
& 3 / 26 / 08 \text { 22:00 } \\
& \text { 3/26/08 23:00 } \\
& 3 / 27 / 08 \text { 0:00 } \\
& 3 / 27 / 08 \text { 1:00 } \\
& 3 / 27 / 08 \text { 2:00 } \\
& 3 / 27 / 08 \text { 3:00 } \\
& \text { 3/27/08 4:00 } \\
& 3 / 27 / 08 \text { 5:00 } \\
& \text { 3/27/08 6:00 } \\
& 3 / 27 / 08 \text { 7:00 } \\
& \text { 3/27/08 8:00 } \\
& 3 / 27 / 089: 00 \\
& \text { 3/27/08 10:00 } \\
& 3 / 27 / 08 \text { 11:00 } \\
& 3 / 27 / 08 \text { 12:00 } \\
& \text { 3/27/08 13:00 } \\
& \text { 3/27/08 14:00 } \\
& 3 / 27 / 08 \text { 15:00 } \\
& \text { 3/27/08 16:00 } \\
& 3 / 27 / 08 \text { 17:00 } \\
& \text { 3/27/08 18:00 } \\
& \text { 3/27/08 19:00 } \\
& 3 / 27 / 0820: 00 \\
& 3 / 27 / 0821: 00 \\
& 3 / 27 / 08 \text { 22:00 } \\
& 3 / 27 / 0823: 00 \\
& \text { 3/28/08 0:00 } \\
& 3 / 28 / 08 \text { 1:00 } \\
& 3 / 28 / 08 \text { 2:00 } \\
& 3 / 28 / 083: 00 \\
& 3 / 28 / 08 \text { 4:00 } \\
& 3 / 28 / 08 \text { 5:00 } \\
& 3 / 28 / 08 \text { 6:00 } \\
& 3 / 28 / 08 \text { 7:00 }
\end{aligned}
$$

\begin{tabular}{|c|c|}
\hline 0 & 106.2 \\
\hline 0 & 106 \\
\hline 1.4 & 105.9 \\
\hline 2.4 & 105.6 \\
\hline 2.4 & 105.5 \\
\hline 2.4 & 105.4 \\
\hline 2.4 & 105.5 \\
\hline 2.4 & 105.5 \\
\hline 2.4 & 105.6 \\
\hline 1.6 & 105.4 \\
\hline 1.2 & 105.5 \\
\hline 1.2 & 105.6 \\
\hline 1.2 & 105.4 \\
\hline 1.2 & 105.6 \\
\hline 2 & 105.8 \\
\hline 2.4 & 105.4 \\
\hline 0.1 & 105.1 \\
\hline 0 & 104.8 \\
\hline 0 & 104.6 \\
\hline 0 & 104.3 \\
\hline 0 & 103.9 \\
\hline 0 & 103.8 \\
\hline 0 & 103.8 \\
\hline 0 & 103.8 \\
\hline 0 & 104.2 \\
\hline 0 & 104.7 \\
\hline 1.3 & 104.8 \\
\hline 2.3 & 105.4 \\
\hline 2.3 & 105.1 \\
\hline 2.3 & 104.5 \\
\hline 2.3 & 104.1 \\
\hline 2.3 & 103.6 \\
\hline 2.3 & 103.6 \\
\hline 1.2 & 103.8 \\
\hline 1.2 & 103.8 \\
\hline 1.2 & 104 \\
\hline 2 & 104.2 \\
\hline 2.3 & 104.4 \\
\hline 2.3 & 104.8 \\
\hline 2.3 & 104.8 \\
\hline 0.1 & 104.8 \\
\hline 0 & 104.6 \\
\hline 0 & 104.2 \\
\hline 0 & 104.3 \\
\hline 0 & 104.3 \\
\hline 0 & 104.4 \\
\hline 0 & 104.6 \\
\hline 0 & 104.5 \\
\hline 0 & 104.6 \\
\hline 0 & 104.7 \\
\hline 1.2 & 104.9 \\
\hline 2.4 & 105.1 \\
\hline
\end{tabular}

\begin{tabular}{rr}
793 & 104.3 \\
793 & 104.3 \\
792 & 104.1 \\
791 & 103.9 \\
791 & 103.9 \\
790 & 103.8 \\
790 & 103.8 \\
790 & 103.8 \\
790 & 103.9 \\
789 & 103.8 \\
789 & 103.8 \\
789 & 103.8 \\
789 & 103.8 \\
790 & 103.9 \\
790 & 103.9 \\
790 & 103.8 \\
789 & 103.4 \\
789 & 103.3 \\
789 & 103.1 \\
788 & 102.9 \\
787 & 102.6 \\
786 & 102.5 \\
786 & 102.5 \\
785 & 102.2 \\
785 & 102.2 \\
784 & 102.1 \\
782 & 101.7 \\
782 & 101.7 \\
781 & 101.6 \\
781 & 101.6 \\
781 & 101.4 \\
781 & 101.4 \\
782 & 101.6 \\
782 & 101.7 \\
783 & 101.8 \\
784 & 102 \\
785 & 102.2 \\
786 & 102.3 \\
786 & 102.5 \\
786 & 102.6 \\
786 & 102.6 \\
786 & 102.6 \\
786 & 102.7 \\
785 & 102.7 \\
784 & 102.6 \\
783 & 102.6 \\
783 & 102.8 \\
782 & 102.8 \\
782 & 102.9 \\
782 & 103 \\
782 & 103.2 \\
782 & 103.2 \\
\hline &
\end{tabular}

$\begin{array}{rr}105.6 & 119.6 \\ 105.4 & 119 \\ 105.2 & 119 \\ 105.1 & 118.2 \\ 104.8 & 117.3 \\ 104.7 & 116.9 \\ 104.7 & 116.3 \\ 104.8 & 116.1 \\ 105.1 & 116.1 \\ 105.2 & 115.9 \\ 105.6 & 115.2 \\ 106 & 115.4 \\ 106.3 & 114.8 \\ 106.6 & 115.2 \\ 106.3 & 114.7 \\ 106 & 114.3 \\ 105.6 & 113.6 \\ 105.2 & 113.9 \\ 104.8 & 114.1 \\ 104.3 & 114.2 \\ 103.8 & 114.7 \\ 103.5 & 115.5 \\ 103.2 & 116.1 \\ 103 & 116.6 \\ 102.9 & 117.1 \\ 102.9 & 117.5 \\ 102.6 & 117.4 \\ 102.5 & 116.6 \\ 102.5 & 115.4 \\ 102.6 & 115 \\ 102.6 & 114.8 \\ 102.8 & 114.2 \\ 103.2 & 114.3 \\ 104 & 114.1 \\ 104.2 & 113.6 \\ 104.7 & 113.6 \\ 104.9 & 114.7 \\ 105.6 & 114.4 \\ 105.7 & 114.1 \\ 106 & 114.1 \\ 106 & 114 \\ 106.1 & 115.9 \\ 105.9 & 117.5 \\ 105.5 & 117.5 \\ 105.1 & 118.3 \\ 104.6 & 119.1 \\ 104.2 & 119.5 \\ 104.1 & 119.6 \\ 103.7 & 120.4 \\ 103.5 & 120.2 \\ 103.6 & 119.5 \\ 103.6 & 117.4\end{array}$




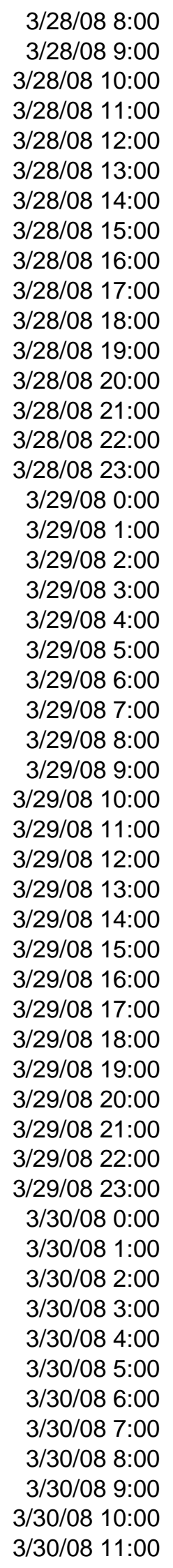

\begin{tabular}{|c|c|c|c|c|c|}
\hline 782 & 103.3 & 2.4 & 105.4 & 103.6 & 117.5 \\
\hline 782 & 103.4 & 2.4 & 105.3 & 103.7 & 116.9 \\
\hline 782 & 103.6 & 2.4 & 105.1 & 104 & 116.4 \\
\hline 782 & 103.6 & 2.4 & 105 & 104 & 115.7 \\
\hline 781 & 103.4 & 2.4 & 104.9 & 103.8 & 115.1 \\
\hline 781 & 103.4 & 2.4 & 105 & 104.1 & 114.1 \\
\hline 781 & 103.4 & 2.4 & 104.7 & 104.5 & 114.1 \\
\hline 780 & 103.3 & 2.4 & 104.6 & 104.5 & 114 \\
\hline 780 & 103.2 & 2.4 & 104.4 & 104.7 & 113.3 \\
\hline 780 & 103.2 & 2.4 & 104 & 104.9 & 113.3 \\
\hline 780 & 103 & 2.4 & 103.7 & 105 & 113.3 \\
\hline 780 & 102.9 & 2.4 & 103.2 & 104.7 & 113.2 \\
\hline 780 & 102.9 & 0 & 103 & 104.6 & 111.7 \\
\hline 780 & 102.9 & 0 & 102.9 & 104.3 & 111.1 \\
\hline 779 & 102.8 & 0 & 102.9 & 104.1 & 112 \\
\hline 779 & 102.6 & 0 & 102.8 & 103.8 & 112.4 \\
\hline 779 & 102.6 & 0 & 102.8 & 103.4 & 113.8 \\
\hline 778 & 102.5 & 0 & 102.9 & 103.1 & 114.5 \\
\hline 778 & 102.4 & 0 & 102.8 & 102.6 & 114.6 \\
\hline 778 & 102.4 & 0 & 103.3 & 102.4 & 115 \\
\hline 778 & 102.2 & 0 & 103.7 & 102 & 115 \\
\hline 778 & 102.2 & 0 & 103.9 & 101.7 & 114.9 \\
\hline 777 & 102 & 1.3 & 104.2 & 101.3 & 115.1 \\
\hline 777 & 102 & 2.4 & 103.9 & 101.2 & 114.5 \\
\hline 777 & 101.8 & 2.4 & 103.9 & 101 & 113.9 \\
\hline 777 & 101.8 & 2.4 & 103.5 & 100.9 & 113.3 \\
\hline 777 & 101.8 & 2.4 & 103.4 & 100.9 & 112.8 \\
\hline 777 & 101.7 & 2.4 & 103.1 & 100.9 & 111.9 \\
\hline 777 & 101.7 & 2.4 & 102.9 & 101.3 & 111.2 \\
\hline 776 & 101.6 & 2.4 & 103 & 101.7 & 111 \\
\hline 777 & 101.7 & 2.4 & 103.1 & 102.2 & 110.8 \\
\hline 777 & 101.7 & 2.4 & 103.1 & 102.9 & 110.6 \\
\hline 777 & 101.7 & 2.4 & 103.1 & 103 & 110.6 \\
\hline 778 & 101.7 & 2.4 & 102.6 & 103.3 & 110.6 \\
\hline 777 & 101.7 & 2.4 & 102.5 & 103.5 & 111.2 \\
\hline 778 & 101.8 & 2.4 & 102.5 & 103.8 & 111.2 \\
\hline 777 & 101.7 & 0 & 102.5 & 103.9 & 111.9 \\
\hline 778 & 101.8 & 0 & 102.9 & 103.8 & 113.5 \\
\hline 778 & 101.8 & 0 & 103.3 & 103.7 & 113.8 \\
\hline 778 & 101.8 & 0 & 104.4 & 103.5 & 114.9 \\
\hline 777 & 101.7 & 0 & 104.8 & 103.4 & 115.4 \\
\hline 777 & 101.7 & 0 & 105 & 103.3 & 115.6 \\
\hline 778 & 101.8 & 0 & 105.4 & 103.1 & 115.7 \\
\hline 777 & 101.7 & 0 & 105.5 & 102.9 & 115.8 \\
\hline 776 & 101.6 & 0 & 105.5 & 102.6 & 115.9 \\
\hline 776 & 101.7 & 0 & 105.2 & 102.5 & 116.1 \\
\hline 776 & 101.6 & 1.2 & 105.1 & 102.3 & 116.2 \\
\hline 775 & 101.4 & 2.4 & 104.8 & 102.1 & 115.6 \\
\hline 776 & 101.6 & 2.4 & 104.8 & 101.8 & 113.7 \\
\hline 775 & 101.4 & 2.4 & 104.8 & 101.8 & 112.7 \\
\hline 776 & 101.6 & 2.4 & 105 & 101.8 & 112.1 \\
\hline 777 & 101.6 & 2.4 & 104.9 & 101.8 & 111.7 \\
\hline
\end{tabular}









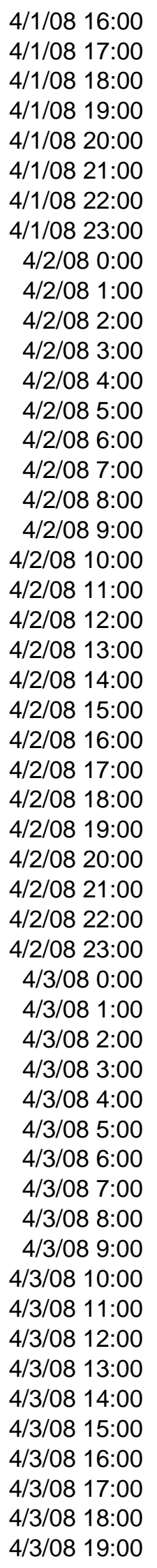

$\begin{array}{rrrrrr}786 & 102.7 & 2.4 & 105.7 & 106.9 & 113.9 \\ 787 & 103 & 2.4 & 105.6 & 107.3 & 113.7 \\ 789 & 103.4 & 2.4 & 105.6 & 107.4 & 113.6 \\ 790 & 103.5 & 2.4 & 105.5 & 107.7 & 113.5 \\ 790 & 103.5 & 0.1 & 105.4 & 107.5 & 113.2 \\ 790 & 103.4 & 0 & 105.2 & 107 & 113.2 \\ 791 & 103.5 & 0 & 105.1 & 106.7 & 114.1 \\ 790 & 103.4 & 0 & 105 & 106.3 & 117 \\ 790 & 103.4 & 0 & 105 & 105.7 & 117.6 \\ 789 & 103.3 & 0 & 105 & 105.2 & 117.6 \\ 788 & 103.1 & 0 & 105.1 & 104.8 & 117.3 \\ 787 & 102.9 & 0 & 105.1 & 104.6 & 116.6 \\ 787 & 102.9 & 0 & 105.1 & 104.4 & 117.1 \\ 786 & 102.7 & 0 & 105.1 & 104.3 & 116.8 \\ 786 & 102.7 & 1.4 & 104.9 & 104.2 & 116.7 \\ 785 & 102.6 & 2.4 & 104.8 & 103.8 & 115.8 \\ 785 & 102.5 & 2.4 & 104.8 & 103.6 & 114.9 \\ 785 & 102.5 & 2.4 & 104.8 & 103.6 & 114.2 \\ 785 & 102.6 & 2.4 & 104.7 & 103.8 & 114 \\ 786 & 102.7 & 2.4 & 104.6 & 104 & 114 \\ 787 & 102.9 & 2.4 & 104.7 & 104.6 & 114.5 \\ 788 & 103 & 2.4 & 105 & 105.2 & 114.5 \\ 789 & 103.3 & 2.4 & 105.2 & 105.9 & 114.6 \\ 790 & 103.4 & 2.4 & 105.5 & 106.8 & 114.5 \\ 792 & 103.7 & 2.4 & 106 & 107.4 & 114.4 \\ 792 & 103.8 & 2.4 & 106.5 & 107.8 & 114.1 \\ 793 & 103.9 & 2.4 & 106.8 & 108.1 & 113.9 \\ 794 & 104.1 & 2.5 & 106.9 & 108.1 & 113.9 \\ 794 & 103.9 & 0.5 & 106.8 & 108.1 & 113.3 \\ 794 & 103.9 & 0 & 106.5 & 108 & 113.9 \\ 794 & 103.8 & 0 & 106.2 & 107.7 & 114.6 \\ 793 & 103.7 & 0 & 106 & 107.3 & 115.9 \\ 793 & 103.7 & 0 & 105.9 & 106.6 & 117.9 \\ 793 & 103.5 & 0 & 105.9 & 105.9 & 118.1 \\ 792 & 103.4 & 0 & 105.9 & 105.3 & 118.1 \\ 792 & 103.4 & 0 & 106 & 104.8 & 118.3 \\ 792 & 103.4 & 0 & 106.1 & 104.7 & 118.1 \\ 792 & 103.4 & 0 & 106.1 & 104.6 & 119 \\ 791 & 103.3 & 2.3 & 106.1 & 104.4 & 117.1 \\ 792 & 103.3 & 2.3 & 106.1 & 104.3 & 115.8 \\ 792 & 103.3 & 2.3 & 105.8 & 104.3 & 114.8 \\ 793 & 103.4 & 2.3 & 105.8 & 104.4 & 114.2 \\ 794 & 103.5 & 2.3 & 106 & 104.6 & 114.1 \\ 795 & 103.7 & 2.2 & 106.2 & 104.8 & 113.9 \\ 796 & 103.9 & 2.2 & 106.5 & 105.2 & 114.1 \\ 797 & 104.2 & 2.2 & 106.6 & 106 & 114.4 \\ 798 & 104.3 & 2.2 & 106.8 & 106.6 & 114.2 \\ 899 & 104.4 & 2.2 & 107 & 107.4 & 114.1 \\ 802 & 104.8 & 2.2 & 107.2 & 108 & 114.2 \\ 802 & 105 & 2.2 & 107.3 & 108.6 & 114.1 \\ 803 & 105.2 & 2.2 & 107.4 & 108.7 & 114 \\ & & 2.2 & 107.3 & 108.9 & 114.1\end{array}$




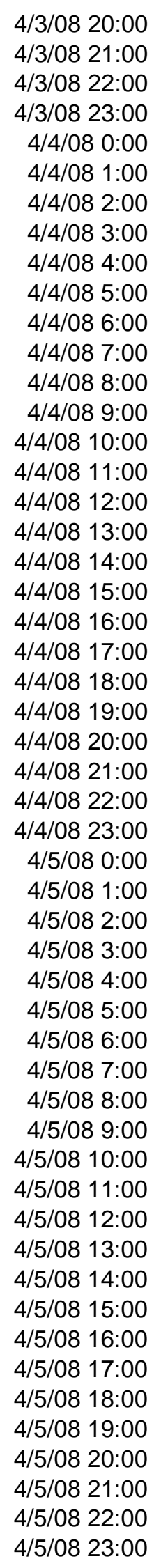

$\begin{array}{rrrrrr}804 & 105.4 & 2.2 & 107.3 & 109 & 113.9 \\ 804 & 105.4 & 1.1 & 107.2 & 109 & 113.7 \\ 803 & 105.2 & 0 & 107 & 108.9 & 114.1 \\ 803 & 105.2 & 0 & 107.1 & 108.5 & 116.1 \\ 803 & 105.4 & 0 & 107.1 & 108.1 & 118.2 \\ 802 & 105.2 & 0 & 107.2 & 107.6 & 118.3 \\ 802 & 105.2 & 0 & 107.1 & 106.9 & 118.6 \\ 802 & 105.4 & 0 & 107.1 & 106.7 & 118.9 \\ 802 & 105.4 & 0 & 107.1 & 106.4 & 118.6 \\ 802 & 105.4 & 0 & 107.2 & 106.3 & 119 \\ 802 & 105.4 & 2.4 & 107.7 & 106.2 & 117.5 \\ 802 & 105.4 & 2.4 & 108.4 & 106 & 115.3 \\ 802 & 105.4 & 2.4 & 108.9 & 106.3 & 114.6 \\ 803 & 105.7 & 2.4 & 109.2 & 106.2 & 113.9 \\ 803 & 105.5 & 2.4 & 109.3 & 106.2 & 113.8 \\ 803 & 105.5 & 2.4 & 109 & 106 & 113.5 \\ 804 & 105.7 & 2.4 & 108.9 & 106.2 & 113.2 \\ 805 & 105.8 & 2.4 & 108.8 & 106.3 & 113.1 \\ 806 & 105.9 & 2.4 & 108.6 & 106.7 & 113.2 \\ 808 & 106.2 & 2.4 & 108.6 & 107.2 & 113 \\ 809 & 106.3 & 2.4 & 108.9 & 107.6 & 113 \\ 810 & 106.4 & 2.4 & 108.9 & 107.9 & 113.3 \\ 811 & 106.6 & 2.4 & 109 & 107.9 & 113.3 \\ 814 & 107 & 2.4 & 109 & 107.7 & 113.2 \\ 815 & 107.1 & 2.4 & 109 & 107.7 & 113 \\ 815 & 107.1 & 0.9 & 109 & 107.9 & 113.1 \\ 815 & 107 & 0 & 109 & 107.9 & 114.7 \\ 815 & 107.1 & 0 & 109 & 107.9 & 115.5 \\ 814 & 107 & 0 & 108.9 & 107.5 & 116.6 \\ 814 & 107 & 0 & 108.8 & 107.2 & 116.9 \\ 813 & 106.8 & 0 & 108.8 & 106.9 & 117.2 \\ 812 & 106.7 & 0 & 108.8 & 106.7 & 117.6 \\ 811 & 106.6 & 0 & 108.8 & 106.5 & 118.1 \\ 810 & 106.4 & 0 & 108.6 & 106.4 & 118.6 \\ 808 & 106.2 & 2.2 & 108.5 & 106.4 & 118.4 \\ 807 & 106 & 2.4 & 109 & 106.3 & 115.7 \\ 805 & 105.8 & 2.4 & 109.4 & 106.4 & 114.3 \\ 804 & 105.7 & 2.4 & 109.7 & 106.7 & 113.5 \\ 803 & 105.5 & 2.4 & 110 & 106.9 & 112.7 \\ 803 & 105.7 & 2.4 & 110.1 & 107.2 & 112.6 \\ 804 & 105.8 & 2.4 & 110.4 & 107.5 & 112.5 \\ 804 & 105.8 & 2.4 & 110.4 & 108.1 & 112.3 \\ 804 & 105.9 & 2.4 & 110.6 & 108.7 & 112.2 \\ 804 & 105.9 & 2.4 & 110.9 & 109.1 & 112.1 \\ 804 & 105.9 & 2.4 & 111 & 109.6 & 112.1 \\ 805 & 106.2 & 2.4 & 111 & 109.7 & 111.7 \\ 805 & 106.2 & 2.4 & 110.9 & 109.9 & 111.8 \\ 805 & 106.2 & 2.4 & 110.9 & 110.1 & 112 \\ 805 & 106.2 & 2.4 & 110.5 & 110.1 & 111.9 \\ 805 & 106.2 & 2.4 & 110.1 & 109.9 & 111.9 \\ 805 & 106.2 & 0.1 & 110 & 109.9 & 112.4 \\ 806 & 106.3 & 0 & 109.9 & 109.9 & 114.6\end{array}$




$$
\begin{aligned}
& \text { 4/6/08 0:00 } \\
& \text { 4/6/08 1:00 } \\
& \text { 4/6/08 2:00 } \\
& \text { 4/6/08 3:00 } \\
& \text { 4/6/08 4:00 } \\
& \text { 4/6/08 5:00 } \\
& \text { 4/6/08 6:00 } \\
& \text { 4/6/08 7:00 } \\
& \text { 4/6/08 8:00 } \\
& \text { 4/6/08 9:00 } \\
& \text { 4/6/08 10:00 } \\
& \text { 4/6/08 11:00 } \\
& \text { 4/6/08 12:00 } \\
& \text { 4/6/08 13:00 } \\
& \text { 4/6/08 14:00 } \\
& 4 / 6 / 08 \text { 15:00 } \\
& \text { 4/6/08 16:00 } \\
& \text { 4/6/08 17:00 } \\
& \text { 4/6/08 18:00 } \\
& 4 / 6 / 08 \text { 19:00 } \\
& 4 / 6 / 0820: 00 \\
& 4 / 6 / 08 \text { 21:00 } \\
& 4 / 6 / 08 \text { 22:00 } \\
& \text { 4/6/08 23:00 } \\
& \text { 4/7/08 0:00 } \\
& \text { 4/7/08 1:00 } \\
& \text { 4/7/08 2:00 } \\
& \text { 4/7/08 3:00 } \\
& \text { 4/7/08 4:00 } \\
& \text { 4/7/08 5:00 } \\
& \text { 4/7/08 6:00 } \\
& \text { 4/7/08 7:00 } \\
& \text { 4/7/08 8:00 } \\
& \text { 4/7/08 9:00 } \\
& \text { 4/7/08 10:00 } \\
& \text { 4/7/08 11:00 } \\
& \text { 4/7/08 12:00 } \\
& \text { 4/7/08 13:00 } \\
& \text { 4/7/08 14:00 } \\
& \text { 4/7/08 15:00 } \\
& \text { 4/7/08 16:00 } \\
& \text { 4/7/08 17:00 } \\
& \text { 4/7/08 18:00 } \\
& \text { 4/7/08 19:00 } \\
& \text { 4/7/08 20:00 } \\
& \text { 4/7/08 21:00 } \\
& \text { 4/7/08 22:00 } \\
& \text { 4/7/08 23:00 } \\
& 4 / 8 / 08 \text { 0:00 } \\
& 4 / 8 / 08 \text { 1:00 } \\
& \text { 4/8/08 2:00 } \\
& \text { 4/8/08 3:00 }
\end{aligned}
$$

\begin{tabular}{|c|c|c|c|}
\hline 0 & 109.7 & 110.1 & 115.5 \\
\hline 0 & 109.6 & 110 & 117.5 \\
\hline 0 & 109.6 & 109.7 & 118.7 \\
\hline 0 & 109.6 & 109.5 & 119.6 \\
\hline 0 & 109.9 & 109.2 & 120 \\
\hline 0.1 & 109.9 & 108.9 & 120.6 \\
\hline 2.4 & 109.9 & 108.8 & 116.7 \\
\hline 2.4 & 109.7 & 108.4 & 115.9 \\
\hline 2.4 & 109.7 & 108.1 & 114.6 \\
\hline 2.4 & 109.7 & 108.3 & 113.7 \\
\hline 2.4 & 109.8 & 108.4 & 113.1 \\
\hline 2.4 & 109.8 & 108.3 & 113 \\
\hline 2.4 & 110.1 & 108.3 & 113.1 \\
\hline 2.4 & 110.5 & 108.5 & 113 \\
\hline 2.4 & 110.7 & 108.5 & 113.1 \\
\hline 2.4 & 110.7 & 108.8 & 113.1 \\
\hline 2.4 & 110.5 & 109 & 112.6 \\
\hline 2.4 & 110.5 & 109.6 & 112.9 \\
\hline 2.4 & 110.4 & 109.7 & 112.7 \\
\hline 2.4 & 110.2 & 109.6 & 112.3 \\
\hline 2.4 & 109.8 & 109.3 & 111.9 \\
\hline 2.2 & 109.7 & 109 & 112.1 \\
\hline 0 & 109.5 & 108.8 & 113.2 \\
\hline 0 & 109.5 & 108.6 & 115.6 \\
\hline 0 & 109.3 & 108.4 & 116.8 \\
\hline 0 & 109.1 & 108.1 & 117.3 \\
\hline 0 & 109.1 & 108 & 117.6 \\
\hline 0 & 109.3 & 107.6 & 118.3 \\
\hline 0 & 109.4 & 107.4 & 118.7 \\
\hline 0.2 & 109.4 & 107.4 & 118.7 \\
\hline 2.5 & 109.7 & 107.3 & 118.2 \\
\hline 2.5 & 109.4 & 107.2 & 116.6 \\
\hline 2.5 & 109 & 106.9 & 115.4 \\
\hline 2.5 & 108.7 & 106.9 & 114.9 \\
\hline 2.5 & 108.3 & 106.9 & 114.8 \\
\hline 2.5 & 108.2 & 106.8 & 114.3 \\
\hline 2.4 & 107.9 & 106.9 & 114.2 \\
\hline 2.4 & 108.2 & 107.2 & 114.3 \\
\hline 2.4 & 108.5 & 107.4 & 114.5 \\
\hline 2.5 & 108.6 & 108 & 114.2 \\
\hline 2.5 & 108.7 & 108.3 & 114.4 \\
\hline 2.5 & 108.7 & 108.6 & 114.1 \\
\hline 2.5 & 108.7 & 108.7 & 114 \\
\hline 2.5 & 108.7 & 108.7 & 113.7 \\
\hline 2.4 & 108.9 & 108.7 & 113.8 \\
\hline 1.3 & 108.9 & 108.6 & 113.7 \\
\hline 0 & 109 & 108.3 & 114.2 \\
\hline 0 & 109 & 108.1 & 115.5 \\
\hline 0 & 108.9 & 108.1 & 116.3 \\
\hline 0 & 108.9 & 107.7 & 117.5 \\
\hline 0 & 108.7 & 107.3 & 118.7 \\
\hline 0 & 108.6 & 107.3 & 119.2 \\
\hline
\end{tabular}

$\begin{array}{rr}806 & 106.3 \\ 806 & 106.5 \\ 806 & 106.5 \\ 807 & 106.6 \\ 808 & 106.7 \\ 808 & 106.7 \\ 808 & 106.6 \\ 809 & 106.7 \\ 809 & 106.6 \\ 809 & 106.6 \\ 808 & 106.3 \\ 808 & 106.3 \\ 808 & 106.2 \\ 808 & 106.3 \\ 809 & 106.4 \\ 809 & 106.4 \\ 809 & 106.3 \\ 809 & 106.3 \\ 810 & 106.4 \\ 810 & 106.4 \\ 810 & 106.4 \\ 810 & 106.3 \\ 810 & 106.3 \\ 809 & 106 \\ 809 & 106 \\ 808 & 105.9 \\ 808 & 105.9 \\ 808 & 105.9 \\ 808 & 105.9 \\ 807 & 105.8 \\ 807 & 105.8 \\ 807 & 105.8 \\ 807 & 105.6 \\ 807 & 105.6 \\ 807 & 105.5 \\ 808 & 105.6 \\ 809 & 105.8 \\ 810 & 105.9 \\ 811 & 106.2 \\ 811 & 106.2 \\ 811 & 106 \\ 812 & 106.3 \\ 812 & 106.3 \\ 811 & 106.2 \\ 811 & 106.2 \\ 811 & 106.2 \\ 811 & 106.2 \\ 810 & 106 \\ 810 & 106 \\ 809 & 105.9 \\ 809 & 106 \\ 809 & 106\end{array}$




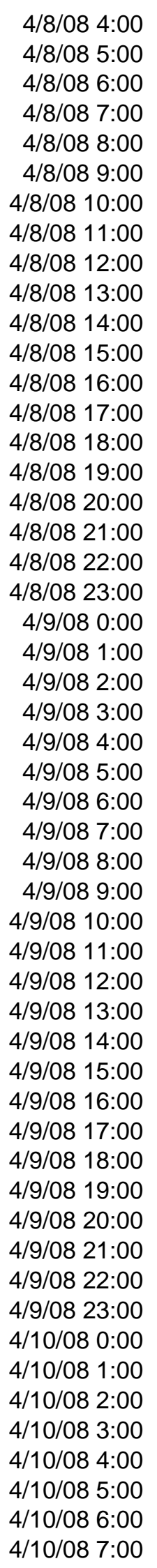

$\begin{array}{rrrrrr}808 & 105.9 & 0 & 108.8 & 107.1 & 120.2 \\ 808 & 106 & 0 & 108.6 & 107.1 & 120.8 \\ 807 & 105.9 & 2.4 & 108.8 & 106.9 & 116.6 \\ 807 & 105.9 & 2.4 & 108.9 & 106.9 & 116 \\ 807 & 105.9 & 2.4 & 109.3 & 106.8 & 114.9 \\ 807 & 105.9 & 2.4 & 109.8 & 106.7 & 114.3 \\ 807 & 105.9 & 2.4 & 110.2 & 107.6 & 114.1 \\ 807 & 105.9 & 2.4 & 110.7 & 107.9 & 114 \\ 808 & 106.2 & 2.4 & 110.9 & 108 & 114.2 \\ 808 & 106.2 & 2.4 & 110.7 & 108.4 & 114.3 \\ 808 & 106.2 & 2.4 & 110.9 & 108.8 & 114.2 \\ 809 & 106.4 & 2.4 & 110.9 & 109.4 & 114.4 \\ 808 & 106.3 & 2.4 & 110.7 & 110.1 & 114.2 \\ 808 & 106.3 & 2.4 & 110.2 & 110.6 & 114.5 \\ 808 & 106.3 & 2.4 & 109.8 & 110.6 & 114.1 \\ 807 & 106.2 & 2.4 & 109.3 & 110.5 & 113.6 \\ 807 & 106 & 2.4 & 109 & 110.4 & 113.9 \\ 806 & 105.9 & 1.3 & 108.6 & 110.1 & 113.9 \\ 805 & 105.8 & 0 & 108.4 & 109.8 & 115 \\ 805 & 105.8 & 0 & 108.4 & 109.7 & 116.1 \\ 804 & 105.7 & 0 & 108.4 & 109.4 & 116.8 \\ 803 & 105.5 & 0 & 108.2 & 109.3 & 117.1 \\ 802 & 105.4 & 0 & 108.2 & 109.2 & 117.1 \\ 801 & 105.3 & 0 & 108.1 & 109 & 117.1 \\ 800 & 105.1 & 0 & 108.1 & 108.8 & 117.5 \\ 799 & 105 & 0.2 & 108 & 108.7 & 117.5 \\ 798 & 104.9 & 2.4 & 107.9 & 108.4 & 117.2 \\ 797 & 104.7 & 2.4 & 107.7 & 108.1 & 116 \\ 796 & 104.5 & 2.4 & 107.6 & 107.9 & 115.2 \\ 796 & 104.5 & 2.4 & 107.5 & 107.9 & 114.7 \\ 796 & 104.5 & 2.4 & 107.6 & 107.9 & 114.4 \\ 796 & 104.5 & 2.4 & 107.5 & 107.9 & 114.1 \\ 797 & 104.6 & 2.4 & 107.5 & 107.7 & 114 \\ 797 & 104.6 & 2.4 & 107.3 & 108.2 & 113.9 \\ 798 & 104.7 & 2.4 & 107.5 & 108.6 & 114 \\ 798 & 104.7 & 2.4 & 107.5 & 109.2 & 113.9 \\ 798 & 104.7 & 2.4 & 107.5 & 109.4 & 113.9 \\ 799 & 104.9 & 2.4 & 107.5 & 109.7 & 113.9 \\ 799 & 104.9 & 2.4 & 107.3 & 109.5 & 113.8 \\ 799 & 104.9 & 2.4 & 107.2 & 109.4 & 113.4 \\ 799 & 104.7 & 2.4 & 107 & 109 & 113.2 \\ 798 & 104.5 & 1.3 & 106.9 & 108.7 & 113.1 \\ 798 & 104.5 & 0 & 106.8 & 108.2 & 113.3 \\ 797 & 104.2 & 0 & 106.8 & 107.8 & 114.5 \\ 797 & 104.2 & 0 & 106.5 & 107.3 & 116.2 \\ 797 & 104.2 & 88.3 & 106.4 & 107 & 117.5 \\ 796 & 103.9 & 99.5 & 106.4 & 106.8 & 117.3 \\ 795 & 103.8 & 99.8 & 107.4 & 106.4 & 117.3 \\ 794 & 103.7 & 99.8 & 108.8 & 106 & 117.3 \\ 793 & 103.5 & 99.7 & 110.1 & 105.9 & 117.3 \\ 792 & 103.3 & 99.6 & 112.6 & 105.6 & 117.3 \\ 792 & 103.3 & 99.7 & 113.2 & 105.2 & 117.2 \\ & & & & & \end{array}$




\begin{tabular}{|c|}
\hline 4/10/08 8:00 \\
\hline 4/10/08 9:00 \\
\hline 4/10/08 10:00 \\
\hline 4/10/08 11:00 \\
\hline 4/10/08 12:00 \\
\hline 4/10/08 13:00 \\
\hline 4/10/08 14:00 \\
\hline 4/10/08 15:00 \\
\hline 4/10/08 16:00 \\
\hline 4/10/08 17:00 \\
\hline 4/10/08 18:00 \\
\hline 4/10/08 19:00 \\
\hline 4/10/08 20:00 \\
\hline 4/10/08 21:00 \\
\hline 4/10/08 22:00 \\
\hline 4/10/08 23:00 \\
\hline 4/11/08 0:00 \\
\hline 4/11/08 1:00 \\
\hline 4/11/08 2:00 \\
\hline 4/11/08 3:00 \\
\hline 4/11/08 4:00 \\
\hline 4/11/08 5:00 \\
\hline 4/11/08 6:00 \\
\hline 4/11/08 7:00 \\
\hline 4/11/08 8:00 \\
\hline 4/11/08 9:00 \\
\hline 4/11/08 10:00 \\
\hline 4/11/08 11:00 \\
\hline 4/11/08 12:00 \\
\hline 4/11/08 13:00 \\
\hline 4/11/08 14:00 \\
\hline 4/11/08 15:00 \\
\hline 4/11/08 16:00 \\
\hline 4/11/08 17:00 \\
\hline 4/11/08 18:00 \\
\hline 4/11/08 19:00 \\
\hline 4/11/08 20:00 \\
\hline 4/11/08 21:00 \\
\hline 4/11/08 22:00 \\
\hline 4/11/08 23:00 \\
\hline 4/12/08 0:00 \\
\hline 4/12/08 1:00 \\
\hline 4/12/08 2:00 \\
\hline 4/12/08 3:00 \\
\hline 4/12/08 4:00 \\
\hline 4/12/08 5:00 \\
\hline 4/12/08 6:00 \\
\hline 4/12/08 7:00 \\
\hline 4/12/08 8:00 \\
\hline 4/12/08 9:00 \\
\hline 4/12/08 10:00 \\
\hline 4/12/08 11:00 \\
\hline
\end{tabular}

$\begin{array}{rrrrrr}792 & 103.1 & 99.7 & 113.6 & 104.9 & 117.4 \\ 792 & 103.1 & 99.7 & 113.9 & 104.9 & 117.3 \\ 793 & 103.1 & 99.7 & 114.1 & 104.9 & 117.3 \\ 793 & 103.1 & 99.7 & 114.6 & 104.9 & 117.3 \\ 794 & 103.3 & 99.5 & 114.9 & 105.2 & 117.1 \\ 794 & 103.3 & 99.5 & 115.2 & 105.4 & 117.1 \\ 795 & 103.2 & 99.3 & 115.7 & 105.8 & 117.3 \\ 795 & 103.2 & 99.1 & 115.7 & 106.3 & 117.1 \\ 796 & 103.4 & 98.9 & 115.7 & 106.7 & 117.3 \\ 797 & 103.5 & 98.9 & 115.8 & 107.3 & 117.3 \\ 797 & 103.5 & 99 & 115.8 & 107.8 & 117 \\ 798 & 103.6 & 98.9 & 115.9 & 108.5 & 117.1 \\ 798 & 103.5 & 98.9 & 115.8 & 109.3 & 117.3 \\ 798 & 103.5 & 98.9 & 115.2 & 110.5 & 117.1 \\ 798 & 103.4 & 99.2 & 115.2 & 111.1 & 117.2 \\ 798 & 103.4 & 99.3 & 115.2 & 112 & 116.9 \\ 798 & 103.4 & 99.3 & 114.8 & 112.5 & 117.1 \\ 797 & 103.2 & 99.1 & 114.8 & 112.5 & 117.1 \\ 797 & 103.2 & 98.9 & 114.7 & 112.5 & 117.1 \\ 796 & 103.1 & 98.8 & 114.8 & 112.4 & 117.1 \\ 795 & 102.8 & 98.7 & 115 & 112.4 & 117.1 \\ 794 & 102.7 & 98.5 & 114.7 & 112.3 & 117.1 \\ 793 & 102.6 & 98.4 & 114.7 & 112.3 & 116.9 \\ 793 & 102.6 & 98.3 & 114.9 & 112.3 & 116.9 \\ 792 & 102.5 & 98.5 & 114.9 & 112.3 & 117.1 \\ 793 & 102.6 & 99 & 115.1 & 112.3 & 116.9 \\ 793 & 102.6 & 99.1 & 115.4 & 112.6 & 117.1 \\ 794 & 102.8 & 99.2 & 115.9 & 113 & 116.9 \\ 796 & 103.1 & 99.4 & 116.3 & 113.6 & 116.9 \\ 797 & 103.4 & 99.6 & 116.9 & 114.1 & 117.1 \\ 799 & 103.6 & 99.7 & 116.9 & 114.6 & 117.3 \\ 800 & 103.9 & 99.5 & 117.1 & 115.4 & 117 \\ 801 & 104 & 99.5 & 117.1 & 116.3 & 117.1 \\ 803 & 104.4 & 99.5 & 117.4 & 117.1 & 117.3 \\ 804 & 104.6 & 99.6 & 117.4 & 117.6 & 117.3 \\ 805 & 104.8 & 99.8 & 116.7 & 118.1 & 117.2 \\ 805 & 104.8 & 99.8 & 116.5 & 118.2 & 117.3 \\ 806 & 104.8 & 99.8 & 116.1 & 118.1 & 117.3 \\ 806 & 104.8 & 99.8 & 116 & 117.8 & 116.8 \\ 806 & 104.8 & 99.9 & 115.4 & 117.6 & 116.6 \\ 805 & 104.8 & 100 & 115.2 & 117 & 117.3 \\ 804 & 104.7 & 99.8 & 114.8 & 116.4 & 116.9 \\ 803 & 104.6 & 99.9 & 114.7 & 115.6 & 117.4 \\ 803 & 104.6 & 99.9 & 114.4 & 114.8 & 117.3 \\ 802 & 104.4 & 100 & 114.2 & 113.9 & 117 \\ 801 & 104.3 & 100 & 113.5 & 113.2 & 117.2 \\ 801 & 104.3 & 100 & 114 & 112.3 & 117.2 \\ 802 & 104.4 & 100 & 113.5 & 111.7 & 117 \\ 803 & 104.6 & 100.1 & 113.7 & 111.6 & 117.3 \\ 806 & 105.1 & 100.1 & 114.2 & 111.3 & 117.3 \\ 811 & 105.7 & 100.1 & 115.3 & 110.6 & 117.4 \\ 816 & 106.5 & 100 & 116.1 & 110.3 & 117.5\end{array}$




$$
\begin{aligned}
& \text { 4/12/08 12:00 } \\
& \text { 4/12/08 13:00 } \\
& \text { 4/12/08 14:00 } \\
& \text { 4/12/08 15:00 } \\
& \text { 4/12/08 16:00 } \\
& \text { 4/12/08 17:00 } \\
& \text { 4/12/08 18:00 } \\
& \text { 4/12/08 19:00 } \\
& \text { 4/12/08 20:00 } \\
& 4 / 12 / 08 \text { 21:00 } \\
& 4 / 12 / 08 \text { 22:00 } \\
& \text { 4/12/08 23:00 } \\
& \text { 4/13/08 0:00 } \\
& \text { 4/13/08 1:00 } \\
& 4 / 13 / 08 \text { 2:00 } \\
& \text { 4/13/08 3:00 } \\
& \text { 4/13/08 4:00 } \\
& \text { 4/13/08 5:00 } \\
& \text { 4/13/08 6:00 } \\
& \text { 4/13/08 7:00 } \\
& \text { 4/13/08 8:00 } \\
& \text { 4/13/08 9:00 } \\
& \text { 4/13/08 10:00 } \\
& \text { 4/13/08 11:00 } \\
& \text { 4/13/08 12:00 } \\
& \text { 4/13/08 13:00 } \\
& \text { 4/13/08 14:00 } \\
& \text { 4/13/08 15:00 } \\
& \text { 4/13/08 16:00 } \\
& 4 / 13 / 0817: 00 \\
& \text { 4/13/08 18:00 } \\
& \text { 4/13/08 19:00 } \\
& \text { 4/13/08 20:00 } \\
& \text { 4/13/08 21:00 } \\
& 4 / 13 / 08 \text { 22:00 } \\
& \text { 4/13/08 23:00 } \\
& \text { 4/14/08 0:00 } \\
& \text { 4/14/08 1:00 } \\
& 4 / 14 / 082: 00 \\
& \text { 4/14/08 3:00 } \\
& \text { 4/14/08 4:00 } \\
& \text { 4/14/08 5:00 } \\
& \text { 4/14/08 6:00 } \\
& \text { 4/14/08 7:00 } \\
& \text { 4/14/08 8:00 } \\
& \text { 4/14/08 9:00 } \\
& \text { 4/14/08 10:00 } \\
& 4 / 14 / 08 \text { 11:00 } \\
& \text { 4/14/08 12:00 } \\
& \text { 4/14/08 13:00 } \\
& \text { 4/14/08 14:00 } \\
& \text { 4/14/08 15:00 }
\end{aligned}
$$

$\begin{array}{rrrrrr}819 & 106.9 & 97.5 & 116.8 & 109.9 & 117.1 \\ 823 & 107.4 & 95.3 & 116.7 & 109.9 & 117.5 \\ 826 & 108 & 95.3 & 116.6 & 110.2 & 117.3 \\ 828 & 108.2 & 95.1 & 117 & 110.8 & 116.3 \\ 830 & 108.6 & 95.1 & 116.8 & 111.1 & 116.5 \\ 833 & 109 & 95.1 & 116.7 & 111.2 & 116.4 \\ 835 & 109.4 & 95 & 116.2 & 111.6 & 116.5 \\ 837 & 109.7 & 95 & 115.6 & 111.9 & 116.5 \\ 839 & 110 & 95.1 & 115.2 & 112.2 & 116.4 \\ 842 & 110.2 & 95.2 & 114.9 & 112.3 & 116.5 \\ 844 & 110.5 & 95.2 & 114.6 & 112.7 & 116.5 \\ 845 & 110.6 & 95.2 & 114.5 & 112.9 & 116.4 \\ 846 & 110.7 & 95.3 & 114.6 & 112.7 & 116.8 \\ 846 & 110.7 & 95.4 & 114.6 & 112.8 & 117.3 \\ 846 & 110.7 & 95.3 & 114.8 & 112.8 & 117.3 \\ 847 & 110.9 & 95.2 & 114.4 & 112.8 & 117 \\ 847 & 110.9 & 95 & 114.8 & 112.8 & 117.3 \\ 849 & 111.1 & 94.9 & 114.9 & 112.8 & 117 \\ 849 & 111.1 & 94.9 & 115 & 112.8 & 117.4 \\ 851 & 111.4 & 94.9 & 115.3 & 112.7 & 117.4 \\ 853 & 111.6 & 94.9 & 115.3 & 112.5 & 117.3 \\ 855 & 111.9 & 96.3 & 115.8 & 112.5 & 117.1 \\ 857 & 112.3 & 96.5 & 116.3 & 112.7 & 117.3 \\ 860 & 112.9 & 96.4 & 116.7 & 112.9 & 117 \\ 863 & 113.3 & 96.4 & 117 & 113.3 & 117.2 \\ 866 & 113.8 & 96.1 & 117.7 & 114 & 117.2 \\ 868 & 114.1 & 96 & 117.5 & 114.8 & 117.5 \\ 870 & 114.5 & 95.9 & 117.7 & 115.6 & 117.5 \\ 872 & 114.7 & 95.8 & 118 & 116.3 & 117.5 \\ 872 & 114.9 & 95.6 & 118 & 116.7 & 117.5 \\ 873 & 115 & 85.3 & 117.7 & 117.1 & 114.9 \\ 873 & 115.2 & 75.7 & 118 & 117.1 & 114.8 \\ 872 & 114.9 & 75.7 & 116.9 & 116.8 & 114.7 \\ 870 & 114.5 & 75.7 & 115.9 & 116.4 & 114.7 \\ 869 & 114.2 & 75.7 & 115.7 & 115.8 & 114.8 \\ 867 & 113.9 & 75.6 & 115.3 & 115.4 & 114.6 \\ 865 & 113.5 & 75.7 & 114.4 & 114.9 & 114.5 \\ 862 & 113.3 & 75.7 & 114.8 & 114.3 & 114.6 \\ 860 & 113.2 & 75.8 & 115.2 & 113.9 & 114.6 \\ 858 & 112.7 & 75.8 & 114.9 & 113.8 & 114.6 \\ 857 & 112.6 & 75.7 & 115.1 & 113.8 & 114.7 \\ 856 & 112.6 & 75.7 & 114.4 & 113.5 & 114.6 \\ 854 & 112.2 & 75.7 & 115.3 & 113.8 & 114.7 \\ 853 & 112.2 & 76.9 & 115.2 & 114 & 115.4 \\ 853 & 112.1 & 96.4 & 115.3 & 114.2 & 117.7 \\ 853 & 112.2 & 96.5 & 115.3 & 114.2 & 117.6 \\ 852 & 112.1 & 96.8 & 115.5 & 114.2 & 117.6 \\ 853 & 112.2 & 96.8 & 116 & 114.2 & 117.6 \\ 855 & 112.5 & 96.8 & 116.3 & 114.2 & 117.7 \\ 858 & 112.9 & 96.8 & 116.5 & 114.2 & 117.7 \\ 858 & 112.9 & 95.5 & 116.4 & 114.7 & 117.3 \\ 860 & 113.2 & 93.8 & 116.8 & 114.9 & 117.1 \\ & & & & & \end{array}$




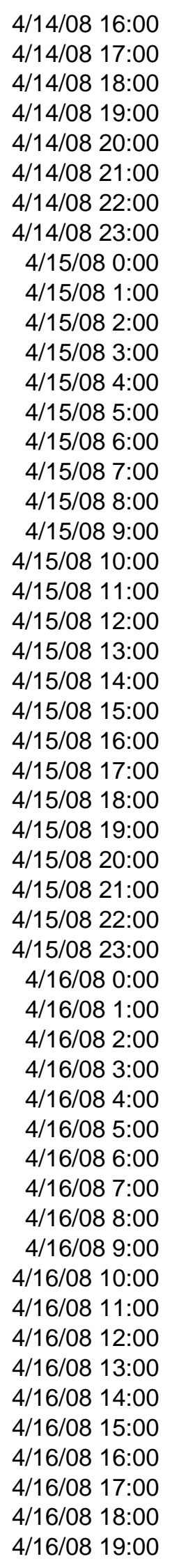

$\begin{array}{rrrrrr}860 & 113.2 & 93.8 & 116.8 & 115.3 & 117.6 \\ 859 & 112.9 & 93.8 & 116.8 & 115.5 & 117.2 \\ 858 & 112.9 & 93.7 & 116.6 & 115.1 & 117.3 \\ 856 & 112.6 & 93.7 & 116.6 & 115.3 & 117.2 \\ 854 & 112.2 & 93.7 & 116.4 & 115.5 & 117.1 \\ 851 & 111.8 & 94.1 & 116.2 & 115.3 & 117.1 \\ 847 & 111.2 & 94.3 & 115.8 & 114.9 & 117.2 \\ 844 & 110.8 & 94.5 & 115.8 & 114.5 & 117 \\ 841 & 110.2 & 94.6 & 115.6 & 114.2 & 117 \\ 838 & 109.8 & 94.5 & 115 & 113.7 & 117 \\ 835 & 109.4 & 94.2 & 114.9 & 113.6 & 116.9 \\ 834 & 109.3 & 94.1 & 115.3 & 113.6 & 117 \\ 833 & 109 & 94.2 & 115 & 113.6 & 117 \\ 833 & 109 & 94.2 & 114.2 & 113.4 & 117 \\ 832 & 108.9 & 94.2 & 115 & 113.6 & 117.1 \\ 832 & 108.8 & 94.2 & 114.7 & 113.2 & 117 \\ 832 & 108.8 & 94.2 & 114.7 & 112.9 & 117.1 \\ 831 & 108.6 & 94.2 & 114.7 & 112.9 & 117.1 \\ 831 & 108.6 & 94.5 & 115.1 & 112.9 & 116.9 \\ 832 & 108.6 & 94.6 & 114.8 & 112.9 & 117.1 \\ 834 & 108.9 & 94.6 & 115.2 & 113 & 117.1 \\ 835 & 109 & 94.7 & 115.5 & 113.1 & 117.1 \\ 837 & 109.3 & 94.9 & 115.3 & 113.4 & 117.2 \\ 838 & 109.4 & 97.3 & 115.7 & 113.7 & 117.5 \\ 837 & 109.3 & 97.8 & 115.5 & 113.8 & 117.3 \\ 837 & 109.3 & 97.7 & 115.7 & 113.8 & 117.2 \\ 835 & 108.9 & 97.7 & 115.7 & 113.7 & 117.4 \\ 834 & 108.7 & 98.5 & 115.7 & 113.8 & 116.9 \\ 832 & 108.5 & 98 & 115.5 & 113.5 & 116.8 \\ 829 & 108.1 & 98 & 115.3 & 113.2 & 116.8 \\ 827 & 107.7 & 98.3 & 115.2 & 113.1 & 116.8 \\ 824 & 107.3 & 98.5 & 114.9 & 112.8 & 116.9 \\ 823 & 107.2 & 98.9 & 114.3 & 112.7 & 117.2 \\ 821 & 106.9 & 98.8 & 114.3 & 112.6 & 117.4 \\ 819 & 106.5 & 98.4 & 114.4 & 112.5 & 117 \\ 817 & 106.2 & 98.3 & 114.2 & 112.5 & 117 \\ 817 & 106.2 & 98.3 & 114.5 & 112.2 & 117.3 \\ 816 & 106.1 & 98.5 & 114.6 & 112.2 & 117.1 \\ 817 & 106.2 & 98.4 & 114.8 & 112.2 & 116.9 \\ 817 & 106.2 & 98.2 & 114.8 & 112.2 & 116.2 \\ 819 & 106.4 & 97.7 & 114.9 & 112.2 & 116 \\ 820 & 106.5 & 97.1 & 113.2 & 112.2 & 116 \\ 822 & 106.8 & 97 & 112.8 & 112 & 115.9 \\ 824 & 106.9 & 97.1 & 112.2 & 112.2 & 116.1 \\ 826 & 107.1 & 97.1 & 111.8 & 112.4 & 116.1 \\ 829 & 107.7 & 97.2 & 111.4 & 112.5 & 116.2 \\ 831 & 107.8 & 99.6 & 111.1 & 112.7 & 116.7 \\ 832 & 108.1 & 101.4 & 111.5 & 113.1 & 116.7 \\ 833 & 108.2 & 101.4 & 111.6 & 113.6 & 116.6 \\ 833 & 108.2 & 101.5 & 111.8 & 114 & 116.6 \\ 833 & 108.2 & 101.5 & 112 & 114.4 & 116.7 \\ 832 & 108.1 & 101.4 & 112 & 114.6 & 117.1 \\ & & & & & \end{array}$




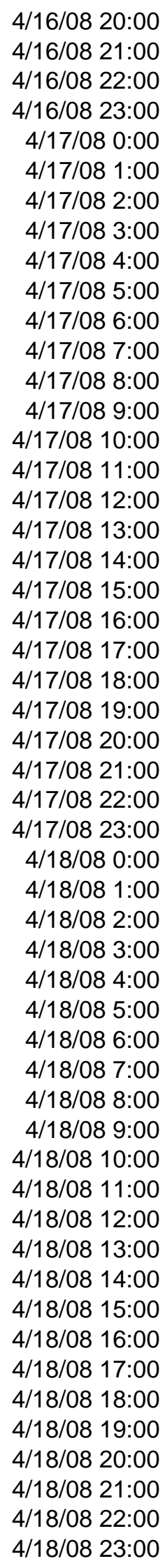

$\begin{array}{rrrrrr}831 & 108.1 & 101.2 & 112 & 114.6 & 117.4 \\ 830 & 107.9 & 101.3 & 112.4 & 114.5 & 117.4 \\ 830 & 107.9 & 101.6 & 113.1 & 114.1 & 117.4 \\ 830 & 107.9 & 101.1 & 113.3 & 113.5 & 117.1 \\ 830 & 107.9 & 101.2 & 113.5 & 112.8 & 116.9 \\ 831 & 108.1 & 101 & 113.6 & 112.2 & 116.9 \\ 831 & 108.1 & 101 & 113.7 & 112.1 & 116.5 \\ 831 & 108.2 & 100.7 & 114 & 111.9 & 116.9 \\ 830 & 108.1 & 100.6 & 114.4 & 111.9 & 116.9 \\ 830 & 108.1 & 100.7 & 114.4 & 111.9 & 117 \\ 829 & 107.9 & 101.1 & 114.8 & 111.9 & 116.6 \\ 828 & 107.8 & 100.8 & 114.9 & 111.9 & 116.5 \\ 827 & 107.7 & 100.9 & 115.2 & 111.9 & 116.5 \\ 826 & 107.6 & 101 & 115.3 & 112.1 & 116.5 \\ 826 & 107.6 & 101 & 115.2 & 112.2 & 116.5 \\ 826 & 107.6 & 100.9 & 115.2 & 112.3 & 116.4 \\ 826 & 107.6 & 100.9 & 114.9 & 112.6 & 116.5 \\ 827 & 107.7 & 100.7 & 115.2 & 113 & 116.4 \\ 828 & 108 & 100.2 & 115.3 & 113.1 & 116.5 \\ 830 & 108.4 & 100.2 & 115.5 & 113.5 & 116.7 \\ 832 & 108.6 & 100.3 & 115.3 & 113.7 & 116.6 \\ 834 & 108.9 & 100.2 & 115.4 & 113.9 & 116.4 \\ 836 & 109.3 & 100.2 & 115.2 & 114.2 & 116.6 \\ 837 & 109.4 & 100.3 & 115.4 & 114.5 & 116.4 \\ 838 & 109.5 & 101.4 & 115.3 & 114.5 & 117.1 \\ 839 & 109.7 & 101.6 & 115.1 & 114.3 & 117.1 \\ 838 & 109.5 & 101.9 & 114.8 & 114.1 & 117.2 \\ 838 & 109.5 & 102.2 & 114.5 & 113.7 & 116.8 \\ 837 & 109.4 & 101.1 & 114.5 & 113.2 & 116.8 \\ 835 & 109.2 & 101 & 114.7 & 112.5 & 116.8 \\ 833 & 108.9 & 100.8 & 114.9 & 112.1 & 116.8 \\ 832 & 108.9 & 100.7 & 114.7 & 112 & 117.1 \\ 830 & 108.6 & 100.5 & 114.9 & 111.7 & 116.9 \\ 828 & 108.4 & 100.5 & 115.3 & 111.6 & 116.9 \\ 826 & 108.1 & 100.5 & 114.7 & 111.5 & 116.9 \\ 824 & 107.9 & 100.6 & 114.9 & 111.2 & 116.9 \\ 823 & 107.7 & 100 & 115 & 111.1 & 117 \\ 822 & 107.6 & 99.8 & 115.1 & 110.8 & 116.8 \\ 821 & 107.5 & 100 & 115.1 & 110.8 & 117 \\ 821 & 107.5 & 100.1 & 114.9 & 110.7 & 116.7 \\ 822 & 107.6 & 100.1 & 115.1 & 111.1 & 116.9 \\ 823 & 107.9 & 100.2 & 115.1 & 111.2 & 117.1 \\ 825 & 108.3 & 100.2 & 115.4 & 111.8 & 116.8 \\ 827 & 108.7 & 100 & 115.3 & 111.9 & 116.8 \\ 828 & 108.8 & 99.8 & 115.4 & 111.9 & 117.1 \\ 830 & 109.1 & 99.7 & 115.3 & 111.9 & 117.1 \\ 831 & 109.2 & 99.8 & 115.2 & 111.8 & 117.7 \\ 832 & 109.3 & 99.7 & 115.3 & 111.8 & 117.7 \\ 834 & 109.6 & 99.6 & 115.1 & 111.3 & 117.5 \\ 836 & 109.6 & 99.8 & 114.9 & 111.1 & 117.5 \\ 835 & 109.9 & 100.1 & 115.6 & 111 & 117.7 \\ & & 100.3 & 115.6 & 111.1 & 117.6\end{array}$




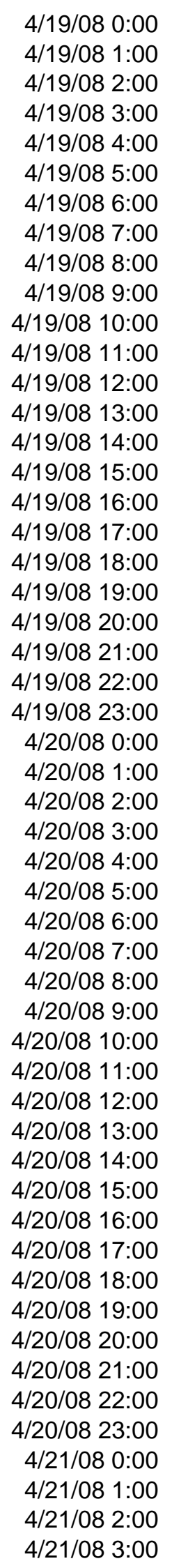

$\begin{array}{rrrrrr}835 & 109.9 & 100.4 & 115.2 & 110.7 & 117.6 \\ 833 & 109.6 & 100.2 & 115.5 & 110.7 & 117.6 \\ 832 & 109.5 & 100.2 & 116.1 & 110.6 & 117.6 \\ 830 & 109.4 & 100.3 & 115.9 & 110.6 & 117.5 \\ 828 & 109.1 & 100.3 & 116.3 & 110.6 & 117.6 \\ 826 & 108.8 & 100.3 & 115.8 & 110.6 & 117.6 \\ 824 & 108.6 & 100.3 & 115.7 & 110.5 & 117.5 \\ 822 & 108.3 & 100.3 & 115.5 & 110.4 & 117.6 \\ 820 & 108 & 100.2 & 116 & 110.4 & 117.5 \\ 819 & 107.9 & 100.2 & 115.9 & 110.5 & 117.6 \\ 818 & 107.8 & 100.2 & 116.3 & 110.5 & 117.5 \\ 818 & 107.9 & 100.2 & 116.2 & 110.5 & 117.5 \\ 817 & 107.8 & 100.2 & 116.4 & 110.9 & 117.5 \\ 817 & 107.8 & 100.2 & 116.6 & 111.7 & 117.5 \\ 816 & 107.8 & 100.2 & 116.3 & 112.6 & 117.5 \\ 816 & 107.7 & 100.1 & 116.2 & 113.1 & 117.5 \\ 816 & 107.7 & 100.1 & 116.2 & 113.4 & 117.5 \\ 816 & 107.7 & 100.1 & 116 & 113.9 & 117.5 \\ 816 & 107.7 & 100.2 & 116.3 & 114.1 & 117.5 \\ 816 & 107.7 & 100.2 & 116.2 & 113.9 & 117.5 \\ 817 & 107.6 & 100.3 & 114.8 & 113.7 & 117.7 \\ 817 & 107.6 & 100.5 & 115.5 & 113.6 & 117.5 \\ 818 & 107.8 & 100.6 & 115.6 & 113.5 & 117.5 \\ 819 & 107.9 & 101 & 115.6 & 113.4 & 117.6 \\ 820 & 108 & 101.2 & 115.6 & 113 & 117.5 \\ 822 & 108.3 & 101 & 115.9 & 113 & 117.5 \\ 823 & 108.3 & 101 & 116 & 112.9 & 117.6 \\ 824 & 108.4 & 101.1 & 116.1 & 112.9 & 117.5 \\ 824 & 108.4 & 101.1 & 115.9 & 112.9 & 117.6 \\ 826 & 108.7 & 101.1 & 115.3 & 112.6 & 117.5 \\ 827 & 108.8 & 101.1 & 115.5 & 112.5 & 117.5 \\ 829 & 108.9 & 101.1 & 115.4 & 112.3 & 117.6 \\ 831 & 109.2 & 101.1 & 115.8 & 112.5 & 117.5 \\ 833 & 109.5 & 101.1 & 116.2 & 112.4 & 117.7 \\ 835 & 109.7 & 101.1 & 116.5 & 112.6 & 117.7 \\ 837 & 110 & 100.9 & 116.8 & 112.7 & 117.8 \\ 837 & 110 & 100.8 & 117 & 113 & 118 \\ 838 & 110.1 & 101 & 117.3 & 113.6 & 117.8 \\ 838 & 110.1 & 101 & 117.1 & 114.1 & 117.8 \\ 838 & 110 & 101 & 117.1 & 114.9 & 117.8 \\ 838 & 110 & 100.9 & 117.1 & 115.6 & 118 \\ 837 & 109.8 & 101 & 117 & 115.8 & 117.8 \\ 836 & 109.9 & 100.9 & 116.8 & 115.8 & 117.6 \\ 835 & 109.4 & 100.5 & 116.3 & 115.7 & 117.4 \\ 834 & 109.3 & 100.6 & 115.8 & 115.4 & 116.9 \\ 831 & 108.9 & 100.6 & 115.8 & 115.4 & 116.5 \\ 829 & 108.7 & 100.8 & 115.7 & 115.2 & 116.6 \\ 829 & 108.7 & 100.8 & 115.3 & 114.5 & 116.6 \\ 828 & 108.5 & 100.9 & 115.1 & 114 & 116.6 \\ 829 & 108.7 & 100.9 & 115 & 113.6 & 116.6 \\ 831 & 108.9 & 100.7 & 115 & 113.5 & 116.8 \\ 833 & 109.2 & 100.7 & 114.6 & 113.6 & 116.8\end{array}$




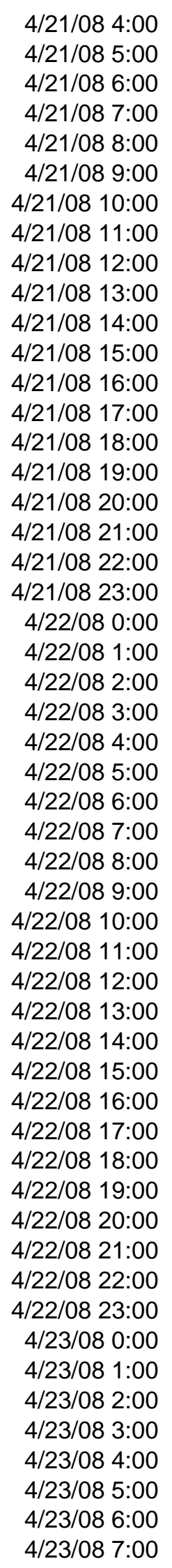

$\begin{array}{rrrrrr}835 & 109.6 & 100.6 & 115 & 113.7 & 116.8 \\ 837 & 109.8 & 100.4 & 114.9 & 113.6 & 116.8 \\ 839 & 110.1 & 100.4 & 114.8 & 113.6 & 116.9 \\ 841 & 110.4 & 100.3 & 115.2 & 113.6 & 116.9 \\ 841 & 110.2 & 100.2 & 115.3 & 113.6 & 117 \\ 842 & 110.4 & 100.3 & 115.6 & 113.6 & 116.8 \\ 843 & 110.5 & 100.3 & 115.8 & 113.7 & 116.9 \\ 844 & 110.6 & 100.2 & 115.9 & 113.7 & 116.8 \\ 844 & 110.6 & 100.3 & 116.3 & 114 & 116.8 \\ 844 & 110.8 & 100.3 & 116.3 & 114 & 116.8 \\ 844 & 110.8 & 100.3 & 116.2 & 114.3 & 116.8 \\ 844 & 110.8 & 100.4 & 116.2 & 114.1 & 116.9 \\ 843 & 110.6 & 100.5 & 116.2 & 114.4 & 117 \\ 843 & 110.6 & 100.1 & 116.3 & 114.1 & 116.8 \\ 843 & 110.6 & 100 & 116.2 & 114 & 116.8 \\ 842 & 110.5 & 100.2 & 115.9 & 114 & 116.8 \\ 842 & 110.5 & 100 & 115.7 & 113.7 & 117.3 \\ 842 & 110.5 & 99.9 & 115.4 & 113.6 & 117.4 \\ 845 & 110.9 & 100 & 115.3 & 113.6 & 117.8 \\ 847 & 111.2 & 100.2 & 115 & 113.5 & 118 \\ 850 & 111.5 & 100.6 & 114.8 & 113.4 & 117.3 \\ 852 & 111.8 & 101 & 114.5 & 113.4 & 117.2 \\ 854 & 112.2 & 100.8 & 114.7 & 113.2 & 117.2 \\ 856 & 112.5 & 100.7 & 114.8 & 113.4 & 116.9 \\ 856 & 112.5 & 100.7 & 115.2 & 113.1 & 117.2 \\ 857 & 112.8 & 100.5 & 115.6 & 112.9 & 117 \\ 858 & 112.9 & 100.1 & 115.7 & 112.4 & 117 \\ 857 & 112.8 & 99.8 & 116.1 & 111.8 & 117 \\ 855 & 112.5 & 99.4 & 116.1 & 111.6 & 117.3 \\ 853 & 112.2 & 99.3 & 115.9 & 111.1 & 117.7 \\ 849 & 111.9 & 99.5 & 116.1 & 110.9 & 117.7 \\ 846 & 111.5 & 99.4 & 115.5 & 110.7 & 118 \\ 843 & 111.1 & 99.2 & 115.4 & 110.8 & 117.8 \\ 841 & 110.9 & 99.1 & 115.3 & 110.8 & 118.1 \\ 840 & 1111 & 99 & 115.2 & 110.6 & 118.2 \\ 841 & 111.2 & 99.1 & 115 & 111 & 117.8 \\ 844 & 111.6 & 98.8 & 114.6 & 111.1 & 118 \\ 847 & 1112 & 98.5 & 114.6 & 111.1 & 117.8 \\ 850 & 112.4 & 98.4 & 114.9 & 111.4 & 117.7 \\ 854 & 1113 & 98.2 & 114.4 & 111.8 & 117.6 \\ 857 & 113.5 & 98.2 & 115.1 & 112.2 & 117.7 \\ 858 & 113.6 & 98.3 & 115.1 & 112.2 & 117.3 \\ 858 & 113.6 & 98.6 & 115.5 & 111.8 & 116.8 \\ 858 & 113.8 & 98.6 & 116 & 111.2 & 117 \\ 858 & 113.5 & 98.8 & 115.4 & 110.4 & 116.9 \\ 857 & 113.4 & 99 & 115.8 & 110.2 & 117.2 \\ 856 & 113.2 & 98.7 & 116.2 & 109.9 & 116.9 \\ 854 & 113 & 98.5 & 116.1 & 109.9 & 117.2 \\ 853 & 112.8 & 98.4 & 115.8 & 110.2 & 116.9 \\ 850 & 112.4 & 98.3 & 116.1 & 110.3 & 117 \\ 846 & 112.2 & 98.2 & 116.2 & 110.4 & 117 \\ & 111.9 & 98.1 & 115.9 & 110.7 & 117\end{array}$




\begin{tabular}{|c|}
\hline 8:00 \\
\hline 4/23/08 9:00 \\
\hline 4/23/08 10:00 \\
\hline 4/23/08 11:00 \\
\hline 4/23/08 12:00 \\
\hline 4/23/08 13:00 \\
\hline 4/23/08 14:00 \\
\hline 4/23/08 15:00 \\
\hline 4/23/08 16:00 \\
\hline 4/23/08 17:00 \\
\hline 4/23/08 18:00 \\
\hline 4/23/08 19:00 \\
\hline 4/23/08 20:00 \\
\hline 4/23/08 21:00 \\
\hline 4/23/08 22:00 \\
\hline 4/23/08 23:00 \\
\hline 4/24/08 0:00 \\
\hline 4/24/08 1:00 \\
\hline 4/24/08 2:00 \\
\hline 4/24/08 3:00 \\
\hline 4/24/08 4:00 \\
\hline 4/24/08 5:00 \\
\hline 4/24/08 6:00 \\
\hline 4/24/08 7:00 \\
\hline 4/24/08 8:00 \\
\hline 4/24/08 9:00 \\
\hline 4/24/08 10:00 \\
\hline 4/24/08 11:00 \\
\hline $4 / 24 / 0812: 00$ \\
\hline 4/24/08 13:00 \\
\hline 4/24/08 14:00 \\
\hline 4/24/08 15:00 \\
\hline 4/24/08 16:00 \\
\hline 4/24/08 17:00 \\
\hline 4/24/08 18:00 \\
\hline 4/24/08 19:00 \\
\hline 4/24/08 20:00 \\
\hline 4/24/08 21:00 \\
\hline 4/24/08 22:00 \\
\hline 4/24/08 23:00 \\
\hline 4/25/08 0:00 \\
\hline 4/25/08 1:00 \\
\hline $4 / 25 / 08$ 2:00 \\
\hline 4/25/08 3:00 \\
\hline 4/25/08 4:00 \\
\hline 4/25/08 5:00 \\
\hline 4/25/08 6:00 \\
\hline 4/25/08 7:00 \\
\hline 4/25/08 8:00 \\
\hline 4/25/08 9:00 \\
\hline 4/25/08 10:00 \\
\hline \\
\hline
\end{tabular}

$\begin{array}{rrrrrr}845 & 111.8 & 97.7 & 116.1 & 110.8 & 116.8 \\ 844 & 111.6 & 97.8 & 116.1 & 110.9 & 116.6 \\ 845 & 111.6 & 97.9 & 116.1 & 111.1 & 116.9 \\ 847 & 111.9 & 97.9 & 116.1 & 111.1 & 116.9 \\ 850 & 112.3 & 97.9 & 116.2 & 111.3 & 116.9 \\ 854 & 112.8 & 97.9 & 116.1 & 111.9 & 116.9 \\ 860 & 113.6 & 97.9 & 116.3 & 112.6 & 117 \\ 864 & 114.1 & 97.9 & 116.2 & 113.3 & 117 \\ 870 & 114.9 & 97.9 & 115.7 & 113.8 & 116.9 \\ 873 & 115.2 & 97.9 & 115.2 & 114.2 & 117 \\ 877 & 115.5 & 97.9 & 115.8 & 114.2 & 117.1 \\ 879 & 115.8 & 97.9 & 115.9 & 114.1 & 117 \\ 881 & 116.1 & 98.1 & 115.7 & 113.5 & 117.1 \\ 880 & 115.8 & 98.2 & 115.9 & 113.1 & 117 \\ 877 & 115.2 & 98.3 & 116 & 113 & 116.9 \\ 874 & 114.7 & 98.4 & 116.1 & 112.7 & 116.8 \\ 872 & 114.4 & 98.7 & 115.9 & 112.3 & 116.9 \\ 868 & 113.8 & 98.9 & 115.8 & 111.9 & 116.9 \\ 865 & 113.2 & 98.7 & 115.8 & 111.3 & 116.7 \\ 861 & 112.5 & 98.7 & 115.5 & 110.8 & 116.4 \\ 858 & 112 & 98.3 & 115.5 & 110.5 & 116.3 \\ 854 & 111.5 & 98.2 & 115.3 & 110.1 & 116.6 \\ 851 & 111.1 & 98.1 & 115.2 & 110 & 116.6 \\ 847 & 110.4 & 98.1 & 115.2 & 109.9 & 116.5 \\ 844 & 110 & 98.1 & 115.2 & 110.1 & 116.3 \\ 842 & 109.6 & 98.2 & 114.9 & 110.2 & 116.5 \\ 840 & 109.2 & 98 & 114.8 & 110.6 & 116.8 \\ 839 & 109.1 & 98 & 114.8 & 111.2 & 116.9 \\ 838 & 109 & 98.1 & 114.8 & 111.4 & 117 \\ 838 & 109.1 & 98.1 & 114.7 & 111.9 & 116.8 \\ 838 & 109 & 98.1 & 114.7 & 112.6 & 116.9 \\ 839 & 109.1 & 98.1 & 114.5 & 113.1 & 116.9 \\ 840 & 109.2 & 98.1 & 114.4 & 113.5 & 117 \\ 840 & 109.2 & 98.1 & 114.3 & 113.7 & 116.9 \\ 841 & 109.4 & 98.1 & 114.3 & 113.9 & 117 \\ 840 & 109.2 & 98.1 & 114.4 & 113.9 & 117 \\ 841 & 109.4 & 98.1 & 114.3 & 113.6 & 117.1 \\ 840 & 109.2 & 98.1 & 114.1 & 113.1 & 117 \\ 840 & 109.2 & 98.1 & 114.2 & 112.7 & 117.1 \\ 840 & 109.2 & 98.1 & 113.9 & 112.3 & 117 \\ 840 & 109.2 & 98.2 & 114.1 & 111.9 & 117 \\ 840 & 109.2 & 98.4 & 114.1 & 111.7 & 116.6 \\ 839 & 109.1 & 98.6 & 114 & 111.4 & 116.3 \\ 839 & 109 & 98.5 & 114 & 111.3 & 116.3 \\ 838 & 108.8 & 98.3 & 114.4 & 111.1 & 116.2 \\ 838 & 108.8 & 98.1 & 114.4 & 111 & 116.1 \\ 838 & 108.8 & 98 & 114.4 & 110.9 & 116.2 \\ 838 & 108.8 & 97.6 & 114.6 & 110.6 & 116.2 \\ 837 & 108.6 & 97.8 & 114.7 & 110.5 & 116.3 \\ 837 & 108.6 & 98 & 114.7 & 110.6 & 116.3 \\ 837 & 108.6 & 98.3 & 115 & 110.7 & 116.2 \\ 837 & 108.6 & 98.5 & 115.1 & 111.1 & 116.2\end{array}$




\begin{tabular}{|c|}
\hline \\
\hline 4/25/08 13:00 \\
\hline $4: 00$ \\
\hline 25/08 15:00 \\
\hline 4/25/08 16:00 \\
\hline 4/25/08 17:00 \\
\hline 4/25/08 18:00 \\
\hline 4/25/08 19:00 \\
\hline 4/25/08 20:00 \\
\hline 4/25/08 21:00 \\
\hline 4/25/08 22:00 \\
\hline 4/25/08 23:00 \\
\hline 4/26/08 0:00 \\
\hline 4/26/08 1:00 \\
\hline 4/26/08 2:00 \\
\hline 4/26/08 3:00 \\
\hline $4 / 26 / 084: 00$ \\
\hline 4/26/08 5:00 \\
\hline 4/26/08 6:00 \\
\hline 4/26/08 7:00 \\
\hline 4/26/08 8:00 \\
\hline 4/26/08 9:00 \\
\hline 4/26/08 10:00 \\
\hline 4/26/08 11:00 \\
\hline 4/26/08 12:00 \\
\hline 4/26/08 13:00 \\
\hline 4/26/08 14:00 \\
\hline 4/26/08 15:00 \\
\hline 4/26/08 16:00 \\
\hline 4/26/08 17:00 \\
\hline 4/26/08 18:00 \\
\hline 4/26/08 19:00 \\
\hline 4/26/08 20:00 \\
\hline 4/26/08 21:00 \\
\hline 4/26/08 22:00 \\
\hline 4/26/08 23:00 \\
\hline 4/27/08 0:00 \\
\hline 4/27/08 1:00 \\
\hline 4/27/08 2:00 \\
\hline 4/27/08 3:00 \\
\hline 4/27/08 4:00 \\
\hline 4/27/08 5:00 \\
\hline 4/27/08 6:00 \\
\hline 4/27/08 7:00 \\
\hline 4/27/08 8:00 \\
\hline 4/27/08 9:00 \\
\hline 4/27/08 10:00 \\
\hline 4/27/08 11:00 \\
\hline 4/27/08 12:00 \\
\hline 4/27/08 13:00 \\
\hline 4/27/08 14:00 \\
\hline \\
\hline
\end{tabular}

\begin{tabular}{|c|c|c|c|c|c|}
\hline 837 & 108.6 & 98.5 & 115.1 & 111.6 & 116.5 \\
\hline 838 & 108.7 & 98.3 & 115.5 & 112.3 & 117 \\
\hline 839 & 108.8 & 98.4 & 115.5 & 112.9 & 117.1 \\
\hline 842 & 109.4 & 98.5 & 115.4 & 113.7 & 117.3 \\
\hline 844 & 109.6 & 98.7 & 115 & 114.4 & 117.3 \\
\hline 846 & 109.9 & 98.9 & 115.3 & 114.8 & 117.4 \\
\hline 848 & 110.3 & 99.1 & 115.2 & 115 & 117.3 \\
\hline 849 & 110.4 & 99.3 & 115 & 115.2 & 117.4 \\
\hline 850 & 110.5 & 99.5 & 114.8 & 115 & 117.5 \\
\hline 850 & 110.4 & 99.6 & 114.5 & 114.8 & 117.8 \\
\hline 850 & 110.4 & 100.1 & 114.5 & 114.5 & 117.6 \\
\hline 850 & 110.4 & 100.5 & 114.4 & 114.1 & 117.6 \\
\hline 850 & 110.4 & 100.8 & 114.2 & 113.6 & 117.9 \\
\hline 850 & 110.4 & 100.9 & 114.5 & 113.2 & 117.9 \\
\hline 849 & 110.3 & 100.9 & 114.4 & 112.8 & 117.8 \\
\hline 848 & 110.1 & 100.7 & 114.6 & 112.4 & 117.8 \\
\hline 848 & 110 & 100.5 & 114.6 & 112 & 117.8 \\
\hline 847 & 109.9 & 100.3 & 114.6 & 111.4 & 117.4 \\
\hline 847 & 109.9 & 100.2 & 114.4 & 110.9 & 117.2 \\
\hline 847 & 109.9 & 100.2 & 114.3 & 110.5 & 117 \\
\hline 846 & 109.6 & 100.2 & 114.1 & 110 & 116.8 \\
\hline 846 & 109.7 & 100.3 & 114.6 & 109.8 & 116.7 \\
\hline 845 & 109.6 & 100.4 & 115.3 & 109.8 & 116.7 \\
\hline 845 & 109.7 & 100.4 & 115.5 & 110.1 & 116.7 \\
\hline 845 & 109.7 & 100.4 & 115.9 & 110.5 & 116.6 \\
\hline 846 & 109.9 & 100.4 & 115.9 & 111 & 116.8 \\
\hline 847 & 110.1 & 100.4 & 116.2 & 111.7 & 116.8 \\
\hline 848 & 110.3 & 100.4 & 116.1 & 112.2 & 116.9 \\
\hline 849 & 110.5 & 100.4 & 116.2 & 112.5 & 116.9 \\
\hline 850 & 110.7 & 100.4 & 116.2 & 112.7 & 117.2 \\
\hline 851 & 111 & 100.4 & 116 & 112.7 & 117.4 \\
\hline 851 & 111 & 100.6 & 116 & 112.8 & 117.4 \\
\hline 852 & 111.1 & 100.9 & 115.7 & 112.5 & 117.6 \\
\hline 853 & 111.2 & 100.9 & 115.5 & 112.2 & 117.8 \\
\hline 854 & 111.3 & 101 & 115.6 & 112 & 117.8 \\
\hline 855 & 111.5 & 101.1 & 115.5 & 111.8 & 118 \\
\hline 856 & 111.6 & 101.1 & 115.2 & 111.5 & 117.7 \\
\hline 856 & 111.6 & 100.9 & 115 & 111.3 & 117.8 \\
\hline 857 & 111.7 & 100.8 & 115.1 & 111.2 & 117.6 \\
\hline 857 & 111.7 & 100.7 & 115 & 111.2 & 117.5 \\
\hline 857 & 111.7 & 100.5 & 115 & 111.2 & 117.2 \\
\hline 858 & 112 & 100.1 & 115.2 & 111 & 117.2 \\
\hline 858 & 112 & 99.8 & 115.4 & 110.7 & 116.9 \\
\hline 858 & 112 & 99.8 & 115.4 & 110.4 & 116.8 \\
\hline 858 & 112 & 99.9 & 115.5 & 110.2 & 116.8 \\
\hline 858 & 112 & 99.7 & 115.8 & 110 & 116.9 \\
\hline 859 & 112.1 & 99.4 & 116.1 & 110.3 & 116.8 \\
\hline 860 & 112.4 & 99.2 & 116.8 & 110.7 & 117.2 \\
\hline 861 & 112.5 & 99 & 116.9 & 111.2 & 117 \\
\hline 862 & 112.8 & 98.8 & 117.3 & 111.7 & 117 \\
\hline 864 & 112.9 & 98.5 & 117.3 & 112.4 & 117 \\
\hline 866 & 113.4 & 98.4 & 117.6 & 113.2 & 117 \\
\hline
\end{tabular}




\begin{tabular}{|c|c|c|c|c|c|c|}
\hline 4/27/08 16:00 & 867 & 113.5 & 98.4 & 117.8 & 114 & 116.9 \\
\hline 4/27/08 17:00 & 868 & 113.8 & 98.6 & 117.8 & 114.6 & 116.9 \\
\hline 4/27/08 18:00 & 869 & 113.9 & 98.5 & 117.2 & 115.3 & 116.9 \\
\hline 4/27/08 19:00 & 869 & 113.9 & 98.6 & 117.1 & 115.9 & 116.9 \\
\hline 4/27/08 20:00 & 869 & 113.9 & 98.8 & 116.9 & 116.2 & 117 \\
\hline 4/27/08 21:00 & 870 & 114 & 99.1 & 116.6 & 116.2 & 117 \\
\hline 4/27/08 22:00 & 870 & 114 & 99.4 & 116.2 & 116.2 & 116.8 \\
\hline 4/27/08 23:00 & 871 & 114.2 & 99.9 & 116.2 & 116.1 & 116.9 \\
\hline 4/28/08 0:00 & 871 & 114.2 & 100.1 & 116.2 & 115.9 & 117.1 \\
\hline 4/28/08 1:00 & 870 & 114 & 100.1 & 116.3 & 115.7 & 117.3 \\
\hline 4/28/08 2:00 & 871 & 114.2 & 100 & 116.6 & 115.7 & 117.2 \\
\hline 4/28/08 3:00 & 871 & 114.3 & 99.9 & 116.5 & 115.8 & 117.4 \\
\hline 4/28/08 4:00 & 872 & 114.4 & 99.6 & 116.6 & 115.7 & 117.4 \\
\hline 4/28/08 5:00 & 872 & 114.4 & 99.5 & 116.9 & 115.7 & 117.4 \\
\hline 4/28/08 6:00 & 872 & 114.4 & 99.3 & 117.1 & 115.6 & 117.4 \\
\hline 4/28/08 7:00 & 872 & 114.4 & 98.9 & 116.9 & 115.3 & 117 \\
\hline 4/28/08 8:00 & 873 & 114.6 & 98.4 & 117 & 115.2 & 116.8 \\
\hline 4/28/08 9:00 & 873 & 114.6 & 98.2 & 117 & 115.1 & 117.2 \\
\hline 4/28/08 10:00 & 873 & 114.7 & 98.5 & 116.9 & 114.9 & 117.2 \\
\hline 4/28/08 11:00 & 873 & 114.7 & 98.5 & 116.9 & 115.1 & 117.3 \\
\hline 4/28/08 12:00 & 874 & 114.8 & 98.5 & 116.8 & 115.3 & 117.4 \\
\hline 4/28/08 13:00 & 875 & 115 & 98.5 & 116.6 & 115.6 & 117.6 \\
\hline 4/28/08 14:00 & 875 & 115 & 98.5 & 116.8 & 116 & 117.7 \\
\hline 4/28/08 15:00 & 875 & 115.1 & 98.5 & 116.8 & 116.5 & 117.7 \\
\hline 4/28/08 16:00 & 875 & 115.3 & 98.6 & 117.2 & 117.3 & 117.7 \\
\hline 4/28/08 17:00 & 875 & 115.3 & 98.6 & 117.1 & 117.7 & 118 \\
\hline 4/28/08 18:00 & 874 & 115.3 & 98.7 & 117 & 118.2 & 118 \\
\hline 4/28/08 19:00 & 874 & 115.3 & 98.8 & 117 & 118.2 & 118.1 \\
\hline 4/28/08 20:00 & 873 & 115.2 & 99 & 116.8 & 117.9 & 117.9 \\
\hline 4/28/08 21:00 & 873 & 115.2 & 99.4 & 116.4 & 117.5 & 117.2 \\
\hline 4/28/08 22:00 & 873 & 115.2 & 99.8 & 116.3 & 116.7 & 116.8 \\
\hline 4/28/08 23:00 & 872 & 114.9 & 100 & 115.7 & 115.7 & 117.1 \\
\hline 4/29/08 0:00 & 872 & 114.9 & 100 & 116.3 & 115.2 & 117.2 \\
\hline 4/29/08 1:00 & 871 & 114.8 & 99.8 & 115.9 & 114.8 & 117.4 \\
\hline 4/29/08 2:00 & 870 & 114.8 & 99.6 & 116 & 114.3 & 117.2 \\
\hline 4/29/08 3:00 & 869 & 114.6 & 99.4 & 116.4 & 114.2 & 117.1 \\
\hline 4/29/08 4:00 & 867 & 114.4 & 99.3 & 116.7 & 114.2 & 117.4 \\
\hline 4/29/08 5:00 & 865 & 114.1 & 99.1 & 117 & 114.1 & 117.1 \\
\hline 4/29/08 6:00 & 863 & 113.9 & 98.9 & 117 & 113.9 & 117.3 \\
\hline 4/29/08 7:00 & 862 & 113.7 & 98.5 & 116.7 & 113.7 & 116.9 \\
\hline 4/29/08 8:00 & 861 & 113.6 & 98 & 117 & 113.7 & 117.1 \\
\hline 4/29/08 9:00 & 860 & 113.5 & 97.8 & 117 & 113.7 & 117.4 \\
\hline 4/29/08 10:00 & 859 & 113.3 & 98 & 116.7 & 113.8 & 117.4 \\
\hline 4/29/08 11:00 & 859 & 113.3 & 98.1 & 116.6 & 113.8 & 117.2 \\
\hline 4/29/08 12:00 & 859 & 113.3 & 98.2 & 116.3 & 114.3 & 117.2 \\
\hline 4/29/08 13:00 & 859 & 113.3 & 98.4 & 116.4 & 114.7 & 117.4 \\
\hline 4/29/08 14:00 & 860 & 113.3 & 98.6 & 116.1 & 114.7 & 117.2 \\
\hline 4/29/08 15:00 & 859 & 113.2 & 98.7 & 116.1 & 115.4 & 117.4 \\
\hline 4/29/08 16:00 & 858 & 113 & 98.8 & 116 & 115.5 & 117.4 \\
\hline 4/29/08 17:00 & 858 & 113 & 98.6 & 116 & 115.5 & 117.1 \\
\hline 4/29/08 18:00 & 858 & 112.9 & 98.6 & 115.9 & 115.5 & 117.1 \\
\hline 4/29/08 19:00 & 857 & 112.8 & 98.8 & 116 & 115.5 & 116.8 \\
\hline
\end{tabular}




$$
\begin{aligned}
& \text { 4/29/08 20:00 } \\
& 4 / 29 / 0821: 00 \\
& 4 / 29 / 0822: 00 \\
& \text { 4/29/08 23:00 } \\
& \text { 4/30/08 0:00 } \\
& \text { 4/30/08 1:00 } \\
& \text { 4/30/08 2:00 } \\
& \text { 4/30/08 3:00 } \\
& \text { 4/30/08 4:00 } \\
& \text { 4/30/08 5:00 } \\
& \text { 4/30/08 6:00 } \\
& \text { 4/30/08 7:00 } \\
& \text { 4/30/08 8:00 } \\
& \text { 4/30/08 9:00 } \\
& \text { 4/30/08 10:00 } \\
& \text { 4/30/08 11:00 } \\
& \text { 4/30/08 12:00 } \\
& \text { 4/30/08 13:00 } \\
& \text { 4/30/08 14:00 } \\
& 4 / 30 / 08 \text { 15:00 } \\
& 4 / 30 / 08 \text { 16:00 } \\
& 4 / 30 / 08 \text { 17:00 } \\
& 4 / 30 / 08 \text { 18:00 } \\
& 4 / 30 / 08 \text { 19:00 } \\
& 4 / 30 / 08 \text { 20:00 } \\
& 4 / 30 / 08 \text { 21:00 } \\
& 4 / 30 / 08 \text { 22:00 } \\
& \text { 4/30/08 23:00 } \\
& 5 / 1 / 08 \text { 0:00 } \\
& 5 / 1 / 08 \text { 1:00 } \\
& 5 / 1 / 08 \text { 2:00 } \\
& \text { 5/1/08 3:00 } \\
& \text { 5/1/08 4:00 } \\
& 5 / 1 / 085: 00 \\
& \text { 5/1/08 6:00 } \\
& 5 / 1 / 08 \text { 7:00 } \\
& 5 / 1 / 08 \text { 8:00 } \\
& \text { 5/1/08 9:00 } \\
& \text { 5/1/08 10:00 } \\
& \text { 5/1/08 11:00 } \\
& \text { 5/1/08 12:00 } \\
& \text { 5/1/08 13:00 } \\
& \text { 5/1/08 14:00 } \\
& \text { 5/1/08 15:00 } \\
& \text { 5/1/08 16:00 } \\
& \text { 5/1/08 17:00 } \\
& \text { 5/1/08 18:00 } \\
& \text { 5/1/08 19:00 } \\
& \text { 5/1/08 20:00 } \\
& \text { 5/1/08 21:00 } \\
& \text { 5/1/08 22:00 } \\
& \text { 5/1/08 23:00 }
\end{aligned}
$$

$\begin{array}{rrrrrr}857 & 112.8 & 99.1 & 115.7 & 115.7 & 117 \\ 855 & 112.4 & 99.3 & 115.6 & 115.6 & 117.1 \\ 854 & 112.2 & 99.5 & 115.2 & 114.9 & 116.9 \\ 852 & 112 & 99.6 & 115.3 & 114.7 & 117.1 \\ 851 & 111.8 & 99.7 & 115.3 & 114 & 116.8 \\ 851 & 111.7 & 99.5 & 115.2 & 113.2 & 117 \\ 851 & 111.7 & 99.4 & 115.6 & 112.8 & 117 \\ 850 & 111.5 & 99.1 & 115.4 & 112.3 & 116.9 \\ 848 & 111.3 & 99 & 115.7 & 111.9 & 116.8 \\ 846 & 110.9 & 98.9 & 115.3 & 111.6 & 116.8 \\ 844 & 110.6 & 98.7 & 115 & 111.4 & 116.9 \\ 843 & 110.5 & 98.4 & 115.5 & 111.2 & 116.8 \\ 842 & 110.2 & 98.3 & 115.5 & 111.2 & 116.6 \\ 841 & 110.1 & 98.4 & 115.5 & 111.4 & 116.5 \\ 840 & 109.9 & 98.5 & 115.5 & 111.4 & 116.6 \\ 840 & 109.9 & 98.5 & 115.4 & 111.6 & 116.4 \\ 840 & 109.9 & 98.9 & 115.6 & 112 & 116.8 \\ 840 & 109.9 & 99.1 & 116 & 112.6 & 116.7 \\ 839 & 109.8 & 99.1 & 115.9 & 113 & 116.6 \\ 839 & 109.8 & 99.3 & 115.8 & 113.7 & 116.7 \\ 840 & 109.9 & 99.5 & 115.8 & 114.1 & 116.6 \\ 839 & 109.7 & 99.6 & 115.6 & 114.5 & 116.7 \\ 840 & 109.8 & 99.8 & 115.4 & 114.7 & 116.7 \\ 839 & 109.8 & 100 & 115.3 & 115 & 116.6 \\ 838 & 109.5 & 100.1 & 114.7 & 115 & 117 \\ 839 & 109.5 & 100.2 & 114.8 & 114.6 & 117.1 \\ 839 & 109.5 & 100.4 & 114.6 & 114.3 & 116.8 \\ 838 & 109.4 & 100.6 & 114.4 & 114 & 116.8 \\ 838 & 109.3 & 100.7 & 114.6 & 113.7 & 116.9 \\ 837 & 109.1 & 100.8 & 114.7 & 113.1 & 116.7 \\ 836 & 109 & 100.5 & 114.5 & 112.7 & 116.7 \\ 835 & 108.9 & 100.5 & 114.7 & 112.5 & 116.7 \\ 835 & 108.9 & 100.4 & 114.9 & 112.1 & 116.5 \\ 834 & 108.7 & 100.1 & 114.8 & 111.9 & 116.9 \\ 833 & 108.5 & 99.8 & 114.7 & 111.7 & 116.9 \\ 832 & 108.3 & 99.6 & 114.7 & 111.4 & 117.2 \\ 832 & 108.3 & 99.7 & 114.4 & 111.4 & 117.2 \\ 832 & 108.3 & 99.8 & 114.4 & 111.4 & 117.2 \\ 832 & 108.3 & 99.8 & 114.7 & 111.7 & 117.2 \\ 833 & 108.5 & 99.7 & 114.8 & 112.1 & 117.2 \\ 835 & 108.9 & 99.8 & 114.9 & 112.7 & 116.9 \\ 839 & 109.4 & 99.7 & 115.1 & 113.5 & 117.4 \\ 841 & 109.8 & 99.6 & 115.6 & 114.3 & 117.6 \\ 844 & 110.2 & 99.5 & 115.6 & 114.8 & 117.9 \\ 847 & 110.7 & 99.4 & 115.9 & 115.5 & 118.1 \\ 850 & 111.1 & 99.3 & & 115.8 & 117.9 \\ 851 & 111.2 & 99.3 & & 116.2 & 118 \\ 852 & 111.5 & 99.3 & & 116.2 & 118.2 \\ 852 & 111.5 & 99.3 & & 115.8 & 118.2 \\ 851 & 111.4 & 99.4 & & 115.3 & 118.1 \\ 852 & 111.4 & 99.6 & & 114.7 & 118.1 \\ 852 & 111.4 & 99.7 & & 114.2 & 118.3\end{array}$




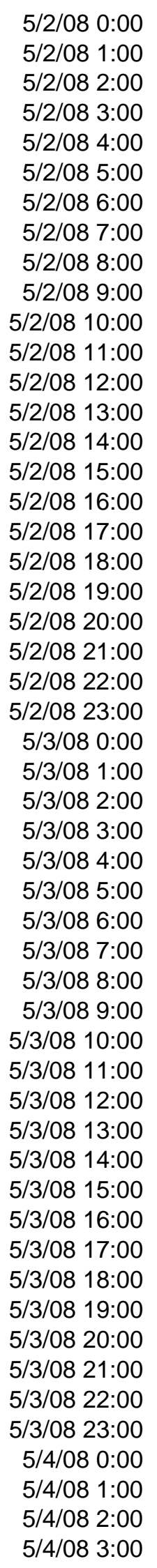

\begin{tabular}{|c|c|c|c|c|}
\hline 851 & 111.4 & 99.8 & 113.6 & 118.1 \\
\hline 850 & 111.1 & 99.8 & 113 & 118 \\
\hline 850 & 111.3 & 99.8 & 112.7 & 117.8 \\
\hline 850 & 111.3 & 100 & 112.3 & 117.4 \\
\hline 849 & 111.1 & 99.9 & 112 & 117.5 \\
\hline 849 & 111.3 & 99.7 & 111.6 & 117.4 \\
\hline 848 & 111.1 & 99.7 & 111.1 & 117.1 \\
\hline 847 & 110.9 & 99.7 & 110.6 & 117.1 \\
\hline 846 & 110.7 & 99.7 & 110.4 & 117.1 \\
\hline 846 & 110.9 & 99.7 & 110.4 & 117.6 \\
\hline 847 & 111 & 99.8 & 110.6 & 117.5 \\
\hline 848 & 111.1 & 100 & 111.2 & 117.5 \\
\hline 850 & 111.4 & 100.1 & 111.9 & 117.4 \\
\hline 851 & 111.5 & 100.2 & 112.8 & 117.4 \\
\hline 852 & 111.7 & 100.1 & 113.5 & 117.9 \\
\hline 853 & 111.9 & 100.1 & 113.9 & 118.2 \\
\hline 854 & 112.1 & 100.4 & 114 & 118 \\
\hline 856 & 112.3 & 100.6 & 114.1 & 118 \\
\hline 858 & 112.7 & 100.5 & 114 & 118.1 \\
\hline 861 & 113.1 & 100.2 & 114.2 & 118.5 \\
\hline 863 & 113.4 & 100.2 & 114 & 118.6 \\
\hline 864 & 113.4 & 100.3 & 114 & 118.5 \\
\hline 865 & 113.5 & 100.5 & 113.6 & 118.5 \\
\hline 866 & 113.6 & 100.5 & 113.3 & 118.2 \\
\hline 867 & 113.8 & 100.7 & 112.9 & 118.3 \\
\hline 868 & 113.8 & 100.9 & 112.8 & 118.1 \\
\hline 868 & 113.8 & 100.7 & 112.7 & 117.9 \\
\hline 868 & 113.8 & 100.5 & 112.7 & 117.5 \\
\hline 868 & 113.8 & 100.6 & 112.7 & 117 \\
\hline 869 & 113.9 & 100.7 & 112.7 & 117.1 \\
\hline 868 & 113.8 & 100.6 & 112.4 & 117.4 \\
\hline 868 & 113.6 & 100.4 & 112.4 & 117.3 \\
\hline 868 & 113.6 & 100.4 & 112.3 & 117.2 \\
\hline 868 & 113.6 & 100.4 & 112.4 & 117.1 \\
\hline 869 & 113.7 & 100.3 & 112.5 & 117.1 \\
\hline 869 & 113.7 & 100.5 & 112.8 & 117.2 \\
\hline 870 & 113.9 & 100.5 & 113.2 & 117.2 \\
\hline 870 & 113.9 & 100.5 & 113.7 & 117 \\
\hline 871 & 114.2 & 100.4 & 114.2 & 117.3 \\
\hline 871 & 114.2 & 100.5 & 114.9 & 117.1 \\
\hline 871 & 114.2 & 100.4 & 115.3 & 117.1 \\
\hline 872 & 114.3 & 100.5 & 115.5 & 117.3 \\
\hline 872 & 114.3 & 100.5 & 115.7 & 117.1 \\
\hline 872 & 114.4 & 100.5 & 115.7 & 117 \\
\hline 871 & 114.2 & 100.7 & 115.5 & 117.3 \\
\hline 871 & 114.2 & 100.9 & 115.4 & 117.3 \\
\hline 870 & 113.9 & 100.9 & & 117.6 \\
\hline 868 & 113.6 & 101.1 & & 117.8 \\
\hline 867 & 113.5 & 101.4 & & 117.4 \\
\hline 867 & 113.5 & 101.2 & & 117 \\
\hline 866 & 113.4 & 101.4 & & 117.3 \\
\hline 865 & 113.2 & 101.3 & 113.8 & 117.3 \\
\hline
\end{tabular}




$$
\begin{aligned}
& \text { 5/4/08 4:00 } \\
& \text { 5/4/08 5:00 } \\
& \text { 5/4/08 6:00 } \\
& \text { 5/4/08 7:00 } \\
& \text { 5/4/08 8:00 } \\
& \text { 5/4/08 9:00 } \\
& \text { 5/4/08 10:00 } \\
& 5 / 4 / 08 \text { 11:00 } \\
& \text { 5/4/08 12:00 } \\
& 5 / 4 / 08 \text { 13:00 } \\
& \text { 5/4/08 14:00 } \\
& 5 / 4 / 08 \text { 15:00 } \\
& \text { 5/4/08 16:00 } \\
& \text { 5/4/08 17:00 } \\
& \text { 5/4/08 18:00 } \\
& \text { 5/4/08 19:00 } \\
& \text { 5/4/08 20:00 } \\
& \text { 5/4/08 21:00 } \\
& 5 / 4 / 0822: 00 \\
& 5 / 4 / 0823: 00 \\
& \text { 5/5/08 0:00 } \\
& \text { 5/5/08 1:00 } \\
& \text { 5/5/08 2:00 } \\
& \text { 5/5/08 3:00 } \\
& \text { 5/5/08 4:00 } \\
& \text { 5/5/08 5:00 } \\
& \text { 5/5/08 6:00 } \\
& \text { 5/5/08 7:00 } \\
& \text { 5/5/08 8:00 } \\
& \text { 5/5/08 9:00 } \\
& \text { 5/5/08 10:00 } \\
& \text { 5/5/08 11:00 } \\
& \text { 5/5/08 12:00 } \\
& \text { 5/5/08 13:00 } \\
& \text { 5/5/08 14:00 } \\
& \text { 5/5/08 15:00 } \\
& \text { 5/5/08 16:00 } \\
& \text { 5/5/08 17:00 } \\
& \text { 5/5/08 18:00 } \\
& \text { 5/5/08 19:00 } \\
& \text { 5/5/08 20:00 } \\
& \text { 5/5/08 21:00 } \\
& 5 / 5 / 0822: 00 \\
& \text { 5/5/08 23:00 } \\
& \text { 5/6/08 0:00 } \\
& \text { 5/6/08 1:00 } \\
& 5 / 6 / 08 \text { 2:00 } \\
& \text { 5/6/08 3:00 } \\
& \text { 5/6/08 4:00 } \\
& \text { 5/6/08 5:00 } \\
& \text { 5/6/08 6:00 } \\
& \text { 5/6/08 7:00 }
\end{aligned}
$$

\begin{tabular}{|c|c|c|c|c|}
\hline 864 & 113.1 & 101.4 & 114 & 117.2 \\
\hline 863 & 113 & 101.3 & 114 & 117.6 \\
\hline 863 & 113 & 101.3 & 113.8 & 118 \\
\hline 861 & 112.7 & 101.2 & 113.7 & 117.9 \\
\hline 861 & 112.7 & 101.2 & 113.8 & 117.8 \\
\hline 861 & 112.5 & 101.1 & 114 & 117.5 \\
\hline 861 & 112.7 & 101 & 114.1 & 117.6 \\
\hline 862 & 112.8 & 101 & 114.6 & 117.6 \\
\hline 864 & 113.2 & 101 & 115.3 & 118.1 \\
\hline 865 & 113.5 & 101.1 & 116.2 & 118.1 \\
\hline 866 & 113.6 & 101 & 117.1 & 118.2 \\
\hline 868 & 114.1 & 100.9 & 117.8 & 118.4 \\
\hline 869 & 114.2 & 100.9 & 118.5 & 118.4 \\
\hline 870 & 114.5 & 100.7 & 118.7 & 118.4 \\
\hline 870 & 114.5 & 100.7 & 119 & 118.4 \\
\hline 871 & 114.6 & 100.7 & 119.2 & 118.4 \\
\hline 871 & 114.6 & 100.7 & 119.2 & 118.4 \\
\hline 871 & 114.6 & 101 & 119.1 & 118.1 \\
\hline 871 & 114.5 & 101.2 & 119.1 & 118.4 \\
\hline 870 & 114.3 & 101.4 & 119.1 & 118.5 \\
\hline 870 & 114.3 & 101.4 & 118.7 & 118.2 \\
\hline 869 & 114.2 & 101.2 & 118.2 & 118 \\
\hline 868 & 114.1 & 101.1 & 118 & 118 \\
\hline 867 & 114.1 & 101 & 117.7 & 117.8 \\
\hline 866 & 113.8 & 100.7 & 117.3 & 117.3 \\
\hline 866 & 113.8 & 100.4 & 117 & 117.2 \\
\hline 866 & 113.8 & 100.3 & 116.6 & 117.2 \\
\hline 867 & 113.9 & 100 & 116.6 & 117.2 \\
\hline 869 & 114.2 & 100 & 116.6 & 117.3 \\
\hline 870 & 114.3 & 100.2 & 116.6 & 117 \\
\hline 871 & 114.5 & 100.1 & 116.8 & 117.2 \\
\hline 873 & 114.9 & 100.1 & 117.1 & 117.2 \\
\hline 875 & 115.1 & 100 & 118.1 & 117.2 \\
\hline 877 & 115.4 & 99.9 & 118.6 & 117.6 \\
\hline 878 & 115.5 & 99.9 & 119.4 & 117.6 \\
\hline 880 & 115.9 & 97.4 & 119.9 & 117.4 \\
\hline 880 & 115.9 & 97.3 & 120.5 & 117.4 \\
\hline 880 & 115.9 & 97.4 & 120.7 & 117.4 \\
\hline 881 & 116.1 & 97.3 & 120.6 & 117.5 \\
\hline 882 & 116.2 & 97.3 & 120.2 & 117.6 \\
\hline 880 & 115.9 & 97.2 & 119.7 & 118 \\
\hline 879 & 115.7 & 97.7 & 118.9 & 117.9 \\
\hline 876 & 115.3 & 97.6 & 118.2 & 117.5 \\
\hline 875 & 115.1 & 97.3 & 117.4 & 117.3 \\
\hline 874 & 114.8 & 97.7 & 116.2 & 117.1 \\
\hline 872 & 114.6 & 97.5 & 115.4 & 117.3 \\
\hline 871 & 114.5 & 97.2 & 115.1 & 117.2 \\
\hline 870 & 114.3 & 97.3 & 114.6 & 116.8 \\
\hline 870 & 114.3 & 97.4 & 114.4 & 116.8 \\
\hline 869 & 114.2 & 97.3 & 114.2 & 116.8 \\
\hline 868 & 114.1 & 97.1 & 114 & 116.6 \\
\hline 867 & 113.8 & 96.9 & 113.9 & 117 \\
\hline
\end{tabular}




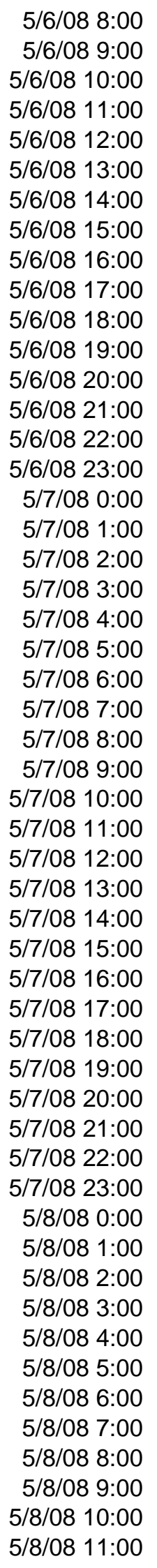

$\begin{array}{rrr}865 & 113.5 & 96.9 \\ 864 & 113.4 & 97.3 \\ 863 & 113.3 & 97.3 \\ 861 & 112.8 & 97.3 \\ 860 & 112.9 & 97.3 \\ 859 & 112.7 & 94.2 \\ 859 & 112.7 & 94.1 \\ 859 & 112.7 & 94.2 \\ 859 & 112.7 & 94.1 \\ 858 & 112.6 & 94 \\ 858 & 112.6 & 94.1 \\ 858 & 112.7 & 94.1 \\ 858 & 112.7 & 94 \\ 857 & 112.5 & 93.9 \\ 856 & 112.3 & 94.2 \\ 854 & 111.9 & 94.3 \\ 853 & 111.8 & 94.4 \\ 852 & 111.7 & 94.2 \\ 850 & 111.4 & 94.2 \\ 848 & 111.1 & 94.1 \\ 846 & 110.7 & 94.1 \\ 845 & 110.6 & 94.2 \\ 843 & 110.3 & 94.2 \\ 841 & 109.9 & 94 \\ 839 & 109.7 & 94 \\ 837 & 109.4 & 93.6 \\ 836 & 109.1 & 93.6 \\ 835 & 109 & 93.9 \\ 836 & 109.1 & 93.7 \\ 836 & 109.1 & 93.8 \\ 835 & 109 & 95.1 \\ 834 & 108.9 & 100.3 \\ 834 & 108.9 & 100.5 \\ 834 & 109 & 100.7 \\ 833 & 108.9 & 100.9 \\ 832 & 108.8 & 101.1 \\ 832 & 108.8 & 101.3 \\ 832 & 108.8 & 101.3 \\ 832 & 108.8 & 101.4 \\ 831 & 108.5 & 101.4 \\ 831 & 108.6 & 101.4 \\ 830 & 108.4 & 101.3 \\ 829 & 108.4 & 100.9 \\ 828 & 108.2 & 100.7 \\ 826 & 108 & 100.9 \\ 826 & 108 & 100.9 \\ 825 & 107.8 & 100.7 \\ 825 & 107.8 & 100.6 \\ 825 & 107.8 & 100.6 \\ 827 & 108.1 & 100.6 \\ 828 & 108.2 & 100.6 \\ 829 & 108.4 & 100.4\end{array}$

\begin{tabular}{rr}
113.7 & 117 \\
113.7 & 117.1 \\
113.7 & 117.3 \\
113.6 & 117.3 \\
113.8 & 117.3 \\
114.4 & 116.9 \\
114.8 & 116.8 \\
115 & 116.8 \\
115.3 & 116.8 \\
115.6 & 116.9 \\
116 & 116.6 \\
116.2 & 116.5 \\
115.9 & 116.6 \\
115.6 & 116.6 \\
115.1 & 116.5 \\
114.6 & 117 \\
113.8 & 116.7 \\
113.1 & 116.2 \\
112.4 & 116.2 \\
112.1 & 116.3 \\
112 & 116.3 \\
112 & 116.2 \\
111.7 & 116.2 \\
111.5 & 116.1 \\
111.3 & 116.4 \\
111.1 & 116.9 \\
111.1 & 116.9 \\
111.1 & 117.1 \\
111.3 & 118 \\
111.7 & 118.2 \\
112.1 & 118.8 \\
112.4 & 119.3 \\
112.6 & 119.3 \\
112.9 & 119.2 \\
113.2 & 119.1 \\
113.3 & 119.2 \\
113 & 119.2 \\
112.4 & 119 \\
111.7 & 119.2 \\
110.9 & 119.3 \\
110.4 & 119.4 \\
110 & 118.9 \\
109.9 & 118.9 \\
110 & 118.4 \\
110 & 118 \\
110 & 117.3 \\
110 & 117.2 \\
109.9 & 117.1 \\
110 & 117.1 \\
110.5 & 117.5 \\
& 117.7 \\
\hline
\end{tabular}




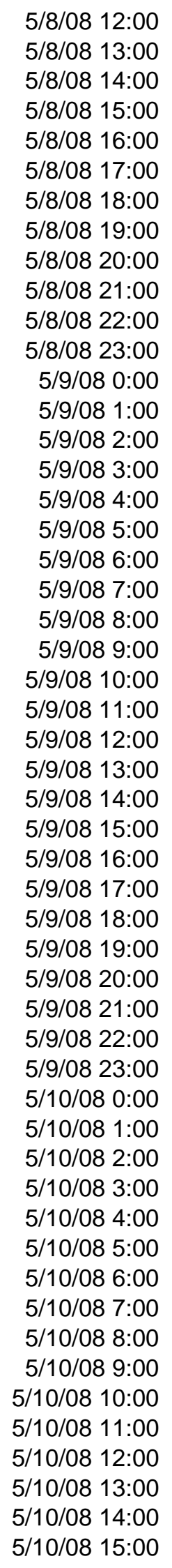

\begin{tabular}{|c|c|c|c|c|}
\hline 830 & 108.6 & 100.4 & 110.9 & 118 \\
\hline 830 & 108.6 & 100.6 & 111.6 & 118 \\
\hline 830 & 108.6 & 100.8 & 112 & 118 \\
\hline 830 & 108.8 & 100.7 & 112.5 & 118.2 \\
\hline 831 & 108.9 & 105.6 & 112.9 & 120.8 \\
\hline 831 & 108.9 & 115.4 & 113.2 & 122.9 \\
\hline 829 & 108.7 & 109.4 & 113.1 & 119 \\
\hline 829 & 108.8 & 107.8 & 113.2 & 130 \\
\hline 829 & 108.8 & 101.9 & 113.1 & 119 \\
\hline 828 & 108.7 & 101.5 & 112.8 & 119 \\
\hline 828 & 108.5 & 101.7 & 112.3 & 119 \\
\hline 828 & 108.5 & 101.9 & 112 & 119.6 \\
\hline 829 & 108.7 & 101.7 & 111.6 & 120 \\
\hline 829 & 108.7 & 101.7 & 111.2 & 119.3 \\
\hline 828 & 108.5 & 101.5 & 110.8 & 119.4 \\
\hline 828 & 108.5 & 101.4 & 110.6 & 119.8 \\
\hline 827 & 108.4 & 101.4 & 110.7 & 119.3 \\
\hline 827 & 108.4 & 101.2 & 111 & 119.6 \\
\hline 827 & 108.2 & 101.1 & 111 & 119.6 \\
\hline 828 & 108.4 & 101.3 & 111 & 119.3 \\
\hline 829 & 108.5 & 99.9 & 110.7 & 119.5 \\
\hline 831 & 108.8 & 100.3 & 110.7 & 119.5 \\
\hline 832 & 108.9 & 100.1 & 110.8 & 119.7 \\
\hline 834 & 109.2 & 99.9 & 111.1 & 119.6 \\
\hline 836 & 109.6 & 98.8 & 111.6 & 120.8 \\
\hline 837 & 109.7 & 99.8 & 111.9 & 120.7 \\
\hline 839 & 110.1 & 100 & 112.3 & 120.1 \\
\hline 840 & 110.2 & 100.2 & 112.8 & 120.1 \\
\hline 842 & 110.5 & 100.2 & 113.2 & 120.8 \\
\hline 843 & 110.8 & 100.2 & 113.5 & 121.1 \\
\hline 845 & 111 & 100.4 & 113.4 & 121 \\
\hline 846 & 111.2 & 101.3 & 113.4 & 121.3 \\
\hline 847 & 111.3 & 101.6 & 113.4 & 121.4 \\
\hline 847 & 111.3 & 102.1 & 113.1 & 121.1 \\
\hline 849 & 111.4 & 115.7 & 112.7 & 120.8 \\
\hline 849 & 111.4 & 114.6 & 112.3 & 120.7 \\
\hline 850 & 111.5 & 112.5 & 111.8 & 121.5 \\
\hline 851 & 111.7 & 101.2 & 111.5 & 121.2 \\
\hline 853 & 111.9 & 101.5 & 111.4 & 121.4 \\
\hline 855 & 112.4 & 101.4 & 111.3 & 121.4 \\
\hline 856 & 112.5 & 101.1 & 111.1 & 121.4 \\
\hline 857 & 112.6 & 100.9 & 111 & 121.5 \\
\hline 858 & 112.7 & 100.7 & 111.1 & 121.4 \\
\hline 858 & 112.7 & 100.4 & 111.1 & 121.3 \\
\hline 859 & 112.9 & 100.3 & 111.3 & 121.2 \\
\hline 860 & 113 & 100.2 & 111.7 & 120.9 \\
\hline 861 & 113.3 & 100 & 111.9 & 120.9 \\
\hline 864 & 113.7 & 99.9 & 112.3 & 120.3 \\
\hline 867 & 114.1 & 99.9 & 112.6 & 120.7 \\
\hline 869 & 114.3 & 99.9 & 112.8 & 120.5 \\
\hline 871 & 114.6 & 99.8 & 113.3 & 121 \\
\hline 872 & 114.9 & 99.8 & 113.5 & 120.9 \\
\hline
\end{tabular}




\begin{tabular}{|c|c|c|c|c|c|}
\hline 5/10/08 16:00 & 873 & 115 & 99.6 & 113.6 & 121.1 \\
\hline 5/10/08 17:00 & 872 & 114.9 & 97.1 & 113.9 & 120.7 \\
\hline 5/10/08 18:00 & 872 & 115 & 97.2 & 114.1 & 120.2 \\
\hline 5/10/08 19:00 & 872 & 115 & 97.4 & 114.1 & 120.2 \\
\hline 5/10/08 20:00 & 872 & 115 & 97.5 & 114.1 & 120.2 \\
\hline 5/10/08 21:00 & 873 & 115 & 97.4 & 113.6 & 120 \\
\hline 5/10/08 22:00 & 873 & 114.9 & 97.4 & 113.4 & 120 \\
\hline 5/10/08 23:00 & 872 & 114.7 & 97.9 & 113 & 119.8 \\
\hline 5/11/08 0:00 & 870 & 114.5 & 97.7 & 112.7 & 119.8 \\
\hline 5/11/08 1:00 & 869 & 114.2 & 97.4 & 112.4 & 119.5 \\
\hline 5/11/08 2:00 & 867 & 113.9 & 97.4 & 112.4 & 119.8 \\
\hline 5/11/08 3:00 & 866 & 113.8 & 97.7 & 112.4 & 119.3 \\
\hline 5/11/08 4:00 & 865 & 113.5 & 97.7 & 112.4 & 119.3 \\
\hline 5/11/08 5:00 & 863 & 113.3 & 97.7 & 112.3 & 119.1 \\
\hline 5/11/08 6:00 & 860 & 112.9 & 97 & 112.2 & 118.1 \\
\hline 5/11/08 7:00 & 857 & 112.5 & 96.9 & 111.7 & 118.1 \\
\hline 5/11/08 8:00 & 855 & 112.1 & 96.9 & 111.6 & 118.1 \\
\hline 5/11/08 9:00 & 853 & 111.8 & 96.9 & 111.6 & 117.8 \\
\hline 5/11/08 10:00 & 852 & 111.7 & 96.8 & 111.7 & 118 \\
\hline 5/11/08 11:00 & 851 & 111.4 & 96.9 & 111.9 & 117.8 \\
\hline 5/11/08 12:00 & 850 & 111.3 & 96.9 & 112 & 117.9 \\
\hline 5/11/08 13:00 & 848 & 111 & 96.7 & 112.4 & 117.9 \\
\hline 5/11/08 14:00 & 847 & 110.9 & 96.6 & 112.6 & 117.8 \\
\hline 5/11/08 15:00 & 846 & 110.7 & 96.4 & 113 & 117.5 \\
\hline 5/11/08 16:00 & 848 & 111 & 96.3 & 113.3 & 117.6 \\
\hline 5/11/08 17:00 & 848 & 111.1 & 96.8 & 113.7 & 118.3 \\
\hline 5/11/08 18:00 & 849 & 111.3 & 96.8 & 113.8 & 118 \\
\hline $5 / 11 / 08$ 19:00 & 850 & 111.4 & 96.6 & 113.6 & 118 \\
\hline 5/11/08 20:00 & 849 & 111.3 & 97.3 & 113.2 & 118 \\
\hline 5/11/08 21:00 & 848 & 111 & 97.2 & 112.8 & 117.9 \\
\hline 5/11/08 22:00 & 848 & 111 & 97.3 & 112.5 & 118 \\
\hline 5/11/08 23:00 & 847 & 110.9 & 97.5 & 112.1 & 118 \\
\hline 5/12/08 0:00 & 846 & 110.6 & 97.5 & 111.8 & 118.1 \\
\hline 5/12/08 1:00 & 845 & 110.5 & 97.6 & 111.7 & 118 \\
\hline 5/12/08 2:00 & 844 & 110.3 & 97.4 & 111.6 & 118 \\
\hline 5/12/08 3:00 & 843 & 110.2 & 97.1 & 111.5 & 118.1 \\
\hline 5/12/08 4:00 & 841 & 109.9 & 96.8 & 111.3 & 118.3 \\
\hline 5/12/08 5:00 & 840 & 109.8 & 96.6 & 111.2 & 118.3 \\
\hline 5/12/08 6:00 & 838 & 109.5 & 96.4 & 110.9 & 118.1 \\
\hline $5 / 12 / 087: 00$ & 838 & 109.5 & 96.5 & 110.8 & 118.3 \\
\hline 5/12/08 8:00 & 838 & 109.5 & 96.5 & 110.8 & 119 \\
\hline 5/12/08 9:00 & 839 & 109.7 & 96.5 & 110.8 & 119.3 \\
\hline 5/12/08 10:00 & 839 & 109.7 & 96.4 & 110.9 & 118.9 \\
\hline 5/12/08 11:00 & 839 & 109.7 & 96.6 & 111.3 & 118.9 \\
\hline 5/12/08 12:00 & 839 & 109.7 & 97.2 & 111.7 & 119.2 \\
\hline 5/12/08 13:00 & 840 & 109.8 & 114.3 & 112.2 & 127.4 \\
\hline $5 / 12 / 08$ 14:00 & 841 & 109.9 & 120.9 & 112.8 & 122.3 \\
\hline 5/12/08 15:00 & 842 & 110.1 & 133.4 & 113.2 & 119.1 \\
\hline $5 / 12 / 08$ 16:00 & 842 & 110.2 & 120.2 & 113.3 & 119 \\
\hline 5/12/08 17:00 & 843 & 110.3 & 139.2 & 113.4 & 120.8 \\
\hline 5/12/08 18:00 & 843 & 110.3 & 149.5 & 113.4 & 121.4 \\
\hline 5/12/08 19:00 & 843 & 110.5 & 149.6 & 113.4 & 121.4 \\
\hline
\end{tabular}




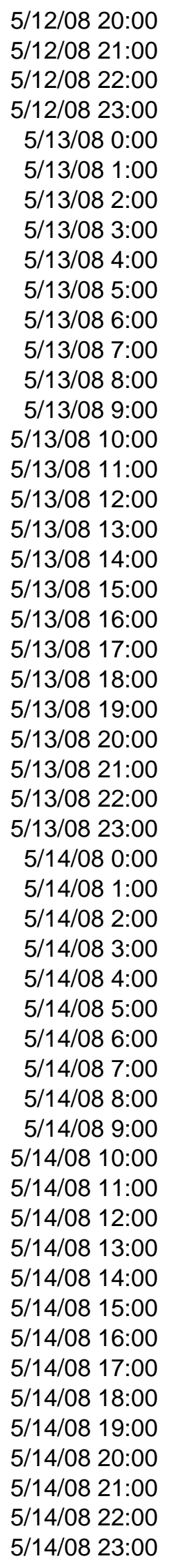

\begin{tabular}{|c|c|c|c|c|}
\hline 843 & 110.5 & 149 & 113.3 & 121.3 \\
\hline 843 & 110.5 & 124.8 & 112.9 & 119.8 \\
\hline 842 & 110.4 & 97.2 & 112.5 & 119 \\
\hline 843 & 110.5 & 97.3 & 112.1 & 119.1 \\
\hline 843 & 110.5 & 97.4 & 111.9 & 119.6 \\
\hline 844 & 110.6 & 97.6 & 112.4 & 119.2 \\
\hline 844 & 110.5 & 97.5 & 113.7 & 119.7 \\
\hline 845 & 110.7 & 97.1 & 114.6 & 119.9 \\
\hline 845 & 110.7 & 97.5 & 114.5 & 120 \\
\hline 846 & 110.9 & 97.4 & 114.4 & 120 \\
\hline 847 & 111 & 96.8 & 114.4 & 120.3 \\
\hline 849 & 111.3 & 96.6 & 114.5 & 119.6 \\
\hline 851 & 111.5 & 97.2 & 114.2 & 120.3 \\
\hline 853 & 111.8 & 97.2 & 113.4 & 120.7 \\
\hline 856 & 112.2 & 97.2 & 112.5 & 120.7 \\
\hline 859 & 112.6 & 97.5 & 112.1 & 119.5 \\
\hline 861 & 112.7 & 97.4 & 111.9 & 119.6 \\
\hline 861 & 112.7 & 97.4 & 111.7 & 119.5 \\
\hline 862 & 112.8 & 97.6 & 111.7 & 119.6 \\
\hline 862 & 112.8 & 97.6 & 111.7 & 119.3 \\
\hline 861 & 112.7 & 97.7 & 111.7 & 119.5 \\
\hline 861 & 112.7 & 97.7 & 111.9 & 119.6 \\
\hline 861 & 112.7 & 97.8 & 111.9 & 119.6 \\
\hline 861 & 112.7 & 97.5 & 111.9 & 119.7 \\
\hline 861 & 112.7 & 97.5 & 112 & 119.8 \\
\hline 862 & 112.7 & 97.3 & 111.8 & 120.6 \\
\hline 863 & 112.8 & 97.4 & 111.8 & 120.2 \\
\hline 864 & 112.8 & 97.4 & 111.8 & 118.6 \\
\hline 865 & 112.9 & 97.5 & 111.8 & 118.6 \\
\hline 865 & 112.9 & 97.1 & 112 & 118.6 \\
\hline 866 & 113.1 & 97.3 & 112.1 & 118.6 \\
\hline 866 & 112.9 & 97.3 & 111.9 & 118.5 \\
\hline 867 & 113 & 97 & 111.9 & 118.3 \\
\hline 866 & 112.9 & 97.6 & 111.9 & 119.4 \\
\hline 865 & 112.6 & 97.4 & 111.8 & 119.2 \\
\hline 865 & 112.6 & 97.1 & 111.8 & 119.5 \\
\hline 864 & 112.4 & 97 & 111.7 & 119.3 \\
\hline 863 & 112.1 & 97.6 & 111.5 & 118.7 \\
\hline 863 & 112.1 & 97.9 & 111.5 & 118.4 \\
\hline 863 & 112.1 & 98 & 111.8 & 118.4 \\
\hline 864 & 112.2 & 98 & 111.9 & 118.2 \\
\hline 865 & 112.2 & 97.9 & 112.1 & 118.4 \\
\hline 866 & 112.3 & 97.9 & 112.8 & 118 \\
\hline 867 & 112.5 & 97.9 & 113.3 & 118.3 \\
\hline 867 & 112.5 & 98 & 113.8 & 118.1 \\
\hline 866 & 112.5 & 97.9 & 114.6 & 118 \\
\hline 865 & 112.3 & 97.2 & 115 & 117.8 \\
\hline 865 & 112.3 & 97.2 & 115 & 117.6 \\
\hline 864 & 112.2 & 97 & 114.9 & 118.1 \\
\hline 864 & 112.2 & 97 & 114.6 & 118.4 \\
\hline 864 & 112.1 & 97.1 & 114.4 & 118.1 \\
\hline 865 & 112.3 & 97.1 & 114.1 & 118.4 \\
\hline
\end{tabular}




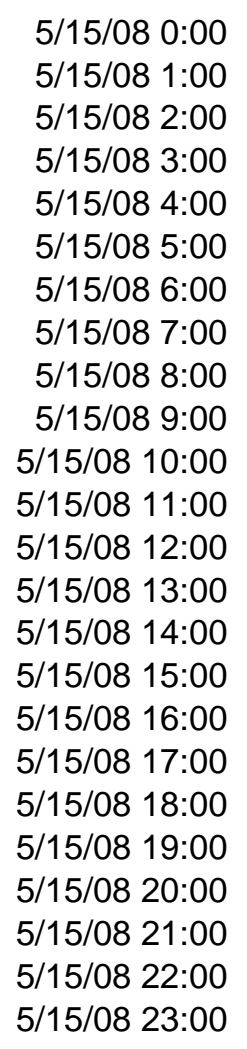

$\begin{array}{rrr}865 & 112.3 & 97.3 \\ 865 & 112.3 & 97.3 \\ 866 & 112.5 & 97.3 \\ 867 & 112.6 & 97 \\ 867 & 112.6 & 96.8 \\ 868 & 112.7 & 96.7 \\ 867 & 112.6 & 97.2 \\ 867 & 112.6 & 97.2 \\ 866 & 112.5 & 97.3 \\ 866 & 112.6 & 97.2 \\ 865 & 112.5 & 97.4 \\ 865 & 112.6 & 97.1 \\ 866 & 112.9 & 97.2 \\ 866 & 112.9 & 97.1 \\ 869 & 113.4 & 97.1 \\ 872 & 114 & 97.1 \\ 875 & 114.4 & 97.1 \\ 876 & 114.7 & 97.1 \\ 878 & 114.9 & 96.9 \\ 879 & 115.2 & 96.9 \\ 880 & 115.3 & 97 \\ 880 & 115.3 & 97.1 \\ 881 & 115.3 & 97.2 \\ 881 & 115.3 & 97.2\end{array}$

$\begin{array}{rr}113.8 & 117.6 \\ 113.7 & 117.9 \\ 113.6 & 117.8 \\ 113.6 & 117.8 \\ 113.6 & 117.9 \\ 113.5 & 118.2 \\ 113.5 & 118.4 \\ 113.3 & 118.4 \\ 113.2 & 118.1 \\ 113.1 & 118.3 \\ 113.4 & 119 \\ 113.6 & 119.5 \\ 114.4 & 119.6 \\ 115.1 & 120.1 \\ 115.6 & 120.1 \\ 116 & 120.1 \\ 116.4 & 120 \\ 116.8 & 120.1 \\ 117.1 & 120.1 \\ 117.3 & 120.3 \\ 117 & 120.3 \\ 116.6 & 120.4 \\ 115.9 & 120.5 \\ 115.5 & 121\end{array}$




$\begin{array}{rrr}\text { BP (mmHg) } & & \\ \text { from ACE web } & \text { discharge } & \text { TW } \\ \text { (feet) } \\ 769 & 175.3 & 15.3 \\ 769 & 152 & 14.3 \\ 769 & 149.9 & 14.1 \\ 769 & 147.5 & 14 \\ 769 & 148.7 & 15.2 \\ 770 & 171.6 & 15.4 \\ 769 & 171.4 & 15.2 \\ 770 & 168.6 & 15.2 \\ 770 & 168.7 & 15.2 \\ 770 & 167.5 & 15.1 \\ 770 & 168 & 15.2 \\ 770 & 168.9 & 15.1 \\ 770 & 168.2 & 15.1 \\ 769 & 168.4 & 15.1 \\ 770 & 168.7 & 15.1 \\ 770 & 169.5 & 15 \\ 770 & 172.1 & 15.4 \\ 770 & 184.6 & 16 \\ 770 & 185.9 & 15.9 \\ 770 & 184.3 & 15.9 \\ 770 & 184.3 & 15.8 \\ 769 & 156 & 15 \\ 769 & 173.3 & 15.6 \\ 768 & 175.8 & 15.6 \\ 767 & 176.8 & 15.6 \\ 767 & 175.5 & 15.6 \\ 767 & 176.1 & 15.8 \\ 766 & 183.6 & 16 \\ 766 & 184.4 & 16.3 \\ 767 & 188.7 & 16.4 \\ 767 & 185.9 & 16.3 \\ 767 & 183.9 & 16.1 \\ 767 & 181.1 & 15.6 \\ 767 & 156.6 & 14.8 \\ 767 & 153 & 14.6 \\ 768 & 154 & 14.5 \\ 767 & 154.9 & 14.4 \\ 767 & 154.4 & 14.3 \\ 767 & 154.9 & 14.3 \\ 768 & 155.6 & 14.4 \\ 768 & 159.4 & 15 \\ 768 & 174.2 & 15.3 \\ 769 & 174.1 & 15.4 \\ 769 & 171.9 & 15.4 \\ 768 & 163.3 & 14.2 \\ 768 & 145.2 & 13.8 \\ 768 & 127.8 & 13.1 \\ 768 & 126.5 & 12.9 \\ 767 & 124.9 & 12.7 \\ & 124.7 & 12.6\end{array}$




\begin{tabular}{rrr}
767 & 125.3 & 12.5 \\
767 & 125.2 & 12.7 \\
767 & 143.6 & 13.6 \\
768 & 145.6 & 13.9 \\
768 & 152.6 & 14.1 \\
768 & 150.6 & 14.2 \\
768 & 149.7 & 14.1 \\
768 & 149.2 & 14.1 \\
768 & 148.6 & 13.3 \\
768 & 136 & 12.9 \\
768 & 134.2 & 12.8 \\
767 & 134.4 & 12.7 \\
767 & 139.2 & 12.9 \\
767 & 140.8 & 12.9 \\
767 & 141.7 & 13 \\
767 & 143 & 13.1 \\
767 & 143.1 & 13.1 \\
767 & 142.8 & 13.2 \\
767 & 142.5 & 13.2 \\
767 & 166.1 & 15.2 \\
766 & 181.4 & 15.4 \\
765 & 180.9 & 15.3 \\
765 & 164 & 14.6 \\
764 & 162.9 & 14.5 \\
764 & 163.1 & 14.5 \\
764 & 163.2 & 14.5 \\
764 & 163.2 & 14.6 \\
764 & 163.4 & 14.7 \\
763 & 162 & 14.6 \\
764 & 160.9 & 14.7 \\
764 & 160.6 & 14.7 \\
764 & 160.3 & 14.7 \\
765 & 159.7 & 14.7 \\
765 & 151.9 & 13.9 \\
765 & 144.8 & 13.7 \\
765 & 144.3 & 13.6 \\
766 & 143.6 & 13.5 \\
766 & 144.2 & 13.2 \\
767 & 147.3 & 13.6 \\
767 & 148 & 13.8 \\
768 & 148.1 & 13.8 \\
768 & 148.3 & 13.8 \\
769 & 143.9 & 13.7 \\
768 & 139.5 & 13.4 \\
768 & 138 & 13.3 \\
768 & 137.9 & 13.3 \\
768 & 138.1 & 13.2 \\
768 & 141.2 & 13.3 \\
767 & 141.3 & 13.1 \\
767 & 144.2 & 13.2 \\
767 & 145.4 & 13.4 \\
767 & 148.2 & 13.7 \\
\hline & &
\end{tabular}




$\begin{array}{rrr}767 & 143.8 & 13.4 \\ 767 & 142.7 & 13.5 \\ 767 & 142.1 & 13.5 \\ 767 & 142.1 & 13.4 \\ 767 & 142.4 & 13.4 \\ 766 & 142.4 & 13.4 \\ & & \\ 767 & 142.4 & 13.3 \\ 767 & 142 & 13.2 \\ 767 & 145.7 & 13.4 \\ 766 & 146.2 & 13.4 \\ 767 & 151.3 & 13.6 \\ 767 & 152.1 & 13.7 \\ 767 & 151.8 & 13.7 \\ 767 & 145.2 & 13.6 \\ 768 & 144.4 & 13.6 \\ 767 & 140 & 13.3 \\ 766 & 138.5 & 13.3 \\ 766 & 139 & 13.2 \\ 765 & 140.8 & 13.4 \\ 765 & 143.4 & 13.4 \\ 764 & 146.7 & 13.6 \\ 764 & 150 & 13.6 \\ 764 & 150.2 & 13.6 \\ 764 & 147.7 & 13.4 \\ 765 & 147.3 & 13.5 \\ 765 & 147.3 & 13.6 \\ 765 & 147.3 & 13.7 \\ 765 & 147.2 & 13.7 \\ 765 & 144.5 & 13.5 \\ 765 & 141.9 & 13.4 \\ 765 & 146.8 & 13.6 \\ 764 & 147.8 & 13.5 \\ 764 & 147.9 & 13.5 \\ 764 & 150.7 & 12.6 \\ 764 & 123.9 & 12.3 \\ 764 & 120.1 & 11.9 \\ 764 & 118.1 & 12 \\ 765 & 116.3 & 12.1 \\ 765 & 111.7 & 12 \\ 764 & 108.5 & 11.9 \\ 764 & 111.8 & 12.1 \\ 763 & 113.9 & 11.9 \\ 763 & 115.1 & 12 \\ 763 & 116.3 & 12.3 \\ 762 & 131 & 12.7 \\ 762 & 131 & 12.6 \\ 763 & 130.9 & 12.5 \\ 763 & 128.1 & 12.5 \\ 764 & 128 & 12.4 \\ 765 & 127.3 & 12.6 \\ 766 & 126.4 & 12.5\end{array}$




$\begin{array}{lrr}766 & 126.6 & 12.6 \\ 767 & 118.5 & 12.1 \\ 766 & 116.5 & 12 \\ 767 & 116.8 & 11.9 \\ 767 & 119.3 & 12.2 \\ 767 & 122.2 & 12.1 \\ 768 & 123.7 & 12.4 \\ 768 & 132 & 12.6 \\ 769 & 133 & 13.1 \\ 769 & 155.1 & 14.1 \\ 770 & 157.4 & 14.5 \\ 770 & 157.6 & 14.8 \\ 771 & 159.1 & 15 \\ 770 & 161 & 15.1 \\ 770 & 161 & 15 \\ 770 & 144.7 & 14 \\ 769 & 135.1 & 13.7 \\ 769 & 133.4 & 13.5 \\ 769 & 133 & 13.4 \\ 769 & 134.5 & 13.3 \\ 769 & 131.3 & 13.1 \\ 769 & 130.6 & 13 \\ 769 & 129.9 & 12.9 \\ 769 & 129.8 & 12.8 \\ 768 & 119.5 & 12.3 \\ 768 & 118.2 & 12.2 \\ 768 & 113.8 & 12 \\ 767 & 117.5 & 12.1 \\ 766 & 117.8 & 12 \\ 766 & 123 & 12.2 \\ 766 & 124.7 & 12.4 \\ 766 & 132.3 & 13 \\ 765 & 152.3 & 13.7 \\ 765 & 154.2 & 13.9 \\ 765 & 154.6 & 14.1 \\ 764 & 154.9 & 14.3 \\ 764 & 156.3 & 14.6 \\ 763 & 157 & 14.7 \\ 763 & 156.4 & 14.7 \\ 762 & 155.9 & 14.7 \\ 762 & 155.9 & 14.7 \\ 761 & 155.9 & 14.7 \\ 761 & 155.6 & 14.7 \\ 761 & 156.2 & 14.6 \\ 761 & 153 & 14.4 \\ 760 & 151.5 & 14.2 \\ 760 & 150.2 & 14.1 \\ 759 & 150.3 & 14.1 \\ 759 & 150.5 & 14.2 \\ 759 & 152.5 & 14.2 \\ 758 & 153.5 & 14.4 \\ 757 & 154.9 & 14.4\end{array}$




$\begin{array}{rrr}757 & 155.8 & 14.5 \\ 756 & 153.2 & 14.3 \\ 756 & 153.7 & 14.4 \\ 756 & 156.8 & 14.4 \\ 756 & 156.9 & 14.5 \\ 756 & 156.6 & 14.6 \\ 757 & 157 & 14.7 \\ 757 & 156.8 & 14.7 \\ 757 & 155.3 & 14.8 \\ 757 & 154.6 & 14.5 \\ 757 & 136.9 & 14.1 \\ 757 & 147.8 & 14.7 \\ 757 & 154.4 & 14.9 \\ 757 & 155.2 & 15 \\ 757 & 164.3 & 15.3 \\ 757 & 175 & 15.8 \\ 757 & 173.3 & 15.6 \\ 757 & 171.4 & 15.6 \\ 757 & 170.3 & 15.5 \\ 757 & 153.1 & 14.6 \\ 756 & 150 & 14.5 \\ 756 & 149.8 & 14.5 \\ 756 & 150 & 14.5 \\ 756 & 150.2 & 14.5 \\ 755 & 150.2 & 14.5 \\ 755 & 150.4 & 14.4 \\ 755 & 153 & 14.7 \\ 755 & 166.7 & 15.3 \\ 755 & 173.9 & 15.6 \\ 756 & 178.6 & 15.9 \\ 756 & 179.5 & 15.8 \\ 756 & 180.1 & 16 \\ 756 & 179.9 & 16.1 \\ 756 & 180.4 & 16.3 \\ 756 & 180.5 & 16.4 \\ 755 & 180.8 & 16.4 \\ 756 & 181 & 16.5 \\ 756 & 180.9 & 16.5 \\ 756 & 181.1 & 16.5 \\ 756 & 181.4 & 16.5 \\ 756 & 182.2 & 16.5 \\ 756 & 180.8 & 16.4 \\ 757 & 182.7 & 16.5 \\ 757 & 182.6 & 16.4 \\ 757 & 182.3 & 16.4 \\ 757 & 182.9 & 16.4 \\ 757 & 182.4 & 16.4 \\ 757 & 156.5 & 15.2 \\ 757 & 142 & 14.5 \\ 758 & 140.1 & 14.4 \\ 758 & 141.4 & 14.4 \\ 759 & 143 & 14.4\end{array}$




\begin{tabular}{rrr}
759 & 142.9 & 14.3 \\
760 & 142.3 & 14.2 \\
760 & 142 & 14.2 \\
761 & 142.5 & 14.2 \\
761 & 147.7 & 14.3 \\
761 & 148.1 & 14.4 \\
761 & 148.2 & 14.5 \\
761 & 148.6 & 14.5 \\
761 & 148.8 & 14.5 \\
761 & 148.4 & 14.5 \\
761 & 147.4 & 14.5 \\
762 & 146.9 & 14.5 \\
762 & 144.1 & 14.3 \\
763 & 143.8 & 14.4 \\
763 & 165 & 15.3 \\
763 & 166.5 & 15.2 \\
764 & 166.5 & 15.3 \\
764 & 167.4 & 15.2 \\
765 & 143 & 13.6 \\
765 & 123.6 & 13.1 \\
765 & 122.2 & 12.7 \\
766 & 111.8 & 12.2 \\
766 & 111.7 & 12.2 \\
767 & 113.7 & 12.1 \\
767 & 113.9 & 12 \\
768 & 113.8 & 11.9 \\
768 & 113.8 & 11.9 \\
769 & 117.9 & 12.1 \\
769 & 124.4 & 12.2 \\
769 & 125.4 & 12.4 \\
769 & 125.1 & 12.4 \\
769 & 125.4 & 12.5 \\
769 & 125.5 & 12.6 \\
768 & 126.1 & 12.8 \\
768 & 141.7 & 13.8 \\
768 & 154 & 14.8 \\
768 & 169.2 & 14.6 \\
768 & 160.6 & 14.6 \\
768 & 159.8 & 14.6 \\
768 & 159.8 & 14.6 \\
767 & 158.8 & 14.5 \\
767 & 137.4 & 12.9 \\
767 & 117.5 & 12.3 \\
767 & 116.7 & 12.2 \\
767 & 115.6 & 11.9 \\
767 & 116.2 & 12.4 \\
766 & 135.3 & 14.2 \\
766 & 159.6 & 14.8 \\
766 & 176.8 & 15.4 \\
766 & 180.2 & 15.6 \\
766 & 179.9 & 15.7 \\
766 & 181.1 & 15.7 \\
\hline & &
\end{tabular}




$\begin{array}{rrr}766 & 180.7 & 15.4 \\ 766 & 168.9 & 15.3 \\ 765 & 168.5 & 15.2 \\ 765 & 168 & 14.7 \\ 765 & 169.4 & 15.5 \\ 765 & 180.1 & 16 \\ 764 & 182.7 & 16.2 \\ 764 & 183.2 & 16.3 \\ 763 & 184.2 & 16.3 \\ 763 & 180.4 & 16.3 \\ 763 & 180.4 & 16.2 \\ 764 & 176.9 & 16.1 \\ 764 & 177.4 & 16.1 \\ 763 & 178.7 & 16.1 \\ 763 & 178.1 & 16.1 \\ 763 & 178.4 & 16.1 \\ 763 & 179 & 16.1 \\ 762 & 178.5 & 15.9 \\ 762 & 151.1 & 14.5 \\ 762 & 126 & 13.8 \\ 762 & 118.7 & 13.4 \\ 762 & 116.3 & 13.3 \\ 762 & 114.9 & 13.1 \\ 762 & 114.5 & 13 \\ 762 & 114 & 12.8 \\ 763 & 113.7 & 12.8 \\ 763 & 113.5 & 12.5 \\ 764 & 111.7 & 12.4 \\ 765 & 111.1 & 12.3 \\ 765 & 111.9 & 12.3 \\ 765 & 114.4 & 12.6 \\ 765 & 133.5 & 14.1 \\ 766 & 170.6 & 15.6 \\ 766 & 178.1 & 15.7 \\ 766 & 188 & 16.6 \\ 766 & 194.9 & 16.8 \\ & 197 & 16.9 \\ 766 & 198.9 & 17.1 \\ 765 & 200.8 & 17.3 \\ 765 & 202.7 & 17.3 \\ 765 & 202.8 & 16.6 \\ 764 & 175.8 & 14.9 \\ 764 & 148.3 & 14.6 \\ 764 & 139.5 & 14.7 \\ 764 & 136.2 & 14.4 \\ 763 & 135.7 & 14.3 \\ 764 & 134.6 & 14.2 \\ 763 & 132.5 & 14.1 \\ 763 & 132.1 & 13.8 \\ 763 & 132.4 & 14 \\ 762 & 137.3 & 14.1 \\ 762 & 137.3 & 14\end{array}$




$\begin{array}{rrr}762 & 136.7 & 13.9 \\ 761 & 136.5 & 13.9 \\ 762 & 144.4 & 14.3 \\ 762 & 184.7 & 16.6 \\ 762 & 198.8 & 17.1 \\ 762 & 199.4 & 17.1 \\ 762 & 199.5 & 17.2 \\ 763 & 199.3 & 17.2 \\ 763 & 198.4 & 17.3 \\ 763 & 199.4 & 17.4 \\ 763 & 189.7 & 17.3 \\ 763 & 194.6 & 17.2 \\ 763 & 195.3 & 17.2 \\ 764 & 195.4 & 17.3 \\ 764 & 161.5 & 15.4 \\ 764 & 140.7 & 14.5 \\ 764 & 130.3 & 14.5 \\ 764 & 132.6 & 14.4 \\ 765 & 132.2 & 13.9 \\ 765 & 131.9 & 14.3 \\ 765 & 131.5 & 14.1 \\ 764 & 130.8 & 14.1 \\ 764 & 134.6 & 14.1 \\ 764 & 134.9 & 14 \\ 764 & 134.8 & 14 \\ 764 & 134.9 & 13.9 \\ 764 & 142.7 & 14.5 \\ 763 & 165.2 & 15.8 \\ 763 & 200.5 & 17.1 \\ 765 & 204.8 & 17.5 \\ 766 & 205.2 & 17.6 \\ 767 & 204.7 & 17.6 \\ 767 & 204.4 & 17.7 \\ 768 & 204.3 & 17.7 \\ 769 & 205 & 17.8 \\ 769 & 204.5 & 17.8 \\ 770 & 205 & 17.8 \\ 771 & 204.5 & 17.8 \\ 771 & 164 & 15.6 \\ 772 & 144.5 & 15.3 \\ 773 & 143.5 & 15 \\ 773 & 136.5 & 14.8 \\ 774 & 135.5 & 14.7 \\ 774 & 133.6 & 14.5 \\ 775 & 133.4 & 14.3 \\ 775 & 133.9 & 14.3 \\ 775 & 132.9 & 14.1 \\ 775 & 131.5 & 14 \\ 775 & 131.8 & 13.8 \\ 775 & 131.3 & 13.8 \\ 775 & 130.9 & 13.8 \\ 775 & 143.1 & 14.3\end{array}$




$\begin{array}{rrr}775 & 173.7 & 15.7 \\ 775 & 191.9 & 16.6 \\ 775 & 193.7 & 16.8 \\ 775 & 193.8 & 16.9 \\ 775 & 194.6 & 17 \\ 775 & 191.7 & 16.6 \\ 775 & 185.6 & 16.5 \\ 774 & 186 & 16.5 \\ 774 & 186.7 & 16.5 \\ 774 & 187.4 & 16.5 \\ 773 & 160.2 & 14.7 \\ 773 & 143.6 & 14.5 \\ 773 & 137.8 & 14.2 \\ 773 & 137.2 & 14.2 \\ 773 & 137.1 & 14.3 \\ 772 & 135.6 & 14 \\ 772 & 136 & 13.9 \\ 771 & 136.5 & 13.9 \\ 770 & 136.7 & 13.7 \\ 769 & 136.9 & 13.8 \\ 769 & 136.4 & 13.6 \\ 768 & 136 & 13.6 \\ 767 & 136.2 & 13.5 \\ 767 & 135.5 & 13.5 \\ 767 & 140.1 & 13.5 \\ 767 & 160.4 & 14.6 \\ 767 & 162.2 & 14.8 \\ 767 & 162.3 & 14.8 \\ 766 & 162.4 & 14.9 \\ 766 & 162.8 & 15 \\ 766 & 139.7 & 13.8 \\ 766 & 137.6 & 13.7 \\ 765 & 137.6 & 13.6 \\ 765 & 137.9 & 13.6 \\ 764 & 139.7 & 13.6 \\ 764 & 140.2 & 13.5 \\ 765 & 125.4 & 12.8 \\ 764 & 113.8 & 12.2 \\ 764 & 109.2 & 12 \\ 763 & 105 & 11.9 \\ 763 & 104.7 & 11.8 \\ 762 & 105.6 & 11.8 \\ 762 & 108.8 & 11.8 \\ 761 & 110.5 & 11.8 \\ 761 & 112.2 & 11.8 \\ 762 & 112.7 & 11.8 \\ 762 & 117.4 & 11.9 \\ 763 & 118.7 & 12 \\ 763 & 117.7 & 11.8 \\ 764 & 119 & 11.9 \\ 765 & 115.9 & 12 \\ 765 & 110.6 & 11.8\end{array}$




$\begin{array}{rrr}765 & 110.5 & 11.8 \\ 765 & 110.6 & 11.8 \\ 766 & 111.8 & 11.8 \\ 766 & 113.2 & 11.7 \\ 766 & 115.8 & 11.7 \\ 766 & 117.6 & 11.8 \\ 767 & 119.1 & 11.7 \\ 767 & 120.1 & 11.8 \\ 767 & 122.1 & 11.9 \\ 767 & 122 & 12 \\ 767 & 118.5 & 12.1 \\ 767 & 119.1 & 12.5 \\ 767 & 135.5 & 13.2 \\ 766 & 136.5 & 13.3 \\ 766 & 135.7 & 13.1 \\ 765 & 116.5 & 12.3 \\ 765 & 113.9 & 12.4 \\ 765 & 126.6 & 13.4 \\ 765 & 141.1 & 13.2 \\ 765 & 142.1 & 13.3 \\ 765 & 140.8 & 13.2 \\ 765 & 139.9 & 13.2 \\ 765 & 139.6 & 13.2 \\ 765 & 139.3 & 13.3 \\ 765 & 139.8 & 13.5 \\ 765 & 141.7 & 13.5 \\ 765 & 142.3 & 13.6 \\ 765 & 154.6 & 14.3 \\ 765 & 156.3 & 14.3 \\ 765 & 155.8 & 14.3 \\ 765 & 166.4 & 14.8 \\ 765 & 168.6 & 14.9 \\ 765 & 169.2 & 15 \\ 765 & 169 & 15.1 \\ 765 & 169.2 & 15.2 \\ 765 & 169 & 15.5 \\ 764 & 171.9 & 15.6 \\ 764 & 168.1 & 15.3 \\ 764 & 166.1 & 15.3 \\ 763 & 166.6 & 15.3 \\ 763 & 167.5 & 15.4 \\ 763 & 162.3 & 15.1 \\ 762 & 162.9 & 15 \\ 762 & 163 & 15 \\ 762 & 171.9 & 15.4 \\ 762 & 174.4 & 15.5 \\ 762 & 173 & 15.4 \\ 761 & 160.4 & 14.8 \\ 761 & 158 & 14.8 \\ 761 & 154.4 & 14.8 \\ 760 & 157.8 & 14.9 \\ 760 & 159.7 & 14.9\end{array}$




$\begin{array}{rrr}760 & 161.5 & 15 \\ 760 & 161.8 & 15.1 \\ 761 & 165.1 & 15.2 \\ 761 & 180.4 & 15.8 \\ 761 & 175.2 & 15.5 \\ 761 & 173.6 & 15.7 \\ 761 & 175.6 & 15.6 \\ 761 & 175.6 & 15.9 \\ 760 & 174.7 & 15.8 \\ 760 & 170.7 & 15.7 \\ 760 & 168.3 & 15.5 \\ 760 & 168.7 & 15.5 \\ 760 & 167.3 & 15.4 \\ 760 & 165.5 & 15.4 \\ 760 & 165.8 & 15.5 \\ 761 & 165.3 & 15.5 \\ 763 & 178.8 & 16.2 \\ 764 & 180.6 & 16.1 \\ 765 & 178.3 & 16 \\ 766 & 175.8 & 15.5 \\ 767 & 140.1 & 14.3 \\ 767 & 127.8 & 13.3 \\ 767 & 120 & 13 \\ 768 & 110.2 & 12.4 \\ 768 & 109.8 & 12.4 \\ 768 & 136.6 & 14 \\ 769 & 161 & 14.9 \\ 769 & 171 & 15.2 \\ 769 & 176.5 & 15.6 \\ 769 & 175.7 & 15.6 \\ 770 & 175.9 & 15.6 \\ 770 & 174.6 & 15.7 \\ 770 & 176.6 & 15.7 \\ 769 & 172.3 & 15.6 \\ 769 & 171.7 & 15.6 \\ 769 & 170.6 & 15.5 \\ 768 & 171.1 & 15.7 \\ 768 & 170.3 & 15.6 \\ 767 & 181.4 & 16.1 \\ 766 & 183.2 & 16.2 \\ 766 & 181.5 & 16 \\ 766 & 179.2 & 16 \\ 765 & 178.5 & 15.9 \\ 764 & 177.3 & 15.9 \\ 764 & 177.4 & 15.8 \\ 763 & 178.2 & 15.9 \\ 762 & 177.1 & 15.7 \\ 761 & 154.7 & 14.8 \\ 760 & 151.7 & 14.6 \\ 759 & 152.1 & 14.6 \\ 758 & 167.1 & 15.4 \\ 758 & 182.6 & 16.1 \\ & & \end{array}$




$\begin{array}{rrr}757 & 185.7 & 16.2 \\ 756 & 185.9 & 15.9 \\ 755 & 178.2 & 15.9 \\ 755 & 199.3 & 17.3 \\ 755 & 208.9 & 17.6 \\ 755 & 215.9 & 18 \\ 755 & 218.7 & 18.3 \\ 755 & 220.8 & 18.4 \\ 756 & 220.8 & 18.5 \\ 756 & 221.4 & 18.6 \\ 757 & 221.4 & 18.5 \\ 758 & 213.9 & 18.4 \\ 758 & 209.4 & 17.9 \\ 758 & 178.6 & 16.5 \\ 758 & 173.5 & 16.3 \\ 759 & 148.2 & 14.9 \\ 759 & 133.4 & 14.3 \\ 759 & 132 & 14.1 \\ 760 & 132.6 & 14.1 \\ 760 & 148.9 & 14.7 \\ 761 & 150.9 & 14.7 \\ 761 & 151.3 & 14.7 \\ 762 & 169.3 & 15.5 \\ 762 & 146.4 & 14.5 \\ 763 & 142.8 & 14.4 \\ 763 & 142.6 & 14.3 \\ 763 & 142.2 & 14.2 \\ 764 & 142.1 & 14.2 \\ 764 & 141.8 & 14.2 \\ 764 & 141.5 & 14.2 \\ 764 & 141.9 & 14.2 \\ 764 & 142 & 14.2 \\ 764 & 142 & 14 \\ 765 & 136.7 & 13 \\ 764 & 123.5 & 12.7 \\ 764 & 122.6 & 12.6 \\ 764 & 118.8 & 12.3 \\ 764 & 117.8 & 12.1 \\ 764 & 118 & 12 \\ 764 & 118 & 11.9 \\ 764 & 121.1 & 12.3 \\ 764 & 131.3 & 12.5 \\ 764 & 131 & 12.4 \\ 764 & 131 & 12.4 \\ 764 & 130.8 & 12.8 \\ 763 & 131 & 12.5 \\ 764 & 132 & 12.1 \\ 764 & 133.1 & 12.5 \\ 764 & 133.5 & 12.4 \\ 764 & 129.6 & 12.3 \\ 764 & 128.4 & 12.3 \\ 765 & 128 & 12.3\end{array}$




$\begin{array}{rrr}765 & 127.3 & 12.1 \\ 765 & 125.3 & 12.1 \\ 765 & 125.6 & 12.2 \\ 765 & 125.6 & 12.2 \\ 765 & 125.2 & 12.1 \\ 765 & 124.9 & 12.1 \\ 766 & 125 & 12.1 \\ 766 & 125.1 & 11.9 \\ 766 & 122.1 & 11.9 \\ 767 & 123.9 & 12.1 \\ 768 & 127.6 & 12 \\ 768 & 128 & 12 \\ 768 & 127.5 & 11.9 \\ 768 & 128.1 & 12 \\ 769 & 128.7 & 11.9 \\ 769 & 129.1 & 12 \\ 769 & 128.8 & 12 \\ 769 & 130.3 & 12.1 \\ 769 & 132.2 & 12.2 \\ 769 & 127.9 & 12 \\ 770 & 128 & 12.7 \\ 770 & 145.8 & 13 \\ 770 & 146.7 & 13.1 \\ 771 & 145.9 & 13.1 \\ 770 & 145.7 & 13.1 \\ 770 & 145.7 & 13.2 \\ 769 & 145.5 & 13.2 \\ 769 & 145.3 & 13.2 \\ 769 & 146 & 13.4 \\ 769 & 161.6 & 14.3 \\ 768 & 165.7 & 14.5 \\ 768 & 166 & 14.7 \\ 768 & 173.9 & 15.1 \\ 769 & 175.6 & 15.2 \\ 769 & 175 & 15.2 \\ 769 & 174.8 & 15.2 \\ 768 & 174.6 & 15.2 \\ 769 & 175.8 & 15.2 \\ 769 & 176.5 & 15.3 \\ 768 & 177.4 & 15.3 \\ 768 & 178.7 & 15.5 \\ 768 & 179.1 & 15.5 \\ 768 & 171.2 & 15.2 \\ 768 & 172.7 & 15.3 \\ 768 & 172.6 & 15.2 \\ 768 & 171.7 & 15.2 \\ 768 & 173.9 & 15.3 \\ 767 & 173.2 & 15.3 \\ 767 & 173.3 & 15.3 \\ 766 & 173.2 & 15.3 \\ 765 & 173.6 & 15.3 \\ 765 & 173.7 & 15.4\end{array}$




\begin{tabular}{rrr}
765 & 173.8 & 14.9 \\
764 & 173.7 & 15.5 \\
763 & 173.7 & 15.5 \\
763 & 174.7 & 15.5 \\
763 & 172.8 & 15.4 \\
764 & 172.4 & 15.4 \\
764 & 170.5 & 15.2 \\
764 & 157.1 & 14.6 \\
764 & 155.6 & 14.6 \\
764 & 154.7 & 14.4 \\
764 & 155.3 & 14.4 \\
765 & 155.6 & 14.4 \\
765 & 155.5 & 14.3 \\
765 & 155.7 & 14.4 \\
765 & 158 & 14.5 \\
765 & 172.5 & 16.3 \\
766 & 197.2 & 16.5 \\
766 & 199.4 & 16.8 \\
765 & 198.1 & 16 \\
765 & 173.5 & 15.4 \\
765 & 157.9 & 14.5 \\
765 & 148.7 & 14.1 \\
764 & 148.2 & 14.1 \\
764 & 147.7 & 13.9 \\
764 & 147.3 & 13.9 \\
763 & 147.8 & 13.9 \\
763 & 147.5 & 14.5 \\
763 & 165.1 & 14.8 \\
764 & 159.1 & 14.5 \\
764 & 156.9 & 14.4 \\
765 & 151.1 & 14.3 \\
765 & 149.4 & 13.8 \\
765 & 141.1 & 13.6 \\
766 & 140.8 & 13.4 \\
766 & 140.8 & 13.3 \\
766 & 140.6 & 13.2 \\
766 & 141.3 & 13.2 \\
766 & 142.3 & 13.2 \\
766 & 145.3 & 13.4 \\
767 & 147.1 & 14.4 \\
767 & 168.6 & 14.7 \\
767 & 169.9 & 14.9 \\
767 & 169.8 & 14.9 \\
767 & 169.3 & 14.9 \\
766 & 169.7 & 15 \\
765 & 169 & 15 \\
765 & 169.1 & 15 \\
765 & 169.2 & 15.1 \\
764 & 170.4 & 15.2 \\
764 & 170.3 & 15.4 \\
764 & 170 & 15.1 \\
763 & 170.7 & 15.3 \\
\hline & &
\end{tabular}




$\begin{array}{rrr}763 & 171.3 & 15.6 \\ 763 & 169.2 & 15.1 \\ 763 & 166.9 & 15.1 \\ 763 & 165.8 & 14.7 \\ 762 & 143.8 & 13 \\ 762 & 120.9 & 12.4 \\ 762 & 108.2 & 11.7 \\ 761 & 107.8 & 11.7 \\ 761 & 113.5 & 11.6 \\ 761 & 115.5 & 11.8 \\ 761 & 119.5 & 11.8 \\ 761 & 141.3 & 13.3 \\ 761 & 142.7 & 13.3 \\ 760 & 142.1 & 13.4 \\ 761 & 142.7 & 13.4 \\ 761 & 142 & 13.4 \\ 761 & 141.5 & 13.3 \\ 761 & 140.3 & 13.3 \\ 761 & 140.4 & 13.2 \\ 761 & 140.2 & 13.2 \\ 761 & 136.8 & 13 \\ 761 & 136.6 & 12.9 \\ 761 & 136.9 & 13.5 \\ 761 & 153.6 & 14.1 \\ 761 & 155.7 & 14.2 \\ 761 & 153.1 & 14.2 \\ 762 & 151 & 14.2 \\ 761 & 150.7 & 14.2 \\ 761 & 150.8 & 14.2 \\ 761 & 150.4 & 13.6 \\ 761 & 134.1 & 12.7 \\ 761 & 113.7 & 11.7 \\ 761 & 109.8 & 11.6 \\ 761 & 114 & 11.6 \\ 761 & 117.5 & 11.6 \\ 761 & 118.5 & 11.8 \\ 761 & 117.4 & 11.9 \\ 761 & 114 & 11.8 \\ 761 & 110.2 & 11.6 \\ 760 & 109.5 & 11.6 \\ 760 & 112.2 & 11.6 \\ 760 & 114.7 & 11.6 \\ 759 & 116.9 & 11.6 \\ 759 & 121.3 & 11.7 \\ 759 & 121.3 & 11.7 \\ 758 & 123.4 & 11.7 \\ 758 & 123.7 & 11.7 \\ 758 & 126.4 & 11.9 \\ 758 & 124.5 & 11.9 \\ 758 & 118.6 & 11.8 \\ 758 & 115.4 & 11.6 \\ 758 & 117.3 & 11.7 \\ & & \end{array}$




$\begin{array}{rrr}758 & 120.2 & 11.8 \\ 757 & 120.4 & 11.7 \\ 757 & 120.8 & 11.7 \\ 757 & 121.2 & 11.6 \\ 757 & 123.7 & 11.7 \\ 757 & 125.1 & 11.7 \\ 758 & 126.6 & 11.8 \\ 758 & 124.8 & 11.8 \\ 759 & 117.1 & 11.8 \\ 759 & 112.5 & 12 \\ 760 & 113 & 12.3 \\ 760 & 129.8 & 12.9 \\ 761 & 131 & 12.8 \\ 760 & 129 & 12.7 \\ 760 & 128.8 & 12.7 \\ 760 & 130.7 & 12.7 \\ 761 & 130.5 & 12.7 \\ 761 & 130.5 & 12.6 \\ 761 & 130.2 & 12.5 \\ 761 & 129.7 & 12.4 \\ 761 & 129.9 & 12.5 \\ 762 & 128.9 & 12.6 \\ 762 & 126.2 & 12.7 \\ 763 & 118.7 & 12.3 \\ 763 & 118.1 & 12.3 \\ 763 & 118.8 & 12.2 \\ 763 & 120.4 & 12 \\ 763 & 125.4 & 12.3 \\ 763 & 148.8 & 13.6 \\ 763 & 148.7 & 13.5 \\ 763 & 152.4 & 14.4 \\ 763 & 174.4 & 15.1 \\ 764 & 175.7 & 15.1 \\ 764 & 155.3 & 14.6 \\ 765 & 154.5 & 14.9 \\ 765 & 155.4 & 14.9 \\ 765 & 155.5 & 14.9 \\ 765 & 155 & 14.8 \\ 764 & 154.7 & 14.8 \\ 764 & 143.7 & 14 \\ 765 & 141.5 & 14 \\ 764 & 141.6 & 13.8 \\ 764 & 141.4 & 13.7 \\ 764 & 142.2 & 13.6 \\ 764 & 158.2 & 14.4 \\ 764 & 157.1 & 14.4 \\ 764 & 155.2 & 14.4 \\ 764 & 155 & 14.5 \\ 764 & 155.5 & 14.6 \\ 764 & 143.7 & 13.9 \\ 763 & 126.7 & 13.1 \\ 763 & 116.9 & 12.4\end{array}$




$\begin{array}{lrr}763 & 109.6 & 11.9 \\ 762 & 106.9 & 11.7 \\ 762 & 111 & 11.6 \\ 762 & 112.6 & 11.7 \\ 762 & 115.5 & 12.6 \\ 762 & 136 & 13.4 \\ 762 & 138.6 & 13.6 \\ 762 & 139 & 13.7 \\ 761 & 139.1 & 13.8 \\ 761 & 153.2 & 14.5 \\ 761 & 153.4 & 14.5 \\ 760 & 158.8 & 14.8 \\ 760 & 159.9 & 14.8 \\ 760 & 167.7 & 15.1 \\ 760 & 164 & 14.9 \\ 760 & 146.1 & 14 \\ 761 & 145.8 & 14 \\ 761 & 153.4 & 14.2 \\ 761 & 151.7 & 14.2 \\ 761 & 151.6 & 14.2 \\ 761 & 150.9 & 14.3 \\ 761 & 151.6 & 14.6 \\ 761 & 152.2 & 14.3 \\ 761 & 152.6 & 14.3 \\ 761 & 153.3 & 14.3 \\ 761 & 153.7 & 14.4 \\ 761 & 157.1 & 14.4 \\ 761 & 157.4 & 14.4 \\ 762 & 158 & 14.6 \\ 762 & 158.8 & 14.6 \\ 762 & 148.5 & 14.4 \\ 762 & 148.5 & 14.9 \\ 762 & 158.7 & 15.3 \\ 762 & 160.5 & 15.1 \\ 762 & 159.9 & 15 \\ 762 & 159.4 & 14.9 \\ 762 & 148.9 & 14.5 \\ 762 & 147.3 & 14.3 \\ 762 & 146.8 & 14.2 \\ 762 & 146.8 & 14.3 \\ 763 & 158.4 & 14.7 \\ 764 & 155.9 & 14.4 \\ 764 & 131.3 & 12.9 \\ 765 & 109.6 & 11.9 \\ 765 & 107.5 & 12.2 \\ 765 & 138.8 & 13.6 \\ 766 & 142.5 & 13.5 \\ 766 & 142.7 & 13.5 \\ 766 & 142.7 & 13.5 \\ 766 & 142.6 & 13.4 \\ 767 & 142.6 & 13.4 \\ & 142.7 & 13.3\end{array}$




$\begin{array}{rrr}768 & 142.6 & 13.3 \\ 768 & 142.6 & 13.4 \\ 769 & 142.6 & 13.6 \\ 769 & 142.6 & 13.7 \\ 769 & 142.5 & 13.8 \\ 769 & 142.5 & 13.8 \\ 770 & 142.4 & 13.8 \\ 770 & 142.3 & 13.8 \\ 770 & 142.2 & 13.7 \\ 770 & 142.1 & 13.6 \\ 770 & 142.1 & 13.5 \\ 770 & 142.1 & 13.5 \\ 771 & 142.1 & 13.4 \\ 771 & 141.9 & 13.2 \\ 772 & 142 & 13.3 \\ 772 & 142.1 & 13.3 \\ 772 & 142.2 & 13.3 \\ 772 & 142.1 & 13.3 \\ 772 & 142 & 13.3 \\ 772 & 141.9 & 13.3 \\ 773 & 141.9 & 13.3 \\ 773 & 141.7 & 13.2 \\ 773 & 140.7 & 13.1 \\ 773 & 140 & 13 \\ 773 & 140.3 & 13 \\ 773 & 140.9 & 13 \\ 773 & 141 & 13.1 \\ 772 & 141.1 & 13.2 \\ 772 & 141.3 & 13.3 \\ 771 & 141.3 & 13.4 \\ 771 & 141.2 & 13.4 \\ 770 & 141.3 & 13.3 \\ 770 & 141.2 & 13.5 \\ 769 & 141.3 & 13.4 \\ 769 & 141.2 & 13.3 \\ 768 & 142.1 & 13.6 \\ 768 & 153.3 & 13.8 \\ 769 & 165.8 & 14.4 \\ 769 & 177.9 & 15 \\ 769 & 178.4 & 14.9 \\ 768 & 166.8 & 14.4 \\ 768 & 166.7 & 14.5 \\ 768 & 154.9 & 13.9 \\ 768 & 153.5 & 13.9 \\ 768 & 142.6 & 13.3 \\ 768 & 141.9 & 13.2 \\ 768 & 141.7 & 13.2 \\ 768 & 142.9 & 13.1 \\ 768 & 142.3 & 13 \\ 767 & 142.7 & 13.4 \\ 767 & 164.7 & 14.1 \\ 766 & 165.6 & 14.1 \\ 7 & & \end{array}$




$\begin{array}{rrr}766 & 162.9 & 14 \\ 766 & 160.7 & 14.1 \\ 765 & 161 & 14.9 \\ 765 & 181.3 & 15.3 \\ 764 & 183.1 & 15.4 \\ 764 & 183.1 & 15.5 \\ 763 & 183.2 & 15.5 \\ 763 & 182.9 & 15.5 \\ 763 & 182.5 & 15.7 \\ 764 & 183.5 & 15.6 \\ 764 & 183.6 & 15.6 \\ 764 & 183.4 & 15.2 \\ 764 & 173.4 & 14.9 \\ 764 & 165.9 & 14.7 \\ 764 & 162.1 & 14.6 \\ 764 & 162 & 14.6 \\ 764 & 162.1 & 14.6 \\ 764 & 162.1 & 14.4 \\ 764 & 150.1 & 14.2 \\ 764 & 149.2 & 14 \\ 764 & 149.2 & 13.9 \\ 764 & 150.6 & 14 \\ 763 & 150.8 & 13.5 \\ 762 & 139.3 & 13.4 \\ 762 & 138.4 & 13.3 \\ 761 & 138.2 & 13.2 \\ 761 & 137.8 & 13.3 \\ 760 & 137.8 & 13.3 \\ 760 & 137.8 & 13.3 \\ 759 & 137.7 & 13.2 \\ 759 & 127.2 & 12.4 \\ 758 & 117.5 & 12.2 \\ 759 & 117.3 & 12 \\ 760 & 117.2 & 11.8 \\ 761 & 117.1 & 11.8 \\ 761 & 117.2 & 11.7 \\ 762 & 117.3 & 11.6 \\ 761 & 117.3 & 11.2 \\ 760 & 117.3 & 11.3 \\ 761 & 118.3 & 11.5 \\ 761 & 126.2 & 11.8 \\ 760 & 126.2 & 11.8 \\ 761 & 126.4 & 11.8 \\ 760 & 127.5 & 12.6 \\ 761 & 147.8 & 12.8 \\ 760 & 144.4 & 12.9 \\ 760 & 150.8 & 13.3 \\ 760 & 151.2 & 13.3 \\ 760 & 151 & 13.4 \\ 760 & 151.2 & 13.4 \\ 760 & 149.8 & 13.3 \\ 760 & 148.3 & 13.4\end{array}$




$\begin{array}{lrr}760 & 148.4 & 13.4 \\ 761 & 148.3 & 13.5 \\ 760 & 148.3 & 13.5 \\ 760 & 148.4 & 13.5 \\ 761 & 148.5 & 13.6 \\ 761 & 148.4 & 13.5 \\ 762 & 148.5 & 13.6 \\ 762 & 148.6 & 13.6 \\ 763 & 148.6 & 13.5 \\ 763 & 148.7 & 13.5 \\ 763 & 148.3 & 13.4 \\ 763 & 148.3 & 13.4 \\ 764 & 148.5 & 13.5 \\ 764 & 148.5 & 13.5 \\ 764 & 148.5 & 13.6 \\ 765 & 148.4 & 13.6 \\ 765 & 148.4 & 13.6 \\ 765 & 148.4 & 13.6 \\ 765 & 148.6 & 13.7 \\ 766 & 149.5 & 13.6 \\ 766 & 161.4 & 14.2 \\ 766 & 161.7 & 14.2 \\ 766 & 161.2 & 14.2 \\ 766 & 163.7 & 14.4 \\ 766 & 164.1 & 14.4 \\ 766 & 164.2 & 14.4 \\ 767 & 164.1 & 14.6 \\ 767 & 165 & 14.8 \\ 767 & 175 & 15.2 \\ 767 & 177.9 & 15.3 \\ 768 & 177.8 & 15.3 \\ 768 & 177.4 & 15 \\ 768 & 164.6 & 14.7 \\ 768 & 164.7 & 14.6 \\ 769 & 164.6 & 14.6 \\ 769 & 165.1 & 14.5 \\ 769 & 164.6 & 14.6 \\ 769 & 165 & 15.1 \\ 769 & 175.2 & 16.3 \\ 769 & 197.4 & 16.5 \\ 770 & 193.5 & 16.4 \\ 770 & 193.6 & 16.6 \\ 770 & 204.4 & 17.1 \\ 771 & 206 & 17.2 \\ 771 & 205.6 & 17.2 \\ 770 & 205.4 & 17.2 \\ 771 & 208.9 & 17.4 \\ 770 & 210.8 & 17.5 \\ 770 & 210.5 & 17.5 \\ 770 & 210.1 & 17.6 \\ 770 & 210.1 & 17.6 \\ 770 & 220.2 & 18.3\end{array}$




$\begin{array}{rrr}769 & 235.5 & 18.3 \\ 769 & 227.5 & 18.3 \\ 769 & 226.8 & 18.4 \\ 769 & 225.9 & 17.4 \\ 769 & 201.1 & 17.2 \\ 769 & 199.4 & 16.6 \\ 769 & 186 & 15.9 \\ 768 & 163.6 & 15.4 \\ 768 & 157.2 & 15.2 \\ 768 & 160.1 & 15.2 \\ 768 & 169.5 & 15.6 \\ 768 & 186.6 & 16.2 \\ 768 & 186.9 & 16.2 \\ 768 & 187.3 & 16.3 \\ 768 & 187.2 & 16.3 \\ 768 & 187.2 & 16.3 \\ 768 & 187.1 & 16.2 \\ 768 & 187.2 & 16.2 \\ 767 & 187.1 & 16.2 \\ 766 & 187 & 16.2 \\ 766 & 187.1 & 16.2 \\ 766 & 186.9 & 16.1 \\ 765 & 186.8 & 16.1 \\ 765 & 187.2 & 16.9 \\ 765 & 207.3 & 17.2 \\ 765 & 208.8 & 17.3 \\ 765 & 208.2 & 17.1 \\ 765 & 191.4 & 16.5 \\ 765 & 188.3 & 16.5 \\ 765 & 165.6 & 15.4 \\ 765 & 163.8 & 15.3 \\ 764 & 163.7 & 15.2 \\ 764 & 165.3 & 15.2 \\ 764 & 164.1 & 15.1 \\ 764 & 163.5 & 15 \\ 764 & 163.4 & 15 \\ 764 & 162.8 & 15 \\ 764 & 162.6 & 15.1 \\ 764 & 162.7 & 15 \\ 764 & 162.7 & 15 \\ 764 & 163.1 & 15 \\ 763 & 162.6 & 14.9 \\ 762 & 162.5 & 14.9 \\ 761 & 162.5 & 14.8 \\ 761 & 162.4 & 14.8 \\ 761 & 161.9 & 14.6 \\ 761 & 146.8 & 14 \\ 761 & 145.2 & 13.9 \\ 761 & 145.1 & 14 \\ 761 & 145.3 & 14 \\ 761 & 145.5 & 13.9 \\ 761 & 145.8 & 13.9\end{array}$




$\begin{array}{rrr}760 & 145.7 & 13.8 \\ 760 & 145.7 & 13.9 \\ 760 & 145.9 & 13.8 \\ 759 & 145.8 & 13.6 \\ 759 & 145.8 & 13.6 \\ 759 & 145.8 & 13.7 \\ 759 & 145.8 & 13.6 \\ 759 & 145.8 & 13.6 \\ 759 & 145.8 & 13.9 \\ 759 & 145.9 & 13.9 \\ 759 & 145.9 & 13.8 \\ 758 & 145.7 & 13.8 \\ 758 & 145.6 & 13.8 \\ 758 & 145.6 & 13.7 \\ 757 & 145.6 & 13.7 \\ 758 & 145.6 & 13.6 \\ 758 & 145.6 & 13.6 \\ 758 & 145.5 & 13.5 \\ 758 & 145.4 & 13.4 \\ 758 & 145.4 & 13.5 \\ 759 & 145.6 & 13.6 \\ 759 & 145.6 & 13.5 \\ 759 & 145.7 & 13.6 \\ 759 & 146.1 & 13.6 \\ 759 & 146.2 & 13.6 \\ 759 & 146.1 & 13.6 \\ 760 & 146.1 & 13.5 \\ 760 & 146.2 & 13.5 \\ 760 & 146.3 & 13.6 \\ 760 & 146.2 & 13.4 \\ 760 & 146.1 & 13.4 \\ 761 & 146 & 13.4 \\ 761 & 146.1 & 13.6 \\ 761 & 146.3 & 13.7 \\ 761 & 146.5 & 13.8 \\ 761 & 157.1 & 14.3 \\ 761 & 158.3 & 14.4 \\ 761 & 158.6 & 14.4 \\ 761 & 157.6 & 14.3 \\ 762 & 157.6 & 14.2 \\ 762 & 157.6 & 14.2 \\ 762 & 157.7 & 14.2 \\ 761 & 157.7 & 14.1 \\ 763 & 167.9 & 14.7 \\ 763 & 181 & 15.2 \\ 763 & 195.4 & 16 \\ 763 & 196.1 & 16.2 \\ 763 & 196.2 & 16.2 \\ 763 & 196.6 & 16.3 \\ 763 & 196.4 & 16.4 \\ 763 & 196.8 & 16.4 \\ 763 & 186.5 & 15.8\end{array}$




$\begin{array}{rrr}762 & 181.1 & 15.7 \\ 762 & 181.1 & 15.7 \\ 762 & 175.6 & 15.4 \\ 762 & 175.3 & 15.4 \\ 763 & 175.2 & 15.5 \\ 763 & 175.2 & 15.5 \\ 763 & 175.5 & 15.6 \\ 763 & 185.7 & 16.1 \\ 763 & 182.3 & 15.8 \\ 762 & 181.3 & 15.9 \\ 762 & 180.9 & 15.8 \\ 762 & 172.5 & 15.4 \\ 762 & 173.4 & 15.5 \\ 762 & 192 & 16.2 \\ 762 & 192.8 & 16.2 \\ 762 & 193.5 & 16.5 \\ 762 & 219.1 & 17.5 \\ 762 & 221.7 & 17.8 \\ 762 & 238.5 & 18.5 \\ 762 & 239.3 & 18.5 \\ 762 & 216.9 & 17.7 \\ 762 & 203.8 & 17.2 \\ 761 & 194.2 & 16.6 \\ 761 & 171.6 & 15.7 \\ 761 & 170.2 & 15.6 \\ 760 & 170.6 & 15.5 \\ 760 & 195 & 16.6 \\ 760 & 199.5 & 17 \\ 760 & 219.6 & 18.1 \\ 760 & 237 & 18.7 \\ 759 & 238.5 & 18.7 \\ 759 & 240.7 & 18.9 \\ 759 & 240.3 & 18.9 \\ 758 & 240.8 & 19 \\ 757 & 240.2 & 18.9 \\ 756 & 228.8 & 18.5 \\ 756 & 231.6 & 18.5 \\ 756 & 221.8 & 17.9 \\ 756 & 212.4 & 17.9 \\ 756 & 210.2 & 17.6 \\ 755 & 210 & 17.6 \\ 755 & 198.7 & 17 \\ 755 & 175 & 16.2 \\ 754 & 172.1 & 15.9 \\ 756 & 170.8 & 15.9 \\ 756 & 170.6 & 15.7 \\ 756 & 170.5 & 15.7 \\ 756 & 170.4 & 15.6 \\ 756 & 170.4 & 15.5 \\ 756 & 170.5 & 15.5 \\ 756 & 170.3 & 15.4 \\ 756 & 170.9 & 15.8\end{array}$




$\begin{array}{lrr}756 & 188.3 & 16.2 \\ 756 & 190.3 & 16.2 \\ 757 & 189.9 & 16.4 \\ 757 & 190 & 16.6 \\ 757 & 190.2 & 16.5 \\ 757 & 190.4 & 16.4 \\ 757 & 189.7 & 16.4 \\ 757 & 189.7 & 16.5 \\ 757 & 187.7 & 16.4 \\ 758 & 187.6 & 16.3 \\ 759 & 188.3 & 16.5 \\ 759 & 188.5 & 16.3 \\ 759 & 188.6 & 16.4 \\ 760 & 188 & 16.2 \\ 761 & 188.3 & 16.2 \\ 762 & 187.9 & 16.2 \\ 762 & 176.6 & 15.7 \\ 763 & 175.8 & 15.8 \\ 764 & 175.8 & 15.8 \\ 765 & 175.8 & 15.7 \\ 766 & 176 & 15.7 \\ 766 & 175.3 & 15.8 \\ 766 & 175.1 & 15.6 \\ 767 & 187.3 & 16.1 \\ 767 & 187.2 & 16.1 \\ 768 & 194.3 & 16.7 \\ 769 & 208.9 & 17.2 \\ 769 & 209.1 & 17.5 \\ 769 & 207.5 & 17.4 \\ 768 & 207.7 & 17.6 \\ 769 & 208.6 & 17.6 \\ 769 & 213.3 & 17.7 \\ 769 & 215.9 & 17.7 \\ 769 & 215.9 & 17.8 \\ 769 & 215.9 & 17.8 \\ 769 & 215.8 & 17.8 \\ 769 & 216.4 & 17.8 \\ 769 & 216.1 & 17.8 \\ 769 & 215.4 & 17.8 \\ 769 & 216.4 & 17.8 \\ 769 & 216.2 & 17.8 \\ 769 & 197.9 & 17.1 \\ 769 & 185.6 & 16.4 \\ 770 & 180 & 16.3 \\ 770 & 180.1 & 16.2 \\ 770 & 179.8 & 16.1 \\ 770 & 179.6 & 16.1 \\ 770 & 179.5 & 16 \\ 771 & 179.5 & 15.7 \\ 771 & 179.3 & 16 \\ 771 & 179.4 & 15.8 \\ 771 & 179.9 & 16.3\end{array}$




$\begin{array}{rrr}771 & 194.4 & 16.9 \\ 771 & 211.2 & 17.6 \\ 771 & 223.5 & 18 \\ 770 & 224.9 & 18.2 \\ 770 & 226 & 18 \\ 770 & 224.4 & 17.9 \\ 769 & 225.2 & 18.6 \\ 769 & 225.2 & 18.3 \\ 769 & 226 & 18.3 \\ 770 & 237.8 & 18.8 \\ 770 & 237.7 & 18.8 \\ 770 & 236.9 & 18.8 \\ 770 & 236.4 & 18.9 \\ 770 & 237.5 & 19 \\ 770 & 237.7 & 19 \\ 770 & 237.9 & 19 \\ 771 & 234.5 & 18.9 \\ 771 & 222.8 & 18.4 \\ 771 & 210.5 & 17.7 \\ 771 & 197.2 & 17.1 \\ 772 & 192.1 & 16.9 \\ 771 & 191.1 & 16.8 \\ 771 & 190.7 & 16.7 \\ 770 & 190.7 & 16.8 \\ 770 & 190.6 & 16.7 \\ 770 & 190.4 & 16.6 \\ 769 & 192.5 & 16.7 \\ 769 & 195.3 & 16.9 \\ 768 & 196.6 & 17.2 \\ 768 & 207.1 & 17.3 \\ 767 & 217.8 & 17.8 \\ 767 & 218.7 & 17.8 \\ 767 & 218.7 & 17.8 \\ 767 & 237.3 & 18.8 \\ 767 & 240.9 & 18.9 \\ 767 & 241.1 & 18.9 \\ 767 & 233.2 & 18.6 \\ 767 & 231.4 & 18.6 \\ 767 & 224.3 & 18.1 \\ 767 & 207.7 & 17.6 \\ 767 & 201.7 & 17.3 \\ 766 & 201.5 & 17.3 \\ 766 & 200.9 & 16.5 \\ 766 & 183.8 & 16.1 \\ 766 & 161.5 & 15.4 \\ 766 & 159.9 & 15.3 \\ 766 & 159.9 & 15.2 \\ 765 & 159.9 & 15.3 \\ 765 & 159.3 & 15.1 \\ 764 & 161.8 & 15.1 \\ 765 & 166.5 & 15.4 \\ 764 & 166.8 & 15.3\end{array}$




$\begin{array}{rrr}764 & 176 & 16 \\ 763 & 186.7 & 16.2 \\ 763 & 196.1 & 16.5 \\ 763 & 195.9 & 16.5 \\ 763 & 196.1 & 16.5 \\ 763 & 196 & 16.5 \\ 763 & 195.4 & 16.3 \\ 763 & 182.4 & 15.7 \\ 763 & 168.5 & 15.2 \\ 763 & 167.8 & 15.1 \\ 763 & 162.3 & 14.9 \\ 762 & 160.4 & 14.8 \\ 762 & 159.9 & 14.7 \\ 762 & 159.5 & 14.6 \\ 762 & 159.6 & 14.8 \\ 762 & 177.3 & 16 \\ 762 & 198.8 & 16.7 \\ 762 & 216.1 & 17.2 \\ 761 & 217.1 & 17.3 \\ 761 & 219.5 & 17.6 \\ 761 & 221 & 17.7 \\ 761 & 220.4 & 17.9 \\ 761 & 228.8 & 18.2 \\ 760 & 229.7 & 18.3 \\ 759 & 229.7 & 18.3 \\ 759 & 231.2 & 18.5 \\ 758 & 231.5 & 18.5 \\ 758 & 231.7 & 18.3 \\ 758 & 221.3 & 17.9 \\ 758 & 200.4 & 17.2 \\ 758 & 183.2 & 16.1 \\ 759 & 163.7 & 15.7 \\ 759 & 162.6 & 15.4 \\ 759 & 162 & 15.3 \\ 758 & 162.1 & 15.4 \\ 758 & 163.2 & 15.1 \\ 758 & 162.1 & 15.1 \\ 758 & 164.7 & 15.2 \\ 758 & 163.9 & 15.2 \\ 758 & 183.8 & 16.3 \\ 758 & 203.9 & 17 \\ 758 & 213.6 & 17.4 \\ 758 & 214.5 & 17.4 \\ 758 & 214 & 17.6 \\ 758 & 213.4 & 17.4 \\ 758 & 212.8 & 17.5 \\ 759 & 212.6 & 17.5 \\ 759 & 205.4 & 17.2 \\ 759 & 202.6 & 17.2 \\ 759 & 203.5 & 17.2 \\ 760 & 200.1 & 17 \\ 760 & 189 & 16.3\end{array}$




$\begin{array}{lrr}760 & 176.7 & 15.8 \\ 761 & 163.9 & 15.4 \\ 761 & 162.8 & 15.3 \\ 761 & 162.7 & 15.2 \\ 761 & 162.6 & 15.1 \\ 762 & 162.7 & 15.1 \\ 762 & 162.6 & 15.1 \\ 762 & 162.6 & 14.9 \\ 762 & 160.1 & 14.9 \\ 763 & 158.8 & 14.8 \\ 763 & 160.4 & 15.1 \\ 763 & 168.9 & 15.2 \\ 764 & 168.9 & 15.2 \\ 764 & 169.4 & 15.3 \\ 764 & 182.6 & 15.8 \\ 764 & 183.4 & 15.8 \\ 764 & 183.2 & 15.8 \\ 764 & 183.4 & 16 \\ 764 & 196.2 & 16.5 \\ 764 & 196.9 & 16.6 \\ 764 & 196.9 & 16.6 \\ 765 & 197.7 & 16.6 \\ 765 & 196.5 & 16.7 \\ 764 & 196.4 & 17.2 \\ 765 & 209.2 & 17 \\ 766 & 209.3 & 17.3 \\ 766 & 206.3 & 16.9 \\ 766 & 196.7 & 16.8 \\ 767 & 196.6 & 16.9 \\ 767 & 196.7 & 15.6 \\ 767 & 197.2 & 16.7 \\ 767 & 196.8 & 16.8 \\ 767 & 197.1 & 16.8 \\ 767 & 208.2 & 17.5 \\ 768 & 219.2 & 17.8 \\ 768 & 219.5 & 17.9 \\ 768 & 219.4 & 17.9 \\ 768 & 219.1 & 18 \\ 768 & 219.3 & 18 \\ 768 & 219.2 & 18 \\ 767 & 219 & 18 \\ 767 & 225.3 & 18.3 \\ 766 & 226.1 & 18.6 \\ 766 & 237.1 & 19 \\ 765 & 238.3 & 19.2 \\ 765 & 237.5 & 18.9 \\ 765 & 237.6 & 19.1 \\ 764 & 237.6 & 19.1 \\ 764 & 238.4 & 19.1 \\ 764 & 238.7 & 19.2 \\ 765 & 238.8 & 19.2 \\ 765 & 238.3 & 19.1 \\ & & \end{array}$




$\begin{array}{rrr}764 & 237.9 & 19 \\ 765 & 222.5 & 18.2 \\ 764 & 209.3 & 17.8 \\ 764 & 196.2 & 17.2 \\ 764 & 195.7 & 17.2 \\ 763 & 196.4 & 17.1 \\ 763 & 188.8 & 16.8 \\ 764 & 187.4 & 16.8 \\ 764 & 187.5 & 16.7 \\ 763 & 207.1 & 17.5 \\ 763 & 207.8 & 17.6 \\ 763 & 207.6 & 17.5 \\ 763 & 207.5 & 17.5 \\ 763 & 208.3 & 17.7 \\ 763 & 229.3 & 18.5 \\ 762 & 231.1 & 18.6 \\ 762 & 230.8 & 18.6 \\ 762 & 231 & 18.7 \\ 761 & 231.4 & 18.7 \\ 761 & 249.1 & 19.5 \\ 761 & 251.3 & 19.7 \\ 762 & 246.6 & 19.6 \\ 762 & 240.2 & 19.4 \\ 762 & 239.5 & 19.3 \\ 762 & 230.1 & 18.9 \\ 763 & 220.9 & 18.5 \\ 763 & 204.6 & 17.7 \\ 763 & 189 & 17 \\ 763 & 171.8 & 16.3 \\ 763 & 158.9 & 15.8 \\ 763 & 158.9 & 15.8 \\ 764 & 168.6 & 16 \\ 764 & 167.4 & 15.9 \\ 764 & 167.4 & 15.9 \\ 764 & 167.4 & 15.8 \\ 764 & 167.2 & 15.7 \\ 764 & 167.1 & 15.6 \\ 764 & 167.6 & 15.6 \\ 763 & 177.2 & 15.9 \\ 763 & 177.6 & 15.9 \\ 763 & 177.7 & 15.9 \\ 763 & 177.8 & 15.9 \\ 763 & 188.1 & 16.4 \\ 762 & 190.5 & 16.4 \\ 763 & 200.2 & 17 \\ 763 & 201.5 & 17.1 \\ 764 & 213.9 & 17.6 \\ 764 & 214.3 & 17.6 \\ 764 & 203.3 & 17.2 \\ 764 & 190.7 & 16.6 \\ 764 & 178.8 & 16.1 \\ 764 & 177.2 & 16\end{array}$




$\begin{array}{rrr}764 & 167 & 15.5 \\ 764 & 155.9 & 15 \\ 764 & 155.4 & 15 \\ 764 & 155.2 & 15 \\ 764 & 155.3 & 15 \\ 765 & 155.3 & 15 \\ 764 & 155 & 14.9 \\ 764 & 154.7 & 14.9 \\ 763 & 154.7 & 14.8 \\ 762 & 154.7 & 14.8 \\ 762 & 154.6 & 14.6 \\ 761 & 154.5 & 14.5 \\ 761 & 154.5 & 14.4 \\ 760 & 154.3 & 14.4 \\ 760 & 154.3 & 14.3 \\ 760 & 154.3 & 14.3 \\ 760 & 159.3 & 14.7 \\ 760 & 157.3 & 14.5 \\ 761 & 157.3 & 14.5 \\ 761 & 157.4 & 14.6 \\ 761 & 160.9 & 14.8 \\ 761 & 167.3 & 14.9 \\ 761 & 168.1 & 14.9 \\ 760 & 168.8 & 15 \\ 761 & 186.1 & 15.7 \\ 761 & 187 & 15.8 \\ 761 & 187.1 & 16 \\ 761 & 192.8 & 16.4 \\ 761 & 193.2 & 16.5 \\ 761 & 193.9 & 16.6 \\ 761 & 193.5 & 16.7 \\ 760 & 193.4 & 16.7 \\ 760 & 193.4 & 16.8 \\ 760 & 205.5 & 17.3 \\ 760 & 206 & 17.3 \\ 759 & 203 & 17.2 \\ 759 & 203.1 & 17.2 \\ 759 & 203.3 & 17.3 \\ 759 & 213 & 17.6 \\ 759 & 214.9 & 18.2 \\ 759 & 236.8 & 18.8 \\ 760 & 236.4 & 18.8 \\ 760 & 231.8 & 19 \\ 760 & 228.1 & 18.7 \\ 761 & 216.6 & 18.2 \\ 761 & 215.2 & 18.2 \\ 761 & 214.9 & 17.9 \\ 761 & 193.2 & 17.2 \\ 761 & 191.8 & 17.1 \\ 761 & 191.9 & 17 \\ 761 & 192.1 & 17.2 \\ 762 & 203.6 & 17.5\end{array}$




$\begin{array}{rrr}762 & 208.9 & 17.8 \\ 762 & 215.9 & 18.3 \\ 762 & 221.2 & 18.5 \\ 763 & 221.9 & 18.6 \\ 762 & 221.4 & 18.5 \\ 762 & 217.6 & 18.4 \\ 762 & 218.7 & 18.4 \\ 762 & 217.3 & 18.4 \\ 762 & 217.4 & 18.3 \\ 762 & 213.1 & 17.8 \\ 762 & 202.2 & 17.7 \\ 761 & 195.9 & 17.3 \\ 761 & 204.7 & 17.7 \\ 762 & 205.8 & 17.7 \\ 762 & 205.1 & 18.2 \\ 763 & 222.4 & 18.5 \\ 763 & 223.2 & 18.5 \\ 763 & 196.7 & 17.1 \\ 763 & 168.5 & 16.2 \\ 763 & 164.5 & 16 \\ 764 & 164.5 & 15.9 \\ 764 & 168 & 16 \\ 764 & 171.9 & 16 \\ 765 & 185.8 & 16.7 \\ 765 & 206.1 & 17.8 \\ 765 & 240.8 & 19.2 \\ 766 & 247.5 & 19.6 \\ 766 & 249.4 & 20.2 \\ 766 & 275 & 21 \\ 766 & 275 & 21 \\ 766 & 274.7 & 21.2 \\ 766 & 275.2 & 21.3 \\ 766 & 272.9 & 21.2 \\ 765 & 271.8 & 21.2 \\ 765 & 271.1 & 21.2 \\ 765 & 268.6 & 21.2 \\ 765 & 267.4 & 21.1 \\ 765 & 266 & 21.1 \\ 765 & 267.3 & 21.2 \\ 766 & 267.4 & 21.3 \\ 765 & 268.2 & 21.3 \\ 766 & 263.9 & 21 \\ 765 & 259.8 & 20.9 \\ 765 & 239.6 & 19.6 \\ 765 & 207.9 & 18.6 \\ 765 & 181.1 & 17.6 \\ 765 & 180 & 17.4 \\ 765 & 180.1 & 17.2 \\ 765 & 182.5 & 17.3 \\ 765 & 207.9 & 18.5 \\ 765 & 222.2 & 19.2 \\ 765 & 227.1 & 18.8\end{array}$




$\begin{array}{rrr}764 & 221.9 & 18.8 \\ 764 & 221.3 & 18.9 \\ 764 & 220.2 & 19.4 \\ 763 & 240.7 & 20.4 \\ 763 & 268.8 & 21.3 \\ 763 & 280.5 & 21.2 \\ 763 & 273.8 & 20.9 \\ 762 & 271.6 & 21.5 \\ 762 & 265.5 & 20.9 \\ 762 & 264.2 & 20.9 \\ 763 & 263.2 & 20.9 \\ 763 & 278.9 & 21.6 \\ 763 & 284.7 & 21.7 \\ 763 & 271.3 & 21.4 \\ 763 & 274 & 21.5 \\ 763 & 273.7 & 21.5 \\ 763 & 271.6 & 21.5 \\ 763 & 272.7 & 21.5 \\ 764 & 273.3 & 21.5 \\ 764 & 270.9 & 21.4 \\ 764 & 270.7 & 21.4 \\ 764 & 270.7 & 21.7 \\ 764 & 292.7 & 22.5 \\ 764 & 313.1 & 23.2 \\ 763 & 311.6 & 23.2 \\ 763 & 312.2 & 23.2 \\ 762 & 305.3 & 23.1 \\ 762 & 303.3 & 23.2 \\ 762 & 308.5 & 23.5 \\ 761 & 313.3 & 23.5 \\ 761 & 313 & 23.6 \\ 761 & 314.5 & 23.7 \\ 761 & 314.3 & 23.8 \\ 761 & 314.5 & 23.7 \\ 762 & 330.8 & 24.3 \\ 762 & 328.9 & 24.3 \\ 762 & 327.4 & 24.1 \\ 762 & 312.8 & 23.8 \\ 762 & 314 & 23.9 \\ 761 & 316.5 & 24 \\ 761 & 317.2 & 24 \\ 761 & 315.6 & 23.9 \\ 761 & 315 & 23.9 \\ 761 & 313.9 & 23.8 \\ 761 & 312 & 23.6 \\ 761 & 299.2 & 23.3 \\ 760 & 298.2 & 23.3 \\ 760 & 297.1 & 23.3 \\ 760 & 297.4 & 23.2 \\ 760 & 296.5 & 23.3 \\ 760 & 297.4 & 23.2 \\ 759 & 297.1 & 23.2 \\ & & \end{array}$




$\begin{array}{lrr}759 & 297 & 23.1 \\ 759 & 293.4 & 23 \\ 758 & 292 & 22.9 \\ 758 & 290.4 & 22.9 \\ 758 & 292 & 23 \\ 759 & 294 & 23 \\ 760 & 293.3 & 22.9 \\ 760 & 280.1 & 22.5 \\ 760 & 279.1 & 22.4 \\ 761 & 279.2 & 22.4 \\ 761 & 264.9 & 21.5 \\ 761 & 248.1 & 21 \\ 762 & 246.8 & 20.9 \\ 762 & 247.1 & 20.6 \\ 762 & 238.3 & 20.4 \\ 762 & 237.5 & 20.3 \\ 763 & 237.9 & 20.2 \\ 763 & 237.8 & 20.1 \\ 763 & 237.4 & 20 \\ 764 & 237.1 & 19.9 \\ 764 & 233.3 & 19.8 \\ 764 & 233.4 & 19.8 \\ 764 & 233.3 & 19.7 \\ 764 & 233.2 & 19.7 \\ 764 & 233.2 & 19.7 \\ 763 & 233.7 & 19.7 \\ 763 & 232.8 & 19.5 \\ 763 & 232.7 & 19.5 \\ 763 & 234.2 & 19.5 \\ 764 & 234.8 & 19.5 \\ 764 & 233.7 & 19.4 \\ 764 & 233.7 & 19.3 \\ 765 & 233.6 & 19.3 \\ 765 & 232.7 & 19.3 \\ 765 & 234.1 & 19.3 \\ 765 & 248.5 & 20.2 \\ 765 & 250.3 & 20 \\ 765 & 249.9 & 20.1 \\ 765 & 250 & 20.1 \\ 765 & 250.9 & 20.6 \\ 765 & 273.3 & 21.2 \\ 765 & 274.9 & 21.9 \\ 765 & 299.4 & 22.3 \\ 765 & 300.9 & 21.9 \\ 765 & 275.2 & 21.1 \\ 765 & 257.4 & \\ 765 & 260.4 & 21 \\ 765 & 272.8 & 21.5 \\ 764 & 257.4 & 21.5 \\ 764 & 276.7 & 22.1 \\ 764 & 287.7 & \\ 763 & 287.6 & \\ & & \\ 763\end{array}$




$\begin{array}{rrr}763 & 293 & 22.4 \\ 763 & 294.4 & 22.4 \\ 763 & 306.3 & 23 \\ 763 & 310.9 & 23.1 \\ 763 & 311.5 & 23.2 \\ 763 & 311.1 & 23.2 \\ 764 & 311.4 & 23.3 \\ 763 & 311.3 & 23.3 \\ 763 & 314.6 & 23.5 \\ 763 & 310.7 & 23.3 \\ 763 & 309.2 & 23.2 \\ 763 & 302.8 & 23 \\ 763 & 302.7 & 23.2 \\ 763 & 304.8 & 23.2 \\ 763 & 305 & 22.7 \\ 763 & 284.4 & 22.8 \\ 764 & 291.8 & 22.5 \\ 764 & 284.8 & 22.3 \\ 764 & 282.1 & 22.2 \\ 764 & 282.9 & 22.3 \\ 764 & 283.9 & 22.3 \\ 764 & 282.6 & 22.2 \\ 764 & 282.5 & 22.2 \\ 764 & 299.5 & 22.9 \\ 764 & 302.6 & 23.1 \\ 765 & 308.2 & 23.3 \\ 765 & 304.2 & 22.9 \\ 766 & 288.2 & 22.4 \\ 766 & 285.7 & 22.4 \\ 766 & 285.1 & 22 \\ 766 & 262 & 21.4 \\ 767 & 259.7 & 21.3 \\ 767 & 261.7 & 21.4 \\ 767 & 265.5 & 21.4 \\ 768 & 266.1 & 21.5 \\ 768 & 267.5 & 21.5 \\ 769 & 266.1 & 21.3 \\ 770 & 250.1 & 20.6 \\ 770 & 241.8 & 20.6 \\ 770 & 240.3 & 20.1 \\ 770 & 237 & 20.1 \\ 771 & 238.4 & 20 \\ 771 & 238.3 & 20 \\ 771 & 238.5 & 19.9 \\ 771 & 238.1 & 19.8 \\ 770 & 239.2 & 19.8 \\ 770 & 238.6 & 19.7 \\ 770 & 238.9 & 20.3 \\ 770 & 261.3 & 20.6 \\ 770 & 262.6 & 20.6 \\ 771 & 261 & 20.7 \\ 770 & 262.1 & 20.5\end{array}$




$\begin{array}{lrr}770 & 241.2 & 19.9 \\ 770 & 239 & 19.7 \\ 770 & 239.1 & 19.7 \\ 770 & 239.7 & 19.7 \\ 770 & 239.6 & 19.6 \\ 770 & 239.8 & 19.8 \\ 770 & 241 & 19.7 \\ 770 & 241 & 19.7 \\ 770 & 240.5 & 19.7 \\ 769 & 241.8 & 19.8 \\ 769 & 251.6 & 20.6 \\ 768 & 257.4 & 20.4 \\ 767 & 272.1 & 21.6 \\ 767 & 287.4 & 21.8 \\ 766 & 288.4 & 21.9 \\ 765 & 289 & 21.9 \\ 765 & 290.1 & 22 \\ 764 & 289.5 & 22.2 \\ 764 & 304.1 & 22.7 \\ 763 & 306.5 & 22.8 \\ 763 & 306.3 & 23 \\ 763 & 307.8 & 23 \\ 764 & 308 & 23 \\ 764 & 307.8 & 23.1\end{array}$





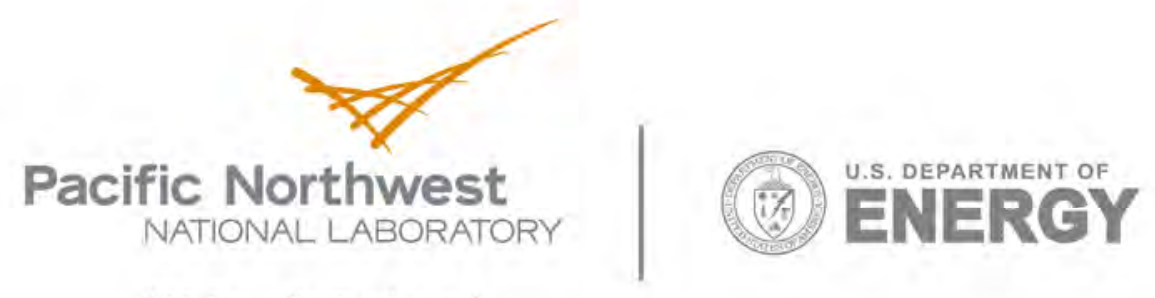

902 Battelle Boulevard

P.O. Box 999

Richland, WA 99352

1-888-375-PNNL (7665)

www.pnl.gov 